

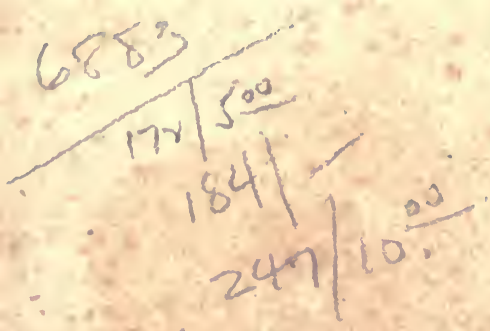


UCSB LIBRARY

$X-62187$

Hogay Imwiris 
Whism. set 


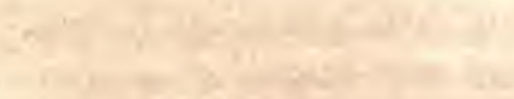

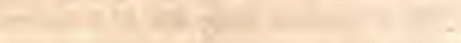


TH E

\section{NEW AMERICAN ORCHARDIST;}

OR, AN ACCOUNT OF

THE MOST VALUABLE VARIETIES

$$
\text { IJ IR UI If IT? }
$$

ADAPTED TO CULTIVATION IN THE UNITED STATES;

WITH THEIR

History, MODES OF CULTURE, MANAGEMeNT, USES, \&c."

\section{WITH AN APPENDIX, ON}

\section{VEGETABLES,}

ORNAMENTAL TREES, SHRUBS, AND FLOWERS,

THE AGRICULTURAL RESOURCES OF AMERICA, AND ON SILK, \&C.

\section{BY WILLIAM KENRICK.}

Fifth Edition, Enlarged and Improved.

\section{BOSTON :}

OTIS, BROADERS, AND COMPANY. 
Entered according to Act of Congress, in the year 1841, By William Kentick,

In the Clerk's Office of the District Court of Massachusetts. 


\section{HON. JOHN LOWELL, LL. D.}

Sir,

I AM happy in being enabled to inscribe this work to a gentleman whose name is so intimately associated with all the great improvements connected with Agriculture and Horticulture, during more than a quarter of a century. The many valuable productions - the donations from Mr. Knight, and from other sources - by you so extensively disseminated; your disinterested and distinguished zeal to encourage and enlighten in all useful pursuits, and especially those to which this work is principally devoted, are not only highly appreciated by contemporaries, but posterity will know and acknowledge their value.

Please to accept this dedication, not only as an acknowledgment of the many favors received, but as an expression of my high estimation of your manifold and successful efforts in all that concerns the best interests of our country.

With the highest respect and esteem,

Your obedient servant, 



\section{ADVERTISEMENT}

\section{TO THE THIRD EDITION.}

The present edition of this work has been revised with very particular attention and care; all the latest and most eminent writers of Europe, which have come to hand, having been diligently consulted, and the experience of the most intelligent of our own country. In this edition, many important improvements will be found, and many additions, particularly in regard to fruits. The list of these, although so complete in the former editions, is yet, in this, greatly improved; and especially in those fine new kinds which have been so lately proved by Mr. Thompson and others, at the Garden of the London Horticultural Society at Chiswick, and elsewhere in England, and in France; or more latterly approved with us. During a visit of the author to those countries, in the autumn of 1840 , much information was collected by him from firstrate sources, from oral and other communications, which will be found in the following pages. 



\section{T A BLE OF CON TENTS.}

Page.

Dedication .....................................

Advertisement. .................................

Acknowledgments to Authorities, Correspondents, \&c........9

List of Authors whose Works are either quoted or referred to.. .9

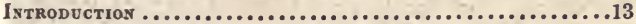

Section I. Climate ..............................16

II Modern or Landscape Gardens.............21

III. Utility of Fruits ......................23

IV. New Varieties of Fruits - Modes in which they are produced - Decline of the Old Varieties....25

V. Of the Growth of Trees and Plants...........34

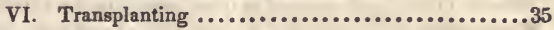

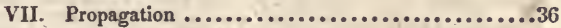

VIII. Inoculating. . . . . . . . . . . . . . . . . . . 37

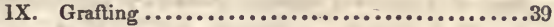

X. Fruitfulness .........................41

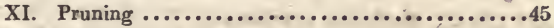

XII. Noxious Insects........................52

APPLE....................................... 58

Prar...........................................115

Old Pears........................................117

New Pears..................................130

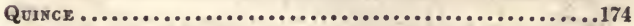

Реасн........................................177

Nectakine.......................................206

AlMond .......................................210

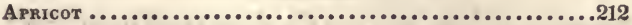

PLUx.........................................216

Cherry........................................231

MULBERRY ...................................212

VIxE ....................................213 
Page.

Currant. ....................................286

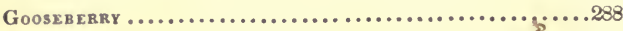

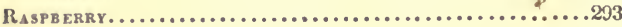

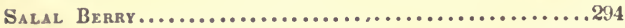

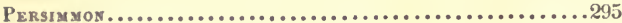

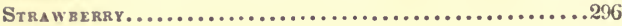

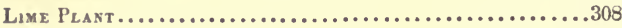

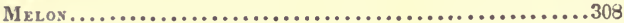

BLACK BERRY . . . . . . . . . . . . . . . . . . . . . . . 312

BerberRy . . . . . . . . . . . . . . . . . . . . . . . . 313

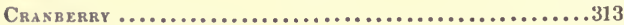

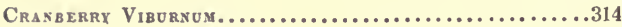

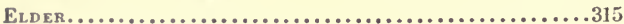

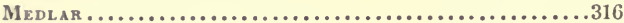

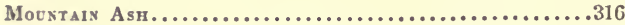

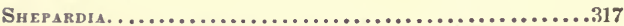

Nuts - Walnuts, Chestnuts, Filberts, \&c. \&c.............317 Southrrn Fruits.

Fig.........................................

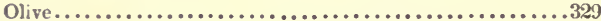

Orange Tribe................................. to 346

Pine-Apple.................................... 346

Plantain and Banana................................... 348

Many other species of Southern Fruits ..............323 to 355

APPENDIX, containing as follows -

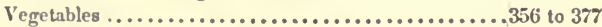

Ornamental Forest Trees and Shrubs..............377 to 396

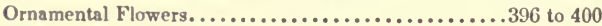

Notes on the Agricultursl Resources of Ameriea, Culture of

Silk, \&c...............................401

Insects ................................427

On Fences, Hedges, \&c.........................429

On Deep Tillage..............................430

Glossary....................................431

Index .....................................433

Index to the Appendix............................445

Select and recommended List of Fruits...................449

(See also the varjeties which are marked with a star.) 


\section{ACKNOWLEDGMENTS TO AUTHORITIES, CORRESPONDENTS, \&c.}

Tre descriptions of the fruits contained in the following pages are drawn from much personal observation, and from the most authentic testimonies and authorities, and from those alone on whom we may with confidence implicitly rely. Although most of them are already in our country, and have been already proved, yet many of them are nero, and of very recent introduction.

To the more common or proper names, I have in many cases annexed the botanical or descriptive names of the species or varieties; this being the only ons and universal name, by which they are alike known in every part of civilized America and of Europe. I have also, to avoid confusion in the nomenclature, endeavored generally to preserve, unaltered, the original or proper names, in the language of their own native country. These will serve in a measure to identify, and also to indicate the country and the climate to which they properly belong.

My obligations to the late Mr. Lowell I have elsewhere acknowledged, - and my obligations to Gen. Dearborn, the first President of the Massachusetts Horticultural Society. I am also under very particular obligations to Mr. Manning, of Salem, for the many descriptions he has afforded me. All those articles marked $\mathbf{R}$. M. are described on his authority, and are such as he has proved them to be in our climate. I have availed also of the valuable communications of Messrs. Downer, of Dorchester; Buel, of Albany; S. G. Perkins, of Boston; of Col. Carr, of Bartram's Botanic Garden, near Philadelphia. I am also particularly indebted to the great intelligence and researches of Mr. Robert Thompson, of the Garden of the London Horticultural Society, and to Messrs. Ronald, Lee, Forrest, and other distinguished and intelligent cultivators in his vicinity; MM. Dalbret, Jamin, Vilmorin, Margat, and Lusette, and other intelligent individuals in or near Paris; M. Emilien De Wael, of Antwerp, in Belgium; and also to those very numerous individuals of our own country whom I have elsewhere named.

\section{LIST OF AUTHORS AND WORKS QUOTED OR REFERRED TO}

Adrom. - Memoir on the Cultivation of the Vine in America, and the best Mode of making Wine, by John Adlum. 12mo. Washington, 1828.

Amrazes d'Horticulture. - Annales de la Société d'Horticulture de Paris. A valuable publication, in monthly numbers. 8vo. 
Barnet. - Description of the great Collection of Strawberries at Chiswick, in Vol. vi. Hort. Trans., by James Barnet, occupying 80 pages quarto.

Bow JARD, - Le Bon Jardinier, edited by M. Poiteau and $\mathbf{M}$. Vilmorin, for the year 1841. Paris. A work of over 1000 pages, annually published in that city for nearly a hundred years.

Bosc. - Louis Auguste Guillaume Bosc, F. L. S. H. S.; author of many articles in Nouveau Cours Complet d'Agriculture, and other works.

Соввгтт. - American Gardener, by Wm. Cobbett, a celebrated political writer.

Coxz. - View of the Cultivation of Fruit Trees, \&c., in the United States of America, \&c., by William Coxe, Esq. 8vo. Philadelphia, 1817.

Ds Candolrs. - L. A. de Candolle, author of several articles in Noureau Cours Complet d'Agriculture, a celebrated writer on Botany, \&c.

Mr. Cовв. - Jonathan H. Cobb, Esq., of Dedham, Mass., author of an excellent Manual on the Mulberry and Culture of Silk, published by order of the Legislature of Massachusetts, and also by order of Congress.

D'Alnret. - Cours Théorique et Pratique de la Taille des Arbres Fruitiers, par D'Albret. 3d edition, Paris, 1840.

Dom. Evcr. - Domestic Encyclopedia, by A. F. M. Willich, M. D. Edition of Dr. James Mease, 5 vols. 8vo. Philadelphia, 1803.

Duн. O. Duн. - Traité des Arbres Fruitiers, par Henri Isewis Duhamel de Monceau. 2 vols. 4to. Paris, 1768.

N. Dorn. - Nouveau Duhamel, ou Traité des Arbres Fruitiers, Nonvelle edition, augmentee, \&c., formerly conducted by Dr. Loisleur Deslongchamps; now still continued by MM. Poiteau and Turpin; several vols. folio, with colored plates. Paris.

En. Exc. - Edinburgh Encyclopædia, American edition, by Dr. Brewgter. The article on Horticulture, to which this principally refers, was drawn up by Patrick Neill, Esq.

Fes. Amer. Gard. - New American Gardener, containing Practical Directions on the Culture of Fruits and Vegetables, \&c., by Thomas G. Fessenden, Editor of the New England Farmer.

Fonsrтh. - Treatise on the Culture and Management of Fruit Trees, \&c., by William Forsyth, Esq. Seventh edition, 8vo. London, 1824.

Count de Hazzx, Counsellor of State of Munich, author of "Complete Instructions for the Plantation and Management of Mulberry Trees, and the Rranive or Sick-Worms." Transmitted by him, through Dr. Mease, to Congress. A professed disciple of the Comte Dandolo and M. Bonafous.

Hookrz. - Pomona Londinensis, containing Representations of the best Fruits cultivated in British Gardens, by William Hooker, Esq., F. L. S. H. S. Sto., with colored plates.

Host. Soc. Car.-Catalogue of the Fruits cultivated in the 
Garden of the Horticultural Society of London, at Chiswick. 8vo. 1826. Also, the Descriptive Catalogue of 1831 , which is ascribed to Mr. Robert Thompson.

Hort. Trans. - Transactions - of the Horticultural Society of London. 4to. 8 vols.

MAG. Hort. - The Magazine of Horticulture, Botany, and all useful Discoveries and Improvements in Rural Affairs, by C. M. Hovey. A highly useful monthly work, published at Boston.

J M Mv. - Catalogue raisonné des Arbres Fruitiers of M. Jean St. Laurent de Jamin, Paris, 1838; and Manuscripts of 1841, from same source.

Mr. Kright. - Thomas Andrew Knight, Esq., F. R. S. L. S., \&c., late the President of the London Horticultural Society, and the author of nearly a hundred articles in the London Hort. Trans., \&c. \&c., and author of several works on Rural Economy.

Lindery. - A Guide to the Orchard and Kitchen Garden, or an Account of the most valuable Fruits and Vegetables cultivated in Great Britain; with Calendars of the Work required in the Orchard and Kitchen Grarden, during every Month-in the Year; by George Lindley, C. M. H. S. London, 1831.

Lounon. - Encyclopædia of Gardening, \&c., by John C. Loudon, F. L. S. H. S., \&c. London, 8vo. 1825. A work of 1233 condensed pages, and several hundred engravings.

Loud. Gard. MAG. - The Gardener's Magazine, by the same author. A most superior work, in periodical numbers.

Michaux. - The North American Sylva, or a Description of the Forest Trees, \&c., with 156 colored engravings, by F. André Michaux. 2 vols. 8vo. Paris, 1819.

Miller. - The Gardener's and Botanist's Dictionary, \&c; by Philip Miller, F. R. S. 2 vols. folio. Revised by Professor Martyn. London, 1819.

NeıcL. - Patrick Neill, Esq., A. M. F. L. S., author of the article on Horticulture in the Edinburgh Encyclopredia, of the "Horticultural Tour," and other works; Secretary of the Caledonian Horticultural Society, \&c

Nouv. Cours Complet. d'Aori. Cours Complet. - Nouveau Cours Complet d'Agriculture, \&c., ou Dictionnaire raisonné et universel d'Agriculture, by the members of the Section of Agriculture of the Institute of France, viz. MM. Thouin, Parmentier, Tessier, Huzard, Silvestre, Bosc, Chassiron, Chaptal, Lacroix, De Perthius, Yvart, De.Candolle, Du Tour, Du Chesne, Feburier, De Brebisson, and Rosier, (R.) 16 vols. 8vo. Paris, 1823.

Cher. Parmentier. - The Chevalier Joseph Parmentier, of Enghein; description of various new fruits in-Hort. Trans.

Dr. Pascalis. - The Silk Culturist, \&c., published in numbers, by Dr. Felix Pascalis. New York. Also author of "Practical Directions on the Culture of the Mulberry and of Silk," \&c.

Phillips. - Pomarium Britannicum; an Historical and Botanical 
Account of Fruits known in Great Britain; by Henry Phillips, F. H. S., \&c. 8vo. London, 1823.

Portyav.-A. Poiteau, one of the conductors of the Bon Jardinier and the New Duhamel; and author of many of the articles in Annales d'Horticulture, \&c.

PoM. MA a. - Pomological Magazine, or Figures and Descriptions of the most important Varieties of Fruit cultivated in Great Britain. 3 vols. 8vo. London. A late work.

Pyres Males Brent. - Pyrus Malus Brentfordiensis, or a concise Description of selected Apples, by Hugh Ronalds, F. H.S., \&c., with colored engravings.

Quintisiz. - The Complete Gardener, or Directions for cultivating of Fruit Gardens and Kitchen Gardens; with divers Reflections on several Parts of Husbandry. In 6 books. By the famous M. de la Quintinie. Made English by John Evelyn, Esq. 1693.

J. Rivers, Jr. - Descriptive Catalogue of Fruits, \&c.; also various articles on fruits in Loudon's Magazine.

Rosizr. - Cours Complet d'Agriculture, theorique, practique, economique, \&c., ou Dictionnaire universel d'Agriculture, \&c. 15 vols. 4to. Paris, 1801 .

Sperchly. - William Speechly; a Treatise on the Culture of the Vine, \&c. 8vo,

Dr. ThaснEr, author of the American Orchardist, and various other valuable works, on history, medicine, \&c. \&c.

Thомpson.- Robert Thompson, of the London Horticultural Society's Garden at Chiswick; distinguished alike for his accuracy, intelligence, and research. Much of what is most valuable in the Pom. Mag. is sscribed to him. Also the undoubted author of the descriptive Cat. Lond. Hort. Soc. for 1831.

Thov1s. - Monographie de Greffes, ou Description technique de diversés Sortes de Greffes, employées pour la Multiplication des Végetaux, par la Chevalier de Andre Thouin, Professor, \&c. in the University of Paris. Paris, \&c. Folio, with plates.

Vas Moss.-Dr. Jean Baptiste Van Mons. Catalogue des Arbres Fruitiers, \&c. Louvaine, 1823. Also, Pomographie Belgique Moderne. 4to., with plates. This work is still in progress, and but a small part of it has been received from him. These are in the Library of the Massachusetts Horticultural Society.

Dr. Willicil. - All thus designated refer to the Domestic Encyclopredia: these were drawn from the works of I. L. Christ, a clergyman of Kronburg, near Frankfort on the Maine. 


\section{N T RODUCTION.}

Horticulture is the most ancient employment ordained by the Creator for man. Its utility and importance have been the pleasing theme of the enlightened in all successive generations. To the rich - to the poor - its resources alike afford subsistence, or a pleasing occupation.

Horticulture is an art coeval with man's Creation and of earth; the Alnighty himself having planted the first garden in Eden, wherein he caused to grow every tree that is pleasant to sight or good for food. Adam was placed therein, "to dress the garden and to keep it " - an occupation most of all calculated to promote happiness, to insure contentment, longevity, and purity of life.

Agriculture is a sister art, and more intimately associated with the pastoral life, with the raising of herds and of flocks; of the cereal grains; of the substantial food and attire of men; of the attire of ships and their freight : by its aid most of all the human family are both clothed and fed. Agriculture is another and kindred science, and with horticulture nearly allied, but of a less ancient date.

A life in the country is, above all others, preëminently calculated to inspire the mind with exalted ideas of that divine character, and Almighty power, whose glorious works are far above all human thought, and mortal praise; - how far above the lifeless emblems, and mortal glories which surround an earthly throne? "Consider the lilies of the field, how they grow; they toil not, neither do they spin, and yet I say unto you, that even. Solomon in all his glory was not arrayed like one of these." Thus spake the Savior, and glorious Shepherd. In the representations of Paradise, or the happy abodes, Nature's works, transcendent and alone, have found conspicuous place, blooming eternal, - flowers of fairest hues, trees yielding fragrant odors, or fruits, or cooling shade.

It is to be regretted that a very considerable proportion 
of our population seem destined to pass their whole lives shut up in cities; excluded, in a measure, from view of al] natural scenes, and forms, and objects, even from light; in whose dark abodes dwell commingled both good and bad; where dwell unknown, - where dwelt Cain, him who first invented cities, - where felons dwell, - where rest secure the men renowned in crime, for whom the solitude of the country, and the transcendent beauties of creation, have no charms. It is equally to be regretted that so many of the rich, who, from their abundant resources, are always enabled to reside where they choose, should prefer the imprisoned air of cities, with all its accompaniments, to the pure and salubrious atmosphere of the country; - its delightful prospect of mountain, or wide-spread plain, - of hill or fertile valley, - of woods and lawns, - its rivers, and crystal fountains, and water-brooks, - its solitudes and rocks; anon those hills and dales, those plains and forests clad in snow, and robes celestial, - its glorious sunshine, the eternal and ever-varying displays of nature which the rural life affords.

A science whose pursuits are alike so conducive to the bealth of the body and of the mind - so calculated to render mankind useful, virtuous, and happy - has never wanted advocates. It has found them with the best and most enlightened of all ages - with every friend to his country and the human race. In our own country, the progress of horticulture has been commensurate only with the untiring zeal and successful efforts of a Lowell, a Buel, a Fessenden, and others, to enlighten and encourage, many of whom have recently gone down to their graves; but their names will long be cherished in grateful remembrance. Eminently distinguished also for their zeal, a host in numbers, and renowned in intellect, still live. We hail its wonderful progress. Success to those numerous and powerful societies which have so lately arisen in our land to its aid, and in the equal aid of agriculture!

First of all in rank and deeds of fame, the Horticultural Society of Massachusetts deserves of me distinguished notice. To the unwearied researches and enlightened zeal of its first president, General Dearborn, I am greatly indebted for much valuable information, which I have to him accredited in the following pages. In pomological investigation and researches, no man in America has done more than Mr. Manning - none so much; to him, 
also, in common with our whole country, I am particularly indebted; also to those numerous individuals whom I have elsewhere named.

England, by the exertions of her most intelligent and influential men, and by her societies, particularly that of London, has, confessedly, done a great deal for the advancement of the science; and no man in England has probably done more in its aid than the late Thomas Andrew Knight, Esq., Iately the distinguished president of the London Horticultural Society, with the exception only of Mr. Loudon, who, for the extent and usefulness of his writings on this and other subjects, may be deemed one of the most remarkable men of the age. In profound horticultural researches, who more distinguished than Professor Lindley and Mr. Thompson, in this decisive day?

To the descriptions of the fruits of the divers climes, which are adapted to the various sections of our country, from the north to the south, and bordering on the tropics, I have added the useful vegetable plants, and the trees and plants of ornament. Also, I have added a select list of fruits, or a recommended list, of a limited number, of those kinds only, which, having been already tried and approved in our climate, can be especially recommended. To many of these $I$ have prefixed an asterisk, or star. But as many of the new kinds, of the highest character, have never as yet borne fruit in our country, and are therefore excluded, it must appear evident that this list will, from time to time, require a revision. - The select - the very best possible list, and such alone as we should most of all be desirous of offering the public - cannot be formed until all those new and excellent kinds, which this extraordinary age has produced in Belgium, are put to trial in our climate. Their names, their numbers, and their excellence, constitute a host, in all probability far greater than all that the former ages had ever produced. For their introduction to our own country, much is due to the individual enterprise of our own citizens, to Dr. Van Mons, of Belgium, and much also to the distinguished liberality of $\mathrm{Mr}$. Knight, and the London Horticultural Society.

\section{Section I. - Chimate.}

The territory of the United States, comprehends the vast middle section of North America, and is principally 
included in the best part, or southern half section of the temperate zone, with a climate one of the most favored, and a soil the most desirable, on earth. It extends from the Gulf of Mexico, and the confines of the equatorial regions, and the Lat. of $24^{\circ}$, to the Lat. of $48^{\circ}$ and the British possessions on the side of the Atlantic. Southwest is Mexico; and on the west, and looking towards Asia, it is bounded by the shores of the Pacific Ocean; and on the nortll by the Lat. of $54^{\circ}$ and the possessions of Russia.

The climate of the Atlantic States has been generally characterized as variable and inconstant. These sudden changes are caused, in a great measure, by the conflicting winds, which blow alternately from the opposite points the sources of extreme heat and of excessive cold. Those, especially, from the south-east and south, bring, alternately, clouds charged with sultry vapors, or storms of rain, or the fiery particles and intense heat which they have inhaled in the equinoctial regions. While the winds from the north-west, coming, as they do, over a vast extent of territory, and from the regions of eternal ice and snow, they bring down with them, at certain seasons, a degree of cold the most piercing and intense. These adverse winds bring by turns, and often by sudden changes, the heat of the tropical, or the extreme cold atmosphere of the polar, regions.

The climate of our country, in regard to its capacity and vegetable productions, is not to be estimated by the measure of its distance from the equator, nor by the average temperature of the winter, or even that of the year; but rather by the mean heat of the summer, and its duration. For while the average temperature, or heat of the year, is greater at Rome and at Marseilles than at Cambridge, Mass., the average heat of the summer months may be nearly equal, since the mean of the greatest heat at Cambridge exceeds that of Rome by $11^{\circ}$, and that of Marseilles by $8^{\circ}$, the mean of our greatest summer heat being $97^{\circ}$; though $100^{\circ}$ and over, in some summers, is not with us uncommon.

From the average of the observations which have been made in 20 cities on the continent of Europe, the climate of America has been compared. And the proportion of rain which annually falls is two fifths greater with us than with them, or as 50 inches to 30 . Yet our rainy days are annually from a fourth to a third less in number, than with 
them, or as 85 or 90 days of rain with us to 122 days with them; the rain with us descending in profuse showers, and often in torrents, with tremendous lightning and thunder; while, on the other hand, the number of our days of sunshine, in the year, is double that of the 20 cities of Europe, or as 130 bright days with us to 64 with them. In this respect our climate is doubly blessed; in our serene skies, and our more perpetual and brilliant sunshine.

The climate of a country is variously inodified by its proximity and situation in regard to mountains and to the ocean. The temperature of the climate on our extensive Atlantic coast, differs considerably from those parts of Europe and of Africa which lie in corresponding latitudes. In like manner, the climate of our country will be found continually varying as we advance longitudinally from its eastern to its western shores.

It has also been observed, that, within the temperate zones, the western coasts of continents and large islands are found to possess a higher mean temperature than the eastern coasts. Our climate, on the shores of the Atlantic, must, therefore, correspond nearly with that of the eastern coasts of China, Japan, and Chinese Tartary, and the islands on their coasts. And the climate of our country which bounds on the Pacific, may correspond nearly with that of Europe on the coasts of the Atlantic, in the corresponding latitudes.

The geographical position of our own country and of China are alike, each having its ovon vast ocean on the cast. China possesses a peculiar country, a parallel only to our own in all its divers latitudes and various climes, in all its vicissitudes and extremes of heat and cold. The French missionaries, who had resided previously in America, had borne testimony to this striking similitude and important fact, at a very early day. All productions, therefore, which flourish in that country, must flourish equally well in our own. Our prevailing winds, during three fourths of the year, are from the west, and are dry and salubrious; they always bring fair weather and bright, sunny days. These winds of the middle latitudes, which extend quite across the Atlantic, are the counter currents of those eternal winds called " trade winds," which, following the course of the sun, blow so continually at all seasons, and in the contrary direction within the tropics. In Europe, this peculiarly favorable position is reversed, and the prevailing or westerly winds, blowing, as 
they do, directly from the ocean, they carry from thence tempestuous storms of rain, with clouds of aqueous vapors, which dissolve the snows of winter and obscure the sun.

It has been observed that those countries possess a more equal temperature during all the seasons, which have an ocean on the north. Such, precisely, is the position of a considerable portion of the whole of Western Europe. In their passage over the ocean, the cold northern winds become modified, but a very considerable portion of moisture is also imbibed, imparting to those countries a cold and chilly atmosphere; both winter and summer, during a considerable portion of the year, the sun's bright rays, with their soul-reviving influence, are not seen. With us, those northerly winds bring clear and fine skies, and a dry, pure atmosphere, like those more invariable winds from the west. But during winter those same northerly winds bring down from high northern regions, and other climes, an atmosphere at times the most intensely cold: no moisture comes with them, to dissolve the snows of winter - those snows which serve as a covering and as a protection to vegetation and to the frozen earth, until a late period in the season; it is from this cause that with us the destructive vernal frosts are not known, or are of but very rare occurrence. Immured in our winters so intensely cold, and so fortunately prolonged, vegetation slumbers profoundly secure, nor awakes till the danger is past.

Elevation above the level of the ocean has the same effect in lowering the mean temperature, as an increase of latitude. Mons. de Candolle has ascertained, by experiments on some mountains in France, that the elevation of 180 or 200 yards affects the mean temperature in the same proportion as a degree of latitude to the north, on that same meridian, and in a similar proportion for any increase of height.

The growth of trees and plants, in rich, moist soils, and in warm and protected situations, is not only unusually rapid, but is also prolonged to a very late period in autumn, or until suddenly arrested by frost; and the inmature wood of a forced growth, being tender, is the more liable to be killed by early frosts and by winter.

On the other hand, those trees and plants which grow on dry and stony or sandy soils, and on the open plains, and on the hills which are most of all exposed to cold winds, the wood completely matures in due season; and such 
trees are found to suffer least of all from early and destructive frosts, and from winter.

Delicate trees and plants, the natives of southern climes, become more hardy, and more capable of supporting the northern winters, by being planted on the north sides of buildings, and in their shade. Their growth being thus modified, the exposure to the most intense degree of cold, in such situations, is more than compensated by the protection which is thus afforded to the plants during winter, from the pernicious and far more destructive rays of the sulı.

More delicate shrubs or plants may be protected by being surrounded by a thin covering of straw. They may also be protected by a few inches of litter placed around their trunks, and over their roots. Moss from the meadows, or evergreen boughs, being more incorruptible, are to be preferred for delicate plants. For it has been lately announced, as an important fact, that the destruction of delicate plants, which is sometimes occasioned by winter, is caused-by the alternate freezing and thawing of the earth at its surface; that death commences at the surface, which this protection will prevent.

Those selections of fruits - those select lists, which the late eminent English writers so highly recommend - were evidently never designed for us; but as peculiarly adapted to other climes, and to high northern latitudes, and to that country for which alone these celebrated works were principally designed; since beneath our serene and cloudless skies, and a sun more powerful and intense in its heat, many of them appear, on trial, to have lost that high reputation, which they could only have acquired in a northern country, with a clouded and humid atmosphere; and, with some few eminent exceptions, they will not compare with those natives of our own climate, or with those of other climates equally favored with us; while, on the other hand, the finest selections, during two centuries, from the innumerable native orchards of America, and the finest fruits from Italy, seem to have shared in that climate a most disastrous fate.

These remarks will serve to show the manifest impropriety of adopting without reflection, and without a trial, those select lists of fruits, which, from necessity, alone, are formed on exclusive principles, and as the best adapted to another and a foreign country, and another climate, and with no reference whatever to a climate like ours. 
The finest fruits of the tropics, when cultivated in countries remote from the cquator, lose their good quality and sweetness. In the climate of England, we are assured, from undisputed testimony, that the finest peaches of America prove "worthless." Even those which, confessedly, travellers with us so much admire, with but two exceptions, prove good for nothing in their hostile climate, not coming to their full maturity and excellence, even on the walls to which their cultivation is confined. The Pavies, particularly, are there denounced generally, while in warmer countries they are preferred to all others. Fifty American kinds were contained in their garden at Chiswick, at the time their account was written. [Sce Pom. Mag. No. 54; also, Cat. Lon. Hor. Soc. for 1826.]

Some others of the finest fruits of America, and of Italy, seem also in that country to have shared a like disastrous fate; and the Pomme Finale, or Mela Carla, which, in the climate of Italy, is reputed to be the finest apple in the world, proves in open culture, in England, but an ordinary fruit, as their writcrs assure us.

The reverse of this is also true; and many fruits of the north will be found to depreciate, when cultivated in a warmer latitude. And the White Moscow, or Astracan, which, by the celebrated M. Christ, is described as a fruit so very extraordinary, "in a suitable situation and climate, vhich is not under $49^{\circ}$ of polar elevation," - this fruit is pronounced but at mediocrity at Paris, and with us proves an indifferent fruit. And many of the fruits, the natives of England, and of other northern countries, and of high reputation there, have proved but ordinary when brought down to our own latitudes, and compared with our owu fruits, and those of climates equally farored with us.

The cherry tree, the pear, the apple, and many other kinds, when carried within the tropics, become unproductive or barren, or the fruit worthless.

The olive and the vine may indeed grow within the tropics; but we arc assured they produce little or no fruit, cxcept in the mountainous elevations.

'The cereal varieties of grain, the annual plants and productions, those most necessary to the subsistence of man, have by him been acclimated from the borders of the tropies to very high northern latitudes.

Man himself has become habituated to all climates, 
The horse, the most noble of animals, and the ox, the most useful, seem, under the guardianship of man, in some measure, alike constituted. The horse and his rider traverse the earth, from the burning deserts of Sahara to the frozen regions of Siberia, and the boundaries of the Arctic circle.

\section{Section II.-Of. Modern or Landscape Gardens.}

In northern latitudes, the location of a garden should be, if practicable, on the south side of a hill. Or it may be screened on the cold quarters, either by hills, or by dense and deep borders of evergreen and other forest trees, intermixed with fruit trees and shrubs of ornament. Beauty alone considered, an undulating surface is by all means to be preferred, and water should not be wanting.

The art of Modern Gardening is to form a landscape the most beautiful. Nature having drawn the outline, art must accomplish the rest; art itself being subservient, or so far concealed, as that all may appear the work of nature alone. Walls and boundary fences should be demolished, or as far as possible concealed. The $h a-h a$ is a concealed wall, constructed in the bottom of a dry ditch, and rising no higher than the surface of the earth. Straight lines and right-lined walks are to be avoided; and in their stead lines direct, or, by nature devious, are prefered, or the gently-waving lines, which bring continual and agreeable change. Striking and agreeable objects in the landscape, whether near or more remote, should be brought frequently, and sometimes suddenly, into open view; while unpleasant objects should, from all conspicuous points, be masked from the sight, by shrubbery or by trees. To the hills an artificial elevation may be given by planting their summits with the stateliest trees. And depth is preserved to the valleys by converting them to lawns. Views of water, it must not be forgotten, are essential to the perfect landscape.

The first garden, of which we have any account on record, was planted by the Almighty - "eastward in Eden," and in it, every tree that was pleasant to the eye, or useful for food. Out of Eden went a river, which watered the garden; and from thence it was parted into four heads:- 1st. Pison, on the side of Havilah. 2d. Gihon, 
on the side of Ethiopia. 3d. Hiddekel, towards Assyria. 4 th. The Euphrates.

The modern style of gardening, in the place of the regular geometric forms, and the right angles, and right lines, has substituted all that is more consistent with nature, and with beauty. Celebrated English writers have ascribed this important change in the style of gardening in England, to the ideas of Lord Bacon, as original; but especially to those ideas which have been more latterly promulgated by Milton and others. I finish, therefore, by selecting the following perfect description of a garden from him :-

"Now nearer, crowns with her enclosure green,

As with a rural mound, the champain head

Of a steep wilderness, whose hairy sides

With thicket overgrown, grotesque and wild,

Access denied; and over head upgrew

Insuperable height of lofliest shade,

Cedar, and pine, and fir, and branching palm,

A sylvan scene, and, as the ranks ascend

Shade above shade, a woody theatre

Of stateliest view. Yet higher than their tops

The verd'rous wall of Paradise upsprung;

Which to our general sire gave prospect large

Into his nether empire neighboring round.

And, higher than that wall, a circling row

Of goodliest trees, loaden with fairest fruit,

Blossoms and fruits at once of golden hue,

A ppeared, with gay enamelled colors mixed :

On which the sun more glad impressed his beams

Than in fair evening cloud, or humid bow

When God hath showered the earth; so lovely seemed

That landscape:" * * * * * * *

"Southward through Eden went a river large,

Nor chang'd his eourse, but through the shaggy hill

Pass'd underneath ingulf'd ; for God had thrown

That mountain as his garden mould high raised

Upon the rapid current, which, through veins

Of porous earth with kindly thirst updrawn,

Rose a fresh fountain, and with many a rill

Watered the garden: thence united fell

Down the steep glade, and met the nether flood,

Which from his darksome passage now appears,

And now, divided into four main streams,

Runs diverse, wand'ring many a famous realm

And country.",

A happy rural seat of variou "Thus was this place

Groves whose rich trees wept odorous gums and balm; 
Others whose fruit, burnish'd with golden rind

Hung amiable, Hesperian fables true,

If true, here only, and of delicious taste.

Betwixt them lawns, or level downs, and flocks

Grazing the tender herb, were interposed,

Or palmy hillock; or the flow'ry lap

Of some irriguous valley spread her store,

Flowers of all hue, and without thorn the rose.

Another side, umbrageous grots and caves

Of cool recess, o'er which the mantling vine

Lays forth her purple grape, and gently creeps

Luxuriant; meanwhile murmuring waters fall

Down the slope hills, dispersed, or in a lake,

That to the fringed bank, with myrtle crown'd,

Her crystal mirror holds, unite their streams."

\section{Section III.- Utility of Fruits for Food and the Preservation of Health.}

The fruits of various countries and climes should be regarded as one of the most valuable gifts which divine Providence has bestowed upon man. And the cultivation of those of superior kind should on all accounts be promoted, - not merely as the source of luxury, but as a substitute for pernicious medicine, and as a delicious, healthy, and most nutritious article of food, which, habitually used, palliates thirst, thus essentially promoting the great cause of temperance. "The palate," says thecelebrated Mr. Knight, "which relishes fruit, is seldom pleased with strong fermented liquors; and as feeble causes, continually acting, ultimately produce extensive effects, the supplying the public with fruit at a cheap rate, would have a tendency to operate favorably, both on the physical and moral health of the people."

The belief is but too prevalent, that fruits produce discases during the montlis of summer and autumn, and especially the dysentery. The belief is untrue; and the very reverse is certainly true, fruits being the true preventives of disease. I might amplify on this subject, but must be brief, and will only add as proofs, and from celebrated physicians, the following from the "Annales d'Horticulture," due to the researches of Gen. Dearborn and the New England Farmer, where I have found them inserted. It is from the writer of another country - a country celebrated for the cultivation of good fruit, and alike celebrated for the remarkably temperate habits of its 
people. "One of the best aliments, and the best appropriated to the different ages of life, is that which fruits afford. They present to man a light nourishment, of easy digestion, and produce a chyle admirably adapted to the functions of the human body.

"There are fruits, which, when perfectly ripe, can be eaten even to excess without inconvenience, such as grapes, cherries, and currants; the other kinds never occasion ill consequences, if they are eaten only to satisfy the demands of nature.

"Thoroughly ripe fruit, eaten with bread, is the most innocent of aliments, and will even insure health and strength.

"In traversing the territories of Germany, there is to be seen near each habitation a vineyard or a garden of fruit trees. The villages are surrounded with them, and there are but few families who do not make use of fruits during the summer, and preserve a certain quantity for winter. The surplus is sold in the cities. There are to be seen upon the Rhine, and other rivers of Germany, boats laden with dried apples, pears, and plums." * * *

The following, from the same writer, is from a passage to be found in "Advice to Pcople upon their Health," by Tissot. "There is a pernicious prejudice, with which all are too generally imbued: it is that fruits are injurious in the dysentery, and that they produce and increase it. There is not, perhaps, a more false prejudice.

"Bad fruits, and those which have been imperfectly ripened, in unfavorable seasons, may occasion colics, and sometimes diarrhœa, - but never epidemic dysentery. Ripe fruits of all kinds, especially in the summer, are the true preservatives against this malady. The greatest injury they can do, is in dissolving the humors, and particularly the bile, of which they are the true solvents, and occasion a diarrhœa. But even this diarrhœa is a protec-
tion against the dysentery.

"Whenever the dysentery has prevailed, I have eaten less animal food, and more fruit, and have never had the slightest attack. Several physicians have adopted the same regimen.

"I have seen eleven patients in the same house; nine were obedient to the directions given, and ate fruit; they recovered. The grandmother and a child she was most partial to, died. She prescribed burnt wine, [burnt brandy 
or high wine?] oil, powerful aromatics, and forbade the use of fruit; it died. She followed the same course, and met the like fate.

"This disease was destroying a Swiss regiment, which was stationed in garrison, in the southern part of France. The captain purchased the grapes of several acres of vines. The sick soldiers were either carried to the vineyard, or were supplied with grapes from it, if they were too feeble to be removed. They ate nothing else; not another died, - nor were any more attacked. with the complaint after they commenced eating grapes.

"A minister was attacked with the dysentery; and the medicines which were administered gave no relief; he saw by aceident some red currants, and had a great desire to eat them; he ate three pounds between seven o'clock in the morning and nine o'clock in the evening; he was better during the day, and entirely cured the next."

I might multiply the facts and evidences from different sources, and the writings of other eminent physicians; but the above' must suffice for this time and place. For other important ùses I would refer to the account of each particular species, in the following pages.

In new countries, and in new settlements, - in places remote, - in the wilderness or on the ocean, - in times of privation, and in the absence of the useful fruits, the habitual use of tobacco, of alcohol, and of strong fermented liquors, has been acquired, all of which create insatiate thirst. - The friends of temperance, who would abolish the use of these, as pernicious, must encourage the cultivation of fruits, as the healthy antidote and useful substitute.

Section IV. - Observations on the new VARIETIEs of Fruits. Modes BY WHICH THEY MAX BE PRODUCED.

\section{On the Decline of the old Varicties.}

The decline of many of the most valuable old varieties of fruit has been noticed by several distinguished writers of different countries, both of the present and of the former ages; and in England, particularly, by the celebrated Thomas A. Knight. In our country, and in the vicinity. of Boston, it has been more especially observed in regard to 
the old pears; for our best varieties of apples, and some other species, are mostly native fruits, or of modern origin

Let no one suppose that the intelligent horticulturists here have never been acquainted with the best of the old pears, which the intelligence and industry of ages had concentrated in France. Who is not aware that, in every good collection, a proportion of the very best are always scnt? How opposed alike to reason and to probability is the supposition, that even one of the best should have escaped! They must have been here received, in the numerous and ever-varying selections - in the nnnumbered importations.

Rosier, in the original edition of his celebrated Dictionary of Agriculture, which was completed in 1801, has candidly informed us, that for his description of fruits he is almost wholly indebted to the no less celebrated Duhamel Dumonceau; and from the whole list of pears which he has described, he has recommended as their essence, for a moderate collection, fifty-three trees of nineteen varieties, in different proportions. These are every one of them known among us; and more than half of them, including the very best, are decidedly of the kinds long since, from their defection, proscribed by those who cultivate for the markets of Boston. And of the list of twelve trees, of nine varieties, which he has recommended as the best of all for a very small garden, three quarters of them, at least, are of the kinds which have long since ceased to produce perfect fruit, with those who cultivate for our markets.

We regret the circumstance, but have ceased to wonder at the cause - since the same complaints of defection have already reached us from other quarters - even from the capital of that country, for which those celebrated works were principally designed.

I shall, in the following pages, designate some of those, in the class of old varieties, once the finest of all old pears, whose duration we had hoped, but in vain, to perpetuate. For, except in certain sections of the city, and some rery few solitary and highly-favored situations in the country around, they have become either so uncertain in their bearing - so barren - so unproductive - or so miserably blighted - so mortally diseased - that they are no longer to be trusted; - they are no longer what they were once with us, and what many of them are still described to be by most foreign writers. 
The late Hon. John Lowell, who prepared the article on fruits in the "New Amcrican:Gardener," has warned us in that work, and in his day, to beware respecting some of them. He was well known with us as first-rate anthority.

In the markets of the city, which formerly abounded with them, they are no longer, or but rarely, to be seen. The cultivators who furnish its supplies have given up their cultivation. . Like the barren fig-tree, they have been destroyed - but not without cause ; for if they had not been accursed, their fertility and good qualities were gone; and they were 110 longer fruitful, but as the sources of vexation.

The practice of renaming those new or unknown varieties, whose original names are lost, after these old kinds, is objectionable, inasmuch as it is calculated to mislead, and to falsify the proofs of their mortality. From some fancied similitude, the barbarous names of antiquity are brought down upon us, applied to existing varieties. From semblance of name alone, the Gergon, or Jargon, of antiquity has reappeared: it has been reclaimed, not merely as kindred, but as, in all probability, identical with varieties still existing.*

According to the theory advanced by Mr. Knight and others, and confirmed by their experience, the different varieties of fruit have their periods of existence fixed by the iminutable laws of nature; and after a certain time, either sooner. or later, comes on their decline and final extinction.

I shall offer some evidence to show that the complaints of defection are not confined to us alone - they have reached. us from other and remote quarters. Bosc, in Nouv. Cours Complet, has asserted the change - that in France many of the kinds have become, from some cause, so altered in the short space of half a century, that it is sometimes difficult to know them, even in the exact descriptions and precise engravings of Duhamel; and with regard to many kinds described by Quintinie, the case is still worse.

* See t. 108 of the Pomological Magazine, where the authority of Menage and Duchat, and of Merlet, are brought forward to justify the supposition, that the Jargonelle, asserted by them to be derived from Jargon, anciently Gergon, in Italian Gergo, in Spanish Geri cona, - all corruptions of Gracum, and by the inference of Merlet the Pyrum Tarentinum of Cato and Columella, the Numidianum Gracum of Pliny, the Graculum of Macrobius, - that all these, named or described near two thousand years ago, are but one and the same; and no.other than the Jargonelle of the' present day. 
In the markets of fruits and legumes at Paris, as the Commissaire General has informed us in his report for 1828 some of these same ancient, and with us once celebrated kinds, are no longer cultivated, even with them. He expresses astonishment at the cause - but the conclusion seems irresistible, that with them, as with us, they are no longer worthy of cultivation; and that, out of that city, and in its vicinity, the country around, these once famous fruits are at this day as liable to blight, and as unworthy of general cultivation, as in the neighborhood of Boston.

'The following are his words, extracted from his report : "One is astonished on viewing in the markets of Paris so very few melting pears. We no longer see the Sucre Vert, the Suere Musqué, the Bezi de la Motte, nor the Bezi d'Airy [Bezi d'Héri?]; vory few Chaumontelles, vcry few Culotte de Suisse; no Royale d'Hiver, [Royal Winter, no Virgouleuse, and, what is to be deplored, no Colmars. [Some of these expressions, it seems evident from what follows, were designed to be understood only in a general sense. K.] These three last species sell from ten sous to two francs each, (about forty cents,) and their cultivation is neglected!

"The Rousselette, so perfumed, so sought after by the confectioners, and distillers, is no longer of good quality. How different this Rousselette from that which they cultivate at the hamlet of Cormontreuil, at the gate of Rheims ! At that place they cultivate the Rousselette almost exclusive$1 y$, and these altogether on espaliers. These espaliers offer at the end of August a sight the most rich and beautiful." [Sce Annales d'Horticulture for 1828.]

The unwearied efforts of the most distinguished cultivators of France, during the latter ages, in their attempts to raise new and valuable varieties of fruits from the seed, appear to have been accompanied chiefly with disaster. And M. Poiteau, in one of his reports to the Horticultural Society of Paris, has asserted that the result of all their labor has been " absolutely nothing." In adverting to the decline of the old French varieties of pears, in the vicinity of Paris, and the necessity of a renewal, he asserts that they must look elsewhere for new varieties to replace the old - any where else but to their ovon country.

$\mathrm{He}$ informs us that the celebrated Duhamel, during the long course of his scientific career, planted the seeds of all 
the best fruits which were eaten at his table, without being able to produce a single fruit worthy of cultivation. Others in that country, as the Alfroys, had, during three successive generations, adopted the same course, and with no better success.

Their practice had been to plant, uniformly, the seeds only of the very best or ameliorated fruits, and to select from these, as the subjects of their experiments, those young plants only, which were furnished with large leaves, and large and fine wood. M. Poiteau ascribes the disastrous results of their experiments to these combined causes, and further states it as a fact recorded by several authors, that the seeds of the Winter Bon Chrétien always produce a detestable fruit. Mr. Knight has asserted that the seed of the Wild Pear, fertilized by the stamens of the blossom of an ameliorated one, will yield a better fruit than the seeds of an ameliorated pear.

M. Van Mons has stated that " the Belgians give no preference to the seeds of table fruits, when they plant to obtain new ameliorated kinds." Those seedlings which are without thorns, and with stout wood, and large leaves, are by them rejected, as these are the signs of an early or inferior fruit." M. Van Mons ascribes the success of their experiments in obtaining so many fruits, which are in all respects so extraordinary, to the principle which they had adopted in the beginning - that in proportion as a fruit becomes removed from the wild state, or state of nature, by repeated regeneration, or planting always the kernels or stones of the last production, in that same degree will the fruit become ameliorated, until it attains the highest perfection of which a fruit is susceptible.

During the process of the amelioration, and of each successive remove, the austerity, or superabundant acid, which is the peculiar characteristic of the wild fruit, is diminished, and the saccharine matter is increased. But as a certain quaritity of acid is an essential ingredient in every perfect fruit, it will appear self-evident that the process of regeneration, when carried too far, may prove injurious, and that excessive sweetness, by a short transition, degenerates into insipidity.

It is asserted by Mr. Knight, that, generally, the old varieties of fruit begin to decay, first, in the colder latitudes; and that a fruit which there begins to decay, may yet be 
successfully cultivated in a more southern climate, or, what is equivalent, in the confined and warmer atmosphere of cities. Those varieties, therefore, which no longer succeed with us, may yet continue for a while to flourish in the middle regions of the Union, and especially in the interior, beyond the limits and influence of those cold eastern breezes from the Atlantic, which, rising with the diurnal appearance of the sun, visit us so regularly and constantly at stated seasons.

There are some, however, who dissent from these opinions and conclusions - opinions which the continued experience of the ages, present as well as past, seems only the more abundantly to confirm. They do not, indeed, deny the fact of the destruction, but they deny the cause. In their attempts to sustain the credit of the old fruits by rendering them immortal, they would ascribe their deterioration to some supposed alteration of climate, and not of ours alone, but of the climate of all those countries where the same proofs of their mortality have appeared.

We awoait the proofs of such changes;-meanwhile, in their absence, I believe all will agree, that in adopting this theory, we adopt the safest course.

Mr. Knight and some others in England, and the Comte de Coloma of Malines, have succeeded in raising some new and valuable varieties of fruit from the seeds obtained by hybridism or cross fertilization. In describing the principles and modes of practice of this art, I have had recourse to Phillips, to Knight, and especially to Lindley and M. Fries Morel, to all of them collectively: The same principles are alike applicable to trees of ornament and to flowers. But we are authorized in asserting, that this is not the mode which has been so generally adopted by Dr. Van Mons and others in Belgium, and that the mode by which so many new and very extraordinary varieties of fruits have been there produced, differs essentially from this which I am now about describing.

The outer circle of the slender threads or filaments, which rise around the centre of the blossom or flower, are called the stamens, or males, and the central are called pistillum, pointals, or females.

The stamens bear at their summit a small ball, called the anther, which contains the fertilizing powder called the pollen. 
At the summit of the pistillum are the organs of secretion called stigmat $\dot{a}$, consisting of one or more intercellular passages leading thence to the base, where are situated the cell or cells in which are placed the ovula, or the rudiments of seeds.

The pollen, when viewed through a microscope, is found to consist of extremely minute hollow balls, filled with a fluid in which swim innumerable particles of an oblong or spherical form, and having an apparently spontaneous motion. When the anther is mature, it bursts or opens with an elastic force, by which its contents are dispersed, and a portion of them falling on the stigma, which is of lax tissue, the moving particles of pollen descend through the tissue of the style, by routes specially destined by nature, into the cells where the ovula are placed, and these, being thus vivified, are converted into the seeds or embryo of a future plant.

The operation of hybridizing, or cross fertilization, must be performed in a dry day, and before the blossom is entirely expanded; the most favorable moment is just before the rising of the sun; the pollen, being at that time humid, is closely attached to the anthers. The blossoms must be carefully opened, and the anthers extracted by delicate scissors, care being taken neither to wound the filaments which support them, or any other part of the flower.

About nine o'clock, the blossoms being exposed to the full influence of the sun, the matured pollen from another variety must be carefully placed on the blossom which it is intended to fertilize, and from which the anthers have been extracted; and this operation must be repeated twice or thrice during the course of the day. By shaking the blossoms over a sheet of white paper, the time when it is perfectly mature will be ascertained. It is necessary to protect the prepared blossoms from the bees and other insects with thin muslin or gauze, which will not exclude the sun or air; and it is proper also to protect them from the rain and dews, till a swelling is perceived in the germ.

By screening the plants from the sun, and by frequent waterings, the maturity of the pollen and the stigma may be retarded.

When the process has been successful, the pollen, which had been placed on the stigma, becomes so attached, that it cannot be removed with a hair pencil; it changes form 
and color, and soon disappears, and the blossom will soon wither and fade. But when the process has been imperfect, the reverse of all this is the case ; the pollen is easily detached from the stigma, its appearance is unaltered, and it remains visible with the duration of the flower, which will continue for a long time.

The fertilized seeds, thus yielded, produce generally flowers which resemble in color, or fruits which inherit mainly the qualities of the kind which furnished the pollen; while the form of the flower, or some of the constitutional qualities of the fruit, will resemble those of the plant which matured the seed.

No cross fertilization can take place between plants or fruits unless nearly related. None, for instance, can take place between the pear, apple, or quince; or between the plum, peach, or cherry, \&c.

Wild plants or fruits, while growing in their native wilds, are generally perpetuated from generation to generation without change; but this is not the case with the hybrids or cultivated varieties, however isolated or far removed the tree may be, which produces the seeds, from any other of its species. Transplanted to other soils, the change begins.

The most intelligent writers have asserted, and it now appears to be admitted as an indisputable fact, that the original number of varieties of the apple were very small ; and that the numerous varieties, differing in size, form, and flavor, and periods of maturity, originated from the vild apple, or $c r a b$, a small and very acid fruit. The pear, from a small and very austere wild fruit, has been in like manner wonderfully ameliorated. Mr. Knight seems persuaded that their fine varieties of native English plums originated from the Sloe plum, a wild and austere, small, black fruit ; or, according to Mr. Neill, from the Bullace, another wild plum, very small, and acid. The gooseberry, originally a small, indifferent fruit, has, by cultivation, not only highly improved in flavor, but wonderfully in size. 'The large Dutch red and the large Dutch white currant are highly productive and improved varieties. But the whitc currant, as Mr. Loudon asserts, is but a variety, produced from the seeds of the red currant.

Cross fertilization may, indeed, effect important improvements, by combining in one object those desirable qualities, which may have been previously possessed by two 
other individuals in separate states. But it can never, of itself and alone, produce or create those opposite qualities, which had never existed before in any individual, but are as directly opposed to all that had ever before existed, as white is to red or to black; and we must look to other causes for such important changes.

The following mode, by which the Belgians have succeeded in obtaining so many new and extraordinary varieties, is from the account written by Dr. Van Mons; and for this valuable article, we are indebted to the researches of General Dearborn, by whom this account was inserted in Vol. vIr. No. 28 of the New England Farmer.

"The Belgians give no preference to the seeds of table fruits, when they plant to obtain new ameliorated kinds. When their plants appear, they do not, like us, found their hopes upon individuals exempt from thorns, furnished with large leaves, and remarkable for the size and beauty of. their wood; on the contrary, they prefer the most thorny subjects, provided that the thorns are long, and that the plants are furnished with many 'buds or eyes, placed very near together. This last circumstance appears to them, and with reason, to be an indication that the tree will speedily produce fruit. As soon as the young individuals which offer these favorable appearances, afford grafts or buds, capable of being inoculated upon other stocks, these operations are performed - the apples on paradise, and the pears on quince stocks - to hasten their fructification. The first fruit is generally very bad; but the Belgians do not regard that: whatever it is, they carefully collect the seeds and plant them; from these a second generation is produced, which commonly shows the commencement of an amelioration. As soon as the young plants of this second generation have scions, or buds, proper for the purpose, they are transferred to other stocks, as were the preceding; the third and fourth generation are treated in the same manner, and until there are finally produced ameliorated fruits worthy of being propagated. M. Van Mons asserts, that the peach and apricot, treated in this manner, afford excellent fruit in the third generation. The apple does not yield superior fruit before the fourth or fifth generation. The pear is slower in its amelioration; but M. Van Mons informs us, that, in the sixth generation, it no longer pro- 
duces inferior, but affords excellent fruits, intermixed with those of a middling quality."

Intelligent writers - those on whom we may rely - have assured us, that the new and numerous class of fruits which have arisen during the last forty years, is far more precious and inestimable in point of quality, than all previously known. They refer in this more particularly to pears. Trees of those already most renowned are here.

Highly satisfactory specimens of many of the new species which are described in the following pages, have been seen and exhibited among us; enough to convince us of the decided excellence of at least a portion of those already proved; but many of the new, foreign, and renowned varieties, of very recent introduction, are yet for trial.

The unwearied labors of Knight, of Van Mons, of Coloma, of Hardenpont, of Duquesne, of Nelis, of Liart, of Dorlain, and others, have probably effected more during the last forty years, than all that had been previously ac. complished during twenty centuries.

All these fruits are recommended as highly deserving of trial in our climate. From them we must make our other selections, at another day, of such kinds only as prove, on trial, alike adapted to our climate, the very best in quality, and the most productive.

\section{Section V. - Of the Growth of Trees and Plants.}

Modern physiologists have demonstrated, that trees and plants derive their nourishment throngh the extreme ends, and blunt, spongy points, of the minute fibres of the roots. These innumerable mouths, or spongelets, absorb and drink in, without discrimination, all the fluid substances which come in their way. These fluids ascend through the alburnum, or sapwood, to the leaves, which are the true laboratories of all plants, as well as the organs of respiration. The circulation of the sap, which commences its movement first in the branches, and last of all in the roots, is produced by the attraction of the leaf-buds and leaves, which are developed by the warmth of spring - their transpiration requiring supplies so great and continual, that some plants are stated to perspire even twice their weight in twenty-four hours. The true sap, thus generated 
in the leaves, and separated from the more watery particles, descends through the inner bark, having now acquired new powers, and being now peculiarly prepared to nourish and give flavor to the fruit; and, continuing its descent, it deposits in its course the cambium, or mucilaginous substance, by which new and successive layers of wood and of bark are annually added to the tree; while whatever is not adapted as aliment to the peculiar wants of the plant, is again returned by the roots to the earth.

\section{Section VI. - Transplanting.}

When trees are removed for the purpose of being transplanted, their roots should, if possible, be preserved fresh and entire. If these precautions have been omitted, their whole bodies and roots must be immersed in fresh water during twenty-four hours; and their tops must be lessened in proportion to the loss their roots have sustained. The sources by which they derive the nourishment which they receive from the earth being diminished, the whole sap of the tree, and even its vitality, would otherwise pass off by transpiration.

October and November, and immediately after the first hard frosts have arrested vegetation, is esteemed the best season of all for fransplanting trees. The peach, the plum, the cherry, and evergreen trees, do especially well when planted early in autumn. But where circumstances render it necessary, tranšplanting may bé deferred till spring.

When trees are transplanted in autumn, the earth becomes duly consolidated at their roots, and they are ready to vegetate with the first advancement of spring.

The holes for receiving the trees, should be dug from four to six feet in diameter, according to the size of the trees, and eighteen inches deep; the yellow subsoil should be cast out to this depth, and replaced at bottom with rich soil, intermixed with a portion of manure. The tree should generally be set no deeper than it stood before, otherwise the lower roots will cease to grow; the fibres should be spread horizontally, in their natural position, and the soil intimately and compactly placed about their roots; manure-may be placed above and beneath, and on every side, but ought never to be suffered to come in contact with the roots, as it is liable, in this case, to 
corrupt and injure them: finish by treading the ground very hard. When evergreen trees are set, it is generally considered indispensable to pour at once a few gallons of water around the tree previous to treading hard the earth: finish earthing, and tread hard an hour afterwards. This is an excellent and safe mode with regard to any tree.

\section{Section VII. - Propagation:}

Most of the species of trees and ligneous plants are propagated by seeds, and some may be propagated by cuttings, and all by layers.

BY SEeds. - In raising trees, \&c., from the seeds, it is generally a good rule to plant or sow them as soon as they are mature and gathered from the tree. Those seeds, however, which are enveloped in a pulp, must first be separated. Those of the hawthorn and many other kinds, which are possessed of a gummy or resinous pulp, will not vegetate till the second year, unless first separated and subjected to the action of frost; or the seeds of the locust and many other kinds, which are possessed of hard shells, and therefore require to be frozen beneath the soil, may be made to vegetate quickly by being covered with boiling water and set in a warm place; as the seeds become swollen, they are separated and planted, and fresh boiling water is poured over the remainder every twenty-four hours, till all are prepared.

'There are many advantages attending the practice of causing seeds of various kinds to germinate before being planted. Such seeds rise at once in advance of the weeds, and strike root downwards while the earth is yet humid, and before the scorching sun has dried up the moisture, thus rendering it impossible for any seeds to vegetate near its surface. .

Small seeds of many species may be enclosed in small liuen bags, or in moss or cotton, and steeped a few hours in lukewarm water; these, being suspended, during night, in a chimney where a fire has been kept during the day, will vegetate by morning. This is an easy mode which has been recommended. More slow-growing seeds, after stecping a day in warm water, are to be kept for several days in a lukewarm atmosphere.

Seeds steeped in a weak solution of muriate of lime, or 
in water containing a few drops of muriatic acid, germinate. still more suddenly; and I find it stated on good authority, that seeds one hundred and twenty years old, which were brought by Boose from the Bahamas, and had resisted every effort to make them vegetate, were yet made to gerninate by steeping them in a weak solution of muriatic acid. Boyse, of Prussia, has accelerated the germination of seeds by moistening with malic acid, (cider.)

When seeds are to be transported to distant climates by sea, it is recommended to preserve them in new and finely-powdered charcoal; or they may be immersed in a thick solution of gum arabic, and after.being dried, they may be closely corked up in glass ressels. Lastly, packing seeds compactly in layers of sugar, is found to be an excellent mode of preservation.

LAYERS are the limbs or suckers of trees, bent down without being separated from the parent tree, and covered with soil; their extreme ends only being left out: thus buried, they will soon strike root, generally; some particular kinds of trees, however, with extreme difficulty : such must be tongued - an operation which consists in cutting the layer half off, below an eye, and splitting it up an inch, or more; the cleft to be kept open by a small wedge, and buried beneath the surface. This operation should be performed in spring; and the plant, when well rooted, may be separated in the autumn or spring following.

Cutrings. There are many kinds of trees which may be raised from cùttings. "Cuttings should generally be from eight inches to a foot in length, and cut off at bottom close below an eye, and planted in a humid soil, two thirds of their length beneath the surface, and the ground trodden hard. With some particular kinds, however, it is necessary to square the bottom of the cutting, and to press it hard down on the bottom of a pot. Other kinds must be planted in pure sand, and protected from the sun till rooted. They require artificial heat in the soil, and a confined atmosphere, which moderates their transpiration.

\section{Sèction VIII. - Inoculativg.}

Inoculating is the operation of transferring any particular and desirable variety of tree upon the stock of an inferior or wild variety. 'The operation is principally practised 
on small trees, and only during the time when the sap flows freely, and cliefly during the months of August and September.

Select for the buds the ripest young twigs of the year, and cut off the leaves, leaving the foot stalk eutire. Having selected a smooth place in the stock, make a perpendicular slit downward quite through the bark, an inch or a little more in length. Make a cross cut at the top of this slit, quite through to the wood, a little slanting downwards; next, with the ivory haft of the knife, raise the bark on both sides, from top to bottom, being very careful not to injure in the least the cambium or sap-wood. Next, and with expedition, proceed to take off a bud; this is effected by entering the knife half an inch or more below the bud or eye, quite through the bark, and separating the bark from the wood to the same distance above the eye; always leaving a very thin slip of wood, of about one third of the length of the bud; this thin slip of wood occupies the middle section of its length. The bud is to be immediately inserted in the stock to the bottom of the slit, and between the bark and the wood; and the top of the bud being squared even with the cross cut, every part, except the eye, is firmly bound and covered with strong wet bass matting.

It is by no means a point so very essential, whether the cross cut is made at the top or bottom of the slit; whether the bud is inserted downwards or upwards; it generally succeeds equally in both cases. The mode of taking off the bud with a thin slip of wood occupying the middle section of its length, is called the new or American mode; as I find it described by no European author. It is the mode best adapted to a warm climate. But when the season is far advauced, and the sap flows less freely, it is deemed the surest mode to take out the whole of the wood, always leaving the root of the bud.

The string is to be taken off as soon as it begins to girdle the tree, which is generally in about ten days.

In spring, after the frost is out of the ground, and as soon as the buds begin to swell, cut off the stock a quarter of an inch above the bud, sloping downwards on the opposite side.

Sonllop Budding is performed by cutting, from a small stock, a thin, narrow scallop of wood, about an inch in length; and taking from a twig a thin scallop of wood, of 
the same length, containing a bud; this is instantly applied and fitted perfectly at top and bottom, and on at least one of its sides, and firmly bound with wet bass matting. This mode may be practised in spring, and if it fails, a second chance will be offered in July. The French are stated to practise this mode on roses.

The above are the principal modes of inoculating adopted in practice, although Professor Thouin has described no less than twenty-three distinct modes of operation.

Dr. Van Mons buds his roses in June, so that they grow and frequently blossom in the same year. He prepares the young and unripe wood by separating the leaves, leaving only their footstalks; in fifteen days after, their buds are swollen, and are now fit for insertion : the stock is cut off six inches above the insertion of the bud, at the time the operation is performed. They are bound with thin strings of bass matting, previously drawn through a solution of alum and white soap, and dried, which renders them impervious to water.

\section{Section IX. - Grafting.}

Grafting is usually performed in spring. Professor Thouin has described forty modes; but the following will answer for all general purposes :

Whip Grafting, or Splice Grafting. This mode is practised principally on small stocks; and it succeeds best when the scion and stock are of an equal size.

The scion, which consists of the young wood of the former year's growth, is cut to the length of about four inches. This and the stock are each to be cut sloping for an inch or more, and tongued. Tonguing consists in cutting a slit in the middle of the slope of the stock downwards, and a corresponding slit in the scion upwards; both are now to be nicely joined, so that one of the sides, at least, if not both, shall perfectly coincide, and to be securely bound with a wet bass matting string, and covering with composition, or with grafting clay. As soon as the scion and stock are completely united, the string is to be removed.

Cleft Grafting. - This mode of grafting is usually practised on stocks of from one to two inches in diameter. It is thus performed. The head of the stock is carefully sawed off at a part free from knots, and the top pared 
smootb; with a thin knife split down the stock through the centre, to the depth of about two inches, and insert a wedge to keep it open for the reception of the scion. The scion is to be prepared in the form of a wedge, with an eye, if possible, in the upper part of the portion thus formed; perfect success is the more certain when this is the case. The scion is now to be carefully inserted, so that the inner bark of the scion and of the stock may both exactly meet. Large stocks require two scions, one on each side; sometimes four are inserted. The whole is now to be carefully covered with the composition, or grafting clay, except two or three eyes of each scion. This mode of grafting is equally applicable to very small stocks; but these, being weak, must be bound with a string of bass matting.

Sadde Grafting. This mode of grafting is performed chiefly on very small stocks; it is much practised by Mr. Knight. The upper part of the stock is prepared in the form of a wedge, by two sloping cuts, one on each side. The scion is prepared by splitting it upwards, and paring out the middle part of each side to a point. When the stock and scion are of equal size, the adjustment may be made perfect; but if unequal, one side at least must exactly meet. The whole is secured by a string of matting, and covered with the composition, or clay. The string, however, is to be removed when a perfect union has taken place.

Root Grapting. This operation is often performed on grape vines, just below the level of the surface, by the usual mode of cleft grafting. It is also performed on portions or pieces of root, where suitable stocks are scarce.

Side Grafting. This mode is sometimes practised on those parts of a tree where a limb is wanting. There are two ways in which it is performed. 1st. The scion is prepared in the same manner as for splice grafting, and the bark and wood on the side of the stock is cut sloping; and, the scion being adjusted as carefully as possible, it is bound on and covered with clay. 2d. The scion being cut sloping, as in whip grafting, a cross cut is made in the side of the tree, on the top of a perpendicular slit; the bark of the tree above the cross cut is pared down slanting to the wood. 'The bark is now raised as in inoculating, and the scion inserted, and bound fast, and covered with clay. 
Grafting by Approscr. This is often practised on trees and shrubs which succeed with difficulty by other modes. The tree to be grafted must be growing very near the tree which is to furnish the grafts. - The limb or limbs of each tree which is to be thus united, must be pared with a long, sloping cut of several inches, nearly to its centre; and the parts of each tree, thus prepared, are to be brought together, and firmly secured by a bandage of matting, so that the bark shall exactly meet on at least one side, and covered with clay or composition. When a complete union has taken place, the trees are separated with a knife, by cutting off the scion below the junction, and cutting off the stock above.

Grafting Clay is made of one third part of fresh horse manure, free from litter, one third of cow manure, and one third of good clay, with a small mixture of hair, well beaten, and incorporated several days before using.

Grafting Composition is made of three parts of resin, three parts of bees' wax, and one part of tallow; melted together; when well mixed, it is poured into water and worked up, like shoemaker's wax, by hand. This composition may be spread, while in a melted state, pretty thickly, with a brush, on very strong brown paper. This paper is to be cut into small strips of suitable size, and is very quickly applied., In cool weather, it may be instantly warmed with the breath, so as to become adhesive.

\section{Section X. - Of Fruitfulness.}

Artificial Means by which Fruitfulness is induced. Whatever operates in repressing the too vigorous growth of the tree, by obstructing the free circulation of its sap or juices, and by causing it to accumulate and become concentrated, has a tendency to render the tree fruitful.

While a tree is yet young and flexible, and exercised by every moving breath of wind, its pores continue open, and the sap is rapidly and uninterruptedly diffused; its whole juices are expended in the formation of leaf buds. $\mathbf{A}$ highly-manured soil, a warm temperature and humid atmosphere, are alike unfavorable to the production of flower buds, by promoting excessive vigor in the tree. But as they grow older, their consistence becomes changed and 
more inflexible; their bark also becomes more thick and rigid, and may therefore operate by compression; and the sap which before passed on uninterruptedly, is now retarded in its progress; it accumulates and develops fruit buds, and the tree falls into bearing. To effect this object by artificial means, various modes have been adopted. 1st. By ligatures, or ringing, or girdling; variously termed decortication or circumcision. 2d. By bending their branches, or by continually shortening the extremities of the young and growing wood. 3d. By subjecting them to a warm and dry atmosphere. Or, lastly, by a combination of each and every mode, as in the case of Chinese dwarf trees, and the Quenouilles of the French.

Suns. 1st. Girdling, or Decortication. Girdling, decortication, ringing, or circumcision, as it is sometimes variously called, consists in making two circular incisions, quite round the limb, through the bark, at the distance of about three eighths of an inch asunder, more or less, according to the size and thriftiness of the tree; then making a perpendicular slit, the ring of the bark is wholly removed to the wood.

Ringing, or decortication, is applicable to every kind of fruit tree, and to the vine. Its operation is twofold. 1st. In the early production and abundance of blossom buds which it induces; or, $2 \mathrm{~d}$. In increasing the size of the fruit and hastening its maturity, according to the season in which the operation is performed.

When the design of decortication is the production of blossom buds, the operation must be performed about the last of June, or begimuing of July. But when the object to be obtained is the enlargement of the fruit and its more early maturity, the operation must be deferred till just at the time when the tree las come into full leaf in the spring. Mr. Knight, from an experience of fifty years in the practice, observes, that when the space from which the bark is taken off, is too considerable, a morbid state of early maturity is induced, and the fruit becomes worthless. The same injurious effects he has always witnessed, whenever the operation has been performed upon very young or very small branches; for such become debilitated and sickly long before the fruit can arrive at maturity. A tight liga- 
ture, applied in the preceding summer, in such cases; he has found to answer all the purposes of ringing, with far less injurious consequences to the tree.

Girdling, according to Mr.-Knight; by causing the current of the sap, while descending from the leaves through the bark, to become arrested in its progress, it accumulates above the decórticated place, whence it is repulsed, and again carried upwards, to be expended in an increased production of blossom buds and of fruit; while the part below, being but ill supplied with nutriment, ceases almost to grow, and in consequence it operates feebly in impelling the ascending current of sap through the decorticated space. And the parts above, being, in consequence, less abundantly supplied with moisture, the early maturity is thus powerfully accelerated, as is always the case in a drought, from whatever cause produced.

Mr. Knight, from his long experience, is not friendly to the practice of ringing or girdling in any mode, except only in those few cases, where blossoms cannot otherwise be obtained, or where a- single crop of very early fruit exceeds the value of the tree.

Decortication may be practised alternately, on portions of the same tree in alternate years.

Subs, 2d. Debarking. Debarking, according to $\mathrm{Mr}$. Neill, is a practice first brought into notice by Sir John Sinclair, in 1815, in a pamphlet. It consists in paring off, in winter, all the outer bark of the stem and principal branches, down to the liber, or inner concentric bark. 'The effect is, that such plants grow more vigorously, and the quantity and quality of the fruit are greatly augmented.

Mr. Loudon has recorded, (Mag. Vol. vir. p. 662,) that this operation has been declared, by one of the best practical men in the Netherlands, a never-failing method of greatly improving the quality and size of the fruit on apple and pear trees, and vines. At the winter pruning, which is given there in February, he cuts off, with his common hooked pruning knife, all the outer bark down ta the liber, of every tree'above eight or ten years old; not so deeply, however, with the young, as with the old trees. It is asserted by those who have witnessed, that this man's practice has never failed of being successful. And another, who has tried it in that country, asserts, that since he had 
practised it, he has always had larger and better flavored fruit. 'This practice, says Mr. Loudon, " is not uncommon in England with apple and pear trees, and very general with regard to vines under glass."

Subs. 3d. Bending the Limbs. This appears to be the most simple, easy, and effectual mode of rendering trees productive. When judiciously performed, its effects are very extraordinary.

The effects appear to be perfectly understood by the Chinese in training their dwarfs. Its effects are also exemplified in the mode of training trees en quenouille, which come into bearing earlier, and bear more abundantly.

Dwarfing is effected by inoculating fruit trees on stocks of comparatively slow growth; the circulation is in consequence retarded, and the effect thus produced is somewhat like that produced by girdling. The apple is dwarfed by being inoculated on the Paradise or Doucin stock; the peach on a slow-growing plum stock; and the pear by being inoculated on the quince stock; - a new mode of dwarfing I shall presently explain; - by means simply of bending, prodigious crops are produced on the vine; [see the article on the cultivation of the vine;] also on the fig; for by this mode Mr. Knight has obtained eight crops in a year. [See the article on the fig.] The system is equally applicable to every species of fruit tree. It consists in bending every limb or twig, to a position below the horizontal, while it is yet in a vigorously-growing state, generally the last of June; with some kinds, which have a prolonged vegetation, it may, perhaps, witl more advantage, be deferred till July, as in the case of the peach. The effect produced in the first instance is a momentary suspension of the growth; the juices are concentrated, and form fruit buds, for the production of fruit in the following year.

According to Mr. Neill, training the bearing shoots of pear trees downwards, generally causes them to produce fruit the second year, which would seldom otherwise produce fruit under six or seven years. And Mr. Knight recommends to bend the young, luxuriant shoots of the peach, instead of shortening, [as recommended in the article below.] They thus produce the finest possible bearing wood for the next year. 
Subs. 4th. Particular Modes of Pruning and Training. Mr. Dalbret, superintendent of the compartments in the Royal Gardens, devoted to the culture of fruit trees and economical plants, (near Paris,) has delivered a course of lectures on Pruning, in the school of Practical Horticulture. He has practised on his theory for a number of years, and is therefore enabled to appreciate its value. "Among the operations which are very rarely practised, and which are scarcely known at a distance from the capital, he has insisted, with propriety, upon the eradication of all useless -buds, which occasion more vigor in the branches destined to produce good wood and fruit; and upon the necessity of not leaving too many lateral shoots or twigs, which exhaust the tree; but few should be preserved for yielding fruit each year, and the others should be cut off within a half an inch of the branch, which will cause fruit spurs to appear. He has also demonstrated the utility of pinching or cutting off the ends of the shoots, particularly of stone-fruit trees, to eheck-the excessive vigor of the main branches, and to cause the branches. which usually consume the sap, to yield fruit; the operation consists in cutting off the yet herbaceous, or young and tender shoots, when they have attained the length of six or eight inches, at a half an inch, or at most an inch, above the old wood; ; if it is done later, the operation will be injurious, instead of insuring fruit for the third year." [New England Farmer, Vol. vur. This article is from the researches of the Hon. H. A.S. Dearborn, and from the Annales d'Horticulture.] For some further particulars, see Currant. Also see Peach.

During the autumn of 1840 , and while at Paris, I occasionally visited the Garden of Plants, where I saw the whole system of pruning as practised by Mr. Balbret himself.- The pear trees at that place are trained in perfect quenouilles or pyramids, with branches quite to the ground, and by the system of spur pruning. By this system the tree is only suffered to advance upwards in proportion to its growth in a lateral direction. . Thus pyramidally trained, a tree will retain its branches in a vigorous state, quite to the ground, as all the lateral shoots receive an equal benefit from the sun, and rain, and dews, and the tree produces abundant crops, from the summit to the base. By other modes of training, the lower limbs are. liable to 
decay and to perish. The trees which I saw thus trained, at the Garden of Plants, were set in very compact order, or about seven feet asunder; but Mr. Dalbret prefers ten feet asunder each way, as the most suitable distance for pear trees thus trained. I found this systen of training and of spur pruning was perfectly understood by the experienced cultivators in the vicinity of Paris. Mr. Dalbret has published a work on the subject.

Spur Pruning, as practised on the pear and other fruit trees, by experienced cultivators in the vicinity of Boston, is thus performed: Near the base of the young wood of the year, is always to be seen a cluster of eyes; in the middle of July they cut off the twig above the eye which is next above the cluster of eyes which are at the base, so that only the upper eye bursts. The middle of September they cut below this eye, and the next year numerous fruit spurs proceed from this cluster, which will produce fruit in the following year, or the year after. Vines are also pruned by this mode.

Subs. 5th. Dwarming. - Grafting and its Effects. The effect of grafting in rendering trees suddenly productive is well known. This effect is produced on the principles before explained.

Dwarfs are extensively used in France for almost every variety of fruit tree, particularly those called Qucnouilles. And they are asserted by them and the English writers to be not only admirably adapted to large fruits, as they are not so much exposed to high winds, but for pears, more especially, they are declared to produce better fruit. A new mode of dwarfing the pear has lately been introduced to practice in France. The quince is inoculated on the pear stock, and after this has grown a year, the pear is inoculated into the quince, an inch above the insertion of the preceding year. The advantages of this mode are many; the section of the quince, being thus elevated, is not so liable to the attacks of the borer as at the surface of the earth. The roots of the pear and those of the quince, require different soils. [See Pear and Quince.] It is asserted that the pear should be dwarfed only for the production of summer fruit. As an argument to prove that the fruit of the pear thus produced cannot partake of the austere quality of the quince, it is asserted that both 
the quince and the pear are alike nourislied from the earth by the same food, in quality and substance; the leaves being exclusively the laboratory in which the juices are prepared which form the fruit. Even the difference in the varieties of fruit of the same species, in taste and flavor, is supposed to be owing to no other cause than some different and peculiar formation or property of the leaf. The Chinese form their dwarfs on the most fruitful limbs of bearing trees; these, when rooted, are separated, and when the fruit is at maturity, being much in demand in China, they bring a price in proportion to the crop they bear; especially oranges, peaches, plums, grapes, \&c. They even extend their practice to flowering and other ornamental trees.

The following mode, as practised in China, is extracted from - the account of John Livingstone, Esq.; of Macao. See Vol. Iv. of the Lond. Hort. Trans.

In the spring, at the time when the trees of fruit or of ornament are in blossom, they commence by selecting. those branches which are most loaded with blossoms, and remove the bark quite round the branch, to the depth of about half its diameter. This part is covered with a large ball, of a composition similar to grafting clay. For large branches of elm, \&c., a covering of straw or coarse cloth is used; but for the orange, peach, \&c., the composition is of itself sufficient.

When it has been ascertained that the roots formed are sufficient to preserve the living system, - and this time varies from six weeks to three months, according to circumstances, from the commencement of the operation, - the branches are separated, and after being removed to pots, their fruitfulness is preserved by cramping their growth; by confining their roots in very contracted earthen vessels; in carefully regulating and stinting their supplies of nourishment; in bending and contorting their limbs into many fanciful shapes, and confining them thus by wires... In the province of Fo-kien, where the best dwarfs are said to be formed, to entice ants to destroy the heart wood, sugar is introduced into small openings made for this purpose.

Staunton, in his account of the embassy of Lord Macartney to that country, has stated that straw was used with the clay, and a vessel of water is placed above, with an aperture sufficient to allow the water to fall slowly, in 
single drops. This was the mode in some of the provinces.

Subs. 6th. Quenourlue. This term is applied by the French to trees trained in a regular pyramidal form; from their resemblance to the ancient distaff, they term it en qucnouille.

In the Department of Maine and Loire, as we are informed in the Annals of the Horticultural Society of Paris, they train their trees en quenouille, not only of the pear and apple, but of the peach, the apricot, the plum, and the cherry, the vine, and other fruits. The pears for this purpose are inoculated on the quince, and the apple on the Paradise stocks.

The trees they use are principally raised at Angers, where the soil is of such extraordinary fertility, that it is possible to raise a tree or quenouille, with all its lateral branches, in a single year from the bud.

There are some kinds of pears which do not incline to throw out lateral shoots. When, therefore, the tree has grown to a sufficient height for the first tier of branches, they pinch off the top for their production. When the vertical shoot has risen to a sufficient height for another set of branches, it is pinched off again, and another tier is produced. And thus the process is continued, till the requisite height is attained, and the tree is completely furnished with its branches, from the bottom to the top. When the lateral shoots incline to grow too fast, these must also be nipped in, that the equilibrium and perfect proportion of the tree may be preserved.

This is an operation which requires much judgment and experience in its application. - It is observed that it always causes a momentary suspension of the growth. If the pinching or clipping off be too near the top, but one single and verticalshoot will be produced; if the top be shortened a little lower, two branches only will put forth; but if it be shortened a little lower still, three or four lateral shoots will put out just below, and a top or vertical one.

Mr. Loudon in his Magazine has described " a long row of pear trees in the garden of Chiswick, trained $\mathrm{cn}$ qucnouille, or, inore correctly, as regards those of Chiswick, $\mathrm{cn}$ pyramide, which, with the additional feature of the points of the shoots tied down, has a rery fine appearance." ** 


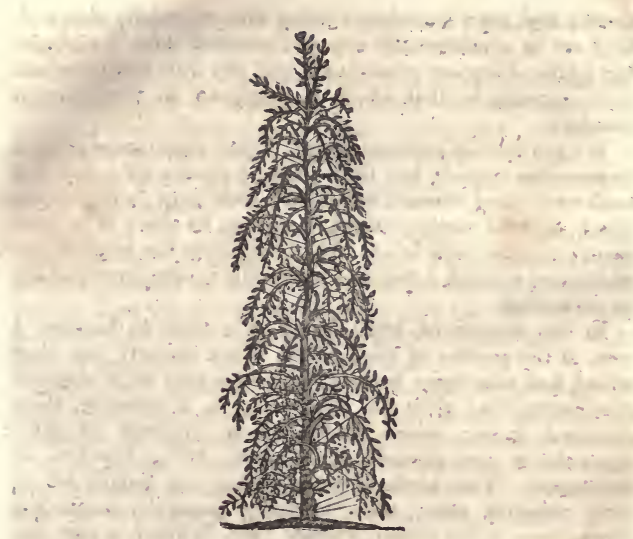

Representation of Quenouille Training.

"In short, this single row of pear trees is the most interesting feature of the garden. The shoots of the current year are bent down when fully grovon, and fixed in a pendent position by shreds of bass. In the course of the winter these shreds are removed, to admit of pruning, when the shoots are found to have taken $a$ set. ${ }^{\prime \prime}$ In the course of the summer, such as grow too vigorously are again tied, the object being to check the vigor of the young shoots, and, by impeding the return of the sap, to cause it to expand itself in those young shoots, in the formation of blossom buds."

These pear trees at Chiswick, as Mr. Lindley informs us, are all inoculated on the quince; they are trained perpendicularly, with a single stem, to the height of about seven feet, with tiers of branches at regular distances; each being generally about eighteen inches long, and the tiers from nine to twelve inches apart. ${ }^{*} *$ * * If the plant be strong and vigorous, it will throw out many more branches than are necèssary; these must be trimmed out, the best only being preserved; these are to be tied 
down; and, their luxuriance being thus materially checked, they are in consequence always furnished with fruit-bearing spurs; they are productive, and the fruit they produce is far superior to that which is produced on the common standard.

We are further informed, that under such management quenouilles require but little room, a square of a few feet each way being deemed sufficient; their fruit, being within reach, may be easily thinned to enlarge its size; it is more secure against high winds, and, being near the ground, the additional warmth it receives materially insures its ripening in perfection.

In the autumn of 1840 , being on a visit to London, I saw, at the garden of the London Hort. Society, the trees which had thus been trained, then in a very high state of productiveness; they still preserved, in a measure, their destined form; those shoots which inclined to grow upwards at the summit of the tree, being checked or shortened. The trees at that garden are usually set in very compact order, their branches generally extending downwards, quite to the ground. Mr. Wilmot, a very distinguished cultivator of fruits for the London market, practises this same system, evidently as the most economical and profitable of any other mode. His pear trees, being set in compact order, and suffered to branch low, produced abundantly. So also at Mr. Kirke's establishment, an eminent cultivator of fruits at Brompton, near London, the same system, and this only, appeared to prevail; his pear and apple trees being planted but about twelve feet asunder, or less, and suffered to branch quite down to the ground, produced the most abundant crops.

Surs. 7th. - Fruitfulness is induced by a suitable season of reposc. - The trees and plants, the natives of the temperate climates, require a winter, or season of rcst; they awaken in the spring, refreshed by their slumbers, to new life and productiveness. Such trees and plants, therefore, become unfruitful within the tropics, finding no rest, nor their wonted season of repose, except only in the mountainous elevations. Yet in some tropical countries, they give to their vines, by artificial means, a suitable time of rest and slumber; and they awake to fruitfulness for a season. [Sce VINE, and its Cultivation.] 


\section{Section XI. - Pruning.}

If the branches of a young tree, issuing at and above the requisite height, be made, by pruning, to diverge from the trunk in every direction above the horizontal, and the interior of these be carefully kept from any interference with each other for a few years, little pruning will ever afterwards be necessary.

Many of my remarks in this section have reference principally to orchards of the apple, the peach, and the pear, cultivated as standards in our own highly-favored climate, and on an extensive scale, and are not intended as applicable to the admirable system of cultivating fruit trees in pyramidal form; or en quenouille.

The complicated systems of the English for pruning the apple, pear, peach, and plum, are not, in all respects, so necessary for us; they are, in part, adapted exclusively to a cold climate. It is not necessary with us to lay open and expose every part of the tree to the direct rays of the sun; the atmosphere being, in our climate, generally, of itself sufficient to ripen the fruit.

Heavy pruning is seldom necessary or advisable; but when, as in the case of grafting, or of heading down for a new growth, it becomes unavoidable, it should always be performed in that interval between the time the frost is coming out of the ground in spring, and the opening of the leaf.

A complete heading for any purpose should never be performed in early summer, or while the tree is in the most active stage of its growth. - It causes a sudden stagnation of the juices, and induces a sort of paralysis. And if the tree does not die outright, it grows no more, or but feebly, during the remainder of the season.

Yet for that moderate pruning which alone is generally needful, June and July, and during the longest days of summer, is the very best time; for wounds of all kinds heal admirably at this period, the wood remaining sound and bright; and even a tree debarked at this season recovers a new bark immediately.

Trees ought not to be pruned in February and March, at the time the frost is coming out of the ground. This is the season when most trees, and particularly the vine and sugar maple, bleed most copiously and injuriously. It 
causes inveterate canker; the wounds turn black, and the bark, for perhaps several feet below, becomes equally black, and perfectly dead, in consequence of the bleeding.

The lower side limbs of young trees in the nursery, should be gradually shortened, but not suddenly closepruned; they are essential for a time to strengthen the trunk, and to the upright and perfect formation of the tree.

\section{Section XII.- Noxious Insects, etc.}

Subs. 1st. Apilis, Puceron, Vine Fretter. Of this genus of insects there are many varieties; they prey on the leaves of different plants. Various modes for their extermination have been successfully tried. Infusions of tobacco-water, or of aloes, or elder leaves, or of Cayenne pepper, thrown on the leaves with a syringe, are said to be effectual. Willis's syringe is the best known for this purpose. Sulphur dusted on them with swan-down puff has been highly recommended. Lime water answers in many cases, and even soap suds. Lastly, hot vinegar is a powerful application.

Suns. 2d. Borer. The borer is a destructive worm, which perforates the wood of the apple and quince at the surface of the earth, or a little below, where the bark is tender. If the insects have once entered the tree, they must be dug out, or destroyed, by introducing a sharp, flexible wire, and the aperture must afterwards be filled with clay or mortar. The eggs which produce this insect are deposited from the last of April to the beginning of June. To prevent their attacks and secure the trees effectually, nothing more is necessary than to surround it, a little before the season when the eggs are deposited, either with a small conical mound of unleached ashes, or clay, or mortar, or with a wrapper of brown paper, as recommended for the peach. For small trees, a solution of two pounds of good potash in seven quarts of water, applied with a brush, from the height of a foot quite down to the surface, is a very cheap, easy, and effectual mode of preserving trees from their attacks, provided the application is made at the suitable season.

In some parts of New Jersey the worm is very destructive to the peach tree. They enter at the surface of the 
earth, or but a little beneath, and where the bark is tender. This worm feeds on the alburnum, girdling the tree beneath the bark. . Refuse tobacco has been applied around the trunk of the tree with good effect. Another mode of effecting the destruction of the worm is by very strong brine, a small cavity being formed around the trunk at the surface ; a pint of brine is poured in; this entering the cavity destroys the worm at once. Old beef brine is supposed to be best. "And it should be applied once in spring and twice during summer. But the preventive of leached or unleached ashes,' as above recommended, is to be preferred. Even a small conical mound of common soil, or of rubbish, placed around the trunk in May, has been found an effectual safeguard; but this mound must be levelled annually in October, that the bark of the tree may harden.

Subs.-3d. Curculo. The curculio, in those parts of the country where it has gained a habitancy, is the most destructive of all enemies to fruit. The curculio is a winged insect or beetle, which rises from its earthy bed, and chrysalis state, about the time the young fruit is forming in spring. They crawl up the trees, and, when sufficiently numerous, they puncture, and deposit an egg in every fruit, particularly those possessed of smooth skins, as the apricot, nectarine, and plum. They are stated to continue their work of destruction till autumn; the egg thus deposited, soon hatches, and produces a worm, which preys on the fruit, causing it, in most cases, to fall prematurely. With those fruits which I have just named, the destruction is usually almost total, in those parts of the country where this insect abounds. 'Yet it is stated as a fact by Dr. Tilton, that of two trees frequently standing so near each other as to touch, the fruit of one has been destroyed, and the other has escaped; so little and so reluctantly do these insects incline to use their wings. After the fruit thus injured has prematurely fallen, and gone to decay, the worms deseend into the earth, where they remain during the winter, in their chrysalis state; till the warmth of spring again calls them forth to renew their depredations The cherry, though equally liable to. their attacks, yet from the multitude of fruits which they produce, and their early maturity, usually escapes with but a partial destruction; and the peach escapes in a great measure, from the rough and woolly na- 
ture of its skin. The apple, although equally obnoxious to its attacks, frequently-survives, although disfigured in its form and lessened in its size. The pear, although sometimes attacked, yet seems to escape the best of them all.

Various modes have been recoinmended and practised to destroy this insect, or avert its attacks. Some have recommended kindling small and numerous fires in the orchard by night, on the supposition that, like the miller, they would be attracted by the light, and precipitate themselves into the flames. And some have asserted that the odor of tar annoys and disconcerts them, and have therefore recommended to suspend slips of shingles to various parts of the tree, which are to be frequently dipped in tar. If the odor of common tar has, indeed, been found so efficacious as is asserted, I would recommend that the coal tar, which may be purchased at the gas works in all our principal cities, be tried with the same intent. 'This last substance has, it is asserted, an odor so lasting, and so powerful and annoying, that experiments are making by gentlemen in Nantucket, by covering with this substance the exposed planks of their ships which sail to the Pacific, to preserve them from the destruction caused by the sea worm.

It has been noticed, that trees situated in lanes and extensive $y$ ards, where numerous cattle are confined, generally escape the attacks of the curculio. This is supposed to be in part owing to the ground being trodden so hard as to render it difficult for the worm to enter the earth, and to the annoyance and fright to which this timid insect is subjected, by the cattle rubbing against the trees. The insects, according to Dr. Tiltou, in such cases of fright, roll themselves into a little ball, and fall to the ground, where they become liable either to be trodden to death, or devoured by the farm-yard poultry as a delicious morsel. Poultry of all species have been recommended as very useful, from the multitudes of insects they devour, they being particularly fond of the beetle tribe.

A case is mentioned by Dr. Tilton [see Dom. Ency.] of Colonel T. Forest, of Germantown, who, having a fine plum tree near his pump, tied a rope from the tree to his pump handle, so that the tree was gently agitated every time there was occasion to pump water. The consequence was, that the fruit on this tree was preserved in the greatest perfection.

Hogs are stated to be extremely useful in orchards, by 
devouring at once the fallen fruit and the insect which it contains. And provided the hogs are sufficiently numerous to devour every fallen fruit, they; will shortly exterminate the insects from the orchard in which they are permitted to roam.

Paving the Ground. This is said to be a most effectual mode of preserving fruit from the attacks of the curculio. By preventing its descent into the earth, it finds no winter habitation. The ground should first be well manured, and the whole surface well paved with the common stones which so often encumber the fields. The trees, in this case, may be set very close. The excess of rain being carried off by the pavement, and their luxuriance being thus, restrained, such trees must not only produce great crops, but from the effect of the sun on the naked pavement, the fruit must be of the finest quality. [See what is further said under the article VINE.]

Another and ingenious mode of destroying the curculio has lately been devised by my friend Dr. Joel Burnet, of Southboro'; Massachusetts, and in the single instance only, in which he has tried the experiment, it has proved completely successful. There stood in his garden a young plum tree of the Prince's Imperial Gage, which was filled with blossoms every year, but bore no fruit. Early in spring, a hen, with an early brood of chickens, was placed in a coop beneath the tree. Thus were all the curculiones destroyed in the interval, soon after they arose from the earth, and before they had recovered strength sufficient to take to their wings, or ascend the tree. This plum tree, in that year, bore, in consequence, a very large crop of fruit. He observed that the curculio often ascended by aid of its wings.

Surs. 4th. Suvg Worm. These insects sometimes appear on the upper surface of the leaves, especially those of the pear, in the month of July ; and sometimes they appear again early in autumn. They are covered with a glutinous substance, and their destruction is easily effected by simply sifting slacked lime over them; dry ashes, however, answers equally as well. For large trees, an oblong tin vessel, perforated at the bottom with numerous small holes, and partly filled with lime or ashes, may be suspended by a string from a long, slender, and elastic pole. This, being, 
shaken over a tree, distributes the lime amongst the leaves, and the slugs are speedily destroyed. A man may go over a large tree in a few minutes.

SuBs. 5th. WAsPS. Mr. Bartram has recommended, for the destruction of wasps, which devour and puncture the grapes in vineyards, that shallow vessels, containing sugar and water, or molasses and water, should be placed on the windward side of the vineyard. The sweet perfume attracts them from a great distance from the leeward; they are thus destroyed, by partaking inordinately of the liquid.

Mr. Knight has informed us, that the wasps disappeared from his vine house, after he had surrounded it in part with a hedge of the yew tree.

For the destruction of some other varieties of insects, see Apple, Pear, Peaci, and Plum.

Subs. 6th. The White Mealy Insect. This insect is described by English writers as an insect of a most pernicious character, covering the trees and branches. Here it is little known. I must refer to them for the remedies. " Take half a peck of quick lime, half a pound of flour of sulphur, and a quarter of a pound of lamp black. Mix the whole together with as much boiling water as will form the ingredients into a thick paint. This composition is recommended to be applied to the stems and limbs of apple trees which are infested with the white mealy insect, having previously removed the moss and loose bark by scraping thein off with a strong knife, or some other instrument adapted to the purpose.

"In using the composition, it will be most efficacious if applied in a warm state, or something more than blood heat." - Lindley.

On young trees, Mr. Lindley further informs us, "vinegar will effectually destroy this insect; but would be too expensive to be applied when the trees are large."

Subs. 7th. The Rose Bug. These insects have of late proved very destructive, by devouring the leaves, not only of rose bushes, but also of the cherry tree, and various other trees; and rewards have been offered by the Massachusetts Horticultural Society, for some easy and effec- 
tual mode of preventing their ravages, and of effecting their destruction. A mode has been proposed and tried, which is asserted to have proved completely successful. It consists in simply dredging the leaves with fine black pepper, from a common pepper-box ; the application may be the most effectual, if applied while the dew is on the leaf. Refuse Scotch snuff, finely pulverized, it is asserted, will answer the same effectual purpose.

Destruction of Insects by Lamps during Night. In France the vines are sometimes infested by a moth or insect called pyrale, which produces a caterpillar, so injurious to the vines, that they often destroy the entire crop throughout whole districts. The evil was considered of sufficient importance to induce the government of that country to employ Professor Adouin, of Paris, to investigate the subject, and to discover, if possible, the remedy. An account of his researches for the destruction of the pyrale was published in France in 1838, and republished in Loudon's Gardener's Magazine. By that account, it appears that the most effectual method for the destruction of the moth which had been discovered, was to place amongst the rines, in the night time, lamps enclosed in glass, and suspended over saucers of oil. The moths fly to the light from all sides, which they are prevented from touching. By repeatedly striking against the glass, in their vain attempts to get at the light, the moths fall down, and are drowned in the oil.

One cultivator, in the year 1837 , placed in his vineyard, in one night, at the distance of twenty-five feet asunder, each way, two hundred of these lamps, each of which burned two hours, during which time 150 moths, on an average, were taken in each saucer of oil, making in all 30,000 insects; a fifth part of these moths. being females, each, of which, on an average, would have laid 150 eggs, which, in a few days, would have produced 900,000 caterpillars. During a similar period in one night, on the 7th of August, 180 lamps in that same vineyard caught 14,000 insects, three fourths of which were females, which, making allowance of more than one half as lost, would have produced $1,080,000$ caterpillars. Fortunately, the pyrale is not known in America; yet it is considered certain, that the same plan might prove equally successful for the destruction of many other insects of an equally pernicious character. It merits trial for the curculiones. [See Appendix, p. 427.] 


\section{A P P L E.-(Pyrus Malus.)}

ThE apple is a large, wide-spreading tree; the leaves are ovate; the flowers, which are produced on the wood or spurs of the former year, or of two years' growth, are in terminating umbels; the fruit is a roundish pome, its base umbilicate, of a color varying from green or white to yellow, to red, or violet ; of a sweet or subacid flavor.

In its wild state it is denominated a crab-apple, and is a thorny tree, with small leaves, and a small, unpleasant, acid fruit; and from the crab-apple it is supposed all our finest varieties have been produced by cultivation. The apple is supposed to have been introduced into Britain by the Romans; and although Mr. Bartram has described a crabapple, a native of our country, the Pyrus coronaria, a globular-formed, beautiful yellow fruit, an inch in diameter, excellent for preserving, with blossoms of a gay and beautiful appearance in spring, yet it is supposed that our stock of apples originated not from this, but from Europe.

The apple is said to flourish in every part of the United States, except the low lands of the maritime districts of Carolina, Georgia, and Florida, and the low prairies or savannas bounding on the Gulf of Mexico; and good judges assert that the apples of England, and of the north of France, are not to be compared, for excellence of flavor, to those produced in our climate.

\section{UsEs.}

Apples, when well ripened, form an exceedingly wholesome food in their raw state; and from the qualities which they possess, their habitual use, according to Mr. Knight, destroys the artificial appetite for strong fermented liquors and the preparations of alcohol. They abate thirst, and, boiled or roasted, says Loudon, " they fortify a weak stom- 
ach, and are, excellent in dysentery, and equally efficacious in putrid 'and malignant fevers, with the juice of lemons and currants. Scopoli recovered from a weakness of the stomach and indigestion by using them." Dr. Willich has also informed us (Dom. Ency.) that, "In diseases of the breast, such as catarrhs, coughs, consumptions, \&c., in their roasted, boiled, or stewed state, they are of considerable service.- They may also be usefully employed in decoctions, which, if drank plentifully, tend to abate febrile heat, as well as to relieve strictures in pectoral complaints." The usual modes of cooking, or preparation for common use, are too well known to need describing.

Deduit of Mazeres [Philips] has found that one third of apple pulp, baked with two thirds of flour, having been properly fermented with yeast for twelve hours, makes very excellent bread, full of eyes, and extremely palatable. . In perfumery, the pulp beat up with lard forms pomatum. And Bosc observes, that the prolonged stratification of apples with elder flowers in a close vessel, gives the former an odor of musk, extremely agreeable. An excellent jelly is thus prepared from them: They are pared, quartered, and the core removed, and put in a closely-covered pot, without. water, in an oven, or over a fire. When well stewed, the juice is to be squeezed through a cloth, a little white of an egg is added, and then sugar; and lastly, it is skimmed, and by boiling reduced to a proper consistence. ,

Apples are preserved for winter use, by being quartered, and boiled in the unfermented juice of the apple, which has been concentrated by long boiling; but for this purpose the boiling sirup of the sugar cane or molasses is preferred; in some cases it is more economical. Apples are also preserved by drying; first being pared by machinery constructed for this purpose, and quartered, they are dried either in the sun or in ovens; in this state they may be long preserved, and form a valuable article for domestic use, for sea stores, or for exportation.

Mr. Knight, in his treatise on the apple and the pear, has informed us, that the juice of both these fruits may be used advantageously on long voyages. He has often reduced it by boiling to the consistence of weak jelly; and in this way, although intentionally exposed to the at mosphere of different tempcratures, he has preserved it for several years 
without the slightest change. In this concentrated state it has been supposed that a few pounds added to a hogshead of water might form a good liquor, similar to perry or cider. It might also, as he supposes, answer as a substitute for the rob of lemons and oranges, and at much less expense.

The late Hon. Timothy Pickering has related the account of the efficacy of sweet apples in the cure of a sick horse : it is also stated that horses, cattle, and swine, fatten in a remarkably short space of time when fed on sweet apples. It is true, cattle may have been injured by breaking into orchards and devouring at once an inordinate quantity of the forbidden fruit; but this is equally true, when they have broken into cornfields; yet neither are injurious when used as regular food. And it is thought by many, that the earliest fruit, the windfalls, may be more profitably consumed by permitting cattle and swine regularly to range the orchards, than by being gathered for the purposes of distillation.

The unfermented juice of sweet apples is sometimes, by boiling, converted into molasses, in those places where this article is not easily obtained. But, for the manufacture of molasses or sugar, it is not altogether improbable that the potato, or the sugar beet, from some late experiments, may offer in future a much more profitable resource.

\section{VARIETIES.}

The varieties of apples are described in three classes.

Class I. - Varieties in cultivation in the United States.

Class II. - Select Foreign Varieties descrving trial with us.

Class III. - Select Varieties for Northern Climes.

Note. - Those described, on the authority of Judge Buel, of the first class, are considered by him as among the best varieties of that country. M. refers to Mr. Manning, and $L_{\text {: }}$ to Mr. Lyman. 


\section{CLASS I.}

\section{A SELECT DESCRIPTIVE LIST OF THE APPLES IN} CULTIVATION IN THE UNITED STATES.

\section{S E C T I O N I .}

\section{SUMMER APPLES.}

\section{1. *americaN SUMMER PEARMAIN.}

The tree bears abundantly. The fruit is of medium size, oblong; of a bright red, streaked and blotched with deeper red next the sun; occasionally a fine yellow ground is visible; the flesh very tender, very juicy, fine-flavored, and excellent either for the dessert or for cooking. It ripens the middle of August, and is highly deserving of cultivation.

2. BEAU. Judge Buel.

"Fruit three inches in diameter, two and one fourth deep; eye in a regular and shallow cavity; stalk short, not projecting beyond the base; skin yellowish green, with a faint blush on the sun side, and dotted with white; flesh white and crisp ;. juice abundant and agreeably acid. A fine dessert and culinary fruit from end of Aug. to Oct."

3. *BENONI.

Medium-sized, of a fine red color, flavor subacid and good. One of the best apples of the season, ripening the last of July. A native, introduced to notice by Mr. E. M. Richards, of Dedham.

\section{4. *EARLY SWEET BOUGH.}

The size varies from medium to large; the form is oblong; the skin smooth, of a pale yellow color; the stalk is short ; the flesh is white, tender, juicy, sweet, and excellent. One of the very best dessert apples of its season, which is early in August.

5. *EARLY haRVEST,

$\left.\begin{array}{l}\text { Prince's Harvest, } \\ \text { Eariy Frencil Reinette, }\end{array}\right\}$ of Coxe.

The tree is of medium vigor; not very productive. At Salem this variety begins to show evident symptoms of decay. A fruit above the medium size; globular, de- 
pressed; of a pale yellow color ; the flesh white, juicy, tender, rather acid, but pleasant. Last of July. It is good for cooking.

\section{EARLY RED JUNEATING.}

\section{$\left.\begin{array}{l}\text { Early Red Margaret, } \\ \text { Early Striped Juneating, }\end{array}\right\}$ according to the Pem. Mag. \\ Eve APPLE of the Irish, $\}$ and Lind.}

This is not the American variety of the same name. The fruit is rather small; rather oblong; greenish yellow in the shade, of a deep red color, with streaks, next the suu; the flesh is white, juicy, pleasantly acid. 'The last of July.

\section{\%. LARGE YELLOW SUMMER. $\boldsymbol{L}$.}

A large fruit of surpassing excellence; the branches are pendulous; the tree bears well, but does not bear young. August, September. Introduced to notice by Mr. Lyman, of Manchester, Conn.

\section{8. *MAIDEN'S BLUSH.}

HawtHORNDEN of the English.

Fine specimens of this excellent fruit have been exhibited by John Mackay, Esq., of Boston, raised on his farm in Weston, and the premium of the Massachusetts Horticultural Society was awarded to him on this fruit in 1833 . The fruit is very large and beautiful; flattened; the skin sinooth, of a yellow color in the shade, finely contrasted with fine red next the sun; the flesh white, tender, and sprightly; remarkably light; good for the table or for cooking. The tree bears certainly and abundantly. Mr. Coxe informs us that it is eminently qualified for drying, and is a very popular apple in the Philadelphia market. August to October.

\section{9. *POR'TER.}

The tree is of upright growth, of medium vigor; a great bearer. 'The fruit above the medium size, oblong, light yellow, with a pale blush next the sun; its flavor sprightly and pleasant. A popular fruit in the Boston market, one of the most productive and profitable; and very beautiful. This native fruit originated at Sherburne, Mass., on the grounds of the Rev. Sinnuel Porter.

\section{0. *PUMPKIN SWEETING of New England.}

The tree grows vigorous and upright; the leaves very large. The fruit is very large, round, flattened, of a yellow russet color; the flesh very sweet and excellent. It ripens from August to October. 


\section{1. "RED ASTRACAN.}

The leaves are long; these and the wood are of a purple color. An eminently beautiful and very early apple, of medium size, nearly globular, of a rich crimson color, covered with fine bloom. The flesh is white, crisp, and juicy, of agreeable flavor. The tree is very productive. A new Russian fruit, which proves fine with us.

\section{RED QUARENDON.}

Medium-sized, globular, or flattened; of a deep red color, approaching to purple; of a sprightly, pleasant, and peculiar flavor. A foreign fine fruit. It is productive at the late Governor Gore's. August to November.

\section{SAINT LAWRENCE. Corse.}

"A large, beautiful, and excellent fruit, ripening in Septembèr." It lately originated near Montreal, where the fruit sells readily for from fifty to sixty cents a dozen. So says Mr. Corse, who has lately forwarded the scions.

\section{SAPSON.}

\section{SAPsorvise.}

The fruit is of medium size ; of a bright red color, deeply stained in its flesh, which is very juicy and pleasant. - A very beautiful fruit, an abundant bearer, and much esteemed. Ripe from August to October.

\section{5. * SOPSAVINE.}

A very early summer fruit, of medium size; covered with stripes of red on a greenish yellow ground; a pleasant and beautiful fruit, ripening the last of July:

\section{6. *SUMMER QUEEN. Coxe.}

The tree grows vigorous; its branches incline downiward; a great and constant bearer. The fruit is one of the most beautiful known, and of the finest quality for the dessert, or for cooking. It is large, contracted at the crown, fine yellow in the shade, striped with red; fine deep red next the sun; the flesh is yellow, rich, sweet, perfumed: It ripens in August.

\section{1\%. SUMMER ROSE.}

A medium-sized, beautiful fruit, of a round or flattened form ; of a bright, shining yellow color, streaked or marbled with red; the flesh juicy, sweet, and excellent, either for the dessert or for cooking. Early in August.

\section{8. *WILLIAMS APPLE.}

A beautiful fruit, of medium size and oblong form; its 
color deep red; flavor sprightly, and very pleasant. It ripens the first of August, and continues ripening to September. A native fruit, found on the farm of Major Benjamin Williams, of Roxbury.

\section{S E C T I O N I I .}

\section{AUTUMN FRUIT.}

\section{AMERICAN NONPAREIL. Coxe.}

A beautiful and excellent fruit ; medium-sized, oblong; contracted at its summit; of a yellow color, streaked and stained with bright red next the sun. Externally it resembles the Hubbardston Nonsuch. The flesh is white, firm, juicy, and good. October and November.

\section{AUNT'S APPLE. Coxe.}

The tree grows feeble, but bears most abundantly. The fruit is beautiful, large, oblong; the skin is smooth, streaked with lively red on a yellow ground; the flesh yellow, melting, and juicy; of an agreeable flavor, but not rich. A popular market fruit, cultivated extensively in the eastern counties of Pennsylvania. November.

21. "BOXFORD. $\boldsymbol{M}$.

A very superior fruit; large, flat, and striped with red on a yellow ground; the flesh is tender, and the flavor excellent. A new variety, which originated on the farm of Mr. Peter Towne, in Boxford, Mass. The fruit ripens in September and October, and the tree is a great bearer.

22. *BRABANT BELLE FLEUR.

Very large and handsome; of great solidity; rather conical ; slightly ribbed; yellow, colored with red stripes; juicy, and of very pleasant flavor; proves a fine fruit. Scions of this fruit were received from the London Hort. Soc. November.

23. CANADIAN REINETTE. Pom.Mag.Bon Jard. Grosse Reinette D'Angleterre of Duh.

Reivette de Canada. Bon Jard.

Reinette Grosse de Canada. Hort. Soc. Cat.

Reinette de Canada a Cotes. Ib.

Reinette de Caen. According to Pom. Mag. Portugal ApPLE. Ib.

Mela Janeera. Ib. Reinette de Canada Blanche.

$\Lambda$ very large and beautiful fruit; globular, flattened, 
with projecting ribs; yellow in the shadè, slightly red next the sun; flesh firm, juicy, with but little acidity, and very good. It has cavities at the centre, and keeps till March. The tree is very productive.

\section{CUMBERLAND SPICE. Coxe.}

The tree is very productive; a fine dessert fruit, large, rather oblong, contracted towards the summit; the stalk thick and short; of a pale yellow color, clouded near the base; the flesh white, tender, and fine. It ripeus in autumn, and keeps till winter, and shrivels in its last stages.

25. *DRAP D'OR OF FRANCE of Coxe and Ronald, but not of Duh. Mr. Manning.

The tree is a most productive variety; the fruit fine and highly deserving of cultivation. It is very large, handsome, of globular form, compressed a little at summit and base; the stalk short; of a fine yellow color, with occasional faint blotches; flesh white, firm, and of good flavor. Season, September, October, and November.

\section{DUCHESS OF OLDENBURGH.}

A very beautiful $R$ ussian apple, valuable for the dessert or-sauce; middle-sized;-globular; color golden, streaked with bright red; flavor pleasant, rather acid. 'September. A good bearer.

\section{DYER, OR POMME ROYAL of some.}

So named for Messrs. Dyer, of Cranston, R. I., and the gentleman who has lately brought this fruit into notice in Massachusetts. A large apple, round, of a yellowish white in the shade, slightly colored with red next the sun; the flesh white, juicy, of a rich, saccharine, subacid, and excellent flavor. A superior fruit, ripening in October. It is sometimes called Woodstock.

28. EMPEROR ALEXANDER. Hort. Trans, Lind. Alexander, Aporta.

The trees of this Russian apple bear-abundantly. 'A specimen was sent from Riga, in 1817 , nueasuring 51 inches in diameter, 4 inches deep, and 16 inches in circumference, and weigling 19 ounces. Fruit very large, cordate, narrow at the crown; the eye in a broad, deep cavity; stalk short, sunk to the level of the base; greenish yellow, slightly streaked with red in the shade, but beautifully marbled and streaked with bright red and orange next the sun; flesh yellowish white, crisp, and very tender, juicy, rich, 
sugary, of aromatic flavor. Ripe in October, and will keep till Christmas. A valuable and excellent dessert fruit.

29. FALL PIPPIN. Coxe. Pom. Mag.

American Fall.

Reinette Blanche d'Espagne.

D'Espagne, De Rateau, Cobbett's Fale, Concombre Axcien. According to Pom. Mag.

This is said to be the national apple of Spain, there called Camuesar. The tree is an abundant bearer; the fruit one of the finest and most beautiful of its season; it is very large, roundish oblong, ribbed at its sides; the stalk very short; the skin smooth, of a yellowish color, but brownish red next the sun; the flesh yellowish, crisp, tender, with a very rich, sugary, high-flavored juice. It ripens in October, and keeps till winter.

\section{0. *FA MEUSE.}

Pomme de Neige.

A middle-sized fruit, of globular or flattened form; the stalk short, deep sunk; the skin light green, stained with bright red, with small dark red streaks; deep red next the sun; flesh white as snow, very tender; juice saccharine, with a musky perfume. Ripe in October. A dessert apple of a most beautiful appearance. It undoubtedly originated in Canada.

\section{1. *FALL HARVEY.}

Large and handsome, of a flattened form, with broad, projecting ribs; skin bright clear yellow, but occasionally bright red next the sun; flesh yellow, firm, rich, and highflavored; and in the opinion of my friend Mr. Manning, without question, the finest fall and winter apple. A good bearer, and deserving of extensive cultivation. Much cultivated in Essex county, Massachusetts, where it is believed to have originated.

\section{2. *GOLDEN RUSSET.}

The tree is very productive; the fruit of medium size; globular; of a golden russet color ; rich, juicy, high-flavored and excellent. A superior fruit, ripening in November. A variety received of Mr. David Towne, of Topsfield, Mass. There are several inferior varieties of this name.

33. (C.) *GRavenstein. Pom. Mag.

Solne assign this fruit to Italy, some to Gravenstein in Holstein; it is said to be the best apple in Germany. The tree grows vigorous, and is very productive. The fruit is 
large, round, but varying in form, angular at the crown; the eye in a broad, deep, knobby cavity; the stalk very short, 'deep sunk ; color clear straw or yellow, with broken stripes of red next the sun; the flesh pale yellow, crisp, with a juice vinous and high-flavored, fragrant and delicious. Not only a first-rate dessert fruit, but its abundant juice affords excellent cider; and it is excellent for drying. It ripens in autumn, and will keep till into winter., This fruit proves one of our handsomest and finest varieties.

34. JENNINGS'S 'SWEET. Dr. S. Hildreth.

A large and most beautiful fruit; yellow, striped with bright red; sweet and fine; very fine for baking. The tree is a great and constant bearer. The fruit originated on the farm of Mr. Jennings, at Marietta, Ohio. October and November.

\section{5. *KENRICK.}

The tree is of medium vigor, compact form, and very productive. A large, round fruit ; pale green in the shade, bright red next the sun; the flesh stained occasionally with red, is tender ; the juice abundant, of a rich subacid, and excellent flavor. A native, which originated on the farm of my father, in Newton.

\section{6. "KILHAM HILL.}

A beautiful native fruit from Essex county; one of the most popular in the Salem market. A large, round apple, striped with bright red, deep red next the sun; the flesh very rich ; juice abundant, of a pleasant subacid, and excellent flavor. Season, October and November.

\section{LYMAN'S 'PUMPKIN SWEET.}

Very large; skin smooth, pale yellow; sweet, juicy, and excellent for baking. The tree bears prodigious crops every second year. Worthy to be in every collection. October and December. Introduced by Mr. Lyman.

38. "LYSCOM.

A large fruit, striped with red, of excellent quality. It ripens in October, and originated in Southboro', Worcester county, and was introduced by L. Peters, Esণr. This fruit is by some called Osgood's Favorite.

39. *MONMOUTH PIPPIN.

A superior, large, handsome fruit, of excellent flavor; a fall fruit. The tree bears abundant crops, and the fruit 
is one of the most salable, productive, and profitable of Monmouth county, N. J., from whence I received this fruit. 40. NEWARK KING. Coxe.

A large, beautiful fruit; oblong, contracted towards the crown; with a smooth skin, of a red color dotted with yellow; of a pleasant flavor. The tree is of vigorous growth, spreading, and an abundant bearer. It ripens in autumn, and keeps till into winter.

41. ORANGE PIPPIN. Pyr. Mal.

Marigold Pippis. Hort. Soc. Cat.

IsLe of Wight Orange.

A beautiful fruit, in size, form, and color, much like a middle-sized orange; juice abundant, and of pleasant flavor; an excellent fruit for the dessert. The tree bears well. October to January. Specific gravity of the juice, I.074. An excellent fruit for cider, according to Mr. Knight. Originated in Normandy. There is a fruit of a similar character and name, but ripening early, much cultivated in Monmouth county, N. J., and there deemed one of the most salable, profitable, and productive of all their fall fruits.

42. *ORANGE SIVEETING, oR GOLDEN SWEET.

The fruit is rather large, flattened at its base and summit; the color yellow, or orange; flesh very sweet and excellent. It ripens in September, and keeps till December. This fruit is in high estimation at Providence, where it is brought in sloops from IIartford, Conn. Highly esteemed there, and wherever known, and very productive.

43. POMME WATER.

Large, round, pale yellow at maturity, sometimes red next the sun; flesh juicy, sweet, and good. An excellent fruit for the dessert, or for baking. From October to January. 44. RED CALVILLE.

Calville Ruuge n'Autome. Bon Jard.

This fruit is of medium size; very beautiful; of conical form; of a fine red color, deep red or crimson next the sun; the flesh stained with red, of a vinous and sweet taste, and the perfume of violets. It ripens in September, and keeps till winter:

\section{5. *RED AND GREEN SWEETING. Coxe.}

I'bince's Large Red and Green Sweeting. Coxe.

'The fruit is very large, of a yellow color striped with red; covered with deep red next the sun; the form oblong, 
somewhat contracted towards the summit; the stalk short; the flesh tender and sweet. A very fine fruit, ripening in September.

\section{6. *RED INGESTRIE.}

- A first-rate dessert fruit, of medium size; globular, flattened; bright golden yellow, but next the sun bright scarlet; flesh crisp, juicy, rich, high-flavored. The tree bears well. Raised by Mr. Knight. October.

47. "SAWYER SWEETING. S. H. S., Esq.

This fruit is as large as the R. I. Greening; its color green in the shade, with a blush next the sun; it is melting, and of a delicious flavor. The tree grows strong and healthy, and the fruit ripens in October and November.

48. SEEK-NO-FURTHER of Autumn.

The tree is of medium vigor; its branches incline. downwards; a moderate bearer. The fruit is large, round, or conical, of a greenish yellow color, covered with broken stripes of red, especially next the sun; the flesh yellow, tender, juicy, rich, subacid, and excellent. October and November. A New England variety.

\section{9. *SPICE SWEET.}

The fruit is large, very beautiful, very sweet and excellent; the tree an early and constant bearer. A native fruit; which originated on the farm of Mr. Spurr, in Taunton, Mass. It ripens in September, and belongs to the autumnal class. This fruit was received of Mr. Jacob Dean, of Mansfield. It is sometimes called the Spurr apple.

50. STROAT, Judge Buel.

Above medium size; rather conical, and regular formed; the skin smooth, yellowish green; the flesh yellow, uncommonly tender and juicy, and of rich flavor. Judge Buel esteems this superior to any other autumn fruit. It originated at Kingston, N. Y.

150. *SUPERB SWEET.

A most superior fruit; over medium size, pale red, and somewhat striped; flesh tender, and excellent flavored. It ripens in September, and keeps several months; but is properly an autumn fruit. The tree is of vigorous growth, bears constantly and abundantly. This excellent native fruit was received of Mr. Jacob Dean, of Mansfield, Mass: It is highly deserving a place in every collection. 
51. *YLLOW INGESTRIE.

The tree bears early and abundantly. The fruit is small, round, of a bright gold color, with pearly specks; flesh yellowish white, tender, delicate, juicy, rich, and high-flavored. September and October. Raised by Mr. Knight. An eminently beautiful apple, which, as Judge Buel observes, bids fair to rival the Lady apple as a fashionable fruit.

52. SWEET RUSSET.

Large and covered with russet; exceedingly rich and sweet; a very superior fruit, ripening in October. A variety introduced to notice by Mr. Lyman, of Mansfield, Conn.

\section{3. *ORK RUSSE'TING.}

- Remarkably large, conically formed, and swollen towards the base; of a yellow color, russeted; the flesh breaking, juicy, subacid, and good. Valuable, as a market fruit, for cooking and other purposes. October to December. The tree grows strong. The leaves are large.

\section{S E C T I O N I I I .}

\section{WINTER FRUIT.}

54. AMERICAN GOLDEN PIPPIN. Judge Buel. A large, yellow, winter fruit, of an agreeable flavor, and highly prized. It has but recently come into notice, but promises to become a standard fruit.

55. ESOPUS SPITZENBERG.

Large, very beautiful, and excellent. The tree grows upright; the young wood is slender and dark. It is very productive. The fruit is oblong, covered with deep scarlet, deepening to dark crimson next the sun; the flesh juicy, of a rich, pleasant acid, and high flavor. A celebrated fruit. Season, December to March. It originated at New York. The Flushing Spitzenberg differs from this in being round or flat, and the young wood strong and red and the tree a bad bearer. 
56. *BALDWIN.

This capital variety is a native of Massachusetts; a large, bequtiful, and famous fruit. - The tree grows vigorous, upright, and handsome. The fruit is round, of a pale color in the shade, fine scarlet or crimson next the sun, sometimes red on every side; the flesh is white, breaking, juicy, rich, saccharine, with a most agreeable acid, and excellent flavor.. The tree bears enormously every other year, and in the interval, occasionally a moderate crop.

No apple in the vicinity of Boston is so popular as this, at the present day.' It is raised in large quantities for the market. It ripens in November, and may be preserved till February, and March, and is recommended for extensive cultivation.

\section{5\%. BALTIMORE. Hort. Trans. Vol. ir. p. 120.}

A remarkably large apple, raised by Mr. Smith, near the city of Baltimore. A Aarge specimen measured in circumference fourteen inches and three quarters, and in height four inches; its weight twenty-three ounces and a half; its form flat; skin a pale citron, with a faint blush next the sun; flesh well-flavored, and close at the core.

\section{8. "BEAUTY OF THE WEST. Judge Buel.}

"A very large, fair, and fine-flavored sweet apple, presented to me by Mr. Morgan, in January, and kept till March." A large, round, beautiful fruit, yellow mixed wịth red, juicy and fine, as proved with us.

\section{9. *BELLFLOWER.}

\section{YELLOW BELLFLower.}

A large and beautiful fruit, of an oblong or conical form; of a bright yellow color, with an occasional blush next the sun; the flesh tender, juicy, rich, and finelyflavored, and alike excellent for the dessert or for cooking. It ripens in November, and will keep all winter. The pericarpium at maturity is very, Iarge, and the seeds rattle when shaken.

\section{BELMONT.}

$A$ new and very beautiful fruit, of first-rate quality. It was raised in Belmont, Ohio. Specimens brought from Rockport, Cayuga county, in Ohio, were sent to the Massachusetts Horticultural Society in January, 1834, by Charles Olmstead, Esq., of East Hartford, Conn. It is large, round, but broadest at the base; the stalk is short; of a 
pale straw color, with brown specks, and a faint blush next the sun; the flesh tender, juicy, with a rich subacid, and excellent flavor. It keeps till March.

160. BLACK COAL.

A most beautiful and singular fruit, of a fine black or reddish black color; of large size, or $3 \frac{1}{2}$ inches in diameter. It keeps till April. This fruit I received of Robert Sinclair, of Baltimore. A superb black fruit, of a similar description, and of German origin, I also received of John P. Cushing, Esq., of Belmont, in Watertown.

\section{BLENHEIM ORANGE:}

Blenheim Pippin. Woodstock Pifpin: Ib.

One of the largest varieties of dessert apples; globular; broadest at the base; depressed; yellow in the shade, dull red, with deep stripes, next the sun; breaking, sweet, juicy, extremely high-flavored. Lately originated. October to March. An English fruit.

\section{2. *BLUE PEARMAIN.}

A large, beautiful fruit, (not uncommon near Boston;) of a dark red color, and covered with a dense blue bloom. It is good for the table, excellent for cooking, and ripens from October to January. The tree grows strong and healthy, and is very productive.

\section{CHANDLER.}

The tree is of low growth, and wonderfully productive; the branches very slender and drooping, like the weeping willow; they are covered with the fruit in thick clusters. A variety which originated on the farm of Mr. Francis Richardson, in Chelmsford, Mass. It was introduced to notice by Gen. Samuel Chandler, of Lexington, who has exhibited specimens to the Massachusetts Horticultural Society. Fruit fine red, flavor moderate.

\section{COS, or CAAS. Judge Buel.}

Large, round, depressed at the base and crown; its form inclined; eye large, in a broad, slightly angular cavity; the stalk short, thick, in a deep, broad hollow; the skin as smooth as oil, pale yellow, with stripes and specks of red; stripes and blotches of bright scarlet, dotted with yellow, next the sun; the flesh nearly white, tender; juice sweet and agreeable. December to March. Mr. Buel informs us that it is a native of Kingston, N. Y., and a great favorite. 
65. CRAAM, or KRAAM. Judge Buel.

"A medium-sized, sweet apple, in very high repute among the Dutch for winter use." Its color green while immature.

\section{CROW'S EGG.}

A remarkably dense apple; oval, or egg-formed ; of medium size; the skin very smooth, and covered with irregular and broken stripes of pale red on a yellow ground; the flesh very firm, juicy, of a rich and excellent flavor. A variety received of Mr. Abijah Fisher, of Dedham.

\section{7. *DANVERS WINTER SWEET.}

Epses Sweet.

The tree is very productive; the fruit large and beautiful; of a bright yellow color, with a faint blush next the sun; the flesh very sweet and excellent; fine for the table and baking. It ripens in winter, and keeps till April. A profitable apple to raise for the market, and recommended for extensive cultivation. The tree bears abundantly. The original tree is on the Derby farm, in Danvers. This has long been a highly-popular market fruit. Introduced by Mr. Manning.

68. DOMINI. Judge Buel.

"A bove medium size; the skin greenish yellow, clouded with brown blotches; the flesh crisp; the flavor highly agreeable." At Kingston, N. Y., it held the first rank as a winter fruit.

\section{DUTCH CODLIN.}

French Codlin. Forsyth.

GLORY OF THE WEST of some collections.

Fruit very large, oblong, with five ribs extending from the base to the crown; stalk short and thick; skin yellow, but of an orange color next the sun; flesh white, rather dry; juice a little sugary or subacid. A culinary apple. From Michaelmas to Christmas.

70. *GARDNER SWEETING.

The tree grows slow, but is very productive. The fruit is above the medium size, round, of a pale color, covered with small specks; a bright blush next the sun; the flesh firm, very sweet, and excellent. A fine fruit from December to March.

\section{GOLDEN PEARMaIN. Coxe. Py. Malus.}

Ruckman's Golden Pearmain. Red Russet. Ib.

The fruit is of medium size, flattened; skin russeted; 7 . 
of a dull red color next the sun; the flesh tender, rich, but not abounding in juice. $\mathbf{A}$ great and constant bearer. This variety is valuable for cider.

72. GREEN SWEETING. Thacher's American Orchardist and N. E. Farmer, Vol. vili. p. 121.

A large, handsome apple, of surpassing excellence, abounding in rich, sirupy juice. It retains its soundness and flavor even till the middle of Jume and July. It is an excellent apple for baking, more uniform and abundant in its bearing than trees in general, and is highly deserving of cultivation. It is supposed to have originated in the old Plymouth colony.

\section{GREEN NEWTOWN PIPPIN.}

The tree grows very slow; the branches are very slender; the bark very rough; the fruit is of medium size, rather flattened; prominent, obtuse, and unequal ribs at the crown, extend, diminishing towards the base; of a dnll green color, changing to yellow at maturity; thin russet covering the base; the flesh pale yellow; juice very saccharine, of an aromatic and very rich flavor, with a lively acid. The tree is a great bearer. The fruit retains its flavor and juices till June. This fruit originated at Newtown, on Long Island. It has Jong heen celebrated, in New York and the Middle States, as one of the first of all apples. Yet to the north of those states, and at Boston, it has never been either very highly esteemed or extensively cultivated, in comparison with many other fruits.

\section{4. "GOLDEN BALL.}

Height near three inches, breadth three and one half inches; calville formed, or ribbed at the sides; color golden yellow; stalk in a broad, shallow cavity, but little depressed; juice very rich, sweet, with a just proportion of acid, aromatic. A very beautiful and superior fruit. Origin unknown. This fruit I received of S. W. Cole, Esq., editor of the Yankee Farmer. No apple, he observes, is popular like this, where known, at Portland, Me.; and none sells half so high. A winter fruit.

\section{HAMPSHIRE GREENING. Judge Buel.}

On excellent authority, this variety stands in the very first class of apples - on that of an Elder, a great traveller, and himself possessing a nursery of many valuable varieties. 
76. HARTFORD SWEETING.

Sometimes called Spencer Sweeting, or Champ Sweeting. A fine, large, and beautiful fruit, of a red color; there are few so fair; the flesh tender, juicy, and sweet. It remains fine till June. This fruit originated near Hartford, Conn., and was introduced to Boston by Dr. E. W. Ball, of that city. The tree grows slow, and pendulous. It bears well.

7\%. HEREFORdSHIRE PEARMAIN. Coxe. Py. Mal.

Winter Pearmain.. Sym. Coxe.

The fruit is above the medium size, slightly ribbed, of a yellow color, covered with bright stripes of red; deep red next the sun; the flesh very juicy and high-flavored. A beautiful and excellent apple, either for the dessert or for cooking. October to April. - Mr. Coxe has added, that this variety is supposed to be the most hardy and uniformly productive apple of the Middle States. The tree grows handsome.

\section{8. *HUBBARDSTON NONSUCH.}

A new and most superior variety, which originated in Hubbardston, Mass, and is esteemed very superior to any other fruit known here, which bears the name of Nonsuch. The tree grows vigorous, large, branching, and handsome. A prodigious bearer. The fruit is large, globular, or conical; of a yellow color in the shade, but mostly covered with irregular, small and broken stripes of pale red; bright red next the sun; the flesh yellow, juicy, rich, sweet, relieved by a slight acid, and excellent. This capital variety ripens in December, and keeps till February, and is recommended for general cultivation.

79. *JONATHAN, Judge Bucl.

PHILIP Rick of the Kingston orchards.

A new winter fruit, which, for its eminent beauty and excellence, is admired above all others, by good judges, in Albany and its vicinity. The fruit is round, two and a half inches in diameter, regular shaped, the eye in a broad, deep cavity; the stem three fourths of an inch, slender, in a deep, round cavity; the skin thin, pale red, blended with yellow, and deepening into bright red and dark purple next the sun; flesh very tender, white, occasionally tinged with red; juice very abundant, rich; and highly-flavored. - Named for Jonathan Har- 
brauck, Esq., from whom Mr. Buel first received this excellent fruit. The original tree is now growing on the farm of Mr. Philip Rick, of Woodstock, Ulster Co., N. Y. This description of Mr. Buel perfectly corresponds with the fruit which he sent me in January, 1834.

\section{HUGH'S BLUSH.}

Large, and excellent; very handsome, red striped; in form of the Wine apple. One of the best fruits of Maryland. It keeps till spring. This fruit I received from my friend Robert Sinclair, of Baltimore.

\section{LADY APPLE.}

Poмme D'API.

The tree grows upright, but slowly; the fruit in clusters. It is very small, but very beautiful; rather flattened; the skin is smooth, of a beautiful yellow in the shade, deep red next the sun; the flesh firm, of a pleasant taste, but not high-flavored.' November to March.

\section{LEMON PIPPIN. Dr.S. P. Hildreth.}

A fruit of good size, of a yellow color, russeted next the sun ; flesh juicy, aromatic, and breaking; and one of the best of dessert fruits; its form is that of a lemon. The tree is a great and constant bearer, and the fruit keeps till January. It originated at Marietta, Ohio.

\section{MACKAY SWEETING.}

A fine native fruit, exhibited at the Massachusetts Horticultural Society, by John Mackay, Esq., of Boston, the produce of his farm in Weston. A large and beautiful fruit, of a globular form, and fine bright straw color; sweet, slightly acid, and of fine flavor. It keeps well in winter. The tree bears well.

\section{MARQUIS. Dr. Fiske.}

The fruit is of handsome size, of a red color; the flesh melting, juicy, and of very fine flavor. The tree is of upright growth, a good bearer, and the fruit keeps till April. Such is the account of the Hon. O. Fiske, of Worcester, Mass., where this fruit lately originated, and where it is stated, that this variety is, by good judges, regarded as one of the finest of apples.

85. MINISTER.

Large, oblong, and tapering to the eye; in form of the Bellflower, but with large projecting ribs, or calville formed; 
striped with bright red on a foundation of pale greenish yellow; flesh yellow, and high-flavored, and excellent; and deserving a high rank in every good collection. Such also is the opinion of Mr. Manning; who esteems this as one of the finest fruits New England has ever produced. It ripens from November to January. This fruit originated in Rowley, Mass., and received its present name from having been first brought into notice by the Rev. Dr. Spring, of Newburyport.

86. *AATE POUND SWEET.

Very large; of a flattened form, and fine pale yellow at maturity; very sweet and delicious. The tree bears well, and the fruit ripens from October to January. This fruit I received of Mr. Samuel Ammidon, of Douglas, Mass. It criginated in Vermont.

8\%. MELA CARLA. Hort. Trans. 'Lind.

Malcarle. Hort. Trans. Charles Apple. Ib.

Ромme Finale. Ib.

One of the most celebrated and famous of fruits. Rather large in size; of a form inclining to globular, but slightly ovate; the eye and the stalk, which is about an inch long, and slender, are each inserted in small, deep cavities; the beautiful waxen skin is without spot, except being a little marbled with a very faint green near the eye; of a pale yellow in the shade, which unites rather abruptly with the splendid crimson with which it is covered next the sun; the flesh is white, tender, delicate, sweet, with the fragrant perfume of roses. It ripens in September, and will keep till spring. This apple is a native of Finale in Laguira. It is cultivated extensively in the territories of Genoa as an article of export and commerce to Nice, Barcelona, Marseilles, and Cadiz.' A far-famed fruit. In the climate of Italy this is supposed to be the best apple in the world; but in England, their writers state, it proves, in open culture, but an ordinary fruit, their climate being unsuitable. Near Boston this fruit proves good, but not excellent, and deserves still further trial.

88. MONSTROUS PIPPIN. Coxe,

New York Gloria Muxdr. Van Dyne.

A fruit of uncommon size - some have weighed over 27 ounces; the skin smooth, yellow, with numerous spots of white; the stalk short and deeply inserted; the eye very deep; the flesh white, tender, juicy, and good, but not 
high-flavored. Excellent for cooking. Only a few trees of this kind are recommended to enter into a good collection, as, from the weight of the fruit, it is liable to be blown down by high winds. It originated on Long Island.

\section{MORGAN'S FAVORITE. Judge Buel.}

"A variety received, with the Beauty of the West, of Mr. Morgan, and which he considers a superior kind. It is nearly as large as the Russian Alexander, and somewhat resembles it in color and shape."

\section{0. *NURPHY.}

A large and splendid fruit ; in appearance resembling the Blue Pearmain, but more oblong, and not quite so large; skin pale red, streaked or blotched with darker red, and covered with a beautiful blue bloom; the flesh white, tender, and good. November to February. Raised by Mr. David Murphy, of Salem, Mass., and introduced to notice by Mr. Manning.

\section{1. *ORTLEY.}

A native of New Jersey. It resembles the yellow Newtown Pippin in its fine flavor and form, but is more oval ; the eye large, not deeply sunk; the stalk slender, and deeply inserted; color bright, clear yellow, but changing to bright scarlet next the sun; the flesh yellowish, crisp, and breaking; juice abundant and fine. An excellent fruit. Season, December to April.

\section{PECK'S PLEASANT. S. H. S., Esq:}

This fruit is one of the most salable apples in the market of Providence. The skin is smooth, of a yellow color in the shade, with a blush next the sun; the flavor is pleasant and good. An excellent dessert fruit. It ripens from November to February.

\section{2. *PENNOCK'S RED WINTER.}

\section{Pelican.}

The tree bears constantly and abundantly. The fruit is large and handsome, generally flattened, and its form inclined; of a deep crimson color, with indistinct streaks of yellow in the shade; dark blotches next-the sun; the flesh yellow, tender, juicy, sweet, and excellent. Season, November to March. $\boldsymbol{\Lambda}$ superior native fruit, highly deserving of cultivation. Some here esteem it equal to the Baldwin. $\mathbf{\Lambda}$ popular apple in the Philadelphia market. 
93. PICKMAN. R. M., Esq.

A fruit of a globular form, and of a straw color; its flavor, combined with a good portion of acidity, is very rich and good. A winter fruit, fine for the table or for cooking; very productive, and deserving of cultivation This is much cultivated by Mr. Ware, at or near Salem who thinks it a native.

\section{POWNAL SPITZENBERG. Judge Buel.}

So named from its native place, Pownal, in Vermont, where the original tree is now growing - also from its resemblance to the Esopus, Spitzenberg. It is esteemed a very superior winter fruit.

\section{PRIESTley. Coxe.}

This fruit is large; the skin smooth, of a dull red color, striped and spotted with pale green; of an oblong form; the flesh is white, of a pleasant, aromatic flavor. An excellent fruit for the dessert or cooking. The tree is a great bearer, and the fruit ripens in December, and keeps all winter. This variety originated, according to Mr. Coxe, in Pennsylvania, and was first cultivated by a Mr.Priestley.

\section{PUTNAM'S RUSSET.}

Large in size, and of uncommon excellence, both for good quality and great productiveness. Most extensively cultivated to ship in Muskingum county, Ohio; where it is esteemed as above all others, of their numerous fine winter varieties, cultivated in that region. This fruit and the description I received from my friend J. B. Russell, Esq., of Cincinnati, Ohio.

\section{7. *RAMSDEL'S 'RED PUMPKIN SWEET.}

A beautiful fruit, over medium size; round or oblong; of a dark and beautiful red, covered with a dense blue bloom ; flesh tender, very rich, and sweet. The trees bear prodigious crops. 'A highly salable and profitable fruit, introduced to notice by the Rev. Hezekiah Ramsdel, of West Thomson, Conn. Some; he observes, have set out whole orchards of this fruit for swine, so great is its productiveness. 'It ripens in November, and keeps till January.

\section{8. *RHODE ISLAND GREENING.}

Jersey, or Burhington Greening of Coxe.

A very large fruil, flattened at its base and summit; at maturity of a yellowish green color, covered with dark clouds or blotches; the flesh yellow, tender, rich, juicy, of 
an agreeable flavor, in which acid predominates. The fruit is at maturity from September to March. This tree is a most abundant bearer every other year, and has been on this account most extensively cultivated in Rhode Island and Massachusetts, and is here preferred for its productiveness to the Green Newtown Pippin.

\section{RIBSTON PIPPIN.}

Formosa Pippin. Hort. Trans.

Glory of Yokr. Hort. Soc. Cat.

Esteemed by the English a very first-rate fruit. A fine fruit with us, but it bears the reputation. of a bad bearer. Middle-sized, globular; pale yellow, mottled with red next the sun; thinly russeted at the crown; flesh firm, pale, saccharine, agreeably acid, rich, aromatic. December to February.

100. RED SEEK-NO-FURTHER.

A large, round fruit, contracted towards the summit; of a fine deep red color; the flavor sweet and excellent, relieved by a slight acid. It ripens in October, and keeps till March. The tree is a very great bearer. A Rhode Island fruit.

\section{1. *ROXBURY RUSSETING.}

This fine old variety is a native of Massachusetts. $\Lambda$ large fruit, of a globular or flattened form; of a brownish yellow russet color, with an occasional blush next the sun; the skin rough; the flesh white, juicy, rich, subacid, and excellent. An old and famous variety, a great and constant bearer; it seldom fails. Great quantities of this fruit are raised in the neighborhood of Boston, for the market and for exportation, and although the Baldwin, the Hubbardston Nonsuch, and perhaps some other winter fruits, far exceed this variety in beauty and excellence of flavor, and at least equal it in productiveness, the Roxbury Russet surpasses them in its property of long keeping. They are fit for use in winter, and keep till June or July.

102. SCALLOPED GILLYFLOWER. Judge Buel.

"Described by 'good judges as far excelling the Black Gillyflower, and much resembling the Cornish-variety, as figured in the Pom. Mag."

103. SWAAR. Judge Buel.

"The Swaar and the Jonathan are esteemed equal, at least, if not superior, to the Newtown Pippins and Spitzen- 
bergs. It is of medium size, round, two and three fourths deep, and three inches in diameter; eye medium-sized, closed by the calyx; stalk three fourths of an inch, slender, deeply inserted; skin greenish yellow, deepening to blush next the sun, thickly dotted with brown specks, intermixed with some of scarlet; flesh nearly white, firm, heavy, and juicy; juice rich, and highly agreeable. Ripe from December to April. Mr. Coxe speaks of this as an uncommon fine fruit. Sioaar, he informs us, implies heavy, in the Low Dutch.

\section{WHITE SPITZENBERG. Judge Buel.}

A beautiful, fair, and fine-flavored fruit, about the size of the Alsopus Spitzenberg. It lasts during winter, and commands a good price in our market.

\section{5. "WINE APPLE.}

Hay's Apple. Coxe syn:

The tree grows large and handsome, and bears abundantly. The fruit is very large and beautiful; bright red next the sun; occasionally a few small stripes and blotches of yellow appear in the shade; the form is globular, a little flattened; the flesh rich and excellent. It ripens the last of October, and may be kept till February or March. A very fine and productive apple, and highly deserving of cultivation, and one among the best of apples. Mr. Coxe has stated that in New Jersey it is variously called Large Winter Red and The Fine Winter; that it is not only an admired table fruit; but excellent for cooking as well as for cider; and is one of the most salable apples in the Philadelphia market.

\section{6. *WINTER SWEETING.}

Seaver Sweeting. Grafton Sweeting.

The tree grows vigorous and upright, and bears abundantly. The fruit is large, round or conical; bright pale yellow, with a blush next the sun; the skin smooth; flesh yellow, juicy, sweet, and fine-flavored. Very valuable as a dessert fruit, or for baking. November to March.

\section{0\%. WINTER WHITE CALVILLE.}

Caltirle Buanche d'Hiver.. Dulh. Bosmet Carré. 1 b.

This fruit is large, of a bright yellow color, with a bright red blush next the sun; its form rather flat, and ribbed; flesh white, tender, and pleasant, and worthy of cultivation. It ripens in November, and keeps till March. 


\section{YELLOW NEWTOWN PIPPIN.}

A large, flat fruit, of a bright yellow color, with a faint blush next the sun; the flesh breaking, juicy, agreeably acid, and fine-flavored. It keeps during the winter. The tree grows more vigorous, and the fruit appears to be in greater esteem about Boston than the green variety.

\section{S E C T I O N I V.}

CELEBRATED CIDER APPLES CULTIVATED IN THE UNITED STATES.

109. HARRISON. Coxe.

The most celebrated cider apple of Newark, New Jersey, where they make so much cider, and some of the finest in the world. It is cultivated more extensively there, and particularly on the Orange Mountain, than any other apple. The tree is of strong and vigorous growth, the wood hard, a certain bearer, and wonderfully productive. One tree in Essex county, New Jersey, produced one hundred bushels in a year. It requires ten bushels for a barrel of cider, which is so strong, that it will produce fourteen quarts of distilled spirits. The fruit is below medium size, rather long, and contracted towards the crown; stalk very long, (hence often called Long Stem,) deeply indented at the summit and base; color yellow, covered with many black spots; flesh yellow, firm, tough; flavor pleasant and sprightly, but rather dry; cider rich, sweet, of great strength. The fruit falls about the first of November, is remarkably sound, and will keep well. It originated in Essex county, New Jersey.

110. TAliafero. Hon. J. C. Gray.

The fruit is the size of a grape shot, or from one to two inches in diametcr; of a white color, streaked with red; with a sprightly acid, not good for the table, but apparently a very valuable cider fruit. This is understood to be a Virginia fruit, and the apple from which Mr. Jefferson's favorite cider was made. 


\section{VIRGINIA CRAB.}

Hewes's Virginia Craib. Coxe, No. 86.

A very small, globular-shaped cider apple; its color a dull red, intermixed with streaks of pale yellow; the juice acid and austere. An old and established cider apple. Mr. Coxe states that the origin of this apple is satisfactorily traced to Virginia, where trees of nearly a hundred years of age were standing at the time he wrote.

\section{SECTION V.}

\section{VARIETIES FOR ORNAMENT OR FOR PRESERVING.}

\section{RED SIBERIAN CRAB.}

The tree is of delicate growth, upright and handsome; the leaves shining and beautiful; a profuse bearer. The tree, when its fruit is at maturity, has a beautiful aspect, and might at a distance be mistaken for a plum or a cherry tree. A very small and beautiful apple, growing in clusters; of a bright scarlet color at maturity; of a globular form; the stalk long. Its principal use is for preserving, for which it is much admired.

\section{YELLOW SIBERIAN CRAB.}

The tree and leaf of this variety are similar to the Red Siberian Crab, and equally beautiful ; it is even more productive than that variety; and a tree loaded in autumn with its golden fruit, presents to the beholder a sight the most rich and beautiful. The fruit, which grows in large clusters, is of the size of a middling plum, globular; the stalk is long; the color fine, clear yellow, or a rich golden hue.

\section{CHINESE DOUBLE FLOWERING.}

\section{Pommer de la China.}

The tree is handsome and upright, does not grow large; the flowers are large, very double, and in clusters, and are beautiful, resembling small roses, of a delicate rose color. It is not uncommon with us ; when in blossom, its appearance is superb. According to my authority, it originated in Chi$\mathrm{na}$; the fruit is small, but tolerable for eating. 


\section{SOUTHER A P P L E S}

The following are stated to be some of the most esteemed varieties of native apples of Virginia. Part are described from the authority of Mr. Coxe, and the remainder on the authority of a Virginian, which I extract from that valuable Journal, the New England Farmer, Vol. vir. No. 1.

\section{BEVERLEY'S RED.}

The fruit is very large, the skin smooth, of a crimson color; flesh very white, of a pleasant flavor. A winter fruit. 116. CARHOUSE, or GILPIN. Coxe.

The tree is a great bearer. The fruit hangs long on the tree in autumn. A small fruit, rather oblong; the skin smooth, of a deep crimson color, with occasional yellow stripes; the flesh yellow, tender, and of good flavor. A native of Virginia ; highly esteemed for its excellence as a table fruit in spring; also a good cider fruit.

\section{1\%. CURTIS.}

The skin is smooth, of a red color; flesh juicy and pleasant. Ripe middle to end of August.

\section{GLOUCESTER WHITE. Coxe.}

'The tree is of vigorous growth, and beautiful form, and very productive; the fruit of medium size, its form varying from flat to oblong; of a fine yellow color, clouded with spots of black; the flesh yellow, breaking, juicy, rich, and delicious. It ripens early in October; and, according to Mr. Coxe, is not only a most excellent dessert fruit, but makes exquisite cider. Much cultivated and of high reputation in the lower counties of Virginia.

\section{JAMES RIVER, or LIMBER TWIG.}

Branches drooping or pendent; the fruit is of a greenish color, with a blush next the sun; the flesh very juicy, and pleasant at maturity. Winter. It keeps a long time.

\section{LIPPINCOT, $R$. Sinclair.}

A fruit of Maryland. Very handsome, and striped; excellent; one of the best of all early apples. July and Aug. 121. PRYOR'S RED.

The fruit is very large; color brownish red; its flesh at maturity juicy, and very fine: $\Lambda$ winter fruit. 
122. RAWLE'S JANET, OR ROCKRIMMON.

The form is globular, flattened; the color red and green; flesh very fragrant, more juicy, and of superior flavor to the Newtown Pippin, and keeps equally as well.

\section{ROYAL PEARMAIN. Coxe.}

Fruit fine, of a large size, flattened; skin rough, of a fine russet color, but red next the sun, and faintly streaked with russet; flesh a rich yellow, firm; but at maturity, tender, sweet, and of very sprightly flavor. A good table apple; excellent for cider; and highly esteemed by the planters of Virginia, near Richmond, from whence Mr. Coxe procured it. The tree bears uniformly and abundantly. It ripens in October, and will keep till February or March.

\section{STRIPED JUNE APPLE.}

The fruit is as fragrant as a pine-apple melon. It ripens thé Jast of Juné and beginning of July.

\section{VIRGINIA GREENING.}

The fruit is of medium size; color green, striped with red; flavor very superior. A winter fruit.

\section{Chass IL.}

\section{SELECT FOREIGN VARIETIES OF APPLES DE- SERVING TRIAL IN THE CLIMATE OF THE UNITED STATES;}

SUCII AS MAY PROBABLY SUCCEED WITH US; ALL DESCRIBED FROM FOREIGN AUTHORITIFS.

The following list consists of celebrated French, German, and a few Italian apples; also the principal part of those kinds which Mr. Ronald, from his great judgment and experience, has stated are rendered exquisite on their walls. Such, evidently, need a climate like ours, to bring them to their full maturity and excellence. Except these, I believe I have brought down to our latitudes but few other varieties of English apples; all celebrated for their excellence, for the dessert, cooking, or for cider. Some of 
these were either originated by Mr. Knight, or sent to us by him; also two highly celebrated Russian apples. I have, however, I must confess, far greater hopes in those very kinds, which, like some of our best American varieties of fruit, prove good for nothing in England, except on their walls - I mean the celebrated Italian apples, for reasons I have stated in the INTroduction, and under the head of Cumate; also for other reasons, stated at the head of Class III.

Gentlemen of intelligence and judgment who have resided both at Paris and in England, have assured me that the apples of those places are not comparable to ours. The late Governor Eustis, I have good authority for stating, expressed the same opinion. This may in part be ascribed to our brighter skies, and more constant and powerful sunshine during summer; and a gentleman of Salem, who has here made trial of a great many celebrated varieties of English apples, has lately stated to me, that he has been greatly disappointed in them.

R. Kinds particularly recommended by Mr. Ronald, as being rendered exquisite on walls, and highly deserving such a situation.

P. Kinds designated by Poiteau ás the best in general cultivation in France, and by him particularly recommended.

C. Kinds described by Dr. Willich, from the celebrated German writer, M. Christ.

K. L. Kinds sent by Mr. Knight to Mr. Lowell.

\section{S E C T I O N I .}

\section{SUMMER FRUIT.}

127. CALVILle ROUGE DE MICOUD. London Hort. Trans. Vol. v. p. 242. M. Thouin.

The account of this extraordinary tree and its fruit is from a communication of M. Thouin. This tree, which produces three crops of fruit annually, originated on the farm of the Baroness de Micoud, near La Charité sur Loire, in the department of the Nievre, and bears three thousand 
apples annually. The tree is striking in its appearance; "its dense, dark green, shining foliage, during three fourths of the year enamelled with numerous clusters of delicate rose-colored blossoms, and scattered over with fruit of a diversity of color, renders it a most interesting object of cultivation, especially as an ornament to our lawns and shrubberies, producing an effect not less novel than agreeable." The first flowering is in April, and abundant. The fruit of the first crop is globular, depressed; its height two inches, its diameter nearly three; of an angular appearance; the color deep dull red next the sun; the flesh is yellowish white, fine, breaking, juicy, a sweetish acid, and agreeably perfumed, with a crystalline appearance. It commences ripening the middle of July, and the fruit is mostly ripe in August, and continues ripening till November. The second flowering is in June, and is less abundant than the first. The fruit of the second crop is fit for the table in the end of October; they are the size of hen's eggs, and are of equal good quality with the first. The third flowering takes place in August, September, October, and November; the fruits are small, no larger than the Pomme d'Api; they are checked in their growth by frost, but will ripen in-doors, and may be eaten raw, but if roasted or stewed they acquire a sweet and delicious flavor.

\section{KESWICK CODLIN. Lindley. Py. Mal.}

One of the most useful and productive of all apples, except the Hawthornden; rather large; ribbed at its sides; pale yellow; very juicy, subacid; it answers for tarts even in June.

\section{S E C TIO N I I.}

\section{AUTUMN FRUIT.}

\section{BELLE DES QUERMES. (J.)}

A new fruit of the first quality, very large and excellent, ripening in winter; very beautiful. This fruit I procured of an amateur in France. Eminently deserving trial with us. 
130. (R.) BRADDICK'S NONPAREIL, Hort. Trans. Vol. II. p. 268. Lindley. Py. Mal. Pl. xxxıv.

A valuable dessert apple, raised by John Braddick, Esq. Sweeter and superior to the old Nonpareil; middle-sized, globular, flattened; skin smooth, brownish red next the sun; juicy, sugary, rich, aromatic. October to January.

131. (R.) BRINGEWOOD PIPPIN. Lindley. $\boldsymbol{P} y$. Malus.

A most excellent dessert apple, raised by Mr. Knight. Small, globular, flattened; color bright golden; russety stripes next the sun; breaking, rather dry; juice saccharine, perfumed, aromatic. October to March.

132. (R.) DELAWARE. Py. Mal. Brent.

A very desirable dessert fruit, supposed to be from America. Beautiful ; middle-sized; flattened ; color rich golden, blotched with deep red; flesh firm, rich, high-flavored; productive. October to January.

133. (R.) (L. K.) DOWNTON GOLDEN PIPPIN. Pom. Mag. 113. Lind.

Kriant's Pippin. Elton-Pippin.

The trees bear early and abundantly. The fruit is of medium size, cylindrical; the stalk short; skin yellow; flesh yellowish; crisp, with a brisk, rich, subacid juice. October to December. Raised by Mr. Knight. A dessert apple, and excellent for cider. Specific gravity of its juice, 1.080 .

\section{4. (R.) FRANKLIN GOLDEN PIPPIN. $P y$. Mal.}

A medium-sized fruit, of American origin. Oblong, a little flatted; fine yellow; flavor brisk, with more acid than the other Golden Pippin. A good bearer.

135. GRANGE. Py. Mal.

An excellent dessert or cider fruit, raised by Mr. Knight. Middle-sized; globular, flattened; flesh close, of pleasant flavor. From October to January. Specific gravity of the juice, 1.079 .

\section{GROS LOCART.}

New and very large, fine yellow in the shade, slightly red next the sun, and covered with bloom. The fruit is very fine and excellent; the tree very productive, Thus it was described to me by Mons. Vilmorin, of Paris. Highly deserving trial with us. 
137. (R.) KING OF PIPPINS. Py. Mal. Brent. PI. XXXvirr.

A first-rate fruit, which no garden should be without; middle-sized; oblong; color clear golden yellow, fine red next the sun; rich and juicy.. Autumn. "Productive.

138. (R.) KIRKE'S GOLDEN REINETTE. Py. Mal.

"Is an improved variety of the old Golden Reinette. The fruit is in general more beautiful, the flavor equal. The tree bears as well, and is more healthy in its growth."

139. (C.) NOBLE PIPPIN." Dr. Willich.

The trees do not grow tall, but bear abundantly. An exquisite dessert fruit; : oblong, diminishing to the crown, smooth, bright yellow, a few streaks of red next the sun. It ripens early, and keeps to the end of April.

140. (R.) PADLEY'S PIPPIN. Pom. Mag. t. 151.

Padlex's Royal George of Ronald ?

A very excellent dessert fruit; rather small ; flattened; skin dull yellow, or orange and russeted; flesh breaking, saccharine, pleasant, aromatic. November and December.

\section{PINE-APPLE RUSSET. Lindley.}

This fruit is described by Lindley as one of the best of all their dessert apples. Juice more abundant, saccharine, spicy, aromatic, perfumed, with a perfect proportion of acrd, and. flavor of the pine-apple. It is medium-sized, roundish ovate, angular; -color yellowish or yellow russet; flesh crisp, tender; one of the finest of the season. September and October.

142. (P.) POMME PRINCESSE. N. Duh. Pl. viI. The fruit is of medium size, flattened; of a beautiful yellow in the shade, striped with red next the sun; the flesh yellowish white, fine, and excellent; juice not abundant, but agreeable and sweet. This excellent apple is one of the best species of Reinettes. October.

143. (C.) PRINCE'S TABLE APPLE. Dr. Willicl. LOSKRIEG.

A delicious autumnal fruit, vying with the pear rennet; it is of the Calville family. Moderately large; somewhat oblong; whitish, and covered on the south side with red streaks. The tree does not rise to a considerable height. 
144. (R.) SCARLET PERFUME. Py. Mal.

Cole Apple. 1b. and Pom. Mag.

A new and very desirable dessert fruit, and good for cooking. Moderately large; flattened; nearly globular, flat-sided; mostly covered with rich, deep red; juicy, rich. flavor spicy. September and October.

145. (R.) WYCKEN PIPPIN. Lindley, Loudon.

A dessert fruit, below medium size; flattened; yellowish green; but pale dull brown next the sun; flesh firm, breaking, sugary, with a little musky perfume. 'The cottagers' apple around Wyken. October to December.

\section{SE C TION I II.}

WINTER FRUIT.

146. barcelona pearmain. Pom. Mag. t. 85. Lind.

Speckled Golden Reinette, according to the Pom. Mag.

Reinette Rovge, according to Lind.

A dessert fruit, of medium size; oval, rather long; brownish yellow in the shade, deep red next the sun; flesh firm, with a rich, aromatic, but slight and agreeable acid. November till February. A good bearer.

14\%. (R.) Beachemwell Seedling. Pom. Mlag. Lin.

An excellent dessert apple, raised by John Motteaux, Esq. Medium-sized, roundish, depressed; pale yellow, but red next the sun; flesh tender, juicy, pleasant. November to $\Lambda$ pril. The tree bears well.

148. BELLE DU HAVRE. (J.)

A new and noble fruit, very large, and covered with bright red; of the first size and quality; ripening in winter. This fruit I procured of an amateur in France. Eminently deserving trial with us.

149. (C.) (P.) BORSDORFER. Dr: Willich.

RED Borsdorfer. Ib. Bórsdorf of Lindley.

A delicious German apple, of large size, beautiful as the Canadian, and in size and form like the Reinette Triom- 
phante, which it almost excels; globular formed, slightly narrowed at the crown; yellow in the shade, but for the most part a fine glossy red; its flesh uncommonly white, tender, juicy, sweet, partaking of the odor of roses; a bright red vein encompassing the core. The tree comes early into bearing, and bears abundantly. It ripens in December.

\section{0. (R.) CHRISTIE'S PIPPIN: Py. Mal.}

A very fine dessert apple, raised by Mr. Christie: in form and shape like a Nonpareil; lemon-colored, with faint red stripes; flesh soft, agreeably sweet, enough of acid. November till February. The tree bears abundantly.

\section{1. (K. L.) CORNISH JULY FLOWER. Py. Mal. \\ Pl. XIx.}

JULY Flower: Hort. Trans.

Very old, above the middle size, oval, with irregular ribs; of an olive green color, streaked with dull red; the flesh of a rich aromatic flavor and fragrant perfume. Not very prolific. It keeps through the winter.

\section{2. (R.) COUR'T OF WYCK, OR RIVAL GOLDEN} PIPPIN, Py. Mal. Brent. Pl. xIs.

"A dessert apple, which vies with the Golden Pippin in richness of flavor, and much excels it in other respects; it is rather large, of a golden hue, with red stripes, very handsome. This is esteemed the finest Christmas apple we have. Keeps well till February or.. March. The tree never cankers, and never fails bearing.

\section{D'ASTEMS.' Py. Mal. Brent. Pl, xxxi.}

Strifling D'Hiver.

A noble kitchen fruit; large, globular; a little flattened; green, with some dull red streaks, chiefly on the top of the fruit. It is a first-rate sort, firm, with a rich flavor, and dresses well; and will keep till March or April."

154. DUTCH MignONNE. Pom. Mag. Py. Mal.

Reinette Doree of Mayer.

Christ's Golden Rewetre of the Taschenbacl, according to the Pom. Mag.

An excellent dessert and sauce apple; over medium size, a little flattened and diminished at its crown; greenish yellow in the shade, next the sun striped and marbled with deep red; the flesh is firm, crisp, juicy, subacid, aromatic. November to April. Tree an abundant bearer. 
155. (C.) EASTER, or PASQUE APPLE. Dr. Willich.

The Easter, or Pasque Apple, is one of the principal and finest of the Calvilles; it is large, with high, projecting ribs, and of a bees-wax color; has a white, tender, juicy pulp, and emits a very grateful odor, similar ta that of roses. The tree bears abundance of fruit.

\section{6. (C.) (P.) FENNOUILLET GRIS. Bon Jard. Dr. Willich.}

Caraway Russet. Hort. Soc. Cat. Spice Apple. Ib.

Brown Apple of Burnt Island. Ib.

Anis. Bon. Jard. Winter Anis Rennet. Dr. Willich.

The tree is very productive; the fruit is under medium size; globular, depressed; the skin of a gray fawn shade, covered with thin russet, and a slight brown next the sun; the flesh is tender, and has the peculiar aroma and flavor of anise. December till February.

15\%. (P.) FENNOUILLET JAUNE. Bon Jard. Lind.

EMbrotdered Pippin. Lindley.

Drap d'Or. Bon Jard. Duh. Pomme de Caractere. $l b$.

The tree is very productive; the fruit of medium size, globular, inclining to oblong; its skin is a beautiful yellow, marked with fine russet lines resembling letters; hence its name, Pomme Caractere. Its flesh is firm, delicate, saccharine, and excellent, with a flavor of the Fennouillet, or Anise. December to February.

158. Fennoulletet ROUGE. Nouv. Cours Compl.

A very excellent fruit, of medium size; globular, flattened; deep gray, but streaked with brown red next the sun; flesh firm, sugary, high-flavored, musky. March. This fruit requires a light, warm soil, and cannot be too much multiplied.

159. (K. L.) GOLDEN HARVEY. Py. Mal.

Brandy Apple.

A small dessert apple; light yellow, flushed with red, and russeted; flesh remarkably compact; very rich in flavor. It will keep till April or May. It is called Brandy apple, from the specific strength and gravity of its juice, which is 1.085. The tree grows feeble; it does not bear well at first, but afterwards seldom fails.

160. (R.) GREEN NONPAREIL. Py. Mal. Brent. PI. XXXIv.

Petworth Nonpareil.

Raised at the earl of Egremont's; larger than the old 
Nonpareil, but of nearly of the same shape; the color green. A valuable apple for the table; crisp, juicy, and high-flavored. February or March. It is a good bearer

161. HUBbaRD'S PEARMAIN. Lindley. Pom. Mag. Golden Vinisg of Pom. Mag.

According to Lindley, the merits of this fruit are unrivalled, and its superior as a dessert fruit, from November to April, does not exist in that country. The fruit is small, oyate or globular, yellow, orange or pale red next the sun; flesh firm, rather dry, juice sweet, rich, of a most highly-perfumed, aromatic flavor. An abundant bearer.

162. (P.) JERUSALEM. Bon Jard. p. 344.

Pomme Pigeon. $l b$.

The tree is of medium vigor, and very productive. The fruit is small, conical; its color that of the changeable rose; flesh fine, delicate, granulous, and very good.

163. (R.) MARGIL. Lindley. Hooker's Pom. Lond.

A very excellent dessert fruit; small, ovate, angular; bright orange, streaked and mottled with rich red and brown; - slightly -russeted; flesh yellow, firm, breaking, juicy, sweet, highly aromatic. November to March. A very excellent bearer.

164. (R.) MARTIN NONPAREIL. Hooker. Lindley.

A new and valuable dessert fruit, small, ovate, depressed; dull green, but tawny orange or red next the sun; thinly russeted ; not handsome; flesh compact, with an excellent flavor; sweet, with a fine acid. They have been kept a year. The tree is a good bearer.

165. (C.) MELA DE ROSMARINO. Dr. Willich.

White Italian Rosemary Apple. Ib.

A very beautiful species of Calville, having no ribs, but a most glossy skin, which resembles the finest virgin wax; and, on the south, somewhat red ; of an oblong figure, and the size of a goose egg; its flesh is white as snow; uncommonly tender, and yielding a saccharine juice of a slightly aromatic flavor. Its large pericarpium côntains twenty kernels in five cells. November till February.

166. NORFOLK BEAUFIN. Py. Malus., Lind.

A beautiful cooking apple; a fruit of great merit for drying, furnishing a luxury at table during winter; rather large, flattened; nearly the whole surface covered with livid red. November till June. "These apples are dried 
by the bakers of Norwich, annually, and sent in boxes to all parts of the kingdom, where they are universally admired."

\section{7. (C.) PEAR RENNET. Dr. Willich. \\ Reinette Poire of the catalogues.}

Both an autumnal and winter fruit; presents a capital yellow apple, of a tender, yellowish pulp, the juice of which has the acidulous flavor of $R$ henish wine. It is sufficiently mellow in the beginning of November, and may be preserved through the greater part of winter. The tree is of slender growth.

\section{PIGEON DE ROUEN.}

A new fruit, of medium size and ovate form, very valuable and productive. Thus it is described to me by Mons. Vilmorin, of Paris; highly deserving trial with us. 169. POMME DE LESTRE. Bon Jard. p. 344.

This apple was found in the department of Vienne, in 1813 , and has been preserved during three years. It is highly esteemed.

170. (C.) (P.) REINETTE DORÉE. Dr. Willich. Nouv. Cours Complet d'Agr. Vol. Xir. p. 213.

Reinette Jaune Tardive. Ib. Dr. Willich.

This apple is equal in goodness to the Reinette Franche, but is nearly gone when that variety begins to be fit for use. It is middle-sized, flattened, deep yellow in the shade, reddish next the sun; flesh juicy, saccharine, vinous, highflavored, a little acid. December to March.

171. (P.) REINETTE FRANCHE. Nouv. Cours Compl. Vol. xir. p. 215.

Fruit large, round, irregularly formed, and very much pointed with brown; sometimes slightly red next the sun; the flesh is firm, yellowish white, saccharine, agreeable. It is, notwithstanding the excellence of the Reinette Grise and the Reinette du Canada, the best of all ; but it varies much in goodness, in size, and duration, according to the soils, expositions, seasons, \&ic.

172. (R.) SCARLET NONPAREIL. Pom. Mag. t. 87. Lindley. Pyrus Malus. Pl. xxxiv.

A dessert apple, admired for its beauty and excellence; middle-sized, roundish, not angular; yellowish green in the shade, deep red next the sun, streaked; flesh frrm, 
yellowish white, juicy, rich, and excellent. Extensively cultivated in England. November to March.

173. (K. L.) (R.) SWEENEY NONPAREIL. Hort. Trans. Lindley.

Rather large, and in form of a Nonpareil ; color green, with patches of russet all over; sometimes a brilliant color next the sun; flesh firm, crisp, with abundance of juice, in which a powerful acid is combined with much sugar. A new dessert apple from November to March. The tree is an abundant bearer.

\section{4. (R.) SYKEHOUSE APPLE. Hooker's Pom.}

The tree grows freely, and, when well established, bears fruit abundantly. "The fruit is small, roundish, depressed; the stalk short; color green, with a good deal of russet ; but in a good season it is ra handsome apple, with some red next the sun; the flesh is rather firm, but of pleasant flavor and extraordinary richness. It ripens in January, and is justly regarded as one of the best dessert apples at present known."

175. (C.) REINETTE TRIOMPHANTE.

Victorious Reinette. Dr. Willich?

"An uncommonly fine, large, and well-formed apple, which, on being deposited on the floor, acquires a deep yellow tint, marked with starry points, and frequently. brown, rough spots, or large warts; its- eye represents aregular star; its flesh beneath the tender skin is yellow, firm, though delicate; yielding abundance of juice, that possesses a pleasant, aromatic flavor. It ripens about Christmas, and may be kept till March. The tree grows luxuriantly, and becomes of considerable size.".

176. LA VIOLETTE. - Nouv. Cours Complet Agri.

Pomme de Quatre Gouts. $1 b$,

Fruit of medium size, oblong; color deep red next the sun, yellow, striped with red in the shade; the flesh fine, delicate, saccharine, having a little of the perfume of the riolet; reddish beneath the skin, greenish towards the centre. This variety is one of the best of apples, and keeps till May.

(R.) Also to the above list, all Nonparerus and all Golden Pippins not here described, are recommended by Mr. Ronald for walls. 


\section{S E C T I O N $\mathbf{I}$ V.}

FOREIGN CIDER APPLES DESERVING TRIAL IN THE UNITED STATES.

THESE WOULD BE LIKELY TO ANSWER WELL IN CANADA.

177. FOXLEY. Lindley.

Raised by Mr. Knight from the Siberian Crab and Golden Pippin. A very small apple, growing in clusters, of a bright, gold color. Specific gravity of its juice, 1.080 .

178. HAGLOE CRAB.

The most famous cider in the world was formerly made from this fruit in England. An old fruit; small, ill shaped; - yellow in the shade, russety red next the sun. Specific gravity of the juice, 1.081. This fruit has been many years in the United States - quite long enough for trial.

179. SIBERIAN BITTER SWEET. Lindley.

Raised by Mr: Knight from the Siberian Crab and Golden Harvey; and was sent by Mr. Knight to the Hon. John Lowell. It is small, not much larger than the Siberian Crab, of a yellow color, with a blush next the sun. It is supposed to contain a larger proportion of saccharine matter than any other apple known. It does not abound in juice, and it is supposed would be a most valuable variety to mix with the more austere sorts. The trees are most abundant bearers.

180. SIBERIAN HARVEY. Lindley.

A small, globular fruit, raised by Mr. Knight from the Siberian Crab and Golden Harvey; of a bright gold color, stained with deep red next the sun; the fruit grows in clusters on slender branches; the juice exceeding sweet. Ripe the middle of October. Specific gravity of its juice, 1.091 .

See Downton Golden Pippin, Grange, and Orange Pippin, which are all cider fruits. 


\section{Cluas III.}

\section{SELECT LIST OF FOREIGN VARIETIES OF APPLES}

\section{DESERVING TRIAL IN NORTHERN CLIMATES.}

The following select list of Northern fruits are chiefly of British origin. They are described by their writers, Lindley and Ronald, as of first-rate excellence; the latter, especially, from his great collection of trees in bearing. Yet, as few of them are by him included in that list of kinds which he has recommended as being highly improved on walls, or as requiring a warmer climate, I have therefore concluded to leave them in high northern latitudes. Other reasons for this will be found in the "INTrovucTION" to this work, and in the article which follows, on "Chmate." I have assigned them to the influence of fine summer skies; to Nova Scotia and the Canadas, and the British possessions in America; also to the northwestern section of our own country, on the side of the Pacific; to Oregon, and our neighbors, the Russians, lying contiguous. For all of them, we might include, also, many other kinds, of the first and second classes, which may have originated in the higher latitudes. Some of them, however, will prove fine with us, and all are now on trial.

\section{S E C T I O N I.}

\section{SUMMER FRUIT.}

181. Astracan. Pom, Mag. Lind. Dr. Willich. White Astracan. Pom. Mag. and Lind.

Grace de Zelande: $I b$. Transparent de Moscovie? $\boldsymbol{l} b$. Russian. Ice Apple. $I b$. Pomme de Gíace: $\boldsymbol{l} b$.

This fruit is said to grow wild about Astracan. It is of medium size, globular, the sides angular; the skin is smooth, and covered with pale bloom; the flesh semitransparent, of the whiteness of snow. Dr. Willich, on the authority of M. Christ, has described it as beautiful, yel- 
lowish white, with fine red flaming streaks; with a saccharine juice, so copious, that it constitutes seven ninths of the weight of the fruit-which is most superior, in $a$ suitable situation and climate, not below $49^{\circ}$ of latitude. [See art. on Climate, in the first pages of this work.] The Pom. Mag. and Lindley inform us, that this fruit is very fine in the climate of England; but at Paris, according to the Bon Jard., the fruit is but at mediocrity; and in our climate, good judges have pronounced it good for nothing.

Borovitsky, (Russian.) Brown's Summer Beauty. Carlisle Codlin. Early Crofton, (Irish.) Early Julien, (Scotch.) Rivelstone Pippin, (Scotch.) Sack and Sugar. Salina. Sugar-Loaf Pippin, Dolgoi Squoznoi, or Long Transparent, (Russian.). Summer Golden Pippin. Wormsley Pippin. Knight's Codlin.

\section{SE C T ION I I}

\section{AUTUMN FRUIT.}

Alfriston. Lind. Beauty of Kent. Bedfordshire Founding. Cowarne's Queening. Devonshire Queen. Dowell's Pippin. Downton Nonpareil. Edgar. Flower of Kent. Frencil Pippin. Golden Burr. Golden Noble. Kentisin Broading. Kentish Fillbasket. Kerry Pippin. Lewis's Incomparable. Kirke's Scarlet Admirabie, or Hollandbury. London Pippin. Lucombe's Seedling. Pearson's Plate. Potter's Large Seedling. Rawlin's Fine Red-Streak. Rymer. Salopian Pippin. Scarlet Crofton, (Irish.) Sops of Wine. Striped Monstrous Reinette.

\section{S I C TIO N III.}

\section{WINTER FRUIT.}

Aromatic Russet. Burrell's Red. Claygate Pearmain. Cockle Pippin. Cornish Aromatic. Devonshire Golden Ball. Duke of Welington. Ham 
bledon Defx Ans: Hoary Morning. Húgh's Golden Pippin. Kirke's Lord Nelson. Lemon Pippin. Marmalade Pippin, (Welch.) Norfolk Storing. Northern Greening. Striped Holland Pippin. Walthim Abbeí Seedling. Yorkshire Greening.

\section{CULT IVATION, \&c.}

The seeds or pomace of the apple should be sown in autumn in a rich soil. When the young plants appear in spring, they should be carefully thinned to the distance of two inches asunder, and kept free from weeds by carefully hoeing during the remainder of the season, or till of sufficient size to be removed.

At one or two years of age, they are taken up, their tap roots shortened, that they may throw out lateral roots; they are transferred to the nursery, set in "rows about four feet asunder, and at one foot distance from each other in the row, in a rich and loamy soil. In the summer following, they are inoculated, or they are engrafted or inoculated the year following.

Size and Age for transplanting to the Orchard.

An apple tree, when finally transplanted to the orchard, ought to be at least six or seven feet high, with branches in proportion, and full two years from the bud or graft, and thrifty. Apple trees under this size belong properly only to the nursery.

\section{Distance.}

The distance asunder to which apple trees should be finally set, when transplanted to the orchard, depends upon the nature of the soil, and the cultivation to be subsequently given. If the soil is by nature, extremely fertile, forty feet distance may. be allowed, and even forty-five and fifty feet - in some very extraordinary situations; for before the trees become old, they will completely shade the ground. 
If, however, the soil is not,very extraordinary by nature, or so rendered by art, this distance would be too great; for the trees would become old, and their growth would be finished, before the ground could be covered by their shadow; - thirty feet, only, may therefore be allowed in land usually denominated of good quality, and but twenty to twenty-five feet in land of ordinary quality. But where economy of time, of land, and of all things else, is consulted, but one half this distance will answer for a series of years.

The quincunx mode is recommended for close arrangement, and short-lived trees may be set in the intervals.

The size to which an apple tree may attain, and the ground which should be allotted to it, depend also, in some measure, on the particular variety of apple; some sorts being well known to attain to a much greater size than that of others.

The period of growth, or the duration of the apple tree, is comparatively limited; this is sufficiently evident from the perishable nature of its timber. Those species of trees only will continue living and growing for numerous centuries, whose timber may be preserved incorruptible during the lapse of a long succession of ages.

\section{Soll and Situation.}

A rich soil, rather moist than dry, is that adapted to the apple tree; but what is usually termed a deep pan soil is to be preferred.

On such a soil, whether on the plains, or in the valley, or on the sides and summits of our great hills, which almost always consist of good land, and even in situations the most exposed, the apple tree will flourish.

One of the most productive apple orchards in this immediate vicinity, is situated on the north and north-west sides of a hill, the most exposed to cold winds. The soil of great hills is generally of far superior quality to that of the plains; and it is a very mistaken opinion, which seems adopted by some, that the soil of all hills must of necessity be dry and deficient in moisture. It is the plains and the knolls that are but too generally thus deficient, not the great hills, which almost always abound in springs. 
Land half covered with rocks, and incapable of being cultivated with the plough, is in some respects admirably suited to the apple tree. For, in such situations, they are not liable to suffer from drought; they receive nearly a double portion of moisture from the rains that fall, and a greater degree of heat by the reflected rays of the sun.

They may even flourish on sandy plains, if, where the tree is to be placed, an excavation is formed six or eight feet in diameter, and three or four feet in depth, and if half filled either with useless small stones intermixed with rich loam, mud from the low grounds, clay, or gravelly clay, or mixtures of any of these substances, with a portion of manure, and the remainder of the excavation filled to the surface with rich loam.

\section{Management of the Land.}

If the ground intended for the orchard cannot conveniently be kept wholly in a state of cultivation during the first years, a portion, at least, ought to be.

A strip of land to each row, of eight or ten feet in 'width, well manured, may be kept cultivated, and the vegetables which.may here be raised will amply repay the expense and labor bestowed during the four or five first years. After this, if the trees have grown well, as they probably must have done, cultivation at a distance in the intervals becomes even more important than within the limited distance of a very few feet from the trunk of the tree.

For on examination it will be found that the small fibres or spongelets, by which alone the tree derives all the nourishment it receives from the earth, are now remote from the trunk of the tree; they are now to be found seeking pasture beyond the limits of its shade, and it becomes necessary that the whole ground should be kept in a high state of cultivation for the four or five following years; after this period, it may occasionally be laid to grass, which, however, should be broken up at frequent intervals, the land being. always kept in good heart.

\section{Pruning.}

I have given directions for pruning the trees while young, under the general directions in the former part of 
this work, at page 51. Those directions are particularly applicable to the apple tree. I would only add, that when these directions have been followed, - when large and profitable crops are desired, - our, cultivators generally avoid robbing their trees unnecessarily of a particle of bearing wood.

Those limbs which interfere with other limbs by galling, the suckers and dead wood, are alone removed; for they consider that the warmth of the atmosphere is of itself sufficient in our climate to ripen the fruit, without attempting to admit the sun to every part of the tree.

These directions are to be more especially observed in regard to old trees in their declining years: their trunks being too old for the reproduction and sustenance of a crop of new and fruitful wood, nothing should be taken away but the dead branches and suckers. We have seen old trees, whose branches were annually loaded with fruit, despoiled at once by the hand of man of half their bearing wood, under the mistaken idea that the destruction of the one half of the tree would confer a benefit on the remainder, and render it still more productive. We noticed, however, that the effect thus produced was directly the reverse, as their total destruction usually followed as a consequence not long after.

\section{INSECTS.}

The apple tree has four destructive enemies - the caterpillar, the borer, the canker-worm, and the curculio.

The Caterpillar usually makes its first appearance with the opening of the leaf of the apple tree: they are readily and easily destroyed if taken in season. They are brought down either by the hand, or by the excellent brush invented by the late Hon. Timothy Pickering, which must be attached to a pole. They should be taken early in the morning, before they leave their nests. When brought down, they must be destroyed. The trees should be examined a second time not long after.

The Borer. The modes of preserving apple trees from the depredations of the borer may be found in the former part of this work.

Of the Canker-Worm. 'In the immediate neighbor- 
hood where I reside, the canker-worm is unknown. I must therefore avail of the experience of others.

The: canker-worm, after it has finished its work of destruction in spring, descends to the earth, which it enters to the depth of from one to five inches. After the first frosts of October, or from the 15th or 20th, those nearest the surface usually begin to rise from their earthy bed, transformed to grubs or millers. They usually rise in the night, and invariably direct their course to the tree, which they ascend, and deposit their eggs on the branches, which are hatched in April or May. They frequently rise during moderate weather in winter, when the ground is not frozen, and in March, and till towards the end of May. When the ground in spring has been bound by a long continuance of frost, and a thaw suddenly takes place, they sometimes ascend in incredible numbers.

Here, then, at the bottom or trunk of the tree, it is necessary to arrest their progress; and prevent the ascent of the grub or miller.

- The usual mode, or the mode generally adopted in practice, is tarring. With this design, the bark around the circumference of the trunk is scraped smooth, and the crevices where the application is to be made are filled with clay or mortar; over this, a strip of canvass three or four inches in width is to be bound around the tree, the lower band to consist of a large tow cord, to prevent the running down of the tar, and its consequent pernicious effect on the tree. On this strip the tar is laid with a brush. The operation must be performed every afternoon a little before sunset, when the weather is moderate, and the surface of the earth not frozen, from the first hard frosts which commence in October, and during the winter, till about the last of May. For the tar, by the heat of the sun; or by dry winds, or other causes, sometimes becomes dry on its surface in a very short time, and in such cases it offers no obstruction to the passage of the insect. Dr. Thacher, in his American Orchardist, "has recommended that a small portion of soft grease or train oil should be mixed with the tar to preserve it from drying. It should be observed that the insect, on finding its passage obstructed, frequently deposits its eggs in great numbers near the base of the tree, in the cracks and fissures of the bark. These may be destroyed by a solution of 
potash. But the tar does not at all times afford a perfect security; for when vast numbers arise at once from the earth, a bridge over the tar is speedily formed of the carcasses of those which first attempt the ascent, and over these an innumerable host may safely pass, and the labor of tarring, previously bestowed, is lost for that season,

The tarring process is a tedious one, requiring constant attention during a long period; the omission of a single night favorable to the ascent of the grubs, may prove fatal to the trees for that season, and the labor previously bestowed is lost.

Various other modes have therefore been proposed, with the design of preventing their ascent; but however-ingenious or effectual they may have proved, they have not to my knowledge yet been introduced to general practice.

The strip of list or girdle to surround the tree, and covered with the mercurial ointment, as recommended by Dr. Spofford, of Bradford, Mass, as an effectual remedy, was tried by Gen. Dearborn in the course of his experiments, and with him has totally failed; it offered no obstruction whatever to the ascent of insects. [See New England Farmer, Vol. vi1r. Nos. 23 and 48.]

What the particular causes of the failure in this instance were, provided it has in other instances proved effectual, we cannot conjecture, unless we suppose that the insects passed over while the mercurial preparation was yet in a new and fresh state, and before it had time to imbibe that portion of oxygen from the atmosphere which Dr. Spofford has asserted renders its poison more active and effectual.

'The Hon. John Lowell has stated in Vol. Irr. No. 4 of the Mass. Agr. Repository, that he caused the ground around sixty apple trees to be dug to the depth of four inches, and to the distance of two or three feet from the roots; it having been ascertained by Professor Peck, that the insect seldom descended into the ground at a greater distance than three or four feet from the trunk. 'The ground being laid smooth, three casks of effete or airslacked lime were spread over the surface thus prepared, to the depth of about an inch. These trees were tarred as well as the others; and, although grubs or worms appeared on most that were not limed, not a single grub was to be perceived on the trees limed.

Mr. Lowell has spoken of the result of the experiment 
as of a single trial, and the first of the kind to his knowledge on-record, and expresses his hopes that it may induce others to pursue still further the experiment; for while tarring is injurious to the tree, and expensive in its application, the lime, which may-consist of sweepings of the lime store, is comparatively cheap; it requires but a single application in a season; it is not only destructive to animal substances, but is useful as a manure.

Professor Peck has recommended that the ground should, in October; be carefully inverted with a spade to the depth of five inchés, and, as far as the branches extend, the clods broken, the surface raked smooth, and rolled with a heavy roller; the rolling to be repeated in March. Lime, reduced to an impalpable powder, he thinks, might be with advantage applied to the surface thus smoothed, not only as being adapted to close the openings which may appear, but useful also from its caustic qualities.

Dr. Robbins, of Rox́bury, has recommended, as an effectual remedy, that a strip of sheet-lead, of four and a half inches in width, be formed into a tube or gutter, by bending over a wooden cylinder; this is again bent round the tree by passing a rope through-it. After being adjusted to a level, it is secured by nailing its inner edge to the tree. This, being soldered at the ends, is filled in , autumn with winter-strained oil, spirits of turpentine, or other liquids; and above this is placed a strip of oiled sheathing paper, cut in proper form, as a screen from the falling rain.

The plan invented by Mr. Abel Houghton, of Lynn, and said to have proved effectual, differs from the above, as the circular gutter is formed of thick pasteboard painted; it is filled with oil, and a pasteboard screen projects from above, covered with painted canvass, to shield it from the rain.

On similar principles Mr. Briggs, of Bristol, Rhode Island, has successfully stopped the ascent of the grub by gutters formed of tin. Four straight gutters are connected by soldering at their corners; these, being adjusted to a level, are supported on strips of boards nailed to the tree; the inner edge of the gutter is so bent as to project over the outer edge, to shield it from the rain. The space between the gutter and tree being filled with swingling tow properly secured, and the gutter being filled half full of 
water, a quantity of thin whale oil is added, and the security is supposed to be complete.

The Hon. H. A. S. Dearborn has further suggested, that gutters formed of earthen Danvers ware, laid on the earth around the tree, might perhaps prove cheaper; and these being filled with a fluid might be equally as effectual.

Lastly, we would recommend for experiment, on the supposition that some one of them may prove effectual, the application of the following substances. For a more particular account of them all, see the article INsEcts, in the former part of this work.

1. Chloride of Lime, to be placed around the roots of the tree in a circular gutter, formed of any material, and screened from rain.

2. Cinders from the blacksmith's forge, applied in a similar manner, which have been found by Professor. Thouin so effectual in obstructing the march of the wire-20orm.

3. The application of coal tar, instead of common tar, to prevent the ascent of the grub. This substance, as has already been stated, possesses either qualities so poisonous, or an odor so powerful, that its application is now said to be effectual in preventing the ravages of the worm which is so destructive to the plank of the ships which navigate the ocean in warm latitudes.

When the canker-worms have once, gained possession of the tree, it is by no means deemed an easy task to dislodge them. Attempts have been made to destroy or dislodge them by fumigations of oil, sulphur, \&c., but the accounts of the efficacy of such attempts are contradictory. They may, however, be dislodged by pounding the limbs and shaking the trees, and their reascent prevented.

Curculio. For an account of the various modes adopted to avert the ravages of this destructive insect, see the article INsEcts, in the former part of the work.

\section{Gathering and preserving the Fruit.}

Various theories have been offered for preserving apples in a sound state for winter use, or for distant voyages. Some have proposed gathering the fruit before it is ripe, and drying it on floors before it is put up; this has been tried; the apples lose their sprightly flavor, and keep no better than by some less troublesome modes. Dr. Noah 
Webster has recommended that they. should be put down between layers of sand which has been dried by the heat of summer. This is without doubt an excellent mode, as it excludes the air, and absorbs the moisture, and must be useful when apples are to be shipped to a warm climate.

Chopped straw has also been highly recommended to be placed between the layers of fruit; but I have noticed that the straw, from the perspiration it imbibes, becomes.musty, and may probably do more hurt than good. When apples are to be exported, it has been recommended that each be separately wrapped in coarse paper, in the manner oranges and lemons are usually put up. This is, without doubt, an excellent mode. And Mr. Loudon has recommended that apples destined for Europe shonld be packed between layers of grain.

Great quantities of fine winter fruit are raised in the vicinity of Boston, and put up for winter use, for the markets, and for exportation. The following is the mode almost universally adopted by the most experienced; and by this mode apples, under very favorable circumstances, are frequently preserved in a sound state, or not one in fify defective, for a period of seven or eight months. The fruit is suffered to hang on the tree to as late a period as possible in October, or till hard frosts have loosened the stalk, and they are in imminent danger of being blown down by high winds; such as have already fallen, are carefully gathered and inspected, and the best are put up for early winter use. They are carefully gathered from the tree, by hand, and as carefully laid in baskets. New, tight, well-seasoned flour barrels from the bakers, are usually preferred : the baskets, being filled, are cautiously lowered into the barrels and reversed. The barrels, being quite filled, are gently shaken, and the head is gently. pressed down to its place, and secured. It is observed that this pressure never eauses them to rot next the head, and is necessary; as they are never allowed to rattle in removing. No soft straw or shavings are admitted at the ends; it causes mustiness and decay. They are next carefully placed in wagons, and removed on the bulge, and laid. in courses in a cool, airy situation on the north side of buildings, near the cellar, protected by a covering on the top, of boards, so placed as to defend them from the sun and rain, while the air is not excluded at the sides. A chill does not 
injure them; it is no disservice; but when extreme cold weather comes on, and they are in imminent danger of being frozen, whether by night or day, they are carefully rolled into a cool, airy, dry cellar, with openings on the north side, that the cold air may have free access; they are laid in tiers, and the cellar is in due time closed and rendered secure from frost. The barrels are never tumbled or placed on the head. Apples keep best when grown in dry séasons and on dry soils. If fruit is gathered late, and according to the above directions, repacking is unnecessary; it is even ruinous, and should on no account be practised till the barrel is opened for use. It has been fully tried.

When apples are to be exported, Mr. Cobbett has recommended that "they should, if possible, be carried on deck; otherwise between decks." Between decks is the place, and in the most dry, cool, and airy part.

\section{CIDER.}

Cider, or the fermented juice of the apple, constitutes the principal vinous beverage of the citizens of New England, of the Middle States, and of the older States of the West. Good cider is deemed a pleasant, wholesome liquor during the heat of summer; and Mr. Knight has asserted, and also eminent medical men, that strong, astringent ciders have been found to produce nearly the same effect in cases of putrid fever as Port wine.

The unfermented juice of the apple consists of water and a peculiar acid called the malic acid, combined with the saccharine principle. Where a just proportion of the latter is wanting, the liquor will be poor and watery, without body, very difficult to preserve and manage. In the process of fermentation, the saccharine principle is in part converted to alcohol. Where the proportion of the saccharine principle is wanting, the deficiency must be supplied, either by the addition of a saccharine substance before fermentation, or by the addition of alcohol after fermentation. For every one must know, that all good wine or cider contains it, elaborated by fermentation, either in the cask, or in the reservoirs at the distillery. The 
best and the cheapest kind is the neutral spirit - a highly rectified and tasteless spirit, obtained from New England rum. Some, however, object to any addition of either sugar or alcohol, to supply deficiencies; forgetful that these substances are the very elements of which all wine, cider, and vinous liquors are composed.

The strength of the cider depends on the specific gravity of the juice on expression: this may be easily ascertained by weighing, or by the hydrometer.

I have described some of the most approved varieties of apples known. The density of their juices is designated by their weight, which I have stated; which is always in proportion to the same measure and quantity of water, weighing 1000. According to the experiments of Major Adlum, of Georgetown, District of Columbia, it appeared that when two pounds of sugar were dissolved in a gallon of rain water, the bulk occupied by 1000 grains of rain water, weighed 1087 grains. From this it would appear that the juice produced by the best known apple, contains about two pounds of sugar in a gallon. Mr. Marshal has asserted that a gentleman, Mr. Bellamy, of Herefordshire, England, has, by skill, "produced cider from an apple called Hagloe Crab, which for richness, flavor, and price on the spot, exceeds, perhaps, every other liquor which nature or art has produced. He has been offered sixty guineas for a hogshead of 110 gallons of this liquor." Newark, in New Jersey, is reputed one of the most famous places in America for its cider. The cider apple most celebrated there is the Harrison apple, a native fruit; and cider made from this fruit, when fined and fit for bottling, frequently brings $\$ 10$ per barrel, according to Mr. Coxe. "This and the Hughs' Virginia Crab are the two most celebrated cider apples of America. Old trees, growing in dry soils, produce, it is said, the best cider. A good cider apple is sar, charine and astringent.

To make good cider, the first requisite is suitable fruit; it is equally necessary that the fruit should be not merely mellow, but thoroughly mature, rotten apples being excluded; and ripe, if possible, at the suitable period, or about the first of November, or from the first to the middle, after the excessive heat of the season is past, and while sufficient warmth yet remains to enable the fermentation to progress slowly, as it ought. 
The fruit should be gathered by hand, or shaken from the tree in dry weather, when it is at perfect maturity; and the ground should be covered with coarse cloths or Russia mats beneath, to prevent bruising, and consequent rottenness, before the grinding commences. Unripe fruit should be laid in large masses, protected from dews and rain, to sweat and lurry on its maturity, when the suitable time for making approaches. The earlier fruits should be laid in thin layers on stagings, to preserve them to the suitable period for making, protected alike from rain and dews, and where they may be benefited by currents of cool, dry air.

Each variety should be kept separate, that those ripening at the same period may be ground together.

In grinding, the most perfect machinery should be used to reduce the whole fruit, skin, and seeds, to a fine pulp. This should, if possible, be performed in cool weather. The late Joseph Cooper, of New Jersey, has observed, em. phatically, that " the longer a chcese lies after being ground, before pressing, the better for the cider, provided it escapes fermentation until the pressing is completed;" and he further observes, "that a sour apple, after being bruised on one side, becomes rich and sweet after it has changed to a brown color, while it yet retains its acid taste on the opposite side." When the pomace united to the juice is thus suffered for a time to remain, it undergoes a chemical change; the saccharine principle is developed; it will be found rich and sweet; sugar is, in this case, produced by the prolonged union of the bruised pulp and juice, which could never have been formed in that quantity had they been sooner separated.

Mr. Jonathan Rice, of Marlborough, who made the premium cider so much admired at Concord, Massachusetts, appears so sensible of the important effects of mature or fully ripe fruit, that, provided this is the case, he is willing even to forego the disadvantage of having a portion of them quite rotten. Let me observe that this rottenness must be the effect, in part, of bruises by improper modes of gathering, or by improper mixtures of ripe and unripe fruit. He always chooses cool weather for the operation of grinding; and, instead of suffering the pomace to remain but 24 or 48 hours, at most, before pressing, as others have directed, he suffers it to remain from $a$ weck to ten days, provided the weather will admit, stirring the mass 
daily till it is put to the press. - [See his communication in Vol. vir. p. 123, $\boldsymbol{N}, \boldsymbol{E}$. Farmer.]

The best cider is made, according to Dr. Mease, by the following process: The liquor, on coming from the press, is strained through hair cloths, or sieves, and put into clean, tight, strong hogsheads; these are filled, and the bung left out, and placed in cool, airy cellars, or on the north sides of buildings; where the air circulates. In a day, or sometimes less, according to the state, of the weather and maturity of the fruit, the pulp begins to rise, and flows from the bung for a few hours, or a day or two at farthest; at the intervals of two or three hours, the hogshead is replenished, and kept full from a portion of the same liquor kept in reserve for this purpose, as it is deemed necessary that the whole pulp should overflow, that none may return again into the liquor. The moment the pulp has ceased rising, white bubbles are perceived; the liquor is; in this critical moment, fine or clear, and must be instantly drawn off. by a cock or faucet, within three inches of the bottom.

On drawing off the cider, it must be put into a clean cask, and closely watched, the fermentation restrained or prevented: when, therefore, white bubbles, as mentioned above, are again perceived at the bung-hole, rack it again immediately, after which it will probably not ferment till March, when it must be racked off as before, and, if possible, in clear weather. As soon as safety will admit, after the first racking, a small hole must be bored near the bung, and the bung driven tight; this must be finally sealed and a spile inserted, giving it vent occasionally, as circumstances require. In $\mathrm{March}_{;}$if not perfectly fine, it is drawn from the lees in a clear day, and fined; this is usually effected by dissolving, in a few quarts of cider, three staples of isinglass, stirring it often; this is poured into the hogshead. It must be drawn off again in ten or twelve days after, lest the sediment should rise ; if not fine now, repeat the fining again.

In Herefordshire, according to Dr. Mease, (Dom. Ency.,) the sediment of the first racking is filtered through coarse linen bags; this yields a bright, strong, but extremely flat liquid; if this be added to the former portion, it will greatly contribute to prevent fermentation, an excess of which will make the cider thin and acid. 
The first fermentation in cider is termed the vinous; in this the sugar is decomposed, and loses its sweetness, and is converted into alcohol; if the fermentation goes on too rapidly, the cider is injured; a portion of alcohol passes off with the carbonic acid.

The design of the frequent rackings, as above mentioned, is principally to restrain the fermentation; but it seems to be generally acknowledged, that it weakens the liquor. It is not generally practised, although the finest cider is often produced by this mode.

Various other modes are adopted with the view of restraining fermentation. Stumming by brimstone is thus performed: After a few gallons of cider are poured into the hogshead, into which the cider is to be placed when racked off, a rag six inches long, previously dipped in melted brimstone, is attached by a wire to a very long, tapering bung: on the match being lighted, the bung is loosely inserted : after this is consumed, the cask is rolled or tumbled till the liquor has imbibed the gas, and then filled with the liquid. This checks the fermentation. Yet the French writers assure us, that the effect of much sulphuring must necessarily render such liquors unwholesome.

Black oxyde of manganese has a similar effect; the crude oxyde is rendered friable by being repeatedly heated red hot, and as often suddenly cooled by immersion in cold water. When finely pulverized, it is exposed for a while to the atmosphere, till it has imbibed again the oxygen which had been expelled by fire. An ounce of powder is deemed sufficient for a barrel. If the cider is desired to be very sweet, it must be added before fermentation, otherwise not till afterwards. Mr. Knight, from his long experience and observation in a country (Herefordshire, England) famous for its cider, has lately, in a letter to the Hon. John Lowell, stated that the acetous fermentation generally takes place during the progress of the vinous, and that the liquor from the commencement is imbibing oxygen at its surface. He highly recommends that new charcoal, -in a finely pulverized state, be added to the liquor as it comes from the press, in the proportion of eight pounds to the hogshead, to be intimately incorporated: "this makes the liquor at first as black as ink, but it finally becomes remarkably fine." 
Dr. Darwin has recommended tnat tne liquor, as soon as the pulp has risen, should be placed in a cool situation, in casks of remarkable strength, and the liquor closely confined from the beginning. The experiment has been tried with good success; the fermentation goes on slowly, and an excellent cider is generally the result.

A handful of well-powdered clay to a barrel is said to check the fermentation. This is stated by Dr. Mease. And with the riew of preventing the escape of the carbonic acid, and to prevent the liquid from imbibing oxygen from the atmosphere, a pint of olive oil has been recommended. to each hogshead. 'The excellent cider exhibited by Mr. Rice was prepared by adding two gallons of New England rum to each barrel, when first made. In February or March, it was racked off in clear weather, and two quarts more of New England rum added to each barrel. - Cider well fermented may be frozen down to any requisite degree of strength. In freezing, the watery parts are separated, and freeze first, and the stronger parts are drawn off from the centre. - I finish by adding the following general rules; they will answer for all general purposes; they are the conclusions from what is previously stated: 1. Gather the fruit according to the foregoing rules; let it be thoroughly ripe when ground, which should be about the middle of November. 2. Let the pomace remain from two to four days, according to the state of the weather, stirring it every day till it is put to the press. 3. If the liquor is deficient in the saccharine principle, the defect may be remedied, in the beginning, by the addition of saccharine substances or alcohol. 4. Let the liquor be immediately placed in a cool cellar, in remarkably strong, tight, sioeet casks; after the pulp has all overflown, confine the liquor down by driving the bung hard, and by sealing; a vent must be left, and the spile carefully drawn at times, but only when absolutely necessary to prevent the cask from bursting. The charcoal, as recommended by Mr. Knight, deserves trial.

Fresh and sweet pomace, directly from the press, and boiled or steamed, and mixed with a small portion of meal, is a valuable article for food, or for fattening horses; cattle, and swine. 


\section{VINEGAR, ETC.}

Vinegar is made of the best quality from hard old cider; it must be placed under sheds in casks but two thirds full, with the bung out, and exposed to a current of air.

Sour casks are purified by pouring in a small quantity of hot water, and adding unslacked lime; bung up the cask, and continue shaking it till the lime is slacked. Soda and chloride of lime are good for purifying. When casks are emptied to be laid by, let them be thoroughly rinsed with water, and drained; then pour into each a pint of cheap alcohol, shake the cask, and bung it tight, and it will remain sweet for years. Musty casks should be condemned to other uses. Cider should not be bottled till perfectly fine; otherwise it may burst the bottles. The bottles should be strong, and filled to the bottom of the neck. After standing an hour, they should be corked with velvet corks. The lower end of the cork is held for an instant in hot water, and it is then instantly after driven down with a mallet. The bottles must be either sealed, or laid on their sides, in boxes, or in the bottom of a cellar, and covered with layers of sand.

The process formerly adopted for obtaining new and excellent varieties of apples was, to plant only the seeds of the very best fruits, and to select from these only those individuals with large leaves and strong wood. Reason seemed to dictate this mode; but reason united to experienge has taught a different. - See the fourth section in the former part of this work. 


\section{P E A R.- (Pyrus Communis.)}

The pear is a tree of pyramidal and elegant form. The leaves are obtuse, elliptical, serrated; the flowers, which are produced on the short spurs of the former year, or of the preceding years, are in terminating villose corymbs; the fruit pyramidally' formed, tapering towards the stalk, but varying in the different species. Its branches in a wild state are covered with thorns. It grows spontaneously, as we are informed, in every part of Europe, as far-north as the latitude of $51^{\circ}$. It will also succeed in those parts of the United States where the apple tree will flourish, provided the soil is suitable. In New England, it flourishes as in its native soil. It is distinguished from the apple tree not less by its form than by its disposition to emit suckers from its roots, whenever these become obstructed by stones or other substances, or-become bruised or broken. The pear tree is a tree of longer duration than the apple. It is stated that, in dry soils, they will continue in health, vigor, and productiveness for centuries.

The timber is of a yellowish color, very firm, compact, and fine-grained, and is used for joiners' tools, \&c. \&c. It takes a fine polish, and, stained of a black color, it resembles ebony. The leáres will produce a yellow dye. In those parts of Europe possessing a climate similar to our own, in Italy and France, the pear is said to be in higher estimation as a dessert fruit than the apple.

Uses, - Good dessert pears are generally preferred to apples; they are characterized by a pulp tender and melting, or subliquid, as in the beurrée pears, with a juice of a sugary, aromatic flavor; or of a firm and brittle or crisp consistence, or breaking. Cooking pears should be of large size, the flesh firm, neither breaking nor melting, of an austere rather than sweet taste.

Perry (poire of the French) is the fermented juice, made in the same manner as cider, from fruit of any size; and the best perry is stated to be little inferior to wine, and the most austere fruits produce the best liquor. The pear is also good for baking, compotes, marmalade, \&c. They are also preserved in sugar or sirup of the cane. Dried 
in ovens, the fruit will keep for years. This mode of preserving is common in France. Bosc has described two modes of drying pears, and adds, that in some of the cantons of that country, the cultivators annually preserve, by these means, supplies of subsistence extremely agreeable and wholesome during winter and spring. He invites . cultivators not to neglect this resource. In this mode of drying, those varieties of middle size, melting and sweet, are preferred. After the bread is drawn from the, oven, they are placed on the swept hearth, or on hurdles or boards. This operation is repeated a second, a third, and a fourth time, according to their size, and the degree of heat. The heat must not be so great as to scorch, and the fruit must not be dried to hardness. Lastly, they are placed in bags, and preserved in a dry place. The second mode of preserving is practised chiefly on the Rousselets and finest-flavored varieties. Bosc states that he has tried them after three years' preservation, and found them-still good; but they are better during the first year. They are gathered a little before their maturity, and after being half boiled in a small quantity of water, they are peeled and drained. They are next carried on hurdles to the oven, after the bread is drawn, or the oven is heated to a suitable degree; here they remain twelve hours; after which they are steeped in the sirup, to which have been added sugar, cinnamon, cloves, and brandy. They are again returned to the oven, which is now heated to a less degree than at first. This operation is thrice repeated, until they are sufficiently dried, or of a clear brown color, and firm, transparent flesh; and finally they are packed in boxes lined with paper.

Thirty years ago, the number of varieties of pears obtained by cultivation, as stated by Dr. Willich, was 1500 . But the number of good sorts is stated by Loudon " to be fewer in proportion than that of apples. Dr. Van Mons, and the Abbe Duquesne, since that period, have obtained from seed, during twenty years, upwards of 800 new and approved sorts, from probably 8000 new seedlings." From no less than 80,000 , is my impression, but I state from memory only. I have detailed their modes of procedure, as stated by Dr. Van Mons, in the former part of this work. Their practice was the reverse of all the popular theories of the day; the results, unlike any thing of the kind before known. 


\section{Cunss 1 . \\ O L D P E A R S .}

The following list of Old Pears comprises all which are described by Duhamel and by Rosier, and some others also of the English writers. Some I have briefly described, and others I have only named. Many of them are still fine. In these descriptions I have availed of every resource. Many of the reasons for the brevity of this review are stated more fully in Section 4, in the former part of this work.

\section{ABBREVIATIONS.}

q. denotes those varieties of pears which will grow when inoculated on a quince stock.

Q. denotes those varieties, which were named or described by Mons. Quintinie, 150 years sgo. I have, in many instances, appended his remarks of that distant day, and refer to the edition of his work translated and revised by Mr. Evelyn in 1693.

M. refers to Mr. Manning, of Salem. These gentlemen

S. refers to Mr. Smith, of Smithfield, R. I. $\}$ have tried, and cast off, near 200 of the old kinds.

t denotes "bad pears," "indifferent pears," or "outcasts," on the authority of those to whose initials this character is annexed.

R. refers to the 53 trees, of 19 varieties, recommended by Rosier.

\section{S E C T I O N I.}

Section I. comprises all the pears described by Rosier, whose descriptions comprehend essentially all those of Duhamel. This section is arranged in the order of their maturity according to Rosier.

1. Amire Jonnnet. St. John's. Petit St. Jean...

The fruit is small, yellow, pyriform; the flesh tender, sweet, not high flavored; juicy, but soon turning mealy. One of the earliest of all pears, and chiefly valuable for its early maturity. (q.) July.

Petit Muscat. Little Musk:" Supreme.

The fruit is very small, yellow, brownish red next the sun; roundish turbinate; half breaking; of a musky flavor. The fruit grows in clusters. July. (q.) (Q.t) The tree cankers, and is subject to blight. (M.t) (S.t) 
Aurate. August Muscat. (S. + ) (q.)

Muscat Robert. Robine. (Q.-)

Muscat Fleuri. Flowered Muscat. (Q.)

2. Madeleine. Citron des Carmes. Early Chaumontelle.

A fruit of medium size, pale yellow, with an occasional blush next the sun; form turbinate; flesh white, melting; perfumed. End of July. A fine old fruit. This variety exhibits strong syınptoms of decay. (M.) (q.)

Hativeau.

[R. I.] Quisse Madame. Windsor. An indifferent fruit. (M.t)

(Q.) Gros Blanquet. (q.)

3. * $(t)$ Epargne of the French. Jargonelle of the English. Grosse Quisse Madame. (Q.)

The tree is one of the most productive of all pears. The fruit is the best of its season; it is rather large, very oblong; of a green color, a little marbled with red next the sun; the flesh melting, juicy, with a slightly acid, rich, and agreeable flavor. It ripens the last of July. In the vicinity of Boston, where this fruit is raised in abundance for the market, it is usually gathered long before fully grown, and mellowed in closely-confined masses. I am sorry to add, that the wood of this capital old variety begins to canker and decay at Salem. (q.)

Ognonet. Archduke of Summer.

SAPIN.

Deux Tetes. Double-Headed. (Q.t)

Bellissime d'Été. Supreme. Beauty of Summer. A middling fruit. (M.t) (Q.t) (q.)

Bourdon Musque. Orange d'Été. (Q.) (q.)

Branquet a Longue-Queue. Long-Stalked Blanket. (Q.) (R. 2.) Petit Blanquet. Little Blanket. (Q.)

Very small and beautiful; the skin very smooth, and yellowish white; breaking, musky; but a very poor fruit. (q.)

Gros Hativeau. Early in August.

Poire d'Ange. Angel Pear. Early in August. 
(†) Poire sans Peau. Skinless. (Q.)

A small, oblong pear; the skin is smooth and thin, of a pale green, slightly colored with red next the sun; the flesh half melting, of a sweet and pleasant flavor. A good fruit, but the wood begins to canker. August. (M.).

Parfum Dªut. August Perfume. (q.) Middle August. Chè̀r à Dame. Prince's Pear. (S.t) (q.)

Fiv OR D'Été. Fine Gold of Summer. Middle August. EPine Rose. Thorny Rose. Summer Rose. (q.)

Salviati. (Q.) August.

Orange Musqée. (Q.) (q.)

Orange Rouge. Red Orange. (Q.t) (q $)$

[R. 2.] Robine. Royale d'Été. Royal Summer. (Q.) (q.) (S. $f$ )

Sangeinole. Bloody Pear. (Q. + ) (q.)

Bon Chrétien d'Eté Musque. Musk Summer Bon Chrétien." (M.t) (Q.t)

Gros Rousselet. Roi d'Eté. (Q.) (q.)

Poire d'CEuf. Egg Pear. Swan's Eg of For. and Coxe. (S.t)

Cassolette. Lechefriand. (Q.) (q.)

Grise-bonne. Last of August.

Muscat Royale. Beginning of September.

JARgonelle of Rosier and the French. Quisse Madame

of the English and Americans.

- This last name has been applied to another fruit; both are called bad. (Q.t) (S.t)

4. Rousselet Hatif of Coxe.

Very small, but much admired as a very early fruit. The tree produces most extraordinary crops every year. Stalk long, fleshy, and curved; color russety yellow, juicy, and excellent. Early in August.

5. [R. 4.] Rousselet de Rneiss. Petit Rousselet. The fruit is small, pyriform; the eye is large, and even with the surface; the stalk ten lines, the fruit twenty-seven lines, and twenty in its transverse diameter; greenish yellow in the shade, brownish red next the sun; the "flesh half melting, musky, very perfumed; excellent to pút in 
brandy and for drying. Last of August. The tree is productive. (q.)

Ali mon Dieu! My God Pear! (q.) Poire d'Abondance. Nouv. Cours Comp.

Valuable only for its productiveness. (位.) (*)

Fin Or de Septembre. Fine Gold of September.

Beginning of September. (q.)

Fondante de Brest. Inconnue Cheneau. (Q.)

6. Epine D’Été. Summer Thorn. Green Catharine.

Rather small, tapering to the stalk, which is long; the eye even with the surface; of a green color, covered with dark, russety blotches: the flesh is breaking, of a very musky flavor. The tree is very productive. Late in August. (q.)

Polre Figue.

Bon Chrétuen d'Eté. Gracioli, Summer Bon Chrétien.

Of great size and beauty, and only esteemed on this account. The tree is a bad bearer, and cankers; the fruit often blights, and soon rots at the core. (q.)

Orange Tulupée. Striped Orange. Tulip Pear. Villaine d'Anjou. (Q.t) (q.)

Berganotte D'Été. Summer Bergamot. Milan de Bcuvriere. $(\mathbf{Q} .+)\left(\mathbf{S}_{+}\right)$(q.)

Bergamotte Rovge. Red Bergamot.

The fruit is rather small, short, turbinate, pale yellow, but red next the sun ; tender, melting, juicy, sugary, highflavored. August. (q.) (M.)

7. "Verte Longue. Mouille Bouche. Long Gren Mouth-woter.

The fruit is rather large; form varying from pyramidal to turbinate; the skin smooth, of a dark green color; the flesh melting, of a sweet, rich, and pleasant flavor. It ripens the beginning of August, and is a most excellent fruit; the tree bears abundantly every year. We are persuaded that this is not identical with that described by Duhamel.

\section{[R. 4.] Beurre. Broun Beurré. Beurié Gris.} Beurré Doré. Beurré Rouge.

Rather large; obovate, tapering towards the stalk; greenish yellow, corered with thin russet, but occasionally 
dusky red next the sun; the flesh melting, buttery, rich, and excellent. October. One of the most ancient, and once the best of all pears. Even at this day, it is still productive and fair in some few gardens of the city, but it is rarely, if ever, seen in its markets. With the cultivators who furnish its supplies, it has now become an outeast. The fruit blights, and the wood cankers.

\section{Angleterre. Beurré ${ }^{d}$ Angleterre. September.}

Doyenné. Doyenné blanc. Beurré blanc. Bonne Enté. Carlisle of Mil.. and others. Yellow Butter. Beurré Doré, or St. Michael, of Coxe. Garner of Rhode Island. Many other names might be added.

The tree was once, with us, most extraordinarily productive; the fruit the fairest, the most beautiful and delicious, and universally admired. This most ancient of all pears has now become an outcast, intolerable even to sight. . In some sections of the city, it is even now productive and fair, but it is seldom seen in its markets. The fruit is of medium size, roundish oblong, diminishing towards the stalk, which is short, thick, and strong; the skin smooth, of a pale lemon color, or sometimes colored with red next the sun; the flesh white, melting, juicy, of delicious flavor. October. Such was the St. Michael once with us. (Q.t) (S.+) (q.)

\section{Bezi de Montigny. (q.)}

Bezi de uA Motre. Bien Armudi. Beurré blanć de Jersey. (Q.)

This old fruit has lately disappeared from the markets of Paris. Nov. (q.)

Bergamote Suisse. Suisse. Striped Bergamot. (Q.t) (q.)

Bergamotte D'Automne. Autumn Bergamot.

The fruit is small, globular, depressed; the skin rough, yellowish green in the shade, dull brown next the sun; the flesh pale, inelting, gritty at the core, juicy, sugary, perfumed. September. (Q.) (q.)

Bergamotte Cadetre. Cadett. (Q.t) September. (q.) Jalousie. Poire dé Jalousie.

Frangipane. Jasmin. (Q.t) (q.)

Lansac. Dauphine, Satin. (Q.) October. (q.) 
Vigne. Demoiselle. (Q.) October. (q.)

Pastorale. Musette d'Automne.

The fruit is large, very long, and in shape like the St. Lezaine; yellow, but red next the sun; half melting, a little musky; good; sweet on dry soils, in dry years, austere otherwise. October, November, to January. (Q.t)

Bellissime D'Automne. Vermillon. Beauty of Autumn Suprême. End of October. (q.)

8. [R. 3.] Messire Jean. Monsieur Jean Doré.

The fruit is short and turbinate; of medium size; of a yellow, or sometimes gray yellow color; the flesh breaking, juicy, subject to grittiness, but of a rich flavor. The tree is a good bearer, and the fruit is by some much esteemed. It ripens late in October, and is good to put in brandy or to dry. (q.)

Mansuette. Solitaire.

Rousseline. (Q.) Muscat a longue Queue.

Bon Curétien D'Espagne. Spanish Bon Chrétien. (Q.t) (M.t)

\section{[R. 4.] Crassanne. Bergamotte Crassanne.}

Some state that this fruit derives its name from crassus, [thick ;] but M. Quintinie says from ecrase, [to crush.] It is over medium size; roundish turbinate; greenish yellow, coated with russet; the flesh tender, melting; juice rich, sugary. October. This fruit is no longer to be trusted; it is liable to canker and to blight.

Bezi de Cassoy. Roussette de Anjou. (Q.f)

[R. 4.] Doyenné Gris, Doyenné Roux. Gray Doyenné. Red Doyenné, according to Pom. Mag.

Medium size; turbinate; the stalk short; of a bright cinnampn color, but red next the sun; the flesh yellowish white, melting, saccharine, rich, and of excellent flavor. Season, October. This once excellent variety has now become as liable to blight at Salem as the St. Michael. (M. $)$ (q.)

Merveille d'Hiyer. Wonder of Winter. Amadot. (Q.) Epine D'Hiver. Winter Thorn. (Q.) (q.)

Louıse Bonne. (Q.) Good Louise. (S.t) November and December. (q.) 
[R. 2.] Martin Sec. Dry Martin.

An indifferent fruit, but good for drying. (Q.t) (M.t) December, January. (q.)

Marquise. Marchionesse. (Q.) (q.)

9. Echasserie. Bezy de Chassery, Mr. Lowell. (M.)

(Q.) Ambrette of Coxe and Fes. New Amer. Gard. Tilton of New Jersey.

The leaves of the Echassery have serratures, the Ambrette none. A fruit below medium size, form varying from nearly globular to oblong; the eye on a level with the regular rounded crown; the skin rough, russet green, coarse, and thick, which eminently qualifies it for keeping; at maturity it inclines to yellow; the flesh melting, juicy, of a sweet and musky flavor. The tree requires a dry, warm soil, and bears abundantly. The fruit is very ordinary in appearance; it keeps well in winter, and should not be eaten too soon, or till long after it is soft. (q.)

Ambretre, [not of Coxe.] Belle Gabrielle. Trompe. Valet. (Q.)

Tree thórny; leaves without serratures. Nov. Feb. (q.) [R. 2.] Chaumontelle. Bezi de Chaumontelle.

A noble old variety; size large to very large; variable in form; at maturity yellow, slightly shaded with red next the sun; the flesh melting, juicy, sweet, musky, excellent. December to January. Although this fruit is still fine and fair in Salem and its suburbs, and in some particular sections of the city, and some few sheltered situations in its vicinity, yet it has long since disappeared from its markets, and is another of the old sorts which are rarely to be seen in the markets of Paris. With us this fruit has become an outcast. (S.t) (q.)

Vitrier. Poire du Vitrier. November and December. Bequesve. (Q. $\ddagger$ ) Good only for baking.

Bezi d'Heri. Besidery. Bezi d'Airy?

This old fruit has lately disappeared from the markets of $P$ aris, and we may rely that it is not without cause. (Q.) [R. 1.] Franc-Real. Fin Or d'Hiver. Good for cooking. (q.) [R. 4.] St. Germain. Inconnue la fare.

An ancient and once celebrated fruit; large, pyramidal, tapering regularly to the stalk; of a green color. but at ma- 
turity of a yellowish cast, covered with russety spots; the flesh very melting, very juicy, saccharine, slightly acid, and delicious. November to March. Such was the St. Germain once with us; but except only in some sections in the city, and occasionally in some sheltered situations near, it has long since become an outcast and abandoned variety. The wood cankers, the fruit blights; and this defection has extended south to $\mathrm{R}$ hode Island, and to some parts of $\mathrm{New}$ York. (S.f) (q.) (Q.)

[R. 4.] Virgouleuse. Chambrette. Poire de Glace. (Q.) Another old, celebrated fruit, rather large, obovate, inclining to pyramidal; the skin smooth, of a deep green color; at maturity pale yellow; the flesh melting, juicy, rich, high flavored, and excellent. November to February. I have before noted that this fruit has disappeared from the markets of Paris, and probably not without a reason. It is sometimes still fair in Boston, but has disappeared from its markets. The tree cankers, and the fruit has long since become an outcast. (q.)

JARdin, Poire de Jardin. December.

[R. 2.] Royale D'Hiver. Royal Winter.

Above medium size; form pyramidally turbinate; the skin smooth, yellow, but bright red next the sun; flesh yellowish, nearly melting, juicy, rich, sweet, and well-flavored. December to February. This ancient and once celebrated fruit has disappeared, as I have before stated, from the markets of Paris; and although it is sometimes still fair in our city, it is yet no longer, or but rarely, seen in our markets. It has become blighted and worthless. (S. 4 ) Angelique de Bourdeaux. St. Marcel. Gros Franc Real. (Q.) January, February.

Saint Augustin.

Champe Rrene d'Italie. December, January. (q.)

Livre. Poire d'une Iivre. See Baking Pears.

Tresor. Poire Tresor $d^{\prime}$ Amor. Good for baking. (Q. $\downarrow$ )

Angelique de Rome. (q.)

Martin Sire. Ronville. (q.)

Bergamotte de Pacques: Easter Bergamot.

Terlina. Winter Bergamot.

(Q.) 


\section{[R. 4.] Colmar. Poire de Colmar, Poire Manne. In-} comparable.

This ancient fruit is rather large; pyramidally formed, inclining to turbinate; the skin smooth, green, changing to yellow at maturity; sometimes slightly colored with red next the sun; the flesh melting, juicy, saccharine, and of excellent flavor. December to April. The disappearance of the Colmars from the markets of Paris, which I have already mentioned, seems a circumstance which they much deplore. And although this fruit is still fair in some sections of the city, it has long since gone from our markets. With us it is considered an outcast. Its defection is noted also in Rhode Island. ( $\mathbf{S}_{\uparrow}$ ) (q.)

Beluissime d'Hiver. Teton de Venus. Beauty of Winter. Tonneau. 'See Baking Pears. (q.)

\section{Donville.}

Trouve. April.

[R:-2.] Bon Chrétien d'Hiver. Poire d'Angoise. Winter Bon Chrétien. (Q.)

An ancient fruit, very large, of a turbinated or pyramidal form; the crown large, sides angular and tapering towards the summit, which is narrow ; the stalk very long, and surrounded by protuberances; the flesh breaking, rather sweet, and juicy. This fruit often grows enormously large, and may be preservéd till May. The fruit is liable to crack, and is not at this day much esteemed either for productiveness or other good qualities. The Pound Pear is thought very superior in every respect. Mons. Quintinie placed this fruit at the head of all old pears on account of its name, (Good Christian,) beauty, size, and keeping qualities, more than for any good quality. (q.)

Orange-d'Hiver. Winter Orange. (Q.t) (q.) Bergamotte de Soulers. Bonne de Soulers. Double Fleur. (Q.t) Sec Baking Pears.

Poire de Prêter.

Poire de Naples. Easter St. Germain. Lent St. Ger main.-(Q.f) -(q.)

Сhat Brusle. October to winter: (Q. $\downarrow$ ) 
[R. 2.] Muscat r'Allemand. German Muscat. (q.)

Considered by many an outcast. The wood cankers, the fruit blights. (S. $)$ (M. ( $)$ (q.)

Imperiale ì Feuilles de Chêne. Imperial Oakleaved. April and May. (q.)

Saint Père. Poire de Saint Père. Baking.

Polre a Gobert. June.

[R. 2.] Bergamotte d'Hollande. Holland Bergamot. D'Alençon.

This fruit keeps till May; and has with some become an outcast. (S.t) (q.)

Tarquin. April and May.

SARAsin. Is considered here as an outcast. (S. + ) (q.)

[R. 4.] Bergamotte Sylvange.

The Sylvange vert d' Hiver is better than this, and the best of all the Sylvanges.

\section{S E C T I O N I I.}

The following old varieties are described by Duhamel and other authors, in the order of their maturity.

Gros Blanquette Ronde. Duh. July.

10. Green Chissel.

The tree is feeble, but productive; the fruit in clusters; is small, nearly globular; color green, but brown next the sun ; gritty, saccharine, perfumed. Last of July.

Sugar Top, or July.

Aмrrosia. 'Early Beurré. Lind.

Medium-sized; form roundish, flattened; skin smooth, greenish yellow; flesh tender, rich, sugary; juice perfumed. Last of August.

Muscat Royal. Duh. End of August.

Autumn Bounty. (S.t) 
Broca's Bergamot. Gansel's Bergamot.

A delicious, round fruit, but miserably unproductive; an outcast here on this account. (S.f) October.

Crassanne Panacué. Rosier.

Leaves variegated; an ornamental variety.

EltoN. Hort. Trans.

An old fruit, of medium size, oval form, russety orange next the sun; flesh breaking and excellent, but soon growing mealy. September.

K. L. Forelle.- Pom. Mag. C. Hort. Trans.

Forellen-Birne. Diel. Poire Truite of the French.

A fruit celebrated by the English and German, writers for its superior beauty, excellence, and productiveness. The size medium, form obovate, color at maturity lemon in the shade, a rich sanguine or crimson next the sun; speckled and covered with broad, ocellate spots; hence called by the French truite or trout pear ; flesh white, juicy, buttery; flavor rich, subacid, vinous.= Dr. Diel assigns its nativity to Northern Saxony. In the vicinity of Boston it has disappointed expectation, and is regarded as a decayed variety. November.

11. Green Pear of Yair. Hort. Trans.

Middle-sized, regular form; green, slightly russeted; flesh yellow, melting, sweet. . A very productive and popular Scotch variety, of great excellence. September.

Ifoldand Green. Coxe. Holland Table Pear. (M. + )

Orange Bergamotte. Ćoxe. (M.t)

Prince's Sugar. Lowre's Bergamotte.

Middle-sized, not very rich, but good. With some it has become an outcast. (S. $\downarrow$ ) Very productive.

Red Cheek. 'English Red Cheek. English Catharine.

Sweet, but soon turns mealy. Not much esteemed. Early in September.

Rushmore's Bon Chrétien.

Esteemed by some in New York. With us only esteemed for baking. An outcast with some. (S. + )

September Orange. (M.t)

Sucre Vert: Duh. Green Sugä. (q.) (Q.)

Middle-sized, round, inclining to pyramidal; the skin smooth, always green; melting, juicy, very sweet. I have 
stated that this fruit has made its exit from the markets of Paris. Last of October. 'Excellent some years.

12. Swan's EgG. Moorfonol Egg of Boston.

Small, oval, turbinate; green, but dull russet brown next the sun ; flesh tender, rich, saccharine, musky. The tree grows rapid and upright, and is productive. A favorite Scotch fruit. November.

Verte Longur Panaché. Culotte de Suisse. Suisse. Striped Dean.

Medium size, pyramidal; striped with yellow on a green ground; pale red next the sun. Indifferent. The bark is striped; the fruit a curiosity. An outcast with some, $\left(\mathbf{S}_{.+}\right)$ and not much esteemed by others. Rarely seen at this day in the markets of Paris. September.

Bon Chrétien d'Auch. D'Auch. (M..t) (S.t)

Rousselet D'Hiver. Duh. Winter Russet? (Q. + )

\section{OLD BAKING PEARS.}

\section{3. *Catillac.}

Forty Ounces.

The fruit is very large, roundish turbinate; pale yellow, but deeply stained with red next the sun; flesh firm and breaking, the flavor astringent. A good bearer; an excellent baking pear, in use all winter.

Double Fleur.

Armenian.

Large, round; at maturity yellow, but purple red next the sun; breaking, juicy. An ornamental variety. (Q.4) Good only for baking.

Double Fleur Panache.

An ornamental variety, with double flowers and striped fruit. Good for baking. February to April.

Gros Rateau Gris. Bon Jard. Quint. Lind.

Brack Pear of Worcester.

Love Pear, Parkingon's Warden.

Pound Pear, but not of Langley.

Poire d'Une Livre.

Grande Monareue of Knoop.

Fruit very large, roundish turbinate; skin rough, yel- 
lowish green, but obscure red or brown next the sun; flesh very hard, coarse, austere, but good baked or stewed. It does not succeed on the quince. November to February. 14. "Iron Pear.

Rather large ; its color a yellowish or iron russet; form rather oblong, regular, narrowing a little towards the summit ; flesh breaking, juicy, and astringent. This pear keeps till May, is a good bearer, and an excellent baking sort.

\section{Poire de Tonneau. Bon Jard. Lindley.}

Belle de Jersey, Uvedale's St. Germain.

Pickering, Uniox, Udiate's Warden:

Fruit very large, oblong, tapering to the crown, but compressed between the middle and the stalk; in form of a cask ; skin smooth, dark green, but brown next the sun; at maturity yellow and red; flesh white, hard, austere; juice astringent. An excellent pear to cook.

WARDEN.

Medium size, turbinate form, of a dark russety yellow color. An autumn fruit, and excellent for cooking. This is a very productive variety.

15. *Pound Pear.

One of the most valuable of our winter baking pears. It is highly esteemed, and is raised in considerable quantities, and barrelled for the markets or for exportation. The trees are extraordinary for their vigorous growth and productiveness; the fruit is very large, oblong, pyramidal, rounded at the crown, diminishing towards the stalk, which is very strong; of a rusty green color, but brownish red next the sun; firm, breaking, juicy, and astringent ; most excellent for baking or preserving. - It will keep till April or May.

It may not, perhaps, be improper here to subjoin a list of such still existing varieties, as M. Quintinie has, in his day, in a more extensive and partly obsolete list, denounced and designated as pears of indifferent quality, and bad pears. I refer to the edition of Mr. Evelyn, printed in 1693 . 'I do not, however, assert that this list is to be considered an infallible guide, but I believe it to be generally so; and if true at that distant day, how much more reason have we for believing it is at least equally true now!

I add the following still existing varieties, which, on the authorities which $I$ annex to each, have been denominated 
Indifferent Pears, Bad Pears, or Outcasts. Those marked B. are, however, good for baking.

Brutte Bonne. Indif. -Q.t|St. Francis. Bad. B. Q.t Caillot Rosat. Indif. Q.f Cluster. Outcast. Q.t Fin Or d'Orleans. Indif. Golden Beurré. Outcast. S.t Q.t Gilogile. Bad. Q.t
Queen of Winter. d'Hiver. Indif. $\mathbf{Q}$. Lott's Bergamot. “ Platt's Bergamot: " $\mathrm{S}_{4}$ S.t S.t Reine Leggett's. S. $\frac{1}{6}$

\section{Chass II.}

\section{N E W P E A R S.}

The following list of new varieties are in part American; a portion of them are English, and a few of French origin; but the greatest portion are Flemish, of all those not otherwise noted. Many additions, and numerous new kinds, mostly of Flemish origin, had been received by us through the liberality of the London Horticultural Society, during the years 1834 and 1835 , their excellence having been proved at their garden at Chiswick. Numerous other varieties also have been sent us from Professor Van Mons, of Louvain, during those same years. More recently, and during the winter of $1840-1$, a valuable donation of new pears, of superior proved kinds, were received from M. De Wael, the secretary of the Horticultural Society of Antwerp, in Belgium.

During the autumn of 1840 , and while in London, I used every exertion to procure all the new fruits of the most renowned excellence, either from the garden of the London Horticultural Society, or from the first sources in is immediate vicinity, and where all had been proved to the latest day, Other new and superior kinds I also procured while at Paris; and since that period; all that may have arisen truly valuable, cannot fail of finding their way hither, from other and first-rate sources.

All those kinds marked J. have been very recently 
proved at Paris, by M. Jamin, and described by him. Those same kinds which are marked. D. have also been lately proved, by M. Dalbret, the superintendent of the compartment of fruits, at the Garden of Plants at Paris. Of the numerous new and fine varieties, which I procured of M. Jamin, I have particularly described in this class but twenty-five kinds, and those only which he designated to me as fruits the most extraordinary; most of them being also quite new, and not then known in commerce. Trees of nearly every kind described in this class, are already in our country.

A. denotes those kinds of American origin.

E. denotes those kinds which are native English.

F. denotes most of those kinds which are natives of France.

Most of all the rest are of the new Flemish kinds.

\section{S E C T I O N I.}

SUMMER FRUIT.

16. D'AMANDE D'ÉTÉ. Thompson.

Large, pyramidal; color green and yellow; juicy and good. Augusț.

17. D'ANANAS D'ÉTÉ. Thompson.

Large, obtusely pyramidal; color brown, but red next the sun; beurrée and good. August,

13. BELLE DE BRUXELles. N. Duh. Nouv. Cours Complet.

The young wood is large, short, gray in the shade, red. next the sui ; leaves small, oblong ; fruit large, pyramidal, its stalk on its summit; skin beautiful clear yellow, but bright red next the sun; the flesh is white, fine, of an agreeable flavor. The fruit is the largest and the most beautiful of the season, which is early in August.

\section{9. *BLOODGOOD PEAR... [A.].}

The fruit is of moderate size and roundish form; of a yellow color throughout, and somewhat russeted; the stalk an inch long. A pear of superior quality, ripening 
in July. This fruit is from Thomas Bloodgood, Esq., of New York, firm of James Bloodgood and Co, of Flushing.

20. BURLINGHAME. Dr. S. $\boldsymbol{P}$. Hildreth.

A seedling raised by Mrs. C. Burlinghame, of Marietta, Ohio. A fruit of medium size; surface smooth, with longitudinal depressions; of a yellow color, changing to rich crimson next the sun; flesh melting, white, very juicy, sugary, and delicious. Middle of July to the last of August.

21. CALEBASSE MUSQUÉE. Lindley.

This fruit is four inches long, irregular, broadly angular, and knobby; its diameter three eighths of its length, compressed below the middle; the color deep yellow next the sull, and partially covered with thin orange gray russet; flesh breaking, a little gritty, juicy, very saccharine. This pear will ripen the last of August with us.

\section{2. *DEARBORN'S SEEDLING.}

[A.]

This pear originated at Brinley Place, the mansion of the Hon. H. A. S. Dearborn, in Roxbury. A seedling of 1818. The tree is of vigorous growth; the fruit of medium size, rounded at the crown, and regularly diminishing in a parabolic manner to the stalk, which is inserted in a small cavity; the skin is smooth, thin, green, speckled with russet points, and a fawn-colored blotch around the stalk, which is short and curved; the skin delicate yellow; the flesh very melting, and fully equalling in flavor the once famous and delicious St. Michael. The first fruit was examined, and thus named, by the committee of the Massachusetts Horticultural Society, in August, 1831.

23. DUQUESNE D'ÉTÉ. Thompson.

Middle-sized; obtusely pyramidal; color brown or pale green; beurrée and good. September. [August ?]

24. EARLY BERGAMOT. Pom. Mag. Lind. [F.]

A medium-sized pear, of a green' color, tinged at maturity with yellow; streaked with brownish red next the sun; of a roundish form, flattened at its base; the flesh yellowish white, very juicy, a little breaking and gritty, but very rich and sugary... Ripe in August.

A new fruit sent by $M$. Thouin to the London Horticultural Society, in 1S20. A most excellent early variety; an abundant bearer. 
25. GREEN SUMMER SUGAR. Dr. Willich. [C.] Sugar Pear of Hoyerswerda,

Sugar d'Hoyerswerda.

An excellent new fruit, of moderate size, raised from the seed of the Green Sugar, (Sucre. Vert,) cultivated in Lower Lusatia; it is oblong, but arched towards the crown ; of a grass green shade, spotted in every direction with green and gray dots; the pulp is mellow, without grittiness, and surpasses in taste all other summer pears. Its juice is of a vinous and subacid taste, decidedly superior, at least in taste, to the Green Sugar. If it be suffered to ripen on the tree, it acquires a greenish yellow shade. Ripe from the middle to the end of August, and it can be preserved only a few weeks.' The tree bears fruit every year; and the wood remains sound in the severest winters.

\section{6. "JULIENNE.}

L'Archidec d'Été. Summer Beurré. Sym. of Coxe.

SUMMer DoYtenké, erroneously.

The tree grows upright and handsome; it bears young and most abundantly. The fruit is of medium size, inclining to obovate, tapering towards the stalk, which is short; the skin is smooth, of a pale yellow color, with a faint blush next the sun; the flesh is perfectly melting, rich, and juicy. One of the most beautiful and valuable fruits of its season, and deserving an extensive cultivation. It ripens the Jast of August.

27. "PASSANS DU PORTUGAL. Thompson.

Of medium size, obovate form; of a pale brown color; juicy and excellent. August. A good bearer.

28. SABINE D'ÉTÉ, Lond. Hort. Trans. Lindley.

Raised in 1819, by Mr. Sloffels, of Mechlin; named for Mr. Sabine. The form is pyramidal, terminating in a round, blunt point at the stalk; the color yellow, but fine scarlet next the sun; the whole surface smooth, regular, and polished; flesh white, melting, juicy, and highly perfumed. It ripens early in August. The young wood is slender. It bears abundantly.

29. SEIGNEUR D'ÉTÉ. Lond. Hort. Trans. Lind.

This pear has been known many years in Flanders. It is above the middle size, a blunt oval; of a fine orange color, but bright scarlet next the sun, and marbled; the flesh melting, free from grit ; a rich and beautiful pear. It 
there ripens the beginning of September, and will ripen here in August. The tree is handsome, and bears well. 30. VALLÉE FRANCHE. Thompson. [F.]

De Valléf.

A middle-sized fruit, of obovate form; of a yellowish green color; juicy and excellent. A good bearer. August.

\section{SE C T ION I I}

\section{AUTUMN FRUIT.}

In this section are included all those new varieties whose period of maturity has not been ascertained.

31. ALEXANDRE DE RUSSIE. Lindley.

An uncommonly fine new fruit, above the medium size, obliquely pyramidal, Bon Chrétien formed, with an uneven, knobby surface; the stalk short, thick, depressed; of a greenish yellow color, almost covered with cinnamon russet; the flesh almost white, gritty, but tender and mellow; juicy, saccharine, with a slight musky perfume. It ripens in September.

32. ALTHORPE CRASSANNE. Mr. Knight. [E.]

Middle-sized, roundish; of a brown and green color; beurrée and excellent. Originated by Mr. Knight, and sent by him to Mr. Lowell in 1832. He says, "This variety is very excellent and rose-flavored. This and the Monarch will not be equalled by any other variety in your climate; both grow rapidly and bear abundantly." November. A vèry valuable, productive, new variety. The tree grows thorny; the fruit nearly equals the winter Nelis in excellence; is recommended highly by Mr. 'Thompson, and to take the place of the Diel, where the latter does not thrive. Fruit middle-sized, of a brownish green shade, beurrée and excellent. It ripens from December to January.

\section{3. * ANDREWS.}

Amory, Gibson.

This fruit is large ; of a form inclining to oblong; melting, and of most excellent flavor ; a first-rate and superior fruit. The tree is very productive. It ripens in September. 
34. BELLE ALLIANCE. [J. $]^{-}$

A large, new fruit, ripening at Paris in October, melting and excellent.

35. BELLE ET BONNE. Pom. Mag.

Schòne ANd Gute of Taschenbrich. Gracievese. Thompson.

This very valuable variety was sent to the London Horticultural Society in 1826, by Messrs. Baumann, of Bollwiller; and, much as our autumn pears have been improved, this ranks among the very best of them, being a delicious Bergamot of the best kind. This fine, new pear has been erroneously cultivated in Europe, under the name of Charles D'Autriche, Belle de Bruxelles, and Bergamotte De Crassanne, which are distinct fruits, "A harvest pear ; magnificent, very large, globular, depressed; the stalk long; skin greenish yellow, but next the sun yellow, with spots of russet; flesh white, sweet, exceedingly rich and agreeable, perfumed. The tree is very productive. September." 36. BELLE ET BONNE DE HÉE. [J.]

Of medium size, melting and perfumed, new, of superior excellence, ripening in September at Paris.

\section{7. "LA BELLE DE Flanders. Pom. Mag.}

Flemish Beauty of Pom. Mag. and Lind.

Bоsch, Boưche Nouvelle.

Imperatrice de la France. Brillant. Pom. Mag.

This new Flemish pear is of the first rank in quality; it is large, very beautiful, and bears abundantly; and will, without doubt, one day become a most important variety in the list of cultivators. The fruit is large, (the engraving sent by Dr. Van Mons is near four inches long and over three inches broad,) obovate, obtuse at the stalk; greenish yellow russet, but tinged with crimson red next the sun; the flesh rather firm; yellowish white, sweet, rich, melting, and excellent. It must be gathered while it adheres yet firmly to the tree, to have it in the utmost perfection. It ripens in October, and will keep a month or two.

38. BELLE HENRIETTE. [J.]

A large; new fruit, balf melting; a valuable fruit, ripening in November at Paris.

39. *BELLE LUCRATIVE. Lindley. Braddick. Thompson.

Fondaxte D'Aótome.

A beautiful new Flemish pear; middle-sized, roundish; tapering to the stalk; of a pale yellow color; slightly rus- 
seted, and red next the sun; flesh a little gritty, but soft and mellow ; very juicy, sugary, with a slight musky perfume. Early in October. Mr. Manning believes this to be Fondante d'Automne; it proves one of the very best and most productive of our autumn fruits ; and is recommended by Mr. Thompson, as very first rate.

40. BELMONT. Mr. Knight. Thompson. [E.]

A new, large fruit, obovate in form, of a pale yellow or brown color; juicy and excellent for cooking. The tree is a great bearer. November. [October ?] $\mathbf{R}$ aised by $\mathbf{M r}$. Knight, and sent by him in 1832 to Mr. Lowell. Mr. Knight calls it " very excellent here in November."

41. *BEURRÉ D'AMAULIS. Bon Jard. Thompson.

Large, obovate, swollen, a little in form of the Calabasse; color, brownish green, blotched with red next the sun; flesh melting, beurrée; juice abundant and excellent. This variety has proved with Mr. Perkins and Mr. Manning a first-rate fruit. September and October.

42. BEURRÉ D'ANJOU. [J.]

New and large; melting, perfumed, and excellent. It ripens at $P$ aris in October.

43. BEURRÉ D'ARGENSON. Thompson.

A large, pyramidal fruit, of a yellowish brown color; beurrée and excellent. November. [October ?]

44. BEURRÉ DE BEAUCHAMPS. [J.] Van Mons. Nouveau Cours Complet d'Agriculture, Vol. xII. p. 127.

This fruit is nearly round; color yellowish green, speckled; flesh almost white, half melting, having a peculiar flavor, which is very agreeable. It ripens in November. The tree is very productive, says Van Mons, who sent us the specimen. - Bosc.

45. BEURRE DE BEAUMONT. [J.]

Under medium size, but of superior excellence; melting, and very fine; perfumed. A new fruit, which ripens at Paris in September:

46. *BEURRÉ BOSC.

Large and very long, terminated by a crown, near three inches in diameter; somewhat calabash-formed; skin gray fawn color, but russety yellow at maturity; flesh white, melting, highly-flavored, and delicious. It ripens in 
October. In England, the Bose has proved a most extraordinary fruit. It is there stated that " the Beurré Bosc, and the Louise Bonne de Jersey, more than rival the Marie Louise." It bears well, and in America bas been found a prodigious bearer.

47. BEURRÉ CRAPAUD. Thompson.

Middle-sized, obovate; color pale green; beurrée and excellent. October.

48. BeURRÉ CURTET. Van Mons. Annales' d'Horticulture. $[\mathrm{F}$. $]$

The fruit is oval, rounded; $\cdot$ its length three inches, breadth the same; the skin is green, thin, striped, and stained with red next the sun; the flesh white, melting, full of sweet juice, quickened by an aromatic tartness, peculiar to the Bergamots. Last of September to middle of October. - New England Farmer, Vol. x. No. 22, inserted by Hon. H. A. S. Dearborn.—Obtained in 1828, by M. Simeon Bouvier, an apothecary of Jodoigne, who has dedicated it to M. Curtet, a physician of Brussels.

49. BEURRÉ DELBECQ. Loudon, from Bulletin Universel.

This is a new autumn pear, and is said to be a very superior fruit. The tree is more lofty, and of handsomer form than any other variety. It was raised by Van Mons from seed sown in 1813.

50. BEÜRRE DUVAL. Chev. Par. Thompson.

A new Flemish pear, raised by M. Duval. Middlesized, obtusely pyramidal; color pale green; beurrée and excellent. Excellent also and productive at the garden of Mr. Manning. October.

51. BEURRÉ D'ENGHEIN.

[J.]

New, of medium size, melting, and of excellent quality ; ripening in October.

52. BEURRÉ KNOX. M. Van Mons. Lindley.

Large, oblong or obovate; tapering to the stalk; of a pale green or yellow color, thinly russeted next the sun; flesh a little gritty, but mellow; - juice saccharine, but without any peculiar flavor. October and November. Raised by Dr. Van Mons, and sent by Mr. Knight to Mr. Lowell in 1823. 


\section{BEURRÉ MOIRÉ. [J.]}

New, of medium size, very fine, excellent, and perfumed. It ripens in October.

\section{BEURRÉ ROMAIN. Nouveau Cours Complet. Calvell.}

The fruit is large, nearly round, flattened at the summit; of a yellowish green in the shade, slightly colored with red next the sun; the flesh is melting and exquisite; but must be eaten at maturity, as it becomes clanmy soon after. Beginning of September. - Bosc.

55. BEURRÉ ROUGE. [J.]

Melting and excellent; a new fruit, under medium size; ripening at Paris in October.

56. *BEURRÉ SPENCE. M. Van Mons.

- This new pear was raised by Dr. Van Mons. It possesses a melting and delicious flesh, its taste inestimable, and, according to some, unrivalled. It ripens in Belgium in September, and merits a distinguished place in our gardens, a ccording to Dr. Van Mons and Mr. Braddick. The Beurré Spence, as cultivated in France, and such as is sold in the London market, is large, ovate or egg-formed; the eye but little depressed; stalk short, in a slight cavity; color pale green, sprinkled with yellow russet, somewhat ruddy or striped next the sun; melting, sweet, and highlyflavored. Mr. Kirke has assured me that the tree is very productive.

5\%. BEURRÉ VAN MONS. Thompson.

Middle size; pyramidally formed; skin russeted; flesh beurrée and excellent. November. [October?]

58. BEZI DE LOUVAINE. Van Mons. Nouv.

Cours Complet d'Agriculture, Vol. xi1. p. 126.

The fruit is long, its transverse diameter two and a half inches; skin a delicate green, but brown red next the sun; the stalk short; the flesh buttery, very agreeably perfumed. It ripens in October. Figured Pl. 101 of the Annales Generales des Sciences. - Bosc.

59. BISHOP'S THUMB. Lindley. Thompson.

Rousseline, (of some.) Thompson.

Large, very oblong, or twice as long as broad; dark green, covered with iron russet, brownish red towards the sun; flesh yellowish green, melting, juicy, high-flavored, and excellent; not handsome. September. 
60. BLEECKER'S MEADOW. [A.]

A native fruit, of small sire, roundish form, of a yellow color; the flesh melting, juicy, sweet, musky, and of fine flavor. A good bearer. October.

61. BON CHRÉTIEN FONDANTE. Lind. Thompson.

A most excellent new Flemish pear. It is large, oblong, regular in its outline; the stalk short, stout; mostly covered with deep cinnamon russet; flesh yellowish white, a little gritty, but rich and buttery, and full of a highly-saccharine, rich-flavored juice, resembling that of the St. Germain. End of October to November. [October?] The tree is a great bearer.

62. BROOME PARK. Mr. Knight. [E.]

Originated by Mr. Knight, who describes it as " a rather small but excellent variety." Scions were sent.by him to Mr. Lowell in 1832.

63. BROUGHAM HALL. Mr. Knight. [E.]

Deseribed by Mr. Knight as " an excellent variety here." Originated by him, and sent by him to Mr. Lowell, in 1832.

\section{4: BUFFUM. [A.]}

The tree is upright and handsome. A native fruit, highly esteemed at Warren, R. I. The fruit is rather small, oval; color russety yellow, but russety red next the sun ; melting; juice agreeable. September.

\section{BURNETT. [A.]}

An excellent native pear, which originated in Southborough, Mass. It received its name for Dr. Joel Burnett, of Southborough, who has introduced this fruit to notice. The fruit large, and in form of the Napoleon; of an iron russet yellow; flesh beurrée, rich, musky, ex cellent. October. November.

\section{6. *CALEBASSE BOSC.}

A new fruit, which I received from Mr. Forrest. Large, or rather larger than the Calebasse, and later, and, like that, nearly allied to the Beurré Bosc, and Paradise d'Automne, if indeed it be not identical with some of them ; of the same form; and covered with dark yellow russet; melting, delicious, sugary, and excellent. The tree bears abundantly. October and November. 
6\%. CALEBASSE FONDANTE. Nouveau Cours Complet d'Agriculture', Vol. xII. p. 124.

The fruit is very much lengthened, knobby; of a uniform red color; its flesh is melting, sugary, agreeable, so far as I could judge from the fruits sent me by Van Mons. It ripens the beginning of October, and grows soft soon after. - Bosc.

68. CALEbASSE MARIANNE. Nouveau Cours Complet d'A Ariculture, Vol. xII. p. 128.

This fruit is very long; about three inches in its transverse diameter, rather narrow in its length; of an orange color; the stalk is short; the flesh white, melting, very sugary, and very perfumed. This is one of the best of all pears. It very much resembles in its form a Calabash. The tree is thorny. This pear is figured Pl. 49 of the Annales Generales des Sciences.-Bosc.

69. *CALEBASSE VASSE.

Large, and calabash-formed; oblong, and nearly allied to the Beurré Bosc and Paradise d'Automne, and, like them, covered with yellow russet; melting and delicious. A prodigious bearer. A fine new fruit, which I received from Mr. Ronalds. October.

\section{0. "CAPIAUMONT.}

Beurré de Ca piaumont. Pom. Mag.

The young wood is brownish red; leaves folded and recurved, and changing to red in autumn; the fruit of medium size, tapering pyramidally to the stalk, rounded at the crown; the eye level with the extremity; stalk half an inch long, inserted on the summit; of a fine, clear cinnamon color, changing to yellow in the shade, rich bright red next the sun; flesh yellowish, melting, beurrée, very rich, and highly-flavored. It ripens in October, and grows equally well on the pear and the quince. The tree bears astonishing crops, and is one of the most valuable and profitable of all pears. Originated by M. Capiaumont, of Mons. This is not the fruit so long known and miscalled near Boston as the Capiaumont, that being the Frederic de Wurtemberg.

\section{1. *CAPSHEAF. [A.]}

A large pear, of a globular form, inclining to turbinate; of an orange russet color ; melting, buttery, sweet, and rich-flavored. September and October. Highly esteemed 
where known and cultivated. A valuable pear, introduced here by S. H. Smith, Esq., of Rhode Island.

\section{COLMAR D'AUTOMNE. Thompson. Lindley.}

Autumn Colmar. Lindley.

A new Flemish fruit, obtusely pyramidal, irregular; the stalk depressed; of a pale yellow or green color, thinly russeted next the sun; the flesh rather gritty, but mellow, or beurrée, with a sugary and slightly perfumed juice. An excellent fruit. Ripe the beginning of September. The tree bears well.

\section{COLUMBIA.}

\section{[A.]}

A large native fruit, of roundish form, very handsome and fine, introduced to notice by the late Mr. Bloodgood, of Flushing, Long Island. October and November.

\section{4. *COMTE DE LAMY. [Rivers.]}

A pale yellow fruit, of medium size, and obovate form; red next the sun; a most excellent variety, abounding in a sugary and refreshing juice. The tree bears well. October. Proved in the garden of Mr. Manning.

\section{CROFT CASTLE.}

New, and originated by Mr. Knight ; form irregular, russety red next the sun, yellowish in the shade; the stalk long; flesh juicy, sweet, and excellent, as proved by Mr. Manning. The scions of this fruit were sent by Mr. Knight to Mr. Lowell. It ripens early in October.

\section{CUMBERLAND. S. H. S., Esq. [A.]}

This native pear is stated by Mr. Smith, to be extraordinary for its size and beauty; some specimens have weighed near a pound. The color is yellow or orange, with a bright blush of crimson next the sun; the flesh is rich, juicy, and melting; little inferior to the old St. Michael. The original tree was first shown to him in 1830, growing in Cumberland, Rhode Island. It is about thirty years old, apparently hardy, and free from blight. It ripens in autumn, and may be kept till into winter.

\section{7. *CUSHING. [A.]}

This native pear originated about forty years ago, on the grounds of Col. Washington Cushing, of Hingham, Massachusetts. The fruit is of medium size, oblong, contracted towards the stalk, which is short; the skin smooth, light green, but brownish red next the sun; the flesh whitish, melting, and full of delicious juice, sprightly, and of firstrate excellence. The tree is a great and constant bearer; 
and although growing in an uncultivated pasture, it has produced annually fourteen bushels of fruit. Season, middle of September.

78. DARIMONT. Lindley. Thompson.

A new Flemish variety; middle-sized, obovate; of a russety color; melting, saccharine, musky, somewhat astringent. September.

\section{DÉLICES D'HARDENPONT.}

A new and fine Flemish fruit, raised by Counsellor Hardenpont, of Mons. The fruit is over medium size, or over three inches long and two and a half broad; oblong, pyramidal, swollen beyond the middle, compressed towards the stalk; its surface rather uneven, or knobby; the stalk an inch long, stout, curved, obliquely inserted in a narrow cavity; skin pale yellow, partially covered with cinnamoncolored russet ; flesh yellowish white, beurrée, abounding in a sugary, slightly astringent, somewhat musky, and perfumed juice. Ripe in October. The tree is a good bearer.

80. DÉLICES DE JODOIGNE. [J.]

A new fruit, of medium size, melting and excellent; ripening at Paris in November.

\section{DÉLICES VAN MONS. [J.]}

Melting and excellent; a new fruit, of medium size, ripening at $\mathrm{Paris}$ in November.

\section{2. *DIX. Mr. Dononer. [A.]}

This very fine native pear originated in the garden of Madam Dix, in Boston. It sprung from the seed about 1812. The tree is of medium vigor; the young wood is thorny. It is very productive. The fruit large, oblong; the skin rough, thick, green, but yellow at maturity, with a fine blush on the side exposed to the sun; the stalk short, and situated on its summit ; flesh melting, juicy, rich, and of fine flavor, and is thought to be even superior to the St. Germain. It ripens from the middle to the last of October, and bids fair to be one of our very best autumn pears, for its beauty, fine flavor, and productiveness.

83. *DR. IIUNT'S CONNECTICUT. J.Prince, Esq.

The scions of this pear were received of Dr. Hunt, of Northampton, who received it from a friend in Connecticut, without a name. "The tree is of uncommonly vig orous growth, and a great bearer. A beautiful pear, of a 
good size, oblong form, yellow color, with a remarkably short stalk; tolerable for the table, and excellent for cooking in October." A valuable, and profitable variety for extensive cultivation.

84. DOYENNE SANTELETTE. Lindley. Thomp.

A new, fine, handsome pear, raised by Van Mons.- Middle-sized, pyramidally oblong, narrow at the crown; pale green, thinly russeted ; flesh white, a little gritty; juice saccharine, with a slight musky perfume. October. [Șeptember ?]

85. DE RACHINQUIN. Annales d'Horticulture. [F.] Vol. Ix. No. 22, of the N. E. Farmer, inserted by the Hon. H. A. S. Dearborn.

"The fruit is round, compressed; the skin rough and brown like that of the Mons Jean ; flesh very melting, buttery' and sugary, and high-flavored. November and December. This variety merits dissemination for the beauty' of the tree and the quality of its fruit. It grows in clusters, and was produced by $\mathbf{M}$. Noisette.

86. *DUChesse D'ANGOUlêMe. [F.] Pom. Mlag.

Hort. Trans., and various authorities.

ANgoulême, Duchess or Angoulême.

I have already, in another place, detailed the mode practised by the most distinguished cultivators of France during the last ages, in their attempts to raise improved varieties of fruit from the seed, and the disastrous results. By planting only the seeds of the very best fruits, they seem to have indulged the expectation that nature might thus be driven to infinite lengths. Nature, already exhausted, seems to have reacted - they witnessed a retrograde. But nature alone, by a great effort, has sometimes accomplished, in that country, all that man, by misguided zeal and false science, had vainly attempted. Such appears to have been the case in the Duchesse d'Angouleme, said to have been discovered growing wild in a hedge of the Forest of Armaille, near Angers, in the department of Maine and Loire. It was there found in July, 1815, on the return of the Bourbons the second time to France.

- Hence its name. "A pear of first-rate excellence, the finest of the late autumn pears. It is not less remarkable and distinct from others in its appearance, in its irregular, knobby surface. It' arrives at a weight rery unusual in 
dessert pears. Specimens from the Island of Jersey have been seen weighing twenty-two ounces. The form is roundish, oblong, tapering towards the stalk, with an extremely uneven surface; the stalk and eye deeply sunk; skin dull yellow, covered with broad russet patches; the flesh rich, melting, very juicy and high-flavored, with a most agreeable perfume. The trees are stated to bear very early, and with certainty. It succeeds equally well on the quince stock or pear." It will ripen here about the last of October. Specimens of this fruit have been here produced, some weighing a pound, and of very first rate quality. The tree is a great bearer.

87. DUNMORE. [E.]

A new and valuable fruit, which was originated by $\mathrm{Mr}$. Knight; large, and in form of the Diel, and very productive.

88. EMERALD. Thompson. [E.]

A new fruit, originated by Mr. Knight, of great excellence, and a great bearer, as are all of Mr. Knight's generally, as fully proved.

89. EYEWOOD. [E.]

A new fruit, originated by Mr. Knight, and which $\mathrm{Mr}$. Thompson describes as " excellent, and very productive;" very lately proved by him, at the garden of the London Hort. Society.

\section{FIGUE DE NAPLES. Thompson.}

Large, oblong, of a brown color, but red next the sun; beurrée and excellent. The tree is vigorous. Nov. [Oct. ?] 91. FONDANTE DES CHARNEUSE. [J.]

A new, medium-sized fruit, melting and excellent. This fruit ripens at Paris in September.

\section{FONDAN'TE VAN MONS. Thompson.}

Middle-sized, roundish; of a pale yellow color; juicy and excellent. November. [October ?]

93. FORME DE DÉLICES. Thompson.

Middle-sized, obovate; of a yellow color, russeted; beurrée and excellent. October.

\section{FOSTER, Dr. Holmes. [A.]}

A native, raised by Capt. Otis Foster, of Winthrop, Me., from the seed of the old St. Michael, planted in 1802. The tree is very handsome, and extraordinarily productive. 
The fruit possesses the flavor and other valuable qualities of this once favorite variety, but is larger, and keeps better. 95. *FREDERIC DE WURTEMBERG.

WURtemberg. Capiaumont of Boston, formerly, but erroneously.

A large and splendid fruit, of great excellence, raised by Dr. Van Mons, and so named by him in honor of, and at the particular request of Frederic, king of Wurtemberg. The tree grows vigorous and upright; the young wood is strong, of a yellow color; the leaves large and expanded; the fruit large, flattened at the base, pyramidally formed, tapering to the stalk, which is placed on its summit ; color fine yellow, covered with beautiful crimson next the sun, melting, and of delicious flavor. The tree bears early, and very abundantly. This fruit was sent by Mr. Knight to the Hon. Jolın Lowell, by mistake, under the name of the Capiaumont. I have received the true Wurtemberg from Dr. Van Mons; also the true Capiaumont, both from him and from several other sources; both have been well proved.

96. *FULTON. [A.]

The tree is a great and constant bearer. A fine native pear, roundish turbinate; of medium size; the skin dark yellow, russeted; melting, juicy, sugary, and of delicious flavor. It ripens the middle of September, and lasts a month. - To have this fruit in perfection, it should be gathered a little before its naturity, and ripened in the shade. Raised from seed by Mrs. Fulton, of Topsham, Maine. It is highly deserving of cultivation.

97. GENDESEIM. Lindley.

The fruit is middle-sized, pyramidal, a little uneven in its outline; the skin yellowish green, covered with specks and thin patches of gray russet ; flesh a little gritty, but mellow, and full of a saccharine, rich, and slightly musky juice. A new Flemish pear, and a hardy and productive tree. Ripe in September.

98. GENESEE. Judge Bucl. . [A.]

$A$ beautiful and excellent fruit, in form like the Passe Colmar, but of larger size. Flavor somewhat like the old St. Michael. September.

99. "GOLDEN BEURRÉ OF BILBOA.

I have adopted this name for a superior fruit, which was 
exhibited at the Massachusetts Horticultural Society, in October, 1831, by Mr. Hooper, of Marblehead, the produce of a tree imported from Bilboa, in Spain. A new Spanish fruit, of medium size, very oblong, rounded at the crown, contracted towards the summit; of a fine bright golden hue, interspersed with patches of golden russet ; perfectly melting, juicy, rich, and of the finest flavor. A beautiful fruit, a great bearer, and highly deserving extersive cultivation.

\section{0. *GORE'S HEATHCOT. [A.]}

A native pear, a capital variety, which deserves to be ranked with the Seckel and Bartlett; raised by Mr. Heathcot, on the farm of the late Governor Gore, from the seed planted in 1812. The tree is remarkably upright and handsome in its growth; the young wood is red and thorny; the fruit is rather large; its diameter is three fourths of its length; contracted towards the stalk; of a fine yellow or straw color, tinged with red next the sun; the flesh is rich, melting, and of most excellent flavor. It is a constant bearer, and the young tree produced, in 1831, five bushels of pears, according to Mr. Toohey, who has introduced this pear to notice. It ripens in September, and is highly deserving of cultivation.

101. "HACON'S INCOMPARABLE. Lindley. [E.]

The fruit is middle-sized, turbinate, irregular; slightly angular near the crown; the stalk stout; skin rugose, pale yellow mixed with green, partially covered with orange russet; the flesh yellowish white, slightly gritty, but very buttery and melting; juice abundant, very saccharine, extremely rich, and possessing a high musky and perfumed flavor. A very valuable and excellent pear, raised by $\mathrm{Mr}$. James Gent Hacon, of Downham market, in Norfolk. The tree sprung from seed in 1814. It bears abundantly, and may justly be considered one of the best pears ever raised in England. The branches grow pendent; and, as above described by Lindley, by Rivers, and others in England, so also has it been proved, by Mr. Manning and others here, to be perfectly delicious, and one of the most productive pears known. November and December.

\section{2. *HARVARD. [A.]}

L'ÉPERGNE, former name.

This fine native pear originated in Cambridge, Mass. The tree is of vigorous, upright, and handsome growth, 
and thorny ; the fruit above medium size, oblong, swollen at the crown; contracted towards the stalk, which is inserted in a cavity; of a russety yellow color, tinged next the sun with russety red; the flesh white, juicy, melting; flavor like the combined flavors of the Seckel and Jargonelle. The tree comes slowly into bearing, but afterwards bears abundantly. It is ripe by the middle of September. Highly prized in the Boston markets.

103. HAZEL. Hort. Trans. Vol. vir. p. 310. Lindley. [E.]

A small fruit, of a yellowish color, and speckled; of an oval, turbinate form; the flesh white, juicy, and sugary. Season, end of October to end of November. A Scotch fruit, and said to be extensively cultivated in Scotland for its good quality and abundant produce.

101. HENRI QUATRE. Lindley. Thomp. Van Mons.

Henry Foúrth. Ilid.

A new Flemish pear, raised by $\mathbf{M}$. Witzhumb. The tree is a good bearer. Middle-sized, pyramidal, oblique at the crown; pale yellow mixed with green, but orange brown next the sun; flesh pale yellow, a little gritty, but very tender and melting; juice abundant, highly saccharine, with a slight musky perfume. A very excellent pear. It ripens early in September, and will keep a few weeks.

\section{HENRI VAN MONS.' Dr. Van Mons.}

New England Farmer, Vol. x. No. 7. Inserted by the Hon. H. A. S. Dearborn, from the Revue des Revues; written for that periodical, by·Dr. Van Mons.

The fruit is very large; contracted in proportion to its length, and swollen about one third of its height; but the largest fruit often assumes a cylindrical form. The skin is smooth; of a greenish yellow, but brilliant red next the sun; the flesh is tender, buttery, sweet, slightly mingled with acid, which renders it very agreeable. It is an excellent autumn fruit, and its true pear flavor should make it in great demand. Named in honor of M. Henri Van Mons, of Brussels.

106. JALOUSIE DE FONTENAY VENDÉE. [J.]

New, of medium size, of superior excellence, melting, and very fine, perfumed; ripening at Paris in September. 
107. JUTTE, OR BUIST.

Largè, oblong, handsome, greenish yellow in the shade, ruddy next the sun, and good; the tree a great bearer, ripening the middle of September. A variety received from the Lond. Hort. Soc., and lately proved by Mr. Manning.

108. KING EDWARD'S.

JACкмAN's MeLting of some English catalogues.

A new fruit, received by Mr. Manning from England, origin unknown; large, and very oblong, pyramidal; the stalk short; skin covered with dark red; the flesh juicy and good, but not rich; remarkable for its beauty. The tree promises to bear well, and the fruit ripens late in Sept.

109. LODGE. Col. Carr.

[A.]

A new seedling, raised in the neighborhood of Philadelphia. A tolerably large pear, of a brown color; melting, juicy, and of delicious flavor; thought by some to be superior to the Seckel. It ripens early, but keeps well; and is thought to be highly deserving of general cultivation.

110. *LOUISE BONNE DE JERSEY. [F.]

Louise Bonye D'Avranches. Bon Jard. Lusette.

A fruit of surpassing excellence, very large, oblong, pyramidal, swollen; brownish green in the shade, changing to yellow at maturity; ruddy, or sometimes of a beauti. ful red next the sun; flesh very melting and fine; juice very abundant, sugary, and high-flavored. 'This very superior fruit originated at Avranches, or at Cherbourg, in France, where it ripens in October. M. Lusette stated to me that the tree was even more productive than the Marie Louise. In England, also, this fruit proves most extraordinary, ripening there in November. It is there stated that "this pear and the Bosc even more than rival the Marie Louise." So states Mr. Thompson.

\section{MADOTTE. [J.] [Margat.]}

Large and beautiful, of a fine yellow color ; even superior in quality to the Duchesse d'Angouleme, as Mons. Margat informs me ; equally as long, but not quite so broad, and of a more beautiful form; ripening in November

\section{MARIE LOUISE. Pom. Mag. Van Mons.} Thompson.

Marie Chrétien. Thompson.

A new and most superior variety, originated by the Abbé 
Duquesne. The tree bears abundantly; the fruit is oblong, tapering towards both ends. The size varies from medium to large; stalk an inch long; skin nearly smooth, yellowish green, interspersed with patches of cinnamoncolored russet; the flesh white, exceeding juicy, melting, buttery, and rich. It ripens early in October, and keeps till November. The tree succeeds equally well on the pear and the quince; one of the most profitable and productive of all pears; the trees as proved both in England and America, bear wonderful crops. Scions of this capital variety were first received by Mr. Lowell, in 1823, sent hither by Mr. Knight.

\section{MARIE LOUISE DELCOUR'T. [J.]}

Melting; perfumed, and excellent. A new fruit, of mediun size, ripening at Paris in November.

\section{MOCCAS. [E.]}

A new fruit, originated by Mr. Knight. A noble fruit, of large size, or as large as Diel, such as I saw at the garden of the I condon Hort. Soc. The tree bears a most abundant crop, as was observed of all of Mr. Knight's new kinds. There are doubts as to the identity of this fruit. On the same tree I also saw another and splendid-looking scarlet fruit, large and pyramidal; which was stated to be the Ramillies.

\section{5. "NAPOLEON. Pom. Mag. Van Mons.}

Medaile. Hort. Soc. Cat.

SAUVAGEON Liart of some, according to Van Mons.

Charles d'Autriche, and Sucre Dore. Thompson.

This new and excellent variety was raised by M. Liart. Mr. Braddick has stated that he found the Napoleon in every good collection on the continent; also the Marie Louise. This variety was sent, in 1823 , by Mr. Knight, to the Hon. John Lowell. ' The fruit is large, in form of the Colmar, contracted in the middle; stalk half an inch long, slightly depressed; the skin smooth, bright green, but at maturity pale green; flesh very melting, with a most unusual abundance of rich, agreeable juice. It ripens with us in September. This variety is a great bearer, and succeeds equally upon the pear or quince stock.

\section{NAUMKEAG. Mr. Manning. [A.]}

This pear was lately originated in Salem, by George Johonnot, Esq., and derives its title from the ancient In- 
dian name of that town. The fruit is nearly round, or roundish oblong; the stalk long; of a yellowish russet color. A valuable pear, and a great bearer. Ripe in autumn.

\section{1\%. *PARADISE D'AUTOMNE.}

A fine new fruit, sent to England as Paradise d'Hiver, large, oblong, or four inches long and two inches broad; rounded at the crown, calabash-formed; the eye small, and not depressed, contracted towards the middle; the stalk an inch and a half long, inserted on the summit; of a fine golden russety color, melting, of a sweet and delicious, aromatic flavor. The tree grows strong and upright, afterwards pendulous. The tree, like the Calebasse and Bosc, to which this variety is nearly allied, is a great bearer, as stated to me by Lee, of Hammersmith, of whom I received the kind. The fruit ripens a fortnight after the Williams Bon Chrétien, and a fortnight previous to the Louise Bonne de Jersey.

\section{PARMENTIER. Thompson.}

Middle-sized, obovate; striped with bright red; beurrée and excellent. October. [September?]

\section{PITFOUR. Mr. Knight. [E.]}

"A rich, melting pear; season, November." Originated by Mr. Knight, and sent by him, in 1832, to Mr. Lowell. The fruit is large, oblong, pyramidally-formed; color russety red.

\section{POIRE DE DUVERNY. [J.]}

Large and excellent; a new and half melting fruit; ripening at Paris in October.

\section{POIRE D'ANANAS. Loudon.}

A fruit of medium size, very handsome, melting, with a fine pine-apple flavor, (hence its name, ripening in November, and considered in Belgium as one of their very best kinds.

\section{POIRE DE MONS. [J.]}

A new fruit, of excellent quality, of medium size, and ripening at Paris in November.

123. POIRE DE LOUVAINE. Lindley.

The fruit is middle-sized, pyramidal, uneven on its surface; of a dull green color, mixed with yellow and spots of russet ; the flesh very tender, slightly gritty, and full of 
a rich, very saccharine, musky juice. A very excellent pear, and hardy tree; it highly deserves cultivation. . Ripe the beginning of October, and fine to the end.

\section{POIRE NEILL. Lindley.}

This fruit is sometimes nearly four inches long, and three and a half inches in diameter; pyramidally turbinate, tapering to the stalk; sometimes obliquely formed; the stalk is short and obliquely inserted; the skin pale yellow, intermixed with green; and mottled with thin gray russet; flesh white, a little gritty, but very soft and mellow, abounding with a saccharine, and slightly musky juice. A very fine and handsome new pear from Flanders, so named in honor of Mr. Neill. Ripe in September, and lasts during October. The tree is a great bearer.

\section{5: POPE'S QUAKER. [A.]}

Large and handsome; of a bright yellow russet color, and good. The tree produces large crops of fruit every year, at the garden of Mr. Manning, who believes tlis fruit to be a native.

\section{6. * PRINCESSE D'ORANGE. Pom. Mag.}

\section{Princesse Conquette. Thompson.}

The fruit is roundish turbinate, the size of the White Doyenne, (St. Michael;) the skin bright reddish orange russet; flesh yellowish white, sugary, and rich; in some seasons, perfectly melting, but occasionally a little gritty. From its great beauty, as well as the good quality of the fruit, this variety is highly recommended to notice, as a valuable autumn pear, ripening in October. Raised hy the Comte de Coloma in 1802. Fine with Mr. Manring.

\section{PRINCE'S SAINT GERMAIN. [A.]}

Raised by William Prince, Esq., proprietor of the Lin. Botanical Garden, Flushing, from the St. Michael and St: Germain. The fruit is rather large, oblong, regular in form; yellow, covered with thin russet;-melting, and of excellent flavor. It ripens in autumn, and will keep till winter. The tree is said to bear well.

\section{REINE DES POIRES. Thompson.}

Large, obtusely pyramidal ; color yellowish green, but red next the sun: flesh breaking and good. September and October. 'The tree is a great bearer. It does not, however, merit its name. 


\section{RICHE DÉPOUILLE. Lindley. Lond. Hort. Trans.}

Riche D'Appoie.

This pear resembles the St. Germain in size and shape. It is large, oblong, the eye prominent; tapering to the stalk, which is rather thick and long; the skin clear citron yellow, covered with numerous asperities, and rough like the orange or lemon, and tinged with scarlet next the sun; the flesh is white, melting, not perfumed, but sweet and very pleasant. A new variety, ripening late in autumn or winter; it succeeds on the quince or pear.

\section{0. *SAINT-GHISLAIN.}

This variety was raised in Belgium by $\mathbf{M}$. Dorlain. A very superior fruit, of medium size; pyramidal or turbinate in form; the stalk on its summit, and fleshy; pale green changing to pale yellow ; flesh juicy, beurrée, rich, saccharine, peculiar, and very delicious. Ripe from the middle of September to end of October. The tree bears very abundantly. Introduced by S. G. Perkins, Esq.

131. SAINT MICHEL ARCHANGE. Bon Jard. [J.]

Very large, and in form of a decanter: yellow at maturity; flesh yellowish white; fine, melting, sugary, relieved by an acid, and excellent. Ripe the beginning of October at Paris. Such also is the account which M. Vilmorin has given me of this fruit.

\section{2. *SECKEL. [A.]}

A most delicious pear, of a size varying from small to medium; of an obovate form; the color varying from yellowish to brownish russet, but generally red next the sun; of a melting, spicy, and most extraordinarily rich and delicious flavor. In this respect, it is, by some, supposed to exceed any other native fruit. It ripens the middle of September, and lasts till the middle of October. The tree is of moderate growth and extraordinarily productive; the fruit grows in clusters, and is recommended as indispensable in every good collection. Dr. Hosack has stated that this variety was first introduced to notice near Philadelphia about 17\%0. It was found either on the grounds of Mr. Seckel or Mr. Weiss.

133. SERRURIER D'AUTOMNE. Annales d'Horticulture. Nevo England Farmer, Vol. 1x. No. 22, inserted by the Hon. H. A. S. Dearborn.

"M. Van Mons says the tree is tall and majestic; the 
leaves small, elongated, and appositely formed." The fruit is very large, oblong, obtuse at both ends; the skin of a delicate green; it becomes yellow at maturity; the flesh is white, tender, melting, full of a very abundant, sugary juice. The epoch of its maturity is towards the end of October, and it may be preserved three weeks. Produced by M. Van Mons.

131. SHOBDEN COUNT. Loud. Mag. [E.] Thom. Raised by Mr. Knight; a fine variety. It possesses a flavor partaking of that of the melon and pine-apple. A very superior and productive fruit.

135. STRIPED BON CHRÉTIEN. N. Duh. Bon Chrétien Panaché. Ib. Pl. 115.

Introduced by M. Vanieville, from Metz, in 1810. The tree comes early into bearing; the young wood is striped; the fruit is very large, and formed like the winter Bon Chrétien, irregularly striped with yellow on a green foundation; the flesh almost melting, sweet, and very agreeable in its raw state. This interesting species merits to be extensively multiplied.

136. "SUMMER FRANCREAL. Pom. Mag. p. 106.

Gros Micet d'Été. Ib. Fraxcreal d'Été. Diel's Pom.

Fondante. Knoop's Pom. France Caniet. Ib.

Preble's Beurré? Mrlay Blano, of France.

Rather large, turbinate, pale yellowish green ; the stalk short and thick; the flesh white; firm, juicy, buttery; melting, rich, and excellent. The tree is a great bearer. The fruit ripens in August. The trees grow compact; the young wood is downy; the leaves also are downy beneath. A fine, productive variety.

\section{7. *SURPASSE MARIE-LOUISE. ' [E.]}

Pitt's Prolific Marie.

For the account of this new fruit I am indebted to Mr. Lee, of Hammersmith. The Surpasse Marie Louise was raised from the seed of Marie Louise, by Mr. Pitt. It is large, and very oblong, somewhat in form of the Bosc, or Calabash-formed, and covered with brown yellow russet; melting, and of fine flavor. Yet in fine quality it does not surpass the Marie Louise, but is a prodigious bearer, even more so than that variety. In England the Marie Louise bears prodigious crops, as with us, but is sometimes liable in that climate to be cut off by late spring frosts; but never so with us. It ripens in autumn. 
138. SUPER FONDANTE. Thompson.

Middle-sized, obovate; of a pale yellow color; beurrée and excellent. It resembles the White Doyenne. It ripens in September.

139. 'THOMPSON'S. Thompson. Rivers.

A new Flemish fruit, and so named by the London Horticultural Society, for Mr. Robert Thompson. Of medium size, obovate form; pale yellow; remarkably juicy, with a high flavor, resembling the Passe Colmar. November.

\section{TILLINGTON. Lond. Hort. Trans. [E.]}

A new variety, raised by $\mathrm{Mr}$. Knight, and sent by him, in 1822, to the Hon. John Lowell. Middle-sized, turbinate, rounded at the crown; the stalk short, fleshy; color dull brick dust red next the sun; the whole russeted. The flesh white, nearly beurrée, a little gritty; sweet, rich, though not very juicy. November.

\section{TRIOMPHE DE LOUVAINE. [J.]}

A new and very superior fruit, of medium size, nelting and fine, and ripening at Paris in October.

\section{2. *URBANISTE.}

BeurRée du Roi of some.

$A$ new and most superior variety, raised by the Comte de Coloma, of Malines. The fruit is rather large and oblong; pyramidally ovate; very regular; the eye slightly depressed; the stalk an inch long, moderately and obliquely sunk; color pale green, inclining to yellow, small gray patches of russet dispersed over its surface; the flesh white, but reddish yellow next the core, which is large and a little gritty; it is quite melting, juicy, and very sweet, with a, little perfume. This variety was sent bv Mr. Knight to the Hon. John Lowell in 1823, and has been by him liberally disseminated. It proves, with us, one of the very finest and most valuable of autumn pears. It ripens the middle of September, and keeps till December. A tree imported from France, in 1822, by John Prince, Esq., of Roxbury, under the name of Beurré du Roi, and on a quince stock, has proved a most excellent bearer, and a very first-rate fruit. The tree, the leaf, and the fruit, are evidence that it is no other than the Urbaniste; its legitimate title having been suppressed in France, and a new one usurped in honor of Charles $\mathbf{X}$. 


\section{VERLAINE.}

New, and rather large, or three inches long, and two and a half broad; ovate; round at the crown, diminishing to the stalk, which is small, short, and inserted in a small cavity; pale green and covered with russet in the shade, ruddy next the sun; melting, of a sugary, aromatic flavor. It ripens in October. The tree bears well, as Mr. Kirk assures me, from whom I received specimens of fruit...

\section{4. "WASHINGTON." [A.]}

A medium-sized native pear, of an oblong form, much compressed towards the stalk; very melting, and of delicious 'flavor. Thus it is described by Mrs. Griffith, of Charlieshope, New Jersey, who has sent this variety to Mr. Parsons. Autumn. The fruit produced by Mr. Lowell and Mr. Manning, is fine.

145. *WILKINSON. S. H.S., Esq. Mr. Downer. [Ä.]

This new and fine native pear originated in Cumberland, R. I., on the farm of Jeremiah Wilkinson, brother to the celebrated Jemima Wilkinson, and was introduced here by Stephen H. Smith, Esq., of Providence, in 1829, and was so named by the committee of the Massachusetts Horticultural Society. The tree is healthy, and a good and constant bearer; the size and form are those of the St. Michael; the skin dark yellow, with a brownish blush next the sun; the flesh is whitish, melting; flavor very peculiar, with a delicious sugary juice, sprightly and pleasant; having distinctly the flavor of the rose and aroma.: Season, October and November.

\section{WHITEFIELD. Thompson.}

Middle-sized, oblong; of a brown or yellow color; beurrée and excellent. The tree is a great bearer. October and November.

\section{7. *WILLIAMS EARLY. [A.]}

This new variety originated on the farm of Aaron Davis Williams, Esq., in Roxbury, Mass., and is stated to be a good bearer. It is rather below the medium size; turbinate; the color yellow; with a deep blush next the sun; it is melting, juicy, and exceedingly fine-flavored. The tree is a good bearer. September.

148. WILliaMS BON CHRÉTIEN. [E.]

BARTLETt.

The fruit is large, irregular, pyramidal, or truncated; 
the eye on the summit; the stalk gross and fleshy; skin at maturity yellowish, mixed with russet brown, tinged with red next the sun; flesh whitish, tender, delicate; juice sweet, abundant, and agreeably perfumed. It ripens early in September, and keeps till October. The tree grows upright, wood yellow, and the leaf and tree are beautiful. One of the most beautiful, productive, and profitable of its season, and extensively cultivated near London, for the market. Its original being for a time lost, it received its latter name from that of the gentleman who has so liberally and extensively disseminated the fruit, Enoch Bartlett, Esq., of Dorchester, Iate vice-president of the Horticultural Society of Massachusetts.

The Williams Bon Chrétien originated in Berkshire, England, in the garden of a Mr. Wheeler, in 1796, and was, subsequently, extensively propagated by Mr. Williams, near London; hence its name. It seems capable of sustaining its good character in a diversity of climates; it flourishes at Malta, and produces equally well on the pear and on the quince.

149. WORMSLEY GRANGE. Knight. Thompson. [E.]

A new variety, originated by Mr. Knight, and sent by him, in 1823, to the Hon. John Lowell. Middle-sized, oblong, of a yellow brown color, beurrée and excellent. October. Mr. Knight describes it as a first-rate variety, requiring to be gathered before it is quite ripe. The lapse of years has not yet satisfied us that this English variety will answer in our warmer climate.

\section{S E C T I O N I I I.}

WINTER FRUIT.

150. *BeURré́ D'AREMBERG. "Pom. Mag. Thompson. Loudon. Knight. Annales d'Hort.

Potre d'Aremberg.

$\left.\begin{array}{l}\text { Duc d'Arembrag. } \\ \text { Cot.mar Deschamps. }\end{array}\right\}$

BeurRé des Orphelines of Deschamps.

The English writers, especially, speak of this new Flem 
ish pear as the very best of all known, - "the prince of pears." - One of the greatest bearers, coming early into bearing, and keeping well. It has been confounded with the Gloux Morceau, another fine pear, but larger. Mr. Knight sent the variety, in 1822, to the Hon. John Lowell, and it has been by him liberally disseminated. It was raised by the Abbé Deschamps, in the garden of the Hospice des Orphelines at Enghein. Deschamps at first called it Beurré des Orphelines, and M. Van Mons soon after named it Beurré d'Hardenpont, and, finally, Beurré d'Aremberg.' 'The Pomological Magazine thus describes the tree and its fruit: "Wood deep yellowish brown, sprinkled with gray spots; leaves middle-sized, ovate oblong, of a rich dark green color. The fruit is large, turbinate; the skin of a delicate pale green, dotted with russet, which becomes a deeper yellow at maturity; the flesh whitish, fine, very juicy, perfectly melting, without any grittiness, and of a very extraordinarily rich, sweet, high-flavored quality. It will keep till March, and is truly characterized, in the Horticultural Transactions, as deserving to be placed at the head of all pears in cultivation. It is a great bearer, either on a quince, or as a standard.

\section{BEURRÉ BRONZE.}

A new fruit, under medium size; ovate form; of a dull brouze color; dull red next the sun; melting and excellent. The tree bears well. The fruit has been produced by Mr. Lowell and Mr. Manning - is highly deserving of cultivation. It keeps into winter.

\section{2. "BEURRÉ DIEL." Pom. Mag.}

Dorothée Royale of Van Mons, according to Lindley.

Bevrré d'Yelee, Lind. Poire de Mreos. Ib.

Beurré Royale. Pom. Mag. Diel's Butterbirae

Gros Dirhen, Colmar Souverais.

Srlvanche Verte d'Hiver of Mr. Knight.

This noble pear was raised by Van Mons, and so named in honor of Dr. Augustus Frederick Adrian Diel. Its great merit, indepeudent of its excellence, is its fertility. It is of the first rank among dessert pears. The tree is of vigorous growth. The fruit, when in perfection, is four inches long, and three inches broad; it is much swollen a little above the middle, going off to the eye either abruptly or gradually, and tapering straight to the stalk, without any contraction of the figure, which is much like the Bon Chré- 
tien, but without the protuberances. The skin at maturity is bright orange, with little trace of russet; its dots surrounded with red; the eye in a deep cavity, surrounded by knobs; the stalk strong, one and a half inches long, in a deep, narrow cavity; the flesh clear white, a little gritty towards the core, but perfectly tender, melting, juicy, with a delicious, rich, saccharine, aromatic flavor, without any perceptible acid; the core small, the seeds usually abortive. This noble fruit, from the specimens here exhibited, bids fair to become:one of our most valuable of all varieties. The Sylvanche Verte, sent by Mr. Knight to the Hon. John Lowell, proves to be identical with the Diel.

\section{BEURRÉ FORTUNÉ. Bon Jard.}

Large, roundish, gray ; flesh beurrée, melting. It keeps till July. This new fruit was produced by M. Parmentier, of Enghein, in 1828. Its character has probably been too highly extolled, and is yet doubtful, and has not justified expectation, as M. Poiteau has informed us.

\section{BEURRÉ GRIS D'HIVER NOUVEAU. [J.]}

Very excellent; a new and valuable fruit, of medium size, melting and perfumed. It keeps till the end of winter, or till spring.

\section{BEURRÉ INCOMPARABI.E. [J.]}

New, large, melting, perfumed; a superior fruit, ripening at Paris in December, and keeping into winter.

\section{BEURRÉ DE NOIRCHAIN: [J.]}

A new and very superior fruit, very melting and perfumed; of medium size. This valuable fruit keeps till spring. This fruit and the following are designated as very extraordinary.

\section{BEURRÉ PICQUERY. [J.]. [D.]}

New and very superior; of medium size; very melting and perfumed. This fruit keeps till into winter, and is stated to be the best of all pears known, and of unrivalled excellence.

\section{8. 'BEURRÉ RANCE. Lond. Hort. Trans. Pom.} Mag.

Hardenpont de Printemps. Bevrrétépine.

This new variety was raised at Mons, by the late Counsellor Hardenpont. It is described by Dr. Van Mons as being the best of the late pears, keeping till May. Mr. 
Knight, in 1823, sent this variety to the Hon. John Lowell. The tree is vigorous, and a good bearer after a few years; the growth is straggling, the shoots sometimes growing pendulous. The fruit is middle-sized, oblong, tapering to the stalk, which is long and slender; the skin deep green; flesh green, melting; having a delicious, rich flavor, with very little acid; it shrivels in ripening.

159. BEURRÉ WITZHUMB. Van Mons. Nouveau Cours Complet d'Agriculture, Vol. xiI. p. 126.

The fruit is oval, knobby, three and a half inches in diameter; skin rough, green, brownish red or dark brown next the sun; flesh white, semi-transparent, melting, perfumed. It ripens in December. This beautiful and excellent pear is figured Pl. 105 of the Annales generales des Sciences. - Bosc.

160. BEZY VAET. Dr. Van Mons. New England Farmer, Vol. x. No. 7. Extracted from an article, written by Dr. Van Mons, in the Revue des Revues; inserted by the Hon. H. A. S. Dearborn.

BEzy DE SAINT VAÉst, according to Dr. Van Mons.

"The Bezy Vaet, according to tradition, and from the name which it bears, was probably obtained by the late Abbé Saint Vaest, or had been disseminated by him. The fruit belongs to the sub-species of Rousselets. Its size and form are those of the Colmar; ground deep green, blotched with purple, and stained in spots of rusty red; flesh both melting and buttery, slightly yellow. It abounds in sugar, and exhales a perfume which cannot be compared to the aroma of any other fruit. The period of its maturity is December and January; but it can be prolonged by gathering the fruit fifteen days earlier than usual. It is superfluous to add that it is worthy of being received by amateurs. Specimens of superior fruit of this name, have been exhibited, by Mr. Downer, to the Massachusetts Horticultural Society.

\section{CARDINALE. $N$. Duh. PI. 62. [F.] \\ Poire d'Ayiral of M. Hetry. Admirax.}

A superb, oblong pear, of a pyramidal form, with a wellrounded base; yellow in the shade, but beautiful red next the sun; flesh white, half melting, coarse-grained, very juicy, sweet, and agreeable. It keeps till March. It is eminently beautiful, and deserves to be better known. 
162. "CLION.

Le Curé. Dumas, Bourgmestre of Boston, erroneously.

Very large, very oblong, pyramidal or truncated; russety yellow in the shade, ruddy or bright scarlet next the sun. Large specimens, produced by John Heard, Esq., of Watertown, have been exhibited, weighing 13 ounces. As a table fruit, it is good at maturity, which is from December to February. A very valuable and profitable variety for its beauty, large size, keeping qualities, and the astonishing crops the tree bears; and, as such, highly deserving of cultivation. A new fruit, which lately originated in France. The proper name, according to $\mathbf{M}$. Vilmorin, should be Clion; or the name of the curate who originated the fruit.

163. COLMAR DEWEZ. Loudon, from Bull. Univ.

This pear, lately originated in the vicinity of Brussels, is said to contain a rare assemblage of extraordinary qualities. The flesh is white, tender, and exquisitely melting; the juice abundant, mild, and of an elevated, agreeable perfume, equal to the Hardenpont d'Hiver, improperly called Beurré d'Hiver.

\section{COLMAR VAN MONS. Nouveau Cours Com-} plet d'Agriculture, Vol. xir. p. 133.

Fruit pyramidal, yellow, with fawn-colored points; of medium size; the flesh half breaking, sugary, very agreeable. It ripens in January, and will keep two years, according to Van Mons. I have eaten of this fruit. The tree is extremely productive. - Bosc.

\section{DOWNTON. Thompson. [E.]}

Middle-sized, pyramidal; color yellow in the shade, dull brownish red next the sun; juicy and excellent. January and February. A great bearer. Originated by Mr. Knight, and sent by him, in 1823, to the Hon. J. Lowell.

166. EASTER BEURRÉ. Pom. Mag.

Bergamotte de la Pentecote.

Bezi Chaumontelle trés gros of $M$. Stoffels.

Beurré d'Hiver de Bruxelles of the Taschenbuch.

DOYenNé D'Hiver of some, according to the Pom. Mag.

CANing, according to Thompson. SeIGNer D'HIVER $\boldsymbol{b}$.

Doyenné d'Hiver. Ib. Doyenné de Printemps. Ib. Philipe DE Pacques. Ib.

This fine new fruit probably originated in Flanders. It is not to be confounded with the Easter Bergamotte, a good but inferior fruit. "Of all the very late keeping 
pears, this is decidedly the best, [for England.] The fruit is large, roundish oblong, broadest towards the eye ; stalk short, thick, deeply inserted; green, but yellow at maturity, with specks of russet brown; the flesh yellowish white, perfectly buttery and melting, and extremely high-flavored. It is a most profuse bearer on a quince stock. It ripens from November to May. This variety bears abundantly, and promises to become one of our finest winter fruits." "

\section{6\%. 'FLEMISH BON CHRÉTIEN. Lindley.}

Bon Chrétien Turc. Thomp. Bon Chrétren de Nouvelle.

Ib. Bon Chrétien de Vervol. Ib.

Very large; its transverse diameter three inches and a half; oblong, turbinate; yellow at maturity, but russeted next the sun; flesh yellowish white, breaking, but mellow at maturity; juice saccharine, slightly musky, perfumed. A.very fine new Flemish pear. It succeeds on the quince. November to January. - But Mr. Thompson describes it otherwise, as obovate, crisp, good for cooking, large, a great bearer.

168. GARNONS. Thompson.

Large, of an oblong form; of a greenish yellow.color. Beurrée and excellent. January.

\section{GLORIA. Mr. Knight.}

- Colmar d'Hiver, former name.

A name implying all that is excellent. A variety sent by Mr. Knight, in 1823, to the Hon. John Lowell. He thus described it: "Shape varying from nearly globular to pearshaped; color yellowish green. A melting pear, of firstrate excellence, and very productive. Season, January." Specimens of this fruit, perfect in form and exterior, were produced by Mr. Parsons in 1831, but of doubtful character. It cannot yet be recommended, except for further trial.

170. *GLOUT MORCEAU. Hort. Trans. Lindley. Knight.

Kron Printz Ferdinand, according to Thompsom.

Beurré Hardenpont. Ib. Hardenpont d'Hiver. $l b$.

D'AREMBerg of the French.

Mr. Knight describes the Glout Morceau as " a very large Belgic variety, of great excellence." Mr. Thompson adds to all this, that " it is a good bearer, hangs long on the tree, which is hardy, an excellent beurrée pear." Large specimens measure four inches long, and three and a half 
in diameter; much like the $D^{\prime}$ Aremberg in form, but larger, more oval, not so turbinate; the stalk an inch long, and rather deeply inserted ; the eye deep, in an uneven hollow; the skin is pale, dull olive green, inclining to yellow; covered with russety specks, and round the stalk russety blotches; flesh whitish, firm, very juicy, but a little gritty at the core. A beautiful and fine variety. Ripe in November, and will keep till March. It grows well on the quince.

\section{ICKWORTH. Mr. Knight. [E.]}

"Melting, rich, rose-flavored." March and April. This new pear was originated by Mr. Knight, and scions were sent by him in February, 1823, to Mr. Lowell and the Massachusetts Agricultural Society.

\section{JEAN DE WITT.}

A very productive, new fruit, melting and fine. It keeps till a late period in winter. At Mr. Wilmot's I found this to be one of his main winter kinds. Mr. Thompson observed, that "the Jean de Witt is somewhat allied to the Glout Morceau, but inferior, in point of flavor, to that excellent fruit ; yet it keeps longer, and is certainly deserving of cultivation."

\section{JOSEPHINE.}

Poire D'Austrasie. Sabive of the French.

J MINETtE of some, according to Van Mons.

This new Flemish pear is of large size; flesh melting, juice sugared, and flavor excellent. It ripens in winter. The tree is beautiful. Mr Thompson calls it a good bearer, and nearly first-rate. It does well on the quince.

\section{LA FOURCROY. Van Mons. Nouveau Cours} Complet d'A griculture, Vol. xı. p. 132.

Merveicle de la Nature.

Fruit oval, two and a half inches in its transverse diameter; skin yellow, spotted; stalk strong; eye little sunk; flesh yellowish white at maturity, melting, slightly acid, excellent. It ripens in January. Figured Pl. 86 of the Annales generules des Sciences. Raised by Van Mons.

\section{LEWIS.}

\section{[A:]}

This valuable pear originated on the farm of Mr. John Lewis, in Roxbury, Mass. The size is medium : form somewhat globular; the stalk long; the skin dark green and coarse; the flesh whitish, very melting, juicy, and excellent. It ripens by the middle of November, and may be kept till February and March. The tree, when loaded, 
droops like the willow. This new and excellent pear is a very great and constant bearer; it is productive to a fanlt, and possesses the valuable property of hanging on the tree to a very late period; and is highly deserving of cultivation. This fruit sells very high in winter in the market.

\section{L'OKEN D'HIVER. Van Mons. Nouvean}

Cours Complet d'Agriculture, Vol: xII. p. 132.

Fruit oval, a little lengthened; its transverse diameter five inches; stalk short; eyé sunk in a cavity; skin of a clear yellow, washed with fawn color; flesh white, melting, pleasant, perfumed, excellent. It ripens in March.-Bosc.

177. LOWELL. Mr. Knight. [E.]

A new pear, raised by Mr. Knight, and so named by him for the Hon. John Lowell, to whom the tree was sent in 1823. Mr. Knight observes, "Our climate is hardly warm enough for it; but in yours I think it will prove excellent, and a very productive variety."

178. MONARCH. Thompson. Mr. Knight. [E.]

$\Lambda$ new pear; middle-sized; obovate; of a yellow brown color; beurrée and excellent, and productive. January. Originated by Mr. Knight, who sent it, in 1832, to Mr. Lowell and the Mass. Agri. Soc. The Monarch, says Mr. Knight, " in my estimation, and that of a great many others, is without a rival as a dessert fruit, of a high musky favor. - The Monarch grows so fast, and bears so well, that I am planting it for perry, convinced it will make a very fine liquor. This, and the Althorpe Crassanne, will not be excelled by any other varieties in your climate. Both grow rapidly and bear abundantly." Until 1840, the true Monarch was not known, either to America or in the garden of the London Hort. Soc.; the first kind sent by $\mathrm{Mr}$, Knight being thorny, and wrong, as he himself confessed with profound regret. Early in 1841, I introduced the true Monarch for the first time.

\section{NE PLUS MEURIS. Thompson.}

A fruit of medium size; roundish; of a brown color, russeted; beurrée and excellent. November to March. One of the best of late pears. The fruit is not handsome, but very fine, and the tree is a very first-rate bearer.

180. NEWTOWN VIRGALIEU, M. [A.]

The tree grows very crooked, bending by the weight of 
its fruit. A large pear of a yellow color, with a very short stalk. A middling fruit only for the table, but an excellent baking pear. A most extraordinary bearer, and recommended for extensive cultivation.

\section{1. *PASSE COLMAR.}

Fondante de Panisel, of Van Mons, according to Pom.

Passe Colmar Epineuse, $\}$ Mag.

Beurré Colmar dit Precel. Hort. Soc. Cat.

Fondante de Mons. Thompson. D'Anaxas. Ib.

Colmar Hardenpont. $I b$. Marotte Sucre Jaune.

A most superior new pear, raised by Counsellor Hardenpont, at Mons. This variety was sent by Mr. Knight to the Holl. John Lowell, in 1823, and has been by him liberally disseminated. The fruit is middle-sized, conical, flattened at the crown; the stalk an inch long, moderately thick, slightly sunk; the skin at maturity yellowish, sprinkled with russet, stained with red next the sun; the flesh yellowish, melting, beurrée, juicy, very rich, and most excellent. With us it proves a most delicious variety, and very extraordinarily productive. John Prince, Esq., of Roxbury, exhibited, in 1830, a branch two feet in length, containing thirty-one pears, and weighing nine and a half pounds. It ripens in November, and may be preserved till February, and is recommended for extensive cultivation.

\section{PENGETHLY. Mr. Knight. [E.]}

"A large, dark brown pear, quite new, and now ripe." This pear was originated by Mr. Knight, and scions were sent by him in February, 1832, to Mr. Lowell and the Massachusetts Agricultural Society.

183. PETRÉ. [A.] Philad. Hort. Trans. Col. Carr.

This native fruit is "large, fair, melting, and of delicious flavor. It ripens in September, and keeps till late in winter." "The tree was planted by the elder Joln Bartram, in 1735, and has been in full bearing seventy years, and has probably yielded four hundred bushels of fruit, which has frequently sold for $\$ 5$ a bushel."

\section{POIRE DE BOULOGNE.}

[J.]

New, large, and valuable; flesh breaking; a winter fruit.

185. PRESENT DE MALINES. Braddick. Loudon.

Rather large; somewhat Bon Chrétien shaped, smooth, and of a beautiful yellow throughout; a melting pear, of a rich and musky flavor, and excellent quality. The tree 
is healthy, of vigorous growth, falls early into fruit, and promises to bear. abundantly, and is a good fruit for keeping. Raised by the Count de Coloma, of Malines.

186. ROUSELENCH. Thompson. [E.]

Large, oblong, swollen in the middle or truncated ; of a pale green color; beurrée and excellent. January and February. The tree is very extraordinary for productiveness.' Raised by Mr. Knight, and sent by him, in 1823, to the Hon. John. Lowell.

\section{SAGERET. Bon Jard. [J.]}

The tree grows pyramidal, and is of a fine vigorous growth; the fruit of medium size; turbinate; green, punctured with brown; flesh melting, 'flavor' pleasant, sugary, little perfumed. It keeps till spring. M. Vilmorin pronounces it very fine. There are two pears of this name; this, being raised by Van Mons, is fine. That raised by Mr. Sageret, of France, is inferior.

\section{SOUVERAIN D'HIVER. [J.]}

New and excellent; of medium size; a very superior melting winter fruit.

\section{9. "VAN MONS LEON LE CLERC.}

A splendid new fruit, raised by $\mathbf{M}$. Leon le Clerc, of Laval, and so named in honor of Dr. Van Mons. This fruit is not to be confounded with another fruit, raised by Dr. Van Mons himself, and called Leon le Clerc, which is not at all to be compared to this. Mr. Langelier, of the Isle of Jersey, exhibited this fruit to the London Horticultural Society; and Mr.-Thompson, and other first-rate judges, believe it to be the best pear in the world. It is thus described by him: "Form oblong, four inches in length, and nearly three inches in breadth; the eye is shallow, small, but open; the stalk rather more than an inch in length, moderately strong, and obliquely inserted; the skin yellowish, every where profusely covered with brown, a little russeted near the stalk; the flesh is yellowish white, buttery, and melting, with a very rich, sugary flavor. It proves a pear of first-rate excellence, combining the properties of large size, handsome appearance, and rich flavor." This Fruit ripens from October to winter.

190. VICOMP'TE DE SPOELBERCH. Van Mons. Extract from an article written by Dr. Van Mons in the Revue des Revues, inserted by the Hon. H A. S. Dear- 
born: The size varies according to the quantity produced. Its form is nearly spherical, swollen, and flattened near the eye, contracted towards the stalk. The skin is thick and rough, of a brownish red next the sun, with purple spots; on the opposite side deep green. The flesh is buttery, saccharine, full of agreeable and sprightly juice, and very high-flavored. This excellent pear is decidedly a winter fruit, and sometimes keeps till spring. It was raised by Dr. Van Mons,

\section{WILHELMINA. [D.] Bon Jard.}

A new fruit, of great excellence; large, and melting; ripening in September. Thus is this fruit described by M. M. Jamin and Dalbret; but the Bon Jardinier describes it as follows: In form of the Doyenne, punctured with gray in the shade, laved with red next the sun; flesh yellowish white, beurrée; juice abundant, sugary, perfumed. February. March.

192. *WINTER CRASSANNE. Mr. Thompson. [E.] A new pear, raised by $\mathbf{M r}$. Knight, and sent by him, in 1832, to the Hon. John Lowell and the Massachusetts Agricultural Society. Very large; turbinate; of a greenish yellow and brown color; beurrée and excellent. January. It is thought by Mr. Rivers, and some others, to be one of the hardiest and most productive pears known. In 1840, a tree of this kind was witnessed, at the garden of the London Horticultural Society, which bore prodigious crops.

193. *WINTER NELIS. Pom. Mag.

La Bonne Malinoise. Mr. Knight. Pom. Mag. Hort. Trans. Nelis d'Hiver. Bonne de Malines. Hort. Trans.

A new variety, raised by M. Nelis, of Malines. Sent by Mr. Knight, in 1823, to the Hon. John Lowell. Represented as a most excellent winter pear. Rather above the middle size; obovate; obtuse at the stalk, which is thick, and over an inch long; the skin yellowish, sometimes covered with russet brown; the flesh yellowish, melting, buttery, juicy, very rich, and high-flavored. Equal to the Chaumontelle. One of the most delicious of all winter pears. None, it is believed, can say, that this variety is very productive. 


\section{Clas HII.}

The following new and celebrated varieties of pears are mostly in our country, and of very recent and foreign origin; a small part only are American. The excellency. and productiveness of a considerable proportion of them are undoubted, and some few are already well known; all are eminently deserving of trial.

\section{ABBREVIATIONS.}

A. $H$. is Annales d'Horticulture. H. T. is London Horticultural. Transactions. Loud. is Mr. Loudon. Lind. is Lindley. Par. is Chevalier Parmentier. Poit. is Mons. Poiteau, in Le Bon Jardinier V. M. is Van Mons. D. is Mons. Dalbret, and J. is Mons. Jamin; and the star which is prefixed to these initials denotes that the fruits thus described by them are excellent. The numeral figures annexed denote the proportion in which those fruits are recommended for cultivation by them; and this is in proportion to their excellency and productiveness, and also to the season of their maturity; a greater proportion being recommended in the winter varieties, on account of their long keeping, and the proportion of them being fewer in number.

\section{SUMMER FRUIT.}

Colmar d'Été. A. H. Good; a great bearer. Aug. De Candolte. Thom. Med. size; juicy and good. Aug. Drapiez d'Éré. Highly spoken of.

Innominée. V. M. Very large; good. Sept.

Lammas. Lind. Small; pyramidal; striped; beurrée; excellent. July.

Mabille. J. 2. Large; beurrée; good. Aug.

\section{AUTUMN FRUIT.}

Ambrosia. Thom. Medium size; roundish; beurrée; delicious. Sept.

Aston Town. Small; beurrée; good bearer. Oct. Autumn Superb. Manning. Large; beurrée; beautiful; not first-rate; good. Aug. 
Berganotte de Partenay. *J. 4 . Medium size; beurrée; excellent. Aug.

Bergamotte des Paysans. Par. Medium size; beurrée; excellent. Sept.

Beurré Coloma. Par. Large size; beurrée; sugary ; good. Aug.

Beurré Duquesne. Thom. Medium size; pyramidal juicy; good. Oct.

Beurré Mortefontaine. *D. 4. *J. 4. Originated by B. Lefebvre, 1832; medium size; beurrée. Oct.

Beurré Pater Nostre. * D. 5. *J. 3. Medium size; beurrée; fine. Nov.

Beurré St. Quentin. A. H. Originated by Noisette; medium size; demi-beurrée; great bearer.

Bon Chrétien de Bruxelles. *D. 3. *J. 5. Large; half-melting; good. Sept.

Bon Chrétien Napoleon. *J. 6. Large; beurrée; excellent. Nov.

Calebasse Fondante. Bosc. Long; red; beurrée; sugary; good. Oct.

Comte de Michaux. Mr. Ives. Large; beurrée. It resembles Napoleon. Aug.

Cróss Pear. Magazine of Horticulture. New ; originated at Newburyport; medium size; roundish; deep yellow and red; beurrée; perfumed; excellent ; productive. October to December.

Dearborn. $\boldsymbol{V}$. $\boldsymbol{M}$. Originated by Van Mons.

Doyenné Boussock Nouvelle. *J.5. Large ; beurrée, and fine. Oct.

Doyenné Panacué. H. T. Doyenné formed; striped with red; beurrée; good. Aug.

Double d'Automne. Lind. Medium size; round. Baking; good. Oct.

Duchesse de Berri, or Capucine. Margat. *J. 4. Large; beurrée; excellent. Sept.

Excellentissimi. J.4. Medium size; beurrée; excellent. Aug.

Green Pear of Yair. * Lind. Medium size; pale green; good. Aug.

Grosse Angleterre de Nonsette. Poit. Originated by Noisette; good. Late. 
Grumkower Winterbirne. Lind. Medium size; pale green, Nov.

Hampden Bergasot. Fingal, or Ellanrioch, erroneously. Thompson. Large and fine.

- Jeschil Armudi. Thom. Turkish; very productive; sweet.

la Colosia. Bosc. Medium size; beurrée; perfumed; good.. Nov.

La Vanstalle. Bosc. Med. size;-pyramidal; deep red. Oct.

L'Incommunicable. Lind. Medium size; pyramidal; beurrée; musky. Oct.

Melon de Knopps. * $J$. 5. Large; beurré; excellent. Nov.

Muscardine. Manning Large; oblong; pyramidal; good. Sept.

Noir Grain. Poit. Medium size ; very productive; esteemed. Sept.

Poire de Louvaine. "D. 4. *J. 4. Medium; beurrée; excellent. Aug.

Polre des Trois Jours. *J. 6. Large; beurrée; firstrate. Nov.

Prince Esterhazy. Margat. Good; allied to Crassanne. Ramilures. Large; oblong; pyramidal ; beautiful ; crimson; brk.

Reine Caroline.

Rostieza. Manning. Small; excellent. Sept.

Shakspeare. *J.6. Small; beurrée; excellent. End of Aug.

Sievlle. Poit. Vilmorin. Has been overrated Oct. Nov. Striped St. Germain. Large; a fine fruit.

\section{WINTER FRUIT.}

Belle de Thouars, or Poire St. Marc. J. 4 . Large; pyramidal; breaking. End of winter.

Beurré de Bolwiller. Thom. Medium size; beurrée; good. Dec. Jan.

Beurré de Flanders. *J. 6. Large; beurrée; excellent. Winter. 
Chaptal. N. D. Large; breaking; perfumed. May. Colmar Sabine. V. M. Bosc. Med. size; beurrée; sugary. April.

Duchesse de Mars. Par. Large; beurré; good. March.

Grande Bretagne Dore d'Hiver. Thom. Medium size; beurrée; excellent. Oct. Dec.

Mrssile d'Hiver. * D.5. * J. Large; beurrée; valuable.

Nov. Dec.

Prince du Printemps. Br. Loud. Small; beurrée; sugary; excellent. March.

Ror de Rome. V. M. Par. Medium size; beurrée: good. Dec. Jan.

Surpasse St. Germain. $\boldsymbol{B} r$. V. M. Medium size; beurrée; good. Winter.

The following new varieties are of unquestionable excellence; scions of which were received during the winter of 1840-1, from Mr. Emilien de Wael, secretary of the Horticultural Society of Antwerp, in Belgium; all of which have been proved by him. These were sent to me, as the selections from his own private and immense collection, from all sources, of over 8000 varieties of fruits.

D'Amande.

Arbre Courbe.

Beurré de Kent.

Beurré Tacon.

Charlotte de Brouner.

Dingler.

Doyenné Caroline.

Doyenné Soulange.

Fausse Spreuvo.

Fondante de Cherneuse.

Fondante Grise.

General Obdam.
Grand Solcil.

Hernandes.

Immense Bis d' Été.

Jaminette d' Hiver.

Las Canas.

Leon Le Clerc.

Louise Morrel.

Marquis de Bedmar. Meuris d' Hiver.

Princesse d'Orange. Rousselette d' Espercw.

Scigneur Tacheté.

For more particular notices of some of these, and of other fruits, \&c., see the Supplement. 


\section{CULTIVATION:}

The pear tree is raised from seed or from suckers The seeds should be sown in the same-manner as directed for apples; and as they incline to grow with a tap root, some recommend that they should be transplanted into beds when but two inches in height, to force them to throw out lateral roots: others defer this operation until they are a year old, when they are taken up, deprived of their tap roots, and transplanted into beds, where they are suffered to remain a year or two; after which they are again transplanted to the nursery rows, and their management afterwards is not unlike that of apples.

The pear tree, in the climate of New England, is not so easily nurtured from the seed as the apple; their long tap roots expose them to be thrown out of the earth by the frosts of winter. But afterwards they resist the most severe cold.

Grafting and Inoculating. - The most durable stocks for grafting and inoculating are the pear. "Dubreuil," says Loudon, " recommends the quince stock. for clayey and light soils, and the free stock pear for chalky and siliceous soils." He further informs us that "grafted on the white thorn, (which, like the quince, renders them dwarfish,) pears come very early into bearing, continue prolific, and in respect to soil, will thrive well on a strong clay; which is unsuitable to those on quinces and wildings. But they are supposed to have an unfavorable influence on the fruit, in rendering it small and hard." By grafting or inoculating on the quince, pear trees come much sooner into bearing, their productiveness is increased, the good quality of the fruit is not changed, but the size and longevity of the tree are diminished. Such pear trees are termed dwarfs. This mode is extensively adopted in France; but all kinds of pears will not grow on the quince stock. Those dwarfs trained in the form of a distaff, are called in that country Quenouilles; for the mode of training which, and also for a new mode of dwarfing thi pear, see the former part of this work.

The pear tree is of an extreme hardihood, exceeding tliat of the quince, and is never annoyed by the borer. 
The quince, when exposed, is liable to danger from the borer in the same degree as the apple tree. Their attacks always commence in the parts exposed above ground, or at the surface of the earth, and never beneath. In transplanting the pears, therefore, the quince stock must always be completely buried, more than an inch beneath the soil. Thus situated and protected, the quince stock, from its nature, will strike root suddenly, new and numerous roots being produced on all sides, quite to the junction of the pear. Such is the mode adopted in practice by S. G. Perkins, Esq., and by other experienced cultivators, for the complete protection of the quince stock from all dangers of every kind.

Soll and Distance. The pear flourishes in rich soils and gentle declivities; they will succeed in the most common, deep, dry soil, and throw out numerous lateral shoots. But they do not flourish in moist situations; in a cold, strong, moist soil, with a clayey subsoil, they throw out very few lateral roots, the fruit is not so fair, nor of so good a quality, and the trees are not so long-lived. They will even grow in poor soils, and in the clefts of rocks.

With respect to distance, the same observations to be found under the head of Apple, may here apply. But the pear, from its pyramidal form, requires much less space. Twenty feet, in suitable soils, is a good distance; but less answers in poorer soils. But Quenouilles are found to answer even at four or five feet distance, producing large crops; and as they occupy but little space, and come suddenly into bearing, they are, for profit, extensively cultivated in France. The specimen pear trees which $I$ saw at the Jardin du Roi, or Garden of Plants, at Paris, in the autumn of 1840 , were under the particular care and management of Mons. Dalbret, the pupil of Thouin, and himself the author of a most valuable work on pruning. These trees were kept in the most perfect Quenouille or pyramidal form, from the summit quite down to the ground, by the systen of short or spur pruning; and although at the distance of but about seven feet asunder, yet they appeared to have ample space, and bore most abundant crops. But M. Dalbret then stated that ten feet was the most suitable distance. In our own climate, and with more heat and sunshine, and finer skies, less distance might suffice. Pears produced on quince stocks are found to be much 
improved in flavor; all but some particular winter kinds, which are said in some cases to become worse.

The young, luxuriant shoots of the pear tree, by being bent downwards, generally produced the finest possible bearing wood for the second year; and by grafting on the quince, and bending the branches, fruit may be produced from a seedling pear in the third or fourth year from the seed, which, in the common course, would require from seven to fourteen years. That system of rendering trees productive I have fully described in the former part of this work, at page 44. I am inclined to believe it to be the best system of all others.

- As to standards, (pyramids,) very little other pruning is necessary, except taking out those few limbs that interfere in keeping the tree well balanced.

The diseases and enemies of the pear tree are few:They are as follows:-

1st. The Slug-Worm. I have given directions for the destruction of this insect under the general head of Insects.

2d. The worm which in summer envelops the leaves and branches with its silken covering, devouring the leaf to a skeleton. These are to be-removed, together with the leaves on which they are found feeding, and destroyed.

3d. Curculio. An account of this insect is to be found under the general head of Insects.

4th. The insect called the White Mealy Insect. See also Insects, under the general head.

$=5$ th. Blight, or, as it is sometimes called, fire-blight, is a malady not very common, which sometimes affects the pear tree during the months of June and July, causing the tree, or a portion of its branches, suddenly to turn black, with a mortal affection; its leaves wither at once, as by a stroke of the sun, and in a few hours become of a brown or black color. Mr. Lowell is persuaded that this disease is caused by an insect, called the Scolytus pyri. He observes, "On the first appearance of this disease, I instantly sawed off all the limbs affected, and proceeded to examine them. I found at last the enemy, not at the point where death ensued, but some inches below it. The insect was very small, and apparently incapable of such extensive mischief; but the effect was certain, and the manner of producing that effect was obvious. It had eaten a complete circle of the alburnum, or sap-wood, not exceeding the size of a knit 15 * 
ting needle, so as completely to intercept the passage of the sap.'" This insect was shown by Mr. Lowell to the late Professor Peck, and in the account of the insect which was soon after published in the Massachusetts Agricultural Repository, the professor observed, that the mischievous effects of this insect may be observed in June and July, and that the dead part of the branches should be cut off without delay, and burnt. Mr. Lowell has stated, [New England Farmer, Vol. v. p. 2,] that by steadily pursuing the system of cutting off the limbs many inches below the apparent injury, and burning them, the insects have been extirpated from his estate.

The account of Professor Peck was republished in the New England Farmer, Vol. 1r. p. 42. Some-writers have attributed this disease to a stroke of the sun; others attribute it to manuring too high; some to excessive moisture at the roots, and too much pruning, which is supposed to cause a surfeit and produce a stagnation. But all agree that the only remedy is to saw off the limb.

\section{Q U I N C E.-(Cydonia.)}

The quince tree is a spreading tree of low growth, its limbs generally distorted; the leaves are roundish or ovate, entire, their petioles short; the flowers are large, pale red or white; the fruit a pome, roundish oblong or ovate; the skin is downy, of a green, yellow, or orange color; the pulp firm, of a harsh, astringent, and aromatic flavor. It is said to be a native of Austria, of Candia, and other parts of Europe. According to Goropinus, "quinces were the Golden apples of the Hesperides, and not oranges, as some commentators pretend." - Phillips.

\section{UsEs.}

The quince is not eaten in a raw state, but is highly esteemed in cookery; preserved in sugar, they are delicious; but previous to being thus preserved, they should be immersed for ten minutes in boiling water; this prevents them 
from becoming hard. Mixed with apples in pies, they communicate a fine flavor. They are also made into marmalade by the confectioners.

"One quart of the juice of-quinces, mixed with one pound of sugar and fermented, affords a delicious wine; on adding to the same quantity one pint of the best French brandy, and four ounces of sugar, a celebrated-liqueur is prepared on the continent, which is greatly prized-as a cordial and stomachic, when taken in the small quantity of two or three spoonfuls before breakfast." - Dom. Ency.

Phillips relates the case of a gentleman completely cured of an asthmatic complaint of long standing, by the use of Quince Wine, made after the following receipt: "The quinces are cut open and deprived of their seeds, for these communicate an unpleasant flavor. After being ground fine, a gallon of water is to be added to every gallon of pomace; - after standing a day or two, it is pressed ; and to every gallon of liquor thus produced, three and a quarter pounds of good, moist sugar are added. The liquor is placed in casks, which are to be stopped quite close till March, when it is racked off, and bottled in the second year."

\section{VARIETIES.}

Orange Quince. Maliforma or Apple Quince is a large, roundish, beautiful fruit, ripening in November. The leaves are oval and woolly the lower side.

Oblong or Pear Quince. Oblonga. This fruit is pear-shaped, lengthened at the base; leaves oblong, ovate.

Portugal Quince. Lusitanica. This fruit is of a variable form, sometimes pear-shaped; very juicy and astringent; it is highly esteemed. It is reputed to be rather a shy bearer. - Leaves obovate, woolly above.

To this list may be, added the Winter Quince, and the French Musk Quince, and the following:

JaPan Quince. Cydonia Japonica, or Japan Pear. Pyrus Japonica. A shrub growing six or eight feet in height; branches contorted and thorny; leaves small, oval, oblong, of a dark shining green ; its flowers splendid, of a fine scarlet, an inch and a half in diameter, and produced in clusters early in April. A native of Northern Asia, and one of the most ornamental plants of the season, and very 
hardy. The fruit is of good size, but is not. thought equal to the other varieties. There is a variety with white double flowers, and another with double red flowers.

Chinese Quince. Cognassier de la China. N. Duh. Pl. 155. A new ornamental variety, unlike all others. This fruit is as singular as superb; blossoms fifteen to eighteen lines in diameter; of a fine rose color ; their odor that of violets; leaves obovate, stiff, pointed, finely serrated, shining green above, becoming reddish in autumn, downy beneath; the fruit is oblong, truncated, regular; the skin smooth, yellowish green; the flesh is yellowish, dry, coarse-grained, harsh, austere; its juice acid, and not abundant. This fruit seldom arrives at maturity in the climate of Paris. But hopes are entertained that by planting the seeds, new and fine varieties will be produced, which will ripen in due season.

\section{is \\ C ULT I V A T I O N.}

The quince is raised from the seeds, from layers, and from cuttings, planted in a moist soil. The valuable varieties are propagated by grafting or inoculation. Quinces are extensively used in France as stocks on which are inoculated pears. This is said to improve the quality and productiveness of the Beurrée or Butter Pears, especially the summer and autumn kinds. But breaking or winter pears are seldom or but rarely inoculated on the quince stock, as they are not so much improved.

Soll, Situation, Pruning. Quinces require a rich, moist soil, and a sheltered situation. They flourish near brooks and rivulets. They require little pruning, except taking out old, useless wood and useless suckers; and eight or ten feet asunder is a good distance. Like the apple tree, they are liable to the attacks of the borer. The same remedies are equally effectual. 


\section{P E A C H.-(Amygdalus Persica.)}

The peach tree is a tree below the middle size, with spreading branches, of rapid growth; the leaves smooth, lanceolate, serrated; the flowers are sessile, their calyces reddish, corollas pale or dark red; the fruit a drupe of a roundish form, sometimes pointed, with a longitudinal suture or groove; the skin is downy in the peach, but smooth in the nectarine, its color varying from white or yellow to red and violet; the pulp thick, fleshy, or succulent, white or yellowish, sometimes red; juice sweet, or subacid, and abundant, of a grateful and delicious flavor; stone hard, ovate, pointed; compressed, irregularly furrowed ; the kernel bitter. The tree blossoms in April ; the fruit ripens from July to late. in autumn. The tree is not of long duration. Persia is considered the original country of the peach, although it is said to have been cultivated from time immemorial in most parts of Asia. Sickler asserts, according to Loudon, that " in Media, it is deemed unwholesome; but when planted in Egypt, it becomes pulpy, delicious, and salubrious." The peach, according to Columella, when brought from Persia into the Roman empire, possessed deleterious qualities; which Mr. Knight concluded to have arisen from those peaches being only swollen almonds, (tuberes, ) or imperfect peaches; and which are known to abound in the prossic acid. The best peaches in Europe are at present grown in Italy on standards.

The best peaches of France, according to Phillips, are those produced at Montreuil, a village near Paris, where the whole population are exclusively employed in their cultivation, and by this have been maintained for several ages. They are cultivated here- on lime-whited walls of great extent. Their climate requires it.

In the United States, they flourish as in their native land, producing fruit of an excellent quality, wherever the maize or Indian corn will ripen to maturity. In New Jersey, there are those who cultivate this fruit exclusively; and at Shrewsbury, on a single plantation, 10,000 bushels are annually produced for the New York market. Another, 
on the Delaware, yields $\mathbf{2 0 , 0 0 0}$ bushels. It is also extensively cultivated in the Middle, Southern, and Western States, for the purposes of distillation; on the refuse of the orchard or distillery, numerous swine are fattened.

UsEs. The peach is not only a first-rate dessert fruit, but it makes a delicious preserve. In cooking, the most delicious pies are made of them. For this purpose they require no preparation; they are used whole, simply placed in deep layers, sprinkled with sugar, and enveloped in the pastry; no further additions are necessary; the stone or kernel communicates its flavor, which is superior to that of the costly spices. - Peaches are preserved by drying, and in this state they may be long preserved; and thus prepared, they may be either eaten at the dessert like raisins, figs, and prunes, or used in cooking; and might form a valuable article for sea stores or for exportation. I will here describe three modes of drying; and will suggest, that in drying them in-doors, the furnace should be placed in the cellar, and the drying effected in the apartment above, by an ascending current of heated air.

In some of the Southern States, the drying process is facilitated by a previous scalding. This is effected by immersing baskets of the fruit a few minutes in kettles of boiling water. They are afterwards halved, the stone separated, and being laid with the skins downwards, the drying is effected in the sun in three days of good weather. They then may be stored in boxes.

In France, as we are informed, peaches and other fruits are thus dried whole. The peaches or other fruits, being pared, are boiled for a few minutes in a sirup consisting of one pound of sugar dissolved in three quarts of water, and after being drained by being laid singly on broad dishes, they are placed in the oven after the bread is taken out, and when sufficiently dry they are packed in boxes. The following is the mode of drying practised by Mr. Thomas Bellangee, of Egg Harbor, New Jersey. He has a small house provided with a stove, and drawers in the sides of the house lathed at their bottoms, with void intervals. The peaches should be ripe, and cut in two, not peeled, and laid in a single layer on the laths, with their skins downward, to save the juice. On shoving in the drawer, they are soon dried by the hot air produced by the stove. In this way great quantities may successively, 
in a single season, be prepared, with a very little expense in the preparation of the building, and in fuel,

Wine of superior flavor may be made from peaches. For this purpose the stones are separated, the pulp is finely bruised, and intimately incorporated with a proportion of water and brown sugar. After remaining in the vat from twelve to twenty-four hours, and being occasionally stirred, the liquor is separated by straining and by pressure, and barrelled. Mr. Gourgas, however, has recommended to incorporate the pulp and water by boiling. After strạining, add sugar, and after standing twelve hours, the clear liquor is poured from the sediment into the cask, which is now to be bunged down.

From the kernels, according to Bosc, an oil is drawn, possessing all the qualities of the oil of almonds.

The leaves steeped in brandy communicate their flavor, and the liquor thus prepared is used in every preparation in cookery instead of foreign spices. And according to Phillips, a liquor resembling the delicious Noyeau is prepared by steeping peach leaves in white brandy; this liquor is sweetened with sugar. candy and fined with milk, and is difficult to be distinguished from the genuine Noyeau of Martinico. The leaves, if I am not mistaken, contain prussic acid; but so does the bitter almond; and this last article forms the basis of the Noyeau, which is prepared in Boston. Creme de Noyeau may also be prepared by adding to a pound of peach kernels, coarsely bruised, a pound of bruised cherry stones, stones and all; three and a half or four gallons of the best brandy, two gallons of water, and five pounds of sugar. Add to each quart of liquor two grains of bruised pepper, and eight drachms of bruised cinuamon. After the whole has stood three days, it is strained through flannel, and bottled for use. Olivier asserts, [according to Bosc, in Nouveau Cours Complet d'Agriculture,] that the inhabitants of Scio employ the leaves in dying silk of a deep green. They are also employed in medicine as a vermifuge, febrifuge, \&c. Collected in autumn, they are used in the preparation of leather; and from the wood of the peach tree.the color called rose pink is said to be produced.

A good peach possesses a thin skin, the flesh thick and firm, abounding in a sugary, vinous, and high-flavored juice; the stone small. 


\section{CLASSIFICATION.}

The systematic classification of peaches, first begun by Miller and Duhamel, and afterwards greatly improved by Mr. Robertson, [See Lond. Hort. Trans. Vol. In. p. 384,] was brought still nearer to perfection by the Count Lelieur, by the editors of the Bon Jardinier, and by Mr. Lindley. The systems of these last named differ not, however, from each other very essentially.

The peach and the nectarine, both considered by the French writers as one and the same fruit, yet form separate classes. They have been divided into four classes - 1st, the Pêches, Freestone peaches, or those whose flesh separates from the stone; - 2 d, the Pavies, Clingstone peaches, or those whose flesh adheres to the stone; - 3d, the Pêches lisse, Smooth peaches, or Freestone nectarines; - 4th, the Brugnons, or Clingstone nectarine. The flowers form three divisions, accordingly as they vary in size; they are also distinguished by their color ; and the leaves, from the difference in their formation, are divided into three classes. Thus by these various distinctions, together with the varying qualities of the fruit itself, and the variation in the growth of the tree, the accurate observer will be enabled with facility, if not with certainty, to identify and to describe any particular variety.

The form of the glands, and their position, are distinctly visible with the complete formation of the leaf; they retain their character permanently, till the leaf falls in autunin. The globose glands are to be found, on the footstalks one, two, or more, and one, two, or more on the points of the serratures. The reniform glands are also situated, some on the footstalks, but those on the leaves grow within the serratures; they connect together, seemingly, the upper and lower teeth of the serratures; the leaves of very vigorous branches have a greater number of glands than are produced on the leaves of the globose varieties. Sometimes, however, glands are only discernible on the leaves produced by branches of vigorous growth.

It has been stated, that the leaves, from the difference in their formation, are divided into three classes; and that the flowers also form three divisions, accordingly as they vary in size The following figures representing the dif- 
ferent forms of the leaf, are from the London Horticultural Transactions.

Cuass I. comprehends those whose leaves are deeply, and doubly serrated, having no glands. See Fig. 1.

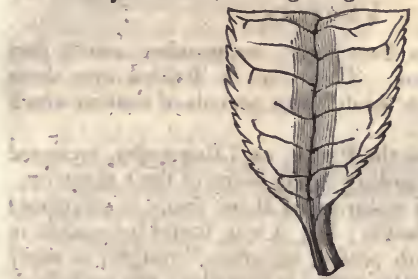

Fig. 1.

Class II. includes those whose leaves are crenate or serrulate, having globose glands. See. Fig. 2.

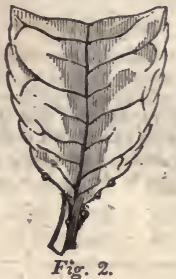

Cuss III. contains those whose leaves are crenate 0. serrulate, having reniform glands. See Fig. 3.

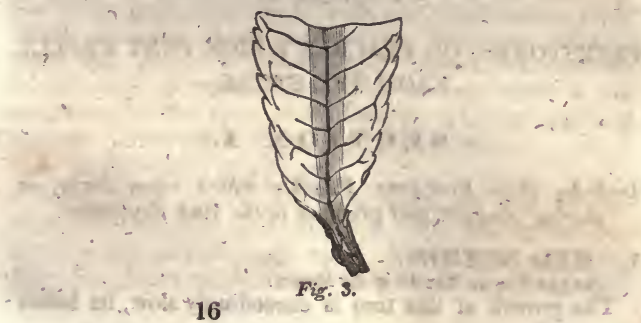


An accurate observer will distinguish other characters in the glands; they are either sessile or pedicellate; but these distinctions are too minute for application on the present occasion.

\section{ARIETIES.}

Class I. includes Freestones, or peaches which part freely from the stone. This class is divided into three sections, according to the different periods of time in which the fruit matures.

Class II. includes the Pavies, or Clingstones, arranged in some measure according to the order of their maturity.

The epoch of the maturity of these fruits is calculated for the climate of Boston; but it was found impossible to define this period with perfect accuracy, brought, as many of them have been, from different latitudes; the periods of their maturity will sometimes vary a little from what I have stated, in different seasons, and from various causes.

\section{ABBREVIATIONS.}

S. denotes those leaves which are serrated, and having no glands.

R. denotes these leaves whose glands are reniform.

G. denotes those leaves which have globose glands.

L., as applied to the flowers, denotes that they are large.

M. denotes that those flowers to which it is applied are of medium size.

$S$., as applied to flowers, denotes that they are small.

p. denotes that the flowers to which it is applied are of a pale color.

r. red.

d. dark.

\section{CHAS I.}

FREESTONES; OR PEACHES WHICH PART FREELY FROM THE STONE.

\section{SECTION I.}

Includes those Freestone Peaches which ripen early, or during August, and previous to the 10th September.

\section{RED NUTMEG.}

Avant Peche Rovge of the French.

The growth of this tree is exceedingly slow, its habits 
dwarfish. The fruit is bright scarlet next the sun; globilar, and very small; it is sweet, juicy, and good. Middle of July. Only valuable for its early maturity.

\section{2. *EARLY ANNE.}

Avant Peche Branche of the French. Anne.

The trees of this variety are of feeble growth; the young wood is subject to mildew; fruit small, white, globular; the flesh white, melting, saccharine, and good. The chief merit is its ripening early. August. [Flowers L.]

\section{EARLY ROSE.}

Of medium size; pale in the shade, red next the sun; of an agreeable flavor; and valuable for its early maturity. It ripens in August, and is of foreign origin.

\section{4. *BURGESS'S BEAUTY.}

Large, and very beautiful; very early, or earlier than the Early York; better, and far more productive. The tree bears uncommon crops, and the fruit is excellent. Such is the character of this fruit, which I received of Mr. Grant, of Middletown, New Jersey, where it ripens in August.

\section{BONAPARTE. Sinclair.}

Large, handsome, uncommonly fine, and very early; ripening in August, or soon after the Nutmeg; so named for Joseph Bonaparte, the Count Survilliers, who imported the fruit, the name being lost. Esteemed by Caleb $\mathbf{R}$. Smith, of Burlington, New Jersey, as the best market fruit known at that place. : This fruit I received of Robert Sinclair, of Baltimore.

\section{6. *TICE'S EARLY.}

Large, the largest and best of all the early peaches; yellow in the shade, deep red next the sun; flesh yellow, juicy, sweet, delicious; flavor unsurpassed. The tree generally bears well, but is not always sure. Such is the character of this fruit at Middletown, New Jersey, where it was originated by Mr. Tice. It will here ripen by the middle of August. This kind I received of Mr. Beers.

\section{7. *WALTER'S EARLY.}

Fruit large; color white in the shade, red next the sun; flesh red, very juicy, and delicious. The tree is very productive, but only on sandy soils. A new variety, received from Mr. Beers, of Middletown, New Jersey; where this 
fruit is esteemed as the very best and most productive of all the earliest peaches. It will ripen here at the 25 th of August.

8. *EARLY CRAWFORD.

Very large and handsome; oblong; pale yellow in the shade; deep red next the sun; flesh yellow, juicy, sweet; relieved by an acid, very rich and excellent; the tree a great bearer. A new variety, which was received from Mr. Beers. It was originated by William Crawford, Esq., of Middletown, New Jersey. It is there esteemed as the very best of all early peaches, the most productive ana profitable. It will here ripen the 25th of August. The tree bears sufficiently full to allow the fruit to grow large.

\section{9. 'COOLEDGE'S FAVORITE.}

Cooledge's Early Red Rareripe.

The tree is vigorous and most extraordinary productive. A large, very handsome, globular fruit; pale in the shade, but of a fine red or crimson next the sun; very melting, juicy, sweet, and of a vinous flavor. This fruit ripens very early, soon after the Early Anne, and is esteemed a first-rate fruit by the cultivators for the markets of Boston. It was originated by the late Mr. Joshua Cooledge, of Watertown, Massachusetts.

\section{0. *EARLY RED RARERIPE.}

The fruit is large; of a deep red color, which covers most of its surface; of a globular form; the flesh stained to the stone with red; melting, juicy, rich, slightly acid, vinous, and excellent. A very valuable early fruit, and deserves to be recommended.

\section{EARLY ROYAL GEORGE.}

A very large, handsome, and superior fruit, of a globular form; of a yellow color in the shade, but of a fine deep red next the sun; the flesh melting, juicy, saccharine, vinous, and most excellent. It ripens in August, and is one of the very best of all peaches, and a most productive kind.

\section{2. *EARLY ROBINSON CRUSOE.}

Large, round, and very handsome; pale in the shade; pale red next the sun; very juicy, sweet, and delicious. A very first-rate fruit, and add to this, the tree bears very extraordinary crops. It ripens the 10th of September. This superior new fruit, which I received of Colonel Carr, was raised by Dr. Coxe, of Philadelphia, from a stone brought 
by Lieutenant Coxe, of the navy, from the Island of Juan Fernandez, in the Pacific Ocean - the far-famed island of Alexander Selkirk, or of Robinson Crusoe.

\section{3. 'EARLY PURPLE. - N. Duk. Bon Jard.}

Pourprá Hative, la Viseuse, Peche du Vis, loid.

One of the most beautiful of peaches; encompassed by a middling suture; of a globular form, flattened at the base; its height twenty-six lines; flowers large, and brighter than those of the Grosse Mignonne; the fruit large, and of a deeper red; the flesh equally melting and fine, vinous and high-flavored. August.

\section{EMPEROR OF RUSSIA.}

\section{Serrated Leaf, or Unique.}

The tree grows' slowly, and is liable to mildew. The leaves are deeply and coarsely serrated, like the teeth of a saw ; the fruit is unequally divided by a deep suture; its flavor good. It ripens in August. [Flowers S.] This variety, according to Mr. Floy, was found wild in the woods of New Jersey.

\section{5. *YELLOW ALBERGE.}

Alberge Jaune, Peche Jaune, Rousanie.

Saint Laurent Jaune. Bon Jard.

Petite Roussane. Bon Jard.

Rosanina. Lindley. Alberge. Coxe.

A middle-sized, globular fruit, of a yellow color in the shade, deep red next the sun; a deep suture extends from summit to base; the flesh deep yellow, but red next the stone, melting, juicy, rich, sweet, vinous, and excellent. A superior fruit, ripening in August.

\section{DOUBLE MONTAGNE. Lind.}

\section{Sion. Forsyth: Early Dodble Mountarn.}

Montauban. Thompson.

Middle-sized, of roundish form ; color greenish white. in the shade, pale red, marbled with deep red next the sun; flesh white, melting, juicy, high-flavored; stone ovate, rugged. A beautiful and excellent fruit, ripening in August. [Leaves S: Flowers L.]

\section{7. *BELLEGARDE.}

Noire de Montrieur, Galande, Bon Jatd.

Violet Hative of some English authors,

Smooth-leaved Royal George of some.

The tree is vigorous and productive; the fruit is of medium size, much colored, and almost black; the flesh resembles the Belle de Vitry; it is firm, saccharine, vi16 * 
nous, and one of the best of peaches. It ripens in August. [Leaves G. Flowers p.]

18. *GROSSE GALLANDE.

Large and very handsome, of round form; white in the shade, red next the sun; flavor excellent. A very superior fruit, which some have confounded with the Bellegarde. It ripens early in September.

19. BUCKINGHAM MIGNONNE. Pom. Mag.

Barrington. Pom. Mag. Lond. Hort. Cat.

"Leaves crenated, with globose glands; flowers large; the fruit is large, roundish, somewhat elongated; pale yellowish green, but deep red and marbled next the sun; the flesh yellowish white, rayed with crimson next the stone; melting, juicy, and very rich. A productive and handsome variety."

20. *GROSSE MIGNONNE.

Mignone, Grosse Mignonie, Veloutée de Merlet, of the French.

Grimwood's New Royal George, Early Vineyard.

Royal Kengington. Pom. Mag. Lind.

Vineuse de Fromentin. Thompson. Trassparent. Ib.

Royal Souverain. Ib. Pourpre de Normandie. Ib.

Belle Beauté. Ib.

Smooth-leaved Royal George. $I b$.

Morris's RED RARERIPE.

This last synonyme $I$ have added on the authority of a gentleman near Boston, of great intelligence and experience. This peach, exhibited by Mr. Vose, has been adjudged as deserving the premium of the Massachusetts Horticultural Society, for one or two successive years, and is probably one of the most beautiful and delicious varieties in cultivation. The fruit is large, depressed, hollow at the summit; its suture moderately deep; the skin slightly downy; of a fine deep red next the sun, marbled on a yellow ground towards the shade; the flesh pale yellow, rayed with red next the stone, melting, juicy, of a rich, vinous flavor; the stone rugged, ovate. Last of August. [Leaves G. Flowers L. d. r.]

21. *GEORGE FOURTH.

The fruit is of medium size, downy; of a globular form, swollen on one side; pale yellow in the shade, dark red next the sun; the flesh pale yellow, but red next the stone; of a rich and excellent flavor. A most superior fruit, which originated, according to Mr. Floy, in the garden of Mr. 
Gill, Broad Street, New York. [Leaves large, G. Flowers red, S.]

22. *HOFFMAN'S FAVORITE.

A large, round fruit;" pale in the shade, red next the sun; the flesh juicy, sweet, vinous, and excellent. Early in September. A very beautiful fruit, of first-rate quality, and very remarkably productive.

\section{3. *JACQUES.}

Roundish oblong, of good size; of a yellowish color, but red next the sun; flesh yellow, melting, juicy, sweet, and excellent. The tree bears well. Early in September

\section{4. *MARIE ANTOINETTE. \\ RED Velvet.}

Large and beautiful; all covered with dark red, and resembling velvet; juicy, sweet, and excellent. Received from Mr. Lyman, of Manchester, near Hartford, Conn., where this fruit is esteemed even as superior to the George Fourth. The tree is very productive, ripéning 1st Sept.

\section{5. *MELLISH'S FAVORITE.}

NoBLESSE, according to some.

A very beautiful and excellent fruit, of good size and globular form; fine yellow in the shade, of a fine deep crimson or purple color next the sun ; juicy, rich, sweet ; of a superior flavor. It much resembles the Washington. The tree is a great bearer. A most capital variety for its fine qualities and great productiveness; very superior to the Noblesse, Early in September.

\section{6. *MONSTROUS FREESTONE.}

Very large and round, very beautiful; high colored, with red next the sun; rich, juicy, sweet; a fruit of extraordinary quality both for flavor, size, and beauty. Early in September. The tree is moderately productive.

\section{7. *MORRIS'S WHITE' RARERIPE.}

Morris's White Luscrons,

The fruit is large, round or oval; of a delicate white color; the flesh white, juicy; flavor sweet, rich, and excellent. Middle of September. [Leaves R. Flowers S. p.] 28. MOUNTAINEER. Thompson.

- Raised from the Red Nutmeg and Early Violet Nectarine The fruit is sometimes partly smooth; the size large; pale yellow in the shade, red next, the sun; of 
excellent flavor. It will ripen in August. [Leaves G. Flowers L.]

\section{9. *OLDMIXON FREESTONE.}

A large peach, of a yellowish white color, with a fine red blush next the sun; the form a little oblong; the flesh is sweet, rich, juicy, and excellent. It ripens the last of August. A beautiful and superior variety.

\section{0. *ORANGE PEACH. APRICOT PEACH of Duhamel.}

The fruit is large, of a globular form; of a fine yellow color; the flesh very sweet, juicy, rich, and excellent. It ripens about the middle of September.

\section{1. *PRESIDENT.}

A large, downy fruit, roundish, approaching to oblong; a shallow suture; pale yellowish green, but red next the sun; the flesh is whitish, juicy, melting, rich, and high-flavored; the stone is large, pointed, rugged. With us this fruit is very first-rate; and add to this the tree is a great bearer. September. [Leaves G.]

\section{2. *RED MAGDALEN.}

Magdeleine a Moyenne Fleurs. Bon Jard.

Magdeleine Rovge Tardive ou a Petite Fleurs. Ib.

Royal George of the English, according to the Pom. Mag.

Millet's Mignone, Lockyer's Mignonne. Il

New Royal Charlotte. Thompson.

That the Red Magdalen and Royal George are identical, has been renewedly asserted by a gentleman here of great observation and experience. I have ventured, therefore, to restore the original, and suppress the English name of Royal George, except as a synonyme. The young wood is liable to mildew. The fruit is large, globular, with a suture moderately deep on one side; dark purplish red next the sun, yellowish white in the shade, mottled with red at the junction of the colors; the flesh white, rayed with red next the stone; melting, juicy, and high-flavored. September. [Leaves S. Flowers S.]

\section{3. * SARGENT.}

So called from the name of the gentleman in Pearl Street, Boston, with whom this variety originated. The tree is of moderate growth, but wonderfully productive; the young wood extremely subject to mildew. A medium-sized, round fruit; of a yellow color in the shade, slightly red next the sun; the flesh is yellow, juicy, sweet, and very 
delicious. A handsome and fine variety. Early in Sep. tember.

34. *SNOW PEACH.

The tree is an abundant bearer. The fruit is of handsome size, round; the skin very thin, white, and delicate; the flesh very tender, juicy, sweet, and delicious. A beautiful and excellent fruit. It is sometimes called White Blossom, or Willow. The blossoms are very white, and the tree resembles a willow.

\section{5. *WASHINGTON RED FREESTONE.}

The tree is wonderfully productive; the fruit is of gaod size, round; of a fine yellow color in the shade, fine dark crimson next the sun; juicy, rich, of a sweet, vinous, and delicious flavor. A most beautiful and superior fruit. Early in September.

\section{6. *YELLOW RARERIPE.}

Large, globular-formed; yellow in the shade, dark purplish red next the sun ; very handsome; flesh șweet, juicy, uncommonly delicious $A$ very extraordinary fruit. "The tree bears prodigious crops. One of the best of all peaches. It ripens 10 th September. There are many varieties of this name, and but few or none equal.

\section{S E C T I O N I I.}

This Section includes those Freestone Peaches which ripen during Mid-Autumn, or from the tenth to the last of September.

\section{3\%. BRAINARD'S LARGE' YELLOW.}

Large; yellow in the shade, red next the sun; of excellent flavor; ripening in September. A fine new variety, which I received from Manchester, of Mr. Lyman, who esteems this one of the best of peaches.

\section{COLUMBIA.}

A large and very singular peach, with an extremely rough and thick skin, of a dull red color, marbled with blotches of a dark, dusky red; its form rather flattened, with a suture well defined; the flesh yellow, melting, juicy, 
rich, fibrous, and well-flavored. September. This peach is a curiosity. Mr. Coxe, who probably originated this variety, calls it a fruit of uncommon excellence.

\section{HOGG'S MALACATUNE.}

Large; yellow in the shade, fine red next the sun. The tree is very productive. This variety I received of Mr. Lyman, who esteems it the best of all the Malacatune family known to him. It ripens the 20th September. Raised by Mr. Thomas Hogg, of New York.

40. *LAFAYETTE FREE.

Size medium to large; round; pale in the shade, fine dark crimson next the sun; flesh very juicy and delicious, and deep stained with crimson throughout. $A$ beautiful variety. Last of August. This fine fruit was received of Mr. Joseph Beers. It much resembles the Brandy Peach.

\section{1. *MALTA.}

Peche Malte. Duh. Belle de Paris. Bon Jard.

Malte de Normandie. Hort Soc. Cat.

Italian Peach of Mil., according to the Pom. Mag.

The fruit is above the medium size; pale yellowish green, but next the sun somewhat marbled with purplish red; globular, a little flattened, encircled with a slightlydepressed suture; flesh yellowish, juicy, rich, vinous, and of superior flavor. An excellent and most productive variety, ripening in September. [Leaves S. Flowers L. p.] 42. *NIVETTE. $\boldsymbol{R}$. $M$.

Veloutée TARDive, Jard. Fruit, according to Bon Jard.

The fruit is large, á little oblong, downy, green in the shade, and deep red next the sun; the flesh firm, saccharine, and high-flavored. A most superior fruit, and highly deserving. September. [Leaves G. Flowers S.]

\section{RED MAGDALEN COURSON.}

Magdeleine de Courson, Magdeleine Rouge.

Paysane. Bon Jard. p. 295.

The tree is vigorous and productive. The leaves have deep serratures, and are without glands; flowers large and pale; the fruit is rather large, round; pale yellow in the shade, of a beautiful red next the sun; flesh firm and vinous. Beginning of September. [Leaves S. Flowers L. p.]

44. WHITE MALACATUNE. Coxe.

White RARERIPE. Coxe.

A large fruit of extraordinary excellence; of a pale yellowish white color; the flesh yellowish white, firm, melting, 
rich, and of excellent flavor ; the stone is not unfrequently cracked. Mr. Coxe states that it is the most admired fruit of the season, which is August, and that, if not too ripe, it makes a most delicious preserve.

\section{5. "YELLOW RED RARERIPE。}

The tree is of very rapid growth. The fruit is beautiful, of a large size, and globular form; of a fine yellow or.golden color in the shade, but dark purplish red next the sun; the flesh deep yellow, rich, sweet, juicy, and of a most delicious flavor. A very first-rate and extraordinary variety. The tree is a great bearer. Ripe middle of September.

\section{S E C T I O N I I I.}

This Section includes late Freestones, or those which ripen from the last of September to November.

46. *BELLE DE VITRY.

Admirable. Duh. Coxe. R. M.

A large fruit, of a fine red color next the sun, yellowish white in the shade; the form globular, divided by a suture; a broad, deep cavity at its base; the flesh is white, stained with red at the stone; melting, jnicy, sweet, vinous, and excellent. A superior fruit. September.

4\%. *BEERS'S LATE RED RARERIPE.

Very large, one of the largest of all peaches; oblong ; white in the shade, pale red next the sun; very juicy, and fine-flavored. The tree bears well.: This fine fruit I received of Mr. Joseph Beers, of Middletown, New Jersey. It was originated by him. At that place it ripens the 15 th of September, and will here ripen on the 25th.

48. *CRAWFORD'S LATE MALACATUNE.

Very large and handsome, round; fine yellow in the shade, dark red next the sun; flesh yellow, sweet, juicy, excellent. In appearance and flesh, it resembles Crawford's Early, or 'Tice's Early, and is the largest, finest, very best, and most productive of all peaches; and so esteemed at Middletown, New Jersey, from whence, and from Mr. Joseph Beers, I received this fruit. Ninety of these 
peaches have filled a basket which contains over three pecks. Originated by William Crawforl, Esq., of that place. It there ripens the 20th of September, and will ripen the last of September with us.

\section{9. *GOLDEN RARERIPE.}

Campen.

Large, round, very beautiful; fine yellow in the shade, orange or red next the sun; flesh juicy, sweet, and delicious. A fruit which I received from Mr. Joseph Beers, of Middletown, New Jersey. It much resembles Crawford's Late Malacatune, and ripens a week previous. The tree bears well, but is not so extraordinary for its productiveness, as is that excellent variety.

50. *HEATH.

KenRICK's Heath.

This noble variety was received from the late Gen. Heath, of Roxbury, of revolutionary memory; hence its name. The tree is very vigorous, and extraordinarily productive, and is probably a native. The fruit is very large, oblong, and beautiful; specimens have frequently been seen weighing half a pound; pale yellowish green in the shade, but beautiful deep crimson or violet next the sun; unequally divided by a slight suture, which terminates in a point; the flesh is melting, juicy, rich, vinous, agreeably acid, and good. A capital fruit. Middle of September.

\section{1. *LATE ROBINSON CRUSOE.}

Large, round; white in the shade, pale red next the sun; very juicy and delicious. The tree bears very extraordinary crops, ripening the 1st of October. This most excellent fruit I received of Colonel Carr. It was raised by Dr. Coxe, of Philadelphia, from stones brought by Lieutenant Coxe, of the United States navy, from the Island of Juan Fernandez, in the Pacific Ocean; hence its name.

\section{MORRISANIA POUND}

HoFrMaN's.

The fruit is very large, round; pale green in the shade, red next the sun; very juicy and delicious; ripening late, about the middle of October. Mr. Floy states that this variety was received of Gouverneur Morris, of Morrisania, near New York; but it was originated by Martin Hoffman, Esq. [Leaves G. Flowers S.] 


\section{3. "SMOCK FREE.}

Very large and first-rate; some have measured 12 inches in circumference; oblong; pale yellow in the shade, dark red next the sun; flesh juicy, fine, a little acid. One of the best of all very late peaches, and so esteemed at Middletown, New Jersey, from whence, and from Mr. Beers, I received the fruit. It there ripens from the last of September to the 15th of October. Generally this fruit will ripen well in our more northern climate; but in some years it may prore too late.

\section{CHINA FLAT. PEACH. Hort. Trans. Braddick.}

Java Píach.

A most singular and curious peach, which is said to be much cultivated and esteemed in China. The diameter from the eye to the stalk is less than three quarters of an inch, and consists wholly of the stone and a skin which covers it. The thickness of its sides is one inch and an eighth, while its transverse diameter is two inches and a halt: The skin is pale yellow; mottled with red next the sun, and covered with fine down; the flesh pale yellow, a beautiful radiated circle of fine red surrounding the stone, which is flatly compressed, small, rough, and irregular. The fruit is melting and good, being sweet and juicy, with a little Noyeau flavor and bitter aroma. In 1840, this curious variety was here received by a renewed importation from Europe, and a first-rate source. [Leaves $R$. Flowers L.]

\section{ISPAHAN. $N$. Duh: PJ. XXIV.}

Prcher d'Ispahan. Ib.

This singular tree was discovered in 1799 , by Brugnière and Olivier, at Ispahan, the capital of Persia, in the vast Royal Gardens, where weré concentrated most of the fruits of Asia. 'The branches are very slender and numerous, the leaves very narrow, finely serrated, of a delicate green color, and unlike those of any other variety known. The fruit is nearly spherical; the skin of a whitish green, slightly downy; flesh greenish white; melting, and separates from the stone; juice abundant and delicious.

\section{YELLOW ADMIRABLE; or APRICOT PEACH} Bon Jard. 1828, p. 293.

Abricoth́, Admirable Jaune, Peche d'Orange,

Grosse Jaune, Peche de Burat, Sandatie Hermaphrodite. The leaves have reniform glands; flowers large; the 
fruit is very large, yellow while immature, but at maturity a little laved with red next the sun; the flesh firm, yellow, with a little of the flavor of the apricot. Very late and fine.

\section{5\%. CARDINALE. N. Duh. Pl. ccxxxvir.}

Cardinale de Furstenberg. Thompson.

The fruit is medium-sized, flattened at its summit; swollen on one side of the suture; the skin dull gray violet, very downy and hoary; the flesh marbled with violet red, but slightly tinged with yellow next-the stone; not very juicy, and deficient in flavor, in the climate of Paris, where it ripens from the 10 th to the 20 th of October. In warmer climates it is good, and in Italy excellent. A variety of the Blood Peach, excellent for preserving. [Leaves S. Flowers 1. p.]

\section{DWARF ORLEANS.}

Pecher Nain. N. Duh. Pl. cccci.

A singular and most diminutive tree. Flowers pale, large, and from twelve to fifteen lines in diameter; the flesh juicy, and generally bitter. This very ordinary fruit does not ripen till late, the middle of October. It is only cultivated for curiosity; and often cultivated in a pot, and brought with its fruit to the table. [Leaves large, S.]

\section{9. *TETON DE VENUS. .}

\section{Royale.}

The tree is one of the most vigorous in its growth known, and very productive. The fruit is large, of a pale yellowish green in the shade, bright red, darkly marbled, next the sun; form globular, a little lengthened; it is encircled by a broad, deep suture, terminating in a large, obtuse point at its summit; the flesh melting, of a greenish yellow, but at the stone it is red; and of a sweet and excellent flavor. It ripens early in October. There are two or three varieties bearing this name. This is the variety described in the New Duhamel, and a most superior fruit. 


\section{Class II.}

CLINGSTONES OR PAVIES; OR THOSE PEACHES WHOSE FLESH ADHERES TO THE STONE.

This class of peaches is preferred to all others, by the inhabitants of warm climates.

\section{EARLY NEWINGTON. Coxe.}

A beautiful fruit, of medium size, and globular form; of a white color in the shade, but red next the sun; the flesh juicy, rich, and high-flavored; the stone is small.: Last of July. [Leaves R. Flowers L.]

\section{1. "CATHERINe. R. M. Esq. Pom. Mag.}

Oldmixon Chixgstone.

Fruit large, round, variable; color a beautiful red next the sun, marbled and dashed with darker shades; pale yellow in the shade; flesh very white, tinged with yellow, but firm, of a deep crimson next the stone ; juice abundant, and of a very rich and sweet flavor; stone middle-sized, roundish oval, very slightly pointed. It ripens with us in September. Mr. Manning has stated that neither this, the Old Newington; nor the Oldmixon Clingstone, can be distinguished from each other by their external appearance, and are all first-rate fruits. [Leaves R. Flowers S.] 62. *DIANA.

Very large, round; pale in the shade, fine red next the sun; rich, juicy, vinous, and excellent. The tree bears constantly and very abundantly. It ripens in September.

\section{3. *LAFAYETTE CLINGSTONE.}

$A$ very beautiful fruit, of a fine yellow color in the shade; bright red next the sun; juicy, and of excellent flavor. The tree is a most productive and excellent variety. August. Sometimes called Meiggs's Lafayette.

\section{4. "LEMON CLINGSTONE.}

Pine-Apple, or KenNedy's Lemor:

The fruit is rather large, oblong, and pointed ; of a deep yellow color in the shade, but of a dark fine red next the sun; the flesh is yellow, rich, vinous, a little acid; it is stained with red next the stone. September. [Leaves R. Flowers S.] 


\section{5. *LD NEWINGTON.}

This fruit is large and globular; pale yellow in the shade, but of a fine bright red next the sun, sometimes marbled with deeper red; the flesh is yellowish white, very juicy, rich, sweet, and well-flavored. An excellent fruit, ripening in September, and productive. [Leaves S. Flowers L.]

\section{RODMAN'S RED, C.}

Large, round, and very beautiful; pale in the shade, fine red next the sun; juicy, vinous, very delicious. The tree is a great and constant bearer. A very popular fruit at Philadelphia. September.

\section{7. *SPANISH. C.}

A large, round fruit, of a pale color in the shade, red next the sun, and very beautiful; very juicy, sweet, vinous, and excellent. The tree bears moderately. Early in October. 68. *WASHINGTON CLINGSTONE.

A large fruit; its color inclining to white, but next the sun a fine blush; of globular from; flesh melting, juicy, sweet, and excellent. A superior fruit, ripening in September. [Leaves R. Flowers S.]

69. PAVIE JAUNE. N. Duh. Pl. CCClxxxix.

Persica Newtonit. Ib.

Pavie Alberge, Perseque Jaune. Bon Jard.

Yellow Perseque.

The petioles have reniform glands; the fruit is very beautiful, very large, round, a little flattened at its summit, and marked with a groove; its diameter thirty-three lines; the skin is downy, yellow in the shade, of a very deep red next the sun; the flesh yellow, firm, not fibrous, and red or of a blood color next the stone; the juice abundant, sweet, and vinous. The stone is oval, obtuse, and of middling size. Ripe 12th September, at Paris. Excellent in warm summers. [Leaves R.]

\section{PAVIE ADMIRABLE. Bon Jard.}

IncomparaBLe of the English and Lindley.

The fruit is large, roundish, swollen on one side; skin pale yellow, but pale red shaded with light scarlet or deep crimson next the sun; the flesh pale yellow, but red at the stone; juice sugary, and well-flavored; stone roundish, and almost smooth. It ripens at the time of the Catherine. [Leaves R. Flowers S. P.] 


\section{GROSSE PERSEQUE. Bon Jard.p. 298.}

\section{Perseque Alloneŕ. Ib.}

The tree is productive in unsheltered situations; the fruit large and oblong, with swellings on its surface, of a red color next the sun. It requires a warm exposition, and will ripen with us late in September. [Leaves $\mathbf{R}$. Flowers S.]

72. PAVIE MAGDELEINE. Bon Jard. p. 294, 296. Pavie Bianc.

The tree is vigorous; the fruit is large and downy; white in the shade, and a beautiful red next the sun; the flesh white, fine, melting, and of an agreeable musky flavor. This fruit will ripen about the last of September.' [Leaves S. Flowers L. P.]

73. MONSTROUS POMPONNE. Bon Jard. p. 297. Pavie de Pomponne, Gros Melecoton, ?

Gros Perseque Rouge,

Pavié Monstreux, Pavie Cornu,

The fruit is the largest of all peaches, and often terminates in a point at its summit. It is downy ; of a waxen white color in the shade, of a very lively and deep red next the sun; the flesh is firm, and excellent cooked. It requires a warm exposition, and ripens, in favorable seasons, the end of October at Paris. This fruit will ripen earlier with us: [Leaves R. Flowers L.]

\section{BLOOD PEACH.}

Large, oblong; downy; of a very dark violet or crimson color; flesh dark crimson or blood red to the stone; flavor ordinary, but highly valuable and beautiful for preserving, and by many deemed even preferable to the quince. The tree is very productive.

\section{5. "HYSLOP'S CLINGSTONE.}

The trees of this variety are vigorous and productive. The fruit is large, rather oblong; of a white color in the shade, changing to fine deep red next the sun; the flesh melting, very juicy, sweet, -vinous, and excellent. This variety ripens in October, and may be preserved till late in November, and is the latest variety which will generally answer in Massachusetts.

\section{6. "WILLIAMSON'S. C.}

The tree is very extraordinary productive. The fruit is oblong, of good size, and terminated by a point; very white 
in the shade, but red next the sun; very juicy and fine-flavored. Middle of October.

\section{SMOCK CLINGSTONE.}

Very large, oblong; yellow in the shade, dark red next the suni f flesh juicy, rich, a little acid; one of the best of all the very late Clingstones, and so deemed at Middletown, New Jersey, from whence, and from Mr. Joseph Beers, I procured the fruit. Raised by Mr. Smock, of that place. In some unfavorable seasons, this excellent fruit may not fully mature in the latitude of Boston, except only in warm situations. New and very productive. 78. HEATH CLINGSTONE.

The fruit is very large, rather oblong, terminated by a point at its summit; of a cream color, with an occasional blush next the sun; the flesh is tender, melting, extremely. juicy, and rich. It ripens late, too late for the climate of New England, except in very favorable seasons. Mr. Coxe informs us that this fruit was raised from a stone brought from the Mediterranean, by Mr. Daniel Heath, and in his estimation is superior to all other peaches known; the stone generally opens, and the fruit, if not too ripe, is one of the most admired preserved in sugar; that it ripens in October, and keeps till December. [Leaves R. Flowers S.]

\section{CLASS III.}

\section{ORNAMENTAL VARIETIES OF THE PEACH.}

\section{DOUBLE FLOWERING PEACH.}

Peche a Fleurs Doubles. Bon Jard.

The leaves have reniform glands. The tree is cultivated for the beauty of its flowers, which are often semidouble and very large. Fruit good and pretty numerous. September.

80. CHINESE DOUBLE FLOWERING PEACH.

Amygdalis Sinensis Pleno.

A new and beautiful variety of Double Flowering Peach, lately received from England.

81. Amygdalus Macrocarpe.

82. Amygdalus Orientalis 


\section{Class IV.}

\section{ADDITIONAL LIST OF PEACHES.}

Some of the following peaches are new, They are mostly native fruits, a small partion of them only being of foreign origin. All of them are undoubtedly, good, and many of them are excellent. Part of them will prove very productive, and all that could possibly be desired in this respect; but doubts exist in relation to the productiveness of some portion of them.

Astor's Seedung. Large; round; yellow and red; de- licious. September.

Belle Chevereuse. Large; red; vinous; excellent. August.,

BennetT's RAReripe. Large; red and white; handsome; productive. Early.

*Bergen's Yellow. Yellow; fine. September. Extra Bourdine. Large; round; red; sweet; vinous.' Sept.

Brandy Peach. Beautiful; medium size; round; deep red; flesh crimson; good. August.

Brodie's C. Beautiful ; large; round; red; juicy; fine; moderately productive. Septémber.

Cunton. Fine and handsome. September.

Cox́ress C. Large; red; juicy ; fine; mod. bearer. Sept.

De Tonoensis. Large; fine; first quality; red and white; moderately productive. September.

Dix Peach. Large; productive; first-rate.

Double. Swalsir. Medium size; ovate; red; fineflavored ; tolerably productive.

Eagle's Red. Beautiful; large; red; fine. 'Sept.'-

Eartix Mignonne. A small variety of the Grosse Mignonne. August.

Eart.y Yoris. Large; excellent; mod. bearer. Auguist. English Chancellor. Large; oblong; red; rich; vinous.

Gilman's Early. Ripe soon after Nutmeg; new; productive; good. August. 
Golden Purple C. Medium size; beautiful; round; yellow, dark crimson; sweet; very productive. August. Jose SweEt. A fine fruit.

Lady Anve Steward. Handsome and fine.

Late Chevereuse. Oblong; medium size; red; good. September.

Late Purple. Medium size; round; deep red; excellent. September.

Magdeleine de Bolwhler. Medium size; red; excellent. August.

Mаммоті C Large; red; juicy; fine. Séptember.

Mifflin's Pennsyluania. Large; fine; from Penn.

Mignonne Frizé. A variety of the Grosse Mignonne; singular. August.

Moore's Rareripe. Large ; round ; excellent; productive. September.

Murray's Malacatune. Large and fine.

Petite Mignonne. Small; round; yellow and red; productive; excellent. Ist of August.

Pinckney's C. Very large; red; excellent; late. Oct. Poole's Late Free. Large and excellent; late; from Philadelphia. October.

Prince's Red Rareripe. Beautiful; round; red; firstrate; moderately productive. September.

Prince's Paragon. Large; beautiful; new. September. St. Michael. New; from France.

Spring Grove. Medium size; round; red; fine; very early. August.

Strawberry. Beautiful; deep red; medium size; flesh crimson; good. August.

Sweetwater. Medium size; white; good. August. Trotu's Early. New; very early and fine; a Jersey fruit. August.

Van Zands. Large; red and white; excellent; moderately productive. September.

Vineuse de Fromentrin. Large; oblong; red and white; excellent; moderately productive. 1st of Sept. 
W ARD's LATE FreE. Large and fine; highly esteemed in Pennsylvania. October.

WeLd's Free: Large; round; excellent. September. White Magdalen. Large; white and red; musky; good. August.

\section{CULTIVATION:}

The peach tree is usually raised by planting the stones in autumn. Some, however, preserve them in soil exposed to the frosts of winter. In spring they are cracked, and either sown in beds or planted in the nursery, in rows four feet asunder, and about a foot distant in the row. In the same year or the year following, they are inoculated. The peach tree is usually inoculated on the peach stock. They are, however, sometimes propagated on the almond; sometimes on the plum stock. Mozard, according to Loudon, "prefers plum stocks, where the soil is strong and black;" and Dubreuil recommends a plum stock for a clayey soil, and the almond stock for such as are light and sandy. The same opinion is held by the Montreuil cultivators: At Montreuil, we understand, the plum stock is not used, because the soil is dry. Use only the peach stock or almond on such soils.

Peaches thrive best near the banks of rivers, and especially those of brackish water. The curculiones are stated to avoid a moist atmosphere and salt air on the borders of rivers or the sea.

Soll, Distance. The most suitable soil for the peach tree is a rich, sandy loam; a light soil answers well. The soil of Montreuil, as above stated, is dry. The peach tree will not flourish on a cold, stiff, wet soil. On such a soil they may grow vigorously, but they produce but little fruit, and that of ordinary quality. Some àssert that they are more uniformly productive on the north side of hills, as it prevents their too early advancement before the vernal frosts are past. Ten or twelve feet asunder is deemed a good distance for the peach tree, in the colder latitudes; but in warmer climes, a greater distance is required. 
Maladies. The maladies to which the peach tree is subject are,

1st. The Curculio. For the remedies for this, see $\mathrm{IN}_{\mathrm{N}}$ sEcTs, in the former part of this work.

2d. The worm which feeds on the sap-wood beneath the bark; principally near the surface of the earth.

The worm is produced by a fly which, from the middle of June to the first of August, deposits its eggs on the bark of the tree, generally at its root, where the bark is tender. These are soon hatched, and the worm shortly penetrates beneath the bark, where it commences its work of destruction, devouring the sap-wood often around the whole circumference of the tree, causing the gum to exude, and often death.

Much has been written and said of this insect; yet the prevention is very easy, provided there is a necessity for it, which is not the case in all soils and situations. It seems with us only an occasional evil, and the remedies are seldom required. Whenever serious suspicions arise, let every tree be carefully searched at the surface of the earth, and the worm destroyed by probing with a penknife or pointed wire. About the beginning of June, form around the trunk of the tree a small conical mound, to the height of eight inches or a foot above the natural surface of the earth. Unleached ashes, which might be preserved for this purpose, are, without doubt, the best and most useful substance, and each tree will require about a peck. Charcoal, broken small, has been recommended; also cinders from the blacksmith's forge, to be placed around the trunk for protection. But any thing else, even a small, conical mound of soil, is found to answer. The design of this is, to protect that portion of the tree where the bark is most tender. Let this mound be levelled in October, and the bark will harden again beneath where it was placed. I am inclined to believe the potash wash, before described, would answer every purpose, as it does with the apple tree, if applied at the suitable time, also the wash recommended by Mr. Lindley. I have already stated, in Section XII. of the former part of this work, that in those soils thus infested, refuse tobacco has been applied around the trunk of the tree and at its foot, the effluvium of which has been found effectual in preventing the attacks of the grub. Poudrette has also been applied around the trunk, the am- 
monia or odor of which has proved an effectual protection. Also coal tar. A gentleman of Nantucket has tried it on the plank of his ships which sail to the Pacific, to preserve thein from the attacks of the sea-worm. The odor it exhales is powerful and lasting.

Another cheap, easy, and effectual mode is practised by Mr. Vose, of Dorchester. About the last of May, the soil is removed to the depth of two inches round the trunk; a composition of clay, ashes, \&c, is applied with a brush, and over this stiff brown paper is wrapped around the tree to the height of a foot, and the earth replaced. Sharp sand placed around the trunk of the tree, in a small, conical. mound, has, it is stated, been found an effectual protection, from experiments made in Pennsylvania. And from experiments made in the state of New York by Mr. Van Rensselaer, it appears that powdered charcoal placed around the trunk to the depth of two inches, is a protection. But the scoria from the -blacksmith's forge would probably prove at least as effectual. Lastly, lime mortar, mixed with sulphur, is found good. And common lime mortar alone, applied round the tree, has been found effectual. With us no remedy is generally needed.

. 3d. But there is another malady, which I beligve is unknown in New England, or at least I have never seen or heard of such a disease with us. It is by some called the yellows; and, according to Mr. Coxe, "the malady which destroys much the largest portion of the trees, has hitherto baffled every effort to subdue it; neither the source nor the precise character of the disease appears to be perfectly understood." "The trees are further stated to languish, the leaves turn yellow, and they perish shortly. The disease is contagious, soon spreading through the whole orchard; and if trees are brought from a sound nursery, and planted on the same land, they usually perish during the first season. And the infected soil cannot be again occupied as a peach orchard, until some years of intermediate cultivation. 'The only-remedy I have heard of for the destruction of this disease, is to destroy at once the infectious trees, before the disease is communicated to the whole orchard; which, according to Mr. Prince, of the Linnæan Botanic Garden, as stated in Thacher's Orchardist, is at the time the trees blossom in spring.

4th. The blossoms of the peach, and sometimes the tree itself, are liąble to be cut off by winter, or by spring frosts, 
which occur after the sap has arisen; the danger in this case being caused by the occurrence of unusually warm weather, either during an open winter, or during the progress of a very early spring, which causes the tree to advance prematurely. Those trees being more especially exposed which are in warm and sunny expositions, while those trees which are situated on the north sides of hills, the most exposed to cold winds, and on the north sides of fences and of buildings, almost invariably escape. I have stated elsewhere, that in Switzerland a mound of eartl is sometimes placed over the roots of plants in autumn, as a protection from winter frosts, to be removed in spring. Completely to protect the tree, and to insure a crop of fruit in all situations and seasons, let the whole surface of the earth beneath the tree, be covered to the depth of eight or ten inches, either with leaves, or coarse, strawy manure, or with coarse hay, in January and February, and when hard frozen. This will preserve the ground in a frozen state, and effectually retard the advancement of the tree till the danger is past, and to a late period in spring.

Pruning, \&c. In our climate the peach is almost universally cultivated as a standard. They are rarely pruned at all. In New Jersey and Delaware, also, the best cultivators prefer to leave the peach trees unpruned, even while standing in the nursery, that they may spread wide; and some there are who prefer close planting. There they are sometimes renovated by heading down, after they have borne two crops, for the production of new and more fruitful wood. This operation should be performed in spring. Trees are very rarely to be seen trained to walls, except occasionally in the gardens of the opulent.

The most extensive peach orchard which has come to my knowledge, is that belonging to Messrs. Isaac Reeve and Jacob Ridgeway, of Philadelphia. It is situated fortyfive miles below the city, on the River Delaware, at Delaware city, and contains 200 acres of trees, in different stages of growth. In 1839, they gathered from this orchard 18,000 bushels of first-rate fruit, from 170 acres of trees, whereof only $\mathbf{5 0}$ acres were then in full bearing. When the fruit has attained the size of a small musket ball, it is thinned. One of those gentlemen informed me, that of that size, they had gathered, in that year, 700 bushels, by measure, of the immature fruit. By this judicious management, while the amount of fruit was but little 
diminished, either in weight or measure, its size and beauty were greatly improved, so that their fruit was the handsomest in the Philadelphia market; and during the best of the season, much of it was sold at from $\$ 4.50$ to $\$ 6$ the basket, of three pecks in measure. Their trees are usually transplanted when but of a single year's growth from the bud; they usually produce a full crop of fruit in the fourth year after being transplanted, and from some of their trees two bushels have been gathered in a single year. They prefer a dry soil, light and friable, on, a foundation of clay, or gravelly clay, a good, but not a very rich soil. Like all other good cultivators, the whole land is always kept in cultivation. For the first two or three years, corn is raised in the orchard, but afterwards the trees are permitted to oceupy the whole gronnd, nothing being suffered to grow beneath their shade, as this would rob the fruit of its nourishment. In Delaware, where the climate is warm and the soil good, twenty feet asunder is the suitable distance recommended for the tree; while on the eastern or Atlantic side of New Jersey, sixteen or seventeen feet asunder is deemed sufficient by some of their most experienced cultivators, on good soils; while farther north, or on poorer soils, a less distance will suffice.

To render peach trees very productive, it has been recommended to shorten the new, young wood in July, by cutting in a few inches; and the shoots proceeding from these are to be shortened again during the course of the summer. This mode is favorable to the production of fruit buds, and the trees will produce more abundant crops the following year. This pruning or shortening may be most profitably performed with very large shears, with long handles, such as are used for clipping hedges; and I am persuaded that, with such an instrument, a man might prune a great many trees in a day. [See Introduction, Section VIII. Subs. 4th.] Mr. Knight, however, recommends to bend downwards the young and luxuriant shoots, instead of clipping: they thus produce the finest possible bearing wood for the second year. This last is the preferable mode. [See Introduction, Sectiọn VIII. Súbs. 3.]

With respect to trees trained to walls, Jean Pierre Savard, at Montreuil, according to Loudon, varies the position of the branches every year, by elevating to a greater angle the weak, depressing the strong, cutting out old, 
naked, or useless shoots; thus presenting at all times a well-balanced tree.

The inference is, that these weakly shoots, by being thus elevated, grow stronger; and the branches, by being annually bent in alternate years, become more fruitful on the principles before explained. Girdling increases the size, and hastens the maturity of the fruit; it should be performed as soon as the tree comes into leaf. Its effects, though surprising, are-ultimately ruinous to the branch on which the operation is performed; yet it may be sometimes advantageously performed on alternate branches of the same tree in alternate years. And there are, I believe, certain cases, where a single crop of very early fruit will very far exceed the value of the tree.

M. Noisette, according to Mr. Neill, against one piece of low wall, places his peach trees, five feet asunder, and trains them all obliquely, and in one direction, at an angle of $45^{\circ}$. The growth of wood being thus restrained, the fruitfulness is promoted, and the tree falls suddenly into bearing, and bears abundantly.

\section{N ECTA R I NE.- (Amygdalus Nectarina.)}

The nectarine has been assigned to Persia; it only differs from the peach in possessing a very smooth and glossy skin, and a pulp of a finer consistence. The French consider the nectarine (Peche lissé) as one and the same fruit as the peach. It is esteemed, however, by some, more wholesome and delicious. According to some authorities, its name is derived from nectar, which was supposed to be the favorite liquor which inspired the heathen gods.

\section{CLASE H.}

\section{FREESTONE NECTARINES.}

\section{AROMATIC. Lindley.}

- A middle-sized fruit, inclining to globular; deep red or blackish brown next the sun; the flesh pale straw, but red 
at the stone; juice of a rich, vinous flavor. [Leaves $\mathbf{R}$. Flowers S.]

2. "EARLY VIOLET. Pom. Mag. Bon Jard. 1828.

Vrolette Hative, Petit Violette Hative, of the French.

Violet, Lord SElby's Elruge, of the English

The tree is productive; its size generally medium; pale yellowish green, but dark purplish red next the sun; flesh whitish yellow, but red next the stone, melting, juicy, rich, sweet, vinous, and excellent. August. [Leaves R. Flowers S.]

3. *ELRUGE.

One of the very best of nectarines; large, roundish oval, deep violet or blood color next the sun; flesh whitish, melting, very juicy, rich, and very high-flavored. August. [Leaves R.]

4. FAIRCHILD'S EARLY. Lindley. Forsyth.

The fruit is very early, and very small ; globular; yellow in the shade, deep scarlet next the sun; the flesh yellow, not juicy, but well-flavored. [Leaves R. Flowers L.]

5. JAUNE LISSE, or ROUSSANNE. Bon Jard. SМоотн YeLLOW.

A small fruit; skin smooth, yellow, a little washed with red next the sun. Its flavor that of the apricot. It ripens very late at Paris, where it requires a warm exposition: [Leaves R. . Flowers L.]

\section{6. "LEWIS'S NECTARINE.}

A fine new variety, raised from the stone of a peach by Mr. Lewis, of Boston. A beautiful fruit, of middle size, heart-shaped; bright yellow, but intense red mottled next the sun; flesh of a fine orange color, firm, sweet; flavor very pleasant and peculiar.

\%. *PERKINS'S SEEDLING.

A seedling raised by S. G. Perkins, Esq., from the Lewis's - Nectarine. A very large, beautiful, fine fruit, globular, bright yellow, of a dark purple crimson next the sun.

8. "PITMASTON ORANGE NECTARINE: Lónd. Hort. Trans.

A new and beautiful fruit, of good size, globular, or heartshaped, pointed; of a fine yellow color, but dark crimson or purple next the sun; flesh golden yellow, but red next the stone; melting, juicy, saccharine, high-flavored. 
9. "SCARLET. For. Lindley.

A middle-sized fruit, rather ovate, of a fine deep scarlet next the sun; the flesh greenish white, but red at the stone; saccharine and well-flàvored. [Leaves R. Flowers S.]

10. TEMPLE'S. For. Lindley.

A fruit below medium size, rather oblong; of a pale red color next the sun; the flesh white; it shrivels at maturity ; very juicy, rich, and of fine flavor. [Leaves R. Flowers $\mathrm{S}$.

\section{1. *WHITE or FlaAnders NeCtarine. Pom.} Mag. Hooker. Lind.

New White, Emmersox's New White. Lind. P. Mag.

A middle-sized, roundish, very pale fruit, slightly tinged with red next the sun; flesh tender and juicy, with a fine vinous flavor. [Leaves R. Flowers L.]

\section{CLAse II.}

\section{CLINGSTONES, OR PAVIES.}

12. VIOLETTE CERISE. N. Duh. Bon Jard.

The flowers are small and delicate. A very small fruit, the size of a Green Gage plum; very beautiful, of a fine cherry red next the sun; good, but not high-flavored. [Leaves R. Flowers S.]

\section{3. *GOLDEN. For. Lindley.}

Rather large, globular, ovate, orange in the shade, bright scarlet, marked with deep red, next the sun; flesh firm, yellow, pale red at the stone, and of good flavor. [Leaves R. Flowers S.]

14. GROSSE VIOLETTE. Bon Jard. p. 298.

Violette de Courson, Brugnon Grosse Violette, $\boldsymbol{b}$.

The fruit rather larger and its flavor less vinous than the Violette Hative, (Early Violet.) Its skin is more marbled, and washed with violet red. Its maturity is also later; or the 15th September. [Leaves R. Flowers S.]

15. ITALIAN. Lindley. Forsyth.

\section{Brugnon. For.}

A large, globular, pale yellow fruit, marked with dark 
red next the sun; of a firm yellow flesh, red at the stone, juicy, rich, and good. It may ripen here in August. [Leaves R. Flowers S.]

6. RED ROMAN. Lindley. For.

A very large, globular fruit, dark red or purple next the sun, yellowish in the shade; flesh yellowish, but red next the stone; juicy, saccharine, and vinous. Early in September. [Leaves R. Flowers L.]

\section{SCARLET NEWINGTON. Lind. For.}

Newington, Late Newington.

The fruit is rather large, globular, fine yellow, but bright red marbled next the sun; of a firm pale yellow flesh, but red at the stone; juicy, rich, sweet, vinous, and excellent. Early in September. [Leaves S. Flowers L.] 18. TAWNY NEWINGTON. Lindley.

Pretty large, somewhat ovate; tawny-colored, marbled with dull red or orange next the sun; flesh pale yellow, but red at the stone; very juicy, sugary, and of a most delicious flavor. Ripening early in August. [Leaves S. Flowers L.]

19. VERMASH. Hooker. Pom. Lond. Pl. xxix.

Not the Vermash or Peterborough of Mr. Forsyth. The tree is very fertile; a small, roundish fruit; skin very smooth, intense red next the sun; flesh white, but red at the stone, of a high, delicate flavor, melting, juicy, sweet, relieved by an agreeable acid. Esteemed by Mr. Padley one of the best known. It succeeds the Early Violet. [Flowers L.]

20. VIOLET MUSK. Bon Jard.

Brugnon Violet Musquíe, Bruonon Musque, $I b$.

RED Roman of Forsyth.

The fruit is as large as the Grosse Violette, but brighter and of a more lively red next the sun; the skin very smooth, amber color in the shade; the flesh yellow, but red at the stone; saccharine, vinous, musky. September. [Leaves R. Flowers L.]

\section{ULTIVATION.}

The nectarine, owing to the smoothness of its skin, is, like the plum, extremely liable to the destructive attacks of 
the curculio. For the preventives, see Curculro, in the former part of this work.' The soil, cultivation, uses, \&c., are the same as the peach. They are usually inoculated on the nectarine, plum, or peach stock.

\section{A L M O N D. - (Amygdalus.)}

The almond, according to the best authorities, is a native of Asia. It is extensively cultivated in the south of Europe and Barbary, as a fruit tree, for its kernel, both for dornestic use and for exportation. The tree bears a striking resemblance to the peach; the leaves, also, much resemble those of the peach, but are more smooth, and of a bright, shining green; their lower serratures are glandular. The sweet almonds are used for the dessert, for confectionary, and for perfumery. The bitter almonds are used in medicine. They abound in prussic acid, and form the basis of the delicious cordial called Crême de Noyeau. This liquor, however, is also made of the kernels of the peach. [See PeAch.] The common almond, and the hardshelled sweet almond, are planted principally as stocks for the inoculation of the better varieties of almonds and the peach. The almond is enveloped in a pulp of ordinary flavor. The principal kinds recommended are the following:-

\section{SWEET SOFT-SHELLED ALMOND. Lind.}

Amande Sultan a Coque Tendre.

The shell is large, about an inch and a half in length; it is flattened on one side, and rounded on the other; it is smooth and tender; the kernel is sweet and good. This sort is said to be much cultivated in France for food.

2. AMANDE PRINCESSE, OU DES DAMES. Bun Jard.

AMande Des Damés. N. Duh. Pl. exxy,

The fruit is two inches in length; the shell is oval, and over an inch in length; it is soft and porous; the kernel is 
soft, sweet, and excellent. This is said to be much cultivated in the south of France for exportation. This fruit is recommended as one of the best for cultivation.

\section{AMANDE SULTAN.}

This variety much resembles the Amande Princesse, but is not so large.

\section{AMANDE PISTACHE.}

Resembles the Amande Princesse, but is of small size.

\section{BITTER ALMOND.}

\section{Amande Amere.}

Of this variety there are several; the two principal which are enumerated, are the following :-

6. BITTER SOFT-SHELLED ALMOND.

Amande Amere a Coque Tendre.

7. BITTER HARD-SHELLED ALMOND. Amande Amere a Coque Dere.

8. PEACH ALMOND.

Amande Pecher.

These are hybrids, produced between the almond and peach; some are large, juicy, but of bitter flavor; some are tolerable for eating, with sweet kernels.

\section{GREAT DOUBLE FLOWERING ALMOND.}

Amandier a Grand Fleve. N. Duh. Pl. cccexxir.

This new variety originated at the Luxembourg; the tree is of fine form; its bark shining, its leaves large; the flowers are superb, of a beautiful white, and two inches in diameter ; the fruit is small, oval, obtuse, downy; its shell very hard, the kernel plump, sweet, and good. Nothing is more beautiful than this almond in spring; it merits a distinguished place among the trees of ornament.

10. DWARF DOUBLE FLOWERING ALMOND. Amaxdier de Géorgie. N. Duh. Pl. xcir.

This is one of the most ornamental of all shrubs; it blossoms very early in spring, and the whole young wood is covered with the red blossoms, which are extremely double, and resemble small roses; their diameter is about an inch. This variety has some single blossoms, which produce a fruit which is oblong, pointed, and about an inch and a quarter in length; its skin green and downy; it contains an almond which is bitter. 


\section{UL T I V'A T I O N.}

The varieties of almond are propagated by inoculation, either on the native stocks of the common almond, or on stocks of the peach or plum. Their cultivation is the same as that prescribed for the peach; they are equally as hardy.

\section{A P R I C O T.-(Armeniaca.)}

The apricot is a low tree, of very irregular growth; the leaves are broad, roundish, pointed, glandular, serrated; their petioles tinged with red; the flowers are sessile, of a white color, tinged with red; they appear very early; the fruit is round, its color varying from white to yellow, and red; it somewhat resembles a peach, but its flesh is firmer; its hard, smooth, compressed stone resembles that of a pluns. It ripens in July in the latitude of Boston.

According to Phillips, it may derive its name from pracox, or early fruit; or, by corruption, a pracox; hence apricock, or apricot. Its native place has been assigned to Armenia. M. L. Legnier, however, asserts, says Phillips, that it is not known to grow in the natural state in any part of Armenia. The inhabitants of the deserts called oases, gather and dry large quantities of apricots, which they bring down to Egypt for sale; it there grows spontaneously; hence Legnier assigns it to Arabia. Pallas states it to be a native of Caucasus, the mountains there being covered with it to their tops. Grosier says it covers the barren mountains west of Pekin. (Phillips.) Regnier and Sickler, says Loudon, assign it a parallel between the (Niger and Atlas.)

Uses. $\Lambda$ s a dessert fruit, the apricot is esteemed next to the peach; it is also esteemed a most superior fruit, when used in pastry, for marmalade, jellies, and preserves; it is also stated to make a delicious liqueur. In France and Germany, according to Dr. Willich, the Orange Apricot is usually preserved in a dried state for winter, when they 
form a delicious ingredient in pies, tarts, \&c. The Chinese, we are told, form lozenges from the clarified juice, which, dissolved in water, yield a cool, rëfreshing beverage. Oil is also extracted from the kernel ; and Loudon informs us, that the young shoots yield a fine golden-cinnamon color to wool.

\section{VARIETIES.}

\section{ALBERGE APRICOT. Bon Jard.}

A large tree, and very productive. The flesh is melting, vinous, and excellent for preserving. The kernel is large and bitter. Early in August. There are two varieties superior in size and flavor; that of Montgamet and of Tours. 2. ALGIERS. For.

An oval fruit, flattened or compressed, of a straw color; juicy and high-flavored.

3. ANGOUMOIS. Lind. Bon Jard. p.,305.

Purple Abricot, Lind. Alemandrian. Ib.

Abricot Violette. Lux Cat.

BLACK Apricot. For:

A small, globular, downy fruit, a little oblong; of a pale red color, becoming deep red or purple next the sun; the flesh pale red, but orange next the stone, a little acid, but good, with a strong odor; the kernel is sweet, and the fruit looks at a little distance like an Orleans plum. Early in July.

4. *BRUSSELS. For.

Highly esteemed for its productiveness. A middle-sized fruit, of a red color next the sun, covered with numerous dark spots; the flesh is yellow, and of a brisk flavor. It separates from the stone; the kernel is bitter.

\section{5. "CRUFT'S LATE APRICOT.}

A large and very superior fruit, which lately originated in the garden of Edward Cruft, Esq., in Boston. Very rich, juicy, sweet; and, in the opinion of the best of judges, a variety of surpassing excellence. August 15.

\section{EARLY MASCULINE. Bon Jard.}

Abricotin, Abricot Precoce, A bricot Hatif Musque, of the French.

Red Mascurixe. Lind.

A small, nearly globular fruit, vermilion color next the sun, yellowish in the shade; the flesh is yellowish, of me- 
dium quality; flavor musky; kernel bitter. Its chief merit is its early maturity. Beginning of July.

\section{GROS MUSCH. Bon Jard. p. 306.}

The tree is vigorous; the fruit perfumed; on one side deeply grooved; it is contracted on the other; a freestone; the kernel is sweet. July.

\section{HEMSKIRKE. Pom. Mag.}

Origin unknown; it bears freely, ripening early, of a high, luscious flavor, superior even to that of the Moorpark. Middle-sized, roundish, slightly compressed; its color and form that of the Moorpark ; flesh bright deep orange; tender, juicy, with a particularly rich, delicate flavor, resembling that of the Green Gage plum; kernel sweet. July.

\section{9. *LARGE EARLY APRICOT.}

Abricot Gros Precoce. Abricot de St. Jean Rouge.

Abricot Gros d'Alexandrie, in Provence. Pom. Mag.

Fruit medium-sized, compressed, a little oblong; skin downy; fine bright orange, with spots of red next the sun, pale orange in the shade; flesh orange-colored, juicy, rich, and parting from the stone. Ripe at midsummer, or on St. John's day; hence its name.

\section{0. *MOORPARK. Hooker's Pom. Lond.}

Anson's, Temple's, Dunmore's Breda, Ib.

The tree is extraordinarily productive; the fruit is very large, of a bright orange or gold color, with dark spots next the sun; flesh orange color, melting, and excellent; the stone is large; there is a pervious longitudinal passage through it, through which a needle may be passed. It is in the edge of the stone, a little aside from the centre.

\section{MUSCH MUSCH. Bon Jard.}

Brought, a few years since, from the city of Musch, on the frontiers of Turkey, on the side of Persia. It is round, deep yellow, remarkable for the transparency of its pulp, through which the stone is visible; the flesh is very fine and agreeable. Early in July.

\section{ORANGE. Lindley.}

Early Orange, Royal Orasge, Royal George.

The fruit is larger than the Masculine, roundish; color orange, spotted with red or dark purple next the sun; the flesh deep orange, succulent, and well-flavored ; not perfectly a freestone; kernel sweet. 
13. "PEACH APRICOT. N. Duh. Pl, civ. Bon Jard Abricot Peche. 1 b. De Nascy.

The best and the largest of all apricots. Form variable, generally flattened; skin slightly downy; of a fawn color next the sun, with reddish spots; flesh fawn color, yellow, melting, excellent ; neither dry nor clammy, like most apricots; juice abundant, high-flavored, peculiar. Excellent. Early in August. All authors concur in this description.

\section{PORTUGAL. Bon Jard.}

Abricot de Portugal, or Male. Bon Jard.

A small, globular fruit ; flesh melting and good. Aug.

15. PROVENCE. Bon Jard.

A small fruit; flesh yellow, sometimes a little dry, but of a sweet, vinous flavor; stone rugged; kernel sweet. July. 16. ROMAN. Pom. Mag. Lindley. Bon Jard. Abricot Commun. Bon Jard:

Blotched Leaved Turkey. Lind: and Pom. Mag.

A vigorous tree, a large fruit in well-cultivated ground, superior to the Angoumois, but insipid when too ripe; kernel bitter. July. A productive variety.

17. ROYAL. Bon Jard. Pom. Mag.

A new variety, obtained at the Luxembourg; better than the Peach apricot: The fruit is next in size to the Moorpark ; rather oval, compressed; dull yellow, slightly red; the flesh pale orange, firm, juicy; sweet, and high-flavored, with a slight acid; kernel slightly bitter.

18. "ROYÁl PERSIAN. Hort. Soc. Cat. Bon Jard. RREDA. Hort. Soc. Cat.

Hollande, Amande Aveline, Bon Jard.

This fruit is small; flesh yellow, melting, vinous, having the taste of the Aveline or Filbert; kemel sweet. July.

\section{TURKEY.- Pom. Mag.}

Large Turkey. Hooker's Pom. Lond.

"An excellent apricot, scarcely known,"' little inferior to the Moorpark. Fruit middle-sized, very handsome, deep yellow, with rich orange red blotches next the sun; the form globular ; the flesh yellow, firm, juicy, sweet, with a little acid, very rich, and excellent; a freestone; kernel sweet as an almond.

20. *WHITE APRICOT. Bon Jard.

Abricot Blanc: Bon Jard.

The flesh is whiter than the Angoumois, and better, 
having a little of the flavor of the peach. It ripens a little after the Early Masculine.

\section{ULTIVATION.}

The apricot is generally inoculated either on the apricot, plum, or peach stock; the soil, and the maladies to which they are sometimes subject, are similar to the peach, but from the smooth skin which they possess, they are more liable to the attacks of the Curculio. For the preventives, see Curculio, in the former part of this work.

Sorl, \&c. The apricot requires a rich, black mould. They will not flourish in a sandy, gravelly, or cold, damp soil. The distances asunder to which they ought to be set, and their cultivation, are similar to that of the peach.

\section{P L U M . - (Prunus.)}

The plum tree rises to a height of from fifteen to eighteen feet, with moderately spreading branches. The leaves are ovate, serrated; the petioles short; the flowers are white. The fruit is a drupe; its color varying from white or yellow to red, to blue, or to black; the pulp is sweet or subacid; the stone smooth, ovate, pointed, compressed. Mr. Knight and others consider the Sloe Plum (P. spinosa $)$ as the parent, not only of the Bullace, $(\boldsymbol{P}$. insititia, $)$ but of all the varieties of the English plums, $(\boldsymbol{P}$.domestica.) The plum tree is supposed to be originally from Asia, but is also found growing in a wild state in North America. It is more hardy than the peach, as it flourishes in Canada; from the confines of the tropics to high northern latitudes.

Uses. The finest varieties are esteemed a delicious dessert fruit; the more ordinary varieties are used for pies, tarts, preserves, \&c. The Perdrigons, the Quetsches, or 
prunes, are dried; and in this state may be long preserved; they are imported principally from Spain, Portugal, and Marseilles. Prunes are deemed extremely wholesome food, and possessed of considerable medicinal efficacy. In the preparation of prunes, the perfectly ripe and sound fruit is arranged singly, and without being allowed to touch each other, on plates of tin or iron; these are placed in an oven after the bread is taken out, and they are occasionally moved or turned. When taken from the oven, if not sufficiently dry, they are exposed to the influence of the sun, and when cold, they are packed in boxes. Prunes may be made even of any kind of plum. Brignoles are prepared in Provence from the Perdrigons, which possess a very sweet taste. The skins being first separated by a momentary immersion in boiling water, and the stones being extracted, they are afterwards dried and preserved in the same manner as prunes.

Ripe plums are deemed wholesome, if eaten in moderate quantities; but unripe plums are extremely unwholesome, more so, it is said, than any other kind of unripe fruit, producing dysentery, \&c. The plum is said also to be capable of producing a good wine; good brandy is also procured from it by distillation. Plums and peaches, it is asserted, may be preserved a year, by placing them in earthen vessels as soon as gathered from the tree; equal parts of honey and spring water, intimately incorporated, to be poured. over them, and the vessels closely covered. The wood of this tree is beautifully veined ; it is therefore highly prized by turners, cabinet-makers, and for making musical instruments.

\section{VARIETIES.}

\section{APRICOT PLUM.}

Prone Abricoté, Prune Abricotée de tours

The fruit is large, globular, depressed, divided by a deep suture; whitish yellow, but faint red next the sun, and covered with bloom; the flesh is firm, juicy, sweet, musky, and excellent. It ripens in August. Branches very downy.

2. BANKER'S GAGE. Buel.

This plum originated in New York. A fruit of fine 
size, and of delicious flavor, and admirably calculated for drying.

\section{3. *BINGHAM.}

Large, oblong, and beautiful; bright yellow in the shade, with specks of red; pale red next the sun; flesh yellow, very sweet and delicious, and adhering to the stone. An excellent fruit. The tree is very productive. Branches downy.

\section{BLEECKER'S GAGE.}

This new and fine fruit was raised by the Rev. Mr. Bleecker, of Albany, from the stone of a German prune. A large, globular fruit, of excellent quality, and very productive.

\section{BLUE GAGE. Col. Carr.}

Very productive. The fruit is of medium size, round; of a blue color; of an extremely sweet, fine flavor. A native fruit, raised from the Reine Claude. It hangs long on the tree, and is deservedly worthy of cultivation.

\section{6. *BLUE HOLLAND.}

A round plum, of a blue color, juicy, and high-flavored. It readily parts from the stone. It ripens in September, and hangs long on the tree after arriving at maturity. A fine fruit, and a great bearer.

\section{7. *BLUE IMPERATRICE.}

Imperatrice Violette.

ImPERATRICE. Hooker's Pom. Lond. Pl. IV.

The branches are very long and smooth; the fruit medium-sized, and rather long, pointed at the base, rounded or broad oval at the summit; the skin is fine violet, very profusely covered with bloom; flesh yellowish next the sun, a little firm at maturity, exceedingly rich and sweet; it adheres to the stone. One of the best of late plums, and one of the most productive. September and October

\section{8. *BREVOORT'S PURPLE BOLMER.}

Breevoort's Pubple Washixgton.

The tree is of very rapid growth, and exceedingly productive; the branches smooth; the leaves are like those of the Washington; the fruit large, beautiful, of an oval form; of a blue color, covered with azure bloom; the flesh adheres to the stone, and is of a sweet and delicious flavor. A new and very superior variety, ripening early in September. 


\section{9. *BRUYN GAGE. R. M.}

A new and very delicious fruit, which in excellence very nearly resembles the Green Gage, both in the wood, the leaf, and the fruit; more nearly, according to Mr. Manning, than any other fruit he has seen. A native, which originated in the garden of Colonel Bruyn, of Kingston, N. Y.

\section{0. *CAledonian. Pom. Mag.}

Prune PÈche of the French. Pom. Mag.

Nectarine. $1 b$. Howele's Liarge. Ib.

The branches are brownish violet next the sun, and glabrous; the fruit very large, rather oblong, like a Nectarine in size and form; of a purple color, covered with a fine ázure bloom; flesh greenish yellow, and adhering to the stone. A superb and excellent fruit, and one of the very best plums yet known of its size. It ripens early in August. The tree is wonderfully productive.

\section{1. *COE'S GOLDEN DROP.}

Coe's Seedling, Bury Sembling, Pom. Mag.

Coe's Imperial. Ib.

The tree is of thrifty growth, and bears well; the branches are smooth, dark; the leaves having two globular glands at their base; the fruit one of the largest, the best, and the most beautiful known; it is oblong and rather bell-shaped; two to two and a half inches long, but less in breadth; of a greenish yellow color, and spotted next the sun with violet and crimson; flesh gold oolor, and adhering to the stone; of delicious flavor; superior, it is stated, to any late plum cultivated in Britain. It ripens early in September, and will hang a long time after on the tree. This most superior fruit was sent by Mr. Knight to the Hon. John Lowell in 18223 .

\section{COL. WETHERELL. Mag. of Horticulturc.}

A new variety of fruit, one of the very latest of plums, and of most excellent quality, and deserving a place in every good collection. Raised by Mr. Corse, of Montreal, and thus described by him.

\section{COOPER'S PLUM. Coxe. Pom. Mag.}

La Delicieuse. ' 16 . Cooper's Red.

Raised by Mr. Joseph Cooper, of New Jersey, from a stone of the Orleans; it is very large, rather oblong, dark purple next the sun; the flesh yellowish green', very rich, juicy, and delicious. Mr. Coxe informs us ", that it makes 
an exquisite preserve if deprived of its skin before too ripe. The tree grows vigorously; the young wood is smooth, and the fruit is liable to perish at maturity. September.

\section{4. *ORSE'S NOTA BENE.}

Large; round; of a bluish or copper color; flesh green, rich, and as highly-flavored as the Green Gage. One of the best of plums. The tree bears wonderful crops. This fruit has been well proved by Mr. Manning and others in this vicinity. It was lately originated by Henry Corse, Esq., of Montreal.

\section{CRUGER'S SCARLET SEEDLING. Mr. Ives.}

A new and beautiful variety, which lately originated in New York. Size that of the Green Gage; of a lilac color in the shade, scarlet next the sun; flesh yellow, sweet, and good. The tree is a great bearer.

16. DAMAS DE PROVENCE. N. Duh. Pl. LXv.

The fruit is roundish, a little oblong; its height eighteen to twenty-two lines; skin reddish violet, covered with thick bloom; the flesh yellowish, tolerably high flavored; juice sweet. 'I'his plum is one of the earliest. It ripens a month earlier than the Royale de Tours. Its early maturity and beauty render it worthy a distinguished place, although its quality is but second rate.

\section{1\%. "DANA'S YELLOW GAGE. $\boldsymbol{R}$. $\boldsymbol{M}$.}

Of medium size; oblong; of a bright yellow color; flesh juicy, sweet, and fine; the tree a great bearer. A new and excellent fruit, which originated in the garden of the late Rev. Dr. Dana, of Ipswich, Mass. Introduced to notice by Mr. Manning.

18. "DIAMOND PLUM. Loudon's Mag. Vol. IIr.p. 215.

The diamond plum is perhaps the largest plum known, and very beautiful. In form it resembles the Magnum Bonum, but its flavor is superior; color dark purple. The tree grows vigorously, and in orchards would form a fine contrast to the White Magnum Bonums. It sprung from the seed, in the nursery of Mr. Hooker, in Kent. The branches are smooth, dark violet; the leaves shining green, the tree one of the most productive known with us.

\section{9. *DIAPRE ROUGE.}

Imperial Diadem. Mimms.

Very large, and eminently beautiful; a little oblong; 
its diameter two inches and a half; of a bright purple next the sun, and covered with thick bloom; the flesh yellowish green, tender; juicy, and very agreeably flavored, resembling in this respect the Orleans. It separates from the stone, which is rugged. The branches are smooth. A late plum of the largest size.

20. DICTATOR. Mag. of Horticulture. Corse.

A new variety, raised by Henry Corse, Esq., of Montreal. It first bore fruit in 1837. One of the largest and finest of all plums, exceeding the Bolmer's Washington in size, and equalling in flavor the Green Gage. The tree is of vigorous growth; the fruit of a brownish purple color, covered with a beautiful bloom; flesh juicy, rich, and high-flavored; the stone, very small. Thus it has been described by Mr. Corse.

\section{1. "DOMINE DULL." $\boldsymbol{R}$. $\boldsymbol{M}$.}

\section{- German Prune.}

A new variety; large, oval, of a dark blue color, inclining to black; the flesh yellow, dry, adhering to the stone; of a sweet and rich flavor. It keeps long, and is eminently calculated for drying. The branches are long, smooth, of a dark color. Raised in New York by a German divine named Dull, from a stone brought from Germany. September.

\section{DOWNTON IMPERA'TRICE. Hort. Trans.}

Raised by Mr. Knight from the seed of the White Magnum Bonum and pollen of the Blue Imperatrice. In shape like the Blue Imperatrice; but larger. Skin dark yellow, very thin; flesh yellow, soft, juicy, with a high-flavored acidity - all characteristics of much excellence. The tree grows very strong; branches long and smooth. It ripens late in September, and will keep a long time.

\section{DRAP D'OR.}

Mirabelle Double. Duh. Cloth of Gold.

Small, roundish, over an inch deep, but of greater breadth; bright yellow, marbled with red next the sun; flesh yellow, tender; juice sugary and excellent, - It separates from the stone. Branches downy at the ends, smooth below. Ripe Iate in July.

\section{4. *DUANE'S PURPLE.}

The tree grows very strong, and upright; branches downy; the leaves pale green, of unusual size; the fruit is very large, round, of a fine purple color next the 
sun, and covered with bloom; juicy, rich, and good. A fruit of the largest size, and of superior quality; imported by Mr. Duane, of New York; the original name lost.

\section{EARI.Y MONSIEUR.}

Monsievr Hatif. 'Duh.

Branches very downy; leaves oblong, glaucous beneath. A globular fruit, of medium size, of a violet or deep purple color next the sun, and covered with a dense bloom; the flesh is yellowish, melting, juicy, and good., It ripens a fortnight earlier than the Monsieur. July.

\section{EARLY YELLOW.}

White Primordian of the English.

Jaune Hative, Prune de Catalogne, Duh.

The branches are slender, downy; the fruit small, oblong, whitish yellow; the flesh is rather dry, sweet, and musky. One of the very earliest plums, ripening in July. It is chiefly valued on this account.

27. *ELFREY. $\boldsymbol{R}, \boldsymbol{M}$.

Under medium size; oblong; of a dark blue color ; flesh firm, dry, but very rich and excellent. The growth is rather slender, the leaves bright shining green. The tree bears most abundantly. A native fruit, and very highly esteemed for its good qualities and great productiveness, at Philadelphia, and in Jersey.

28. *GERMAN PRUNE.

A large and very oblong fruit, bell-shaped, of a blue color; flesh yellow, verý juicy, sweet, and delicious. It ripens the last of August, and continues on the tree till winter; and shrivels till it becomes quite dry. A fine fruit.

29. GOLIAH. Hort. Trans.

ST. Cloun of some collections.

This fruit is remarkably large, some weighing four ounces; compressed; the skin is a deep reddish purple, covered with blue bloom; the flesh pale, firm, and adhering to the stone; well-flavored, but not rich. It is very useful for cooking. Ripe early in September. The branches are downy. A fine, handsome fruit; the tree uncommonly productive.

30. *GREEN GAGE.

Great Queen Claudia of the English.

Grosse Reine Claude, Dauphine,-Abricote Vert.

A middle-sized, round fruit, of a yellowish green color, 
of a purplish russety red next the sun; me.ting, juicy, and of delicious flavor. Last - of August. Lindley informs us that the name of Gage was derived from the circumstance of the Reine Claude being sent from France to the Gage family, with the name obliterated ; and through ignorance of the real name, it was called Green Gage. Branches smooth. An old and famous fruit.

\section{GROS DAMAS ROUGE TARDIF. N. Duh.}

$\mathrm{Pl}$. cccxciv.

Large late Red Damask.

The fruit is very handsome, oval; its height twenty lines; skin thick, hard, bright red, covered with azure bloom; the flesh yellow and melting; juice sweet and good. This fine fruit will ripen here the last of August.

\section{2. "ICKWORTH IMPERATRICE. Thompson.}

A new and very superior fruit, which was originated by Mr. Knight. Very large, or much larger and richer than the old Imperatrice. Of first-rate excellence, as abundantly proved at the garden of the London Horticultural Society, where the tree first bore in 1837 .

\section{3. "ITALIAN DAMASK.}

Damas d'Italiz. Duhamel.

This fruit is rather large; globular, a little flatted at the base; blue or violet next the sun, and covered with pale blue bloom; the flesh is yellow, sweet, and high-flavored, and separates from the stone; . branches smooth. August. This variety is beautiful, and extremely productive.

\section{4. *JENKIN'S IMPERIAL.}

The growth of the tree is very strong, the branches smooth, leaves very large; the fruit is very large, oblong; of a blue or purple color, and covered with bloom; of superior excellence. This variety has been by some confounded with the Caledonian, or Nectarine plum, but is very distinct, and is esteemed by good judges as one of the best of plums.

35. *KIRKE'S PLUM. Lindley. Forrest.

Branches smooth; the fruit is rather large, roundish oval, broadest at the base; skin dark purple, covered with a copious azure bloom, which is difficult to remore; flesh greenish yellow, firm, juicy, rich, and separates from the 
stone. A very handsome variety, and most excellent bearer. A fruit of the very first rate. August.

36. *KNIGHT'S LARGE GREEN DRYING.

\section{Thompson.}

A new and very extraordinary fruit, originated by the late Mr. Knight, former president of the London Hort. Soc. A tree in the garden of that society first bore specimen fruit in 1838. Very large, round, green or yellowish green; as large as Bolmer's Washington, and much higher flavored - distinguished praise. Eminently valuable either for preserving, or as a delicious dessert fruit.

\section{LARGE SWEET DAMSON.}

Horse Plum.

Large, roundish oval, of a dark blue color, covered with bloom; the flesh firm, yellowish green, juicy, sweet, and good; it adheres to the stone. The tree is productive.

\section{LOMBARD. $\boldsymbol{R} . \boldsymbol{M}$.}

The fruit is large, round, and very beautiful; of a purple color, with red dots on its surface; flesh good and agreeable. Very valuable for its great beauty and productiveness. The growth is strong, the branches smooth and ramous. A new fruit, which was originated by Judge Platt, of Whitesborough, New York, from a stone received from Amsterdam. The tree was subsequently disseminated by a Mr. Lombard; hence its name.

39. "LUCOMBE'S NONSUCH. Pom. Mag. t. 99. Lindley.

This plum is large, and compressed at summit and base ; its breadth two inches; its color at maturity, as well as form, resembles the Green Gage, but more streaked with yellow or orange; flesh firm, and adhering to the stone; juice abundant; of excellent flavor, and nearly equal to the Green Gage, and superior to the Orleans; branches smooth. A remarkably handsome and valuable new variety. A sure and never-failing bearer, ripening in $\Lambda$ ugust. 40. MONSIEUR. N. Duh. Pl. ccxli.,

Prune de Monsieur. $\boldsymbol{l} b$.

A handsome fruit, depressed; its diameter from fifteen to twenty lines; violet red, covered with azure bloom; the flesh green or yellowish, melting; juice sweet, sometimes very agreeable. It parts from the stone, and ripens 
twelve or fifteen days after the Monsieur Hâtif. Branches very downy; leaves glaucous. August.

41. MOROCCO.

Black Morocco, Earty Morocco, Black Damiscus, Earty Buack Damask, according to the Pom. Mag.

A blackish purple fruit, of medium size, covered with pale blue bloom; globular, a little depressed; the flesh greenish yellow; juice rich and high-flavored. A productive fruit. Branches downy; the leaves having globose glands. July.

\section{2. *ORLEANS.}

Damas Rovge of the French. Red Dasask.

A middle-sized fruit, globular; of a red color, but blue or purple next the sun, and covered with bloom; the flesh is pale yellow, juicy, rich, and astringent, and readily parts from the stone. A great and constant bearer,-and very valuable fruit. The branches downy. It ripens in August.

\section{3. *POND'S PURPLE.}

A large, round, purple plum, of a sweet and fine flavor. It ripens early in August, and was so named, by the committee of the Massachusetts Horticultural Society, for Mr. Samuel Pond, of Cambridge, who has introduced this new kind to notice. A new and handsome fruit, which originated in the garden of the late Henry Hill, Esq., in Summer Street, Boston.

\section{PRECOCE DE TOURS. Hooker's Pom. Lond.}

EarLY DE Tours. Ib.

The tree is vigorous and fertile; the fruit the best early variety in Britain; small, oval, dark purple, covered with fine bloom; flesh greenish yellow, tender, juicy, of very agreeable flavor; branches downy. It ripens in July:

45. PRUNE D'AGEN. Bon Jard.

Very oblong, of a blue black color. Of this fruit they, make the celebrated prunes of Agen.

46. *PRINCE'S IMPERIAL GAGE.

White Gage.

An eminently valuable fruit; the tree is very vigorous and upright in its growth, and extraordinary productive. The fruit is larger than the Green Gage, and of excellent quality.: A single tree of this variety, at Charlestown, owned by Mr. Samuel R. Johnson, has, for several suecessive years, yielded crops, which were sold at from forty 
to fifty dollars per annum. This valuable variety was raised by William Prince, Esq., of the Linnæan Botanic Garden, Flushing, from a seed of the Green Gage. Branches downy. One of the most productive fruits known. Sept. 47. RED GAGE. Col. C'arr.

The tree grows vigorously; branches dark, smooth; the fruit of a greenish yellow in the shade, deep red next the sun. A delicious fruit, raised from the Reine Claude.

\section{RED MAGNUM BONUM.}

IMPERIAL VIOLETTE of the French. IMPERIAL.

A large, oval plum, two inches to two and a half in length; deep red next the sun, and covered with blue bloom; the flesh is yellowish, harsh, acid; it parts from the stone, which is sharp-pointed. Good for cooking, and fit for little else. August. Branches smooth.

\section{RED PERDRIGON. Lindley.}

Perdrigon Rouge. Hort; Soc. Cat.

An excellent plum, of the first class; middle-sized, roundish oval, of a fine red color, with gold dots and a fine bloom; flesh bright yellow, transparent; juice sweet and delicious. Peeled and dried it makes excellent prunes; not inferior to the White Perdrigon. August. Branches downy.

50. *RED QUEEN MOTHER.

A large plum, of a bright red color, covered with pale bloom; the flesh is yellow, sweet, and excellent. It ripens in September. This is a very handsome and productive variety, and highly deserving of cultivation. The origin of this fruit is unknown. It resembles the Isabella.

51. *REINE CLAUDE VIOLETTE. Loudon's Mag. Purple Gage. Violette Queen Claudia.

A new seedling variety of the Green Gage, of a purple color, equally good, and a better bearer. It hangs longer on the tree, and is the best red plum we have. The Pomological Magazine confirms this account, and adds, that it is not, like the Green Gage, disposed to crack. Fruit roundish oval, somewhat flattened at the ends stalk long, thick ; skin violet, covered with pale blue bloom, beneath which are pale yellow dots; flesh amber-colored, rich, sugary, exceedingly high-flavored; stone oval, compressed; the branches dark, smooth; the leaves shining. One of, the few purple plums which will rival the Green Gage in point 
of flavor, and ripening at the same time. In 1837, as Mr. Thompson stated, no plum exceeded this. It hangs long on the tree, improving as it shrivels.

\section{RIVERS'S EARLY. Rivers, Jun.}

A new seedling plum, raised by Mr. Rivers from the Farly de Tours; of medium size; very fine, and earlier than that variety; the tree hardy and very productive.

53. *ROYAL HATIVE.

A new and extraordinary variety, from France. A fruit fully equal to the Green Gage had already been found in the Reine Claude. Violette, a purple plum, and ripening at the same time. But in the Royal Hative,' a most desirable variety has been discovered, equalling in excellence those before-named varieties, but ripening from two to three weeks earlier, or at a different period of time. In Noisette's Manual it is described as a large violet fruit, in flavor resembling the Reine Claude Violette. Such is the account of this new fruit, as stated by Mr. Thompson. $\mathrm{He}$ adds, that this is distinct from every other variety, except, perhaps, the Mivian, so called, and probably a-synonyme of this; scions of which had been received of $\mathbf{M}$. Stoffels, of Mechlin. The fruit is thus described by him. Shoots very downy; leaves slightly pubescent above; (two characteristic traits which will always prevent its being confounded with the Reine Claude Violette, whose shoots and leaves are smooth;) fruit larger than the Reine Claude Violette, which it greatly resembles both in flavor and appearance; in form roundish, but rather broader next the stalk, which is about a half an inch in length, thick, and not inserted in a hollow; skin purple, dotted, and traced with a golden brown; flesh yellow, slightly adhering to the stone, but parting from it at maturity; flavor exceedingly rich; stone small, ovate, and compressed. It ripens early in July.

54. ROYALE. N. Duh. Pl. ccxLII.

LA Royate of Hooker's Pom. Lond.

A large, very handsome fruit, diameter eighteen lines; the skin thick, of a homely, dull brown red, concealed, however, by a thick violet or azure bloom; the flesh fine, yellowish green, firm, and cracking; juice abundant, highflavored, and delicious. An excellent plum. September. 55. *ROYAlE DE TOURS. N. Duh. Pl. xiIr. The fruit is globular, flattened; its length eighteen lines: 
a red violet next the sun, and covered with azure bloom; the flesh is yellow, fine; good; juice abundant and sweet; high-flavored, and of superior quality to the. Monsieur plum; and it ripens eight or ten days earlier. Branehes downy, and nearly white. July and August.

56. "ST. CATHERINE. Hooker's Pom. Lond. Pl. xxIV.

A medium-sized, oblong fruit; narrowest towards the stalk, broad and flattened at the summit ; of a bright gold color next the sun, spotted with red, and covered with bloom; the flesh yellow, tender, sweet, and of fine flavor; stone oval, flat; it separates from the flesh. It ripens a little before the Imperatrice. Branches smooth. The tree bears well.

\section{5\%. ST. MARTIN'S QUETSCHE.}

" A most excellent late purple plum,", and, according to Mr. Thompson, eminently deserving. A new fruit, which was received into the garden of the London Hort. Society from the late Mr. Fischer, of Gottingen.

58. *ST. MARTIN ROUGE.

St. Martin. Bon Járd.

Cox's. FINE LATE RED of vurious catalogues.

An excellent fruit, as large as the Reine Claude Violette, of the same color; of an oval form; the latest of all plums. This fruit is highly esteemed both here and in England, where known. One of the best of all late plums. It is there known under the erroneous name of Coe's Fine Late Red. The branches are downy.- October.

59. *SEMIIANA.

Prune Sersse. N. Duh.

Prune d'Altesse, Monsifur Tardif.

The fruit is very handsome, round, flattened; its diameter eighteen to twenty lines; color varying from bright violet to deep blackish blue, and covered with azure bloom; the flesh greenish yellow, cracking and melting; juice very abundant and delicious. Not uncommon near Boston. An excellent fruit, ripening in September. Branches smooth; the tree very productive.

60. *SHARP'S EMPEROR.

Denyer's Victoria, Queer Victoria.

Very large and beantiful; as large as the Red Magnum Bonum; of a roundish ovat form and red color; covered with a fine bloom; of a fine flavor. An excellent fruit, and eminently deserving. The tree grows very strong; branches 
downy; leaves very large, broad, well rounded, smooth; the stone tender; the tree remarkably productive.

\section{1. "SMITH'S ORLEANS.}

The tree is very vigorous and productive; the fruit is large, of an oval form and purple color; its flavor excellent. A highly-esteemed variety.

62. SURPASSE MONSIEUR. Bon Jard. p. 308.

"This superb fruit was raised by M. Noisette. It is more-beautiful and more perfumed than the Monsieur."

63. VIRGINALE. N. Duk. PI. xxxv.

The tree is strong, vigorous, and productive; the fruit is round, slightly depressed; its color yellowish, stained with violet or rose next the sun, and covered with dense bloom; the flesh is melting; juice abundant, and very agreeable; it adheres to the stone.- One of the best of plums. 64. "WASHINGTON.

Bolmer's Washington, Frankin.

A very large, globular plum, inclining to oval; "greenish yellow next the sun, approaching to pale orange, and covered with a bloom, and occasionally crimson specks; this plum has sometimes weighed over four ounces ; its flesh is yellow and firm, sweet and delicious; it parts readily from the stone, and ripens in September. Branches downy. August. This plum is equal in flavor to the Green Gage; and a very valuable variety, of American origin.

65. WHITE MAGNUM BONUM. Hort. Cat.

Imperiale Blasche." Duh. Egg Plum.

IVhite, Mogul, White Holland, of the English.

Gros Luisante Hort. Cat. Wentwortu.

The tree grows remarkably strong; the branches smooth; the leaves unusually large. An oval fruit, of extraordinary size; of a yeilow color, covered with pale bloom; the flesh yellow, firm, acid, and austere; it adheres to the stone, which is oval, and very pointed. This plum is excellent for conking or preserves. Early in September.

66. WHITE PERDRIGON.

Branches downy; a middle-sized, oblong fruit, tapering from the stalk; of a pale yellow, with red spots next the sun, and covered with white bloom; flesh yellow, rich; saccharine, separating from the stone. Last of August. 67. "WILMOT'S NEW EARLY ORLEANS. Mr. Hooker, in Hort. Trans. Vol. IIt. p. 392.

Raised by Mr. John -Wilmot. Earlier than the Nevo 
Orleans; as early as the Morocco, and Precoce de Tours, as large as the Old Orleans, and more juicy ; a certain bearer; a fruit above the middle size, round, its suture deep; dark purple next the sun, and covered with bloom; the flesh greenish yellow, of excellent flavor, sweet combined with a pleasant acid; it separates from the stone. Mr. Hooker considers this plum as decidedly superior to any of its season at present cultivated. Its beautiful appearance will obtain it a preference in the market. Branches downy.

\section{SLOE. Loudon.}

\section{Prunus Spinosa.}

A thorny tree, a wild plum of Britain. The fruit is small, very black, and astringent. The ripe fruit is excellent to preserve; unripe, the inspissated juice forms the German acacia, and affords an ink almost indelible for marking on linen. The juice is used mixed with various wines, to communicate the dark red color and rough taste of Port wine. The leaves are employed to adulterate the tea of China.

\section{DWARF TEXAS PLUM. Mr. Russell.}

A low, dwarfish tree or shrub, rising 2 or $\mathbf{3}$ feet or more; the blossoms white, profuse, of a beautiful appearance, and in early spring resembling snow; the fruit of different colors, according to the variety, some being yellow, some red, and some purple; the flesh of delicious flavor; the produce most abundant. This new tree, or shrub, was lately introduced to our country from a small district in the colder part of Texas, and the upper Colorado, by my friend John B. Russell, Esq., of Cincinnati, Ohio. He is persuaded it must prove hardy.

\section{U L T I V A T I O N, \&c.}

The plum tree flourishes best in a rich, sandy loam, neither too dry nor too moist. A cold, wet, clayey soil, or a dry, sandy situation, is not deemed so favorable.

The varieties of plum are inoculated on the plum stock. Those raised from the seed are preferred, and some varieties will flourish on the peach stock; but this is not deemed so suitable for a very high northern latitude. 
The mode of pruning, and the distances to wnicn the trees should be set asunder, vary but little from that of the peach. The plum, from its possessing a very smooth skin, is extremely liable to the attacks of the curculio. For the. modes of prevention, see Curculro, in the former part of this work. Particular varieties of the plum tree are also liable to be attacked by a worm, which causes large black bunches to be formed on the limbs. - Some varieties, however, are exempted from this disease. The remedy is easy; and consists in separating every bunch; every badly-affected brauch, or even tree, and committing them to the fire. No affected tree should be suffered to exist near the orchard. In this way; and in this alone, the worm and the disease may be exterminated with certainty and but little trouble.

\section{H E R R Y.-(Prunus Cerasus.)}

The cherry is a tree of medium size; the branches are shining, of an ash color; the leaves are ovate, serrated; the flowers are white, and produced in umbels; the fruit is a roundish drupe, of a yellow, red, or black color, and shining; of a sweet or acid flavor; it encloses a smooth stone.

The native country of the cherry has been assigned to Asia. It was brought to Rome before the Christian era, by Lucullus, from a town in Pontus, called Cerasus; hence its name.

Uses. The cherry is a highly-esteemed summer dessert fruit. It is also extensively used in cookery, in pies, tarts, \&c. The dried fruit forms an article of luxury and food. In the forests of the mountains of the east of France, says Bosc, where the Merisiers formerly abounded, great quantities were dried, and constituted an important article of food, during the winter, of the Charboniers, a half savage, but kind and hospitable race. Their soups were prepared by boiling the dried fruit in water, with bread, a small portion of butter being added. From the juice a 
fine wine is prepared. The Kirschenvasser or Kirswasse of the Germans is identically the celebrated Marasquin of Venice, which, was fabricated so extensively on the mountains of ancient Macedon. It is prepared by distillation from the fermented juice of the Merisiers or Mazzards, a portion of the bruised stones being added. But when other varieties are used, - the more acid varieties, - five or six per cent., by weight, of sugar, is added to the juice. The Mazzard cherries, the Morillos, and the fruit of the Virginia cherry, are steeped in brandy or rum, to improve its quality and flavor. The gum which exudes from the cherry tree is stated to be, in every respect, equal to gum arabic, and is so extraordinarily nutritive, that, according to Hasselquist, more than a hundred men were kept alive during a siege of nearly two months, with no other sustenance than a little of this gum gradually dissolved in the mouth. The wood of the eherry tree is hard and tough, and is much used by the turner and cabinet-maker, especially the Virginia cherry, which is capable of receiving a fine polish, and has reddish streaks resembling mahogany. The bark of this last species, according to Dr. Mease, is powerfully tonic, and has frequently been substituted with success for the Peruvian Bark. The bark of the roots is more powerful.

\section{VARIETIES.}

The following list of cherries has been divided into two classes. The distinction thus formed will be apparent on inspection of the tree and the fruit.

Cuass I. - This class includes, 1. The Bigarreaus, which are distinguished by possessing a firm and hard flesh. 2. The Heart Cherries. 3. The Mazzards. This class includes the Bigarreautiers, the Guigniers, and the Merisiers of the French. The trees of this class generally grow tall and handsome, or in a pyramidal form; the young wood is strong; the leaves large, oblong, pointed, of a bright green; the blossoms large; and the fruit sweet. The dry wood, according to Bosc; weighs fifty-five pounds to the cubic foot.

Class II. - To this class belong the Dukes, the Morillos, and similar kinds - the Cerissiers or Griottiers of the 
French. The trees of this class are generally of lower growth than those of the first class; of more compact form; the branches more slender and numerous; the leaves are of less size, of firmer consistence, of a dark green color; the flowers of less size, but more open; the fruit is round, tender, of a subacid or acid flavor. The dry wood of this class, according to Bosc, weighs $47 \frac{1}{2}$ pounds to the cubic foot. In addition to these, a few ornamental varieties of four distinct species will be described.

\section{Class I.}

BIGARREAUS, HEAR'T CHERRIES, \& c.

\section{1. "KNIGHT'S EARLY BLACK. Hort. Trans.}

Raised by Mr. Knight, from the Bigarreau and May Duke combined. The blossoms of this new variety are produced in abundance, before those of any other sort; and while the May Duke, in the same aspect, is yet a very unripe fruit, the Early Black Cherry has assumed its rich, dark hue, and its flesh is then firm and juicy. It resembles in its external appearance the Waterloo, but the stalk is shorter. It is abundantly sweet, and, though not very rich, of a pleasant flavor, and remarkably early. A fruit of large size, obtusely heart-formed, and ripe in June.

\section{2. "DAVENPORT'S EARLY BLACK.}

Very early and excellent. The tree is of compact and fine form; the leaves large, light glossy green; it bears early and abundantly. The fruit is-large, at maturity dark shining purple or black; the flesh firm, sweet; of a pleasant subacid and fine flavor. One of the finest and most productive early cherries known. A vety popular fruit, and highly valuable for the market. It ripens the middle of June, and from eight to twelve days earlier than the European May Duke. This fine new variety originated on the farm of Mr. Davenport, in Dorchester. 


\section{BOWYER'S EARLY HEART.}

A fruit of medium size; obtusely heart-formed; flesh tender; flavor fine. An excellent cherry, ripening early in Jume. Valuable alike for its very early maturity and productiveness.

\section{RIVERS'S EARLY AMBER HEART. J. Rivers, Jun.}

A new fruit, which was originated by Mr. Rivers. Large, heart-shaped, of an amber color; a very early variety; the tree very productive.

\section{5. *AMBER CHERRY.}

Below medium size, perfectly round; color of amber, but red towards the sun; of a very delicate appearance; the flesh is melting, the taste lively and very sweet. It ripens with the May Duke.

\section{MANNING'S EARLY WHITE HEART.}

A new and valuable variety, which was raised by Mr. Manning from the White Turkey Bigarreau; medium sized; heart-formed; pale red, or amber colored next the sun, white in the shade; sweet, fine, and remarkably early, or ripening in June.

\section{BIGARREAU DE MAI.}

$A$ new and very early fruit, of a red color, and medium size; of a fine, sweet flavor; its name dubious. Imported by Col. Wilder, from Messrs. Baumann, of Bolwiller, as the very earliest variety known to them. It ripened perfectly its fruit, near Boston, in 1841, even before cherries had appeared in the markets of Philadelphia and New York.

\section{8. bigarreau de ROCMONT. N. Duh. Pl. CCCLXX.}

Belle de Rocmont, Ceeur de Pigeon, Bon Jard.

The tree is vigorous and productive; the fruit large, heart-shaped, red, marbled, and shining; a beautiful fruit, an inch in height; flesh white, very little breaking; juice not abundant, rather sprightly, good. Middle of June.

\section{9. *NEW LARGE BLACK BIGARREAU.}

The tree grows vigorous and handsome; the leaves large; the fruit is very large, beautiful, and even surpassing that of the Black Tartarean; obtuse heart-shaped; at maturity black and shining; the flesh black violet; juice of a deep red dye ; of a sweet, rich, and high-flavored taste. This Bigarreau is one of the most beautiful and the best of its species known. Ripening late, or in Aug. A 
new and superior variety, from France. Cultivated by Messrs. Edward Sparhawk, of Brighton, and Aaron D. Williams, near -Boston.

10. BLÁCK BIGARREAU OF SAVOY.

A variety lately imported from Savoy, and the vicinity of the Alps, by George Brown, Esq., of Beverly, and much resembling the Bigarreau Gros Noir, or Tradescant's Black Heart. Fruit very large, black, flesh firm or hard, and good; ripening in August, or very late.

\section{1. *MANNING'S BLACK BIGARREAU.}

New, valuable, and originated by Mr. Manning. Large, round, and black; the flesh sweet and of excellent flavor; ripening in August, and highly deserving a place in every good collection. The tree grows handsome, is very productive; the foliage very large, shielding the fruit.

\section{MADISON BIGARREAU.}

-New, valuable, and very productive ; originated by Mr. Manning. Large, amber colored next the sun, pale in the shade; flesh firm, flavor excellent ; ripening in July.

\section{2. *NAPOLEON BIGARREAU.}

Bigarreau Napoleon, Louruan, Hort. Soc. Cat.

Latermann. Dr. Willich. Bigarreau Gros Monstreux. Thom.

Gros Bigarread de Lauermann.

The tree is extraordinary for the vigor and beauty of its growth; the leaves are very large, and plain or smooth on their upper surface; the fruit very large, heart-shaped; pale yellow in the shade, with bright red spots next the sun ; flesh remarkably white, solid, of a sweet, and agreeable, and excellent flavor. The largest and most beautiful of the heart-shaped cherries. It ripens early in July.

13. WHITE BIGARREAU.

Graffion. Lind. Bigarreav. Hooler.

TURKey Bigarreav.

Very large, obtuse, heart-shaped; fine red next the sun, yellowish amber color in the shade ; flesh firm, white, sweet, and well-flavored. A beautiful and excellent fruit, not very productive. The tree, says Mr. Hooker, "evidently ex hibits the characteristics of age and debility."

14. *BLACK EAGLE.

Of a size varying from medium to large, obtuse heart formed ; of a dark purple color, or nearly black ; flesh very tender, rich, and of excellent flavor, and ripens early. 
The tree grows strong and very upright, and is very productive; the leaves very large. This new variety was sent by Mr. Knight, in 1823, to the Hon. John Lowell, and was raised by Miss Elizabeth Knight, of Downton Castle, in 1806, from a seed of the Bigarreau, fertilized by the May Duke.

\section{5. *BLACK HEART.}

\section{Guignier a Frutr Notr. Duh.}

Rather large, heart-shaped; dark purple, approaching to black at maturity; the flesh is dark red, tender, of excellent flavor. Ripe early in July, and a good bearer. The true Black Heart is one of the best of cherries.

\section{6. *BLACK TARTAREAN.}

Black Rugsian, Black Circassian, Superb Circassian.

Frazer's Black Tartarean, Ronald's Beack Heart, Pom. Mag.

Very large and beautiful, and of most superior quality ; heart-shaped; of a dark purple or black color; the flesh firm, dark red or purple, and of most excellent flavor. The tree is elegant; of upright and extraordinary rapid growth; its productiveness very great. It ripens the first of July. Supposed to have originated in Spain; thence carried to Circassia, or Russia ; from Russia it was brought to England, in 1796, by Mr. John Frazer. - Pom. Mag. - But according to Mr. Hooker, it was brought from Circassia, in 1794, by Mr. Ronalds.

\section{7. *DOWNER CHERRY.}

A new and valuable variety, reared by Samuel Downer, Esq., of Dorchester. The tree is very vigorous, and upright in its growth; the leaves very large, dark green; a constant and great bearer. A large, light red cherry, of roundish form; the flesh firm, flavor good and sprightly. Very late, and one of the most productive. It ripens after most other superior varieties are gone, and is on this account the more valuable, and highly prized in the markets.

\section{DOWNTON CHERRY. Hort. Trans. Thomp-} son.

A new variety, raised by Mr. Knight, from the Elton or Waterloo. It is large; nearly round, inclining to heartshape; of a pale yellow color, sprinkled with minute red spots and larger patches of dull red or maroon; the flesh pale amber color, tender and juicy, very sweet and highflavored. An excellent fruit. The tree bears well. 
19. ELTON. Mr. Knight. Hooker's Pom. Lond. PI. vir.

Raised by Mr. Knight from the seed of the Bigarreau and pollen of the White Heart. The tree is very vigorous and very productive. The fruit is pretty large, heartshaped; pale glossy yellow in the shade, but marbled with bright red next the sun; the stalk slender, two inches long; the flesh firm, sweet, and rich. Very early. Sent, in 1823, by Mr. Knight, to the Hon. John Lowell.

20. FLORENCE. Hort. Trans. Vol. iI. p. 229.

Large, heart-shaped, depressed ; of a yellow amber color, marbled with bright red in the shade ; bright red next the sun; tolerably firm, juicy, rich, and sweet. A beautiful cherry, introduced by Mr. Houblon, from Florence.

\section{1. *GRIDLEY.}

This excellent variety, which is sometimes called the Apple Cherry, originated on the farm of Deacon Samuel Gridley, of Roxbury. The tree bears constantly and very abundantly. The fruit is of handsome size, round, black; the stalk short; the flesh very firm, like all others of the Bigarreau class; juicy, of a fine, vinous flavor. During long-continued storms, it is sometimes liable to crack at maturity. A popular fruit for the market. It carries well, and is ripe soon after the early cherries are gone, or early in July.

\section{HEREFORDSHIRE BLACK. $\boldsymbol{R}$. $\boldsymbol{M}$.} Late Black Heart.

A large, black, and heart-shaped cherry; a most excellent fruit; a great bearer, and more valuable for ripening late, when most varieties are gone.

23. RED RUSSIÁN CHERRY.

A new and superior variety, which was imported from Russia, about thirty years ago, into Brooklyn, N. Y.; its original name lost. A large, dark red cherry, of excellent flavor and quality. Ripening very late, or in August. The tree is very productive.

\section{4. "SPARHAWK'S RED HONEY CHERRY.}

A most superior native fruit, and so named for Edward Sparhawk; Esq., of Brighton, who has introduced this capital variety to notice. The tree grows upright and handsome, and is wonderfully productive. The fruit is large, bright red,' tender, juicy, of a very sweet and delicious 
flavor. It is sometimes called the Honey cherry. A fine, profitable cherry, from its excellent qualities and very extraordinary productiveness, to cultivate for the market. It ripens late, and is one of the best of all cherries.

25. WATERLOO. Hort. Trans.

A large, round, dark red fruit, inclining to black at maturity; the flesh is firm, and of excellent flavor. Raised by a daughter of Mr. Knight, and so named from its perfecting its first fruit soon after the battle of Waterloo. The tree is of strong, but irregular growth. This fruit was sent by Mr. Knight, in 1823, to the Hon. John Lowell.

\section{6. *WHITE TARTAREAN.}

Transparent, White Transparent Crimea.

Rather large, beautiful, and obtuse heart-shaped; pale yellow, approaching to an amber color next the sun; flesh half breaking, and of excellent flavor. A much admired fruit, which ripens early in July. The tree grows upright and handsome, and bears well; the leaves are large, smooth. One of the best fruits of the class of white cherries.

\section{Chass II.}

DUKE CHERRIES, MORELLOS, \&c.

\section{7. *ARCHDUKE.}

LATE DUKE. Thompson.

Griotte de Portugal. Duh. Portugal Duke.

A large, globular-formed, red cherry; like the May Duke, it grows in clusters; but the tree grows more vigorous than that variety. An excellent cherry, and a great bearer. It ripens in July, and hangs a long time on the tree, improving in flavor; and is, on all accounts, a valuable fruit.

28. BELle DE CHOISY. Pom. Mag. Bon Jard.

Doucette, Cerise de Palembre.

A middle-sized, roundish fruit, growing in pairs on a forked stalk; skin transparent, red, mottled with amber; the flesh amber-colored, tender, and sweet; ripe rather before the May Duke. It bears well as a standard. 
29. BELLE ET MAGNIFIQUE.

This fine cherry was introduced to notice by General Dearborn. The tree is of vigorous growth, and moderately. productive; the fruit of the largest size; round, of a dark red color, mottled with white spots, and abounding in acid. Valuable from its late maturity. The fruit is from France.

30. *EARLY PURPLE GRIOTTE. Thompson.

Of medium size, heart-shaped; of a dark red color; flesh tender and excellent: It ripens the beginning of June. A valuable cherry, particularly for its early maturity.

\section{GERMAN DUKE.}

Griotte d'Alesmage. Nouv. Cours Complet d'Agr.

De Chaux, Du Comte de Saint Maur; 16 .

Equally as large as the Archduke; almost as black; the flesh deep red, and very acid. "It ripens the middle of July. The tree is of middle size, and not very productive.

\section{2. * MAY DUKE.}

A large, globular, red cherry, usually growing in clusters. At maturity the flesh is tender, juicy, of an agreeable but acid flavor. This kind is usually gathered in June, and while it is yet sour and immature, for the markets, being one of the earliest varieties. The tree is of moderate vigor, compact in its form, and productive.

\section{MONTMORENCY.}

Cerisier de Montmorency a Gross Fruit. Bon Jatd.

Long. Stem Montmorency.

The fruit is large, flattened at its extremities, of a lively red color; the flesh of a yellowish white, slightly acid, and excellent. The tree is not very productive. It ripens in July. The Short Stem Montmorency, or Gros Gobet, is a fruit of less size, and the tree less vigorous.

\section{MORELLO.}

Milan. Lang. Cerise do Norn of Noisette. Lind.

Middle-sized, round; nearly black at maturity; tender, juicy, of an agreeable flavor, in which much acid predominates. July. This fruit is used for preserving.

\section{5. *PLUMSTONE MORELLO.}

A very large, dark, round cherry, nearly black, of a rich, acid flavor, and deemed superior to all European Morellos. The stone is very large, and resembles that of a plum. A native fruit from Virginia, introduced to no- 
tice by William Prince, Esq., of the Linnæan Botanic Garden; Flushing.

\section{ORNAMENTAL VARIETIES.}

\section{LARGE DOUBLE FLOWERING CHERRY.}

The tree is of vigorous and upright growth; the flowers are very large, very double, and beautiful, resembling clusters of small roses. The appearance of the tree when in full blossom is striking and highly ornamental. The tree belongs to the Merisiers, or trees of the first class.

37. SMALL DOUBLE FLOWERING CHERRY.

The tree is of slow, dwarfish growth; the blossoms, however, are not less beautiful than the preceding. The tree belongs to the Morellos and Dukes, or to the second class. 38. SERRULATE DOUBLE FLOWERING CHERRY.

Cerasus Serrulata pleno.

This new variety is one of the most beautiful of all the double flowering cherries. Both this and the following kind were introduced to America in $\mathbf{1 8 4 0 .}$

\section{CHINESE LARGE DOUBLE FLOWERING CHERRY.}

Cerasus Graxdiflora Sinengis pieno.

By information lately received from Mr. Lee, this variety is understood to be new, and more beautiful than the Serrulata, or any other species of double flowering cherry. 40. TOBACCO LEAF.

Bigarreavtier a Feullees de Tabac. Bon Jard.

A small, pale red fruit, of indifferent flavor; a poor bearer. The growth of this tree is strong, but crooked; the leaves of enormous size. It is said to have received its name from the supposition that its fruit would prove proportionally large; cultivated only as a curiosity. The tree belongs to the first class.

\section{VIRGINIA WILD CHERRY.}

Cerases Virginiana.

A native. It is found growing wild in the forests and pastures, and is a distinct species from any others here 
described. The trees grow large, and the fruit is produced in clusters, like currants. It is very small, of a pleasant sweet, slightly bitter, and very astringent taste. This variety is one of the most esteemed of all for brandy.

\section{WEEPING CHERRY.}

\section{Cerisier de Siberia.}

This beautiful tree is of low growth, its branches slender and drooping; its leaves are very small, oblong, lanceolate; they are of a deep shining green above, and of a pale. shining green below. The fruit is small and nufmerous, of a bright red color, and extremely acid. This highly ornamental tree is generally inoculated at an elevated height on the Mazzard cherry.

\section{COLONG DWARF CHERRY.}

A new species of cherry, a native from beyond the Rocky Mountains, and near the sourcés of the Columbia River; lately brought thence by the hunters from the far West. A low tree or shrub, the leaves small, oblong, serrated, pale green. When but two feet in height, it blossoms profusely. The fruit is a cherry of a small size and oval form; of a black color and pleasant taste. It bears very abundantly, and the branches, when loaded with fruit, sometimes trail on the ground.

\section{CULTIVATION.}

The stones of the cherry are sown in autumn, in a rich, well-prepared soil. The second year they are transplanted to nursery rows four feet asunder, and at a foot distance from each other in the row. They are inoculated the third year. The best soil is a rich, dry, sandy loam, or calcareous soil, and an elevated situation. A cold, clayey, moist soil does not suit them. If the tree grows in suitable form, pruning is neither much practised nor recommended.

The suitable distance for planting the cherry tree in orchards, varies according to the goodness of the soil, and other circumstances,.. and may be stated generally at from fifteen to twenty feet asunder. 


\section{UL B E R R Y . - (Morus.)}

The mulberry is a genus comprising many species. Its origin has been assigned to China; but several species are found growing in a wild state in America. The fruit is a berry of a roundish or oblong form; of a color varying from white to red or black; its pulp envelops numerous sinall seeds.

Uses. Most of the varieties of the mulberry are esteemed dessert fruits. When perfectly mature, they are grateful to the taste and very wholesome. The sirup is useful in mitigating inflammations of the throat. The juice, when properly fermented, affords a pleasant vinous wine. Mixed with apples, they afford a delicious beverage called mulberry cider, of a deep red color, like Port wine. Lastly, the leaves of the various species of the mulberry constitute the principal food of the silk-worm. Not every kind, however, is equally suitable. Those most esteemed are the Mrorus alba, M. lucida, M. tartarica, M. Moretti, M. Dandolo, Mr. Multicaulis, and the new Canton variety.

\section{VARIETIES.}

\section{BLACK MULBERRY.}

Morus Nigra.

This tree is a native of Asia Minor. It rises from twenty-five to thirty feet. The leaves are large and rugged. Its fruit is large, black, aromatic, juicy, subacid, and good. An agreeable wine is made from its juice. The juice is used for imparting a dark color to liquors; the bark of the root is a powerful cathartic; and from the bark of the tree, strong cordage and brown paper are made. RED MULBERRY.

\section{Morus Rúbra.}

A native of America. The tree rises to the height of from thirty to forty feet; the leaves are large, cordate, often palmated, and more often three-lobed, dark green above, downy beneath, rugged; the fruit is of a very deep red color, and excellent. This variety is esteemed superior to the Black mulberry as a fruit, and the tree is more hardy.

For an account of other useful varieties of mulberries, see the Appendix. 


\section{ULT I V A T I O N.}

These varieties of mulberry will flourish in almost any soil, but grow most luxuriantly in a deep, sandy loam, rather in a humid than dry soil. They are propagated by seeds or by layers, and sometimes by cuttings. The seeds are obtained by washing the bruised pulp of thoroughly ripe fruit; they are carefully dried, and sown early in April, in a rich soil, and covered to the depth of half an inch with loam, and pressed down compactly. The second year, they are transplanted to nursery rows.

\section{I N E.-(Vitis vinifera.)}

The grape vine is a deciduous tree, with an irregular, contorted stem, and long, flexible branches. They trail on the earth, or, connected by their tendrils to trees, they rise vertically, even to the summits of those which crown the forest. The leaves are large, smooth, or downy, serrated, lobed, or entire. The leaves and footstalks of the white or yellow grapes, change from a gréen to a yellow color, late in autumn; and those of the red or black grapes, to a reddish hue. The blossoms are produced in long clusters or racemes, from the wood of the same year; they possess a fragrant odor. The fruit is in clusters, the berries round or oblong; their color varying from white or yellow to red, to blue, or to black. The pulp contains a juice, rich, saccharine, and abundant, of surpassing flavor. The berries contain from one or two to five small stones. Those, however, of the Ascalon, or Corinth, and the Sultana, have none.

The vine is a native of the temperate regions. Its history is traced to a very ancient date in Persia. It is cultivated extensively for wine in every part of Europe favorable to its growth, from the Mediterranean Sea to the latitude of $51^{\circ}$; also in South Africa, and the African isles of the Atlantic, and in Greece. It is also cultivated in Barbary and Egypt, and in all those parts of Asia 
which are possessed of a suitable climate; but not, however, so much for wine, its use being forbidden to the disciples of Mohammed. It does not flourish within the tropics; it may, indeed, grow there, but produces but little fruit, except in the mountainous elevations. Yet in some tropical countries, as at Bombay, where unceasing summer allows no rest to the vine, or its wonted repose, they give them, by artificial means, a suitable season for slumber; and the vine, thus recruited, becomes productive. [See Cultivation.]

The vine is extremely long-lived : it is stated that some have lived six hundred years; and, according to Bosc, there are vines in Burgundy four hundred years old. The native vines of America, as of other countries, ascend to the summits of the highest trees of the forest, growing sometimes of enormous dimensions. And vine timber is stated to be of very great durability; of this fact, the long life to which the vine tree will attain, might alone be deemed sufficient evidence. It is deemed too valuable to be applied to common purposes, its use being confined, almost exclusively, to furniture, statues, \&c.

Uses. The fruit of the grape has been highly prized, in all ages, as a delicious and wholesome dessert fruit. They are used as preserves, in pastry and in cookery. Sugar is also made from the juice of the grape, good, but coarse-grained; and the unfermented juice, when boiled to the consistency of honey, is esteemed a delicious article of food, being used, both in Europe and in the Mohammedan countries, either with or without sugar, as butter or honey is used.

$R$ aisins are prepared from the matured fruit of the grape. The clusters, without being separated from the branches, are dipped in a ley of wood ashes, containing a small portion of the oil of olives, and then dried by exposure to the sun. By another mode, though not so good, they are dried in an oven. Raisins are esteemed, not only as a delicious, but a wholesome and nutritious food, when used in moderation. They are of extensive use, both for the dessert and in cookery. A good wine may also be pre pared from them.

The grapes which are imported from France and Spain, are packed in alternate layers of saw-dust, which has been thoroughly dried in an oven; and we are assured, that 
grapes may be preserved a year, by being gathered in the afternoon of a dry day, and enclosed in a dry, tight cask; being laid singly, and in layers, between alternate layers of thoroughly kiln-dried bran.'

Sherbet constitutes a cooling and wholesome drink of the Mohammedans. It consists of the unfermented juice of the grape, mixed with water, sugar, and spices.

The unfermented juice of the grape, which constitutes the essential elements of wine, consists of, 1st, water; $2 \mathrm{~d}$, sugar; 3d, tartaric acid; 4 th, mucilage ; each in different proportions. But after fermentation, wine contains," by chemical analysis, 1st, water ; $2 \mathrm{~d}$, alcohol ; $3 \mathrm{~d}$, sugar ; 4 th, tartaric, carbonic, and malic acids. It also contains tannin, a coloring matter, and a volatile oil.

Gross or watery wines are extremely difficult to preserve and manage. It is far otherwise with those which contain a suitable proportion of the essential elements; these being comparatively of very easy management. Where the elementary principles are deficient, they should be added at once in the beginning, and before the fermentation has commenced.

In modern France, sugar is now added, when its presence is essentially wanting; and vineyards which before would never make any thing, or but very poor wine; are now, by this addition alone, rendered productive in good wine; and the sugar produced from the potato, is now, it is said, much used for this purpose in that country; - and for this purpose it seems to be peculiarly adapted, its taste being intermediate between the sugar of the cane, and the sugar which is produced from the grape.

From a pound and a half of potato starch, one pound and a quarter of crystalline brown sugar has been obtained. And starch, according to Davy, is converted into sugar by the very simple process of boiling in very diluted sulphuric acid. One hundred parts of starch, four hundred parts of water, and one part of sulphuric acid, by weight, are kept boiling for forty hours; the loss of water by evaporation being supplied by new quantities. The acid is to be neutralized by lime, precisely as the acid which is contained in the juice of the sugar-cane is neutralized, and the sugar is crystallized by cooling.

The moderate use of good wine is deemed wholesome, especially to convalescents recovering from malignant fe- 
vers, and to those of debilitated habits, as it accelerates the circulation. On the other hand, its too liberal or immoderate use undermines the constitution, and lays the foundation of a train of diseases. It paralyzes the mental faculties, and induces those disorders of body which not uncommonly terminate in death.

The varieties of the grape are very numerous. The following comprises a selection of the best varieties known.

\section{Varieties.}

In the arrangement of grapes, I have divided the whole into five classes.

Chass I. Those called Chasselas grapes. These are early.

Crass II. Those called Muscats, or Frontignacs. The Muscats are more tardy in ripening than the Chasselas grapes.

Class III. Other foreign varieties. Black, blue, and purple grapes.

Class IV. Other foreign varieties. White grapes.

Class V. American grapes.

\section{CIASS I.}

\section{CHASSELAS GRAPES.}

The Chasselas grapes are in high estimation at Paris, and in the north of France, as well for their excellent quality, as for their early maturity.

1. WHITE CHASSELAS.

Royal Muscadise, d'Arbotcr; For. Lindley.

Chasseras de Fontainbreau. Bon Jard. Sweetwater.

The wood grows pretty strong; the bunches are large and shouldered; the berries are large, round, greenish yellow, golden or amber-colored at maturity; the flesh is juicy, rich, vinous, and excellent. A capital and very productive variety. At Paris it is generally cultivated on walls. Near Boston it is considered one of the very best for our climate, ripening well its fruit in open culture, in 
favorable seasons and situations. A gentleman here, of great experience and observation, is confident that the Sweetwater, and the Chasselas de Fontainbleau, are but one and the same; and that the difference which they sometimes assume, is owing to no other causes; than a difference of exposition.

\section{2. *GOLDEN CHASSELAS.}

Chasselas Doré, Bar gur Aube, Duh. Bom Jard.

Ratsin de Champagne. Bon Jard. p. 366.

YELLOW CHASSELAS OF THOMERY.

Gros Covlard.

The wood of this fine variety is of medium vigor, the joints short; by this it is distinguished from the White Chasselas. It is also a fortnight earlier than that variety, but is not so exuberantly productive. The bunches are large; the berries large and round, of a yellow amber or gold color, melting, pleasant, sweet, and excellent. The bunches of this variety are somewhat peculiar, having mostly quite large berries, intermixed with some few of small size on the same bunch. This fine variety has been introduced by S. G. Perkins, Esq., and produces good crops in open culture in warm expositions. To produce great crops, and enable the fruit to set well, it must be screened from high winds from the time of blossoming till the fruit becomes of the size of peas. The Chasselas Doré, Bar sur Aube, of the old Duhamel and the Bon Jardinier, must not be confounded with the White Chasselas, or Chasselas de Fontainbleau, which is sometimes miscalled by this same name.

\section{BLACK CHASSELAS." Lindley.}

Chasseuas Notr of the French.

Buack Muscadine of the English.

The bunches are the size of the White Muscadine; the berries are of a globular form, of a black color, and covered with blue bloom; the flesh is rich, and of very good flavor. 4. MUSK CHASSELAS. Duh. Bon Jard.

Chasselas Musque. Bon Jard. Duh.

The bunches are of medium size; the berries are round and of moderate size, of a green or greenish yellow color; the pulp is sweet, high-flavored, and musky. This variety is rather later than the Golden and White Chasselas.

5. RED CHASSElas. Bon Jard. For. Lindley.

Chasselas Rouge. Bon Jard. Red Muscadine.

The bunches are of medium size, but very compact; the 
berries smaller than the White Chasselas, of a dark red color, sweet, and of good flavor. This variety is not so early as the White Muscadine.

6. VARIEGATED CHASSELAS. Neill. Lindlcy.

A new variety, raised by Mr. Knight, from the seed of the Chasselas, fertilized by the pollen of the Aleppo. The berries are striped, and very beautiful, with a thin skin, and juicy. The leaves in autumn become variegated with red and yellow. A very productive and hardy variety, ripening well in the open air. Thus has Mr. Neill described it, According to Mr. Lindley, the bunches are long, the berries rather small, globular, deep purple next the sun, tender, very-saccharine, and of pretty good flavor.

\section{CLASS II.}

MUSCATS, OR FRONTIGNACS.

The Muscats, or Frontignacs, are highly esteemed for their delicate and delicious musk flavor. They are not quite so early in their season of maturity as the varieties of Chasselas, and require more heat of climate.

7. BLACK FRONTIGNAC. Forsyth. Lindley.

Bloe Frontignac, Violet Frontignac, Speechly.

Muscat Nolr of the French.

The bunches are rather short, and below medium size, and loosely formed; the berries are of medium size, round, black, and covered with blue bloom; the flavor is vinous, sweet, and musky. This is not so highly esteemed at Paris as the White Muscat. It rarely ripens in open culture, either there or near Boston.

\section{CANNON HALL-MUSCAT.}

The bunches are large; the berries large, oval, yellow or amber-colored; of delicious flavor. Each berry has but one seed. A new and very superior variety, in high repute in England. Earlier than the Muscat of Alexandria, and fully equal to that variety. It is stated, that at Chatsworth the duke of Devonshire has a vineyard completely filled with this farorite variety. A favorite also, and much cul- 
tivated at the celebrated fruit establishment of Mr. Wilmot. It requires considerable heat, and is very productive.

\section{RED FRONTIGNAC. Mr. Neill.}

Grizzly Frontignac, ib. Moscat Rovge: Bon Jard.

The bunches are rather large, long, and moderately compact; the berries are pretty large, round, of a red color, and of a high vinous and musky flavor. This variety ripens earlier than the White Frontignac, and although not so high-flavored as that variety, it is more esteemed in France than the Violet and Black Muscat.

10. RED MUSCAT OF ALEXANDRIA. For. Lind. Red Frontignac of Jerusalem of Miller.

It resembles the White, except in regard to color. The bunches are rather large, and shouldered; the berries rather large, oval, of a red color; the skin is thick; the flesh firm, juicy, saccharine, musky, and high-flavored. Bradley calls this one of the very best of grapes. It is also said to be more esteemed about Paris than the White Muscat ; and there, against good walls, it ripens very well.

\section{1. *WHITE FRONTIGNAC.}

Muscat de Frontrgac, Mubcat Branc, Bon Jaid.

The bunches are very long, conical, compact; the berries the size of the Chasselas; round, a little elongated; white, but slightly yellow next the sun; the pulp white, crackling, of an exquisite sweet and musky flavor. Very productive, Highly esteemed near Boston, where its cultivation is principally confined to vineries, as it-seldom comes to maturity in out-of-door cultivation.

\section{2. *WHITE MUSCAT OF ALEXANDRIA. Neill.}

Weite Malaga. Hort. Soe. Cat.

Muscat d'Alexandria Branc. Bon Jard.

Passe longue Musque. I $b$.

Muscat of Jerusalem. Miller.

Passe Musquée. Hort. Soc. Cat.

The bunches are very large, long, irregularly formed; the berries very scattering, large, oval, of an amber color at maturity; the skin is thick; pulp hard, musky, juicy, racy, and high-flavored; the berries have one or two seeds, or none. Highly esteemed by the English; it is also highly esteemed at Paris; but they consider their climate too cold for all the Muscats. The Muscats are there placed in the angle formed by two walls, the one facing east, the other south. In the Catalogue of the London 
Horticultural Society, the Malaga is put down as a synonyme of this.

13. *WILMOT'S EARLY MUSCAT.

Wilmot's Early Prolific Muscat.

A new seedling grape, of the Muscat' species, which is stated to be one of the most productive bearers. In the vinery it produces its ripe fruit in perfection from March till October. 'This is one of the four principal kinds which, exclusively, are cultivated for profit by Mr. Wilmot, of Isleworth, near London, - the selections of all others.

\section{CLAss III.}

\section{OTHER FOREIGN VARIETIES.}

\section{BLACK, BLUE, AND PURPLE GRAPES.}

\section{ALICANT. Miller. No. 31.}

Black Portugal. Hort. Cat. Brack Spanish of some.

Teinturier. Hort. Cat. Gros Notr d'Espagie.

Bunches very long, unshouldered; berries of moderate size, somewhat oval; skin thick, of a black color; flesh tender, juicy, of an agreeable flavor; the seeds very large. In autumn the leaves become beautifully variegated with green, red, and yellow. This vine requires heat or a warm exposition.

15. *BLACK CAPE.

The bunches are very large and shouldered, sometimes weighing over two pounds; the berries extraordinary large, oval, and black; of excellent flavor and quality. In highlyfavorable seasons and situations, it ripens well in the vicinity of Boston in open air. Imported by S. G. Perkins, Esq., from the Cape of Good Hope. An acquisition to the country. It is a most productive variety ; and three vines, in open culture, have ripened at Mr. Perkins's more than 500 pounds in a single season.

16. BLACK DAMASCUS. Lindley.

The bunches are middle-sized and loosely-formed; the berries are globular and of different sizes; the large berries have two seeds, the small have none; their color is black; flesh delicate, juicy, and of most superior flavor. 


\section{7. *BLACK HAMBURG.}

WARNER's Black HambURg, according to Lindley.

Red Hamburg. Hort. Soc. Cat.

The bunches are large, well-shouldered, and compact; their breadth is nearly equal to the depth; the berries large, oval, of a deep purple color, or nearly black, and covered with a blue bloom; the flesh is tender, saccharine, and of excellent flavor. A very productive and excellent variety; a great favorite at Boston, and much cultivated in their grape-houses. In favorable seasons and situations, it ripens. at that place in open culture. The wood of this variety is strong and luxuriant; the clusters of fruit are beautiful, and sometimes weigh two pounds.

\section{BLACK LOMBARDY. Loudon's Mag. Lind-} ley. For.

West's St. Peter's. Lindley.

The wood is short-jointed; the bunches are long and large-shouldered; the berries are large, round, black at maturity; the skin is thin; the pulp juicy and high-flavored.

\section{9. *BLACK PRINCE. Neill. Hort. Trans.}

Lison', or Portugat, according to some.

Cambridge Botaxic Garden Grape of some catalogues.

The leaves are broad, deeply-lobed, widely-serrated, their long footstalks tinged with red; the bunches are very long, sometimes, but rarely, shouldered; the berries are oval, dark purple, and covered thick with blue bloom; the flesh is pale, juicy, sweet, and well-flavored; each usually containing five. seeds. This excellent grape, it is stated, sometimes ripens even on the open walls in the south of England; the bunches have sometimes weighed a pound and a half.

20. BLACK RAISIN GRAPE. Lindley. For.

The bunches are large, long; the largest are shouldered; the berries are large, black, of an oval form; the skin is thick; the flesh is firm, juicy, and very high-flavored. The wood is long-jointed.

\section{BLACK S'T. PETER'S.}

\section{Black Grape, from Palestine. Speechly.}

The bunches are large, long, sometimes shouldered; they resemble the Black Hamburg, but are longer; the berries are large, roundish oval, of a black color, and thin skin ; very juicy, delicate, and fine-flavored. Near Bostoin, this grape is seldom cultivated, except under glass. 


\section{MILLER'S BURGUNDY.}

Le Meunier, Morillon Jaconné.

The bunches are short and compact; the berries small, round, black, and covered with blue bloom; the flesh is tender, juicy, very sweet, and good-flavored; the under surface of the leaves is covered with hoary down, like meal; hence the name of Miller's Grape. One of the hardiest varieties, and extensively cultivated in Burgundy for wine. 23. *CONSTANTIA.

The wood of this variety is large; the leaves rough and downy; the bunches are of good size; the berries are round, of a purple color, and of a most delicious, sweet flavor. The fruit ripens well in the open air in our climate, but only in highly-sheltered situations. The berries contain but two seeds, and sometimes but one. This grape was imported by S. G. Perkins, Esq., from the Cape of Good Hope, and is supposed to be one of the most valuable in the country, and remarkably productive.

\section{ESPERIONE. Hort. Trans. Vol. III. p. 93.}

Turner's Black. Hort. Cat.

The bunches are large, the size of the Black Hamburg, shouldered, pretty compact; the berries are round, or flattened at the head, of a deep blue or black color, and covered with bloom; the flesh adheres to the skin, and, though neither melting nor high-flavored, is pleasant. The Esperione is productive to an extraordinary degree, very hardy, very early, equally so with the Sweetwater and Muscadine; and in unfavorable seasons, has a decisive advantage over these varieties.

\section{FRANKENTHAI. Lindley.}

Frankendale.

The bunches are large and well-shouldered; they somewhat resemble the Black Hamburg; the berries are oval, flattened at the head, indented at the side, of a purple or black color, covered with blue bloom; the flesh is tender, juicy, rich, sweet, and of excellent flavor.

26. GROS GUILLAUME. N. Duh.

The bunches very large and compact; the berries are large, oval, black, and covered with azure bloom; the skin is thick; the flesh green, melting; the juice abundant, and without color, pleasant, and sweet. They have generally three small seeds. It produces abundantly, ripening the middle of September. In good years it ripens well on 
espaliers. Its cultivation is not yet extended in the environs of Pars, but it merits to be cultivated for the table.

\section{GROS MAROC.}

\$ The bunches are of good size, sometimes very large ; the berries are large, oval, of a dark purple or violet color, and covered with bloom; the skin is thick; the flesh juicy and high-flavored. It ripens in open culture near Boston, but only in favorable seasons and situations.

\section{LANGFORD'S INCOMPARABLE. Lindley.}

' The bunches are of good sizé, compactly-formed, and shouldered; the berries are of moderate size; the smallest are round, the largest oval, of a dark purple color, covered with blue bloom. The flesh is tender, juicy, saccharine, and resembles the Miller's Burgundy. Mr. Lindley states that a single vine, growing at Mr. Langford's, produced two hundred and twenty-five pounds in a single year; he esteems it the best and most hardy out-of-door grape known in that country.

29. *SEEDLING OF BLOOM RAISIN. Thompson.

$A$ new and superior váriety, produced for exhibition from the garden of the London Hort. Soc.' in 1S37. Bunches as large as the Black Hamburg, but more loose; berries blacker, and of higher flavor. It ripened by the side of the Black Hamburg near a month earlier; hence it will be duly appreciated by those who cultivate early fruits. One of the most deserving fruits which appeared. Thus was it described by Mr. Thompson,

\section{0. *WILMOT'S NEW BLACK" HAMBURG.}

Nëw Dutch Black Hamburg.

A new and capital variety, extensively cultivated by $\mathbf{M r}$. Wilmot at Isleworth. The bunches are large; the berries larger than those of the Black Hamburg, and in appearance very remarkable, resembling bodies, rendered globular by the blows of a hammer. A vêry large and beautiful fruit, of a dark blue-black color, and covered with fine azure bloom; delicious, excellent, and very productive.

\section{RED, OR REDDISH PURPLE GRAPES.}

\section{POONAH. Hort. Trans. Vol. Ivं. p. 516.}

The bunches are large, well-shouldered, tapering to a point; the berries are nearly oval; pale red in the shade, 
but darker red next the sun; sweet, but not very juicy; they have generally' but two' seeds. This vine was introduced from Bombay by Sir Joseph Banks, in 1817. The grape keeps a long time, and is extensively cultivated at Poonah, and the ripe fruit sent thence annually to Bombay and its dependencies. This grape eminently deserves trial. 32. RAISIN DE CARMES. Hooker's Pom. Lond. Pl. $x$.

Raisix de Cab́o. For. Neill.

The vine is vigorous and bears well; the fruit is in long, loose bunches; the berries very large, interspersed with a few of small size, of an irregular, oval form; the skin is rather thick, of a dusky reddish purple, covered with bloom ; the flesh is rather firm, extremely rich, though somewhat acid; the seeds are large, seldom more than one.

33. RED HAMBURG. Mr. Neill.

WARNER'S RED HAMBURG. Ib.

Brown Hamberg. Hort. Soc. Cat.

Gibraltar. I $b$.

The bunches are large and similar in size and shape to the Black Hamburg; the berries rather large, oval, dark red or purple; the skin is thin; the flesh juicy, delicate, and vinous. This variety, according to Mr. Lindley, is the famous Hampton Court vine:

\section{CHASG IV.}

OTIIFR FOREIGN VARIETIES.

WHITE GRAPLS.

34. EARLY WHITE MUSCADINE. For. Neill. White Muscadive, Royal Muscadine, Pom. Mag.

Amber Muscadine: For.

Early White Grape of Teneriffe of Speechly.

The bunches are generally small, but very numerous; but they are sometimes considerably large, loosely-formed, and shouldered; the berries are round, medium-sized, of an amber color; the flesh is firm, saccharine, rich, but not high-flavored; very productive; and, for the certainty of its ripening, it is considered one of the best European varieties for a northern climate. 


\section{WHITE CORINTH.}

Corintue Blasc. Duh. and Bon Jard.

The bunches are small, oblong, compact; the berries very small, round, yellow, juicy, sweet, and without seeds. The Violet Corinthe differs from this only in color, and is probably identical with the Black.Corinth, Zante, or Black Ascalon, known in commerce as the Zante currants, which we receive from the Mediterranean in a dried state. It has been estimated that 6000 tons are annually shipped from the Ionian Islands.

36. MALMSEY MUSCADINE. For. Lindley.

Marvorsée Musque of Bradley.

It resembles the White Muscadine, but the bunches and beries are smaller. It is very sweet, and of high flavor; it bears well, and is a valuable grape. It requires a vinery in England - so say Forsyth and Lindley. Bradley says it is one of the richest musked grapes; that it came from Montserrat, and grows plentifully about Turin.

3\%. PITMASTON WHITE CLUSTER. Hort. Trans.

Raised by John Williams, Esq., of Pitmaston, from the seed of the Aivernat, or Miller's Burgundy. The bunches are rather larger than the Auvernat, compactly-formed. It ripens earlier than that variety or the Sioeetwater. The berries are round, a little flattened at the apex, of an amber color, but-bronzed with russet-next the sun; the flesh is tender and pleasant.

38, SCOTCH WHITE CLUSTER. Thom. Rivers.

The bunches are compact; berries roundish oval; of a white color; of a sweet and excellent flavor. This grape is very early and very productive.

39. *SWEETWATER, NEW GROVE END. Thom. Rivers.

A superior variety; the bunches long; berries oval, of a white color; skin thin; the juice sweet and excellent. Early and very productive. At Mr. Wilmot's celebrated fruit establishment, a superior and favorite variety is cultivated under the name of New-Sweetwater, which may prove identical with this.

40. SYRIAN. Mr. Neill.

One, of the coarsest of the grape kind; the bunches large, broad-shouldered, of very regular form ; the berries are large, white, oval; the pulp firm and hard, of tolerable 
flavor if well ripened. An excellent bearer ; and the bunches, when ripe, will remain many weeks longer than any other variety. This grape would not probably ripen in the open air in the climate of New England. Mr. Speechly has stated that he raised at Welbeck a bunch of this variety measuring nineteen and a half inches in breadth, twentyone and three fourths inches in depth, in circumference four and a half feet, and,weighing nineteen and a half pounds.' 'This is supposed to be the kind mentioned, Numbers XIII. 23.

\section{TOKAY. Duh.}

White Morillon. Speechly's Syn. Grizzly Muscat.

The bunches are of moderate size, compactly formed; the berries, inclining to oval, are rather small, faintly tinged with gray or red; saccharine and pleasant. This grape ripens in good seasons near Boston in open culture; and is the variety of which the celebrated Tokay wine is made. 42. VERDAL. Mr. Neill. Bon Jard.

Verdelho. Ib. Bon Jard. p. 367.

The vine grows vigorously; it is remarkably productive; the bunches are variable in size, but beantiful; the berries are oval, of a fine amber color, of a very rich, saccharine taste and good flavor.- Much cultivated in Languedoc, and there called Verdal. It was brought from thence to Paris, where it is highly esteemed as the best and sweetest of all dessert grapes; but it there requires a warm summer and the best exposition to bring it to maturity, when the bunclies become beautiful, the berries large, each containing two seeds. This is the Verdellio grape, of Madeira, of which Madeira wine is principally made.

43. WHTTE HAMBURG. Speechly. Lindley.

White Portugal, White Lisbor, Hort. Soc. Cat.

White Raisis, Raisin Muscat.

The bunches are large and loosely-formed; the berries large, of an oval form and greenish white color; the skin is thick, the pulp hard, and the juice sweet, slightly mixed with acid. Mr. Lindley informs us, that this grape is by many much admired, that it keeps long, and is the same that is annually imported into that country from Portugal, to the value of $£ 10,000$ in the winter season, and sold in the shops for Portugal grapes. We may perhaps ascribe its long keeping to jts hard pulp and thick skin, and would suggest that it might prove a profitable article of cultivation and export from the Southern States. 


\section{WHITE ST. PETER'S.}

Saint Pierre. Bon Jard. p. 363. Moscow.

The bunches are large, very beautiful, and compactlyformed; the berries are round, white, and excellent. A valuable new variety, and well deserving trial with us.

\section{ALEPPO. Speechly.}

RAISIN SuIsse.

The bunches are formed of berries of different colors; the berries are round, of medium size; sonie are black, some white, but mostly striped with black and white; the skin is thin, the flesh juicy, and of superior flavor; the leaves are beautifully and variously striped in autumn with red, green, and yellow. This grape is rarely cultivated near Boston; except under glass.

\section{CLAss V.}

\section{AMERICAN GRAPES.}

\section{ALEXANDER.}

Schurleill Muscader.

This vine is a great and sure bearer. A large grape, blue or black, somewhat eliptical ; sweet and luscious, when perfectly mature. Major Adlum states that he has made a wine of this grape, which Mr. Jefferson has pronounced "worthy the best vineyard in France." Not so suitable for the climate of Boston as the Isabella and $\mathbf{C a}$ tawba, and by no means equal to them.

\section{BLAND.}

Buand's Madeira, Mazzer.

This fine native grape does not ripen well in our climate, except in favorable seasons; and is thus described by Mr. Bartran in a letter to Doctor Mease :-

"The bunches are large, branched, and well-shaped, six or eight inches in length; the berries large, and round or oblate; when perfectly ripe, of a dark purple or red wine color; the juice sweet and lively, having a little musky flavor, with a small portion of an agreeable astringency, sonewhat like our best bunch wild grapes, though much 
sweeter than any of them. If this grape is what I take it to be, a genuine American, it is a hybrid, or variety:"

48. CATAWBA.

This superior variety was introduced to notice by Major John Adlum, of Georgetown, D. C., and is esteemed by him the very best native grape for making wine, known; and the wine made by him at his vineyard, of this grape, is deeined by good judges excellent. The bunches are of very handsome size and form, and shouldered; the berries are of a deep purple next the sun; the skin is thin, juicy, sweet, rich, and vinous, with a very little of the native or musky taste. This vine is very vigorous and hardy, requiring no protection, and is a great and certain bearer. This and the Isabella are, for the climate of New England, decidedly the very best native grapes hitherto known with us. Mr. Adlum has stated that he has no doubt but by his discovering the Catawba grape to be an excellent wine grape, that it will be worth to the United States one hundred millions of dollars before the end of this century. See his Memoir on the Cultivation of the. Vine in America.

\section{ELSINBURGH.}

Small, very hardy, and very productive; of a blue color, very juicy and sweet, free from pulp and musky taste.

\section{0. "ISABELLA.}

This fine native grape was introduced into New York about the year 1818, by Mrs. Isabella Gibbs, the lady of George Gibbs, Esq., of St. Augustine, then a resident of Brooklyn, L. I. It was received from Dorchester, Soutlı Carolina, and was named Isabella, in honor of that lady, by William Prince, Esq., of the Linnæan Botanic Garden. From him I first received this vine, about 1820. The vine is extraordinary for the vigor of its growth, and wonderful productiveness. It has been stated that a single vine in the garden of General Swift, of New York, produced above eight bushels per annum, during each of the years 1820 and 1821; and the astonishing produce which we have here witnessed, confirms our belief in all that has been stated. The bunches are of large size; the berries are large, of an oval form; of a dark purple color, approaching to black, and covered with bloom; the skin is thin, with but very little pulp; the flesh is juicy, rich, sweet, and vinous. By hanging the bunches in a room, it has been 
ascertained that they lose that very small portion of muskiness which they possess. This grape makes excellent wine, and requires no protection in our climate.

\section{LUFFBOROUGH.}

Berries very large, of a deep purple color; pulp dissolving in a sweet, musky juice. Major Adlum says, the Luffborough makes an excellent red wine.

\section{ธ2. *NORTON'S VIRGINIA SEEDLING.}

This very superior native grape was originated by Dr. N. Norton of Magnolia, one mile from the city of Richmond, in Virginia. The fruit is rather below medium size; fine as a table grape, and most excellent for wine. The wine is of a dark violet color, or of the color of Port wine, with a just proportion of astringency, and excellent flavor. The vine bears surprisingly. Not only the Catawba, but also the Prince Edward grapes, and the Norton's Virginia Seedling, are much cultivated by Dr. Norton and others of the vicinity of that city, where first I witnessed the wonderful crops of fruit which these vines bore. - Through the kindness of Dr. Norton, I am favored with a full account of this grape, which I subjoin in his own words. In all his statements I have perfect confidence.

“Vitis Nortoni. Produced by artificial impregnation from the Bland and Meunier. Foliage somewhat resembling the Bland. The shoots are of a red color, hardy, and resisting the greatest degree of cold which happens in any portion of the Union; thriving with little care, and never failing to produce abundant crops of fruit, which has not, within the last 15 years, been known to mildew or rot. Fruit blackish, or of a dark purple; ripens in September, and will remain perfect until the hardest frosts; largest bunches 9 or 10 inches long, sometimes shouldered, and moderately compact, weighing one fourth of a pound; must rich, and of a dark reddish violet color.

"Norton's Seedling stands unrivalled as a field and garden fruit in Virginia; crops always surprisingly abundant, and yielding wines, which, with proper care, will be found inferior to none of the imported drinks from Madeira or France. I obtained this variety by artificial impregnation, after the manner of Knight. I consider it capable of doubling the amount of our exports, when it is properly attended to, througbout the Union; for there is not a single state in our associated confederacy, which will not be found 
propitious to its growth. Wherever the hickory and the oak are to be found, there also you may expect to rear this fruit. In whatever climate the Indian corns mature their seeds, the Norton's Seedling grape will certainly return a most astonishing yield to the cultivator. In France, if its properties were understood, it would supply the place of much of that useless trash, which just now so unprofitably clothes her fair bosom; no casualty would then cause any serions diminution in the vintage, - which circumstance alone, independent of the improvement of her vines, would be, in a national point of view, of incalculable benefit to that country."

Mr. John Carter, of the vicinity of that same city, who also cultivates this and the Catawba and Prince Edward vines to a considerable extent for the purposes of wine, has informed me, by a letter of a simultaneous date, as follows : - "With regard to the value of this grape, I will say, that if your climate admits the Catawba and Isabella to mature their fruits before frost, this grape, being rather earlier than either of them, will produce at least 1000 gallons per acre, of such wine as sells here readily for $\$ 3$ per gallon."

\section{3. *CUNNINGHAM PRINCE EDWARD.}

A very superior grape, found growing in Prince Edward county, Virginia, much cultivated by Dr. Norton, Mr. John Carter, and others at Richmond and its vicinity, and highly approved by them all as a most excellent table grape, and fine for wine. From Dr. Norton I am favored with the following more particular account of this fruit, which I here subjoin :

"The Cunningham grape, from the county of Prince Edward, in this state, does not often rot or mildew; it is certainly a fine-flavored fruit, resembling in taste the $\mathrm{Ni}$ grillo of Madeira. It possesses, next to Norton's Seedling, more saccharine principle than any other fruit we cultivate; it has so far, however, proved a shy bearer. - Leaf three irregular lobes, obtusely serrated, resembling the Bland, the under side yellowish green; length of the footstalk $2 \frac{1}{2}$ inches; the largest bunches, weighing one fourth of a pound, are of unusual length; berries round, black, sweet, and vinous, irregular in size, some nearly as large as the Bland, being a sack of juice without pulp; ripens the last of September, and by no means inferior to any foreign variety." 


\section{WOODSON PRINCE EDWARD.}

A remarkable variety, found growing in Prince Edward county, in Virginia; cultivated to considerable extent by Dr. Norton, Mr. Carter, and others in the vicinity of Richmond. Dr. Norton has kindly favored me with the description of this fruit, which is as follows:- "Three indistinct lobes form the leaf; the terminal lobe more pyramidal than "usual, and more minutely elongated; indentures of the leaf obscurely defined; upper surface of a dark shining green, under portion glaucous; length of the footstalk three inches. The Woodson is a great bearer, ripens later than most other fruits, requiring the action of a slight frost to bring it to a proper state for the press. I consider it a proper fruit for the manufacture of sparkling wine. Such only will it yield, upon which you may certainly make a calculation. The must is replete with pulpy matter, difficult to throw down from the mass."

Mr. Carter, by a letter of a simultaneous date; states generally, that the Woodson Prince Edward is very productive, a certain bearer, and fine wine grape. I have the most perfect confidence in the statements of these gentlemen.

\section{5. *SCUPPERNONG.}

This fine species is a native of North Carolina and Virginia, and is found growing spontaneously at Roanoke Island, and in various other places. It is believed to be rather earlier than the Isabella. The fruit is large, roundish; of a color varying from white, or brick red, to black; of a sweet, rich, and aromatic flavor. The wine made of. this grape is of a very extraordinary and peculiar flavor. For the following account of this singular fruit I am indebted also to Dr. Norton.

"The wood is smooth and remarkably hard, rarely exhibiting that shaggy appearance of the bark usual with most other vines; the bark of the old wood is of a light iron color; that of the young wood is of a brighter hue, marked with small specks of grayish white ; the leaf is finely indented or serrated, and highly glazed both above and below; it is-tough and durable, remaining attached to the stem till the hardest frosts; the berry is of a greenish white color; the skin of a satin-like texture, varied with minute chocolate-colored dots. It is pulpy, but easily dissolves in the 
mouth, and is of a honey-like sweetness, and musky flavor and scent. The berries are congregated in bunches of from two to six each, the weight of the largest being eighty grains, and the smallest forty grains. The vine is a great grower and abundant bearer; its flowers have no odor; and it ripens its fruit here (at Richmond) the last week in September. The vine differs from the Black Scuppernong only in respect to color. This vine produces a wine much like one of high value in Madeira, (Aqua de Mel,) only 4 or 5 pipes of which are made there each season on a single estate."

Much wine is made of this grape in North Carolina. Many barrels are made in a single season from a single vine. They are trained on arbors over the large court which usually separates the main houses in that country from the kitchen, which is in the rear; and a single vine will soon cover a space of a hundred feet by forty. The climate of New England is not so well suited to this vine. Accounts have been stated of single vines which would produce forty bushels in Carolina. They are said to flourish, and their roots will find nourishment in sandy land, good for nothing else.

56. WORTHINGTON.

This grape, according to Professor Rafinesque, produces smaller berries than the Frost grape; the juice sweet and rough, of a dark red color. Major Adlum calls it a very great bearer, and states that the wine of this grape, mixed with the Schuylkill, gives it a degree of roughness between Port and Claret.

\section{U L T I VA T I O N, S O IL, \&c.}

The grape vine is propagated by layers; also by cuttings, which should be cut of the length of two or three eyes, and close below the lowest eye, and set in a warm situation, and humid soil, with but a single eye above the surface; or it is raised even from the cuttings of a single eye. They may also be grafted at the root by the common mode of cleft grafting. 
The vine requires a deep, light soil, and a warm exposition, to produce fruit of superior quality. In cold, moist, strong soils, the fruit is gross and watery, and later in the season of its maturity. The vine flourishes in soils of volcanic origin; also in calcareous soils, and even in sandy soils. On land half covered with rocks, they never suffer from drought, and receive a double portion of the rains, and a double portion of heat from the reflected rays of the sun.

The vine is a native of the temperate climates, and requires a winter, - or a suitable season of repose. In the tropical countries, therefore, it becomes unproductive; finding no repose, nor its wonted season of rest, except only in the elevated regions of mountains. Yet in some tropical countries, as at Bombay, they give to their vines, by artificial means, a suitable time for profound rest and slumber, and they awaken to fruitfulness for a season. This repose lasts twenty-five or twenty-six days. In October, and immediately after the rainy season is past, the roots are laid bare for fifteen or sixteen days; the vines are then pruned, and in about a week afterwards, the buds will begin to break. The roots are then re-covered with soil, and the ground manured; water is also given morning and evening, till the fruit attains its growth; and afterwards but once in three or four days, till the fruit is ripe. By varying the season of the operation, a succession of fruit is insured at all times.

The young wood of the European vines requires protectión in the winter, in the Northern and Middle States. However the modes of training and management may vary, protection is alike necessary in all and every system; except, only, the wood of three years' growth, which, with most varieties of the European vine, is deemed hardy:

In treating of the culture and management of the vine, I shall confine my remark's chiefly to its cultivation in the open air; and more especially to those modes of management which-are practised in a country one of the most enlightened on earth, and possessing a climate not very much unlike our own; where the vine has been cultivated as an article of commerce and subsistence for two thousand years, and where six millions of acres are cultivated in vineyards. 
From all the accounts which we have been enabled to receive, it will appear that the climate of America, in the latitude of Boston, the capital of New England, differs not very materially, in the average amount of heat and cold during the summer half of the year, from the climate of Paris, in the north of France. Their spring time, from its commencement, which is early in March, is obnoxious to storms, and the occasional and destructive frosts of winter. Our springs, from their not commencing till a later period, are more. frequently intermingled with the heat of summer; and the vine, with us, never, or but rarely, begins to vegetate till the vernal frosts are gone. With us, vegetation slumbers long, and profoundly secure, imnured in our winters, so intensely cold, nor awakes till the danger is past. For the longer duration of their springs, their summers, and their autumns, we are more than recompensed, even in our winters, so rigorous and so fortunately prolonged; and in our skies, so serene and unclouded; and in a sun less inconstant, and far more intense in its heat, from its greater elevation.

In the middle and northern departments of France, and in vineyard culture, the vines are kept low, like plantations of the raspberry; the vines being planted in close order; or they are trained to low stakes, from two to four feet in height, which are renewed every year. When the vine has risen to a height sufficiently above, it is bent over and passed to the top of the next stake, and secured in its rear; its luxuriance being thus restrained.

Midway, on the direct route from Havre to Paris, and 3 little beyond the city of Rouen, commences the region of vines; considerable portions of the land being covered with vineyards to the hill tops. Universally the rines are planted in close order, and kept low, being trained to vertical stakes of but about four feet in height. In autumn these stakes are taken up, and stacked on the ground, or housed. So also it is in Portugal, according to. Mr. Loudon. There, too, the vine is trained in the same manner as in France, at least in those districts where it is cultivated for making wine. The plants are seldom allowed to grow more than 3 or 4 feet high, and the roots are planted about the same distance asunder. The young shoots are trained on poles of reed, or trained horizontally on the tops of each 
other; and there is only one pruning given in the course of the year, which is in February or the beginning of March.

The same system of restriction is practised at the Clos de Vougeaud; the vines being kept low, and the ground never manured. This is regarded as the best vineyard in France, and was sold during the revolution, and in 1794, for $1,100,000^{\circ}$ francs. This vineyard is walled round. The soil is calcareous, on a foundation of limestone or calcareous rocks.

I subjoin, in this place, the remarks of the Hon. John Lowell, from the New England Farmer, inserted by him. "From a history of the culture of the vine in France, which I have carefully gone over, $\mathrm{I}$ find that the plan of planting the vines very near to each. other, in all the middle, and especially the northern provinces, has been of high antiquity. In 1763, an innovator appeared in France. M. Maupin, in his treatise entitled "A new Method of Cultivating the Vine," contended that -the vines should be planted four feet from each other. All France was alive to the question. The experiment was fairly tried, and failed, and the French returned to their old system of close planting and short pruning."

The finest grapes of France are those of Thomery. By enlarging particularly on their modes of cultivation, I am describing not theirs alone, but other systems too, whose principles may all here be found, this being the combined and perfect system of other most perfect systems; the principles which are in this system developed, not being adapted exclusively to the vine, but will serve to enlighten and instruct in regard to the management of other trees and plants.

The village of Thomery is situated in the Forest of Fontainbleau, about a league from the palace, and about twenty-eight miles from Paris. It was formerly occupied by vineyards, producing a poor vin du pays, and has not been : enclosed for the cultivation of table fruit until the last forty-five years. At present, says Mr. Robertson, about six hundred acres are walled in for this purpose, in numerous small properties and divisions.

The first introduction of the system of training and managing the vine at Tliomery, to the notice of the American public, is justly due to Mr. Lowell. His account, 
which was inserted in the New England Farmer, was a translation by him, from the Bon Jardinier, a work of 1000 pages, which has been annually published at Paris for nearly a hundred years, with continued improvements. In that work, this mode of training and pruning, and this mode alone, is described by MM. Poiteau and Vilmorin, the distinguished editors, this mode being considered by them as the perfection of all and of every mode and system that had ever been devised. The system has since been introduced to notice in England, with more important particulars, by Mr. Robertson; and his account in the London Horticultural 'Transactions is from the Bon Jardinier, and also the Pomone Francaise of the Comte Lelieur, and other sources. With very considerable portions of Mr. Lowell's account, I have incorporated some valuable portions of Mr. Robertson's ; together, also, with some personal observations of my own on this system, which were made during a transient sojourn in that country. My account, thus combined, and from every source which has come to hand, is also theirs essentially, and is as follows:-

A light and deep soil is that which is best adapted to produce grapes of excellent quality. In poorer soils, the vine languishes; in soils more consistent and strong, its productions will be too gross, too watery, and its fruit will have fewer good qualities. In the climate of Paris, the vine requires a warm exposition, in order to ripen perfectly its fruit; and it is seldom, except protected by a wall facing to the south or east, that it finds the lieat necessary to its perfection.

Of all the modes adopted, of training or of pruning the vine, we shall speak only of one - that practised at Thomery, a village near Fontainbleau, because it appears to us preferable to all others, both for its simplicity and its results.

As to its results, all the world knows them. The grapes of Fontainbleau are proverbial. It is well known that the most beautiful and the best grapes in the markets of Paris come from Thomery, under the name of the Chasselas of Fontainbleau.

It has been supposed that the excellence of these grapes is owing to the nature of the soil, and the favorable exposure of Thomery. By no means. Thomery has not a happy exposition. The quality of the soil is inferior, in 
many parts sterile; it is on the side of a hill facing north and east, and sloping to the River Seine, which washes its base; the soil is clayey, cold, and almost incredibly hard to cultivate. We must admit, then, that it is to their treatment of their grapes alone, that their excellence and superiority are owing.

Before we describe their method, we would remark, that they are very cautious in selecting their varieties. They select their cuttings from such branches only as bear fruit distinguished by some superior quality, as size, early maturity, setting sure, or any other property they would wish to perpetuate; and they maintain that they thus actually improve their quality. -The kind most in repute at Thomery, is the Chasselas de Fontainbleau. When other varieties are planted, the latest kinds are always trained to the lowest bar, as they are there found to ripen earlier.

The walls with which they form their enclosures, and against which they' train their grapes or trellises, are about eight feet high, built of clay, plastered on the outside with a cement of lime and sand, and covered with a chaperon or coping, projecting nine or ten inches on each side. To this coping they attribute the good effects of protecting the wood and blossoms of the vine from the late spring frosts and heavy rains, sheltering the grapes, and protecting them in good condition on the wall, even till after Christmas, and moderating the luxuriance of the rine.

The following plan of training the vine at Thomery was engraved from Loudon's Gardener's Magazine, and is similar to that in the London Horticultural Transactions. In this engraving, the vines are represented as set two feet asunder, rendering it necessary to bring the whole of the fifth cordon from the background, through a perforation in the wall. I have directed to place the vines but nineteen or twenty inches asunder, as directed in the Bon Jardinier, which enables them to cover completely the whole wall, all being planted in front.

On the southern, eastern, and western exposures of the wall, they are furnished with trellises, the upright standards of which are two feet apart, and the horizontal rails are nine inches apart; the lower one six inches only from the ground. 

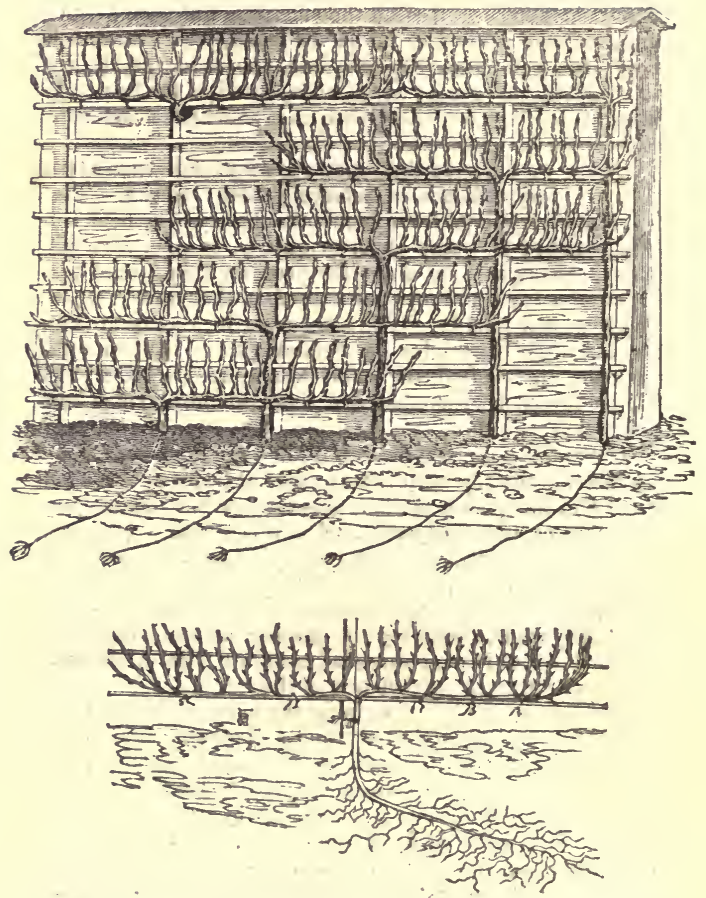

The grape border, along this wall, is dug or manured to the width of five or six feet, and to the depth of fifteen or eighteen inches. . If the soil is moist or strong, they slope the border so as to throw off the rains from the wall; this prevents the accumulation of water at the roots of the rines, and is essential to success. When the border is prepared, they open a trench at four feet distance from the wall, and 
parallel to it, two feet wide and nine inches deep. They have ready prepared a quantity of cuttings sufficient for the wall; these are about two feet long, and from being taken with a piece of old wood attached to the heel, are called croisettes, [cruciform;] but this form is not considered indispensable. These they lay across the trench at the bottom, with the top towards the wall, and at the distance of twenty inches asunder, and cover them with four or five inches of soil, and tread them down; at the same time raising the upper end, which was towards: the wall; nearly to a perpendicular; then fill the trench two thirds full, and spread the residue over the border. They then put into the trench three inches of manure, which keeps the plants fresh and moist, and prevents the ground from becoming dry.

In March, [November with us,] they cut in the plant to two eyes above ground; they weed, dress, and water the border during the first season, if needful, for the young planted grape requires a gentle degree of moisture. They tie the young shoots of the year to some supporters, and do every thing to favor its growth. The second year, if any of the plants have more than one branch, they pre, serve only the strongest. . They bury the new wood as in the first year, and so on till they reach the wall. At every time they lay the shoot, they cut in till they reach strong, ripe wood, well furnished with good eyes. It will generally take three years before it reaches the wall; but in the mean time they gather some fine bunches of fruit.

We now come to the formation of the cordons or horizontal branches. If the wall is eight feet high, it will require five cordons, [or five tiers of branches;] the first six inches from the ground, and the four others eighteen inches asunder, upon the horizontal rails of the trellis, which had been previously so arranged as to effect this object. The stalk destined to form the lowest cordons, [or horizontal branches to right and left,] will be cut just at the required height, if it has at that place a double eye. If it has not, you must cut it above the eye which is next above the lowest rail of the trellis. These two eyes are destined to furnish the two. lowest branches or horizontal arms, the one to the right, the other to the left, on the lowest rail. The one that is too high must be bent down gently, and that which is too low trained up, and then bent. The 
first year, however, these branches are trained obliquely, as they would not bear being bent and confined to their destined horizontal position till the next year, when both are finally secured to the trellis in the same horizontal line.

The second cordon, [or horizontal line of branches,] being at two feet distance from the ground, cannot be formed as soon as the first ; the third will be still later, and so on. Whatever be the height you design to advance your stalk or stem, you ought not to advance it more than twelve or fifteen inches each year, and preserve its lateral buds to increase its growth, and furnish fruit. But as soon as the stem has reached the requisite height, it is absolutely necessary to suppress and cut off, all lateral buds on the main stem throughout.

Let us now suppose, that all the stems have arrived at their required or destined height, and that the two last branches are extended, the one to the right and the other to the left, to form the two arms of the cordon, [horizontal branches; ] we will now show how these two arms are to be cut, till they have gained the length of four feet each.

The first year you will cut so as to leave three good eyes or buds, from four to six inches apart. Two of these eyes will form bearing wood; the third will be employed to lengthen the branch. Care must be taken to train vertically the shoots destined to bear the fruit; the other is trained obliquely the first year, and bent down and secured in its horizontal position afterwards. At the second pruning, the bearing shoots thus trained vertically must be cut, leaving only two eyes, or buds; and the terminal branch must in like manner be so trimmed, as that there will be three eyes, two of which will be reserved for bearers, and the third to prolong the shoot, as in the former year ; and so proceed till each lateral branch shall have reached the length of four feet. Each branch ought then to have eight bearing eyes or shoots, all, if possible, on the upper side. When all the five plants shall have reached their height and length, you will have, on a surface of eight feet square, eighty coursons, or bearing branches, of two eyes each, each producing two branches, which will each bear at least two bunches of excellent grapes, or three hundred and twenty bunches on eight feet square of surface, [sixtyfour square feet.]

According to Mr. Loudon, at Montreuil they practise a 
more expeditious, though perhaps less perfect mode; and instead of requiring three years for the vine to reach the wall, the vines are laid in horizontally, a few inches beneath the surface, and their tops brought to the wall at once. In this case the vines are bent and surrounded by brickbats, and thus forced to throw out innumerable roots.

The eyes at the bottom of the shoots of the grape are very close together, and extremely small. There are no less than six in the space of two lines, or the sixth of an inch. When you cut the bearing branch long, say one or two inches, these little eyes become extinct or lie dormant; and do not push; but if you cut close to them, they develò - they grow, and produce beautiful clusters. Able gardeners are ivell aware of this; they always cut their coursons, or bearing branches, at the distance of a line, (or one twelfth of an inch,) sometimes even less. It is for this reason that these branches never become long under their management. Those who are ignorant of the nature of the vine cannot conceive how a bearing branch shall have given fruit for twenty years, and not be at the end of the time an inch long.

As soon as the young shoots of the vine have grown to a sufficient length, they are attached to the treillage, the stronger ones first, but loosely, until they have acquired sufficient elasticity. Great caution is here necessary; you ought not to force them into a vertical position till the berry is large, for they break off easily when young.

The lateral shoots which break near the eyes, on the young wood, and the tendrils, should be suppressed while young: And if there be more than two buds which start from the same courson, [spur,] the supernumerary ones must be suppressed, even though they exhibit fruit. Two bourgeons, [branches,] each decorated with two beautiful clusters, are more, valuable than a greater number of inferior size. But caution is here necessary; those supernumerary shoots which start from the base should not be removed too soon, for if removed too suddenly, it gives a shock to vegetation, or occasions wasteful bursts of sap, you wait until the wood has acquired some consistence, and until new channels are provided for the expenditure of the sap by the expansion of the leaves, and until after the grapes are set,

At Thomery, the young wood is pinched at its extremity, 
after the bloom is set, as soon as it reaches the cordon next aboye it. This has the effect of momentarily suspending the flow of sap in these shoots, and by that means it accelerates their maturity, and renders them more ligneous. It promotes the growth of the eyes, and is indispensable for filling the lower eyes of the spurs on which cultivators rely for the next year's crop; pinching or stopping the wood either prematurely or tardily is alike productive of bad consequences. Weak shoots are pinched sooner in proportion to their strength, but none are permitted on any account to push beyond the cordon. Should it appear that the shoots of the extremities of the cordons [horizontal arms] impoverish those of the centre, the former are pinched repeatedly, until the equilibrium is restored.

The season they generally prefer for the winter pruning, is from the first of February to the first of March, before the first movement of the sap takes place. The earliest pruned vines are found to break first. The vignerons avoid.cutting close to the eyes, lest they might be injured by the wood dying down to them, the wood of the vine, from its spongy nature, not healing readily, and being liable to decay at a wound. To guard against this, they always cut midway between the eyes, sloping the cut to the opposite side of the shoot, so that the eye may not be damaged by its bleeding.

When vines are planted at once close to a wall, and in a level, deep border, and at an extended distance, they absorb an immoderate degree of nourishment, which gives rise to a rank and late vegetation, which retards the ripening of the fruit. At Thomery, the vines, being planted so close, have a more limited range for food, and the numerous roots produced by the frequent laying in of the stems, occupy the sloping borders so fully as to prevent any redundancy of moisture, and excess of nourishment ; all luxuriance is restrained; by this means the branches complete their growth within the bounds prescribed; they are furnished with short, well-ripened shoots, closely set with bearing eyes, which, when the ground is well manured, seldom fail to produce abundant crops.

We admire, say Messrs. Poiteau and Vilmorin, as many others do, those branches of the vine which are carried to two hundred feet in length; and we admit that there are 
parts of a wall which can only be covered by branches, the roots of which are very distant; but we recollect that when a branch has extended beyond a certain distance, it no longer gives fine clusters but at its extremities; the spurs of the centre no longer produce any thing but inferior. bunches, [grappillons,] and generally die. of inanition. This inconvenience doubtless occurred to the Thomery. gardeners; and by an admirable calculation they fixed upon the length of eight feet for each vine; * * * * yet though only eight feet in length, they do not throw out extraordinary shoots, because the plants being set but twenty. inches asunder, their roots dispute or contend with each other for nourishment. The cover of the wall also, extending over the vine nine or ten inches, by contributing. to check its too luxuriant growth, its fruit has all the qualities which it is susceptible of acquiring.

According to this system, when once the cordons are completed, the pruning and training become so uniform and simple, that it may be intrusted to any intelligent workman. But what may render the practice of still greater consequence in a northern climate, is, that the fruit of these small spurs, aloays ripens earlier than on the strong voood.

Tillage, Manuring, \&c. In tillage they use no other instrument than the hoe; they stir the ground but lightly, lest they should injure or disturb the roots : this is done twice in the year, first after the summer training, which generally takes place [there] in May, and again. when the Jeaves fall; the ground is, besides, always kept perfectly clean and loose on the surface, to admit the air and dews. They manure their vines every three years, always preferring old manure nearly consumed, and of a light, warm nature. They are justified in this practice by the result, for their grapes are always superior, in size and delicacy of flavor, to any others to be met with, either at Paris or elsewhere.

Management and Care of the Fruit, \&c. While the fruit is yet very small, the bunches-should be looked over, and the extremities of such as are very long, cut off, for they generally ripen late and imperfectly. Such varieties as the Frontignacs, which have very close bunches, should have their berries thinned out at the time when 
they are about the size of peppercorns. When the grape has nearly attained its size, it is beneficial to water the fruit from a water-pot in the form of rain. This makes the skin tender, and increases the size of the berries. You gradually uncover the berries, and expose them to the sun, to heighten the color and improve the flavor; if the leaves are removed with this intent, they are separated at the extremity of the footstalk, which is left behind to attract the sap and nourish the bud at its base.

If they wish to leave them out till after frosts, they are either covered with paper bags, which are of use also in protecting them from insects and birds, or they are often preserved till Christmas by screening them from frost with cloth, matting, or fern. The fruit is always gathered in a dry day; if stored moist, it would quickly spoil. Those intended for keeping are cut before they are quite ripe; some are hung up on hair lines, in reverse, with their shoulders down, as that position prevents the berries lying so close as to rot; and some are spread on beds of fern.

M. Noisette, according to Mr. Neill, trains grape vines to a low trellis, three feet in advance of the walls where his peach trees are trained. These vines are planted but three feet asunder; each vine has but a single arm, proceeding horizontally from a vertical stem. These arms extend six feet, being trained in one direction, each plant alternately secured to the upper and lower rail. M. Noisette showed him a triple contre-espalier of vines, the outermost trained to a rail only one foot from the ground; the second two feet high, and the third or inmost at three feet from the ground; it being, as Mr. Neill states, a common remark of the vignerons, that the nearer to the ground the bunches are produced, the richer is the flavor of the grapes.

M. Noisette stated to Mr. Neill that it was not uncommon to have a vine of a single shoot of the Muscat of Alexandria trained to the top of a south wall ten feet high, and over the peach trees.

Early Maturity. - 1st, Girding, \&c. Girdling affords a resource in cold climates and unfavorable seasons; it not only hastens the maturity of the fruit, but increases its beauty and size. A portion of fine wood of the uppermost branches should be selected, and the place where the operation of girdling is to be performed, should be just 
below the wood of the former year's growth, which should be strong, and remain of good length; and as the effects of girdling are, in the end, destructive to the branch, the operation should be performed on different portions of the same vine in alternate years. The most suitable period for girdling the vine is early in July, and as soon as the fruit is formed.: With a sharp and hooked knife, make two circular incisions around the trunk, and quite through the bark, at the distance of from one fourth to three eighths of an inch asunder; then make a perpendicular cut, and remove the ring of bark quite clean to the wood. If the vine is very vigorous, this section may soon close, in which case it must be reopened. [See Groding, in the former part of the.work.]

2d. Early maturity is induced by confining the roots to a very limited range near the surface of the earth, and by limiting their supplies of moisture. Or, 3d, by securing the vines very near to the walls, which are covered with a black paint, formed of lime, tar, and charcoal. 'The black color enables the wall to absorb and retain the heat of the sun's rays, which are given out gradually to the vine. But where the wall is farther removed from the vine, it must be rendered white, with paint or lime, that the heat of the sun's rays may be reflected.

In cold countries, according to Chaptal, and in vineyard culture, and where the vine requires the whole heat of the sun, the vines should be supported on trellises or stakes, or elevated on poles placed perpendicularly in the earth. And in this mode, the vines 'may be very closely planted. The earth being left uncovered, and receiving all the activity of the sun's rays, and these reverberated, the whole plant is exposed to its action; and being so near, the produce may be thus multiplied on equal surfaces. But in warmer climates, the earth requires to be sheltered from the excessive heat of the sun, and the vines may be supported on arbors, or suffered to creep on the ground.

- In vineyards, close planting is most expensive at first, but the ground is thus more suddenly and completely filled; and small vines are more easily managed than large ones. Of European varieties, two thousand seven hundred vines may be required to an acre, the rows being four feet asunder, and the vines at four feet distance in the row ; each vine being extended, and rising from the surface with many vertical shoots within the row. But the American 
native vines cannot be thus controlled; they require a far wider range, and more ample space. Of these, nine hundred vines will suffice for an acre; the rows being six feet asunder, and the vines being planted at eight feet distance in the row.

The most favorable exposition for vineyards with us, on the shores of the Atlantic, is without doubt a south, or south-western, removed as far as practicable from woods, swamps, or standing water. An easterly exposition does not suit them; the eastern sea breezes are unfavorable, from their coldness and humidity.

Dr. S. A. Shurtleff, from his own successful experiments in Boston, on a hill.which faced the sea, has added his testimony to confirm the truth of the above position. He directs that the trellises should run in the direction of the south-east and north-west, thus having a south-western exposition, and he prefers horizontal training. The wood on the north-east side is never pruned at all, but is allowed to grow, forming a vinous hedge, which defends the fruit from the humid and cold eastern and north-eastern winds, which cause mildew, by chilling and enfeebling both the wood and fruit; while on the south-west side, the genial warmth is still further preserved by pruning all lateral shoots and tendrils, and useless wood. Late pruning, or pruning after July, as he justly observes, enfeebles the vine, arresting its growth and that of the fruit, and causing it to turn soft and sour, instead of ripening; - the leaves also should be preserved, being alike essentially necessary, and designed by nature to nourish the fruit, as well as to protect from the scorching sun by day, and the cold autumnal nights. By pursuing this method, he has, during several years of trial, infallibly succeeded in obtaining good crops, while all other methods and positions have failed.

The grapes of 'Thomery and Fontainbleau, so famous, are the White Chasselas, or Chasselas de Fontainbleau, which are better there than elsewhere, in any place or country. At Fontainbleau, they are trained on the south side of a wall, half a mile long, and 10 feet high, and in some places 18 or 20 feet. This wall was built in the time of Francis I., and has been rebuilt many times since. On this wall, which is now appropriated to vines, other plants have been cultivated at different times. The vines are under the care of Mr. Brassin, who has had them in charge since 1832 , and, according to Mr. Loudon, but one vine now re- 
mains which was there at the time he came." He never uses animal manure; he uses only the scrapings of roads and ditches; and the parings of pasture, after it bas lain in the compost heap two jears. When the fruit is fully grown, instead of thinning the leaves which shade the fruit from the sun, according to the common practice, which is so injurious, he removes only the leaves between the grapes and the wall, in order that the heat of the wall and the sun's rays may be reflected on the grapes. For, as $M$. Poiteau has truly observed, no leaves can be safely removed by any one who does not possess some just notions of vegetable physiology; the leaves being the essential organs which duly mature and give flavor to the juices of the fruit.

Vines trained to vertical walls, and growing in confined or humid situations, are in our climate subject to mildew ; and on walls of this description which face due south; the sun, during midsummer, never shines till an advanced hour in the morning; and the benefits are never but partial, from the oblique rays of a sun which at noonday must be nearly vertical.

The Hon. Richard Sullivan, whose former successful cultivation of the vine at Brookline is well known, had at one time suggèsted to me the idea of an inclined plane, as preferable to vertical walls, which cause mildew. Mr. Lindegard, in Denmark, for the purpose of hastening the maturity of his grapes in his vinery, placed boards beneath the fruit with perfect success. In the Annales d'Horticulture is contained an account, that in France, in 1827, one portion of a vine growing under a south window, having ascended over the slated roof of the portico, it was found that the fruit on this part of the vine had become black, while the fruit on the other parts of the vine was still green.

In our own latitude, or the latitude of Boston, - where, during midsummer, the sun at midday is nearly at the zenith, - an inclined plane, or roof, or wall, sloping, and literally facing the noonday sun, will afford an exposition much more favorable to the vine than vertical walls; or at that angle which will face the sun at that time, when, most of all, his rays are needed, or towards the autumnal equinox. Over this, and at suitable distance, the trellis may be elevated, and upon this, the vines displayed, whether they arise at the foot of the plane, or are brought up from 
the distance of forty or fifty feet from the roots below. In such a favored situation, they will receive the full benefit of the morning sun, and the more effectual advantage of the noonday sun, both by his direct rays and by reflection. The excess of moisture, the nightly dews, and a stagnant atmosphere, the combined causes of mildew, will be dissipated by the morning, sun, or by the direct influence of southerly winds; or by the indirect influences of northerly winds, in the eddies and counter currents.

The inclined planes, or roofs, or walls of wooden structure, by being shaded with a vegetable covering, are liable to speedy decay. But this objection does not apply to those with a covering of coal tar, or of slate; or to the cheap, enduring, and admirable coverings which are now formed of zinc.

From the experiments of Mr. James Macdonald, of Scotland, in his statement recorded by Mr. Loudon, it even appears, that, when the vines of the Black Hamburg, and the White Muscat of Alexandria, were trained on trellises at the distance of about ten inches above the sloping roofs of glass, and exposed to the open air, and to the direct rays of the sun, and to the heat caused by the rays of reflection, the fruit ripened equally. as well, and as early, as did the fruit of those which were trained beneath its surface. And it is a well-known fact, that at a certain angle of obliquity, the rays of the sun do not pass through common glass at all, or but partially, both the rays of light and of heat being reflected, and by all other systems lost.

Vines may be trained to very great advantage on poles or espaliers, over the flat or inclined. surfaces of barren rocks. And all those useless stones which encumber our fields may be gathered into piles of a pyramidal, an oblong, or of any other form, and the vines planted around and trained over them as near as may be, allowing the fruit sufficient space to hang without touching the stones and rocks. The heat caused by the reflection would powerfully aid in maturing and giving flavor to the fruit. No leaves should be removed which shade and protect the fruit from the sun's burning rays: those leaves beneath, which obstruct the heat reflected from the rocks, may alone be removed. Thus it is that the vine is trained in the Pyrenees, according to Murray, as stated in Loudon's Magazine. In the valley of the Arriege, between Tarascon and Foix, the slopes of the hills being productive in grain, the 
warmer and more sheltered rocks are clothed with vineyards. In all those cornfields, the stones which would otherwise encumber the ground, are gathered in heaps of various sizes and forms. Among these heaps of stones the vines are planted, and trained over them on poles or espaliers; the effect of this arrangement being beautiful, and may be mistaken for a garden, and the clumps of vines for parterres.

Paving the Ground, - It has been remarked, says Mr. Robertson, that vines and fruit trees planted against buildings with a pavement, which prevents the ground from being either manured or cultivated, produce not only more abundant and finer crops, but are longer lived:

"At Thomery," says the Comte Lelieur, " the grapes on the lower cordon of a vine, planted to a wall of about fifteen feet high, having been injured by. the drip of its eaves dashing the earth of the border against them, the owner paved it for the breadth of about two feet from the wall. The good effects of this remedy' were soon apparent, not only in the preservation of the fruit from injury, but in the improvement of its size and flavor; the reflection of the sun's heat from the pavement augmenting both, and hastening its maturity." "The growth of the vine, also, became more moderate and regular.

The foreign as well as native vines succeed admirably in our cities; and especially so when planted beneath pavements, and in paved court-yards. Not being so liable, in such situations, to suffer from excess of moisture, the quality of the fruit becomes proportionally improved, from the causes already explained.

When it is attempted to train a single vine with two or more sets of cordons, proceeding at unequal heights from the same vertical stem, the upper cordon becomes the superior, and the equilibrium is destroyed; and the lower or inferior cordons languish, being robbed of their nourishment by those above, and the tendency of the sap to pass uninterruptedly upwards.

If the position which is here assumed be correct, then the ingeniously-devised system of the celebrated Mr. Cobbett must fail in practice. I will first give the outline of his system, and then, by a partial demolition, or by a partial inversion, and by one important alteration, this same mode will be made to appear in the likeness of another and ex- 
cellent system for vineyard or open culture. His plan is as follows: -

From a strong, vertical stem, of about four or five feet in height, eight branches alternate, are in the third year trained horizontally, four on each side, and secured to the horizontal rails of the trellis; the destined space allotted to each being eight feet from the centre. Four only of these are destined, and to be reserved for producing fruit in the following year, namely, two branches alternate, on each side, each of which is to be shortened in autumn to eight feet. The other four branches are cut off, at the same time, to within one eye of the yertical stem; and in the following year, these same eyes will throw out the four branches of reserve, which are to be trained horizontally to their destined rails, as before, and deprived of their lateral shoots, as produced. While those other four branches, after they have once produced fruit, are never suffered to bear fruit again, or to remain, but are in their turn cut off in the autumn to within an eye of the stem, to furnish the reserve wood for the next year. And thus the system is continued.

The following mode is recommended for vineyard culture. It conforms, in the main, to the mode recommended by Mr. Bartram; and also to the system of Mr. Cobbett, after its partial inversion; but differs in some essential particulars from both.

The first year, suffer but a single shoot, and that the lowest, to grow; the supernumerary ones are to be checked and taken off gradually; this shoot is to be trained to a pole, the lateral shoots to be taken off as they are produced, at the distance of a single eye from the main stem. When a few feet in height, the top is occasionally nipped in. Late in October, cut this down to three good eyes; in November, (if a European vine,) bury with leaves, litter, or soil. The next year, three good eyes only are suffered to grow, which are to be trained to a pole and pruned, as before. In autumn, preserve the two uppernost, which, if strong, must be cut to the length of five feet, and trimmed throughout, and secured to the surface by hooks, and covered with soil. The remaining one is shortened to three good eyes, and buried, as in the former year. In the following spring, two good stakes will be required; the vines, left at full length, are each to be twisted several times around a pole, and secured at the top, and these will throw out 
shoots from every eye, which will each probably produce two bunches. These bearing shoots are to be nipped in, four or five eyes beyond the fruit. The shoot cut down will this year furnish three shoots; these are to be trained, as at first directed, to another pole, for these three are to furnish fruit for the following year, and are to be pruned and laid down at full length in autumn. As' to those which have once borne fruit, they are not permitted to bear fruit a second time, but are each cut down to two eyes; to furnish the reserve wood for the following year; and so proceed till four bearing limbs are annually elevated and twisted around two poles, and an equal number of supernumerary or reserve branches are annually raised up and trained to two other poles. Always observe to cut so as to have your wood start from a low point, near the surface ; for this purpose it may be sometimes even necessary to cut back the old wood.

The bearing wood on trellises, in like manner, should, in early spring, be bent and confined in a serpentine manner, with short turnings; or the ends bent downwards; but the young reserve branches, which must never be -allowed to produce fruit the first year, should be trained straight, or with a little deviation.

The long canes of the vine, the production of a single year, if left to themselves, will only break and produce fruit at their extremities. To enable them to produce fruit throughout their whole length, art is necessary. Before vegetation commences in spring, the long cane or vine of the former year's growth, may, if in vineyard culture, be trained spirally, around a stake or pole.- Or otherwise it may bé tied in a coil. By either mode of treatment, the buds will break, and grow equally from its extremity to its base. When the buds have grown an inch or a little more, the vine may be uncoiled, and secured to its destined position on the rails or trellis. This art is perfectly understood by those who raise grapes in the vineries around Boston. In this way astonishing crops are produced.

The numerous and flourishing vineyards of America, which have been of late years established in the Middle, Southern, and Western States, for the manufacture of wine, consist principally of the native varieties which I have described. American grapes are found to do best for America in vineyards: It was deemed a capital error that 
European kinds were at first tried in preference. Ours require no protection in winter. The average value of vineyards in France per arpent, (100 rods and 22 feet of our measure,) as stated by Mr. Young, was $\$ 210$; but the very best vineyards were worth from $\$ 2000$ to $\$ 3000$ per arpent.

In making wine of the American grapes, some distinguished practitioners first grind the grapes by a roller, then bring the must at once to the proper standard or weight, which, for wines as strong as Burgundy or Claret, should be 1.125 , - equal to about $12 \frac{1}{2}$ per cent. heavier than rain water, or sixteen degrees of Beaume's saccharometer. After remaining in the vat four days, more or less, according to the heat of the season; it is drawn off, or pressed, and removed to the cask. Where the grapes superabound in mucilage, sugar, the all-essential element of every good wine, is added, and sometimes water, in just proportion.

The vines of America are of extraordinary vigorous growth, and cannot be restrained to that degree as the vines of Europe, but require less pruning, and a wider range, and more extensive latitude; in which case they will produce enormous crops. Mr. Longworth, of Ohio, has made 1470 gallons of wine from a single acre of the Isabella. Both Mr. Longworth and Major Adlum are agreed, that the Catawba is the very best American wine grape which was known to them.

The excess of fermentation to which wine is sometimes liable; from the heat of the weather, or from weakness, is sometimes arrested in its progress by sulphuring; but sulphuring, it is admitted, renders the liquor unwholesome; or excess of fermentation may. be restrained by black oxide of manganese. [See Cider. See Vine.]

When wine has partially undergone the acetous fermentation, the acid may be neutralized by salt of tartar; or seized by alkalies, ashes, chalk, lime, or litharge; (the last is well known to be a poison;) or the acid may be concealed by the addition of a saccharine substance. But such wine can never be recovered, inasmuch as the process of fermentation never retrogrades.

The Muscadel flavor of Frontignac and of Cyprus wine is said to be exactly imitated by an infusion of the flowers of Meadow Siceet; Mountain wine, by the infusion of Florentine orris root, powdered, with a small proportion of 
orange and lemon peel, or by the addition of the bruised seeds of grapes; Sack, by the addition of a soirit distilled from the leaves of Clary and malt spirits.

Grafting the Vine. The mode of grafting the vine, of Mr. Gowan, which is so highly recommended by Mr. Loudon, and tried and approved also by Mr. Thompson, is as follows:- Select a scion with but one single good eye ; pare it beneath the eye, and on the opposite side, in the form of a wedge. For a stock, a branch of the preceding year' is rather to be preferred. Cut this off a little above the second eye from its base. With a sharp knife, split it down the centre nearly to the old wood. Out of each half of the stock, but chiefly out of that half which is opposite the bud, pare with a penknife as much as is necessary to make it fit the cutting perfectly on that side. Insert the scion with its eye opposite to the eye which is left on the top of the stock, and crowd it down nearly to a level with that. Tie up and clay, covering all the scion except only a small hole for the eye, and another hole for the eye left on the top of the stock. Tie over a little moss, to be occasionally sprinkled with water. It is very essential and all important, that the young shoot on the top of the stock should be allowed to grow for ten or fifteen days; then cut it off, leaving only one eye and one leaf to draw the sap, and keep alive the circulation, till both scion and stock are perfectly united.

Maladres. The chief malady to which grapes are subject, in low and confined situations, is mildew. Mildew, is supposed to a arise from a slow circulation of the sap, and a debilitated state of the wood and fruit, caused by a chilly and damp or stagnant atmosphere, and perhaps by inaction. And it has been observed that the fruit which trails on the earth always escapes, as it does also on airy hills. Mildew is remedied by dredging the fruit with flour of sulphur, on its first appearance. But the most approved mode of applying the sulphur is as follows :-

On the bottom of a vessel place a pint and a half of sulphur; on this lay a lump of good unslacked lime, the size of a fist, and on this pour two gallons of boiling water ; after the lime is slacked, stir it well, and when the liquor is cold, add more cold water, and stir it again ; and as soon as the liquor has become clear, pour it from the sediment into a barrel which must be filled with cold water. When 
the grapes have attained the size of peas, throw the liquid on the fruit with a syringe, and repeat this twice a week for three successive weeks. With Willis's Syringe whole vineyards may be despatched in a very little time.

Modes of raising Grapes by artificial Heat in Vineries. The most approved mode of heating vineries, as well as hot-houses and conservatories, at the present day, is by the hot water system. This system consists of a boiler placed at one end of the building, the water contained in which is connected with that which is contained in a cistern at the opposite end of the house, and on the same level, by means of two large tubes of copper or of cast iron, one of which forms the communication a few inches above the bottom of each vessel, and the other forms the communication near the top: Thus, when the fires are kindled, the heated water flows or circulates in one continual current from the top of the boiler to the cistern, while the water at the cistern, which has become more cool, is continually returning to the bottom of the boiler by the lower pipe. 'The water of the cistern communicates a genial moisture to the atmosphere, which is highly essential to the progress of vegetation.

At the celebrated fruit establishment of Mr. Wilmot, at Isleworth, near London, the hot-houses and vineries are warmed by means of hot water, but by a new and beautiful system, which, according to Mr. Loudon, bids fair to supersede all other systems and modes. From my observations, on a transient visit, of late, to that establishment, a short account of the system is here subjoined. The house, the subject of that examination, was eighty-four feet long, sixteen feet broad in the clear, and fourteen feet. high in the highest part. Within the main body of the house, and in the back part, and extending the whole length, is a narrow air-chamber, formed of inch boards. . This airchamber extends from the foundation below, to the height of about three feet above the floor, and may be abont thirty inches in width. 'Throughout the whole length of this air-chamber, the hot water circulates through four cast iron pipes, each four or five inches in diameter, and placed at the distance of three or four inches asunder. These pipes are elevated at different heights, one above another, obliquely, or like stairs or steps; the two uppermost communicating witl the top of the boiler and of the 
cistern, the other pipes forming the communication below. Square wooden tubes, or about eighteen inches by twelve, and formed of boards, and connected with the back wall, carry the heated air upwards from the air-chamber, into the highest parts of the house. These tubes are arranged at the distances of about six or eight feet asunder, throughout the whole extent; the heated air, thus admitted in the back part, soon fills the house. : In the front, and in the lowest part of the house, is a walk from end to end ; the bottom of this walk being formed of gratings composed of bars of iron or of wood; and through these gratings the cooler air descends continually, passing to the rear by subterraneous passages, to be heated anew. Thus the circulation can be rendered perpetual.

At that establishment, several distinct buildings are warmed by a single boiler; the hot water pipes being conducted on the surface of the earth, and protected from the cold by a slight covering. According to Mr. Loudon, Mr. Wilmot even asserts, that, compared with this new system of heating, and of circulation, all other systems are $a$ farce. The pine-apples, also, which are raised by this mode, are stated to be far superior in flavor to all others, artificially raised by other modes. Perkins's system of heating by small hot water pipes, is another new and extraordinary system. The most sanguine hopes and expectatious are entertained of its results.

The most extensive establishment for the cultivation of the vine by the aid of artificial heat, in the United States, is that belonging to Nicholas Biddle, Esq., and situated at his beautiful residence at Andalusia, on the River Delaware, but a few miles above the city of Philadelphia. The grape-houses of Mr. Biddle, at this place, comprise ranges of buildings of the extent of 1500 feet, all of which are covered with glass; and on first-rate authority it is stated, that each extent of one hundred feet in glass, is capable of producing, continuously, grapes worth $\$ 3000$ per annum. Large quantities of grapes of the first quality are here raised both by in-door cultivation, and by open culture, for the markets of the cities of New York, Philadelphia, and Baltimore. All things at this establishment are conducted on the best of systems; the grape-houses and gardens being refreshed, in times of drought, by supplies of water furnished by aid of an engine from the river. 


\section{U R R A N T . - (Ribes.)}

The Red Currant is a low, branching shrub; the wood is smooth; the leaves pubescent and doubly serrated; the flowers are yellowish, and in racemes; they are produced in April ; the fruit in clusters like grapes; the berries round, smooth, of an acid taste. A native of America and of the north of Europe.

The White Currant is stated to be but a variety, produced by cultivation from the seed of the Red.

The Black Currant is a distinct species, a native of the north of Europe and Asia; a low shrub, with smooth wood; the leaves are three-lobed, pubescent, with a strong odor; the flowers are in racemes, the fruit in clusters, black, and odorous; of an astringent taste.

Uses. The red or white currant is used as a dessert fruit, as it possesses a pleasant acid taste ; it is also used in pies, tarts, preserves, jellies; \&c. Currant wine is made by adding to the expressed juice of fifty pounds of ripe currants, seven gallons of water, and thirty-three pounds of good dry Havana sugar. This liquor is put intogood casks, which must never be quite filled, as the pulp must never be suffered to work out, as its presence is essential to the goodness of the liquor. The bung is left out forty-eight hours, then laid on loosely a fortnight, then driven tight ; and in five months it will be fine and fit for use. The first young leaves of the common currant bush, gathered as soon as they put out, and dried on tin, can hardly be distinguished, it is said, from green tea. From the black currant a jelly is made, of considerable medicinal efficacy; a wine is also made from them, which possesses far superior medicinal virtues to Port wine. The jelly has been highly recommended for disorders of the throat, and as a necessary article in the stores of ships sailing to the East Indies. A liquor is prepared from the black currant, which Mr. Forsyth states is possessed of great medicinal efficacy in obstinate coughs, \&c. The currants for this purpose are bruised, and being placed in a jar, whisky or any other species of alcohol is poured over them; the jar is then covered close for a fortnight; after this the liquor is strained and bottled. We are informed, by Mr. Neill, 
that a small leaf of the black currant, gathered in spring, and laid for a few minutes in an infusion of bohea tea, communicates its flavor, which has been compared to that of green tea.

\section{VARIETIES.}

\section{1. *Black English:}

The berries are of large size, and thê trees are very productive; very valuable for its medicinal virtues; it makes a fine jelly, and a wine of celebrated medicinal efficacy, of peculiar flavor, which, to those long accustomed to its use, is delectable.

\section{American Black Currańt.}

This possesses similar qualities to the preceding, but it is not so highly esteemed.

\section{Black Naples.}

This is a new variety, highly recommended.

\section{Champagne.}

The fruit of this variety is pale red.

\section{5. "Large Red, or Red Dutch.}

The growth is strong and upright, the berries large; it is extraordinary productive and good.

\section{6. "Large White, or Spanish. Imperial, Large-Dutch} White.

The young wood grows upright; the berries and clusters are very large, of a yellowish white color, and excellent quality; it is extraordinary productive; the branches of the bearing wood trail beneath the weight of their fruit. 7. Jefferson, or Missouri Fragrant Currant.

This variety is very distinct from the other kinds. Its growth is tall; its berries are very few, are black, and of ordinary quality ; its flowers are in clusters, of a yellow color and extraordinary fragrance.

\section{Scharlet Currant.}

In the valley of the Columbia River, according to $\mathrm{Mr}$ : Parker, a new Scarlet currant has been discovered, resembling a strawberry in sweetness; it grows on a low bush, and is very benutiful: 'There also grow other new varieties.

9. Snowy Currant. Ribes niveum.

A new species of currant, rising seven or eight feet in height. The flowers are white, pendent, numerous, and 
ornamental; fruit black; size of the black currant; fineflavored; rather too acid to be eaten raw, but delicious for tarts. A very hardy ornamental variety, which was brought by Mr. Douglass from the N. W. Coast of America.

\section{$\underline{-}$ \\ C ULT IVATION, S O IL, \& c.}

The currant requires a rich soil ; its cultivation is similar to that of the gooseberry, which see.

Pruning. "Mr. Macdonald," says Mr. Neill, [Edin. Ency. Vol. x. p. 5\%6,] "raises currants, both red and white, of the finest quality. He prunes the bushes at the usual season, in midwinter, shortening the last year's shoots to an inch and a half. Next summer the plants show plenty of fruit, and at the same time throw out strong shoots. As soon as the berries begin to color, he cuts off the summer shoots to within five or six inches above the fruit. This is commonly done with garden shears, with which a man may go over half an acre of bushes in a day. Sun and air this get free access, and more of the vigor of the plant is directed to the fruit; the berries are found not only to be of higher flavor, but larger than usual." Mr. A. D. Williams, of Roxbury, practises winter pruning on perfectly similar principles, and with the most successful results.

\section{G O OSE B E R R Y.-(Ribes Uva-crispa.)}

A native of America and of Europe. A low, branching, prickly shrub, rising to the height of from three to six feet; the leaves are three-lobed, and sometimes pubescent; the fruit pendulous, hairy or smooth, round or oblong ; its size sometimes equals that of a good-sized plum; of a green, white, yellow, red, or violet color; and of a sweet, vinous, or acid flavor; a fruit wonderfully improved by cultivation. According to Loudon, it is found wild in Piedmont, where it is eatable, but astringent and neglected; in Italy and 
Spain, scarcely known, and little esteemed in France. " $\mathbf{A}$ moderate temperature and humid climate seem best to suit the fruit." Cultivated in greater perfection in Lancashire than any other part of the world. But Neill observes, "It must be admitted that although the largest gooseberries make a fine appearance on the table, they are deficient in flavor, or their skins are thick and strong, compared with some of smaller size." , Some large kinds, however, are of good quality..

Uses: The gooseberry is considered an excellent dessert fruit, either raw or preserved in sugar; and a very valuable fruit for pies, tarts, sauces, \&c. - In cool cellars, they may be preserved for winter use, in bottles filled first with gooseberries, and then with water, and closely corked and sealed. But by plunging the bottles into cold water, which is to be heated gradually to the boiling point, they are said to keep better.

According to Phillips, wine made from green gooseberries is but a shade inferior to Champagne; and the ripe black gooseberry affords a luscious wine. And he asserts that fields might be covered with this fruit for the making of wine, as profitably as the vineyards of the south.

Champagne Wine, as we are informed, is in England very successfully imitated from the juice of unripe gooseberries, and in great quantities. The saccharine principle is in this case supplied by the addition of loaf sugar.

\section{VARIETIES. - (Chiefly from Lindley.)}

The following varieties, from Lindley, the Pomological Magazine, and Mr. Hooker, are recommended by them as the best selection from many hundred varieties.

\section{RED.}

1. Capper's Top' Sawyer. 24 dwts. Branches somewhat drooping; fruit late, very large, oblong, pale red, hairy near the base; very excellent.

\section{Champagne.}

Branches erect; fruit late, middle size, somewhat oblong, dark red, hairy; most excellent. 
3. Farmer's Ronring Lion. 31 dwts. 16 grs.

Branches somewhat drooping; fruit late, very large, oblong, dull red, smooth; the largest of all gooseberries.

4. Knight's Marquis of Stafford.

Branches somewhat erect; the fruit late, large, roundish oblong, bright red, hairy; excellent.

5. Melling's Crown Bob. 22 dwts.

Branches drooping; fruit rather late, large, oblong, bright red, hairy; very good.

\section{Old Rough Red.}

Brainches somewhat drooping; fruit small, round, dark red, very hairy; most excellent for preserving as gooseberry jam, and best for bottling when green.

7. Wilmot's Eariy Red. Hooker's Pom. Lond.

One of the very best of all gooseberries, and is cultivated by $\mathrm{Mr}$. Wilmot to a great extent in his celebrated fruit garden. He prefers it to all others he has seen. He states that it is of large size, very early, of excellent flavor, and incredibly productive.

\section{GREEN.}

\section{Early Green Hairy.}

Branches erect; fruit early, small, round, deep green, hairy; excellent.

9. Edward's Jolly Tar. 19 dwts. 17 grs.

Branches somewhat drooping; fruit early, of a middle size, roundish oblong, smooth, with yellowish veins.

10. Massey's Heart of OAK. 16 dwts.

Branches drooping; fruit rather early, large, oblong, smooth, with pale yellow reins; excellent.

11. Nixon's Green Myrtle.

Branches somewhat drooping; fruit late, large, oblong, smooth, tapering to the base, pale green.

12. Parkinson's Laurel. 17 dwts. 18 grs.

Branches erect ; fruit rather late, large, roundish oblong, pale green, very downy.

13. Wainwright's Ocean. $20 \mathrm{dwts} .8 \mathrm{grs}$.

Branches drooping; fruit early, large, oblong, or ovate, smooth; the largest of this color. 


\section{WHITE.}

14. Cleworth's White Lion. 19 dwts. 9 grs.

Branches somewhat drooping; fruit late, roundish oblong, slightly hairy, sometimes nearly smooth.

15. Crompton's Sheba Queen. 18 dwts.

Branches somewhat erect; fruit early, pretty large, roundish oblong, downy; excellent.

16. Moore's White Bear.

Branches somewhat erect; fruit early, large, roundish oblong, hairy, or somewhat bristly.

17. Saunpers's Cheshire Lass. 20 dwts.

Branches erect; fruit very early, large, oblong, downy ; excellent for tarts early in the spring, when few are ready for that purpose.

18. Wellington's Glory. 23 dwts. 14 grs.

Branches erect; fruit pretty early, large, somewhat ovate, very downy; excellent.

19. Woodward's Whitesmith. 16 dwts. 7 grs.

Branches erect; fruit pretty early, large, roundish oblong, brownish when exposed, very downy; very excellent, and more in esteem than any other gooseberry of this color.

\section{YELLOW.}

20. Dixon's Golden Yellow.

Branches drooping; fruit early, pretty large, roundish. 21. Gordon's Viper. 24 dwts. 17 grs.

Branches drooping; fruit early, large, somewhat turbinate, greenish yellow, smooth.

22. Hamlet's Kilton.

Branches somewhat drooping ; fruit early, large, roundish oblong, bright greenish yellow, slightly hairy.

23. Hardcastle's Gunner. 27 dwts. 1 gr.

Branches somewhat erect; fruit rather late, large, obovate, with large veins, hairy or bristly.

24. Hill's Golden Gourd.

Branches somewhat drooping; fruit very early, large, oblong, greenish yellow, slightly hairy; very excellent.

25. Propher's Rockwood. . 23 dwts. 4 grs.

Branches erect ; fruit very early, large, roundish oblong, dark yellow, slightly hairy. 


\section{OTHER VARIETIES,}

RECOMMENDED IN THE POMOLOGICAL MAGAZINE.

RED. - Boardman's British Crown, large. - Red Warrington, large, late, - Red Champagne, small. - Early Black, small.

Whiтe. - White Crystal, small. - White Champagne, small.

Green. - Pitmaston Green Gage, small.

Yellow.-Hayroood's Invincible, large.-Yellow Champagne. - Rumbullion, small.

I add, on good authority, the "Wonderful," the largest gooseberry known.

In the valley of the Columbia River, according to Mr. Parker, there are native gooseberries of several varieties one a yellow gooseberry; an excellent kind, of a pleasant flavor; it grows on a shrub free from thorns. Another kind is of a deep purple color, of the taste and size of our winter grapes; flavor fine, the bush thorny.

\section{U L T IV A T I O , S OIL, \& c .}

Gooseberries require a very rich soil; and in an airy situation or shade they are but little liable to mildew. In all low lands, and in confined situations, in our climate, the fruit of the gooseberry almost invariably mildews; but never on the open hills, and in places exposed to drying winds. They are raised from cuttings planted very early in April, in a moist soil ; every eye should be cut out except the two uppermost above the surface. In autumn cut off the lower shoot very close; and shorten down the one left to six or nine inches. The bushes must be so managed as to be furnished with limbs diverging in every direction, continually increasing in number as they advance from the centre. With this object in view, the young leading shoots of the last year are annually cut back to six or nine inches, and a proportion of the others are cut quite close. Thus the bushes will continue extending, every part being duly 
filled with bearing, wood; sufficient space being left to admit the sun and a free circulation of air. The largest prize gooseberries are raised on vigorous young bushes, which have not more than five or six branches, and but one, two, or at most three berries on a branch. With no pruning whatever, they bear most abundantly near Boston.

\section{R A S P B E R R Y . - (Rubus idaus.)}

The raspberry is a shrub of low growth; its leaves are pinnate, and composed of five leaflets; its flowers in panicles; its root is perennial; its top generally biennial; it produces its fruit on the wood of the former year.

Uses. The raspberry is an admired dessert fruit, but sugar improves its flavor. It is fragrant, subacid, cooling, and grateful to the taste, and, like the strawberry, it does not produce acidity on the stomach. The juice fermented with sugar, produces, wine, very fragrant, and of the most delicious flavor. It is also used for jams, pies, tarts, sauces, preserves, \&c; and, according to Loudon, it is much used for distilling, to make a cordial, spirituous liquor, to which it gives name; and raspberry sirup is next to the strawberry in dissolving the tartar of the teeth. The wine mixed with water, according to Dr. Short, "is a good reviving draught in ardent fevers." "He further recommends it in scorbutic disorders.

For a choice selection, the following are particularly recommended by different authors.

1. "Red Antwerp.

Burley Antwerp.

An excellent and productive fruit, large, and highly esteemed near Boston. The branches must be bent down in autumn, and protected with soil during winter.

2. *Whité Antwerp.

Yellowo Antwerp.

The fruit is large and fine; highly esteemed near Boston, and very productive; like the red, it requires protection in winter: 
3. Barnet. For. Loudon. Pom. Mag. Lindley. Cornwalls Red Prolific Seedling, Large Red.

Produces large fruit and abundant crops; a profitable variety; perfectly hardy and twice bearing at Boston.

4. Red Cane. For. Loudon.

A good sort for the main crop.

5. "Double Bearing. Neill. Loudon. Pom. Mag. Lindley.

Perpetual Bearing, Red Double Bearing, Siberian.

Produces a crop in July, and another in September and October; hardy and abundantly productive at Boston.

6. Cornish. Lindley.

7. Bromley Hill. Pom. Mag.

8. Williams's Doúble Bearing.

Pitmaston's Double Bearing. Loudon.

9. Williaus's Preserving. Lindley.

10. Woodward's Red Globe. Lindley. Forsyth.

11. Red Alpine Montuly.

Framboisier des Alps de Tous les Mois a Fruites Rouge. Recommended in the Bon Jard.

There are several American varieties, quite distinct from the above, which may deserve to be enumerated; these are, 12. Black American Raspberry; 13. White American Raspberry. Also in the valley of the Columbia River, according to Mr. Parker, besides the cominon kinds of raspberries, there is a new species, of thrice the size, and of a very delicate and rich yellow color.

Other varieties are named by Lindley, but not particularly recommended, as the Antwerp Double Bearing Yellow ; Antwoerp Late Bearing, or Knevet's Antwerp ; Brentford Cane; Rough Cane; Lord Exmouth; Oak Hill; Old White; Prolific Early; Red Malta; Spring Grove; Superb; Taylor's Paragon, or Scarlet Paragon; Wilmot's Early Red.

\section{CULTIVATION A N S IL.}

A moist, rich soil is recommended for the raspberry; they do well, producing abundantly, even when moder- 
ately shaded. In forming plantations, Lindley has directed that the rows should run from east to west, and the tallest sorts be planted in the north rows, and in the rear, at a large distance asunder; and those of small growth in the south rows, and at less distance asunder in the row. Thus all the varieties receive the full benefit of the sun. He directs as follows:-

1st or north row, Cornish, set 4 feet asunder in the row. 2d row, Woodward's Red Globe, do.

3d row, $\boldsymbol{R e d} A$ Antwerp, set $3 \frac{1}{2}$ feet asunder in the row. 4th row, White Antwerp, do. do.

5th row, Cane Raspberries, set 3 feet asunder.

6 th row, Double Bearing, or No. 8, do. do.

Large plantations, of any kind, are to be set out on the same principle.

He also recommends that three young plants should be placed in each hill, in a triangular form, six inches apart. These should be cut at the time, within a few inches of the ground. In autumn cut off all wood that has borne fruit; also all weakly shoots, and shorten the strong shoots to four fifths. Stakes or rails are not absolutely necessary. The tops of each stool may be tied together in summer at their tips; or it is recommended to tie one half of two hills together at the tips: thus they form arches or festoons. With regard to the double bearing varieties, it is recommended to cut down every alternate. stool to within a few inches of the ground, in the annual pruning. Thus a succession of large, late crops is always maintained.

The raspberry plantation is in its prime the third year, but must be annihilated after it has stood síx years; and new ones must in the mean time be formed.

\section{PER SI M MON.- (Diospyrus Virginiana.)}

American Date, or Prune.

The persimmon flourishes as far north as the River Connecticut, in the latitude of $42^{\circ}$, but is dwarfish. In a suitable soil and climate, it rises to the height of sixty feet, or forty diameters of its base. The leaves are oblong, 
entire, of a fine dark green abore, and glaucous below, and from four to six inches long. The fertile and barren blossoms are produced on different trees. The fruit, which is abundant, is round, of the size of a small plum, of a reddish color, and fleshy; they contain six or eight small stones; their taste is very astringent, but when ameliorated by frost, they are sweet and agreeable. The fruit, when bruised and fermented, produces brandy, which becomes good by age. This tree is raised from the seeds, which should be planted in autumn; and fine varieties inay be propagated by inoculating or grafting.

\section{S T R A W B E R R Y .-(Fragaria.)}

The strawberry is a low, creeping, perennial plant; a native of the old continent; also of America, where it is found growing in a wild state. Botanists consider them a genus comprehending three species.

Uses. The strawberry is a fragrant and delicious dessert fruit, whether eaten alone or with cream and sugar ; and forms a fine preserve. It is deemed very wholesome, as it never causes acidity on the stomach. Boërhave considered its use as one of the principal remedies in putrid fever; and Hoffinan asserts that he has known consumptive people cured by the use of strawberries. It is also asserted that by eating plentifully of strawberries, rheumatic complaints are averted or cured. They also dissolve tartarous incrustations on the teeth. And lastly, Phillips asserts that the Pine strawberries make an agreeable dessert wine, as rich as Mountain, but possessing greater fragrance and acidity.

\section{VARIETIES.}

Mr. Barnet [see Vol. vi. of the Lond. Hort. Trans.] has divided strawberries into seven classes. Mr. Lindley has adopted the same course. And in describing the size of the fruit, I shall have reference to the general size of the particular class. I have adopted the same system. 


\section{CLASS I.-ALPINE AND WOOD STRAWBERRIES.}

The Alpine and Wood strawberries agree in their general habits and character. The fruit, however, differs. The Alpines have conical fruit, and are fruitful in autumn. The Wood strawberries are more globose; they only produce fruit in summer. - Barnet. - See Vol. vi. of Hort. Trans. 1. Red Alpine, (Fraisier des Alps,) with runners.

The fruit is small and conical, ripening in summer and autumn.

2. Red Bush Alpine.

Possesses similar qualities to the White Bush Alpine, but differs in color.

3. White Alpine, (Fraisier des Alps a Fruit Blanc,) with runners.

The fruit is small and conical, ripening successively in summer and autumn.

4. White Bush Alpine.

This has the same qualities, but is thought to be more productive, as it does not exhaust itself by runners,

5. RED Wood. Fraisier Commun.

An old variety, extensively cultivated near Boston for the markets. It ripens in summer. The fruit is scarlet and round, and highly esteemed near Boston as one of the most sure, and productive, and profitable, of all strawberries. Of this variety there are no males.

6. White Wood. Fraisier Commun a Fruit Blanc.

This variety ripens in summer; the fruit is white and round; an old, good-flavored variety, much cultivated and esteemed near Boston.

\section{CLASS II: - BLACK STRAWBERRIES.}

The fruit of this class is middle-sized, conical, with a neck, of a very dark color at maturity; the seeds slightly. imbedded; the flavor very rich and highly-perfumed; the leaves of this class are small, rugose, pale green. - Barnet. - See Vol. vi. of Hort. Trans.

7. Downton. Knight's Seedling. Pom. Mag. Lind. Barnet.

The fruit is large, ovate, with a neck; the early fruit is 
sometimes of a cockscomb shape; of a dark purple scarlet; the flesh is scarlet, firm, of an aromatic flavor. Originated by Mr. Knight.

8. Sweet Cone. Pom. Mag. Lindley.

Small, conical, with a neck, hairy, bright shining scarlet; flesh pale scarlet, hollow, very high-flavored.

\section{CLASS III. - CAROLINA, OR PINE STRAWBERRIES.}

The leaves of this class are nearly smooth, of firm texture, with obtuse serratures, of a dark green; the fruit large, varying from nearly white to almost purple; the seeds prominent, on a smooth surface; the flavor sweet, and often perfumed. - Barnet. - See Vol. vi. of Hort. Trans.

9. Bishop's StrawberRy.

The fruit is large, of a dark, shining crimson, and very beautiful; growing in large clusters, and of delicious flavor. It grows rapidly, and is a great bearer; and very far superior in this respect to the Keen's Seedling and Wilmot's Superb, while it fully equals them in size. In the opinion of some good judges, who have thoroughly proved the kind, this is the finest of all strawberries, and better suited to our climate than any other of the large imported kinds.

10. Bath Scarlet. Hort. Trans. Vol. vi. p. 200. New Bath Scarlet.

Fruit roundish ovate; neck short, rather small for the class; seeds very prominent, of a dark, shining red; flesh soft, with a large core, pale scarlet, and very coarse, without any particular flavor. So proved in England; but with us it has proved one of the most productive and profitable varieties, and as such is much preferred. Of this variety there are no males.

\section{Black Prince.}

Wilmot's Black Imperial. Lindley. Barnet.

Middle-sized, spherical, depressed, hairy; of a very dark violet color; with a highly-polished surface; the flesh of a rich, dull scarlet, with a very small core, high-flavored. 
12. Elton Seedling. Pom. Mag. Lindley. Barnet. The fruit is large, ovate, often cockscomb-shaped, of a rich, shining dark red; the seeds yellow, with ridged intervals; the flesh is firm, with a small core, deep red, juicy, with a sharp, rich flavor. This variety is by some esteemed as the most productive and best of all for a late crop.

\section{3. *Hover's Seeduing.}

A new variety, a seedling of 1834 , raised by Messrs. Hovey and Co., of Boston, editors of the Magazine of Horticulture and of Botany This account is extracted from that highly-valuable publication. "Fruit very large, round, or slightly ovate, conical; deep shining red, paler in the shade; seeds inserted in a slight cavity; flesh scarlet (paler in the largest berries) and firm, abounding in an agreeable acid and high-flavored juice, not surpassed by any other variety; footstalks long, elevating the fruit from the ground, and every berry attaining a good size; leaves large, and rather light green ; vines very vigorous." This new seedling received two or more premiums of the Massachusetts Horticultural Society, where it was exhibited during the years, 1838,1839 , and 1840 , and is furthermore stated to be wonderfully productive.

\section{Keen's Seeduing. Pom. Mag. Lindley.}

Keen's Black Pine, Keen's New Pine, Keen's New Seedling.

The fruit is very large, globular, or ovate; of a dark purplish scarlet, hairy; it sometimes assumes the cock'scomb shape; the surface polished, seeds slightly imbedded; flesh firm, solid, scarlet, high-flavored. Introduced to the vicinity of Boston, by Mr. Pratt ; also by Mr. Haggerston. The fruit grows high, which is much in its favor. Raised by Mr. Michael Keen, from the seed of Keen's Imperial, which is a good fruit, but very inferior to this. This variety is but little cultivated near Boston for the market. It is here deemed unproductive, compared with the old Red Wood, and some otler kinds.

\section{Mulberry. Cherokee, King, Mahone.}

A strawberry much cultivated near Boston, and highly recommended by Messrs. Senior and Haggerston. From them I understand this fruit was sent to the late Governor Gore, and to England, by the late Hon. Rufus King, from the back parts of New York. The fruit is of medium size, ovate, with a short neck, of a dark red; flesh tender, of a red color, and good flavor; very productive. 
16. Old Pine, or Carolina. Pom. Mag. Lind. Barnet. Old Pine, Barham Down, Black Carolina, Cockscomb Pine, Devonshire Scarlet Pine, Kew Pine, Large Carolina, Large Pine, Miss Gunning's, North's Seedling, Old Carolina, Large Scarlet Pine, Pine, Regent's Favorite, Scarlet Pine, Varnished, Windsor Pine.

Fruit large, ovate, conical, with a neck, sometimes cockscomb-shaped in the early fruit; of a bright scarlet; the flesh pale scarlet, rich, juicy, with a very grateful flavor; a good bearer, and very highly esteemed.

17. Turner's Late Pine.

New, and in high estimation in England, and very valuable, according to all accounts received.

\section{CLASS IV. - CHILI STRAWBERRIES.}

The leaves of this class are very villous, hoary, with small leaflets of thick texture, with very obtuse serratures; the fruit is very large and pale, with prominent seeds; the flesh in the type, which is the true Chili, is insipid. - Barnet, in Vol. vi. of Lond. Hort. Trans.

18. Wilmot's Superb. Barnet. Lindley.

The early fruit is very large, irregular, sometimes cockscomb-shaped; afterwards they are invariably round, very hairy, pale scarlet, and polished; the seeds are brown and projecting; flesh very firm, pale scarlet near the outside, but whitish within, with a small hollow in the centre, and a core; flavor good, buttery, and rich, mixed with acid. This variety is but very little cultivated for the market, or for any other purpose, near Boston. It is here deemed unprofitable and unproductive, like the famous Keen's Seedling, and some other large kinds.

\section{CLASS V.-GREEN STRAWBERRIES.}

The French cultivate several varieties of this strawberry. The Green Pine is much known in England, but it seldom bears perfect fruit; it bears well only in some particular situations. Their character is dwarfish, much 
resembling the Wood strawberry. The leaves are light green, and strongly plaited. - Barnet, Vol. vi. Lond. Hort. Trans.

Lindley has described the Green. Strawberry, (Fraisier Vert,)-Caucasian, Green Alpine, Green Wood, PineApple, - but ascribes their defection to the multitude of runners, and has no doubt but if these were restrained, they would prove productive.

\section{CLASS VI. - HAUTBOIS STRAWBERRIES.}

The leaves of this class are highly elevated, rough, and of a thin texture; the scapes or stems tall and strong; the fruit middle-sized, pale greenish white, tinged with dull purple; the seeds slightly imbedded; the flavor musky. Barnet, in Hort. Trans. Vol. vr. Supposed to be so named on account of their bearing their fruit high-Hautbois, or: High Wood.

19. Large Flat Hautbors. Barnet. Pom. Mag. Lind. Bath Hautbois, Formosa Hautbois, Sowder's Hautbois, Salter's Hautbois, Weymouth Hautbois, White Hautbois.

The fruit is large, round, depressed, light red; the seeds are imbedded; the flesh is greenish, juicy, delicate, without a core.

20. Prolific, or Conical Hautbors. Barnet. Pom.

Mag. Lindley.

Double Bearing, Dwarf, Hermaphrodite, Hudson's Bay, Regent's, Sacombe, Sir Joseph Banks's, Spring Grove.

The fruit is large, conical; of a dark purple color ; flesh solid, greenish, and high-flavored; an abundant bearer, and by far the best of the Hautbois strawberries. The flowers are the largest of the class; and it usually produces two crops.

CLASS VII. - SCARLET STRAWBERRIES.

The Fragaria Virginiana of botanists is the type of this class. The leaves are nearly smooth, thin, dark green, with sharp-pointed serratures; the fruit mostly small, of a 
bright scarlet color; the seeds more or less deeply imbedded, with ridged intervals; the flavor acid, with a slight perfume. - Barnet, in Hort. Trans. Vol. vi.

21. Black Roseberry. Pom. Mag. Barnet. Lindley.

The fruit is of good size, obtusely conical, deep purplish red, and shining; the seeds are slightly imbedded; flesh dark red near the outside, solid, buttery, and juicy, and of excellent flavor.

22. Duke of Kent's Scarlet. Barnet. Pom. Mag. Lindley.

Austrian Scarlet of Lindley, Cluster Scarlet, Globe Scarlet, Nova Scotia Scarlet, Duke of York's Scarlet, Early Prolific Scarlet.

The fruit is nearly globular, of rather small size; of a fine scarlet; seeds deeply imbedded, with sharply-ridged intervals; the flesh is solid, pale scarlet; flavor sharp, pleasant, and peculiar.

23. Grove End Scarlet. Barnet. Pom. Mag. Atkinson's Scarlet, Wilmot's Early Scarlet.

A first-rate strawberry, and an abundant bearer. The fruit is of considerable size, depressed, spherical, of a bright vermilion color; seeds slightly imbedded, with flat intervals; flesh pale scarlet, firm, with a core; flavor agreeable, and slightly acid.

24. *Methyen Scarlet. Hort. Trans. Vol. vi. p. 172. Methven Castle, Southampton Scarlet.

Fruit very large, cordate, compressed, or cockscombformed at times, or conical; dark scarlet; seeds pale yellow, not deep set; flesh scarlet, very woolly, sometimes hollow. One of the most productive and profitable for cultivation, and as such it is highly esteemed near Boston. Of good flavor, but not first-rate.

25. * Old Scarlet. Pom. Mag. Lindley. Barnet.

Ecarlate de Virginie of the French, Scarlet, Early Scarlet, Original Scarlet, Early Virginia Scarlet.

A middle-sized, globular fruit, of a light scarlet color; slightly hairy; seeds deeply imbedded, with ridged intervals; flesh pale scarlet, firm, and high-flavored. A good bearer, ripening early; valuable for preserving. Esteemed, near Boston, as one of the most sure and profitable of strawberries for an early crop. There are no male varieties of this fruit. 
26. Roseberry. Barnet. Pom. Mag. Lindley. Aberdeen Seedling, Prolific Pine, Rose Strawberry, Scotch Scarlet.

An abundant bearer ; the fruit is large, conical, pointed, dark red, hairy, with a very short neck. The early fruit is sometimes cockscomb-shaped; seeds yellow, deeply imbedded with ridged intervals; flesh firm, pale scarlet, with a core; flavor not rich, but agreeable, and much admired by many.

The whole list of strawberries which I have just described, (with the exception of the Black Prince, the Wilnot's Superb, the Mulberry and the Wood, the Bush Alpine and Methven Castle,) are but the select list which is particularly recommended in the Pom. Mag. for a small garden.

Mr. Lindley has since particularly recommended the same list for a small garden, with the exception of the Bromley Hill, and the addition of the Black Prince, and Wilmot's Superb. I have added the Mulberry on good authority here; also I have added the two varieties of Wood strawberries, and the two varieties of Bush Alpine.

Mr. Lindley has described sixty-two varieties. Mr. Barnet has recommended for a select list the same, generally, as the Pomological Magazine and Mr. Lindley.

In 1822, the London Horticultural Society, by their circulars, congregated from all quarters a vast collection of strawberries at Chiswick. The whole were examined by Mr. Barnet; there were two hundred distinct names or synonymes, and fifty-four varieties; his account' of them occupies eighty pages quarto. - See Hort. Trans. Vol. vi. p. 145.

Let us enumerate the names of the strawberries which Mr. Lindley has described, and which are not recommended either by him, or in the Pom. Mag., for a small garden. Some of them may yet, perhaps, prove fine in our climate, as-is the case with the Mulberry strawberry and Methven, the Red Wood, the Bath Scarlet, and Bishop's; and all are evidently thought worthy in a large collection.

In this list I omit the numerous synonymes generally. American Scarlet. Autumn Scarlet. Bath Scarlet. Bishop's Seedling Scarlet. Blood Pine. Bostock, or Wellington. Bullock's Blood.' Carmine Scarlet.' Charlotte. 
Chinese. Clustered Scarlet. Cockscomb Scarlet. Common Hautbois. Conjcal Hautbois. Dutch. Dwarf White Carolina. Garnestone Seedling. Gibbs's Seedling Black. Glazed Pine. Globe Hautbois. Green. Grimstone Scarlet. Hudson's Bay Scarlet. Keen's Imperial. Knight's Large Scarlet. Lewisham Scarlet. Methven Scarlet, or Methven Castle. Morrissiana Scarlet. Mulberry. Nairn's Scarlet. Narrow-Leaved Scarlet. Oblong Scarlet. Pitmaston Black. Pitmaston Black Scarlet. Red Wood. Round White Caroline. Scone Scarlet. Sir Joseph Banks's Scarlet. Surinam. True Chili. Variegated Pine. Vernon's Scarlet. White Wood. Wilmot's Late Scarlet. Yellow Chili.

Other varieties, which were unknown, or are not described, by those authors, and which may prove fine in our climate :

27. New Black Musk Hautbois.

28. French Musk Hautbois.

29. Southiorough Serding.

30. Large Lima.

31. Melon, \&c. \&c.

32. Swannon's.

This last is new, and lately originated in England; of medium size and good flavor; possessing the remarkable quality of producing its fruit all summer; having blossoms, green fruit, and ripe, on the vines at the same time.

\section{ULTIVATION.}

It is recommended that, as early in summer as the young runners have taken root, they should be transplanted into nursery beds five or six inches asunder. By this management they will by autumn have become fine, strong plants, capable of producing fruit the following summer.

For the reception of these plants, the ground may be trenched twenty inches deep, and a quantity of half-rotted manure incorporated to half this depth. For economy, it is also recommended, in the final transplanting, to set the plants in beds of four rows each; the rows run- 
ning in a longitudinal direction; the distance between the beds to vary from two to two and a half feet, according to the sorts to be planted; as some varieties require much more space than others. As to the distances of the rows asunder, and the distance of the plants in the rows, I will lay down, on Lindley's authority, the following rules :

$3 d$ Crass. In rows fifteen inches asunder; the plants fifteen inches' distance in the row. Wilnot's Superb the same.

2d and 4th Classes, (except Wilmot's, as above.) In rows fifteen inches asunder; and twelve inches' distance in the rows.

6th and 7th Classes. In rows twelve inches asunder; and twelve inches' distance in the rows.

1st and 5th Cuasses. In rows twelve inches asunder; and nine inches' distance in the rows.

During the first year, the runners are to be carefully destroyed before they have taken root. Around such as show fruit, grass or straw is placed; (Keen recommends the same; for the plant derives its name from this circumstance.) This protects alike the soil from washing rains, from a scorching sun, and the consequent evaporation of its moisture ; it protects the fruit from becoming soiled. 'But as soon as the fruit is gathered, this covering is to be removed, and the soil kept clear of weeds by the hoe till autumn.

In autumn, he directs the leaves to be cut off, (only a portion, I presume,) and all the spaces, including the alleys, to be dug carefully over with a pronged fork, so as not to injure their roots. Both Keen and Mr. Knight, however, direct manure to be applied before this last operation is commenced; and Mr. Knight has particularly cautioned against digging so deep as to disturb the roots, as it weakens the force of the plants.

The second summer, Lindley further states that the plants will bear their best crop and finest fruit ; the beds and outside of the alleys should be covered with mown grass or with straw three or four inches thick; by this method he states he has found the fruit not only more abundant, but of finer quality.

It has been recommended to raise the Alpines from the seed. But Mr. Williams, of Pitmaston, (Hort. Trans.,) condemns the practice. - Lindley joins him in this; for having procured a good sort, it is recommended to increase 26 * 
and continue it; and have no mixture of inferior sorts, with the idea that such mixtures will improve. Some have directed, in regard to the Alpines and Hautbois; that a certain proportion of male or sterile plants should be preserved. But the experience of Lindley and some others seems opposed to this practice. - These sterile plants, never producing fruit, outgrow all the rest; they overrun those which produce fruit, and soon take possession of the whole soil; they are neither useful nor necessary, but, on the contrary, ruinous, as the whole bed soon becomes barren. But by excluding the sterile plants in the beginning, the whole will remain productive.

As to the Alpines, Lindley directs to set them out in August; and by spring the beds will be covered with runners : these are not to be disturbed or removed, as in the case of other sorts; for they will produce fruit during autumn.

Management of Alpine and other Sorts of Strawberries, when large and late Crops are desired. The Alpine strawberries are chiefly valuable on account of their continuing fruitful after all other varieties are gone. In order to make the utmost of this valuable property which they possess, Mr. John Williams, of Pitmaston, has directed (see Hort.Trans.) to form the beds in August; by spring the beds will be well stocked with plants. When they have come into full blossom in spring, cut off every flower, without injuring the leaves. This operation is to be again repeated as soon as a second set of blossoms appear. The third set of blossoms are suffered to remain; and, the plants having by this system accumulated strength, heavy crops are produced after other strawberries are gone, and when alone the Alpine strawberries are highly valuable.

Another mode has been stated, by which a large crop of the common varieties of strawberries is produced in autumn. When the first crop is gone, the plants are shorn of every leaf, and at suitable intervals profusely watered: by this mode, they not only renew their leaves, but a crop of blossoms and fruit is produced.

With regard to the produce of strawberries, all agree that the crop of the second year is more valuable than any succeeding crop. I will briefly detail a few of the most approved modes in relation to this subject. 
1st. The mode adopted by Mr. Keen.

2d. That adopted by T. A. Knight, Esq.

3d. Modes of management much approved and in practice near Boston.

Mr. Keen forms his beds in the spring. - The Hautbois and Pines are placed in rows, three feet asunder, and eighteen inches in the row; [other classes at a proportionate distance.] The object in placing them at this great distance is, that there may be room for the feet of the gatherers; also room for the vines to spread, to the end of the third year, when the bed is taken up and the ground planted anew. The first year, little fruit is expected - the second year, a very great crop - the third year, a very moderate crop. Mr. Knight condemns this system in part; his mode is as follows:- Like Mr. Keen, he forms his beds in the spring: he places the Pine and Hautbois in rows, sixteen inches asunder, and only eight inches in the row; [other classes at a proportionate distance.] This is from three to four times the number of plants on the same ground as Mr. Keen. Mr. Knight takes off no runners, except for the purpose of forming new beds; and he thinks he must obtain near twice the produce in the second year, - which all acknowledge to be the fruitful year, - from the same ground as Mr. Keen. For Mr. Knight leaves no unoccupied ground for the feet of the gatherers; as he considers the amount thus destroyed very inconsiderable, compared with the waste of land. Mr. Knight destroys his beds in the autumn of the second year, after the first great or main crop is taken off. He esteems this the most economical mode.

In the vicinity of Boston, the following mode is often adopted:- The vines are usually transplanted in August. The rows are formed from eighteen inches to two feet asunder. The runners, during the first year, are destroyed. In the second year, they are suffered to grow and fill the interval, and in the autumn of that year, the whole old rows are turned under with the spade, and the rows are thus shifted to the middle of the space. The same process is repeated every second year.

Another mode, which may be recommended generally, is to plant the strawberries in rows thirty inches asunder, and nine inches' distant in the row, and suffer the vines to extend to the width of eighteen inches, leaving twelve inches' 
space for an alley; or allow eighteen inches' width to the alleys, and three feet asunder to the rows; and to form new beds every three years, or never to suffer the bed to exist over four years; and to plant out in August in preference to spring.

\section{M E PLAN'T.-(Podophyllum peltatum.)}

A hardy and singular production of nature. The stem, foliage, flower, and fruit, are formed in the earth; and after the plant has come up, there is nothing more than an extension of parts. The stems, at the height of from eight to twelve inches, branch out into two arms: at the extremity of each is a large palmated leaf. From the fork proceeds the fruit stem. The fruit is about the size of a large lime, green while growing, and yellow when ripe; it has the flavor of a pine-apple, and as to eating, is little inferior to that fruit. The plant requires a moist soil, in a cool, shady situation. It may be propagated by seed, but best by dividing the roots, which are jointed and creeping. The root is medicinal. A native of America.

\section{E L O N.}

MUSKMELON. (Cucumis Melo.)

A delicious, large, oblong or globular fruit, too generally known to need a particular description. It is a native of Asia, and besides its use at the dessert, it forms, while young, an excellent pickle.

\section{VARIETIES.}

1. BцAск Rock. Lindley.

Very large, oblate; yellowish skin; flesh thick, orange colored, and of an excellent flavor. 


\section{Daree Melon. Hort. Trans.}

Fruit large, ovate or oval, pale green; flesh white, thick, crisp, melting, very sweet.

3. Duтch Rоск. Lindley.

An oblate, medium-sized fruit, with a thick, yellow, rough skin; flesh orange-colored, thick, melting, sweet, and high-flavored.

4. Early Cantaloupe. Lindley.

Small, globular, ribbed ; skin pale green; flesh orangecolored, juicy, of good flavor.

5. Early Polignac. Lindley.

A small, round fruit, with a pale yellow, rough skin; flesh yellow, thick, sweet, and highly-flavored.

6. Green Melon. (Ostrich's Egg.) Hort. Trans.

A green, oval, handsome fruit; flesh very thick, green, melting, very sweet, and high-flavored.

7. Green Hoosainee. Hort. Trans.

A handsome, egg-shaped fruit; flesh greenish white; tender, delicate, juicy, highly-perfumed. A very excellent and productive variety.

8. Italian Green-Fleshed. Hort. Trans.

A small, round, pale green fruit ; flesh pale green, soft, juicy, very sweet, and high-flavored.

\section{Large Germek. Hort. Trans.}

A large, excellent, and productive round fruit, of a sea green color; flesh clear green, very thick, firm, juicy, rich, and high-flavored.

10. Melon de Carmes. Lindley.

A very large, oblong, bright orange-colored fruit; flesh very thick, salmon-colored, tender, not juicy, sweet, and good-flavored.

11. Melon of Keising. Hort. Trans.

A beautiful, egg-shaped fruit, bright lemon color ; flesh very thick, nearly white, very juicy, delicate, sweet, and high-flavored, like a Beurrée Pear.

12. Montagu Cantaloupe. Hort. Trans.

Form round or oval, small, greenish white; flesh thick, reddish, soft, sweet, juicy, and delicate.

13. Orange Cantaloupe. Lindley.

A small, round, yellow fruit; flesh deep orange red, jucy, sugary, and extremely high-flavored. 
14. Romana, Neill.

A middle-sized, oval, pale yellow fruit, ribbed; flesh yellow, firm, and well-flavored.

15. Scarlet Rock. Lindley.

An oblate, deeply-ribbed, pale green fruit; flesh reddish; tender, juicy, sweet, and highly-flavored.

16. Silver Rock. Lindley.

Middle-sized, oblate; skin green and yellow, blotched; flesh pale red, sweet, and well-flavored.

17. Smooth Scarlet-Fleshed. Lindley. Hort. Trans.

Form round or oval ; skin greenish yellow; flesh scarlet; firm, and high-flavored.

18. Sweet Melon of Ispahan. Hort. Trans.

Fruit large, ovate; skin smooth, of a sulphur color; flesh white, very thick, crisp, sugary, and very rich.

19. Dampsha Melon. Hort. Trans.

Fruit oblong, yellowish green; flesh green, melting, and of excellent flavor.

20. Green Valencia. Hort. Trans.

Form oval, pointed, slightly ribbed, of a dark green color; fiesh pale straw color, firm, saccharine, juicy, and pleasant. The latter crops of the two last-named varieties keep till winter.

We may also enumerate the following fine varieties:-

Green Citron, (fine,) green flesh ;

Murray's Pine-Apple, do.

Persian, do.

Nutmeg, do.

Minorca, do.

Large Cantaloupe ;

Star; very late;

Pomegranate, or musk, (fine,) odoratissimus ;

Palermo, very rich and fine; flesh green, and keeps late in the season.

Cultivation. The muskmelon is raised from seed planted in April or May, in a highly-manured, warm, loamy soil, in hills six or eight feet asunder. Those kinds intended for seed should be raised remote from inferior varieties. The vines should be pruned of superfluous branches, and all superfluous fruits must be removed as soon as they appear. 


\section{WATERMELON. (Cucurbitus citrullus.)}

A native of Asia, and cultivated in all the warm and temperate countries of Europe, Africa, and America. A very large, round or oblong fruit, too well known in our climate to need a particular description.

UsEs. The watermelon is a very refreshing and wholesome dessert fruit in the warm season : it mitigates thirst. From the watermelon an excellent sweetmeat, called artifcial citron, may be prepared as follows:-

\section{American Citron.}

Pare the dark green from the outside, and scrape the soft from the inside, of the melon; cut it in different forms, and boil it in alum water until clear; throw it into spring water, where it may remain two or three hours, changing the water frequently.

"To one pound of fruit, take two of sugar; make a sirup of half the quantity, and boil in it all the citron until done, when it will be transparent. At the expiration of two or three days, take the jelly from it, add the remaining half of sugar, boil and pour it over the citron, which will be ready for use. Season it with ginger ; sliced lemon is preferable."

The inspissated juice of the watermelon of the sweetest kinds, affords a bright, light-colored sirup. A conserve and marmalade is also prepared from the fruit. At Sarpa, on the River Volga, says Pallas, they brew beer from the juice.

\section{Varieties. - 1. Long Carolina; 2. Round Carolina.}

Cultivation. The cultivation of the watermelon is in all respects the same as the muskmelon. Innumerable and nameless fine varieties continually appear-- But the same precautions are necessary to preserve the seed in its purity, as are recommended for the musk-melon. They require a highly-manured, rich, warm, and rather sandy soil. 


\section{B E R B E R R Y . - (B̈rberis.)}

The berberry, or barberry, is a prickly shrub, rising to the height of ten feet, with numerous branches. The bark is ash-colored outside, and yellow within; the fruit is in clusters, of a red color and acid taste. It is said to be a native of Asia, but abounds in the Northern and Middle States of America. Some species of grain are liable to become affected by rust, if raised in its vicinity, particularly rye.

Uses. The fruit is used for pickling, and for preserving; a decoction of the berries, sweetened, is deemed a useful as well as pleasant drink in fevers. The inner bark is said to be used in France for dyeing cotton and silk of a bright yellow; also for staining wood, by cabinet makers; and in Poland it is used for coloring leather.

\section{VARIETIES.}

\section{Red Berberry.}

Of this there are two varieties; one the common berberry, with stones; the other without.

\section{Whte BerberRy.}

Fruit large, agreeable, but not productive.

\section{Bi.ack Sweet. Loudon.}

Requires a warm situation.

\section{Chinese Berberry.}

This variety in some respects resembles the red, but differs some in appearance, and is deemed the nost ornamental.

5. Holly-leaved Berberry. Berberis aquafolium.

A new and curious variety from the Rocky Mountains; very different from all others. This appears to be a variety with thornless wood, and with leaves larger and by far more handsome than the other species, with prickly points. A low, sub-evergreen shrub. The blossoms are produced in numerous yellow clusters, and are beautiful.

Soll and Cultivation. The berberry prefers a dry soil, but will succeed in almost any soil or situation. It is raised from seeds, from layers and suckers. 


\section{B L A C K B E R R Y. \\ (Bramble. - Rubus fruticosa.)}

1. Bush Blackberry. Rubus Americanus.

A shrub rising to the height of ten feet, somewhat ribbed or angled, and armed with hooked spines. The fruit, which grows in clusters, is oblong, an inch in length, of a shining black, of an agreeable taste, sweet, or subacid, and astringent. This plant thrives in a rich, moist, sandy loam, and is often cultivated in gardens, where its fruit is much improved in size, and its crops very abundant.

2. Trayling Blackberry. Devoberry. Rubus procumbens.

This is a plant with low, trailing branches; its stems are weak, and bend to the earth, and there take root. The fruit is large, nearly globular, of a black color, and covered with bloom, of a sweet, subacid, lively taste ; this plant succeeds in dry, hilly land.

Uses. The blackberry is considered a pleasant and wholesome dessert fruit, if used with moderation; it is used in pies, tarts, \&c. A jelly is made of the blackberry of considerable medicinal efficacy in nephritic disorders. It is singular that a fruit so productive as the tall blackberry should be so little cultivated. Both species may be propagated either from seed or from layers, and are wonderfully improved by cultivation.

3. White-Fruited Bramble. "Rubus alba.

A variety with white fruit.

4. Doubie White Flowering. Rubus albo-pleno.

$A$ beautiful and ornamental variety.

\section{CR A N B ER R I ES.-(Oxycoccus macrocarpus.)}

A low, trailing vine, an indigenous fruit, growing wild in bogs and meadows. The berry has a very acid taste, and 
is much used in pies, puddings, tarts, preserves, \&c. The cranberry is a plant of easy culture; and with but little expense, not a doubt exists that meadows which are now barren wastes, or yield nothing but coarse herbage, might be converted into profitable cranberry fields. According to Loudon, Sir Joseph Banks, who obtained this plant from America, raised, in 1831, on a square of eighteen feet each way, three and a half Winchester bushels, which is at the rate of four hundred and sixty bushels to the acre. A man with a cranberry rake will, in a good cranberry meadow, gather from twenty to fifty bushels in a day; any meadow will answer. Capt. Henry Hall, of Barnstable, has cultivated the cranberry twenty years. They grow well on sandy bogs after draining; if the bogs are covered with brush, it is removed, but it is not necessary to remove the rushes, as the strong roots of the cranberry soon overpower them. It would be well if, previous to planting, the land could be ploughed; but Capt. Hall usually spreads on beach sand, and digs holes four feet asunder each way, the same distance as for corn; the holes are, however, deeper. Into these holes, sods of cranberry roots are planted, and in the space of three years the whole ground is covered. The planting is usually performed in autumn. Mr. F. A. Hayden, of Lincoln, Mass., is stated to have gathered from his farm, in 1830 , four hundred bushels of cranberries, which brought him, in Boston market, $\$ 400$.

An acre of cranberries in full bearing will produce over 200 bushels; and the fruit generally sells, in the markets of Boston, for $\$ 1.50$ per bushel, and much higher than in former years. Although a moist soil is best suited to the plant, yet, with a suitable mixture of bog earth, it will flourish, producing abundant crops, even in any dry soil. There is said to be a variety of cranberry in Russia of a superior size.

\section{CRA NBERRY VIBURNUM. ( $V$. oxycoccum.)}

The cranberry tree, or shrub, rises to a very moderate height. The blossoms are white, forming a flat surface 
from a common centre; or in terminating cymes; and very beautiful. Its fruit is a berry about the size of a cranberry, of a bright red color, and very austere taste. They are valuable for pies, tarts, preserves, \&c. The tree is propagated by layers, and suckers or seeds.

In the valley of the Columbia River, a new species of bush cranberry has been discovered, called Pambina.

\section{E L D E R.-(Sambucus nigra.)}

A low, bushy tree, of an ornamental appearance; its bark is smooth and gray, becoming rough by age; leaves pinnate; the flowers in terminating cymes; the berries black and abundant, of a sweet but not agreeable flavor; the tree and its leaves are narcotic. Noxious insects avoid it.

Uses. Although the berries are deemed poisonous to poultry generally, yet they are employed in the manufacture of an excellent, powerful and enlivening wine, remarkably wholesome. But the wine of white elder berries is said to resemble grape wine. A sirup and cordial are also prepared from the berries; and in Germany a very pure and strong spirit is said to be distilled from the fruit. The inner green bark is said to be an ingredient in black dye. And Professor Martyn, according to Loudon, has stated that the tree is a whole magazine of physic to rustic practitioners; nor is it quite neglected by more regular ones. Fruit trees, plants, \&c., whipped with the fresh branches, are effectually secured from the depredations of noxious insects. The wood of old trees is bard and fine-grained, and takes a fine polish, and is used by turners as a substitute for box wood. A new variety of sweet elder has been discovered, which is peculiar to the Oregon region. 


\section{ED L A R . - (Mespilus Germanica.)}

A low, spreading tree; the branches are woolly; the leaves are oval, lanceolate, serrate, and woolly towards their points; the fruit is round or turbinate, the size that of a plum; the pulp is thick, and contains five wrinkled stones. An ornamental shrub, when in bloom, and a native of the south of Europe.

Uses. The fruit is much esteemed by some; but it is never eaten till ameliorated by frost, and in a state of decay.

\section{VARIETIES.}

1. Nottingham Mediar. Loudon.

A fruit of a quick and pungent taste.

2. German Medlar, or Dutch Medlar.

A low, crooked, deformed tree, with very large leaves, entire, and downy beneath; the flowers are very large; the fruit very large, somewhat resembling an apple in shape. This variety is the largest of the medlars, and is deemed the best.

Sorl and Cultivation. Raised by seeds, planted while fresh; and in autumn; also by layers; or by grafting and inoculating, either on the medlar or on the quince, the hawthorn or the pear. They require a loamy, rich soil, rather moist than dry, on a dry subsoil.

\section{MOUNTAIN ASH.-(Sorbus aucuparia.)}

This tree rises erect, in a beautiful, pyramidal form, to the height of twenty-five or thirty feet; the leaves are pinnate; the flowers are white, in corymbs; the fruit is round, of a fine coral red. The berries of this tree are eaten, according to Loudon, in some parts of Scotland and Wales; they are also used for preserving; they are also stated to afford 


\section{SALAL BERRY.- SILVER-LEAVED SHEPARDIA, \&C. 317}

an agreeable fermented liquor; and by distillation, a considerable quantity of strong spirit. - According to Mr. Neill, in France they are frequently grafted on the service tree, and the fruit is thus rendered of larger size, and more abundant. - It is one of the most ornamental of all trees, when loaded with its large clusters of red berries in autumn.

\section{SALAL BER R :}

The salal berry is a new fruit, which has been discovered in the valley of the Columbia River; about the size of the common grape, of a dark purple color, and sweet and pleasant flavor.

\section{SILVER-LEAVED SHEPARDIA.}

Buffalo Berry Tree. (Shepardia eleagnoides.)

A beautiful, hardy tree, so called from its silvery leaf. This, tree was discovered by Professor Nuttall, in Missouri, in 1810 , and was introduced here by the Messrs. Winship. The tree is of upright growth and thorny; the leaves are small, of a delicate, silvery appearance; the fertile and barren flowers are produced on different trees; the fruit is of the size and appearance of a large currant; of a fine scarlet color, and beautiful appearance; they envelop the branches in profuse clusters. It is of a rich taste, and valuable, with preparation, for preserves, tarts, \&c.

\section{N U T S.}

\section{WALNUT. (Juglans regia.)}

\section{English or Madeira Nut.}

The walnut is a native of Persia and China. It is a lofty, spreading tree, with pinnated leaves, of a powerful 
odor. The fruit is roundish oblong, smooth, green, enclosing a nut of a yellow color and irregular form, which contains a four-lobed kernel of an agreeable taste.

Uses. The walnut is an esteemed dessert fruit; it also forms an excellent pickle when gathered, while it is yet so tender as to be easily probed with a needle. In France, an oil equal to the oil of almonds is drawn from them. This oil does not congeal by cold, is highly prized by the painters for mixing delicate colors and varnish, and is excellent in medicine. The young preserved nuts are an excellent sweetmeat; good to be eaten in the morning, in time of pestilential distempers, to prevent infection. - $\mathbf{A}$ most superior family medicine when eaten in the small quantity of a single nut. They are prepared as follows:-Green walnuts, in the state fit for pickling, are boiled till tender; then take them out, and to every pound of nuts add a pound of moist sugar, a little water, lemon peel, mace, cloves, and simmer till the sirup is thick, and let them stand ten days; then clarify half as much more sugar, and boiled as before; and when cold, cover them close for use.

The decoction of the leaves annoys or destroys noxious insects and worms.

The timber is dark and beautiful, and is very extensively used for gunstocks, being deemed lighter, in proportion to its strength and elasticity, than any other wood.

Cultivation, Soll, \&c. The walnut is raised from the seed, planted in autumn; the second year, they are transplanted, and deprived of a portion of their tap root. They require a rich soil of loam and sand rather than clay. The varieties may be inarched - or budded from the minute buds at the base of the young shoot, inserted in the summit of the two years old wood.

\section{BLACK WALNUT. (Juglans nigra.)}

A majestic tree, with a round, spreading head, which sometimes rises to the height of seventy feet, with a diarneter of from four to seven feet. The leaves are pinnate, and consist of six or eight pair of leaflets. They are acuminate, serrate, and downy. The fruit is large, and surrounded with a thick, globular, smooth, green husk; the shell is rough, uneven in its surface, odoriferous, hard, 
thick, and black. It encloses a four-lobed kernel, which is large and sweet.

UsEs. From the nut an oil is expressed equal to olive oil for food, and useful for the painter." From the husk a brown dye is procured, of different shades. The sap-wood is white, but the heart is violet, becoming nearly black. It is very strong, fine-grained, compact, and heavy, and admits a beautiful polish, and is employed for furniture, and the stocks of muskets, and for the naves of wheels. It is extremely durable; and it is said to be never attacked by the sea-worm.

Cultivation, Soll, \&c. The cultivation of this tree is the same as the walnut. It flourishes in any good soil ; but prefers the deep, fertile, and alluvial soils on the margins of creeks and rivers.

\section{BUTTERNUT.}

\section{(Juglans cathartica.)}

OIL Not, Whtte WaLNuT.

A large tree, with a broad, spreading head. In suitable situations, it rises fifty or sixty feet, with a diameter of from three to four feet at this distance from the ground.

When young, this tree and its leaf strikingly resemble the Black walnut; but when older, they are easily distinguished. The fruit is similar, in most respects, to that variety, but is oval oblong; and the nut which is enclosed is oblong, rounded at the base, and pointed at its summit. The kernel is sweet, and abounds in a valuable oil.

Uses. The fruit is eaten at the dessert: for pickling it is superior, and is equally valuable as the walnut. Its fruit; preserved in the same manner as directed for the walnut; is equally excellent, and of equal medicinal efficacy. Pills formed by evaporating a decoction of the inner bark to a viscid consistence, are said to form one of the very best cathartics known. The timber is of a reddish hue, not strong, but light and durable. It is never attacked by the sea-worms. It is not liable to split, and its uses are the same as the bass wood.

Cultivation. The cultivation of the Butternut is the - same as the walnut; it flourishes in any good soil, on cold, unproductive, and rocky soils, on the steep banks of rivers. 


\section{CHESTNUT. (Castanca.)}

The European chestnut was so named from Castanea, a city of that name in Thessalia, from whence the Romans first received them. The chestnut is a large tree, of a fine form, rising sometimes to the height of eighty feet. The leaves are of an elongated form, coarsely serrated, of a fine, shining green. A large, globular, prickly bur encloses two or three nuts of a dark brown color.

UsEs. The fruit is used either boiled, roasted, or in a raw state. Phillips informs us that in the south of France, in Italy, and Savoy, they are made into puddings, cakes, and bread. And "chestnuts stewed with cream make a much-admired dish; they make excellent soup; and stewed and served with salt fish they are much admired." We are also further informed that there is now at Fortsworth, in Gloucestershire, a great chestnut tree, fifty-two feet round, which in 1150 was so remarkable that it was called The great chestnut of Fortsworth. And Marsham states that this tree is $\mathbf{1 1 0 0}$ years old. Lastly, the timber of this tree is almost incorruptible, and more durable than oak. Its durability is commensurate with the long life of the tree. Corsica, it is said, exports annually of this fruit to the amount of 100,000 crowns. The American chestnut differs very little from that of Europe. The fruit is smaller, but equally good. Its growth is very rapid. The bark for tanning is superior to oak.

Cultivation. The chestnut is raised from the seeds, planted in autumn; the second year, they are transplanted, and fine varieties are extended by grafting. A sandy or gravelly loam, with a dry subsoil, best suits them.

\section{CHINQUAPIN. (Castanea pumila.)}

The Dwarf chestnut rises to the height of ten or twelve feet, but sometimes thirty or forty feet. The tree and its fruit are, with but little variation, a miniature of the chestnut just described. But the timber is finer grained, more compact, heavier, if not more durable. It flourishes in any dry soil. Its cultivation is the same as the walnut and chestnut. It is not found wild north of Pennsylvania. 
SHAGBARK HICKORY. (Juglans squamosa.)

The Shagbark, or Shellbark, is an elegant tree, of a tall and stately form, rising to the height of 80 or 90 feet. Its height is very tall in proportion to its dimensions near the base; often from forty to fifty diameters.

The leaves are oval, acuminate, in five leaflets, of a beautiful shining green above, glaucous beneath. When it has arrived to middle size, the outer bark separates in long, thin plates or scales, warped out at the ends, giving the tree a shaggy and bristling appearance. In this respect it differs not only from other trees, but from other hickories; also in the fruit, which is round or oval, its hull very thick, covering a nut whose shell is always thin, and four-lobed kernel, sweet. The timber of the shagbark always splits clear; it works smooth; it is very compact, strong, and elastic, and is preferred to any other wood or hickory for axe-handles, ox-bows, and various domestic utensils, where all these qualities are required.

Cultivation, Sorl, \&c. The cultivation of this tree is the same as the walnut. It flourishes in any good soil, even in low, wet land.

\section{PACANE NUT. (Juglans olivaformis.)}

A beautiful tree, rising, with a straight, well-proportioned trunk, to the height of 60 or 70 feet. Each leaf consists of six or seven leaflets. The nut, which is encompassed with a thin hull, is an inch and a half long, cylindrical, - pointed at its extremities, and has four slightly-projecting angular ribs. The shell is smooth and thin, the kernel fourlobed, and sweet.

\section{FILBERT. (Corylus.)}

A large shrub, with wood of an ash color; leaves alternate, roundish cordate. Its fruit is well known and highly esteemed. They are extensively cultivated in Europe: "In the neighborhood of Avelino, in Italy," says Swinburn, "the whole face of the neighboring valley is covered with them, and in good years they yield a profit of 60,000 ducats. And from a single wood near Recus, in Spain, sixty thousand bushels have been gathered in a single year, and shipped from Barcelona; whence they are called Barcelona nuts." - Phillips. 
Phillips further informs us, the produce of a single acre planted with filberts, has sometimes been sold for fifty pounds. And Loudon states that its returns are very profitable.

\section{VARIETIES.}

1. Frizzled Filbert. Pom. Mag. One of the very best. The fruit is produced in threes or fives, sometimes more; rather small, oblong, flattened, the shell moderately thick, filled with the kernel, which is of good flavor. Very productive. The branches grow pendulous.

2. Cosford Nut. Pom. Mag. A large, oblong nut; shell thin; kernel white, sweet, and of excellent quality. Very productive.

3. Red Filbert. Loudon. Pom. Mag. Very fine flavored, but not productive.

4. Coвnut. Loudon. A large nut; shell thick, kernel sweet.

5. Pearson's Prolific. Pom. Mag. A great bearer.

6. *Prolific Dwarf. The shell is rather thick. This variety bears most abundantly when only two feet high.

7. Spanish, or Barcelona. A large nut, with a thin shell. This is the sort we usually import.

8. Knight's Large. Pom. Mag. Very fine.

9. American Filbert, or Hazel Nut. (C. Americana.) This native variety is small, but sweet, and very productive; and by cultivation it may undoubtedly be wonderfully improved in size.

Cultivation. By seeds is not the best mode of raising, except to produce new varieties; by layers is best, as this preserves the kinds. A deep, dry, sandy loam, on a dry subsoil, is the best; according to the English writers, a wellmanured soil. In a rich, moist soil; they grow too luxuriantly to produce fruit. They require pruning and trimming, to be kept low ; the leading shoots are every year to be shortened two thirds or more. 
SOUTHERN FRUITS. - CLASS I. - FIGS.

\section{SOUTHER N F UITS.}

\section{Chass I.}

FRUITS WHICH MAY BE CULTIVATED IN THE SOUTH-WESTERN AND SOUTHERN STATES, , TO THE LAT. OF 25 .

Most of these, however, may flourish in the Middle States, and a small portion may succeed in the North-western and Eastern States, to the latitude of $43^{\circ}$, and in Oregon.

\section{FIG, (Ficus carica.)}

The fig tree is a native of Asia; a deciduous tree in the temperate climates, but an evergreen within the tropics. In a warm climate, it grows to a very large size. The branches are smooth, of a dark ashen color; the leaves cordate, ovate, three or five-lobed, thick; the fruit grows on the wood of the former year in the axils of the leaves; its form is turbinate; it contains a pulp of a.sweet and delicious flavor. The fig forms an important article of culture in Barbary, Greece, Italy, Spain, and the south of France, for drying, and on the coasts of the Mediterranean and its isles. In these countries, it grows to a large size. It is also cultivated pretty extensively near Paris, for the supply of its markets. Here they are kept low, that they may be with the greater ease protected in winter. They are planted on the south sides of walls, buildings, and the southern declivities of hills. Phillips informs us that there is an orchard of a hundred standard fig trees near Worthing, in Sussex, England; its extent is three quarters of an acre. The trees are of the size of large apple trees, and ripen their fruit as well as in any part of Spain.' 'They are annually productive, and very profitable, ripening in August, September, and October.

Uses. The fig is a wholesome and delicious article of the dessert; and in those countries where it is extensively cultivated, it is not only eaten in a green or dried state, but fried or stewed, and in various ways, with or without bread 
or meat, as food. Figs are prepared by dipping them in scalding ley, made of the ashes of the fig tree, and then dried in the sun. And according to Dambourney, [see Dom. Enc.] " in dyeing, a decoction of the green branches and leaves imparts a deep gold color, of a brownish red shade; but the leaves alone impart a very deep yellow color. And the substances thus dyed retain a very agreeable fragrance for many months, even after being washed. The wood of the fig tree is almost indestructible, and was formerly much employed, in the East, for the preservation of embalmed bodies." [I $b$.

\section{VARIETIES.}

\section{ANGÉLIQUE. Lindley. Bon Jard.}

Mélite, Courcourelle Blanche, Hort. Soc. Cat.

Yellow Angélique. Bon Jard.

The fruit is small; its color yellow; form pyramidal; its pulp is white, but red at the centre, and of excellent flavor. This sort is cultivated in the neighborhood of Paris.

\section{COMMON BLUE. Mr. Neill.}

Sometimes called the Purple Fig; is of an oblong shape, and the tree is a great bearer. August.

\section{LARGE BLUE. Lindley.}

Laree Purple.

Fruit large, oblong; skin purple, or dark brown, covered with a thick blue bloom; pulp deep red, of a very good flavor. A very hardy sort, and a most excellent bearer.

\section{BOURDEAUX. Lindley.}

Poire Figur, Violette de Bourdeaux, of the French.

The fruit is long and pyramidal, rounded at the crown, its length three inches; its color is naturally a deep violet; its pulp is deep red or purple, succulent, and sweet. This fig is stated to be cultivated throughout France, and although not of very high flavor, it is very productive, producing annually two crops.

5. FIGUE BLANCHE RONDE. N. Duh. Pl. Iv.

Round White.

This fig is esteemed the most suitable for the climate of Paris; it is the most multiplied, and is there preferred to all others for its productiveness, and the superior quality of its fruit. The fruit is turbinate, two inches in diameter; color at maturity yellowish green; the flesh is white, very sweet and delicious. The first crop begins to ripen at the 
end of June. The second crop begins to ripen the middle of September, and lasts till hard frosts commence.

\section{BRUNSWICK. Mir. Neill.}

\section{Madona.}

The form is long and pyramidal; the color brown, with but little flavor. The Pomological Magazine and Lindley agree that it is sweet, extremely rich, and high-flavored; and that it is the largest and best purple fig they have, adapted to their climate. It is early.

7. BLACK GENOA. Mr. Neill.

An oblong fruit, of a dark purple color, almost black, and covered with purple bloom ; the pulp is bright and highflavored. The tree is a good bearer. End of August.

8. PURPLE GENOA.

The,fruit is large and long; the skin dark purple at maturity; the flesh extremely sweet and delicious.

9. WHITE GENOA. "Mr. Neill.

A large and almost globular fruit, of a yellowish color at maturity; the pulp is of a light red color, and of good flavor. The tree is considered rather a shy bearer.

10. BLACK ISCHIA. Mr. Neill.

Sometimes called Blue Ischia; is a very good sort; the fruit is short, of medium size, a little flattened at the crown; at maturity the skin is dark purple, or almost black, and the inside of a deep red; the pulp very high-flavored. The tree is a good bearer. End of September.

\section{BROWN ISCHIA. Mr. Neill.}

Sometimes called Chestnut-colored Ischia; a very large, globular fruit; its pulp is purple; sweet, and of very good flavor. It ripens early, and seldom fails of producing a good crop. Middle of August.

12. GREEN ISCHIA. For.

The fruit is oblong; its summit nearly globular; its skin is green, thin, and brown at maturity; flesh purple and high-flavored.

13. YELLOW ISCHIA. For.

The fruit is large, the color yellow, the flesh purple, and well-flavored.

14. BLACK ITALIAN. Mr. Neill.

A small, roundish fruit ; the skin purple; its pulp of a dark red color, and high-flavored. The tree bears well. 


\section{BROWN ITALIAN. Mr. Neill.}

A small, roundish fruit; the skin of a brown color at maturity; the pulp is red and high-flavored. The tree bears abuudantly.

\section{LONG BROWN NAPLES. For.}

This fruit is long, compressed at its summit; the color dark brown; the flesh is of a reddish color, and of good flavor; the seeds are large.

17. MALTA. Mr. Neill.

A small, brown fruit; the pulp is sweet and well-flavored. When permitted to hang on the tree till it shrivels, it forms a fine sweetmeat.

\section{MARSEILLES. Lindley.}

Figue Rlanche of the French.

The fruit is small; its form turbinate; its height two inches, its diameter nearly the same; color at maturity yellowish white; the pulp is white, dry, sweet, and rich.

\section{MURREY. Mr. Neill.}

Brown Red Naples.

A large, globular-shaped fruit, of pretty good flaror; it is distinguished by the murrey-colored skin. September.

\section{NERII. Lindley.}

The fruit is small, turbinate, pale greenish yellow; pulp similar in color to that of the pomegranate. The richest of the yellow, white, or green species, with a slight, delicate, agreeáble acid. The Nerii fig is cultivated by Mr. Knight, at Downton Castle.

21. BROWN TURKEY. Lindley.

Brow i Italas of Forsyth, according to Lindley's Guide.

Fruit small and round; of a red or purple color; pulp very delicious.

\section{VIOLETTE. Lindley and Bon Jard.}

Figue Violette.

Fruit small, of a deep violet color ; form globular, slightly turbinate, and about two inches in diameter; flesh white near the skin, the centre tinged with red, and excellent. This sort is cultivated in the vicinity of Paris for the market.

23. SMALL EARLY WHITE. Mr. Neill.

Its form is globular; the pulp sweet, but without much flavor. It ripens early. Indeed, it seldom fails of producing a crop. 
CULTIVATION, SOIL, \&ic.

The fig tree is raised from seeds, from layers, and from cuttings. They require a friable, loamy, but not wet soil, and an airy, warm situation. They differ from most other trees in producing several crops annually. Even in the climate of Boston, I am persuaded that figs of good quality may be raised, if the trees are placed in warm situations, south of walls or buildings, on the declivities of hills, as at Argenteuil, near Paris. Mr. Knight has obtained, in his hot-louse, eight successive crops in a year, by bending the limbs in a position below the horizontal. And Mr. Lowell, in his experiments, has succeeded in obtaining four crops. The tree will produce tolerable crops in the second year, if rung or decorticated; and by this process the maturity of the fruit is accelerated, and its size increased. Its maturity is also hastened by a practice which prevails in France, which consists in pricking the fruit with a straw or quill dipped in olive oil. In Italy, according to Loudon, a wound with a knife is sometimes made on the broad end of the fig, or a very small part of the skin is removed for the same purpose. Lastly, by the mode communicated to the public by the Hon. John Lowell, which is as follows :"The fig, like the fruit of the vine and peach, attains a certain size, and then remains stationary for several weeks, until it begins to color; when its volume, in three or four days, is greatly increased, often 'doubled, and even trebled. My figs [in a hot-house, 28th August] were dark green, showing no tendency to ripen. I took about a third of a tea-spoonful of sweet oil, and, dipping my finger in it, I rubbed it very slightly over every alternate fig, leaving the others untouched, as a test of the effects. At the end of three days, the color of most of those touched with oil began to change, and the size to increase; and now, on the fifth day, they have nearly the color of mature figs, and are twice and three times as large as those not touched with oil, which still remain of a dark green color."

Mr. Phillips recommends that for a cold climate, like England, the tree should be table-trained; that is, to keep the branches tied to stakes about two feet from the ground; thus forming a regular star from the trunk. In the winter 
they are easily lowered to the earth, and secured by hooks, and protected.

Mr. Loudon seems persuaded that by combining the system recommended by Mr. Knight with that recommended by the Rev. G. Swayne, the most desirable results would be produced; they are both calculated for cold climates.

Mr. Knight highly disapproves of training the branches of fig trees perpendicularly. If the stems are many, he reduces them to one only. And from the tops and parts near it, lateral branches are trained horizontally and pendently, and secured close to the wall. All troublesome luxuriance is thus restrained, and the wood becomes extremely fruitful.

Mr. Swayne trains his trees horizontally. His "specific" is designed to remedy the deficiency of bloom, in the early spring, on the whole of the last year's wood, excepting on a few joints at its extremities. The remedy which he has for a long time successfully practised, is, to simply rub off, as soon as they can -be discovered, all the figs which are produced after midsummer on the same year's shoots. Those figs which thus exhaust the tree, and will never ripen without artificial heat, are thus removed, and new figs are formed. in embryo, for the crop of the following year, on one, if not on both sides of every fig thus displaced. The tree should be examined once a week from the commencement of the operation, which should be begun early in August or September, and continued to the end of the season, according to latitude and climate.

Protection. In the north of France, fig trees are protected in winter by being secured to the earth by hooks, and covered with soil. This is the mode adopted at Argenteuil, near Paris, where almost the whole population are employed exclusively in their cultivation. In England, Forsyth and others recommend to protect with straw, meadow hay, moss, \&c., and over this branches of pine or other evergreen are secured. They flourish with little care and no protection in the Southern States. They will even ripen their fruits in open cnlture near Boston, but require greater heat to give them flavor. 
OLIVE. (Olea Europaa.) Bon Jard. Loudon. Phillips. Rosier.

The olive is a low, evergreen, branching tree, throwing out numerous suckers from its roots; it rises to the height of from twenty to thirty feet; the leaves are stiff, narrow, simple, very entire, and more or less lanceolate in different varieties, dull green above and whitish below. The flowers are in small axillary bunches, of a yellowish white. The berry is a drupe, of a black, violet, or red color, sometimes white; its hard, thick, fleshy pulp encloses a stone.

The olive requires a greater degree of heat than the vine, but not so great as the orange. It will - not flourish within the tropics. M. Poiteau informs us, that in Europe, $45^{\circ}$ of northern latitude is the extreme boundary for the cultivation of the olive. He also informs us, that during his abode in the equinoctial règions of America, in the latitude of $17^{\circ}$ north, he saw the olive trees 30 feet in height; they grew, but they never produced fruit. The olive has been cultivated from time immemorial in Egypt and Barbary, and in every part of Europe and Asia, where the soil is favorable to its growth; it is naturalized to the south of France, Spain, and Italy. The trees are said to live to an incredible.age.

Uses. The olive has long been cultivated as the most useful of all trees, and to the farmer the surest source of wealth. "And it has become a proverb, "If you want to leave an inheritance to your children, plant an olive." The tree begins to bear at two years of age, and soon repays all expense. In twenty years they begin to bear good crops, yielding fifteen or twenty pounds of oil annually. And an old, lollow tree, near Gricomi, to the east of Rome, has produced 240 English quarts of oil in a year. Mr. Jefferson esteems the olive as the most precious gift of Heaven to man - more precious than even bread. He informs us that, "in passing the Alps at the Col de Tende, where there are mere masses of rocks, wherever there hap. pens to be a little soil, there are a number of olive trees, and a family supported by them. Take away these trees, and the same ground in corn could not support a single family. A pound of oil is equivalent to many pounds of flesh, by the quantity of vegetables it will prepare and ren- 
der comfortable food. Without this tree, the country of Provence, and territory of Genoa, would not support one half, perhaps not one third of their present inhabitants." * * * * "Little is carried to America, because Europe has it not to spare; we therefore have not learned the use of it; but cover the Southern States with it, and every man will become a consumer of it, within whose reach it can be brought in point of price." In the deserts of Northern Africa and Asia, as we are informed, wherever the olive groves are found, you find inhabitants; but take àway the olive trees, and the country returns again to the desert.

The, other varieties are used at the dessert as a pickle. For pickling, the unripe fruit is steeped in water some days, and then in a ley of water and barilla, or kali and lime; and afterwards bottled or barrelled with salt and water. According to some, they are scalded.

But the principal use of the olive is for the production of the oil known in commerce as the olive oil. For this purpose, they are gathered by hand when five sixths are ripe, in a fine dry day, and laid on scaffolds three or four inches thick; here they are to remain five, six, seven, or eight days, till the moisture contained in their pulp has evaporated, when they are ground between mill-stones, and put into bags of hemp or rushes, carried to the press, and the oil is extracted by its action, without, however, crushing the stone. This oil is used as an article of food and medicine. That which is afterwards obtained by crushing the stone, from the remaining pulp, and from the kernel by the application of hot water, is of inferior quality. This last is used by the apothecary for various unguents; it is used in the preparation of wool in the manufactures; in the preparation of soap, \&c. But the very best oil is made from the fruit gathered from or beneath the trees at perfect maturity, and ground and pressed immediately.

Olive oil is possessed of great medicinal efficacy. Captain Stoddard, an American sea captain, while at Havana, was cured of the yellow fever after the black vomit had commenced, by drinking at once a pint of olive oil - by the direction of his physicians. During the periodical visitations of the plague at Smyrna, it has been observed that the boatmen and others, who are engaged in the transportation and management of the oil of olives, and whose bodies are in a manner encased in garments saturated 
with oil, invariably escape the plague, how much soever exposed.

\section{VARIETIES.}

In the Cours Complet of Rosier, and Bon Jardinier, we have the following account of some of the very best varieties known in cultivation:-

1. Olive Galiningue, Oulivière, Laurine; (O. angulosa.) Gouan.

A hardy variety ; its fruit is reddish; it is used in many places for preserving; its oil is of medium quality according to Gouan, but very good according to others.

2. Olive Aglandeat, Calanne, Dec. (O. subrotunda.) Fruit small, round, very bitter; oil excellent.

3. Olive Amellon, Amelingue, Plant d’Aix. (O. amygdelina.) Gouan.

This is a variety the most generally cultivated; its fruit is large, and in form somewhat resembles an almond ; it is sometimes used for preserving, but its oil is very sweet. The tree is very productive.

4. Ouive Cormeav. (O. craniomorpha.) Gouan,

The branches incline towards the earth; it is very productive; the fruit is small, crooked, pointed, very black; stone sharp at its two extremities. The oil is fine.

5. Olive Ampoulleav, Barrilanque. (O. spharica.) Gouan.

The fruit is more round than any other variety; the oil is delicate and fine; much cultivated in Provence and Languedoc.

6. Olive Picholine, Saurine. (O. oblonga.) Gouan.

The fruit is reputed best for preserving. The oil is fine and sweet. According to Rosier, some have given the same name to another and different fruit.

7. Olive Verdole, Verdau. (O. viridula.) Gouan.

It preserves its green color a long time; it is liable to perish at the period of its maturity; it, is highly esteemed at Pont-du-Saint-Esprit and Montpelier, \&c., but neglected elsewhere. Is this owing to soil or cultivation?

8. Olive Moureau, Mourette, Mourescole, NeGRETTE. (O. pracox.) Gouan:

Fruit oval; very deep color; the stone is small; oil es- 
teemed. There are several varieties of the Moureau. Much cultivated in Provence and Languedoc. The leaves are large, thick, pointed, and numerous.

9. Olive Bouteilleau, Boutiniane, Nopugète. (O) racemosa.) Gouan.

This is less sensible to cold than other olives; it is variable in its produce; the oil is good.

10. Olive Sayerne, Salierne. (O. atrorubens.) Gouan.

The tree is of medium size, and sensible to cold. It grows in flinty and calcareous, rocky soils. The fruit is black or violet; the oil is of the finest quality.

11. Olive Marbrée, Pigau. (O. variegata.) Golian.

Fruit variable in size and in form; it changes from green to red, marbled with red, violet, and white.

\section{Olive Turquorse. ( $\boldsymbol{O}$. odorata.) Rosier.}

Leaves large and numerous; fruit long, of an agreeable odor, excellent to preserve; the oil is very sweet. The tree is productive; it requires a good sun, but is less sensible to cold than most other species.

13. Olive d'Espagne, L'Espanole, a variety of Eiguieres. (O. Hispanica.) Rosier.

The largest olive of France; esteemed for preserves; the oil bitter.

14. Olive Royale, Triparde, Triparelle. (O. regia.) Rosier.

Fruit large, suitable to pickle; oil of bad quality.

15. Ohive Pointue, Punchude, Rougetre. (O. atrovirens.) Rosier.

Fruit long, pointed at its extremities; red at maturity, oil esteemed.

16. 17. Amongst all the varieties in cultivation, we must not omit to mention the SweEt White Olive and the Sweet Black Olive, which, when ripe, may, unlike the others, be eaten without preparation.

By the aid of the resear ches of the Hon. H. A. S. Dearborn, I am enabled to give an account of two other varieties. They are two varieties of the most hardy description, and the most important of all for the United States. In the southern part of the Crimea, which lies between the latitude of $44^{\circ}$ and $46^{\circ}$, two varieties of olives have been discovered, 
which have existed there for centuries. . They yield great crops, and resist the frost. The tree of one of these varieties is of a pyramidal form, and produces an oval fruit; the other has pendent branches, and a large, heart-shaped berry. These olives have been cultivated in the Royal Imperial Garden of Nikita, to preserve and multiply the species, with plants which had been received from Provence, and have endured the rigorous winters of 1825 and 1826, while those of Provence, in the same exposure, perished even to the root. Measures have been recently taken in France for the introduction into that country of "these two precious varieties, which are capable of resisting ten or twelve degrees of cold below the zero of Reaumur's thermometer" equal to five degrees above the zero of Fahrenheit.

\section{CULTIVATION AND SOIL:}

The olive is raised from seeds. For this purpose, the fruit is stripped of its pulp, and steeped in an alkaline solution; they are then buried compactly in soil near the surface; and those which have not been opened by frost during winter, must be cracked in March, and planted. The best foreign - varieties may be inoculated on the Olea Americana; or Devil wood, a species of wild olive which grows in the Carolinas and Georgia ; also by cuttings, layers, suckers from the roots, and by inoculation. But it is propagated, in Italy, from the uovoli, which are small knots, swellings, or tumors in the wood, occasioned by the sap not flowing freely to the roots, but swelling through the bark of the stock, thus forming excrescences containing embryo buds. These are easily detached by introducing a sharp penknife close to the trunk of the tree, which sustains not the least injury by this operation, - Remarks of Signor Manetti, of Monza, near Milan, Lombardy. Loudon's Mag.

The olive flourishes best in a rich, moist, deep soil ; but the fruit is of much better quality in a dry, flinty soil, intermixed with calcareous rocks: it also suffers less from the frost in such situations.

The olive was extensively cultivated in France; but the winters of 1709,1766 , and 1787, were dreadfully destructive; the dreadful winter of 1789 , destroyed all the olives between Arles and Aix, where, in 1787, oil was produced to the amount of 300,000 francs. During the intensely cold 
winter of 1820, nearly every tree in Provence was killed. Under these discouragements, its cultivation is in that country principally confined to a portion of the territories of Provence and of Languedoc; to the department of the eastern Pyrennees and the Maritime Alps: not one fourth part of the oil consumed in France is now produced in that country; and it is stated that more than $\mathbf{5 0 , 0 0 0 , 0 0 0}$ francs are annually paid for supplies imported from Spain, Italy, and the Levant.

M. André Michaux is persuaded the olive will one day be extensively cultivated in the Southern States of America.

\section{CAROB. (Ceratonia caroubier.)}

A tree cultivated extensively in the south of Europe. The pods of this tree contain a sweet, eatable fœcula. A medium-sized tree, which flourishes in the central part of France and Genoa. The flowers are in clusters, of a deep purple; fruit a foot long, containing a reddish pulp, of an agreeable, sweet taste, when dry. They are both food for man and horses. It is raised from seeds.

\section{CUSTARD APPLE. (Annona.-Corossal.)}

Of this fruit there are several varieties. In congenial climates, it is said to be highly esteemed as an article of the dessert; particularly the cherimoyer (A: cherimolia) of Peru, which produces its fruit in the south of Spain, is described as a superior fruit. This variety is also cultivated in Brazil.

The Alligator Apple, (A. palustris,) the Sweet Sop, (A. squamosa,) and Sour Sop, (A. muriata,) are esteemed West India fruits. The fruit resembles a middle-sized apple, filled with a soft, sweet pulp. The tree is deciduous. It is propagated by seeds, and by grafting, either in the roots or above.

There is a variety, a native of Kentucky, (A. glabı u.) [Bon Jard. Loudon. Hort. Soc. Cat.]

\section{EUPHORIA LONGANA. (Dimocarpus, Longan.) Lou-} don. Hort. Soc. Cat.

LONG-YEN.

The tree has compound leaves, like the ash. It grows in China. The fruit is a berry, of a light brown color; it is surrounded with a thin, leathery coat. The pulp is a thin, 
colorless substance, and contains in its centre a brown seed. The flavor of the pulp is slightly sweet, subacid, and particularly pleasant to the taste. The fruit is sometimes imported in a dried state from China, and has a rich, sweet taste.

It is raised from seeds and layers. The Li-tchi and Rambutan both possess superior qualities to the Long-yen.

\section{GRANADILLA: (Passiflora.) Loudon. Bon Jard.}

Passion Flower.

Of this fruit there are a variety of species.

1. P. Quadrangularis.

This plant flourishes near Paris, with a Jittle protection in winter. The leaves are oval, five or six inches long, and entire; the stem four-cornered; the flowers are odoriferous, red within, and white outside. The fruit is very Iarge, six inches long, and fifteen inches in circumference; greenish yellow at maturity, soft and leathery, with a smooth skin; the rind is very thick, the pulp soft and succulent, of a purple color, mixed with seeds in a sort of sack. Wine and sugar are commonly added. The flavor is sweet, and slightly acid, and it is very grateful to the taste, and cooling in a hot climate. A native of Jamaica.

2. Apple-Frutted, or Sweet Calabash. (P. maliformis.)

Fruit round, smooth, two inches in diameter, of a dingy yellow color; the skin is thick; the pulp pale yellow, and very agreeable. A native of the West Indies.

\section{Purple-Frutied Granadilla. ( $\boldsymbol{P}$. edulis.)}

The color of the fruit is livid purple, the shape elliptic; it is two inches long, and an inch and a half in diameter; the pulp is orange color, the seeds numerous; the taste acid, with the flavor somewhat like an orange. A native of Brazil.

4. Flesh-Colored Granadilia. May Apple. (P. incarnata.).

A native of Virginia. The flowers are sweet-scented, variegated with purple; the fruit is about the size of an apple, orange-colored, with a sweetish yellow pulp.

Cultivation. All the varieties of Passiflora may be propagated from seeds, from layers and cuttings. 
GUAVA. (Psidium.) Loudon. Bon Jard.

1. White Guava. (P. pyriferum.)

A West India tree, naturalized in the interior of France, where it produces perfect fruit. A tree nine to twelve feet high, with numerous branches. The fruit is the size of a hen's egg, roundish or oblong, smooth, yellow ; the rind is thin; pulp fine, full of hard seeds, flesh-colored, sweet, aromatic, and pleasant. It is eaten with avidity, both by West Indians and Europeans - raw in the dessert, and preserved in sugar.

2. Red Guava. (P. pomiferum.)

A beautiful fruit, formed like a pomegranate, but not so agreeable as the white.

3. Citrley's Guava. (P. Cattleyanum.) Hort. Soc. Cat.

A new species from China. This fruit is larger than the others I have described, nearly spherical, of a fine, deep claret color. The skin has the consistence of a ripe fig, but is thinner; the interior is a soft, fleshy pulp, purplish red next the skin, and changing to white at the centre. It is juicy, and much in consistence like the strawberry, to which it bears some resemblance.

The guava is raised from the seeds. This last described, and the cherry-fruited, are stated to be the best. The plants of the yellow and red have produced abundant crops in England.

\section{JUJUBE. (Zizyplus sativus.) Loudon. Bon Jard.}

LOTE.

A branching, thorny shrub, from Syria, of the easiest culture in Italy, Barbary, and China, and abundantly productive. It is cultivated in Provence, from whence they are sent to Paris. They are served up as a sweetmeat in Italy. The leaves are oblong, obtuse, shining; the flowers very small, and yellow; the fruit is yellow, the size and shape of an olive. According to Loudon, the kaki are orange or apple shaped. A fruit known for its excellence as a preserve.

LOQUAT. (Mespilus Japonica.) Loudon. Hort. Soc. Cat. ERHobotrya.

A plant nearly hardy, from Japan, cultivated in the south of France and at Malta. A lofty tree, with thick, knobby branches; the leaves are narrow, a span long; the fruit is about the size of a gooseberry, and in taste resembling an apple. It is raised from seed, from cuttings, and layers, 
but the best way is to graft it on the common.Mespilus. Sir Joseph Banks considers the fruit equally as good as that of the mango.

\section{LUCUMA.}

A new genus of fruit. It grows in Chili; in taste and size it is somewhat similar to a peach. $-E d$. Enc.

\section{MADI.}

This plant grows in Chili. It is said to be a new genus; its seeds afford an oil which has been preferred to any of the French olive oils. - Ed. Enc.

OLEASTER. (Eløagnus angustifolius.) Hort. Soc. Cat. Bon Jard.

A tree of medium size, with leaves of a white color, and lanceolate; the flowers small, numerous, and of a yellowish color, and an agreeable odor. The fruit is held in some estimation in Persia, and the fruit, or Persian date, when dried, resembles an oblong plum, with a tough, reddish skin, with' a flavor not unlike that of the date, but more grateful. Raised from layers. :

PINUS PINEA, or Stone Pine.

A tall evergreen, growing spontaneously in Italy, Spain, and Portugal. The kernels which are contained in the cones are eaten in those countries at the dessert, being preferred to almonds. They are esteemed useful in colds, coughs, \&c. The trees flourish in any soil, but prefer a sandy loam.

\section{PISTACHIA. (Pistacia vcra.) Bon Jard.}

A native of Syria. A tree rising to the height of twenty feet. The flowers are in clusters, and the barren and fertile blossoms are produced on differeut trees, but the barren may be ingrafted into the same tree producing fertile flowers. The fruit is of a crimson green color, and contains a greenish kernel of an agreeable flavor. It is much used by the confectioners.

The pistachia has been naturalized to the middle of France, and it flourishes in the Luxembourg, producing good fruit, but it is there treated as an espalier.

\section{PRICKLY PEAR. (Cactus. Cactier.)}

Of this singular fruit there are several varieties; we enumerate $C$. opuntia - The upright prickly pear, a na- 
tive of Virginia. The stems are jointed and without leaves; they are broad, flat, thick, with bristling spines, and trail on the ground. 'The fruit is in form of a fig or pear, with clusters of spines on the skin; its pulp is of a reddish purple color, and of an agreeable subacid flavor. Loudon enumerates several varieties, as the great Indian fig, or upright prickly pear, (C. funa,) oblong Indian fig, ( $\boldsymbol{C}$. ficus indica,) \&c.

The Virginia prickly pear (C. opuntia) appears hardy, and will endure the hard winters, unprotected, near Boston, and flourishes with great luxuriance in New Jersey. Mr. Braddick, according to Loudon, has tried the plant in open ground, unprotected, during several hard winters. He cultivates them in a composition of half-lime rubbish, or carbonate of lime, and the other half equal parts of clay and bog earth. The plant is raised on a small hillock; stones and pebbles are laid, to prevent the leaves or fruit touching the ground. Raised from seeds or cuttings.

\section{POMEGRANATE. (Punica.)}

A low, deciduous tree, rising from fifteen to twenty feet high, armed with thorns; the leaves are long and narrow. A native of the south parts of Europe and China. It is used for hedges in Languedoc and Italy. There are several varieties enumerated by Loudon and others.

1. The Subacid fruited; 2. Large flowored, single $\boldsymbol{R} e d$ and White; 3. The semidoublc, and double Red and White; 4. The Yellow flowered; 5. The Variegated flowered; 6. Proliferous.

\section{Pomegranate. (Punica granatum.)}

Swoet Pomegranate. N. Duh. Pl. 22.

Grenadier a Fruit Doux. Ib.

The tree grows of moderate height; the flowers are brilliant red, and appear in succession from June to September; one of the greatest ornaments of the gardens. The fruit is large, compressed at its base and summit; its diameter three or four inches; its skin is thick, coriaceous, of a deep yellow color, spotted with red points, and colored with red next the sun. Its interior is divided into various unequal compartments, in which are contained a great number of angular seeds of the color and size of red currants; the pulp contains a juice, sweet, abundant, and agreeable. 
Cultivatron. The pomegranate is raised from seed, from layers, from cuttings, and suckers. It may be inoculated or grafted. It requires a strong, rich soil.

\section{TEA. (Thea.)}

The tea tree is a native of China. It is chiefly cultivated between the 30th and 40th degree of latitude. It is a low tree, resembling in its appearance a myrtle; its roots, that of a pear; the flowers, those of the wild rose. The fruit is of the size of a small plum, two or three growing together.

The quantity of tea annually imported into Europe and America from China, probably exceeds $100,000,000 \mathrm{lbs}$. Good tea is deemed wholesome, if taken in moderation, with a due proportion of cream and sugar; but the fresh leaves of the shrub, when made into tea, are highly narcotic, producing giddiness and stupefaction, before the noxious properties are dissipated by roasting. And it is not recommended to drink of the infusion till it has been gathered and prepared a year. There are, it is asserted, but two kinds of tea, the green and the black. The rest are either combinations of these, or products of different sorts, or times of gathering and modes of management. The tea plant might be easily cultivated in the Southern States, and grows well in the Carolinas and Georgia. It is said to have been successfully cultivated by a society of nuns at Wurtzburg; in Franconia, in the lat. of $49^{\circ}$ or $50^{\circ}$ north. $\therefore$ The tea tree, in China, grows equally in the level and mountainous districts, but flourishes best in a light, rocky soil. The seeds are sown in March, and transplanted into rows four feet apart, and three feet in the row; but it is not generally allowed to grow more than six or seven feet high. The trees begin to yield crops at the end of three years; but at the end of six years the trees must be renewed, as the leaves begin to grow hard and harsh. The leaves which are gathered early in the spring are of a bright green color; those of the second crop are of a livid green; and those which are gathered last, or in the latter end of spring, are of a dark green, and of the third quality. The leaves of the extremities of the branches are most tender. Those of the lower parts are the most coarse. After the leaves are gathered, they are exposed to the steam of boiling water. They are then made to shrivel or roll together by being placed on plates of copper or iron, or of baked 
earth, over the fire, and next dried by exposure to the sun. But the green teas and those of the first quality are not dried by exposure to the sun, as this causes them to turn black. And in the preparation of some of the fine sorts, especially that called Tchu-tcha, every leaf is rolled singly in the hand, with great care; after drying, it is packed in boxes lined with lead.

The operation of rolling every individual leaf by hand, of the finer sorts of tea, belongs exclusively to those countries where labor is cheap. By the aid of machinery, the Americans will, if necessary, perform, at the cheapest rate, this same task. It has been satisfactorily ascertained that after drying to a certain degree, and the application of a powerful pressure, the leaves of herbs, and of all other plants, may be preserved, retaining all their virtues and fragrance for a long time. The society of Shakers have successfully adopted this mode, for the preservation of all savory herbs. The discovery is not new; by this same mode are the coarser kinds of teas prepared in some parts of China at this day. Already do the Americans consume from 12 to $20,000,000$ pounds, annually, of the imported tea of China, and by this same most economical mode, will they, ere long, prepare their own tea for their own immense consumption. Transported to our shores, and to our own genial climate and soil, the tea tree of China will here flourish spontaneously; and the consumption must still increase, in proportion as alcohol is renounced, and to an astonishing extent.

By a statemient in the Westminster Review, it would appear, that next after the Chinese and Japanese, the English are the greatest consumers of tea. Great Britain consumes $40,000,000$ pounds annually; and next after them, the United States consume $10,000,000$ pounds; while all the rest of Europe and America consume but 15,000,000 pounds. Those European nations, and their descendants, who consume less tea, use more coffee and chocolate. So also the Mohammedans, who are forbidden the use of wine or alcohol, drink largely of coffee and of tea. The Turks and the Turcomans ase extensively the fine green tea.

In all Asia east of Siam and Camboja, tea is used by all ages, sexes, and conditions, constantly and universally, from morn to night; often without sugar, and always without cream. Here and on that side, a population of $370,000,000$ are supposed to consume 500,000 tons annually. The next greatest consumers are the Japanese. 
Throughout Mongolia and Siberia, all classes are almost as great consumers as in China. The tea used by these is called brick tea ; it is in hard cakes, eighteen inches long; nine broad, and near an inch thick. This is boiled in milk, thickened with rye meal, and seasoned with salt ; the Tartars making a meal of what the Chinese drink. All this comes from China, and is genuine. Extensively also is tea used in Tonquin, Cochin China, Camboja, Siam, and the country of the Burmese. These last receive it over land from Yunan, in large balls, compactly formed, of about five inches in diameter, or of the size of an eighteen pound shot. In this way, as the Jesuits assert, the coarse teas of Yunan are always prepared.

\section{TCHEE-TSE.}

A fruit of China, which resembles a fig, about the size of an ordinary apple, and which, when dried and flattened, is called.Tchee-ping, and is then equal to the best figs of Europe. - Ed. Enc.

\section{TUNA.}

A species of Indian fig, which grows in Chili, and is equal to any European fig. - Ed. Enc.

\section{SOUTHER N F UITS.}

\section{Chass II.}

FRUI'S WHICH FLOURISH - ONLY IN COUNTRIES SITUATED EITHER WITHIN, OR NOT VERY REMOTE FROM, THE TROPICS.

All the following fruits will probably succeed in the south of Louisiana, and especially in the innumerable islands and maritime districts of Florida, from the latitude of $24^{\circ} 20^{\prime}$ to $30^{\circ}$ north, and many of them in the south of Alabama and Mississippi.

\section{ORANGE. (Citrus.)}

Scientific writers have divided the Orange tribe into five leading species, which are all natives of Asia, viz., the 
common Orange, the Lemon, the Citron, the Lime, and the Shaddock. In many countries they rise to the height of fifty feet; - but in more temperate latitudes the common character belonging to them, is that of low evergreen trees, with oval, Janceolate, or ovate, entire or serrated leaves. Those raised from seeds have often axillary spines; the flowers are in peduncles. The fruits are round or oblong, and of a yellow color. The petiole of the orange and shaddock is winged, but naked in the lime, lemon, and citron. These three last are considered of one species. The orange and shaddock are oblate or spherical, and of a red or orange color; the lime is of a pale color, and spherical; the lemon oblong, with a rough sk in and a protuberance at the end; the citron is very rough, oblong, with a very thick skin.

All the species of citrus, according to the authority of Loudon, endure the open air at Nice, Genoa, and Naples. At Mola, in Italy, and at the water's edge in view of the Bay of Gayetta, and on the supposed ruins of one of Cicero's villas, is a garden of 700 orange and lemon trees. It comprehends about two acres, and yields a rent of about 600 scudi, or about $\$ 555$ per annum. But at Florence and Milan, and often at Rome, they require protection. The orange has been long cultivated in Florida, particularly at St. Augustine. The orange groves are said to be extremely productive and profitable.

The orange has been much cultivated in Louisiana, and will succeed well in all the maritime districts and sea islands of Florida, of Mississippi, and Alabama.

"In the south of Devonshire," according to Loudon and Phillips, " and particularly at Saltcombe, one of the warmest spots in England, may be seen, in a few gardens, orange trees that have withstood the winter in the open air upwards of a hundred years, the fruit as large and as fine as any from Portugal. Trees raised from the seed and inoculated on the spot, are found to bear the cold better than trees that are imported.".

\section{VARIETIES.}

The two principal varieties of the Orange are - 1st, the Sweet Orange; 2d, the Bitter Orange, or Bigaradier of the French. 


\section{Sect. L. - Sweet Orange.}

\section{Common Orange. (Citrus Aurantium.)}

An evergreen tree, of medium size, with prickly branches in its wild state; the fruit is round, from two to three inches in diameter, of a yellowish red or golden color. A native of India and China, but now cultivated in Spain, Portugal, and Italy, in Africa, and the warm latitudes of North and South America.

2. Mandarin Orange. (Citrus nobilis.)

The Mandarin or Noble orange is so called from its superiority to all others. A most delicious varjety, but very lately introduced to Europe. The trees appear as hardy as other kinds. The skin is of a deep saffron color, or an orange scarlet. There are two varieties of the Mandarin orange. The large variety is often five inches in diameter; but the Chinese greatly prefer the smaller variety, which is a distinct species from the common China orange, (Citrus aurantium.) It is distinguished not only from this, but from all others, by its curious form and superior excellence. A native of Cochin China, and cnltivated at Canton.

3. Blood, or Red Malta Orange. C. Aurantium Melitensis.

This, according to the Rev. Mr. Bigelow, is the boast of the Island of Malta, and a most delicious fruit. "The pulp inclines to the color of red, but not so much in mass, as intermixed in streaks. It is not only more luscions, but less husky, than the ordinary varieties of orange, and in size is far surpassing."

To this section also belong the Portugal orange, and many other varieties.

Sect. II. - Bitter Orange. Bigaradier of the French. 4. Sevirle Orange.

The leaves of this variety are larger and more beautiful than those of the China orange, Its taste is agreeably bitter. The varieties of the Bigarades are numerous.

To the above sections belong also the Willow-leaved or Turkey Orange; the Dioarf Nutmeg Orange; the Double flowering, and the Variegated leaved, \&c. \&c. 
Uses. The use of the orange as a dessert fruit is well known. The juice of the orange, from its pleasant, subacid flavor, is serviceable in inflammatory or febrile diseases, by diminishing heat and allaying thirst. It is a powerful antiscorbutic. Orange wine of superior quality is thus made: A gallon of water and three pounds of sugar are boiled and skimmed for twenty minutes, and when nearly cool, the juice expressed from eight Seville (sour) oranges is added, together with the shavings of the outer rinds; the whole to be placed in a barrel, and after frequent stirrings for two days, to be bunged down for six months or more, till fit for bottling. The outer rind also forms the basis of an excellent conserve, and when preserved in sugar, is deservedly prized at the dessert, being one of the best stomachics, and a grateful aromatic bitter. The flowers of the orange tree have a highly odoriferous perfume; they have a slightly pungent, bitter taste, and communicate their flavor by infusion to rectified spirits, or by distillation to spirit and water. An essential oil is also prepared from the flowers, of a perfume more delicate and agreeable in its fragrance than even the Otto of Roses. It is prepared in Italy and Portugal, and there called $E s-$ sentia Neroli.

CITRON.

(C. medica.) Loudon.

A beautiful evergreen, prickly, and upright tree, rising to the height of eight or ten feet, with horizontal or reclining branches; the leaves are smooth, oblong, ovate, alternate, serrate, pale green; the fruit is six inches long, ovate, rough, with a protuberance at the summit. There are two rinds; the outer rind is thin, the inner thick, white, and pulpy. The outer rind has innumerable glands filled with a fragrant oil. This fruit ripens successively at all seasons. The citron and. lemon are not deemed so hardy as the orange, and will not endure so great a degree of cold.

Uses. The citron forms an excellent preserve or sweetmeat. The juice, with sugar and water, forms the refreshing beverage called lemonade. It is used in cookery and in medicine, and is powerfully antiscorbutic. There are many varieties. 
LEMON. (C. medica; var. limonum.) Loudon.

The lemon and citron differ but very little. The wood of the lemon tree is more knotty, the bark rougher; the fruit is rather longer, more irregular, less knobby at the extremities, and the skin thinner than that of the citron. The uses are the same. Of the lemon there are many varieties.

\section{LIME. (Citrus acida, or C: Limetta.) Loudon.}

A crooked tree, with many diffuse, prickly branches, which rises to the height of eight feet; the leaves ovate, lanceolate, nearly entire; the fruit nearly globular, an inch and a half in diameter, with a protuberance at its summit; the skin shining, yellowish green, and very odorous; the juice very acid. A native of Asia.

Uses. The lime is said to be rather preferred to the lemon in the West Indies, as the acid is by many thought more agreeable than that of the lemon. Hedges are formed of the tree in the West Indies. The varieties of limes are very few.

\section{SHADDOCK. (C. decumana.)}

Orange Pamplemouse of the French.

The tree rises above the medium size, the branches spreading and prickly ; leaves ovate, neither acute nor obtuse; the petioles cordate, with very broad wings; fruit spheroidal, its surface regular, of a greenish yellow color; the rind is white, thick, fungous, bitter ; the pulp is red or white, with a subacid, sweet juice. This fruit is deemed the least useful class. Yet its extraordinary size gives it a striking appearance. It is stated to grow sometimes to the diameter of from seven to eight inches, and to the weight of fourteen pounds. But it requires two years to arrive at maturity in the climate of Europe. The leaf is the most beautiful of all the orange tribe. The juice is excellent to allay thirst, and from the thickness of the skin, it will keep longer in sea voyages than any other species.

Cultivation. The trees are propagated either by seed, cuttings, or layers. If raised from seeds, they must be inoculated, inarched, or grafted when of suitable size; for the seedlings vary as much in quality, as the seedlings of the apple or pear. The best stocks are raised from the 
seed of the common citron or lemon, and next to these, from the Seville orange. The cuttings are prepared by stripping the lower leaves, and cutting at the bottom close to an eye; these are to be placed in a pot, touching the bottom, or a piece of potsherd, and put in a warm situation, carefully shaded and covered with a hand glass till rooted.

All the varieties require a strong soil, and a warm and protected situation in unfavorable climates.

PINE-APPLE. (Bromelia ananas.) Hort. Trans. Loudon, Phillips, Lindley, and other sources.

The pine-apple is a native of Brazil and of Mexico, from whence it has been introduced to Asia, Africa, and Europe. According to Swinburn, it flourishes, unprotected, at Reggio, near Naples. In America, it grows as far north as the Bermudas. According to Loudon, it is by no means so delicate as many imagine; as it will bear a higher degree of heat, and a degree of cold which would have destroyed the foliage of the vine and peach in a state of vegetation. The most northerly points where they are known to be cultivated in Europe, unprotected, in the open ground, are, at Reggio, near Naples, lat. $40^{\circ} 50^{\prime}$; in America, at the Bermudas, in the latitude of $32^{\circ}$. This fruit will flourish in all the sea islands and maritime districts of Florida, from the latitudes of $24^{\circ} 20^{\prime}$ to $28^{\circ}$ north.

"The leaves of the pine-plant are long, narrow, channeled, and in general furnished with spines or prickles on their edges. The flowers are on a loose spike, on a scape, which is leafy at top; as the spike ripens, it takes the form of a fleshy, scaly strobile, or fruit composed of many berries, which have scarcely any cells or seeds."

The fruit, in form, bears some resemblance to the cones of some species of pine; its flesh is pretty firm, of a delicious fragrance; and for richness of flavor it is thought unrivalled. Some have described its flavor like that of strawberries with wine and sugar. Extraordinary specimens have weighed from nine to ten pounds.

Uses. The pine-apple is considered the best of the dessert fruits; it is also preserved in sugar, and is used in the preparations of marmalades and other confectionaries; and the juice of the pine-apple, fermented, affords a delicious and wholesome vinous liquor. 


\section{VARIETIES.}

1. Antigua Queen. Lindley.

Fruit large, oval; pips large and prominent; flesh deep yellow, rich, and highly-flavored.

2. Black Antigua. Brown Antigua. Neill. Lindley. Leaves of a brownish tinge, with strong prickles; fruit shaped like the frustum of a pyramid, but somewhat oval, of a large size; flesh pale yellow, and high-flavored.

3. Buack Jamaica. Neill. Lindley.

The fruit is large, pyramidal, brownish yellow; flesh deep yellow, and high-flavored.

4. Enville. 'Cockscomb. Lindley.

The fruit is pyramidal, or oval-oblong, of medium size, deep orange; flesh pale yellow, and well-flavored.

5. Montserrat. Indian Black Pine. Neill. Lind.

The leaves are broad, long, recurved; fruit roundishovate; color pale; pips angular; flesh pale yellow, very sweet, and high-flavored.

6.- New Black. Jamaica. Lindley.

The leaves are long; the fruit is large, pyramidal, dark brown; flesh pale yellow, rich, and very high-flavored.

7. White Providence. New Providence. Loud. Lind.

The leaves are very large and long; the fruit is the largest of all pines, oval-oblong; flesh very pale, sweet, and juicy. Weight from six to fourteen pounds.

8. Queen. Olḋ Queen, Narrow-leaved Queen. Lind. Neill.

Esteemed the handsomest kind; fruit of medium size; oval form, of a gold color; flesh yellow; juicy, and sweet, with a very pleasant acid.

9. Russian Globe. Lindley.

Fruit large, oval, dark orange; the flesh yellow, rich, and high-flivored. A very excellent fruit.

Cultivation and Sorl. The pine-apple is propagated by seeds only for obtaining new varieties; but, generally from suckers, or else from the crowns or excrescences growing on the fruit. The most suitable soil appears to be a mixture of good loam, or with a suitable proportion 
of sand and vegetable mould or manure. The pine-apple requires much heat and moisture.

\section{PLANTAIN. (Musa Paradisiaca.) Phillips. Loudon.}

Some assign this plant to Guinea, some to the East Indies, whence it was carried to the Canary Islands and the West Indies and Egypt. It is an herbaceous perennial plant, as it dies or is cut down annually. It rises with a soft, herbaceous, conical stalk, fifteen or twenty feet high, with leaves issuing from the top, six feet long and two feet broad. The fruit is produced on the summit in spikes, which sometimes weigh forty pounds. It is nine or ten inches long, and formed like a cucumber, but pointed at the ends; of a pale yellow color, and soft, sweet, luscious flavor. The fruit makes excellent tarts, and excellent sweetmeats, and is the most wholesome of all confectionary. It forms a principal part of the food of the negroes, who either broil or roast it; they boil it with salt beef, pork, and salt fish, and prefer it to bread, as do the Europeans. Dr. Wright says, the Island of Jamaica would scarcely be habitable without this fruit, as no species of provisions could supply its place. Dampier calls it the king of fruits. A plantation affords a succession of fruit for a whole year. It thrives only in rich, flat-ground, and is propagated by suckers from the roots.

\section{BANANA 'TREE. (Musa sapientum.)}

It differs little from the plantain, having the stalks marked with dark purple stripes and spots, and the fruit is sliorter and rounder. The fruit is more mellow, and is either eaten raw, or roasted, in fritters, preserves, marmalade; and the fermented juice affords an excellent wine. This fruit, according to Swinburn, grows in the open air at Reggio. From the fibres of the tree of the Banana, cloth and cordage are made, of uncommon strength.

M. Humboldt has calculated that the same ground which will produce four thousand pounds of bananas, will only produce thirty-three pounds of wheat, and ninety-nine pounds of potatoes.

\section{AKEE TREE. (Blighia sapida.) Loudon.}

The fruit is esteemed in the West Indies as rery whole- 
some and nourishing; a native of Guinea, and grows from twenty to twenty-five feet high, with numerous branches; leaves like the ash, alternate and pinnate. The fruit is reddish or yellow, the size of a goose egg, with a pulp of. a grateful, subacid flavor. It is propagated in a rich soil, from seeds, cuttings, and layers. -

\section{ALligator PEAR; or Avocado Pear. (Laurus Persea.) Loudon.}

It grows, in the West Indies, to the height of thirty feet, with a large trunk; the leaves are like the laurel, of a deep green; fruit the size of a large pear, and held in great esteem where it grows. The pulp is pretty firm, and has a delicate, rich flavor - so rich and mild, that most people make use of some spice or pungent substance to give it poignancy - either wine, lime juice, but mostly pepper and salt. It is raised from seeds.

\section{ANCHOVY PEAR. (Grias cauliflora.) Loudon.}

This is, in the West Indies, an elegant tree, rising to the height of fifty feet ; the leaves are two or three feet long, and oblong; the fruit is oval, the size and shape of an alligator's egg. It is pickled and eaten like the mango of the East Indies, which it greatly resembles in taste. It is raised from the stones, and grows in moist bottoms or shallow waters.

\section{araUCanian PINE, or Peheun,}

Is by some supposed a new genus; its branches form a quadrangular pyramid; the leaves are three inches in length, heart-shaped, hard, and shining; its fruit attains the size of a man's head, and in taste resembles the chestnut. It grows in Chili.-Ed. Enc.

\section{BREAD FRUIT. (Artocarpus incisa.)}

A native of the South Sea Islands, where it attains the size of the oak; the leaves alternate, glaucous, and two feet long. The whole tree and its fruit, while unripe, abounds in a tenacious, milky juice. The fruit is the size and shape of a child's head, with a rough surface and thin skin. It is eatable to the core, which is the size of the handle of a small knife. The eatable part is as white as snow, of the 30 
consistence of new bread. - It is roasted before it is eaten. It is slightly sweet, and its taste somewhat insipid at first. Two or three of the trees of the bread fruit will suffice for a man's yearly supply.

Raised from seeds, layers, or suckers.

\section{CASHEW NU'T. (Anacardium.)}

A native of the East and West Indies and of the Brazils. The tree grows to the height of twenty feet, with leaves like a walnut in form and odor; the flowers in tufts, and odoriferous. The fruit is in size like an apple, of a white, yellow, or red color; its taste like a cherry - most of them sweet and pleasant, but sometimes sharp and astringent. The expressed juice affords a fine rough wine, and, by distillation, a spirit superior to arrack, rum, or brandy. The seed is not enclosed in the fruit, but grows on its summit; it is kidney-shaped; its hard, rough, black shell encloses a large kernel, the finest in the world. When roasted, they are far superior to pistachios and almonds, and ground with cacao, they make superior chocolate. From the trunk there annually exudes often ten or twelve pounds of a fine semi-transparent gum, similar in quality and equal to gum arabic. The tree produces fruit the third year, and continues productive one hundred years.

\section{CACAO. (Cacao theobroma.)}

The chocolate tree is a native of South America, and of Mexico. It is there an article of commerce, next only to gold and silver. The tree is beautiful, rising from sixteen to twenty feet in height; it resembles the cherry tree in its form and its leaves, and is splendid when in bloom. The flowers are small, scarlet and yellow. The fruit is an oval-pointed pod, enclosing from ten to thirty compressed nuts, an inch in diameter, enveloped in a soft, sweet pulp, of a refreshing taste. When ripe, the pulp and seeds are separated from the pod, and laid on platforms, in masses, to sweat for two days, when they are washed and dried in the sun. The fresh fruit of the chocolate tree, eaten raw, is highly antiscorbutic; and the nuts, when roasted and ground, are moulded into cakes of chocolate - a highlyesteemed, nutritious, and wholesome food. In France, small cakes of chocolate sweetened with sugar, and of 
various forms, are prepared for eating - a fine and nutritious article of food, thus rendered portable, and in great demand. The tree is raised from seeds and from cuttings.

\section{COFFEE. (Coffea Arabica.)}

The origin of this tree has been assigned to Arabia, and by some to Ethiopia. An evergreen tree, rising from eight to eighteen feet, with leaves like a bay tree, or laurel ; the flowers pure white, like snow; they resemble the jasmine, and have a fragrant odor. When in full bloom, they resemble trees in the leaf covered with snow. The fruit, which is produced in clusters, is a drupe, of a deep red color, resembling a cherry; the pulp of a sweetish, unpleasant taste; it encloses two berries. The pulp is separated by a fluted roller and movable breast board, and by washing; when dried, the inner covering or skin is broken by a heavy roller. Coffee should be roasted moderately, and infused immediately after: Good coffee has an aromatic flavor, and is deemed wholesome; it is medicinal, and when used immoderately, causes wakefulness.

Coffee may be cultivated in the peninsula of Florida. A climate where the temperature is seldom below $55^{\circ}$ is most suitable; a soil on gentle declivities. The trees may be set five or six feet asunder; they begin to yield good crops at three years of age, and the average produce of a tree is two and a half pounds.

The consumption of coffee is very great in Mohammedan countries, and especially Turkey, where their religion forbids the use of wine and spirituous liquors. In our own country, its consumption is already very great, and is rapidly increasing; 15,000 tons we now annually consume.

In Paris, the best coffee in the world is made by the following process. This is the celebrated liquor there called café au lait. The coffee is generally roasted in a rotary cylinder, over a small furnace of charcoal, and usually in the open air, until it becomes of a brown cinnamon color; it is then turned into a wooden tray, and stirred till nearly cool. The pot in which coffee is usually made, is compound, and formed of two parts, of equal dimensions; the lower pot being made of the usual form; the spout being kept covered and closed during the process; by a small cap, thimble-formed. The upper pot is nicely fitted to the 
top of the lower pot, of which it forms a lid; it is pierced at the bottom with very fine holes, and thus forms a fine strainer; in the bottom of this pot, and on this strainer, the fresh and finely-ground coffee is placed, and the top of this pot is closed by the insertion of a shallow tin cup, full of larger holes, which serves for a coarser strainer; and through this, either boiling water, or, most commonly, a strong infusion of boiling coffee, is poured, which has been formed by boiling the grounds of the former day, which had still retained a large portion of their original strength; thence the whole fluid slowly and gradually descends to the lower pot. Thus a very strong, clear, and black infusion is prepared, which, on being brought to the table, is reduced by the addition of at least an equal quantity or more of boiling milk; sugar being added to suit the taste. Nothing can be more fragrant and delicious than coffee thus made.

\section{COCOA-NUT. (Ćocos núcífera.)}

A native of the East and West Indies, and an eminently useful tree to the inhabitants of those countries. It rises with a straight trunk to the height of sixty feet. The leaves issue near its summit; they are from twelve to fourteen feet in length, with numerous alternate, sharp-pointed leaflets. The flowers grow near the summit, in clusters; the fruit, in large clusters of from ten to twelve, is enveloped in strong husks; it is a drupe, very large, ovate, with three sharp, longitudinal ribs; the shell is a hard, brown, bony substance, almost incorruptible; to its inner surface, the kernel adberes, which is white, firm, and sweet. While the fruit is young, its capacious centre is filled with a milky liquor, very sweet, agreeable, and wholesome; as the fruit grows older, the milk becomes sharp and cooling, and is of great service in putrid and inflammatory fevers, and highly antiscorbutic. The sap drawn from the trunk produces, by fermentation, wine and vinegar, and by distillation, arrack. The husks form very strong and elastic cordage and cables. From the leaves are formed baskets, brooms, and parasols, mats, hammocks, sail-cloth, \&c. The tree is raised from the nuts, planted in a moist soil There is a small but very excellent variety, not larger than a walnut, a native of Chili. 


\section{DURION. - (Durio zibethinus.) Loudon.}

A lofty East Indian tree, with leaves like a cherry, the flowers in clusters of a pale yellow color; the fruit the size of a man's head, roundish or oblong ; it resembles a rolledup hedgehog, with a hard skin or rind; the pulp is of a creamy substance, of a delicate taste. Rumphius says it is much the most excellent fruit of-India. Its smell is at first heavy and unpleasant, but those accustomed to this fruit consider it the most excellent of all.

\section{MANGO TREE. (Mangifera Indica.)}

A large, spreading East Indian tree, with lanceolate, shining green leaves, of a resinous smell; the fruit is a drupe, kidney-shaped, some as large as a man's fist ; covered with a smooth, softish, pale green, yellow, or half-red-skin, and containing an ovate, woody, fibrous, compressed nut or stone, within which is an ovate kernel, soft and pulpy, like a Damascene plum. "When ripe, it is replete with a fine, agreeable juice. It eats like an apple, but is more juicy. It is esteemed very wholesome, and, except pineapples, it is preferred to any other fruit in India."

Raised from cuttings or from seeds.

\section{MANGOSTAN. (Garcinia mangostana.) Loudon.}

A native of the Molucca Islands, but cultivated in Java and Malacca. An elegant tree, rising twenty feet, with a parabolic head, a taper stem, branching like a fir tree, with oval leaves seven or eight inches long; the flower like a single rose; the fruit round, the size of an orange, the shell like the pomegranate; the seeds are disposed like those of the orange, and surrounded by a soft, juicy pulp, of a rose color, of a delicious flavor, partaking of the strawberry and the grape, and esteemed the richest fruit in the world. It is wholesome alike for those -in health or in sickness.

\section{MAMMEA. (Mammee Americana.)}

A native of the Caribbee Islands. The tree grows tall and handsome; the leaves are oval, shining; of a coriaceous consistence; the flowers, in - peduncles, are large," white, of a sweet odor; the fruit is roundish, of the size of an 
egg. In its flavor and consistence, it is not unlike an apricot. It is eaten either in its raw state and alone, or in slices in sugar and wine; or it is preserved in sugar.

\section{PALM TREE, or DATE. (Phœnix dactylifera.)}

A native of Syria, Palestine, Egypt, and the other warm countries; it there rises to the height of 100 or 150 feet. In Europe it grows as far north as Geneva and Nice; it flourishes also in Spain. No tree, perhaps, is more useful for its fruits, throughout Barbary and Egypt, the deserts of Northern Africa, and Arabia. The fruit is an oval drupe, of a yellowish color; the pulp soft, saccharine, of a vinous flavor; it encloses a large, oblong stone. The date constitutes an important article of food in many countries. They are imported in a half-dried state. A strong and excellent liquor is obtained from the fruit by fermentation, which is much used in Mohammedan countries. From the fruit also palm oil is made. This oil is used as a substitute for butter, and possesses a strong and agreeable odor. The tree is raised from seeds and suckers; they commence bearing at from three to six years of age. The timber is eminently useful, and almost incorruptible.

\section{ROSE-APPLE. (Eugenia.) Loudon. Bon Jard.}

\section{JAMrosade. E. JAMBos.}

A tree from India, rising to the height of from ten to thirty feet; leaves long, lanceolate, and shining; the flowers are in clusters, of a yellowish white color; the fruit the size of a hen's egg, with the taste of an apricot, and of the flavor of the rose. Some are white, some are red, and some are yellow.

Malay Apple. (E. Malaccensis.) Another species; the tree and the leaves are larger; the fruit is ovate, an incli and a half in diameter, fleshy, with a sweet odor, like the rose, agreeable to the taste and sight, and deemed wholesome. Common in most of the South Sea Islands. They are raised from seeds, and require a warm, moist atmosphere.

\section{TAMARIND. (Tamarindus.) Phillips.}

So called from Tamar, (Date, in Arabic.) The tamarind is cultivated in Arabia, Palestine, Egypt, and the East and 
West Indies. The tree is very large, with spreading branches, and thick, beautiful foliage ; the leaves are pinnate, smooth, oblong, entire, of a bright green; they close at night. The fruit is a pod from two to five inches long, enclosing from two to five seeds; the outer pod is thick, the inner as thin as parchment, enclosing the pulp, which is a soft, pulpy substance. The fruit may be preserved in jars, with alternate layers of sugar. But in the West Indies the following mode is adopted : The ripe fruit is taken out of the pod, and placed in layers in a cask; and the boiling sirup from the first copper in the boiling house, just before it begins to granulate, is poured in till the cask is filled; when cool, the cask is headed.

TRIPHASIA. (Aurantiola.) Hort. Soc. Cat.

Three-Leaved Tryphasia. Limonia trifoliata.

The fruit resembles a small orange, and is aromatic. It rises to a compact shrub or tree.

VARRONIA PLUM. (Varronia alnifolia.) Hort. Soc. Cat.

This fruit resembles a small plum. It grows against a south wall, (in England.) It has borne fruit in the Botanic Garden of Madrid, and is believed to be a native of Mexico. 


\section{A P P E N D I X.}

\section{VEGETABLES.}

\section{AN ACCOUNT OF THE MOST USEFUL KNOWN.}

IN THREE CLASSES.

Class I. Nutritious Roots.

Class II. Pulse, Vegetable Tops, \&c.

Class III. Salads, Pickles, Savory Herbs, Pregerves, \&c.

A part of the article on vegetables was prepared for the former edition; but its publication was then given up for the time, and the materials, so far as prepared, were given up to a friend, to be transferred, if he saw fit, to another publication. I have, in this article, consulted the first authorities.

\section{Preparation of the Soll.}

The ground, for the reception of fine seeds of vegetables, should be broken up in the preceding year, and well manured in autumn, and rendered fine in spring by repeated ploughing and barrowing or raking. Plough and manure deep for deep-rooted vegetables; but manure near the aurface only for all others. Potatoes and Indian corn answer well, and produce large crops, in ground newly broken up. Very fine seeds should be sown in a newly-prepared, fresh soil, and covered only a quarter of an inch deep; larger seeds deeper in proportion to their size; and the ground to be immediately trodden hard, or rolled with a heavy roller. This enables the earth to preserve its moisture at its surface, where, at the same time, the seeds may receive the necessary degree of heat from the sun, and vegetate at once, striking root downwards. Fine seeds, if sown too deep, are liable to perish.

\section{Hot-BEDs.}

By bringing forward many kinds of vegetables in a hot-bed, and transplanting as soon as the weather becomes sufficiently warm, you nay be enabled to produce ample supplies, of many kinds, a month earlier than in the open ground, many of our finest vegetables being natives of the tropical countries.

The materials for the formation of the bed may consist of leaves, tanner's bark, or fresh, strawy manure from the horse stable. The 
last for this purpose is to be preferred; but one third part of tan, mixed with two thirds of manure, makes a heat less violent, and more durable than manure alone.

A frame six feet square is composed of four boards; the front board a foot deep; the back or north board eighteen inches. This frame is covered with two sashes; formed of small, cheap glass, five by seven inches. The sashes may be provided with hinges on the back side, for the purpose of raising the front and giving air occasionally. The surface of the earth; aa Mr. Knight has recommended, should be inclined towards the horizon in an angle of 15 degrees. Prepare, therefore, the surface of the earth by sinking the front only to the required depth, and of a width and length exceeding that of the frame. The manure from the stable is now to be built up on this foundation by placing successive layers of manure, with a fork, to the height of about tourteen or fifteen inches, and pressed or trodden gently throughout, its surface corresponding in its inclination with its earthy foundation; the dimensions six inches wider on every side than the frame. On this the frame is placed, and covered with the sashes, and in about two or three days, if the weather is pleasant, cover the surface with rich loam from seven to twelve inches deep; and again put on the lights. If the excess of heat and fermentation is too great, raise the glasses a little in front, and when the earth is of the right temperature, or in about ten days from the commencement, plant your early cucumber, radishes, lettuce, cabbages, \&c. \&c.; and as these increase in size, they may be transplanted either to the open ground or into other hot-beds, and allowed more space, and thence to the open field. In cold, wet weather, the sides may be protected by straw or litter placed around them; and the heat may be renewed by cutting down square the outside, and piling fresh manure around the sides and the frame. The hot-bed should be prepared in March, and made ready by the end of winter.

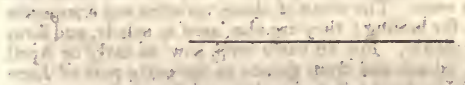

\section{CLASS I. - NUTRITIOUS ROOTS.}

\section{ARACHIS HYPOGAA, or GROUND NUT.}

An annual plant, with long, trailing stalks. A native of Mexico, but now cultivated in the West Indies for its nuts, which are oblong, and grow beneath the surface. These are used by the negroes as food. But in France they are now cultivated for the abundance of the oil they produce. This is said to be equally as valuable, for the table and other purposes, as the oil of olives, and superior to that for burning: A bushel of the nuts produces by cold expression a gallon of oil; but more may be produced by heat, but of a quality inferior.

\section{ARRACACHA, of the order of Umbelliferce.}

A plant from South America, which some have supposed may supersede the potato. Its main root divides into four or five large 
prongs. It is cultivated at Santa Fe and Caraccas, and is light, starchy, and wholesome. It is said to thrive best in the elevated regions of mountains, where the medium heat does not exceed $60^{\circ}$. It deserves trial with us.

\section{ARROW ROOT. Maranta.}

A perennial plant, a native of Sonth America. The roots are tuberous, jointed, and produce a starch, one of the most nourishing of vegetable substances, and useful in medicine. Its successful cultivation has been introduced in the Southern States. 'It requires a light, rich soil, and is propagated by dividing at the root. It is very productive, for, according to Mr. Russell, from two small tubers twelve bushels wère produced in two seasons at St. Helena.

4. BEET. Beta.

An annual plant, a native of the south of Europe. The leaves are long, thick, and succuleñt; the root large, of a tuberous or conical form, and sweet taste.

I shall describe the beet under three heads : -

1st. Those whose roots only are used for culinary purposes.

2d. Poires, or those whose tops constitute the main part which is used in cookery.

3d. Beets for forage of domestic añimals, or for sugar.

\section{BEETS.}

1. Early Blood Turnip-Rooted.

2. Early Dooarf Blood.

3. Long Blood Beet.

4. Early Orange, or Yellono Turnip-Rooted.

5. Early White Scarcity.

No. 1 is of fine quality, and is deemed earliest; it will grow in thin soils, and the tops are valuable for greens. No. 3 is the most valuable for the main crop. The roots of these varieties are a superior class of vegetables for boiling; they are also used as salads, and form a highly-esteemed pickle. For an early crop, sow as early in April as the ground will admit, and from thence to the early part of June for the winter crop; in rows a foot asunder, and four inches apart in the row.

\section{POIREES.}

6. Sir John Sinclair's Beet, or Swiss Chard.

7. Green Beet.

The Swiss Chard has leaves nearly three feet long; the stalks are remarkably large, long, white, tender, and succulent. They are boiled like ssparagus, and the leaves like spinach. It is much used in Switzerland and in France, furnishing a very superior article for greens during summer. No. 7 is used for soups and stews.

III. BEETS FOR FORAGE OR THE FOOD OF DOMESTIC ANIMALS, AND FOR SUOAR.

8. Mangel Wurtzel, or Disette, or Scarcity.

9. French Sugar Beet, or White Silesian.

Both these varieties grow about half way out of ground, and of extraordinary size. For these reasons they are peculiarly calculated 
for being raised in large quantities, as food for horses, cattle, \&ic, both kinds producing enormous crops. In 1824, Messrs. T. \& H. Little, of Newbury, Mass., raised on a single acre a crop of mangel wurtzel weighing 74,518 lbs. The ground ahould be thrown in ridges two feet asunder by back furrowing, the top being levelled, the seed sown and covered two inches deep, and the ground well rolled; the plants being finally left a foot asunder in the row. Mangel wurtzel, according to the analysis of Sir. Humphrey Davy, contains more nourishment than carrots, and late experiments seem to have proved it. No. 9 is the kind recommended by $M$. Achard as the best of. all for sugar; great quantities of sugar are made in France from this root, and the refuse affords a most nourishing and fattening food for horses, cattle, and swine. All kinds of beets should be gathered before hard frosts commence; wring off the tops and lay them in conical piles, cover first with leaves and then with earth, and before winter sets in, remove them to the cellar.

\section{BITTER ROOT. Racine Amere.}

A new plant, found growing in the valley of the Columbia River, in form resembling a carrot. It is used as an article of food by the Indians and hunters, and although not.very pleasant to the taste, its use as food is considered by them as very conducive to health.

6. BREAD ROOT, Psoralea esculenta.

A southern perennial plant, a native of Missouri. Its roots are eaten like those of the potato, and with cultivation produce abundant crops.

\section{CAMMAS.}

A new species of plant, found growing in the valley of the Columbia River; a truncated root, which grows in moist, rich land, in the form of an onion.- It is first roasted, then pounded, and made into loaves, like bread, and has a liquorice taste. An article of food' of great importance to the Indians.

\section{CARAWAY. Carum carvi.}

A hardy biennial plant, rising three or four feet in height. The seeds are used in confectionary, cakes, Ac., and to flavor alcohol. They are esteemed the finest of stomachics and carminatives. The roots are long and tuberous or conical, arid esteemed even more delicious than the parsnip, and fully equal, on all accounts, even to Scorzonera. Cultivation the same as for carrots, which see.

\section{CARROT. Daucos carota.}

A hardy biennial, rising to the height of three or four feet; the roots long and conical. They are boiled with meat and fish, and used in stews and soups. They are excellent food for horses and cattle, being but little, if any, inferior to mangel wurtzel.
1. Early Short Orange, (for forcing.)
2. Early Horn.
3. Long Orange.
4. Purplè.
5. White Altringham.
6. Lemon.

No. 2 is fine for the table. No. 3 is fine for the table, and suitable for the main crop. The Purple is highly prized in the West Indies. The Altringham and Lemon are the suitable kinds to raise for horses 
and cattle, from the very great crops they produce. The Altringham or White Carrot is a new Belgian variety, of fine quality, and the inost productive of all; sown in A pril or May, in rich, sandy loam, in rows a foot asunder, the plants being left four inches' distance in the row. Bury the seeds half an inch in depth, and roll the ground: Gather in the crops as soon as the first hard frosts commence, and house them before winter, in warm cellars.

\section{COWISH.}

A new species of plant, or biscuit root, found growing on dry land in the valley of the Columbia River; its size that of a walnut, but sometimes larger. In taste it resembles the sweet potato, and is prepared for food by the same process as the cammas, in which state it is a tolerable substitute for bread.

\section{S.S. 11. GINGER.}

An herbaceous perennial plant, a native of the East Indies or the Western World; cultivated in New Spain, but especially in Jamaica, to a great extent. The stalks rise like reeds to the height of two and a half feet; the leaves narrow and lanceolate; the roots creeping, in tuberous joints. In autumn the soundest roots are scraped clean, and carefully dried in the sun. But the poorest roots are scalded previously to drying. Ginger forms the finest preserve in the world. For this purpose, they are dug as soon as the stalk has risen six inches; these, being scalded and peeled, are washed in cold water, and steeped during three days, the water being often changed; they are then preserved in sugar, and placed in jars.

Ginger Sirup. A most superior and useful sirup is made of ginger. The dried roots, being broken into small pieces in a mortar, are steeped in water over night. In the morning, increase the quantity of water to two gallons, and boil down to seven pints; when settled, strain it through a fine strainer, and to every pint of liquor add a pound of sugar; then boil an hour, and scum it well: and when cold it is to be bottled.

\section{LEEK. Allium porrum.}

\section{Large Scotch.}

2. London.

A species of onion. Its uses and cultivation are much the sane. Sow in April or May. As the plants approach maturity, cover the bulbs with earth, to blanch, and give them a sweet flavor.

\section{LIN-KIO. Ed. Enc.}

A species of Water chestnut, which grows in China ; of a cooling and agreeable taste. It is sometimes sold, like filberts, in a green state; sometimes dried, powdered, and made into soup, and sometimes baked in the oven with sugar and honey. They sow the seeds at the end of autumn, in the shallowest places of ponds and rivers, in a south exposure.

14. ONION. Allium cepa.

1. White Portugal.

2. Yellono or Stravo Color.

3. Large Red.

4. Tree Onion.

5. Potato Onion.

The White and Yellow are esteemed superior to the Red onion. 
The Tree onion is a perennial, producing bulbs on the summit of its stalks, which are valuable for pickling or other uses; it ia propagated from the bulbs of its tops or roots. Sovr the seeds of onions, from the tenth of April to the first of May, in rows a foot asunder, the plants finally to be thinned to two inches apart, the seeds to be covered one fourth of an inch, and the ground rolled. For an early crop, sow early in autumn, and protect during winter by a covering of litter. Another is the mode recommended by Mr. Knight for producing very large and early crops; it consists in sowing the seeds very thick, upon poor ground, and beneath the shade of trees. These grow only to the size of peas the first season, when they are taken up and dried, and planted the following spring. The Potato onion is very hardy, mild, productive, and exceedingly early. It is raised only by planting the bulbs. Plant the bulbs, early in April, in rows a foot asunder, and eight inches apart in the row, an inch deep. Earth them up as they grow; they reproduce in large clusters. Onions should be gathered as early in autumn as the tops decay, and dried and preserved in a dry place, secure from frost.

In the valley of the Columbia River, a new species of onion has been discovered, which produces a beautiful red flower; it sometimes grows on volcanic scoria, where no other vegetable is found.

\section{OXALIS CRENATA. Loudon.}

An ornamental plant, a perennial, a native of Chili, and there lately discovered by Douglas. The flowers are beantiful, of a yellow color, and in umbels; the stalks and leaves are succulent, of an acid taste, and useful as salads; the roots or tubers are prodaced in clusters; their taste, when boiled, somewhat resembles a chestnut. They are raised from the tubers, and are extraordinary productive, and as easy to cultivate as the potato, and decidedly superior in flavor. They require a rich soil, and, like the potato, they are stored during winter in cellars.

\section{PARSNIP. Pastinaca sativa.}

\section{Guernsey Parsnip. 2. Common Parsnip.}

The parsnip is a biennial plant; the root is very long and conical; a delicious and sweet food when boiled for the table. A superior food for cattle. Cows fed on parsnips yield milk in great abundance, and of extra quality.

The Guernsey is an improved variety. Sow the seeds in April, in rows a foot asunder, and thin the plants to three inches' distance in the row. On rich lands 1,000 bushels per acre have been produced.

S. S. 17. PEE-TSEE. Ed. Enc.

A species of Water chestnut, which grows only in the southern provinces of China, in shallow rivers and ponds, with leaves like a bulrush, and hollow like the stalk of an onion; its fruit in the capsule of its root, like the husk of a chestnut

\section{POTATO. Solanum tuberosum.}

A perennial plsnt, a native of South America. The varieties are innumerable. Where great crops are desired, plant the potatoes in shallow furrows, three feet asunder. Or, in ploughing, plant in. rows, in every alternate furrow. Choose the most productive and 
best kinds; cut the largest in two or four pieces. Plant at the rate of twenty bushels to the acre, according to the state of the ground and the productiveness of the kind; sometimes twenty-five bushels to the acre are required, more being generally lost by an illjudged parsimony in the first instance than by overstocking the ground.

But the precise quantity depends on various circumstances; six or seven hundred bushels to the acre is not unusual. Never earth up potatoes. Potatoes afford, in some cases, a large portion of starch; and this starch, by some slight alteration, may be converted into nearly its own weight of sugar. Plant from A pril to the last of July, near the surface; cover three inches; hoe twice or thrice.

\section{ROCAMBOLE: Allium scorodoprasum.}

A hardy, bulbous, perennial plant, of the onion or garlic species; the root resembling the latter, but of more delicate flavor. Its cultivation is not much unlike that of the onion.

\section{SALSAFY, or VEGETABLE OYSTER. Tragopogon porrifolius.}

A hardy biennial, producing beautiful flowers of a fine blue color; the root long and tapering or conical, of a white color and sweet taste. The outer rind being scraped off, they are steeped in vinegar to extract the bitter taste, then boiled or stewed like parsnips. Sow the seeds in April, and manage the same as for parsnip.

\section{SALSILLA. Edible alstræmeria.}

A very beautiful herbaceous plant, a native of Peru. Its roots are eaten like the potato. It is cultivated in the West Indies, and may answer well in many parts of our country.

\section{SCORZONERA. Scorzoneta Hispanica.}

A perennial plant, a native of Spain. The root is small and tapering. Prepared by steeping in vinegar, as directed for salsafy; and boiled and stewed, it is an excellent vegetable. Sow, as for parsnips, in April, but allow less distancé.

\section{SHALLOTS. Allium ascalonicum.}

A species of onion, the bulbs compound, like those of garlic. A hardy perennial plant, a native of Ascalon and of Palestine. It is used to give flavor to roast beef gravies, and beefsteaks, \&c., also to give a flavor to pickles. They are cultivated by division of the bulbs. Mr. Knight directs to place the bulbs on the surface of a rich soil, the mould being raised for support on either side. As soon as firmly rooted, the earth is removed to the bottom of the bulbs, and they are at once well watered, and thus growing wholly on the surface, they soon assume the size and form of onions; the crop is thus rendered more abundant, and the quality greatly improved.

\section{SKIRRET. Sium sisarum.}

A perennial plant, a native of China. Its roots are tuberous and branching. When boiled, stewed, or fried, with butter, pepper, \&c., its flavor is sweet and agreeable. Sow the secds in April or May, and cultivatc as for salsafy or parsnip. 


\section{SWEET POTATOES, or CAROLINA POTATO. Con- volvulus batatas.}

A tender perennial plant, a low, creeping vine, a native of the Southern States. The roots are long tubers, of a white or red color; when boiled, baked, or roasted, they are of a sweet, agreeable taste, and form a nourishing and wholesome food. It is raised from slips of the roots. The sweet potato is often cultivated as far north as Boston; the slips are usually' procured from New Jersey, as they are difficult to preserve, except in dry, warm chambers, secure from frost. These are placed vertically in a hot-bed in April. When sprouted, they are transplanted to the open field, in a dry, warm situation, to a sandy, but well-manured soil; they are placed in elevated hills, six feet asunder each way. The vines, as they extend, must not be suffered to strike root.

26. TARO.

A bulbous-rooted plant, of the genus arum, a native of the valley of the Columbia River. It is planted in hills, and cultivated in the manner of rice, on ground so situated as to be partially flooded with water. It comes to maturity in eight or ten months from the time of planting - To prepare them for food, they are roasted; they then become a substitute for bread; or they are made into poi, hy pulverizing and converting them to a paste.

27. TRAPA NATANS. Neill.

Tbis plant grows in ponds, and is eaten like the chestnut. The canal of Versailles is covered with the plant, and the root is sometimes served up at table.

28. TURNIP. Brassica rapa.

A hardy biennial plant.

1. Early White Dutch.

2. Early Stone.

3. White Flat.

4. Large English Norfolk.

9. Ruta Baga, Russian, or Yellono Swedish.

5. Yellono Stone.

6. Yellowo Maltese.

7. Long Yellowo French.

8. Yellowo Aberdeen.

Turnips may be sown broadcast; very early for the early crop; as late as midsummer for the late or main crop; or, they may be sown in rows at distances proportioned to their sizes. No. 1 is esteemed the best for an early crop. Nos. 5, 6, and 8, are new varieties, of superior quality, of \& rich taste, and fine for keeping. No. 9 is also of a fine, rich quality, retaining all its goodness to a late period in spring. This kind prodnces enormous crops, and is a valuable article of winter food for cattle. No. 7 is a very superior new kind, from Teltoro, near Brandenburg, of small and slender form; those sown at midsummer keep till spring, and are of great excellence, whether stewed, or cooked by other modes. The best for the table are raised in poor ground; some have a skin of a coal black color.

29. WAPPATOO. Sagittifolia.

A bulbous root, a new species of the arrowhead, which is found only in the valley of the Columbia River, below the Cascades. It grows in shallow lakes, and in marshes covered with water. When roasted, it becomes soft, and is then both a palatable and nourishing 
food, and is much used by the Indians as an article of trade. The Indians search for the roots with their feet, and these, being extracted by their toes, rise to the surface of the water.

\section{S. S. 30. YAM. Dioscorea sativa.}

A climbing plant, cultivated in the East and West Indies. Its roots are very large, flattened, sometimes palmated. It is boiled or roasted like the potato, and is wholesome, palatable, and nutritious. The flower is also used for puddings and bread. D. alata is equally cultivated; its root is three feet long, and often weighs thirty pounds. Of both kinds there are numerous varieties.

\section{CLASS II. - PULSE, VEGETABLE TOPS, \&c.}

\section{ARTICHOKE. Cynara scolymus.}

A native of Italy and the south of France. The Globe artichoke is preferred. The flower heads, after the bristles or choke is removed, and while in an immature state, are boiled in water, with a little salt, till tender, and thus eaten; sometimes they are fried, and used in ragouts; and while very young, they are used as salads; at other times, they are pickled. This is not the Jerusalem artichoke, which is a native of Brazil. It is a perennial, and is propagated by offset suckers, separated in April, and three or four are planted in a hill; the hills in rows four feet asunder, and two feet distance in the row, in a deep, rich soil. They require to be slightly protected by litter in winter.

32. ASPARAGUS. Asparagus officinalis.

A perennial plant of the most hardy description. The young sprouts are delicious food boiled.

1. Large Early Dutch.

2. Battersea.

3. Gravesend.

4. Large White Reading.

Sow the seeds an inch deep, in spring, and when the plants are a year or two old, plant them in rows fifteen inches asunder, and a foot apart in the row, in a soil made exceedingly rich, to the depth of ten inches. The asparagus, in its native state, is a dwarfish plant, with fibrous roots, which do not go deep; but to be raised in its greatest perfection, and of a large size, the ground must not only be made rich at first, but kept so by being covered every autumn with a coat of manure, which is to be forked in, very early in spring.

\section{BEANS. Phaseolus.}

An annual plant or vine; a native of the warm latitudes. It nises from two to ten feet, the stalk thick and angular, the leaves pinnate; the flowers of fragrant odor; the seeds large, ovate, flat tened-enclosed in a long pod. 


\section{ENGLISH DWARFS.}
1. Broad Windsor.
5. Horse.
2 Early Mazagan.
3. Green Nonpareil.
4. Heligoland.
6. Swoord Long Pod.
7. Droarf Bonavista.

These are gathered and shelled when green. Sow them in rows three feet asunder, and three inches in the row, and two inches deep, in a dry soil, as early in. April as the ground will answer, after the hard frosts are over. No. 7 is said to be one of the most productive and finest of Bush beans.

\section{KIDNEY DWARFS, OR STRING BEANS.}

8. China Droarf.

9. Moharok.

10. Marrozo, or Thousand-to-One.

11. Early Quaker.

12. Early Yellow Cranberry.

The China Dwarf is the earliest; the Mohawk is early and very hardy; the Marrow, or Thousand-to-One, is early, and long in bearing, the pods remarkably tender, and the finest of all string beans. Soil and distance the same as English Dwarfs; sown from the first to the last of May.

\section{POLE OR RUNNING BEANS.}

17. Large White Lima.

18. Small White Lima, or Saba.

19. Large Scarlet Runners.

20. Large White Dutch Runners.

21. London Horticultural.
22. White Dutch Case Knife.

23. Red Cranberry.

24. White Cranberry.

25. Yellow Cranberry.

26. Prolific Lima.

No. 23 is a new kind, from South America; from the extreme tenderness of its pods, it is a superior string bean. No's. 23 and 24 are valuable string and shell beans. No. 21 is a productive bearer and excellent shell bean. Nos. 17 and 18 are unrivalled in their flavor as shell beans only. No. 26 is said to be the best of all beans, and fully equals the Lima, but hardier. Plant as soon as the ground will answer, in May or the last of April, in hills four feet asunder, and ten beans in a hill. Plant the Lima beans 10th of May.

\section{BORECOLE. Brassica oleracea, var. sabellica.}

A species of kale, or cabbage, of the most hardy description. The head open, the leaves wrinkled or curled. The crown, or centre, when ameliorated by frost, is cut and boiled; they are extremely delicate, tender, and sweet. Sow the seeds in April and May, and manage as cabbages. Before winter, transplant to trenclies, and cover with straw for winter use. The stalks planted in spring produce delicious sprouts.

35. BROCCOLI. Brassica oleracea, var.; botrytis, subvar.
1. Early Purple.
2. Early White.
3. Large Purple Cape.
4. White Cape, or Cauliflozer.
5. Brimstone, or Portsmouth.

A biennial plant, much resembling the cauliflower; one of the finest luxuries of the garden; the heads are boiled and eaten with $31 *$ 
butter, or the gravy of meat. The Portsmouth is very large; the Large Purple Cape is very fine:- Sow in April and May, in a very rich soil, in rows two feet asunder, and two feet in the row, several seeds together, and tread the ground very hard. Leave, finally, but a single plant in a place. Hoe frequently, but shallow, and earth once. They flower from August to late in autumn.

36. BRUSSELS SPROUTS. Brassica oleracea, v.; sabauda, subv.

A delicate species of cabbage, which rises three or four feet in height. Small heads, an inch or two in diameter, issue from the base of the leaves; these, after being duly ameliorated by frost, form a delicate article when boiled. Protected during winter, they furnish fine sprouts in spring. Sow in May, and cultivate as for cabbages.

37. CABBAGE. Brassica.

1. Early York

10. Pancalier Savoy.

2. Early May.

3. Early Low Dutch.

4. Early Battersea.

5. Early Sugar Loaf.

6. Chou de Milan.

7. Yellow Saroy.

8. Large Cape Savoy.

9. Green Globe Savoy.

11. Large Bergen, or Great American.

12. Large Late Drumhead.

13. Large Scotch.

14. Large Green Glazed.

15. Red Dutch.

16. Turnip-Rooted.

17. Turnip-Rooted, or Arabian.

A biennial plant. When boiled, it forms a wholesome and agreeable food. In making sour krout, the heads of cabbage, after being chopped fine, are strewed in layers in a barrel, and a handful of salt, mixed with a few caraway seeds, are strewed between eacls layer, till the barrel is filled. A heavy weight is now placed on the mass, and as soon as the fermentation, which soon commences, has subsided, the weight is removed and the barrel is headed. . A fine article for the sea stores of ships sailing on distant voyages - a powerful antiscorbutic, and highly relished by all who become accustomed to it, when boiled with beef.

Savoy cabbages are deemed nearly equal to cauliflowers. No. 10 is said to be the best of all; and cabbages set in spring produce fine sprouts. The Red Dutch, after being salted forty-eight hours, forms a good article when pickled in vinegar. The Large Dutch and Drumhead are profitable to raise for the food of cattle; 44 tons were raised in 1821, by E. H. Derby, Esq., of Salem, on an acre. For early cabbages, sow in March, in a hot-bed. For a late crop, sow in May, stamping the ground hard. Set the small kinds two feet asunder each way, the large kinds three feet apart every way, and hoe often. In autumn, strip the outside leaves, and set the cabbages in earth, in compact beds; protect by a covering of straw or sea-weed. No. 18, or Red Variegated Russian, is a beautiful ornamental varicty.

38. CARDOON. Cynara cardunculus.
1. Spanish Cardoon.
2. Cardoon of Tours.

A gigantic plant, rising from four to five feet, much esteemed and cultivated in France. The thick ribs, or stalks of the leaves, when full grown and blanched, are tender and of a delicate flavor. Sow the seeds in April or May, in the bottom of trenches which 
are dug six inches in depth, and in rows four feet asunder, and eighteen inches apart; leaving, finally, but a single plant in a place ; the soil deep, light, and rich; water in dry weather. When the plant is nearly full grown, or in September, and in a dry day, tie up the leaves lightly, bringing the ribs in contact, with strong matting. Cover the whole two thirds of its height, by winding closely a twisted hay band, an inch and a half in diameter, from the bottom, upwards; they will soon become blanched and tender. To secure from hard frosts, earth up, in a dry day, against the bands, and otherwise secure the plants in winter. It is used in stews, soups, and salads.

\section{CAULIFLOWER. Brassica aleracea botrytis.}

A species of cabbage, of a most superior kind, the head or flowers only being used. Sow in September, and preserve the young plants during winter, for an early crop. For a late crop, sow in April. Transplant into very rich, and rather moist loam, three feet asunder every way. Tie up the tops gently, but close over the head, to blanch them. Boiled in a linen eloth, and eaten with melted butter, this vegetable is superior.

\section{DANDELION. Léontodon taraxacum.}

A well-known and extremely wholesome vegetable for early greens and salads, of a slightly bitter, but agreeable taste. It is reputed to possess valuable medicinal properties. Sow in April or May, in a rich soil, or it may be propagated by division of roots, and - improved by blanching.

\section{S. S. 41. EGG PLANT. Solanum melongena.}

\section{Purple, (useful.) 2. White, (ornamental.)}

An annual plant, which rises two feet or more in height ; the fruit, which is produced in abundance, is very beautiful. In size and form, it resembles an ostrich's egg. Sliced and properly fried with ham, it is a delicious vegetable. Sow the seeds in a hot-bed in March, and transplant to the distance of two feet asunder in the open air, in May. A good portion of heat and of moisture are necessary, otherwise the seeds do not readily germinate.

\section{HIBISCUS. Hibiscus esculentus. (Gombo.)}

A tender annual variety of Hibiscus, a native of the West Indies, and now cultivated in the south of France. It rises four or five feet, and produces capsules, which are used, while green, in soups, or eaten with butter.

\section{INDIAN CORN. Zea mays.}

\section{Nevo Early Droarf.}

2. Sweet, or Sugar.

These are the two principal kinds used at table. The New Early Dwarf is very early, and good for boiling. The Sweet is a kind well known; it shrivels in drying, and is superior to all others for boiling. To preserve this kind for boiling in winter, it is first boiled in the husk, at the time while the kernel is yet tender, and after being husked, it is hung up by the husks in the sun, till, thoroughly dry, it is shelled and laid by for use. When wanted, the corn is steeped in water over night, and to this same water beans are afterwards added, and the whole are boiled together. A delicious article; 
it is called Succatash. Plant as soon as the ground becomes warm, in April or May, in rows four feet asunder, and in hills two feet apart in the row; eight kernels in the hill; cover two inches deep.

44. KALE. Brassica oleracea, var.; sabellica, subvar.

Casarean Kale, or Covo Cabbage.

Green Curled Scotch Kale.

The Cæsarean kale, in congenial soils and climates, is a gigantic plant of the cabbage tribe; a most profitable article for the food of cows

45. PEAS. Pisum sativum.

1. Bishop's Early Dwarf. 1 foot.

2. Russell's New Early Droaif Prolific. 1 foot.

3. Dwarf Blue Imperial. $1 \frac{1}{2}$ feet.

4. Dvarf Blue Prussian. 21 feet.

5. Dwarf Cimeter.

6. Knight's Dwarf Marrowfat. $2 \frac{1}{2}$ feet.

7. Knight's Tull Marrovofat. 6 feet.

8. Woodford's Newo Tall Prolific. 5 feet.

9. Dwarf Sugar (eatable pods.) 3 feet.

10. Tall Sugar, (eatable pods.) 4 feet.

11. Egg Pea.

12. Spanish Morotto.

13. Cedo Nulli.

Sow early peas as soon as the ground will admit, in March. A quart of Early Dwarf peas will sow a row of 300 feet, rows three feet asunder. Nos. 1 and 2 are reputed the finest of the early kinds. Nos. 3 and 5 are very productive, and of delicious flavor. Nos. 6 and 7 are most superior late kinds for flavor and productiveness. No. 8 is of a fine grcen color, and bears well a long time. Nos. 9 and 10 , or the Sugar or String peas, are fine, sweet, and productive kinds, the pods and peas being of delicious flavor. The Egg pea and Spanish Morotto are famous for their hardiness and productiveness. The tall species of peas are sustained by brush-wood set in the rows. Some sow them in small circles; as they rise, they support each other. No. 13 is new, and remarkably early.

46. PUMPKINS. Cucurbita pepo.

1. Connecticut. 2. Mammoth. 3. Harrison Pumpkin.

Plant the seeds in April or May, in very rich ground; two plants to a square rod are sufficient. Pumpkins are valuable food for the table, either baked or stewed; and valuable for fodder for fattening cattle or swine. Great crops are raised in cornfields with Indian corn, by dropping a seed in every eighth hill. The seeds produce a valuable oil on expression. The Mammoth pumpkin has weighed 226 pounds. The Harrison pumpkin is another new variety, and probably one of the most productive known. In 1840, and of this variety, E. H. Derby, Esq., of South Fields, in Salem, raised a crop, which produced at the rate of over 50,000 pounds to the acre.

Pumpkin Sugar. According to an article contained in Loudon's Gardener's Magazine, a method of making sugar from pumpkins has been discovered by M. L. Hoffinan, in Hungary, and the right secured to him by patent. In conjunction with M. Devay, he had established a small manufactory at Zamdor, where 4000 pounds of sugar had been made, some of which had 
been refined. From between 2600 and 2700 pounds of pumpkins, 100 pounds of sugar are obtained, and an equal quantity of sirup. In making the sugar, the pumpkins are first cut in pieces, and the seeds being separated, the pumpkins, together with their rinds, are then grated fine, in the same manner as beet root, and the juice, being extracted by pressure, is purified and evaporated by the same process as that employed for the beet sugar. 100 pounds of pumpkins will yield as much sugar as 100 pounds of beet root; yet it is stated, that more than thrice the quantity of pumpkins can be obtained on a hectare of land than of the beet root; and that the juice is far preferable to that of the beet root, because the latter more quickly ferments and spoils, while the juice of the pumpkin retains its virtues during 24 hours.

The seeds yield, on expresaion, an excellent oil; and from five pounds of seeds, one pound of oil may be obtained.

-In places remote from the seaboard, the making of sugar from the pumpkin will probably obtain a preference over that of the beet root; so easily is the pumpkin raised.

47. SECHIUM. Mag. of Hort. Sechium edulis, or Siegos edulis.

A new vegetable from Sonth America; in size and form resembling a very large bell pear; the akin smooth, of a pale green color; the flesh solid. For the table it is prepared in a manner similar to the squash, and is stated to be of a more delicate flavor. It has but one single flat seed, which is larger than a Lima bean. A new vegetable, imported by Mr. Buist, of Philadelphia, and altogether unlike any thing before known or cultivated here.

48. SEA KALE. Crambe maritima.

A hardy perennial plant; a delicious and superior vegetable, as yet but too little known. It is said to grow wild on various parts of the sea-ghore of Britain, where it is eagerly sought after in early spring. The young, tender, and unexpanded leaves and stalks, in a blanched state, are extracted from the pebbles and sand in which they are found buried, and cut off several inches beneath the surface, at the crown of the root. It will yet grow well in the interior, in any good, deep, dry soil, for the root goes deep. The plants should be placed in rows four feet asunder, and a foot or eighteen inches in the row. In March, cover it with sand or earth, in boxes or pots, to blanch it; this renders it more beautiful to the eye, more tender, and delicate. Or it may be forced, by covering the pots or boxes with hot manure. Boll it thoroughly in water, or milk and water is better; serve it up with melted butter, like the cauliflower. Sow the seeds as soon as ripe, and they readily vegetate, but if kept till spring, they require to be cracked. Plantations are readily formed of pieces of roots two inches long, placed up right beneath the soil.

49. SPINACH, or SPINAGE. Spinacia oleracea.

1. Round-Leaved, or Summer.

2. Prickly-Leaved, or Fall.

3. Nevo Winter.

4. Neno Zealand.

A most superior vegetable for greens; an annual plant. The seeds of No. 1 may be sown in a rich soil, from April to July. No. 2 may be sown in Angust or September for early spring. The New 
Winter is a kind, not common, from France; the leaves fourteen inches long, eight inches broad, very thick and succulent. The New Zealand (Tetragonia expansa) is a fine spreading plant, yielding a supply of leaves during the whole summer. Sow this last early, in a hot-bed, or warm situation, in April or May, and transplant, giving them three feet space.

\section{SQUASH. Giraumon.}

A superior vegetable for boiling, baking, or stewing; a native of the warm latitudes.

1. Early Orange.

2. Early Long Warted.

3. Early Scallop.

4. Acorn.

5, Canada Crook Neck.

6. Long Yellono Crook Neck.

7. Commodore Porter's Valparaiso.

8. Autumnal Marrovo.

9. Scarlet Summer.

The Early Orange is a new summer variety, very early, and of superior quality. The Canada Crook Neck is, without doubt, far superior to sny and all others, for the late or main crop. It is finegrained, mealy, and of a sweet, excellent flavor. By being kept in a dry and suitable temperature, they may be preserved till the following summer. Sow in April or May, as soon as the frosts are over, and the earth becomes warm; the early or summer varieties in hills six feet asunder; the winter varieties in hills eight feet asunder, and four plants may remain in a hill.

Autumnat Marrow Sevash. Cucurbita succado.

Introduced to notice by John M. Ives, Esq., of Salem. A fine new variety, of an ovate form, pointed; the skin extremely thin, of a cream color; the flesh orange; the grain delicate, flavor excellent; seeds large, pure white. Average weight, eight pounds. It keeps well in winter.

The Scarlet Summer Squash ia a new and beautiful flat variety, from France, of the acorn species, of a fine scarlet color.

51. SWISS CHARD. (See Beets, No. 2, Poirees.)

The finest kind of beet for greens is the Swiss Chard. The stalks of this are of large size, white, tender, and excellent; they boil like asparagus. It is sometimes called "Sir John Sinclair's beet."

\section{CLASS III. - SALADS, PICKLES, SAVORY HERBS, PRESERVES, \&c.}

\section{BASIL. Ocymum basilicum.}

An annual plant from the East Indies, sometimes used in salads in France, but principally and extensively used in that country in high-seasoned dishes and soups. The leaves are aromatic, and have the strong flavor of cloves. Sow early, in a hot-bed or warm expo- 
sition; transplant into rows a foot asunder, and a few inches apart in the row.

\section{CaRAWAY. "(See Vegetabe Roots, No. 6.)}

53. CELERY. Apium graveolens dulce.
1. Large White Solid.
2. Rose-Colored Solid.
4. Italian.
3. Large White Hollono.
5. New Silver Giant.
6. Celeriac, or Turnip-Rooted.

The stalks of the leaves, when blanched, are used as salads, from autumn to spring; they are also boiled, to flavor soups, and sometimes to be used at dinner. Celeriac is cultivated for its root alone; it is excellent sliced in soups, for its peculiar flavor; or, boiled till tender, it is eaten with oil and vinegar; or it is stewed, to flavor rich sauces. This last kind is sown in April, in a hot-bed or warm exposition, and transplanted to fifteen inches asunder every way, in moist ${ }_{2}$ rich ground, but the plants are never earthed up. The former kinds are sown in April or May, in fine, rich earth, and shaded or covered with a board till the seeds vegetate. Transplant to trenches a foot wide, a foot deep, the plants a foot asunder; preserve every leaf, but destroy offsets. Earth up in dry weather, to blanch the leaf-stalks.

\section{CHERVIL. Ciosma cerefolium.}

\section{Common.}

2. Curled-Leaved.

An annual plant; the leaves have a warm and aromatic flavor, and are esteemed for salads; also in high-seasoned dishes and soups. Sow in rows a foot asunder, every three weeks, from April to September.

\section{CHIVES, or CIVES. Allium schanoprasum.}

A beautiful perennial; a species of small onion. The tops are used in early spring for salads, and the tops and roots as early onions. It is cultivated by divisions of the roots, set six inches asunder.

56. CORIANDER. Coriandrum sativum.

A hardy annual plant; the leaves are fragrant, the seeds aromatic, of a pleasant, spicy flavor. They are used as spices and in confectionary. Sown in April.

57. CRESS. Lepidium sativum.

1. Peppergrass, or Curled Cress.

2. Broad-Leaved Garden. Cress.

\section{Water Cress.}

A hardy annual plant, of a spicy taste; used as a garnish, and in salads. It may be highly improved by cultivation. Sow as for lettuce, and at intervals from April to September.

58. CUCUMBER. Cucumis sativa.

1. Early Frame.

2. Eurly Short Prickly.

3. Early Green Cluster.

4. Long White Spined.

A tender vine, an annual plant. The fruit is used raw in its green state, sliced in vinegar. When young, they are extensively
5. Long Green Turkey.

6. Long White Turkey.

7. Long Green Prickly.

8. Girkin, or West India. 
used in pickling. Sow as soon as the ground becomes. warm in apring; cover a half an inch deep; plant in hills six feet asunder every way, a dozen seeds in a hill, but leave finally but three. The ground must be rich, and manured well in the hill. For very early use, sow in small pots, in a hot-bed; turn them into the open ground in May, protecting from the sun and late frosts. For pickling, plant from 10th of June to 10 th of July, after a crop of early peas, or a crop of hay. No. 3 is a short and productive kind for open ground. The Green and White Turkey are fine, either in the open ground or for early forcing.

\section{ENDIVE, or SUCCORY. Cichorium endivia.}

\section{White Curled. \\ 2. Large Green Curled. \\ 3. Broad-Leaved Batavian.}

A hardy annual from the Eaat Indies; esteemed for salads. Sow as for lettuce, at intervals from April to July, in a very rich aoil. When fully grown, tie over the outer leaves to blanch the lieads for use. Boiled during three hours, like dandetions, and eaten plentifully, endive has been found an effectual remedy for the jaundice, as recently discovered by the physicians of France.

\section{FENNEL. Anethum faniculum.}

This variety is perennial, a native of Italy. It is propagated by sceds sown in April, or by divisions of roots. In a boiled atate it is served up with fish.

\section{FLORIDA COFFEE. Mr. Dupont.}

Such is the name described in the Florida Herald of an annual plant growing wild in Cuba, and now growing wild in some parts of Mississippi and about St. Augustine. The grains, which are ploduced fitty or sixty in a pod, are of the size of wheat, of an olive color; their flavor superior to the green coffee of $\mathrm{Cubs}$, becoming by age, in three months, equal to the best of coffee. A plant of the easiest culture in any poor soil. An acre will produce from 1500 to 2000 pounds. This valuable plant is a native, and grows abundantly in Attakapas, in Louisiana. Can this be Okra?

\section{GARLIC. Allium sativum.}

A hardy perennial, a species of onion; a native of the south of France. It is propagated by a subdivision of the bulbs. These are set in rows a foot asunder, and five inches in the row. Early in autumn take up the roots and dry them.

\section{HORSERADISH. Cochlcaria armoracia.}

A hardy perennial plant. The long and branching roots have. a very strong and pungent taste; and scraped in vinegar, they are lighly estcemed as salads in winter and spring. It is raised fronı the crowns, each with an inch or two of root. These are planted in a very rich, deep, and humid soil; in rows a foot asunder, the plants nine inches apart in the row. Or it may be raised from small pieces of the roots, placed upright and buried an inch beneath the surface. With sugar, the roots form a useful preserve.

\section{ITALIAN CORN SALAD. Valeriandla eriocarpa.}

A new variety, superior to the common kind, and earlier. An annual plant, which is used through winter and early in spring as 
a salad; it is also valuable early in apring, when boiled as greens Sow in August or September, cover lightly, and thin the plants to three inches.

65. LETTUCE. Lactuca sativa.
1. Early Curled Silesia.
7. Brown Dutch.
2. Tennis Ball.
3. Royal Cape.
8. Magnum Bonum Cos.
4. Large Drum Head.
5. Savoy Cabbage, or Green Head.
6. Large Imperial.
9. Ice Cos.
10. White Cos, or Leuf.
11. Green Cos.

A hardy annual plant, one of the finest of salads known. The milky juice of the plant produces drowsiness, like opium. No. 1 is fine and early. No. 2 is fine and early, with amall heads; both these and the Royal Cape are the kinds best known and most highly esteemed in the Boston market. The Cabbage or Head lettuce grows spreading, with round heads. The Cos lettuce grows upright and oblong, and is aweetest. Sow in February and March, in hot-beds, for early use, and transplant in April; and at intervals of three weeks, from April to September, in rows a foot asunder; the large-headed kinds may remain a foot apart in the row.

66. MARJORAM. Origanum.

\section{Sioeet Marjoram.}

2. Pot Marjoram.

The Sweet marjoram is biennial, a tender plant, a native of Portugal; highly esteemed for its savory taste, in highly-seasoned cookery. Sown in April in a hot-bed, or in a warm situation, and transplanted. The Pot marjoram is a hardy perennial, a native of Sicily; its uses are the same as the preceding. It propagates by division of roots in apring.

\section{MARTYNEA. Martynea,}

An annual plant, with conspicuous, showy flowers. The green pods are fine for pickling. Sow in May; the plants may remain two feet asunder.

\section{MARIGOLD. Calendula officinalis.}

The common marigold is a beautiful, annual, hardy plant, sometimes used in soups. Sow from April to May. The tops may be preserved by drying.

69. MUSTARD. Sinapis alba.

An annual; the young plants of White mustard are fine for salads. The seed of the Black mustard, (S. arvensis,) ground, is a strong and most pungent seasoning for meat. A tea-cup of water and powdered mustard is an instantaneous and powerful emetic to dislodge poison from the stomach. Sow in April. A hardy plant, of the easiest culture, and of the tallest kind.

70. NASTURTIUM, or INDIAN CRESS. Tropaolum majus.

An annual plant, a native of Peru. Its flowers, of a beautiful orange color, serve as a garmish for dishes; the leaves are excellent in salads, and the green pods make a pickle esteemed by many su- 
perior to capers. Sow the seeds in April or May, an inch deep, on the borders of fences or palings, as they are low climbers; or sticks of brush may serve as their support.

71. OKRA. Hibiscus esculentus.

An oruamental plant, extensively cultivated in the tropical countries of America; an ingredient in soups. The seeds, when ripe and roasted, form, by infusion, a drink difficult to distinguish from coffee. Sow early in May, cover an inch deep. Cultivate like peas.

\section{PARSLEY. Apium petroselinum.}

1. Curled, or Double.

2. Dioarf Curled.

3. Hamburg, or Large-Rooted.

A hardy biennial plant, a native of Sardinia. A well-known and agreeable savory herb in stews, soups, and the gravy of roasted meat. Sow in row a foot asunder, from April to July. Soak the seeds in a warm place for twelve hours, to make them vegetate; water till the plants appear, as often as the ground becomes dry.

\section{PEPPER. Capsicum annuum.}

1. Long, or Cayenne.

2. Squash.

3. Cherry, or West India.

4. Suceet Spanish.

A tender annual plant, rising two feet or more in height; the fruit round or oblong. The whole fruit and seeds, all but the Sweet Spanish, have a most pungent and fiery taste. No. 1, when dried and ground, forms the Cayenne pepper of commerce. No. 2 grows large, has a thick shell or pulp, and when fully grown and still green, it is the best of all for pickling. No. 3 is a very small variety, from the West Indies. It is used for pepper sauce, a seasoning for meat. A quart bottle of peppers will last a family for years, keeping it filled with fresh supplies of vinegar. No. 4 has a delicate taste, and is used as a salad. Sow in March in a hot-bed, in April or May in the open air; transplant at the end of opring into a rich soil, the plants two feet asunder every way.

\section{RADISH. Raphanus sativus.}

\section{Early Frame.}

2. Early Short-Top Scarlet.

3. Early Long Salmon.

4. Purple Short-Top.

5. Long White Summer, or Naples.

6. Scarlet Turnip-Rooted.

7. Vialet-Colored Turnip-Rooted.

8. White Turnip-Rooted.

9. Black Fall, or Spanish.

An annual plant; the root is long, of a pleasant and pungent flavor; it is used in salads. Sow every fortnight, from April to September, in a sandy, well-manured, and finely-pulverized soil. Nos. 6, 7, and 8 are best for early sowing.

\section{RAMPION. Campanula rapunculus.}

A hardy biennial plant, a native of Europe. It rises to the height of two feet, with handsome blue flowers. The root is long, white, and in the shape of a spindle; like the radish, it is eaten raw, having a nut-like, pleasant flavor. In winter, the root and leaves are cut into salads. Sow the seeds in May, a quarter of an inch deep, in a 
warm situation, and water occasionally. Finally, thin the plants to four inches asunder.

76. RAPE. Brassica napus.

A hardy biennial plant, valuable for greens early and late in spring. It is used, mixed with mustard and cress or peppergrass, as salad. The seeds produce a fine oil. Sow from April to June.

7\%. RHUBARB. Rheum undulatum.

A hardy perennial plant, a native of Asia. The leaves are very broad, and two feet long. Their petioles or atalks are large, and these only are used. They are agreeably acid and vinous, very wholesome, and much admired, whether stewed alone with sugar, for tarts and puddings or pies, or combined with other fruits. Its use with us is fast increasing, and although its introduction to the London market did not take place, it is said, till 1815, yet now, we are told, a thousand cartloads are there annually sold.

Rhubarb Wine. The leaf-stalks of green-colored rhubarb, being cut in pieces as for tarts, and bruised with a mallet, to extract the juice, will make a delicious wine, quite equal to green gooseberry wine, and very closely resembling Champagne. Of the red rhubarb a fine red wine is made.

Rhubarb Jam and Jelly. A superior jam, or jelly, is thus made from the tender leaf-stalks of rhubarb, equal or superior to that from currants, and of excellent flavor. To one pound of the stalks cut as for tarts; add one pound of loaf or brown sugar; boil till the ingredients acquire a proper consistence. Unground ginger and lemon peel added to the jelly have been found a decided improvement. Buck's Early Scarlet rhubarb has a preference in point of color, which is beautiful red; it is also of fine flavor, though not, perhaps, snperior, in this respect, to other varieties. Rhubarb will answer for jelly three months before the currant is ripe. An excellent preserve is also made of rhubarb. For this purpose the stalks are cut into inch pieces, and preserved in the usual way, with sugar.

\section{VARIETIES.}

1. Buck's New Early Scarlet Rhubarb. A new and beautiful variety, and very early. The stalks and the juice are of a beautiful red color, and quite as high-colored as the juice of red currants, and of excellent flavor. Fit for use, in our climate, in A pril.

2. Tовоцsк. A new and very.superior variety; the earliest of all the early, not excepting; perhaps, Buck'a Early Scarlet. The stalks are of a beautiful pink color, and of excellent flavor. Originated in England by Mr. Youle, and fit for use here in April.

3. DuleEx's Gourar. A new variety, which growa to a very large size.

4. Dulley's Admiral. A variety of a still more recent date, and remarkably large.

5. Elfort Rhubarb. (Var. Undulata.)

6. Giant Rhubarb. A new and large species. 
7. Wilmot's EarLy RED. Early and fine, with red stalks.

8. MYatt's Victoria. A magnificent production, with leaves and stalks of enormous size, exceeding, in this respect, all other va. rieties. New, and of excellent quality.

9. Australian Rhubarb. (Rheum Australe.) Loud. Mag.A new variety and valuable acquisition; later in its vegetation than any other kind : it also continues to grow vigorously, and to furnish a supply of leaves long after all other varieties are gone, or till hard frosts. By protection and a frame, it lasts till January. The flavor of Rheum Australe resembles apples; and, though thought by some to be more medicinal in its effects than other sorts, yet those who have used it for years, have never found it prove injurious.

Cultivation. Sow the seeds in September, an inch deep, in a rich, dry, deep, sandy loam, and they vegetate with certainty. In spring, their vegetation is less sure. Water frequently, but very moderately, and shade from the scorching sun till their roots are strong. But the particular and finest named varieties are only raised by dividing the roots. Plant the roots in a rich, very deep soil, in rows four feet asunder, and three feet distance in the row. Young seedling plants only need to be protected the first winter by soil. Rhubarb may be forced very early, by being covered with boxes or barrels, surrounded by horse manure at the top and sides. The rhubarb is highly deserving of cultivation by every family.

78. SAGE. Salvia officinalis.

A perennial savory plant, extensively used as a seasoning for various meats. It is cultivated by division of the roots, or from the seeds sown in April or May. Before the plant blossoms, the tops are clipped and dried for use.

79. SAVORY. Satureja.

The Summer Savory is an annual plant, from Italy. Its leaves have a warm and aromatic taste, and are used in seasoning meats, \&c. Sow in April or May, and shade the ground till the plants have taken root. Winter Savory is a perennial, and is raised from seeds, or from slips of roots.

\section{SESAMUM ORIENTALE, or BENNE.}

An annual herbaceous plant, rising to the height of two feet; the stalk four-cornered; the leaves oval, oblong, opposite; the flowers in spikes, like the foxglove; the seed very small, like mustard; they are used, like rice, for food. Cultivated throughout Asia and Africa, and the West Indies, also in the Carolinas, for food, but more especially for the oil which is obtained from the seeds on expression. Nine pounds of seed, it is stated, yield two quarts of oil, perfectly sweet, and never becoming rancid. This oil is pleasant, and equal to olive oil for food. It is also used, mixed in the beau tiful varnish of China and Japan. A plant of the easiest culture.

\section{THYME. Thymus vulgaris.}

A low-growing, savory plant. The tops, either green or dried, are ooiled in soups, and used as a seasoning for various meats and sauces. 
Sow the seeds in April, cover a quarter of an inch. There are two kinds, the Commion and the Lemon thyme.

82 TOMATO. Solanum iycopersicum.

An annual; a trailing plant, a native of South America, and now most extensively used in Italy, where it is called Pomi d'Amore, or Love-Apple. The fruit, which is produced in great abundance, is nine or ten inches in circumference, round, flattened; it resembles the capsicum, or peoper. It is used in soups, and stewed it forms a fine sauce, of a pleasant acid flavor. The fruit, when ripe and red, is cut in halves, and squeezed sufficient to extract the water and seeds, and, being put in a pan, with a pepper, or capsicum, and a small portion of beef gravy or butter, it is stewed over a slow fire for an hour; is afterwards rubbed through a sieve into a clean stewpan and simmered a few minutes, salt and pepper having been added. A superior and wholesome vegetable. The tomato is reputed to be possessed of highly-valuable medicinal virtues, and forms a most wholesome article of food. With sugar they form a, very valuable preserve. It may be sown in April, in a hot-bed; or in May, in a warm situation, and transplanted as soon as the season will admit. A middling soil produces more fruit and less vines than a very rich soil. Extensively used wherever known.

\section{ORNAMENTAL FOREST. TREES AND SHRUBS, CLIMBING PLANTS AND HONEYSUCKLES.}

I will here briefly enumerate or describe a few of the most ornamental hardy trees, shrubs, dc. - those sorts, particularly, which may be easily obtained, and at moderate prices ; a just proportion of which are at this day considered indispensable appendages in every handsome garden.

The finest effect is produced where an extensive range of trees is formed in continuous clusters of each particular species; thus masses of pine may be succeeded, but not too abruptly, by clusters of larches, and these being succeeded by elms, lindens; or other trees. Outside every tree is allowed space, that thus they may preserve their lower limbs and fine forms entire.

In the disposition of trees and shrubs for avenues and the borders of walks, it is recommended to set them on either, or on both sides, in four ranks or ranges, according to their heights.

The first range, or that nearest to the avenue or walk, to consist of roses and shrubs of the lowest growth.

The second range to consist of shrubs, \&c., which never attain to a greater height than from six to ten feet.

The third range, to consist of those trees which never attain to a very great height.

The fourth range, or outer rank, to eonsist of those trees only which attain to the greatest elevation. 
But, in forming avenues, whether gently meandering, or in direct lines, to be perfectly beautiful, to be consistent with nature, and the most consummate modern art, allow uncommon and proportionate width and space; width also for spacious borders. Set the trees, not in direct or continuous lines, but in irregular clnmps; each clump being either all varieties of the same family, or of the same kind, as nature sows the ground. Clusters of other distinct families, or species of trees or shrubs, to succeed each other alternately, allowing to each individual tree sufficient space, and leaving distance, or more or less spacious openings between each clump, where the prospect requires. Yet, wherever it is desired to exclude or bound the prospect, set each clump or family contiguons, so as even to overlap. For those continuous clumps, the following order of arrangement has been suggested by $\mathrm{Mr}$. Loudon, as appropriate : 1. Oaks, intermixed with a few larches; 2. Chestnuts, and a few pines; 3 . Sycamores; 4. Lindens; 5. Elms; 6. Oaks; 7. Larches; 8. Spruce firs ; 9. Pines; 10. Beeches. Other and beautiful trees or shrubs may also here find conspicuous space, as clumps of Purple beech, of Scotch laburnum, \&c. \&c. \&c.

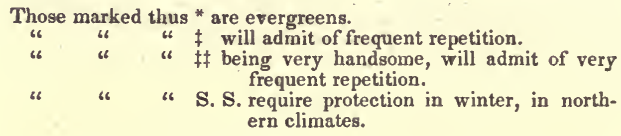

\section{CLASS I. - TREES OF THE TALLEST GROWTH,}

\section{YOR THE FUURTH OR OUTER RANGE.}

1.

A tree of rapid growth, rising to a great height; the leaves are cordate, pointed, of a very dark green above, perfectly white and woolly or downy beneath. The petioles are slender, and, like the aspen, are set in motion by every breatls of wind; and the lively contrast of the upper and under surface gives the tree a striking appearance. It is raised from suckers.

2. HArlantuus, or Tree of Heaven. Ailanthus glandulosa. A tree from Japan or China, which there rises to an enormous height; with a slender and very straight trunk; the leaves are pinnate, and from three to four feet in length; the leaflets very numerous and beautiful. An elegant tree of extremely rapid growth. It answers well in the latitude of Boston. It is sometimes called Tallou, or Tillou. It is raised from seeds and from suckers.

3. (1.) Ash. Fraxinus excelsior.

A fine, stately tree, which rises to a height of sixty feet, with pinnate leaves. The timber is very strong and compact. Raised from seeds.

(2.) Manna Asa. F. rotundifolia. This tree is from Calabria; it 
grows tall and stately, with pinnate leaves. - Manna is procured from this variety: That which naturally rexudes is called tear manna; but that which is obtained by incision is called canulated or flaky manna.

4. †Bегсн. Fagus sylvestris.

The $F$. ferruginea, or AMERicAN BEEch, is a tree of a tall and majestic form; the leaves oval, acuminate, serrate, shining; the fruit small, triangular; the kernel sweet; it affords an oil. The timber is fine: It is raised from seeds.

5. $\ddagger$ Butron Wood. Platanus occidentalis.

A tree. which sometimes attains an enormous size. Its growth is very upright; its leaves very large, alternate, of a beantifut shining green, and deeply lobed; the flowers are a globular ball, an inch in diameter. The bark is smooth, separating in scales. A noble tree. It is raised from seeds.

6. S. S. †CAMPHOR. Laurus camphora.

A native of Japan; a tree rising one hundred and fifty feet in height, which M. Michaux is persuaded will do well in Georgia. It may succeed in Florida. The leaves are oval, pointed; the flowers of a white color; the fruit deep purple. The wood of the tree, and especially the root chopped small, yields camphor by distillation in water.

7. \#Catalpas. Bignonia catalpa.

A native of America; a large tree, with a round head; the leaves are very. large and cordate, of a bright green; the flowers are in very large clusters, of a white color, touched with purple; they appear in July, and are very showy and beautiful. Long cylindrical pods, a foot or more in length, enclose the seeds. The bark is tonic, stimnlant, and powerfully antiseptic. It is raised from seeds. The timber is very durable.

8. Virginia Cherry. See page 223.

9. (1.) \#Horse Chéstrut: Esculus hippocastanum.

A noble and extremely hardy tree, evidently from Northern Asia. It rises from fifty to sixty feet, in elegant and compact proportion. The leaves are large, palmated, in five leaflets on a common petiole, of a dark. green, and the tree forms an impervious shade; the blossoms appear in May or June; they are in large clusters, of a white color mottled with red, and of a superb appearance. The fruit is large, enclosed in a prickly hull. They are devoured by cattle. They produce a fine starch. It is raised from seeds.

(2.) $¥$ Variegated-Leaved Horse Chestrut. $\mathbb{E}$. fol. varieg. A new variety, of a very remarkable and striking appearance, which originated in the nursery grounds of the author, and was there first discovered in 1841. Some of the leaves are wholly of a pure white color; others of a pure white on one half to the central division; others striped with pure white and green.

10. †Crpress.

We enumerate two varieties, 1st, Deciduous Cypress, (Cupressus disticia, ) a native of the Southern States, where it grows to an enormous size, vory erect and stately, and bears the climate in the lati- 
tude of Boston. The foliage is light green, and very delicate. 2d, ${ }^{*}+$ White Cedar, (Cupressus thyoides, a tree which rises, with a very straight trunk, from seventy to eighty feet; the leaves are flattened and branching; a beautiful evergreen tree.

\section{1. tElм. Ulmus. Scotch Elm, Wych Elm. Ulmus montana.}

The leaves are large, oval, acuminate, pointed, serrated. The tree grows erect, and sometimes attains an enormous size. The bark assumes a black cast. The timber is very valuable. 1. American Elm. (U.Americana.) The growth of this variety is very irregular; it attains a large size and height, and the branches droop like the willow. It rises sometimes to a hundred feet. 2. Red Elm. Slippery Elm. (Ulmus rubra.) Ainother handsome variety. The bark of the red elm is medicinal; it is highly nutritious, and is capable of sustaining human life. 3. Cork Bark Elm. (U. suberosa.) All these varieties are fine for avenues and lawns. 4. Ulmus effusa. A remarkable tree, distinguished from all otbers, both in winter and summer. A new variety.

\section{HLime, or Linden. Tilia.}

The European Linden rises in an elegant and pyramidal form. The American, or bass wood, has a round head; the leaves are large, alternate, round, obtusely pointed, cordate, serrated; the blossoms, though not slowy, have a sweet and highly-fragrant odor. Both varieties are of rapid growth, and form fine shades for streets and lawns. The wood is light, soft, and not liable to split. The Tilia of Holland is another beautiful European variety, with red wood. Raised from seeds and layers.

\section{3. *†нмцоск. Pinus Canadensis. Weeping Spruce.}

An elegant tree, and neglected for no other reason than because it is so common. The foliage is very delicate. The tree rises from seventy to eighty feet. The bark is used in tanning leather. Raised from seeds.

\section{4. 扎arch. Pinus larix, Larix Europea.}

Sometimes called Scotch Larch. This is a noble tree, cf a pyramidal form, and larger and more valuable than the American variety. Its branches are disposed in stages, and grow in a horizontal direction; it is of extremely rapid growth, will flourish in almost any soil, and resists the severest cold; a beautiful tree while in leaf; its timber is valuable, and of great durability. As the tree advances, the branches droop, growing somewhat pendent; it then becomes a splendid tree, and incomparably more beautiful than the American variety. This tree is said to be cultivated in England, for timber, to a far greater extent than all other trees beside, and is thought to be the most valuable of all timber trees grown in Britain, from its rapid growth, and great strength and durability. It serves for a great variety of uses, and answers many of the purposes of oak.

\section{AAmerican Larch, or Hacmatac. Pinus microcarpa.}

This tree is of rapid growth; it attains to the height of eighty or one hundred feet. The tree is besutiful while in blossom and in leaf, and has a aweet odor. The timber is heavy, very strong, and exceeding durable 


\section{6. tLocust. Robina pseud-acacia.}

A tall, beautiful tree, of very sapid growth, with pinnate leaves ; the flowers are produced in racemes; they are white, and have a sweet, fragrant odor. This tree, so valuable for its timber, is liable to the destructive attacks of a worm. In some of the calcareous soils of New Jersey, and where the locust is never annoyed by the borer, no tree is found to be so profitable to raise for timber as this. In that climate, the tree grows very tall and exceedingly rapid. 'And many hundred trees will grow on an acre, and the timber commands a very high price. A tree of the easiest culture, either from seeds or division of roots.

\section{HHoney Locust, or Three-Thorned Acacia. Gleditschia triacanthos.}

A tree of rapid growth, which attains a stately size. The foliage is beautiful; the leaves are pinnate; they close at night; the seed pods are a foot or more in length. The tree is armed with triple or branching thorns, sometimes a foot long, of formidable appearance. A hedge, properly trained, would soon be impassable to man or beast. The stems should be allowed to rise six feet in height, when they must be checked in their advancement to force out lateral shoots.

\section{8. \#Magolia, Blue Flowerivg. M. acuminata.}

This tree is very hardý. It rises erect and in beautiful form to a great height in a congenial climate. The leaves are handsome; the flowers are of a blue color.

\section{9. 㩁carlet Maple. Acer rubrum.}

A large tree, of a very handsome form; the leaves are cordate, lobed, dentate, downy beneath. The blossoms appear early in April; they are of a rich crimson hue. The leaves in autumn change to beautiful deep crimson.

20. ISúgar Maple. Acer saccharinum.

A beautiful tree, of medium height; the leaves are large, three or five-lobed; from its sap sugar is produced; a tree of utility.

21. "\#White Pive. Pinus strobus, or Weymouth Pine.

A beautiful evergreen tree, which has been termed the Palm tree of the north. It rises, with a straight trunk, to an enormous height. Mention is made, in Cox's Travels, of a tree at the mouth of the Columbia River forty-six feet in circumference, one hundred and fifty feet to the lowest branches, and three hundred feet high, there called by the traders Roi.des Pins. The leaves are very delicate and beautiful; the timber extremely valuable.

22. *Pines Lambertiana.

A splendid genus of the Pine, discovered by Donglas in the north of California. One specimen seen measured two hundred and fifteen feet in height, and fifty-seven in circumference. The cones measure sixteen inches in length.

Pinus Donglasi, Pinus grandis, and Pinus monteola, are described as immense and beautiful trees, found growing on the Northwest coast of America.

23. Eluastic Pine.

A new and remarkable variety of pine, found growing in the valley of the Columbia River; the leaves resemble those of the Pitch 
pine, but are not so large and long. The bark and the trunk of the tree resemble the larch. The trees grow tall and straight, and are without limbs, except near the top. The wood is firm and elastic, and so strong that it is exceedingly difficult to break a limb of an inch in diameter. The tree, it is stated, is admirably calculated for masts and spars, from its great elasticity and strength.

24. *\#Silver Fir. Fir Balsam, Balm of Gilead. Pinus balsamea.

A native of the northern parts of America. An evergreen tree, of a tall and elegant appearance; the leaves are-of dark green above and of a silvery hue beneath; a tree much admired for the beauty of its form and foliage.

25. *†Sprdce. Pinus.

The Black Spruce ( $P$. nigra) and the Red Spruce $(P$. rubra) are ornamental varieties, and deserving a place in every large garden. The branches of most of those varieties incline to grow horizontally. 26. "HNorway Sprdce Frr. Pinus abies.

The branches, as the trees advance, grow pendent or drooping, and are of a dark green color, and most strikingly picturesque. The most beautiful and splendid tree of all the evergreen or fir tribe for northern climes, and nearly equalling in beauty the cedar of Lebanon. 27. HSrcamore. Acer pseudo platanus.

The tree grows tall and of elegant form; the leaves are very large, broad, of a dark green hue. A tree of ornament. 2d, StripedLeaved Sycamore. (A.fol.var.) A variety with beautiful striped leaves.

28. \#Tulp Tree. Liriodendron tulipifera.

A very beautiful, majestic tree, which rises, with a straight trunk, to the height of eighty or a hundred feet. The leaves are large, of a singular form, of a bright green. The flowers appear in June, and much resemble the tulip; of a greenish yellow, touched with red.

29. \#Weeping Wrulow. Salix Babylonica. Parasol.

A well-known tree, rising to the height of forty or fifty feet; its branches drooping; one of the most elegant of all shade trees. Its outline, when standing insulated, is pleasing and very striking. 2d, Golden Willow. (S. vitellina.) A variety of a gold color, which attains a stately size.

30. †NAPOLEÓN WiLLOW.

A variety raised from the tree which grows over the former tomb of Napoleon, at St. Helena. It is at least equally as hardy, but the tree droops less than the Weeping willow.

\section{CLASS II. - TREES OF SECONDARY HEIGHT,}

FOR THE THIRD RANGE.

31. †Acacia, Purple Flowering. Robinia viscosa.

A tree which never grows tall; the young wood is glutinous, and the flowers are of a purple color, and in large racemes.

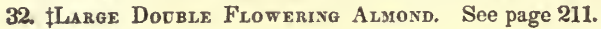


33. Alnus Cordifolia.

-A new and very beautiful species of alder. A highly-ornamental variety, with large heart-shaped leaves.

34. †Chivese Double Flowering Apple. See page 83.

35. $\nmid$ Red Siberian Crab. See page 83.

36. $\ddagger$ Yellow Siberian Crab. See page 83.

37. †CURLEd-Leaved Ash. Fraxinus atrovirens.

A very curious and striking variety, a most singular tree. The growth is very upright; the young wood very thick and stout; the leaves curled, of the darkest green shade.

38. Golden Ash. Fraxinus aurea.

The bark of this singular variety is of a gold color:

39. Chinese Ash. Fraxinus sinensis.

An ornamental and singular variety ; the leaves are small and very narrow, of a dark green shade. The young wood is reddish black.

40. †W Eeping Ash. Fraxinus pendula.

A variety, with pendent branches, and very ornamental.

41. \#PURple BeEch. Fagus purpurea.

A tree remarkable for its leaves, which are of a dark crimson or purple hue, which appear to most advantage in June or July. In autumn they fade to purplish green. It is eminently beautiful.

42. $\ddagger \ddagger$ Modntain Ash. Sorbus aucuparia, or Roan Tree.

A tree rising, in an elegant and pyramidal form, to the height of thirty feet. The tree itself is an ornament, and its flowers, which are in large clusters. In autumn the tree is covered with large clusters of red berries, and its appearance at this time is very striking and beautiful. - A new variety, of France, has yellow berries.

43. S. S. \#Cabbage Tree. Chamarops palmetto.

A superb tree, growing on the shores of the ocean, from Cape Hatteras to the Gulf of Mexico. It rises, with a straight trunk, to the height of forty or fifty feet, but never branches. Its regular summit is crowned with tufts of palmated leaves of a shining green, their footstalks twenty inches long; the undeveloped leaf is folded like a fan, and opens five feet in diameter. The fruit is a small berry, and in clusters. The wood is spongy, and has therefore been used in the construction of forts. It resists the sea-worm.

\section{S. S. *HCarica Papata.}

A beautiful evergreen, which Mr. Bartram pronounces the most graceful and elegant production known. It grows. only in the southern parts of the Union. It rises fifteen or twenty feet, but never or but seldom branches. Its trunk is straight, smooth, of a bright ash color, and polished like leaf-silver. Its top is spherical, and formed of very large lobe-sinuate leaves, supported on very long footstalks. The fruit, like figs, comes out singly, and in the axils of the leaves, and in continual succession. The tree is in continual flower.

45. *RED CEDAR. Juniperius-Virginiaca.

Or Black Cypress. A dark evergreen tree, of conical form. The 
wood is extremely durable, and has a fine odor. Hedges formed of this material, by clipping, become remarkably compact.

46. 抽uble Flowering Cherry. See page 240.

\section{7. 侽honanthus, or White Fringe Tree, Mountaiv} Snow Drop Tree. Chionanthus Virginiaca.

A low-growing tree, with numerous branches; the leaves are large, oblong, entire, nearly opposite; the flowers are in long bunches, of pure white, resembling llakes of snow, or cut in narrow segments, like fringe; the berries are black; they contain an oblong, hard seed. An elegant tree.

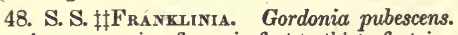

A tree growing from six feet to thirty feet in a congenial climate. Universally admired for its large and beautiful white flowers, with a yellow centre, and of extraordinary fragrance.

49. Hercules's Club. Angelica Tree. Aralia spinosia.

A tree of low growth, of a singular aspect; the limbs are covered with stiff thorns; the flowers are in large bunches, and last a long time.

\section{Judas Tree. Cercis siliquastrum.}

A low tree, which produces its flowers very early, before the appearance of the leaf; it is at that time an ornamental variety

\section{Kentucky Coffee Tree, or Bonduc. Gymnocladus Can- adensis.}

A singular tree in its appearance; the young wood is remarkably stout and thick; the berries are said to be used as coffee.

52. \#Laburnum. Cytissus laburnum, or Golden Chain.

An elegant, small tree; there are two varieties, the common, and the AlpiNe, or Scotcr; the latter is the most beautiful, a native of the Alpine Mountains; the leaves are pinnate; the blossoms are produced profusely, in long, pendent clusters, or racemes, near a foot in length, of a bright yellow color, and splendid; one of the most beautiful of all trees when in bloom, and the greatest ornaments of the garden. In France there is a new white blossom variety.

53. \#Magnolia.

Of this splendid tree there are many varieties; all are beautiful.

1. Chinese Purple Flonering, (Magnolia obovata,) with flowers of a fine violet purple outside, and white within.

2. $¥$ The Chandelier Magnolia, or Yulan. (Magnolia conspicua.) A nother Chinese variety, with large, elegant white flowers; these grow in clusters resembling a chandelier.

3. $¥$ The Magnolia cordata, or Yellow Twoice Flowcring. The flowers of this variety are yellow. A very beautiful and hardy tree.

4. \$.Magnolia glauca; for description, see third section.

5. $\ddagger \ddagger$ Splendid Magnolia macrophylla, large-leaved. The leaves of this variety are over two feet in length; the blossoms very large, and of a yellowish white, very beautiful, with a fine odor.

6. $\$$ Magnolia purpurea. Highly spoken of by Mr. Loudon.

7. $\$$.Magnolia tripetala. (Umbrella Tree.) A tree which rises to a very moderate height, with very large leaves, and very large single flowers, five inches in diameter, of a white color, and fragrant odor 
S. S: * $¥$ Great Flonoering Magnolia. M. grandiflora. A tall, superb evergreen tree, rising in a congenial climate to the height of sixty or eighty feet; the leaves are oblong, of a shining green. The flowers are very large, of a fine, fragrant odor. It does not bear a northern climate.

\section{4. $\ddagger$ Ash-Leàieb Maple.}

$A$ new and beautiful tree of the first class. The leaves in five leaflets, serrate, greenish yellow'; the young wood is green.

\section{5. \#Mountain Srow Drop. Chionanthus montana.}

The tree rises from ten to twelve feet in height; the leaves are oblong, broad, laurel-shaped, of a blackish green; the flowers are in clusters, very singular and white, like flakes of snow. Last of May and June.

56. †Chinese Paper Mulberry. Brousonetia papyrifora.

A large tree, with a round head; the leaves are large, rough; some are cordate, some entire, some five-lobed. The fertile and barren blossoms are produced on different trees. The tree is of rapid growth, and ornamental.

57. \#Chinese Molberry. Morus multicaulis. See Appendix.

A beautiful tree, of rapid and upright growth; leaves very large and cordate; the upper surface is curled or convex, of a deep shining green.

\section{HOsage Orange. Maclura aurantiaca. Bow-Wood.}

A native of the Arkansas and Missouri, where it rises, in beautiful proportion, to the height of sixty feet, and has been pronounced one of the most beautiful of our native trees. The leaves are oval and lanceolate, of a bright shining green; they resemble those of the orsnge, and the branches, like those of the orange, are covered with long thorns. The fruit is nearly as large as an ostrich's egg, of a golden color, and the trees, when laden with fruit, appear splendid, but the fruit is not eatable. The wood, according to Mr. Sevier, Member of Congress for Arkansas, is perhaps the most durable in the world, and for ship-building esteemed preferable to live oak; it is valuable for furniture, as it receives the finest polish, and yields a fine yellow dye. It is remarkably tough, strong, and elastic, and preferred by the Indians to all other wood for bows. It deserves trial for hedges. I know of no wood so beautiful for this purpose. Perfectly hardy on the hills near Boston, but not in every valley.

59. "†Pinus Cembro. Bon Jard.

A medium-sized tree, of a beautiful form, with a straight trunk; the leaves are very long, like those of the Pinus strobus; they grow in fives; the cones-are roundish, the size of an egg; they contain large seeds, which are eatable and good. The wood of this tree exude's a powerful and pleasant odor. At the Chateau of Tarasp, in Switzerland, every apartment is wainscoted with the wood of the Pinus cembro, and various articles of the furniture are formed of this wood, and, although the wainscoting is now some centuries old, it still exudes, with undiminished strength, an odorous perfume. Bull. Univ. (Loud. Mag.)

60. (1.) Реасн. $\ddagger$ Double Flowering Peach.

Highly ornamental when in bloom. See page 198.

(2.) Amygdalus Macrocurya.

(3.) Amygdalus oricntulis 


\section{1. \#S. S. Pride of India. Melia azedarach.}

A tree from India or China, of very rapid growth, much used in the southern cities for of namenting streets. The leaves are pinnate, of a deep shining green, and beautiful; the flowers are in large, oblong clusters, of a bluish white or lilac, and of a fragrant odor.

62. \#Shepardia, or Buffalo Berry Tree. See page 317.

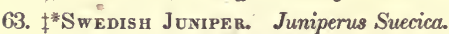

A hardy and beautiful evergreen tree, which does not rise to a very great height. . Its appearance is very singular when trained in a narrow, pyramidal form, by tying in the branches.

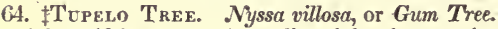

A beautiful tree, growing tall and handsome; the leaves resemble a regular star. It is sometimes found in woods as far north as Boston.

\section{Black Willow. Salix nigra.}

A low tree; the young wond of this variety is of a shining deep violet or black, and covered with a pale blue bloom.

66. tRive Willow. Salix annularis.

A very curious and singular tree; the leaves are curled in the form of a ring or hoop. Also called Hoop Willow.

6\%. \#Venetian Sumac. Rhus cotinus. Smoke Tree. Purple Fringe Tree. Aaron's Beard. Jupiter's Beard.

An elegant shrub or tree, rising froin six to twenty feet, with a round head; the leaves are round, and have the bdor of citron. The flowers are very striking, and have a beautiful appearance; they appear in June, are in large tufts, of a purple color. In September and October they change, and appear like masses of wool. One of the most beautiful shrubs; its appearance is very conspicuous and superb.

\section{S. S. HWild Oravee. Cerasus Caroliniana.}

A beautiful evergreen tree, of rapid growth, found growing on the coasts of the Carolinas, Georgia, and Florida, rising to the height of from thirty to forty feet. The leaves are three inches long, oval, acuminate, smooth and shining above, and the trec affords an impenetrable shade. The flowers are small and numerous; the fruit nearly black; the pulp, which is not eatable, encloses a soft stone.

\section{CLASS III. - TREES OF LOW GROWTH, OR SHRUBS,} VARIETIES WHICH SELDOM ATTAIX TO A GRRATER HEIGHT THAN FROM $81 X$ TO TEX FEET,

FOR THE SECOND RANGE.

69. †Rose Acacia. Robina hispida.

A low-growing shrub, which produces a succession of large clusters of pale blue or purple flowers. 
70. \#Althes.. Hibiscus Syriacus. fl. pleno. Althea frutex.

A native of Asia, but bears the winters of Boston perfectly well. One of the most ornamental of all shrubs, rising to the height of from six to twenty feet. The leaves are three-lobed. The chief varieties of the Double Althea are the Double Blue, Double Purple, Double Red, Double White Striped, or Pheasant Eyed, and Double White, \&c. \&c.- This last does not flower well -in the latitude of Boston. The Altheas commence flowering not long after the hardy roses are gone, and continue blooming till late in autumn. They are very beautiful, and indispensable in every good garden.

71. HAzalea.

This variety of honeysuckle is much admired. The pink and the white are the most common, and are natives of our woods; they are extremely fragrant and beautiful when in bloom. The varieties known in cultivation may exceed a hundred.

72. Calycanthos. C.floridus. Allspice, or Sweet-scented Shrub.

A hardy shrub, rising six or eight feet in height; the flowers are of a brown purple or dark red, of an agreeable odor, like spices. The leaves and the wood are very fragrant.

73. fChinese Calycanthus.

A variety with white flowers; there is another Chinese variety with yellow flowers.

\section{4. 攼eping Cherry. See page 223 .}

75. $†$ CoLutea.

Of this shrub there are the Colutea arborescens, with clusters of yellow flowers during summer - and seed in a thin, inflated, mem. braneous case; also the C. Pococki, with dark yellow flowers. Both are ornamental.

76. Missouri or Jefferson Currant. Ribes Missouriensis.

A shrub rising to the height of six feet, with clusters of bright yellow flowers, of a fragrant odor in spring.

\section{Indian Currant. Symphoria glomerata.}

A low shrub; the leaves are very small, oval; the fruit, for which alone it is remarkable, is profusely clustered on the branches, and of a red color, but not eatable.

\section{8. fProfuse Flowerivg Currant. Ribes multiflomum.}

Has long bunches of flowers, and is but little known.

\section{ISnowy Flowering Currant. Ribes niveum.}

Flowers white, pendent, and abundant, and ornamental. The fruit is black. A fine, hardy, ornamental shrub, brought by Douglass from the N. W. Coast. See Currant.

80. Dirca Palustris.

Leuther Wood, so called from the uncommon flexibility of the tree and its branches. It rises from four to six feet, in form of a tree; the flowers are yellowish white; the leaves are oval.

\section{Bloodx Dogwood. Cornus sanguinea. Red-twigged Dog- wood.}

The flowers are produced in clusters, but neither these nor the 
leaves are very striking. In winter the wood assumes a beautiful crimson color, and in that season is much admired.

82. White Flowering Dogwood. Cornus alba.

A shrub not very uncommon in our woods, producing a 'profusion of blossoms of a dull white, resembling the single rose. 83. †English Fly Honeysuckle. Lonicera xylosteum.

A small tree or shrub, rising to the height of seven or ten feet; the leaves are dark green above, downy beneath; the flowers small, of a straw color, but not very conspicuous; the berries are bright red; the shrub is considered ornamental; the flowers ap. pear in June and July.

84. \#RED Tartarean Honeysuckue.- Lonicera tartarica.

An elegant shrub, rising from four to ten feet in height. The flowers are small, of a pale red color, very beautiful and fragrant, and appear early in April. This shrub is much admired.

85. \#Caucasian or White Tartarean Honeysuckle.

A variety of the last named; a most elegant shrub, with blossoms of a pure and beautiful white.

86. \#Dwart Flowering Horse Chestnet. Asculus macrostasia.

A native of America; it rises to the height of five or six feet, producing large spikes of beautiful white flowers, of a fine odor and elegant appearance.

87. S. S. 捛

There are two varieties of this tree, the $H$. diptera, and $H$. tetraptera; the former the two-winged, the latter the four-winged - the blossoms are pendent, and of a pure white, bell-formed and beautiful. 88. †HAw thonn. Cratagus oxyacanthus.

A tree of medium size, of many highly ornamental varieties; some of which are distinguished for the elegance of their flowers, and some for the beauty of their fruit.

1. Dovble White Hawthorw. Covered in early spring with a beautiful sheet of white bloom.

2. New Scarlet Hawthorn. Covered in spring with splendid and profuse scarlet bloom.

3. New Double Pink Hawthors. Covered with a beautiful pink-colored bloom. Other varieties are distinguished for the beauty of their fruit in autumn - particularly,

4. Oriental Hawthorn. Cratogus Orientalis. var. Sanguinea. Produces large Port wine colored fruit.

5. Large Yellow-Fruited Hawthorn. C. tanacetifolia. Has remarkably large and striking leaves, and large yellow fruit; other beautiful varieties are the Leeana, \&c. \&c. The Hawthorn is much employed for hedges; particularly the English Hawthorn, and the Washington Thorn; the Cockspur or Nerccastle Thorn, or Crus Galli. This last is the best. See article Hejges.

89. †Irdigo Shrub. Amorpha fruticosa.

This produces spikes of blue flowers in great abundance, of hand. some appearance; they appear in June.

90. \#Linac. Syringa vulgaris.

A beautiful shrub, rising from six to eight feet in height; it flow 
ers in large clusters in April and May, of a fragrant odor. Of the lilac there are several fine varieties, all of the most hardy character. 1. Purple Lilac; flowers large and splendid, but too common. 2. White Lilac, with pure white blossoms. 3. New White Lilac, more beautiful. 4. Syringa Charles $X$., new and beautiful. 5. Syringa Sauge. 6. Syringa Varin. 7. Syringa Josikaa, a new and beautiful species of lilac; flowers fine blue.

91. \#Persian Lilac. S. Persica.

This shrub rises six or seven feet in height. The leaves are pointed, and of less size than the common lilac. The flowers are smaller and more delicate. There are several varieties. 1st, Purple Persian L.; 2d, White Persian L.; 3d, Cut-leaved, or Chinese L., with curious leaves.

\section{2. \#ł Magnolia Giadca. Glaucous Magnolia.}

A tree or shrub, with oblong glaucous leavea, and beautiful white flowers of a fragrant odor. The plant is very hardy, and flourishes best in a mixture of bog earth and common soil.

93. "HMountain Laurex Broad-Leaved Kalmia Kalmia laifolia.

A superb evergreen shrub, very hardy; a native of the Northern States of America. It rises five or six feet; the leaves are oblong and shining; the flowers are in large convex clusters, of a rose or carnation hue, and appear in June or-July, and are beautiful.

\section{Mountain Rose, or Raspberry. Rubus odoratus.}

A low shrub, remarkable for its large green leaves, and a succession of blue flowers like sinall single roses. There is a variety with large white flowers.

\section{S. S. "HPalmetto Royal, or Bayonet Bush.}

A very singular production. It rises several feet, with a stiff, ligneous stem; the summit is crowned with leaves in a cluster, of a dark green color, with crenated edges; they are very stiff, dagger or sword-shaped, and sharp-pointed; and they form hedges impenetrable to man or beast, at Savannah and St. Augustine; the flowers are white, tulip-formed; they crown the summit in a pyramid; the fruit like a cucumber in size and form; the skin smooth and shining, of a deep purple color; the pulp soft, juicy, agreeable, aromatic, and somewhat bitter.

\section{S. S. \#Pomegranate. "See former page.}

\section{7. $\ddagger$ Prim, or Privet. Ligustrum vulgare.}

A sub-evergreen, rising eight or ten feet; the leaves are lanceolate, of a very dark green, like the myrtle; the flowers are white; the berries black, in large clusters. This plant forms a beautiful hedge. 2d. †Variegated Leaved Privet. (L. variegatum.) The leaves of this variety late in autumn are blotched with a bright gold color. 3d. $\ddagger$ Chinese Privet. (L. sinensis.) A variety with leaves of the same dark green as the preceding, but of much larger size.

98. \#JAPAN Quince. Cydonia Japonica, or Pyrus Japonica. Japan Pear. See page 175.

99. †Chinese Quince. See page 176. 
100. *ttRhododendron Maximum. Rose Bay. Great Rhododendron.

An evergreen shrub; a native of America. It rises from six to sixteen feet in height, with numerous branches; the leaves are large, oblong, and thick; of a dark shining green, and beautiful. In July the flowers appear in large convex clusters, at the end of the shoots, of a reddish hue; they are extremely beautiful, and last a long time. A moiat soil is the most suitable. A very hardy variety.

\section{1. * ftRhododendron Ponticum, or Pontic Rose Bay.}

A beautiful variety, of foreign origin. The leaves are large, shining, and beautiful; the flowers appear in midsummer, on the ends of the shoots, in large clusters, and are of a violet or purple color. A very beautiful shrub. A moist, sandy soil suits it best. This variety is not so hardy as the former species.

\section{2. \#Sxow BaLL, or Guelder Rose. Viburnum opulus.}

An elegant shrub, blooming very early and profusely in apring, in large, round, white cluaters, like balls of snow.

\section{Japan Sophora. Sophora Japonica.}

A tree, rising, with a straight trunk, to a great height, in congenial climates. The branches are pendent; the flowers in clusters, of a dull white. It was for a long time known that this tree produced the Japan Imperial yellow dye; but the bark, leaves, and wood failed of producing it; but it is lately discovered to be produced from its fruit.

\section{Spirsia.}

Of the Spiræas, there are several varieties; they are all orna. mental. We enumerate,

1. †Guelder Rose Spira.a. Spircea opulifolia, or Nïne Bark. A shrub. rising six or eight feet, with large round clusters of whito flowers in spring.

2. \$S1berla n Spirea. S. lavigata: A shrub rising five or six feet high, producing large, beautiful spikes of white flowers in spring.

3. RED Flowering. S. tomentosa. Produce handsome red spikes of flowers, and is neglected only because it is ao common.

4. \$Nepal. S. bella. Produces elegant red flowera.

105. fStra wberry Tree. Euonymus.

Of this tree or shrub there are several varieties. In autumn the trees are covered with a profusion of red berries, and are then deemed very ornamental.

\section{6. 损rringa. Philadelphus coronaris.}

A very ornamental shrub, producing a profusion of white flowers very early in spring, of a sweet fragrance.

1. $¥$ Carolina Large Flowering Syringa. Philadelphus grandiflorus, or Garland Syringa. Very hardy. The flowers are in garlands, and continue a long time.

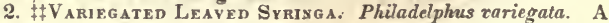
beautiful and much admired variety, with leaves variegated with green and white. 


\section{CLASS IV. - SHRUBS OF LOW GROWTH.}

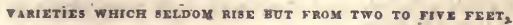
FOR THE FIRST, OR INNER RANGE.

107. \#Dwarf Double Flowering Almonn. Amygdalus nana.

A superb shrub, flowering early in spring, in profuse clusters of very double blossoms, like small roses, of a rose or pink color; one of the most ornamental shrubs of its season. See page 211.

108. Yellow Dienviluá. Diervilla lutea, or Acadian Honeysuckte.

A low-growing, hardy, ornamental shrub. The wood is perfumed when broken; the flowers are small, of a yellow color, and slightly fragrant.

109. Candleberry Mrrtle. Bayberry. Myrica cerifera latifolia.

A low, hardy shrub, rising from three to five feet in height; a native of the Middle and Northern Atlantic States. The leaves are broad, shining green; when rubbed, they emit a fragrant odor. They remain on the tree till late in winter. The berries, profusely clustered on the limbs, are round, of the size of peppercorns ; each berry contains a small stone, and is covered outside with a waxen substance which resembles a thick azure bloom. The wax is extracted by boiling. The berries, being placed in a boiler, are covered, until the water rises six inches above their surface, and these being continually stirred while boiling, the wax is separated, and this, rising to the surface like oil, is skimmed off continually. As oft as the berries beeome exhausted, and will yield no more wax, they are withdrawn, and replaced by fresh quantities, the process of boiling continuing unceasingly, till the stock of berries is exhausted. This oil, being strained through a coarse cloth, and cooled, is solidified, and being placed on lined cloths, the superfluous water soon dries; it is then of a dull green color, and semi-transparent.

Candles made of myrtle wax burn with a peculiarly clear, white flame, producing a beautiful light with but little smoke; and yield, while burning, a balsamic fragrance, and delicious perfume. The roots abound in the Gallic acid, and, when pulverized, they form a snuff of extraordinary medicinal power.

The Candleberry myrtle will grow and flourish with little care; a light, sandy, and somewhat moist soil seems most congenial to its growth.

The Myrica Cerifera Angustifolia is another variety, with smaller seeds, a native of Louisiana, and there growing from ten to twelve feet high. Those trees produce seven pounds of seeds each, which yield about one fourth of their weight in wax. This wax is precisely similar in quality to the wax of the northern-shrub. The balsamic fragrance yielded by the burning tapers formed of the new wax, is considered by the Louisianians as powerfully restorative to the sick. In that country, and at the suitable season, men go down to the seaside, or wherever the trees abound, where they encamp with their whole families, and build a hut of palin leaves, and commence the process of gathering and of boiling, and cohtinue while the berries last 
With the view of rendering the produce of this plant a lucrative article of commerce, the French government have encouraged its growth; and plantations of this shrub have been begun at Ram. bouillet and at Orleans.

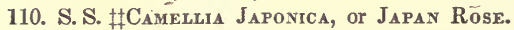

A beautiful evergreen tree, producing flowers like roses, of various shades, extraordinary beauty and fragrance. It requires effectual protection in the Northern and Middle States. It flowers in winter.

\section{1. \#Corchorus Japonicus. Kerria Japonica. Japan Globe Flower.}

An elegant shrub from Japan, rising, with many flexible stalks, to the height of five or six feet. The flowers, which are produced in succession from spring to autumn, are very double, and of a globular form, and bright yellow color. This plant is strikingly beautiful. It bears the winters well in the latitude of Boston, with a very slight covering of straw or leaves, but generally without any protection whatever.

112. †Cotroneaster.

A native of Sweden, a cold country. In June it presents a sheet of bloom, of snowy whiteness, and is of surpassing beauty; in winter it is mantled with berries of fine scarlet. Varieties: 1. C.acuminata, 2. C. mumularia; 3. C. frigida; and 4. C. affinis. The two last are of remarkably rapid growth.

\section{3. $\ddagger$ Daphne Mezereov.}

A low shrub, rising from two to three feet in height, with small, lanceolate leaves. In March the whole plant is decorated with flowers of a violet or red hue, and beautiful appearance. An elegant shrub.

‡White Flowering Mezereos is beautiful, but taller than the red.

\section{4. \#Tree Lupin. Lnpinus arborescens.}

A singularly handsome, new shrub; the flowers are large, and produced in beautiful clusters or racemes.

115. \#PEONIA.

The Tree Pconias are as hardy as oaks. The flowers are of large size, and splendid in appearance. They are from China, and of several varieties.

1. Paconia Moutan Banksii, or Chinese Purple Tree Pæonia; flowers magnificent and fragrant.

2. Paonia roseo odorata, or Chinese Rose-Colored Tree Pæonia, with magnificent fragrant flowers.

3. Paonia papaveracea, or Chinese Poppy Flowered Tree Pæonia, with large single white flowers, with a purple centre.

\section{Sт. Johv's Wort. Hypericum.}

Of these there are several varieties; the $\boldsymbol{H}$. frutescens is a low shrub, which produces in summer a profusion of flowers of a yellow color.

117. 捻сотсн Ввоом. Spartium scoparium.

A singular shrub, rising in many flexible stalks, like a broom; the 
flowers are yellow and very showy; the appearance of this shrub is atriking. 2. Siberian Broom, a low, trailing shrub, producing a succession of small yellow flowers.

118. \#SNow BERRY. Symphoria racemosa.

A very hardy shrub from the Rocky Mountains. The berries, which are of the size of a cranberry, are in clusters, and are very white and delicate, like wax, and very ornamental.

119. HRese. Rosa.

The rose is justly called the queen of flowers, for its size and various beautiful shades and delightful fragrance. The colors vary from a pure white to red, to deep violet, and nearly to black. The yellow rose is not very uncommon. The rose is an indispensable requisite in every good-garden. The lists enumerate at least one thousand names of hardy roses.

120. S. S. Chiva Roses.

These require a little protection during winter, in the Northern States. They are mostly ever-blooming, and universally admired on this account. They should be planted in the open ground in June, and may be again taken up in September; or protected with moss or evergreens, and suffered to remain out all winter. The most common are the China Blush and. Sanguinea; the Champney's Blush Cluster, and Noisette; of these last there are many varieties, all blooming in superb clusters. Others, less common, are the Knight's Resplendent, the Grandval, or Hermite, more splendid still; but both these last are of a dark crimson hue; the Blush Tea Scented, of exquisite fragrance, and the Undulata. The Multiflorus, Blush, and White, and the Lady Banks's White and Yellono, and the Grevilli, are all running roses, and blossom in beautiful clusters; but they do not blossom well except in a warm exposition. The Belle de.Monza, the Yellono Tea Scented, and Yellowo Noisette, are not common, but celebrated new kinds. - Also La Triomphe d'Arcole, \&c. \&c. There are, also, many other kinds eminently beautiful.

\section{CLASS V. - HONEYSUCKLES AND CLIMBING PLANTS.}

\section{Aristolochin Sipho.}

A rapid growing vine, with very large leaves, which are round, cordate, entire, of a bright green; the flowers, which appear in June and July, are of an obseure purple, and of curious form, resembling a pipe; admirably calculated for arbors, from the large size of the leaf:

122. \#Bignoira Radicans, or Scarlet Trumpet Flower.

A rapid growing plant, a native of America, which extends its branches to a great distance; the foliage of a fine green, and numerous ; from every joint roots are emitted, which attach themselves to the earth, and walls, and structures of wood; the flowers are in clusters, each flower about four inches in length, in form of a trumpet, of a beautiful flame color.

There is a very superior variety called the Minor. 
123. \#Bignonia Grandiflora.

A variety from China, but not so rapid in its growth; a fine climber. The flowers are large, and more in the form of a bell than trumpet, and of a fine flame color. Both are very showy and beautiful.

\section{4. \#Chinese Glycine. Glycine sinensis, or Wistaria conse- quana.}

A beautiful vine, of rapid and very extended growth ; the flowers are very numerous, in long clusters, or racemes, of a purple color ; a magnificent flowering plant from China, and perfectly hardy on hills and elevated situations near Boston.

\section{5. \#Cluster Flowering Glycine. Glycine frutescens.}

This appears to be of more vigorous growth than the Chinese, in our climate; a very rapid growing vine, the flowers of a deep purple color, and in long clusters, or racemes, of a beautiful appearance; a native of the Southern States, but hardy.

\section{6. 拉y, Evergreen, or Irish Broad-Leaved Giant Ivy. Hedera helix.}

This, perhaps, is one of the most beautiful of all plants for covering arbors and walls. I suspect, however, our summers are too warm for it. On the north sides of buildings alone, I have observed, it flourishes in unfading beauty.

127. †Virgivia Ivy, or American Ivy. Cissus hederacea.

A remarkably rapid growing vine, and eminently calculated for covering walls, \&c.; the leaves are large and palmated, changing in autumn to a fine crimson. This ivy is deciduous.

128. Roses. Climbing varieties.

1. $\ddagger$ Boursault. Maheka. A beautiful running rose, and the strongest and most rapid growing rose of all in northern climates. It blossoms most profusely, and with a brilliant display, in early spring, and occasionally during summer. The blossoms are double, of a deep crimson dye.

2. †Countess of Larma. A beautiful variety of Double Ayrshire

3. †Doubie Crimson Sweet Brier.

4. $\ddagger$ ERIPHYLA. A very beautiful double blush and sweet-scented running rose, a fine climber.

5. †Felicité Perpetú. Very fine.

6. ‡Great Unknown. A new variety of Double Ayrshire.

7. ‡Lovely RAmbler. Double Ayrshire, new variety.

8. $¥$ Marie Leoní́a. Very fine and new.

9. $\ddagger$ Myrianthes. New and fine.

10. $\ddagger$ Rosa RUBifolia. A beautiful and strong growing running rose, a native of the west, a fine climber. The flowers are small, and perfectly single, but grow in superb clusters, like Noisettes, with flowers of different shades on the same cluster. This rose flowers in July, after most other hardy roses are gone.

11. †Splendens. Double Ayrshire.

12. †illiams's Double Yellow Sweet Brier.

13. S.S. "łłGrevilli. Very rapid growing; flowers in fine clusters of different shades.

14. S. S. " $\ddagger$ Blush Multiflora. Rapid growing; flowers in superb clusters. 
15. S.S. "†White Moltiflora. M. Alba. Superb white clusters of roses ; beautiful.

16. S. S. "tLADY BANKs's. Two varieties, the white and the yellow; both very beautiful, flowering in clusters.

17. S. S. "Cherokes. Not remarkable for the beanty of its flowers ; of very rapid growth; used in Carolina for hedges.

\section{Virgin's Bower. Clematis.}

Of this plant there are several varieties; some are hardy, and some are tender. The Traveller's Joy $(C$. vitalla $)$ is one of the most. hardy and rapid growing varieties. C. viorna, $C$. viticella, and $C$. flamula are beautiful.

\section{Honersuckues. Lonicera. Twining Honeysuckles.}

1. †Early, White Italian. Lonicera caprifolium. The flowers of this variety are white, and of a very delicate appearance; they appear very early, but their duration is short; the vine is of very rapid growth.

2. †EARLY VÁriegated Belgic, or Woodbine. A variety similar to the monthly, variegated in its blossoms; but it diflers from that in flowering but once, very early and profusely.

3. \#CHINese VARIEgated HoneyseckLe, or Chinese Evergreen Twining. Lonicera flexuosa sinensis. This beautiful honeysuck]e is from China, and like many other productions of that country, it appears to be perfectly hardy; the vines are very flexible, and of rapid and very extended growth; it rises to a very great height; the flowers are in pairs, or triple, covering the plant in profusion, from spring to autumn; they are beautifolly variegated with red, white, and yellow; of delightful fragrance.

4. $¥$ Variegated Monthly Honeysuckle, or Belgic. Lonicera Belgicum. One of the most beautiful of all varieties; the flowers last from spring till late in autumn; the colors are variegated with white, and yellow, and red; they are very fragrant.

5. \$Scarlet Trumpet Monthly Honeysuckla, or Coral: Lanicera sempervirens. Almost an evergreen; one of the most rapid growing of all; the flowers are of a fine scarlet, in form of a trumpet, and are produced in profusion from spring till winter, and inodorous; the foliage is large and beautiful, of a dark shining green. A native.

6. ¥¥ Yellow Monthly Trumper. Lonicera Frazeri. The foliage of this is of a bright green; the flowers differ from the Scarlet Trumpet only in being of a bright golden yellow color; like that, it is a native of America.

7. † Orange-Coloren Pebescent. Lóniceta pubescens. This is a native of the north-western coast of 'America; the leaves are downy; the flowers are large and beautiful, of an orange color.

8. S..S. $\ddagger$ JAPAS HONEYSUCKLE. Lonicera Japonica. The flowers of this variety are produced in profusion, of a pale yellow color. It requires protection in northern climes.

There are many other varieties. 'The Douglasi, or Canadian Stravocolored Honeysuckle is a native of America, has very large foliage.

9. $\ddagger$ Etruscan, or Tuscany, Orange-Colored. Lonicera etrusca. $A$ new and beautiful variety, with flowers of an orange color.

10. 
and very remarkable variety of Honeysuckle, or flowering vine, which is found in the valley of the Columbia River, and which the Rev. Mr. Parker has described as one of the first ornaments of nature. He calls it the Vining Honeysuckle. Washington Irving has also described the same plant in his "Astoria." The leaves are oval, and disposed in threes, of a rich green color; each flower is composed of six petals, about three inches long, of a beautiful crimson color, spotted inside with white. The plant olimbs to the topmost branches of trees; after which, continuing to grow, it descends, perpendicularly, extending from tree to tree, until, finally, its vinous stalks connect and interlaee the grove like, the rigging of a ship. From the fibres the Indians manufacture baskets of so close a texture as to hold water. The stems of this vine are tougher and more flexible than willows, and are stated to grow from three hundred to six hundred feet in length.

\section{FLOWERS.}

The lists of flowers recommended by most authors, are much too extensive for general purposes. I have made choice of the list recommended by Mr. Neill, (Ed. Ency. Vol. x. part 2,) as the foundation, and from this I have taken some, and added many, new and fine. It includes the most showy and conspicuous varieties known. 1. Florists' Flowers.

These flowers are in a peculiar manner distinguished by the title of Florists' flowers. They are cultivated in beds by themselves: the principal are these-1. the Tulip; 2 . the Ranunculus; 3 . the Anemone; 4. the Iris; 5 . the Dahlia; 6. the Pink; 7. the Carnation; 8.. Polyanthus; 9. Auricula; 10. Hyacinth; 11. Polyanthus Narcissus; and, 12. the Crocus.

2. Perennials.

Tull-growing, showoy flowers, to intermix in the shrubbery border.

For the shrubbery border, the following are recommended as the most suitable tall-growing, herbaceous plants - 1. Holly hock, (Althaa rosea,) of different colors; September till hard frosts; 2 . Goat's Beard Spiræa, (S. aruncus;) 3. Foxglove, (Digitalis,) biennial ; 4. Monkshood, with blue and yellow flowers, (Aconitum;) 5. Larkspur, (Delphinium grandiflorum and cxaltatum, and $D$. sinensis;) 6 . Columbine (Aquilegia) varieties; 7. Iris, of the large species, (Germanica, samucina, and siberica;) 8. Willow herb, (Epilobium angustifolium ;) 9. Double Feverfew, (Pyrethrum parthenium, ) are showy in flower; 10 . Tall species of Asters, (A. puniceus, multiflora, and linarifolia,) with blue and white flowers; 11. Tall species of Solidago; 12. Perennial Sunflowers, particularly Helianthus decapetelus and $H$. multiflorus; to these may be added, 13. Rudbeckia laciniata. 14. I add to this list the Tiger Lily, (Lilium tigridum.) Besides tall plants, some of humbler growth may be added, as patches of, 
15. Sweed Woodruff, (Asperula odorata,) and patches of, 16. Double Wood Anemone, (Anemone nemorosa,) and, 17. the Lily of the Val ley, (Convallaria majalis;) there is a double red flowered variety of this; also the Yucca filamentosa; the Yucca gloriosa, and Great Black Astrantia, (Astrantia Major.)

3. Border Flowers.

The borders for perennial flowers are seldom less than four or five feet in breadth. One of the most ornamental tall-growing perennials is, 1. Double Scarlet Lychnis, (Lychnis chalcedonica, fi. pl.;) 2. Hyssop-leaved Dragon's Head, (Dracocephalum speciosum, ) and the Grest Flowered, (D. grandiflorum, ) with elegant blue flowers, and D. denticulatum; 3. Silver-rod, or Branched Asphodel, (Asphodelus ramosus, ) with fine white flowers; 4. Verbascum ferrugineum, Rusty Flowered, and $\boldsymbol{V}$. pheniceum, or Purple Flowered, may be admitted; together with, 5 . the Fine Branched Lythrum, (L. virgatum, ) which is cuvered for three months with purple flowers; 6 . two. or three species of Centaurea, such as $C$. orientalis, with yellow flowers, and C. Caucasica, with white flowers, and C. montana, with blue flowers; all hardy perennials; 7. Double Siberian Larkspur, (Delphinium elatum,) flowers fine dark azure, and $D$. sinensis, elegant deep blue; 8. Phlox pyramidalis and $\boldsymbol{P}$. paniculata, $\boldsymbol{P}$. suaveolus, $\boldsymbol{P}$. Shepherdi, and $P$. tardiflora, are handsome, showy flowers; 9 . Linear Leaved Willow Herb, (Epilobium anyustissimum, and spicatum, foliage fine, and flowers large, of a beautiful purplish red; 10. Coreopsis verticellata, and $C$. lanceolata, flowers fine deep yellow; 11: Of the species of Speedwell, these are elegant-Veronica virginiana, flowers blush-colored, and with white flowers; and $V$. longifolia, flowers blue, white, or flesh-colored; 12. Variegated Monkshood, (Aconitum variégatum;) 13. Rudbeckia purpurea, with large flowers; 14. Liatris spicata deserves a place in every collection; 15. Acanthus mollis; 16. Of the fine genus Spiraa, the Queen of the Meadow, $S$. ulmaria, and Dropwort, or S. filipendula; 17. Of Campanula, or Bell Flower, a hundred species have been named; there are several showy perennials, as Pesch-leaved, (C. pérsicifolia,) with single blue, and single white, and with double flowers; Nettle-leaved Bell Flower, (C. trachelium;) Pyramidal, or C.pyramidalis, and C. grandiflora.

18. Light Loosestrife, (Lysimachus erecta,) with showy yellow flowers, may be added.

19. Darlis. Belonging also to this class, the Dahlia is a noble plant, a native of Mexico; a plsnt but lately known amongst us, rising from three to ten feet in height. It flowers profusely in autumn, after the hardy roses are past, and continues in flower till hard frosts commence. The flowers are magnificent; they are of a grest variety of shades, and surpass those of the rose and camellia in size and splendor, although they fall short in fragrance. Its roots are large, oblong tubers.

4. Ornamental Plants of midding Size.

1. Of the species of Achillea; Sweet Mandin, (A. ageratum, Sneezewort, (A. ptarmica, ) with double flowers; 2. Spring Adonis, (A. vernalis, ) with large yellow flowers, in April; 3. An elegant double variety of Rose Campion, (Agrostemma coronaria;) 4. Perennial flax, (Linum perenne;) 5.- Round-headed Rampion, (Phyteuma orbicularis ;) 6 . Sweet William, (Dianthus barbatus ;) 7. Of the spe- 
cies of Eryngium, E. alpinum and E. amcthystinum are very ornamental; also, the Statice, or Thrift, in particular, S. latifolia, scopa. ria, tartarica, and speciosa ; 8. Fraxinella, or Dictamnus albus, is both beautiful and curious; by approaching a candle to the flower, in a warm, dry and clear night in June, a slight explosion takes place, from the inflammable gas it exhales; 9. Cardinal Flower, (Lobelia caxdinalis,) a very elegant scarlet flowering plant, but is in a great measure now supplanted by the $L$. fulgens, of still greater brilliancy; there is also L. splendens, and L. siphilitica; 10 . Catananche carulea, flowers of a fine blue ; Canadian Columbine, (Aquilegia canadensis,) highly ornamental; 12. Garden Wall Flower, (Chciranthus cheiri,) when double and of a dark color, is much prized; 13. The Red and Scarlet Chelone, $(\boldsymbol{C}$. obliqua, and barbata, ) very late and pretty; $C$. major, fine peach-colored flowers; the most showy of the genus; 14. German Goldylocks, (Chrysocoma linosyris,) with bright yellow flowers in the form of an umbel; 15. Tritoma media, produces its beautiful spikes of orange flowers in autumn; 16 . Two species of Monarda; the Oswego Tea, or 'M. didyma, with scarlet flowers, and MI. fistulosa, with purple flowers; 17. The Perennial Lupin, (Lupinus perennis,) but a more showy plant is the L. nootkatcnsis, and $L$. polyphyllus; 18. Of the Perennial Poppies, the Oriental, (Papaxer orientalis, ) with large, bright orange-flowers; and the Welsh, (P.cambricum, with flowers of a deep yellow, and $P$. bracteata, or Caucasian; 19. Red Valerian, (Valeriana rubra,) highly ornamental when of a dark color; there is a white variety, which forms a fine contrast.

20. P жOnres. Belonging also to this class, several kinds of PæOny are magnificent border plants, and in splendor not by any means inferior to the Dahlia; many of them are very superior to that in point of fragrance, in whicli some of them equal the rose; all are of the most hardy character. The most beautiful are, J. P. albiflora, or Single White; 2. P. Whitleji, or Chinese Double White, flowers large, splendid, and fragrant; 3. P. albiflora fasta, or Makoya, new and beautiful, with double flowers; 4 . P. Reeresii, new and beautiful, with large double flowers, of a light pink color; 5. P.Ro$s e o$, or Double Rose-colored, changing to very pale; 6. P. Carnca, or Double Flesh-colored; 7. P. Humei, or Chinese Double light Crimson; R. P. Rubra, and, 9. P. rubra tennifolia, or fennel-leaved, both with deep single crimson flowers; 10 . $P$. Rubra pleno, Double Crimson; and, 11. P. frograns, or Chinese Rose-scented, with superb dark crimson flowers, extremely fragrant; 12. P. Pottsii, dark crimson.

21. Smooth-leaved Bell Flower, (Campanula nitida,) very ornamental, and completely covered with blue flowers. There is a double variety of this, but it is very rare. Of the numerous genus of Asters, with fine blue flowers, the Italian Starwort, (A.Amellus, ) the Alpine, (A. alpinus, ) and the A.spectabilis; Ragged Robin, (Lychnis flos cuculi.) beautiful when double. 23 . The varieties of $L$. dioicia, with double red and double white flowers, are very showy; sometimes called Bachelor's Buttons: 24. The Plantain-leaved Crowfoot, (Ranunculus amplexicaulis,) pure white flowers, in April or May ; 24. Garden Rocket, (Hcsperis matronalis,) double white and double purple; these are excellent border flowers, being at once both showy and fragrant; 25. Virginia Spiderwort, (Trodescantia virginica,) with fine blue flowcrs, and with red and white flowers, blooming 
from spring to autumn; 26. Asiatic Globè Flower,.(Trolliás asiuticus,) its rich orange-colored flowers are very brilliant; T. euroficus, flowers fine yellow and handsome; 27. American Cowslip, (Dodecatheon meadia, very elegant flowers, in May and June. The varieties of the Chinese Cbrysanthemums, of almost every color, are particularly elegant. I must not omit the Day Lily, (Hemerocallis

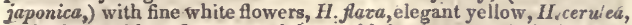
with elegant blue flowers and large shining leaves; Asclepias tuberosa; also, Iris pallida, is elegant, 'with large pale, sky blue flowers; Iris Swertii, new, and most beautifully variegated; Iris flava, fine yellow; and Gladiolus maximus, with fine dark red flowers; and $G$. natalensis, with superb red and yellow flowers. $G$. purpurea, with pale flowers, and $G$. Cardinalis, with scarlet flowers, are both fine. Double Cardamine, (Cardamine pratensis, pl.) Alpine Clematis, (Clematis Alpinus;) Early Anemone, (Hepalica triloba,) and Crimson Monarda, (Monarda didyma,) are fine.

\section{LOW-GROWIVG Flowers for the Front of THE Border.}

1. Double Purple Jacobea, (Senecio elegans;) strictly speaking, this is only an annual, but double varieties may be continued by cuttings; 2. Several varieties of Phlox are very ornamental, particularly the common Lychnidea, ( $P$. suavealens;) the early flowering, ( $P$.divaricata ;) awl-leaved, or $P$. subulata; the' Snow White, $P$. Nivalis and $\boldsymbol{P}$. Drummondi, and $\boldsymbol{P}$. stolonifera, or creeping; 3 . The great flowered Siberian Fumitory, (Fumaria nobilis,) is very handsome, and continues long in flower, $\boldsymbol{F}$. formosa, with delicate blush-colored blossoms; and the Yellow speeies, $(\boldsymbol{F}$. lutea, $)$ is valuable; 4 . Common Bloody Crane's Bill, (Geranium sanguineum,) is not unworthy of a place; and the striped variety, $(G$. Lancastriense, $)$ and the streaked Crane's Bill, (G. striatum;) 5. The Yellow species of Monkey flower, from Chili, (Mimulus luteus, ) is an acquisition, and very pretty; and, 6. Different species of Enothera, though of humble growth, produce fine yellow flowers, particularly $Q E$. frazeriana, $Q E$. finticosa, $\mathscr{E}$. pumila, and Large White Primrose, (WE. specíosa;) 7. Marsh Marigold (Calthra palustris) is likewise very showy, and for several weeks makes a brilliant appearance, but prefers a moist border; Feather grass (Stipa pinnata) is justly admired for its light, airy, and delicate appearance; 8. Violets of different kinds are well known - the Canadian, (Viola canadensis) is particularly elegant, and the Sweet or March Violet, $(\boldsymbol{V}$. odorata; $)$ also Double Blue, $(\boldsymbol{V}$. ceruleo, pl.;) Double Purple, (V. purpurea, pl.;) and Double White, $(V . a l b a$, pl.). all fragrant, but the large flowered variety is beautiful; 9. The Anemones, with blue flowers, as the splendid Pasque flower, ( $A$. pulsatilla, ) and different varieties of the Star Anemone, ( $A$. hortensis, and $\boldsymbol{A}$.Apennina, and $\boldsymbol{A}$. pretensis;) 10 . The Gentians are also fine border plants, particularly the Gentiana saponaria, and G.acaulis, both with blue flowers. Orchis fimbriata and O.-blephariglottis are fine. Also Splendid Scarlet Verbena, (Verbena Melindris;) White and 'Red Ladies' Slipper, (Cypripedium spectabilis,) and Double White Ranuneulus, (Ranunculus aconitifolius, pl.,) are beautiful.

\section{Biennials.}

Some of the most common are, 1. Honesty, or Satin Flower, (Lunaria annua,) both white and purple; 2. French Honeysuckle, (Hedysarum coronurium, red and white; 3. Yellow Horned Poppy, 
(Glaucium luteum ;) 4. Tree Primrose, of several species, Enothera biennis, \&c., and Moth-mullein, (Verbascum blattaria,) yellow and white flowered.

\section{FLOWERS FOR ROCK WORK.}

Masses covered with Lichens, especially, 1. Lichen atro-flavus, geographicus, ventosus, perellus, and stellaris, are very desirable. The following are very proper and ornamental; 2. Cotyledon umbilicus, and all plants which grow naturally in dry soil, are fit for rock work ; 3. Dianthus deltoides, D. armeria, and D.cosins; 4 . The Red Valerian, (Valeriana rubra,) and the white variety ; 5. Erinus alpinus; 6. Madwort of different species, particularly Alyssum saxatile and deltoideum; 7. Cerastium repens; 8. Erigeron alpinum; 9. Cyclamen europaum and herderafolium; 10. Spring Gentian,(Gentiana rerna;) 11. Soldanella alpina; 12 . Saxifraga oppositifolia and S. granulata, fl. pl.; 13. Verbascum myconi; 14. Lychnis alpina; 15. Primu'a nivalis, $P$. integrifolia, $P$. helvetica, and $P$. marginata; 16. Basil-leaved Soapwort, (Saponaria ocymoides;) 17. Stone crop, in particular, Sedum album, glaucum, rupestre, aizoon, and sexangulaire; 18. The Cobweb species of Houseleek, (Sempervivum arachnoideum.)

8. Aquariom.

In the pond may be placed various marsh plants, as, 1. Marsh Calla, (Calla palustris;) 2. Yellow and white-fringed Bog Bean, (Menyanthes nymphoides;) 3. The Flowering Rush, (Butomus umbellatus ;) 4. Water Violet, (Hottonia palustris;) 5. The Cat's Tail, (Typha latifalia and $T$. angustifolia) has a singular appearance Lastly, some of our own native aquatics may be recommended for their beauty and fragrance. The Nymphæ, and in particular the White and Yellow Water Lily, (N. alba and $\mathcal{N}$. lutea.) The White rivals the rose in beauty and fragrance. Also, the Double Flowering Arrowhead, (Sagittaria, fl. pleno.)

\section{Annuals.}

1. The Indian Pink, (Dianthus chinensis, 2. The Winged Thunbergia, ( $T$. alata,) and, 3. The Sensitive Plant, (Mimosa sensitiva,) though, strictly speaking, biennials, are often cultivated as annuals. Many of the annuals are very beautiful; those of each species only which are the most showy, will be particularized. 4. Elegant Coreopsis, (C. tinctoria;) this is very showy; 5 . Beautiful Clarkea, (C. pulchella;) 6. White and Purple Candy Tuft, (Iberis umbellata;) 7. Daisy-leaved Catch-fly, red and white Silene lellidafolia; 8. Venus's Looking Glass, (Campanula speculum;) 9. Sweet Alyssum, (A. maritatum, ) are very ornamental; 10. Convolvulus, major and minor; 11. African Marigold, (Tagetes erecta,) and French do. (T. patula;) 12. Loyé in a Mist, (Nigella damascena;) 13. Variety of Scabius, (Scabiosa;) 14. Ten Weeks Stock Gilliflower, (Cheiranthus annuus;) 15. The rich and elegant Double Balsams, (Impatiens balsamina,) their capsules are curious; 16. Hibiscus trionum, with yellow flowers ; 17. Many varieties of Larkspur, (Delphinium ajacis,) single and double ; 18. Varieties of Lupin, (Lupinus,) and of, 19. Sweet Pea, (Lathyrus odoratus ;) 20. Scarlet Malope, (M.trifida ;) 21. Carnation Poppy, varieties, (Papaver somniferum, ) are very showy ; 22. Purple-Eyed Crepis, (C. barbata ;) 23. Tangiers Scorzonera, (S. tingitanum ; 24. The Eternal flower, varieties, red, white, purple, yellow, and blue, (Xeranthemum, is unsurpassed; its splendid flowers retain their beauty through the winter, and make a fine appearance in 
vases; 25. Mignonette (Reseda odarata) is universally admired. The following are less hardy, and should be sown in a warm situation, and transplanted, to bring them forward early : 26. Amaranth, (Amaranthus caudatus,) or Love-lies-bleeding, and, 27. Prince's Feather, (A.hypochondriacus;) and 28. The Chrysanthemums, particularly $C$. tricolor and $C$. lutea. The following are tender annuals, and may be planted early in a hot-bed, and transplanted: Crimson Cypress Vine, (Ipomaa quamoclit;) 29. Many varieties of Cockscomb, (Celosia cristata,) with scarlet, purple, and yellow heads, are extremely ornamental; 30. Globe Amaranthus, (Gomphrana globo$s a_{s}$ ) of various sorts, with the Amarantlus tricolor, with each leaf of three colors, bright red, yellow, and green, are very showy; 31 . The Egg plant is showy on account of its elegant berry, of the size and shape of a large egg; 32. The Ice plant (Mesembryanthemum crystallinum) is curious, its leaves and stalks being covered with crystalline globules like icicles; 33. And the well-known Sensitive plant, (Mimosa pudica.)

\section{CULTIVATION.}

The seeds of flowers are sown in the spring, in fine and newlyprepared fresh soil. Very fine seeds should be covered but a quarter of an inch deep, larger seeds deeper in proportion to their size; and the ground is then to be immediately trodden hard; this enables it to retain its moisture at the surface, which coöperating with the warmth of the sun on the seeds, they vegetate at once.

NOTES ON THE, AGRICULTURAL RESOURCES OF AMERICA, AND THË CULTURE OF SILK.

\section{CHAPTER I.-HISTORY OF SILK: ITS ANTIQUITY AND COMMERCE.}

Silk, or the splendid material produced by the silk-worm, was first known in ancient Ser, or Serica, in China. It was there first discovered in its own native forests of the mulberry tree. In thiat country it was called Se, and by transition it was called Ser by the Greeks, and Sericum by the Romans; and herice, by the different nations of Italy, of France, and of England, it is variously called Seta, Soie, and Silk, at the present day. Anciently, also; it was called Bomlykya', or Bombycina, from Bombyx, a caterpillar which spins a web.

The silk-worm, or Bombyx mori, is a precious insect, which is thus denominated from morus, the plant on which it feeds; otherwise, and anciently, the Bombyx Assyrian, or Syrian improperly so calléd, since the country of the Seres, or Chinese, was another country, the most remote, and bounded on other shores; many a nation and fas distant country intervening. 
The cultivation of silk commenced in China 700 years before Abraham, and 2,700 before Christ. The Emperor Houng-ti, "the Emperor of the Earth," who reigned over China more than a hundred years, and whose name is rendered immortal for his noble and useful deeds, - he who taught the Chinese to construct houses, ships, mills, carts, and other works of usefulness, - he also persuaded his first consort, Si-ling-chi, ta bestow her attention on the silk-worms, it being his earnest desire that his empress also might contribute to the welfare of the empire. Aided by the women of her household, the Empress Si-ling-chi gathered the silk-worms from the trees, and introduced them to the imperial apartments. Thus sheltered and protected, and abundantly supplied with the leaves of the mulberry, they yielded silk superior in quality to that produced in the forests. She also taught them its manufacture, and to enbroider.

Silk and its manufacture, and the weaving, continued to be the principal occupation of the succeeding empresses, apartments being especially appropriated to this purpose in the imperial palace; and soon, from the highest rank of females, it became the occupation of all ranks in China; and ere long, the emperor, the learned class, the princes, the mandarins, and courtiers, and all the rich, were attired in the splendid fabrics of silk, uritil, finally, silk became the great and inexhaustible resource of the wealth of China.

From China it was exported to India, to Persia, to Arabia, and indeed to the whole of Asia. The caravans of Serica performed long journeys of 243 days, from the far coasts of Clina to those of Syria. Silk was also rewoven and manufactured at a very ancient date, in the island of Kos, situated in the Archipelago, from the substantial fabrics which were received from Seres. It was here that Pamphila first invented and taught her nymphs to unravel, and with her loom to recompose, from the precious material, the thin, transparent gauze, and the other fabrics of an equally extended nature.

The expeditions of Alexander to Persia and to India first introduced the knowledge of silk to the Grecians, 350 years before Christ; and with the increase of wealth and luxury in the Grecian court, the demand of silks prodigiously augmented. Persia engrossed, for a time, the trade of Greece, and became rich in the commerce of silk, which they procured from China. The ancient Phœnicians also engaged in the traffic of silk, and finally carried it to the east of Europe. But, for a long time after, even those who brought it to Europe knew not what it was, nor how it was produced, nor where situated was the original country of Serica, from whence it came.

Ser, or Serica, was called Sereinda, a name evidently conposed of Seres and of Indi, the names of two distinct and separate countries, which the ancients had thus confounded; even as the name of India has been, and still is, often indiscriminately applied to all the countries of the whole east of Asia, at the present day.

Ammianus Marcellinus, the celebrated historian, has described the Seres as a sedate and gentle people, living in perpetual peace with the neighboring nations, and therefore exempted alike from the calamities and the alarms of war; with no occasion for offensive weapons, or even the knowledge of their use. Blessed with a soil the most fertile, and a climate the most delightful and salubrious, they are represented " as passing their happy days in the most perfect tranquillity and delightful leisure, amid shady groves, fanned 
by gentle breezes, and producing fleeces of downy wool, which, after being sprinkled with water, are combed off in the finest threads, and woven into sericum."

This fable, which undonbtedly served for ages to deceive the nations, is supposed to have been the invention of the Seres them. selves, that they might appear to the wondering world as a peculiar people, on whom blessings were profusely showered down from heaven, in which no other nation could expect to participate.

At Rome, and so late as A. D. 230, a silk attire of purple was accounted by an emperor as a luxury too expensive even for an empress, and that empress his wife, Severa; its value being equal to that of gold, by weight. Others there were at Rome, and enough even at that day, who were by no means thus scrupulous in regard to price. But it was not till long afler the seat of the Roman empire had been transferred to Byzantium or Constantinople, that the distinct and more perfect knowledge of the nature and origin of silk became known, and the mystery of the long songht "golden fleece" was revealed to Europe.

In the sixth century, two monks arrived at the court of the Emperor Justinian, at Constantinople, from a missionary expedition to China. They had brought with them the seeds of the mulberry, and communicated to him the discovery of the mode of rearing the silkworms. And, although the exportation of the insects from China was forbidden, on pain of death, yet, by the liberal promises and persuasions of Justinian, they undertook a new expedition; and at length they returned through Boukharia and Persia to Constantinople, in 555, with the eggs of the precious insect concealed in the hollow of their canes, or pilgrims' staves, which they had obtained in the far and still more distant country. Until this time, the extensive manufactures of the Phœnician cities of Tyre and Bergtus had received their whole supplies of raw gilk through Persia, from China. Even to the days of Justinian, according to ancient historians, no person at Constantinople knew, to a certainty, that silk was the production of an insect, It was generally supposed to be produced from the bark or leaves of trees, or growing, like the finest hair, from their branches. A new era now commenced.

The whole value of the silks manufactured in France, in 1835, amounted, by computation, to $140,000,000$ francs, and it was estimated in Europe, that, in that year, silks to the amount of $50,000,000$ francs were exported from that country to the United States slone.

Yet in France, although they raise so much silk, they still import, annually, to the amount of $43,000,000$ francs of raw silk, or nearly one third of all they consume, for the supply of their manufactures.

In England, the climate, from its humidity or other causes, is found to be unsuited to its growth; for this reason alone, the trials to raise it there have failed. Yet from 1821 to 1828 , according to a late and authentic work on the silk trade, they imported, of raw silk,

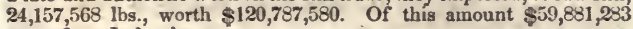
came from Italy alone.

At the present day, the silks which were consumed in Great Britain alone, 80 late as 1835 , amounted to the enormous sum of $\$ 28,282,582$ annually, at the wholesale prices, besides the whole amount of all they exported.

The sudden and extrsordinary extension of the silk manufactures, 
both in France and in England, during the latter years, has been mainly ascribed to the machine invented in France by M. Jacquard; and the powerful impulse thus given, has been assigned to the Jacquard Loom. This loom performs all those labors. which had heretofore been exclusively confined to the must skilful hands, with important economy of time, and of labor in the preliminary steps, and is so decidedly superior to all other looms, for all the curious varieties of figure-silk weaving, that it has superseded them all, both throughout France and England.

According to the report of the Secretary of the Treasury, the value of silks imported into the United States during the year ending 30th September, 1835 , amounted to $\$ 16,597,(180$; this being the original or first cost in the foreign countries. During this period, only $\$ 486,562$ worth of this great amount was exported; and the actual cost of the above to the American people, or the whole vetail cost to the actual consumer, may be estimated at more than $\$ 22,040,000$ for the year. Most of all this was imported from Italy, Switzerland, and from France. Formerly, half our imports were frón Clina. Yet neither the articles of raw silk, nor any of those numerous, substantial, and elegant fabrics, which are composed of part silk and part cotton, or mixtures of silk and worsted, are included in the above amount. In no year previous to 1821 had the annual amount consumed arisen to one fourth of what it was in 1835. But in no year previous to $1830 \mathrm{had}$ the annual consumption arisen to one half this amount; the increase during fifteen years being fonrfold.

In the year ending September, 1836, the importations of silk amounted to $\$ 22,000,000$, at the first cost in foreign countries; and the imports of those fabrics, composed of part silk and cotton, and part silk and worsted, amounted to $\$ 6,000,000$ more, in that same year. And during ten years previous to 1840 , we had imported more than $\$ 40,000,000$ of wines, $\$ 34,000,000$ of iron, and $\$ 118,000,000$ of silks, comprising an amount equal to $\$ 242,000,000$, - for articles with which we either could have dispensed, or produced by our own industry from our own soil.

In the year ending September 30,1839 , and during the progress of a very extraordinary bank expansion, the prices and profits on manufactures suddenly rose from this cause, and the importations of that year were, in consequence, exceedingly great, not only of all that we wanted, hut of a vast amount also which we needed not; - of iron, $\$ 12,000,000$; of linen goods, $\$ 6,000,000$; of cloths and kerseymeres, $\$ 7,000,000$; of cotton goods, $\$ 14,000,000$; of silks, $\$ 23,000,000, \& c$. \&c. : in all it amounted to $\$ 170,000,000$ for the year, which was $\$ 75,000,000$ more than all our domestic exports. Silks and wines alone were not the only agricultural productions of all that vast list of imports. The enormous foreign debt thus incurred, and the extraordinary deluge of foreign goods thus introduced, not only caused the terrible reaction which so quickly followed, but it paralyzed our agriculture, and, for a time also, it crushed our manufactures.

Whence came those vast importations? A large proportion came from Pritain, whose laws, in regard to trade, are founded, in a great measure, on monopoly, and not on any reciprocal right; it being the policy of that nation to sell to other nations all the productions of their agriculture, and manufactures, and mines, which they can 
produce; while almost every article of agriculture, or of manufactures, which the subjects of Britain can produce, is shut out from their ports by heavy duties, or by total prohibitions. This system of Britain, while it enriches them, is directly calculated to exhaust and impoverish our country continually; they have, in fact, excluded almost every production of our industry and our soil which we can furnish in exchange for their productions, except only our cotton, our silver, and our gold.

The colossal power of Britain is mainly derived from their agriculture, and their mines of coal and of iron. By aid of these last, their engines and machinery are formed, which are employed in their stupendous manufactures and in commerce; and these, as has been estimated, together with their mills moved by wind and water, accomplish labors equivalent to a hundred millions of men.

In Britain, where labor is cheap, and lands are very dear, it has been stated, on good authority, that the proportion of animal power, or the power of oxen and horses, \&c., which they apply in their agriculture, is ten times as great as the human power which is thus employed, and far greater than in any other country of the old world. In America, lands being both fertile and exceedingly cheap, cheaply, therefore, are we enabled to maintain the vast animal power; the plough being truly the American instrument, by whose aid we are enabled to cultivate those lands at a diminished cost, and far less than by any other mode, or by any other nation on earth; ours being the vast, the unbounded prairies and pastures, and " the cattle on a thousand hills." The proportion of animal power which is thus employed, is, in America, transcendently great.

Already, in many parts, our fields of grass are mown by aid of horse power, and by this same power the produce thus mown is raked, and gathered into barns; by horse-power fields of, wheat are also reaped; and low plantations of the mulberry may thus be shorn of their folisge by machinery formed of numerous, parallel, and prong-shaped knives, with guarded sides, and edges vertical.

We have mountains of anthracite and mountains of iron ore lying contiguous. The United States contain at least 80,000 square miles of coal and of iron, or sixteen times the area or amount of all Europe; and one vast uninterrupted field, extending 900 miles in length, from Pennsylvania inclusive, to Alabama, contains 50,000 square miles.

Our advantages are indeed very great : to be duly appreciated, they must be estimated singly and individually: how much greater and more striking will they then appear, if considered collectively. Our innumerable rivers and rapid streams, our immense forests and mines, the exhaustless treasures of fuel and of flame, the combined elements of water, earth, and of fire, offer resources of mighty power, unknown and immeasurable, and willing aids in abridging the labors of man.

The same transcendent power of steam, which drags the hnge ship, or ponderous car, will, ere long, become the mighty instrument, or universal power, by whose aid every agricultural operation will be performed.

Hail, progress of improvement! all hail! How swift its speed! in all things how great, how wonderful in this our day! In vain do those false men oppose, - those false men, in fine, who, denouncing 
all as innovation, have ever been the unceasing opponents of every improvement in every age, - in vain do they strive to obstruct its progress and to cause a retrograde; or, to stop its march, which is on ward and irresistible.

\section{CHAPTER II. - HISTORY OF THE SILK-WORM.}

The silk-worm, or Bombyx mori, is a caterpillar; its body formed of twelve membranous rings: these rings support the legs, which are sixteen in number, and in pairs. Six of these are in front and inflexible, and situated beneath the three first rings, and are each covered with a scale. The other ten are flexible and membranous, their positions beneath the rings; these are called climbers or holders, and are provided with sharp hooks or claws, to aid in climbing. The head has a horny covering, like a scale; the jaws are very strong, the teeth sharp, serrated, or indented like a saw. The mouth is vertical and peculiar, and not horizontal, as in most other beings ; two broad objects in its forehead, which might be mistaken for eyes, are but bones of the skull. The eyes are sinall, fourteen in number, aeven on each side of the head, and near the mouth. The organs of respiration are eighteen in number; equidistant, and situated along the body, are the holes or openings, nine on each side, which serve for breathing.

The substance of which the silk is composed is a liquid, transparent gum, of a fine yellow color, and is contained in two separate sacs, of slender dimensions. Each of these vessels is about ten inches in length, and wound in the stomach in spiral folds: near the jaws two ducts convey the silken fluid; these, uniting in one, serve to compose the silken thread, which is usually from 400 to 1,200 feet in length.

The eggs of the silk-worm are of a dark lilac or slate color. The silk-worms are at first black and extremely small; as they advance in age and size, they cast off their outer covering or skin, usually from three to four times, at different periods, according to the variety. These successive changes are called moultings; and the times intervening are termed ages. In a colder temperature, the duration of these several periods is prolonged; but in a warm climate, the period or season of the first moulting, which terminates the first age, usually occurs on the fourth or fifth day of its existence; the second on the eighth or ninth day; the third on the thirteenth or fourteenth day; and the last on the twenty-second day. At each of these critical periods, the silk-worms remain in a torpid state, eating little, or absolutely nothing, for a day or more. At the end of about ten days more from the last period, or in about thirty-two days from the beginning, the insect, now fully grown, is about three inches and one third in length, transparent, of a yellowish white or pearl color. Having now completed their fifth or last age, they eat no more, but ascend to the leaves or brush-wood, which are placed for the purpose, and commence the formation of the cocoons ; and, in the construction of these, the insect works busily and incessantly night and day, during four days. The labor finished, the insect in the centre becomes transformed to the clirysalis state. 
The vital functions of the silk-worm are accelerated by warmth, and the time occupied in passing through the various mutations is hastened, not only by the 'increased temperature, but materially by the degree of attention which is bestowed on the insects. In Mladras, according to Dr. Anderson, and where the climate is very warm, the silk-worm passee through all its evolutions in twenty-two days. Here, then, is not only a saving in regard to time and labor, but a great and very important saving also in regard to food.

The cocoon is usually an inch and a third in length, of an oval form; the color yellow, or straw, or pure white. The outer covering is like finest wool, and is called flos, and is easily detached; this being removed, the end of a thread is discovered, of extreme fineness.

After an interval of from fifteen to twenty days' repose, the moth ejects from its mouth a liquor, which mojstens the gum and diseolves the thesiveness of the texture of the ball; and by frequent motions of its head, it lonsens and forces aside the filaments, without sundering a single silken thread, until it reappears, transformed to a large butterfly, of a grayish white color, with four wings, two eyes, and two black, feathery horns or plumes. Unshrouded, in this its last and perfect form, both male and female, they come forth to the light of day : from this time they take no visible food to the day of their death.

They commence laying their eggs in twenty-four or thirty-six hours after leaving the cocoon. Each female usually lays four hundred eggs; which firmly adhere to the paper, on which they are arranged in a handsome and circular form. In a few days after, their inultifarious labors being ended, the insect dies.

The silk-worm remains in the chrysalis state a length of time corresponding with the temperature of the climate. In England they remain 30 days; in France, 21; in Spain and Italy, 18 or 20 ; in the United States, about the same; and in India, but 11 days.

A silk-worm sometimes measures more than three inches in its greatest length; but few attain to dimensions so large. If the longitudinal dimensions of an insect which attains to 40 lines be compared during the different ages, and their length at the period of hatching being unity, or 1, their length at the end of the first age.will be 4 ; at the end of the second age, 6 ; at the end of the third age, 12; at the end of the fourth age, 20 ; at the end of the fith age, 40 .

The silk-worm, like other caterpillars, is a cold-blooded insect, its temperature that of the atinosphere in which it breathes. Sudden changes from cold to heat are highly injurious; yet it has been found that the silk-worm is capable of enduring a great degree of heat; if uniformly maintained. Such a degree they must at times endure in their own native forests, not only of light, but also of heat, with no shelter from the scorching sun but the shadow of a leaf. Yet in no case is a due degree of warmth more needful, than while the insect is forming the cocoon. If, at any time while they are performing this most important labor, they are permitted to suffer frons cold, they cease from their labors, and remain inactive, or move but slowly, as may be discerned while the cocoons are yet transparent. It has been proved, on dissection of the silk-worms which. thus suffer and become torpid through cold, that the glutinous mat- 
ter in their silk reservoirs had become so congesled and tenacious from eold, as to resemble strong tendons; which sufficiently accounted for the inability of the insect to draw forth the silken filament. Yet no sooner is the temperature increased, than they will resume their labors with increased activity; but will again desist, if exposed again to cold. If neglected at this critical period, they assume, in due time, the chrysalis form, but, for want of sufficient strength, leave incomplete their silken tomb.

\section{CHAPTER HI. - VARIETIES OF SILK-WORMS.}

1. Sina Silk-Worm. This is a variety imported into France from China, by Lours XVI., in 1784 ; a large, pure white, and extremely beautiful variety, which is preferred, in that country, to all others. Their cocoons are pure white, large, and fine, and the silk-worms hatch simultaneously.

2. The Large Single-Crop Worm. A very superior variety, whether of a pure white or brown. Their period of hatching may be hastened or prolonged to a late period in summer; and thus they will yield two crops or more. The cocoons, being of large size, are on this account more profitable to raise or to reel, than any other variety except the Sina.

3. The Silk-Worm of Two Crops. A small variety, from Italy; a pale, white worm; the silk is white, and very fine; the cocoons are also small, and, on this account, deemed unprofitable.

4. Silk-Worm of Eight Crops, or Dacey. At the silk establishment of the British East India Company at Jungepore, in Bengal, besides the common silk-worm, which produces but a single crop annually, they have also another silk-worm, called Dacey, which produces eight crops or harvests, and is supposed to be indigenous.

5. Friuli Silk-Worms. 'There is a variety of silk-worms found in Friuli, so very large, that two of these, when fully grown, will outweigh five of the common kind; and their cocoons weigh almost in the same proportion. The quantity of food is one tenth less in proportion to the weight of cocoons produced, than the common kind, but they require five or six days longer in their evolutions before they begin to spin. Their cocoons are four times as heavy as those of the small variety of silk-worm. Each eacoon yields nearly 8.1 grains, and measures almost 1,300 yards; and 100 cocoons weigh a pound, and 1,091 will yield a pound of pure reeled silk. Friuli silk is said to cause more trouble and waste in its manufacture, than that of either France or Lombardy. This may be owing, either to the breed of silk-worms, or, what is much more probable, to its being imperfeetly reeled.

For an account of the two following kinds of silk-worms, which are described as peculiar to Hindoostan, I am indebted to the researches of General Dearborn, who has deseribed them from Milburn's Oriental Commerce.

6. Arrindy Sillk-Worm. This silk-worm is a species totally different from any hitherto described or known, and is called Arrindy, from the name of the plant, the Rhicinus, or Palmi Christi, on which 
the insect feeds. It is peculiar to the districts of Dinagepore and Rangpore, in the interior of Bengal, where it is reared by the natives in a domestic state; as they do other silk-worms. The Palma Christi is largely cultivated in India, as it is also in many parts of France, and some other countries, for the abundant produce of oil which is obtained from its seeds, which is known in cammerce as the Castor oil. This plant is therefore cultivated for the double use of seeds and also of its leaves.

The cocoons thus produced are remarkably soft, and white or yellowish, and the filament is so exceeding delicate, that it cannot be wound, as are other cocoons, but must be spun like cotton. The cloth woven of this substance, is white, coarse, and of a seemingly loose texture, but of incredible durability. It is used for the clothing of both men and women, and will wear constantly for ten, fifteen, or twenty years. The merchants also use it for packing fine cloths, shawls, and silks. Hot water dissolves its texture, causing it to tear; it is therefore washed only in cold water.

The Arrinda or, Eria silk is reared in Assam, as in almost all Hindoostan, but entirely within doors. It is fed principally on the Hera, or Palma Christi. It affords a fibre which at first looks rough, but after repeated washings becomes soft and silky. The poorest people of Hindoostan are clothed with this material, which is warm, and of incredible durability, the whole lifetime of a single person being seldom sufficient to wear out a garment made of this silk, which descends from mother to daughter for generations. Twelve broods of this silk are sometimes raised in a year. In Assam alone, 80,000 pounds of this silk are annually produced.

The Palma Christi flourishes in all the states of the south, and as far north as the latitude of Boston.

7. Tusseh, or Wild Silk-Worm of India. This is a species of silkworm which cannot be domestioated. They are so abundant in many parts of Bengal, and the provinces adjoining, as to have afforded to the natives of those countries, and particularly to the Bramins, from time immemorial, considerable supplies of a most durable, coarse, dark-colored silk, which is woven into a fabric called Tusseh-dootie.

This species of silk-worm might, it is supposed, prove highly useful to the inhabitants of the south of Europe, and also of the Southern States of America, where cheap, light, cool, and durable dress is much wanted - such a dress as this silk affords, and such as is worn by the Bramins of India. Once introduced, they would probably flourish, unaided by the care or assiduous attentions of man.

In the province of Assam, in Hindoostan, Asia, which bas lately come into the possession of the British power, amongst other productions hitherto unknown, there have been found about a dozen species of silk-worms, which produce the materials for valuable fabrics, including also the Arrinda.

8. The Muga Silk-Worm is never domesticated, or reared in houses; they feed on the leaves of a variety of trees. The eggs are laid on wisps of hay, which are collected and placed on the trees, where they soon hatch; plantain leaves being tied around the bottom of the tree, over which the worms will never pass. When a tree is stripped of its foliage, they descend, and are removed to other trees, by means of dishes of bamboo attached to poles. - They feed 
thirty days, when they descend to the plantains, and, being gathered, and placed on dry leaves, they form their cocoons. Their cocoons are two inches long, and thick in proportion; they are not reeled like common silk, but spun like cotton or worsted. The silk is wove into cloth for scarfs, turbans, sashes, \&c. In that climate they produce six crops in a year. 50,000 pounds of this silk is annually made in Assam. It may be the same silk-worm as that last described.

There is another sort of these silk-worms, which produces a fibre of great lustre; and a fourth kind, very large, the moths measuring ten inches across the wings.

\section{CHAPTER IV. - MULBERRY, (Morus.)}

The mulberry, or morus of the botanists, is a genus comprising many species. It derives its name from Mor, in Celtic, black. Its origin has been assigned to China, but several apeciea have been found growing in a wild state in America. In cold climates it is a deciduous tree, but an evergreen tree within the tropics. It was cultivated at a very early period of time in Western Asia and in Europe, but only for its fruit. The fruit is a berry of a roundish or oblong form; of a color varying from white to red or black; its pulp envelops numerous small seeds.

Usss. Most of the varieties of the mulberry are esteemed dessert fruits. When perfectly mature, they are grateful to the taste, and very wholesome; the sirup is useful in mitigating inflammation of the throat. The juice, when properly fermented, affords a pleasant, vinous wine; mixed with apples, they afford a delicious beverage called mulberry cider, of a deep red color, like Port wine.

The wood of the mulberry tree is compact, elastic, and hard, and susceptible of a fine polish ; it is therefore sought after by the upholsterer, the carver, and the turner. The strength of the timber renders it valuable to the joiner, and also for building boats: its power of resisting the action of water has been compared to oak.

The roots of the mulberry tree are of a yellow color, and strike downward; and the tree is extremely long-lived. Mi. de Saint Fond saw, in 1802, one of the original or parent trees of all the white mulberry trees of France, which the followers of Charles VIIl. had brought from Italy, on his invasion of that country in 1494. M. Lachaux had caused this tree to be encompassed by a wall, to evince his respect and veneration, and to serve as a monument to a tree so ineatimable.

Whoever would enter extensively and at once on the cultivation of silk, let them, first of all, bestow their attention on the culture of the abundant supplies of food; this prinoipal and essential fuod being no other than the material leaves of the various species of the mulberry tree. Not every kind, however, is equally suitable. Linnrus has enumerated seven species of those which were known in his day; and amongst these there are two species, the Tinctora and Indica, which are not used as the food of the silk-worm. The Tinctora is the Fustic of commerce, and is used only as a dye.

The nourishment which is contained in the mulberry leaf is not 
completely developed till the leaf is fully grown. The leaf, according to the analysis of Count Dandolo, contains, 1. The fibrous substance; 2 . The coloring matter; 3 . Water; 4 . The saccharine substance; 5 . The resinous substance. The saccharine substance is that which nourishes the insect, augmenting its growth and size. 'The resinous substance is that which, "separating itself gradually from the leaf, and attracted by the animal organization, accumulates, cleans itself, and insensibly fills the two reservoirs or silk vessels." The proportion of this nutriment depends on the variety of the mulberry, the age, the soil, and the moisture or dryness of the season.

\section{CHAPTER V. - VARIETIES OF THE MULBERRY.}

Space will not admit a very particular description of every variety. We will briefly describe a few, all fine for silk.

1. JAPAN PAPER Mulberry. Broussometia papyrifera.

The tree is of rapid growth, and rises to a large size, with a round head; the leaves are rough, either cordate, entire, lobed, or palmated. It is a native of China and Japan, and the liber, or inner bark, by being beaten to render it pliable, serves for paper, and as an article of clothing in those countries. The fruit is round and curious, but not edible. The leaves are eaten by the silk-worms; and for this purpose, it is now successfully cultivated in France.

A beautiful vegetable silk is procured from the bark of the young branches of the papyrifera, as has been proved by $M$. la Rouverie. He directs that the bark be separated, while the tree is in full sap, and beaten with mallets, and steeped in water, by which process he affirms fibres are obtained almost equal to silk in quality, and which, when woven, form a cloth whose texture resembles silk.

2. Shining-Leaved Mulberky. Morus lucida.

Leaves very large, pointed, cordate, and shining; fine for silk.

3. Tartarean Mulberry. Morus Tartarica.

The fruit resembles the Morus nigra. A variety from the vicinity of Asoph. It abounds on the banks of the Volga and Tanais. Leaves large, oval, oblong, serrated, shining; excellent for silk.

4. White Italian. Morus alba.

A native of China, naturalized in Italy ; already described; too well known to need a more particular description. The leaves are small, but fine for silk; the fruit insipid; the bark forms a preparation resembling silk. The young wood being gathered in September, and steeped by day in still water, and spread on grass by night; for three or four days, may then be prepared and woven like flax.

5. Moretti Mulberry. A new variety, sometimes miscalled Alpine. Leaves ovate, sharp-pointed, entire, cordate at the base ; thin, smooth, large, of a beautiful and rather deep-shining green; the silk fine.

6. Morus Arata. Leaves large and beautiful.

7. Roman Dura. Leaves large, yellowish green, shining, and beautiful. The Morus Expansa proves identical with Roman dura.

8. Brussa. A variety from the vicinity of Constantinople, some- 
times called the Asiatic. Leaves large, and of excellent quality. Other fine varieties, with large leaves, are the

9.-Morus Alba Giazzola; 10. Folia Doppia; 11. Rose-Leaved; 12. Small Queen; 13. Spanish.

14. Cushing's New Chinese Mulberry.

A new variety, lately introduced from China, by John P. Cushing, Esq., of Belmont, in Watertown. It was received from his Chinese friend in Canton, in the spring of 1837 , and was imported in a growing state. Many trees of this fine variety have been liberally disseminated by him. I have thence affixed his name to the tree. The tree is of the most rapid growth; the leaves very large, generally entire, but varying in the same_species; some being palmated or lobed, and of a beautiful shining green, and very numerous or thick set. The tree and its leaf are splendid, far more so than any other variety yet known; the Morus multicaulis only excepted, which is evidently with this species very nearly allied. It produces silk of the first quality. The Canton Mulberry, so called, which was introduced by Dr. Stebbins, is evidently a variety of the same species.

15. Monus Molticaulis. Perrotet Mulberry. Morus Alba Sinensis.

A new variety, which is also called, by way of excellence, the Chinese Mulberry; a tree of surpassing beauty ; a new and most valuable variety for the nourishment of silk-worms; a tree which is represented as possessing such decided superiority over all others, that it will speedily be substituted for them all, in every region of the globe.

It originated in the elevated regions of China, a country famous from antiquity for its silk; a parallel only to our own, in all its various climates and divers latitudes. It is to this tree, that the disciples of Confucius acknowledge their indebtedness for the prosperity and solidity of their empire.

The tree grows vigorous, upright, and beautiful ; the leaves, large, soft, and tender, are petiolate, cordate, acuminate, serrated towards the summit, marked with nerves, always entire; their upper surface is convex or curled, of a deep and beautiful shining green. The form and dimensions of the leaf vary in different soils. In a dry and arid soil they are of diminished size, their form elliptical, and without the heart-shaped indentation at the base, their breadth being six inches, and their length eight; but in a light, rich, and friable soil, the produce of the foliage is most abundant, the leaves large and cordiform, extraordinary specimens having sometimes measured more than a foot in breadth, and fifteen inches in length.

The Morus multicaulis differs from all others in the uncommon vigor of its growth, and the property which the roots possess of throwing up numerous flexible stalks, the great length which these stalks acquire in a short space of time, and the facility with which it is propagated from layers, or even from the cuttings of a single eye. No other variety will strike root thus readily from cuttings, but all others with difficulty. It differs; also, from the remarkable size which the thin, soft, and tender leaves speedily acquire, and the promptitude with which they are renewed.

In all the maritime districts, from Long Island Sound to Georgia, in point of hardiness, both the Morus multicaulis and the Canton mulberry bear great resemblance to tlie oak; so also on the elevated 
grounds near Boston. But in the low plains of the interior, and in the valleys of the north, they are liable to be injured in their tops by winter; yet in spring they start forth from the root with fresh vigor and renewed luxuriance. Both varieties, being of a prolonged growth, are therefore admirably calculated for the production of numerous crops of silk in a season.

\section{CHAPTER VI. - SUBSTITUTES FOR THE MULBERRY.}

Various are the substitutes whish have been proposed for the mulberry, which seems, indeed, the only suitable food. The Osage orange, or Maclura, is, in fact, a species of the mulberry, and is found to answer well; but the leaves cannot be gathered, except with inconvenience, on account of the numerous thorns. Latterly the Ramoon tree, a plant which grows only in the tropics, has been introduced to our notice as admirably adapted as food for the silk-worm, in its own proper climate.

The RAmoon TrEe (Trophis Americana) is an evergreen tree, a native of the East and West Indies. In Jamaica it has been long known and used as the food of horses and cattle, and especially during the dry months, when, in soine of those withering seasons, the most fertile valleys and pastures become the scenes of utter desolation - all being destroyed by a scorching sun.

The Ramoon tree flourishes in the most barren and arid soil, producing at all seasons a succession of fresh leaves, and never suffers from drought. The leaves are oblong, acuminate or lanceolate, smooth, and entire. A quantity of silk-worms having been imported, and all other substitutes failing, the leaves of the Ramoon were tried with signal and unexpected suecess. A Jamaica paper of March 9, 1838 , states, that the silk-worms not only devoured them greedily, but appeared also to thrive better on them than on the mulberry. The silk produced was of a pure white color, and worth forty shillings a pound; and it was calculated that three crops would be produced in a year. The Honse of Assembly of Jamaica have voted the discoverer the sum of fifty ponnds, "with a view to a future grant," as he progresses in the rearing of the silk-worm.

\section{CHAPTER VII. - SOIL, SITUATION, CLIMATE, \&c.}

Although the mulberry flourishes most luxuriantly in a moist and rich soil and protected situation, yet the leaves which are produced in such soils are more crude, and not of a quality so nourishing. The growth of the tree in such soils and expositions, besides being more rapid, is prolonged to a later period in autumn, or until suddenly arrested by frost ; and the immature wood of a forced growth, being more tender, is consequently more liable to be killed by early frosts and by winter. Such appears to have been the case in the winter of 1831-2, which destroyed so many full-grown trees of the hardiest 
description, even to the root. The ravages of that destructive winter seem to have been confined to particular situations and soils; to the productions of the forced growth of a summer not less uncommon and extraordinary.

In a state of nature, and in the shades and protection of the forest, or of herbage, the growth of the young tree being slow, and the wood completely matured in due season, the case is far otherwise; the bountiful covering of moss, of herbage, or of leaves, with which provident nature clothes the ground, being amply sufficient to modify the growth of the plant, and defend, at the root. This protection, like the fleecy snow, being twofold, it defends alike from the blasts of sudden and excessive cold, also from the still more destructive and pernicious rays of the sun. These remarks are equally applicable to the very young trees of the different varieties of the mulberry, to those especially which late in autumn have been transplanted to new positions, or the forced trees of but a single summer's growth : defenceless, unprotected, and all exposed, on an unsuitable and naked soil, they meet the frosts of autumn and of winter unprepared.

A dry, sterile sand is unsuitable ; and a shallow soil on a foundation of clay produces leaves of bad quality. In low, rich grounds, and extensive plains or prairies, near ponds, and in the valleys of rivers, the mulberry tree indeed grows most vigorously, yet the leaves being more watery, though voraciously devoured, they prolong the labors of the insect by inducing weakness, and injure the quality of the produce. These grounds are alike exposed to the destructive frosts of winter and of summer: the moisture of the atmosphere in such situations causes the leaves to become spotted and to mildew, and the leaves thus infected, if given to the insects, are the sare sources of disease and of death.

Sunny expositions and the declivities of hills, those especially which slope to the south, east, or west, are favorable. The cocoons of mountainous countries are deemed superior to those of the plains; although not so large, they are usually of a whiter color. Plant the mulberry tree on the high uplands, and on the hills, for here they are neither exposed to suffer from the early and the latter frosts, nor are the leaves liable to become spotted or diseased from the mildew; and from these combined causes, the growth of the tree will be consequently prolonged for a double length of time.

Prepare the soil by suitable nutriment, to the depth of eighteen inches beneath the tree, and to a proper distance around. The roots of the mulberry tree strike downwards; other plants may therefore be profitably cultivated beneath its shade, which is not deemed pernicious, the whole ground being kept as a garden during the first years.

The proper soils for the inulberry tree are "dry, sandy, or stony." And trees growing on $d r y$, sandy, or stony soils, and situated on the open plains, and on hills the most exposed to cold winds, will be found to suffer least of all from the destructive frosts of autumn and of winter. With all authors I must agree in recommending a soil of but moderate fertility, and least of all a cold, moist, and heavy soil, on a clay foundation, or even a very rich soil; a dry soil, on a friable subsoil, on gentle elevations or declivities, being the most suitable of all for the mulberry from China.

Land of middling quality will answer admirably - land less calcu- 
lated for other profitable cultivation. Land half covered with rocks may be profitably covered with mulberry trees, which will here find ample moisture, and nourishment, and warmth, from the direct and reflected rays of the sun.

By cultivsting the mulberry tree in hedge-rows, the ground will, in a short space of time, produce double the amount of food which can be obtained in any other way. And an equal amount of leaves may be gathered from the trees in hedge-rows, at less than one half the labor and expense which would be required from standard trees. It is thus that the mulberry is cultivated in China; in autumn their hedges are annually cut down to near the surface of the ground, for the production of a new and more luxuriant crop of leaves in the ensuing season.

In Persia, as we are informed, the trees are kept low, and not suffered to rise over six or eight feet in height. Broussa, a-city of Turkey, at the foot of Mount Olympus, is famous for its silk, snd is surrounded by mulberry plantations. The trees, says Commodore Porter, are planted in rows, not more than two or three feet apart, and kept pruned low for use, in the season for gathering the/leaves, so that a man may reach the top. At other places in this great silk district, the same system is pursued. In stripping the leaves, those at the tip ends of the twigs are always left. But, in hot countries, the silk-worms are fed wholly on prunings, as the leaves thus for a longer time preserve their needful freshness and moisture.

John P. Cushing, Esq., of Belmont, in Watertown, a gentleman who has resided many years in China, has stated that the most approved mode of cultivating the mulberry, as practised in that coun. try, consists in keeping them low by annual prunings, like plantations of raspberries. The same mode is also practised in India. This system of close planting and low pruning is in perfect conformity with the highly-approved node of management whieh is now so extensively adopted with the grape vine, in vineyard culture, in modern France.

During her residence at Broussa, Miss Pardoe visited the establislıments of the silk-worms, and made very particular inquiry as to the mode of feeding and management. The silk-worrns, as she states, are fed indiscriminately with branches of the red and the white mulberry, the last being preferred. The branches are strewed on the floor, and the silk-worms are never touched with the hand; the withered mass being never removed, and when ready to spin, osk boughs, about four feet high, are planted in the mass, like a miniature forest, and in their leaves the silk-worms form their cocoons. Every crevice of the apartment is carefully closed to exclude the admission of air, and a fire of "charcoal ashes" is constantly kept up throughout both day and night. Mesnwhile, as she states, it sppears certain that this mode of feeding and of management greatly increases the quantity of silk, and diminishes the labor of the feeders. This is the mode of feeding the silk-worms which produce, in the neighborhood of Broussa, an extraordinary quantity of silk. There is scarcely.a house in the neighborhood of Broussa which does not contain several apartments filled with silk-worms, whose produce is disposed of to the spinners, of which there are a considerable num. ber in the city.

In one day, and of those only which entered at one single gate of 
the city, and passed directly beneath her window, she counted upwards of two hundred individuals, each driving before him a horse, mule, or donkey, and bearing boughs and foliage of the mulberry, compactly loaded. These mulberries, covering the immense plain, are each year cut down to the trunk closely. In the height of sum. mer, the far-spreading mulberry woods assume the appearance of the locust-blighted landscape; every tree being left a branchless trunk, without a sign of foliage.

\section{CHAPTER VIII. - CLIMATE, HABITS, AND MANAGEMENT OF THE SILK-WORM.}

Wherever the mulberry finds a congenial climate and soil, there also the silk-worm will flourish; such a climate and soil, and such a country, is ours throughout its whole extent, from its eastern to its western shores.

The silk-worm is a native of China, a country famous from remote antiquity for its silk, and renowned for its industry, a parallel only to our own in all its various climates, and divers latitudes, in all its extraordinary vicissitudes of heat and cold. From China, also, we derive the tree, the essential food on which the insect most delights to feed. Transported to our slores, the silk-worm of Asia has here found a genial climate, a salubrious atmosphere, and the abundant pasture so well suited to all its wants. Wherever the Indian corn will mature its seeds, wherever the peach will mature its fruits, there also the mulberry and the silk-worms will flourish with extraordinary luxuriance, as in their native clime.

Serene skies and days of unusual brightness are the characteristics of our climate; those days of continuous heat, of brilliant light and sunshine, being necessary, and these alone being allsufficient duly to mature and to elaborate the juices of the leaves of the mulberry in all its varieties, thus converting them into the most healthy and nutritious food. Not every country is thus highly favored by nature.

In England, first of all countries for its agriculture, they cannot raise silk, how much soever they consume. There, owing to the coldness and humidity of their climate, as their latest writers assure us, the mulberry in all its varieties will not mature its leaf, so as to become the wholesome and nutritious food of the silk-worm. (See the popular Encyclopedia now publishing in London, article Morus.) Neither will the Indian corn mature its seeds, nor the peach ripen its fruit; in open culture, in that climate and country.

In Europe, they usually lose from 35 to 60 per cent. of their silkworms; the latter being the nsual loss among the peasants. And, according to M. Beauvais, while the French have usually lost near 50 per cent. of their silk-worms, the Chinese, according to their best historians, lose not one in a hundred: This is in a measure to be ascribed to their superior climate; but in part, also, it is justly due to their superior skill and management. In part, also, it may be ascribed to their rejecting, in the first instance and invariably, those 
few worms which hatch prematurely ; but principally their extraordinary success is to be ascribed to their subsequent treatment of the insects, and particularly to their modes contrived for the purposes of ventilation and the preservation of a high temperature and pure atmosphere, and to the great attention which they bestow on them; to their constunt and night feeding, as well as by day. Forty times during the first twenty-four hours are they fed, and thirty times on the second day, a less number on the third day, and a still less number on the subsequent days.

Aware of the immense importance of the silk culture to the interests of France, the government of that nation have established an experimental silk-farm at Montgeron, in the north of that country, nnder the superintendence of M. Camille Beauvais. Already, and previous to the year 1835 , by his extraordinary management, had M. Beauvais succeeded in producing thirteen pounds of silk from the same number of silk-worms which, in France, usually produce but five pounds, and in Italy seven and a half pounds, and in India twenty pounds, and even in that cold climate he then expected soon to be able to produce an equal number of pounds. In the year 1837 was he enabled to produce 185 pounds of cocoons from 2,000 pounds of leaves, a quantity which had been found sufficient for that same number of silk-worms, or for 40,000 , which, being of a aize so superior, must have been more than sufficient for the production of 20 pounds of silk. By him, also, the wants of the silk-worm having been made fully known by new discoveries, and these wants being all supplied, losses from disease are no longer known.

The silk-worm is a cold-blooded insect, its temperature that of the atmosphere in which it breathes; its evolutions being wonderfully quickened by heat, and prolonged by cold. 77 to 84 degrees of heat is its proper element, as now fully ascertained by $M$. Beauvais. Combined with this suitable degree of heat and of purity, $a$ certain degree of moisture in the atmosphere is indispensably necessary. In their native condition, the silk-worms are exposed to dangers continually, either from cold furious atorms, or from devouring foes. In such a temperature, and under the benign protection and care of man, they flourish with extraordinary luxuriance, completing their evolutions with great economy of time, of labor, and with augmented production, all their labors being brought suddenly to a close.

The habits of the silk-worm are peculiar to itself, both in regard to the time of taking its nourishment and its sleep. These habits differ essentially from those of the human race. The silk-worm takes no liquid with its food, except only what is contained in the fresh leaf on which it feeds. If neglected, or fed only at long intervals, and during the day, even though at such times fed abundantly, a large proportion of the food is thereby wasted. The leaves thus, for a long time exposed, becoming dry, the silk-worms refuse to eat, suffering irrecoverable injuries by day, and also during the long night, both by reason of hunger and tormenting thirst. They suffer doubly, also, from the voracity with which they then devour their food in the morning. But by fresh feeding, at short and frequent intervals, by night as well as by day, the food is all devoured, and half the quantity will suffice, none being wasted; and half the expenses of gathering the leaves and of cultivation being saved; even less 
than one hundred pounds of leaves thus fed, being found amply sufficient for the production of a pound of silk. The cocoons thus formed will be large and heavy, the thread or filament substantial and strong, not liable to break in reeling, thus causing neither trouble nor waste. And eight pounds of cocoon of this superior size, will, with careful and skilful reeling, produce a pound of raw silk; and in the manufacture of this silk the waste will be exceedingly small.

The silk which is produced by the silk-worm is formed wholly from the excess of food suddenly consumed, over and above what is necessary to sustain life, as is also the fat of animals; and the same principles, in regard to feeding, are alike equally applicable; in both cases the true economy and great profit being the result of full and constant feeding; a certain amount of food and liberal supply, and this rightly administered, being indispensably requisite completely to fatten the stall-fed ox during the accustomed period of a few months. But if this same quantity of food were parsimoniously given to this same animal, as its only subsistence, even during one whole year, the effect would be lost, and the animal, thus ill fed, would, at the end of this prolonged period, still remain the same lean beast as before. In the former case, the profit from feeding, to the owner, might indeed be very great, but in the latter case, quite the reverse; as, independently of the great loss of time, the whole labor of feeding is also lost, and all the amount of food thus bestowed.

The days devoted by the silk-worms to sleep are those of their moulting, or changes; and except they sometimes pause for a few moments, at all other times their sleep must be but transient, if, indeed, they ever sleep at all at any other time. In its native condition, the fresh leaf of the mulberry becomes its permanent abode. From the first dawn of their existence they eat almost continually, except only on those particular days, and until they begin their cocoons, when they eat no more, but work incessantly during three days and three nights; until, this their last work being finished, they no longer work any more, but, entering the chrysalis state, they slumber profoundly for a season.

\section{CHAPTER IX. - PROFITS OF THE SILK CULTURE IN FRANCE AND ITALY.}

The profits of a crop of silk are usually indicated by the size and quality of the cocoons. If the cocoons are very large, like the products of the well-cultivated and highly-fertilized fields, it portends a profitable and abundant harvest.

One of the most celebrated of all the English writers on the useful arts, and on manufactures, is Dr. Andrew Ure; and on agriculture, one of the most distinguished is M. Puvis, president of the Agricultural Society of Ain, in France; the subject of silk having been fully investigated by both, both writers being especially of the latest day, and both having in their remarks a particular reference to France. "In a great part of that country, the soil and cli- 
mate being favorable, both authorities concur in stating, that the planting of the mulberry trees and the raising of silk-worms, are, in this day, the most profitable of all agricultural pursuits.

The mulberry tree, says Dr. Ure, is valued. in Provence at from $6 d$. to $10 d$. sterling each, (or 12 to 21 cents, ) or, this being its cost at the age of four years, at which time they are transplanted; they may be stripped of their leaves in the fifth and sixth years, or three years from the time of grafting, and the seventh year it yields leaves worth one shilling sterling, or twenty-two cents; and they go on increasing for twenty or thirty years, when the leaves bring thirty shillings, or $\$ 7,20$. Large trees in the south of France will yield three hundred pounds, or, according to Dr. Ure, a tree will yield from one hundred to three hundred pounds, according to its magnitude and mode of cultivation.

The cost of cultivation is one franc (eighteen and a half cents) per hundred pounds. The average cost of leaves, in good years, is three francs, or fifty-five cents per hundred pounds on the trees, in that country.

The silk husbandry in France, is coinpleted in six weeks from the first of May; thus affording the most rapid of all. agricultural returns, and requiring only arsmall advance of capital for the purchase of the leaves.

- Cocoons are found to lose"seven and a half per cent. in weight, in the first ten days, by the perspiration of the chrysalides. The proportion between the weight of silk which can be reeled, and that of the coarse floss which can only be spun, is found to be in the average proportion of nineteen to one in perfect cocoons. But this does not include the outer floss, of a loose, furzy texture, which can never be reeled.

1,000 onnces of perfect cocoons have been found to produce $150 \frac{1}{2}$ ounees of pure cocoon. Thus every perfect ball, as soon as completed, contains more than one seventh part of pure cocoon; but this includes the floss and the pellicles. The length of the filament is usually from 500 to 1,200 feet. Count Dandolo states that it seldoin exceeds 1,875 feet.

Count Dandolo has stated, that twenty-one pounds of leaves, with economy in feeding, will produce one and a half pounds of cocoons. Again he has stated that, in Dalmatia, he has procured one and a half pounds of cocoons from fiftecn pounds of leaves.

In 1814, which was considered a season extremely unfavorable for silk-worms, Count Dandolo obtained fifteen ounces of very fine silk frem seven and a half pounds of cocoons; and from the same weight of refuse cocoons he obtained thirteen ounces. These extraordinary cases are stated only to show the result of good and right management.

At Cevennes, where the finest silk is produced, and where the coenon is cast out, when seven eighth parts are reeled, thirteen pounds of cocoons, of a thread of four or five cocoons, are required for a pound of the purest silk in the world. .

The silk of Cevennes, in France, is probably the finest in the world. I have particularly stated the mode in which it is reeled, for to this cause, in a measure, it owes its celebrity. There is indeed one kind which is sold at Lyons for from $\$ 1,42$ to $\$ 4,64$ the English pound; but there is a kind still finer, which brings $\$ 9,60$ a pound. 
Four hundred thousand pounds of silk of superior quality was raised in Cevennes in 1832, and since that period, this quantity has been greatly increased; as, among all employments of capital, none is so productive as the mulberry tree. It was yielding, at the above period, from fifteen to twenty per cent. profit to the intelligent agriculturist. Thus states Dr. Ure.

There is a description of white silk, which is produced in the department of the Upper Ardèche, which is of a quality so superior, that it is purchased by the lace manufacturers of Normandy, for more than fifty francs $(\$ 9,20)$ a pound. But a few years since, it commanded a price as high as 150 francs a pound, (equal to $\$ 27,60$.)

The pound of silk, when well reeled, is capable of being converted into sixteen yards of the ordinary quality of $\mathrm{Gros}$ de $\mathrm{Na}$ ples, or into fourteen yards of the first quality, and worth its weight in silver.

The expense of reeling the excellent silk of Cevennes, which is but of four to five cocoons to a thread, is, according to Dr. Ure, but three francs and fifty centimes per Alais pound, which is equal to ninety-two one hundredths of a pound English, for reeling silk of this superior quality. This is about equal to sixty cents per English pound. In Italy, and during June, July, and August, a woman attending the kettle, and a girl to turn the reel, they work sixteen hours in a day, and' then they 'wind a rubo, or ten pounds' weight of cocoons, which yields from one fifth to one sixth of their weight of silk, when their quality is good; the whole expense of reeling amounting to $2 s$. $6 d$. sterling per English pound; (equal to sixty cents.) Such are the statements of Dr. Ure. 'There, as in France, one person attends the pans, while another is employed in turning the reel.

In most agricultural operations, and in manufactures, there is great saving, both of labor, of time, and of all things else, when these are managed on an extensive scale : silk is by no means an exception to this general rule, as this same system of $\mathbf{M}$. Beauvais most fully proves; so also the Comte Dandolo had taught before. That silk may be cultivated to profit on every farm and domestic establishment, however small, is a truth now established beyond dispute. Those distinguished masters have also proved, that, when skill and science have come in aid, the silk business may be carried on to profit far greater in large establishments and on an extended scale.

\section{CHAPTER X. - SYSTEM OF M. CAMILLE BEAUVAIS.}

At the Government Establishment, or experimental silk-farm, near Montgeròn, in the north of France, M. Camille Beauvais, the superintendent, has adopted, with signal success, the more complete system of ventilation and of warming the apartments, invented by M. D'Arcet.

By this system, a high temperature being at all times preserved, the silk-worms are fed twenty-four times a day, for three days, during the first age, eighteen times a day during the second age; twelve 
times a day during the third and fourth ages; and eight times a day during the fifth, or last, and longest age, during which they eat many times more than during all the previous ages - the most perfect cleanliness and a pure atmosphere being at all times preserved as indispensable.

In conjunction with this high temperature and continued feeding, a certain degree of moisture or constant dampness is indispensable ; since it is found that a drying heat has the effect, not only to absorb suddenly all the moisture of the leaves, thus rendering them unfit for food, but to absorb slso the moisture from the lungs and bodies of the insects. With a temperature of $81^{\circ}$ to $84^{\circ}$ of $\mathrm{Fahr}$., a degree of moisture must be preserved, equal to from $85^{\circ}$ to $89^{\circ}$ of Saussure's hygrometer. Without this suitable degree of moisture, a high temperature was found by $M$. Beauvais to be utterly destructive. The same destructive effect, it is well known, is produced on the hnman system from similar causes. By this system of management he has also ascertained that the worms eat more, while the consumption of leaves is diminished, becsuse they make much less litter and waste; the education being completed with a very grest saving of time, and, consequently, economy in all things. So great was this saving, that, in 1836, the whole process was completed in twenty-one days, while in a common temperature it lasts usually from thirty-one to thirty-three days.

\section{CHAPTER XI. - M. D'ARCET'S SYSTEM OF VENTILATION.}

The salubrious Magnanarie, or healthy cocoonery of M. D'Arcet, is described as consisting of an oblong building with four ranges of hurdles; in the end is a brick flue or chimney, and near this the ap. paratus for warming the apartments, when required, is placed, in the cellar. This may consist of nothing more than a common cast-iron box stove, the stove a little elevated. This stove is surrounded on all sides, except the front, with a single wall built up roughly of brick work, as high as the floor, leaving a space of about a foot, on three sides of the stove, with a few openings at the bottom of the brick wall, for the admission of cold air from without; this space forms the air-chamber. The stove pipe rises a few feet; then, descending within this narrow space, it passes off horizontally through this brick work into the chimney. A little fire being kindled within the stove, the cold air within the air-chamber, becoming heated, rises to the top; thence dividing into four main branches, it is carried, by four main horizontal tubes of wood, beneath the floor, and directly beneath the hurdles. From these wooden tubes the heated air is permitted to escape upwards through the floor by numerous holes or openings, which are about two and a lialf feet asunder: these holes are of unequal size, the first being about an inch square, the size of each gradually increasing, as the current diminishes continually as it proceeds. In the garret, corresponding wooden tubes are used, with holes opening downwards through the ceiling. These tubes, uniting in one, enter the chimney; these carry off the impure or cold air of the whole apartment. Near the chimney, and in the garret, and connected with these tubes, is a fan-wheel or 
blower, of thrice the dimensions of the wooden tubes, in excessive hot and calm or sultry days, when not a breath of air is stirring. By this simple process, artificial currents may be at any time produced, and a hot, impure, stagnant atmosphere is speedily drawn out; fresh, cool, and pure air, rising through the openings from beneath, until the whole interior air is completely changed. I must observe, that, in warming the apartments by this mode, it is absolutely necessary that a small portion of moisture or steam should be infused along with the heated air. The silk-worms require it.*

In most of our northern cities, at this day, numerous private dwellings, and public houses and churches, and most of our great manufactories, are warmed in this way, by currents of heated air from the cellar; this being the most economical and perfect mode which has hitherto been devised. But during the calm and sultry days, and days of excessive heat, in some parts of India, the apartinents of the opulent are refreshed by cool breezes artificially produced, a man standing at the door with a vast fan.

It has been very lately stated by Dr. Ure, that the five-guinea fan of Messrs. Lillie and Fairbairns operates to admiration. In some of those vast manufactories of Manchester, where its use has been introduced, the whole impure and unwholesome air is completely and suddenly expelled and driven out, its space being supplied by air, pure, fresh, and wholesome.

The Thermometer is an instrument of the most simple kind, which measures the degrees of heat and cold with as unerring certainty as a watch measures time. A child may learn its use in a moment, and be able to teach its use to thousands. It consists of a small bulb of glass, of the size of a bullet, connected with a small glass tube : the bulb and part of the tube being filled either with quicksilver, or with pure alcohol, double distilled from purest rum or brandy, the'top of the glass tahe is hermetically sealed, by melting the glass, by aid of a blowpipe, in the blaze of a lamp; a scale of thin brass, iron, or wood being now added, it is graduated by another thermometer. As the heat of the atmosphere increases, the spirit expands and rises in the tube; by cold, the spirit contracts and descends. The cost of the instrument need not exceed a dollar, and it can never get out of order. In regulating the temperature of apartments, of baths, in evaporation, and in distillation, its use is necessary, and in breweries and in hot and green-houses it is indispensable. They are found in the mansions of our citizens in every town and village of our land; and those gentlemen who, while they approve, yet discourage the use of this instrument, have egregiously mistaken the character of our countrymen. Eminently useful as it is, they will both know and possess the instrument.

The Chinese regulate the temperature of the apartments devoted

* Flame fires are not approved for giving warmth to the apartments of the silk-worms, in recent practice. They do indeed promote circulation, but they scoreh the air. An iron stove heated to redness burns the vital air, consuming the oxygen as much as does burning charcoal; although it may emit no mephitic vapor, yet it reuders the air obuoxious to men and all animals that breathe. 
to their silk-worms, wholly by their own sense of feeling - a very uncertain mode. With them the use of the thermometer for measuring heat and cold, is as little known as is the watch for measuring time.

Thermostat. The thermostat serves to control and to modify the temperature. Letters patent were granted to Dr. Andrew Ure, of England, for an instrument of this kind, in 1831. It is formed by firmly uniting, face to face, two long, thin slips of metal, of different expansibilities; one formed of steel, and the other of hard, hammered brass, both firmly riveted or soldered face to face, is found to answer well. Sueh a compound bar is found to warp or bend more or less, according to the degrees of heat or of cold, and may be made to operate in various ways. When formed in the shape of a ring or hoop, but not closed, by the unequal expansion or contraction on either side, it opens or closes more or less by cold and heat; and, finally, being employed as an agent for the opening of valves or stove registers, or air ventilators, \&ce, it serves not merely to indicate, but to control and regulate the temperature of the apartment.

$\mathrm{Mr}$. Loudon states, that instruments for this purpose have been in use, latterly, in England, for regulating the temperature of hothouses; and as the temperature can never remain long perfectly stationary, those registers or ventilators are found to open or shut continually, almost every moment of time.

Tнг HYGrometer is a very simple instrument, to ascertain the moisture of the air. A piece of sponge will make a good hygrometer. Let the sponge be washed in pure water, then dried, and then let it be washed in a solution of sal ammoniac, or salt of tartar and water, and again dried. If the air becomes moist, the sponge will grow heavier; but if dry, the sponge grows lighter. It may be attached to a beam like a steelyard, with an index, which will rise or fall with every change. Saussure's hygrometer is deemed one of the most perfect.

Hornzes are usually formed either of thin boards or of wicker, but those formed of twine netting, with meshes five eighths of an inch asunder, have been much approved. In the first ages, finer hurdles of brass wire have been used and preferred. These hurdles are placed an inch above others, formed of boards or of laths covered with stout paper. When the leaves are placed on the netting, the worms ascend, and the litter falls through. These hurdles slide, and are arranged in stages one above another, about fourteen inches asunder. The chrysalides in the cocoons are destroyed by exposing them on sheets to the noonday sun for a few hours, or in a confined room of glass,-exposed to the sun; or they may be stifled by the fumes of burning charcoal, or by other modes. But the very best way is, if possible, to reel the cocoons as soon as formed. The reel most highly approved is the reel of Piedmont. The operation by this machine is the most perfect; the threads having a lateral motion, no two being laid in the same place, otherwise the gum with which they abound would cause adhesion, and spoil the silk. In the reel of Piedmont, the threads are wound spirally along the reel - the thread comes not in exactly the same place until after more than 2,000 revolutions of the reel. Its operation and construction are simple, but of the most perfect kind. 
A SYNOPTICAL TABLE,

PUALAHED AY DIRECTION OF THB FAENCF MINIgTER OF COMUERCE AND

AGRCULTURE,

Shoning THE MOST RAPID PROCESS FOR REARING SILK WORMS, according to the Plan of M. Camille Bravvajs, connected with D'Anczx's Method of Ventilation; by B. DE LA Gravaz, Student of C. Bzaurars. Translated from the French, in 1839 , and frot published in America by W. Crx $\mathbf{X}$. A ND Brothres, Conductors of "The American Silk-Cronoer and Farmer's Manual," Burlington, $\mathcal{N}$ : $\boldsymbol{J}$.

Hatchina ex Antryrcial Heat. - 1at day, from $70^{\circ}$ to $72^{\circ}$ Fahrenheit; $2 \mathrm{~d}$ day, $75^{\circ} ; 3 \mathrm{~d}$ day, $77^{\circ} ; 4$ th day, $79^{\circ} ; 5$ th day, $82^{\circ} ; 6$ th day, $84^{\circ} ; 7$ th day, $86^{\circ}$. Hatched this day. The moisture of the atmosphere, as iodicated by the bygrometer of Saussure, was from $70^{\circ}$ to $85^{\circ}$.

\begin{tabular}{|c|c|c|c|c|c|c|c|c|}
\hline \multirow[b]{2}{*}{ 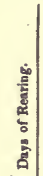 } & \multirow[b]{2}{*}{ 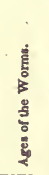 } & \multirow[b]{2}{*}{ 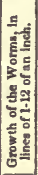 } & \multirow[b]{2}{*}{ 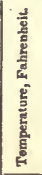 } & \multirow[b]{2}{*}{ 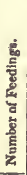 } & \multicolumn{3}{|c|}{$\begin{array}{l}\text { For one ounce of Eggs, } \\
\text { about } 40,000 \text { Worma. }\end{array}$} & \multirow[b]{2}{*}{ DAILY ATTENTIONS. } \\
\hline & & & & & 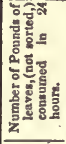 & 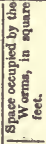 & 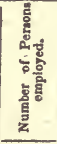 & \\
\hline 1 & 1 & 8 & $86^{\circ}$ & 24 & (a) 1 & 2 & 1 & The worms are taken \\
\hline 2 & 2 & & $84^{\circ}$ & 24 & & $" 6$ & 1 & batching-room to the cocoonery. \\
\hline 3 & 3 & & $82^{\circ}$ & 24 & (b) 4 & 6 & 1 & Cleansing and dividing by \\
\hline 4 & 4 & & $79^{\circ}$ & & (d) 1 & 10 & 1 & means of nets. $(c)$ \\
\hline 5 & 1 & & $77^{\circ}$ & 18 & (e) 8 & "6 & 1 & Cleansing. \\
\hline 6 & $<$ & & $77^{\circ}$ & 18 & 11 & "6 & 1 & \\
\hline 7 & สี & & $77^{\circ}$ & & 1 & 20 & 1 & \\
\hline 8 & 1 & & $77^{\circ}$ & 12 & 7 & 4 & 1 & Cleansing and dividing. \\
\hline 9 & 2 & & $77^{\circ}$ & 12 & 15 & " & 1 & \\
\hline 10 & 3 & & $77^{\circ}$ & 12 & 40 & $"$ & 1 & Cleansing \\
\hline 11 & मे & & $77^{\circ}$ & 12 & 30 & 6 & 1 & \\
\hline 12 & 5 & & $77^{\circ}$ & & 3 & 50 & 1 & \\
\hline 13 & 1 & & $77^{\circ}$ & 12 & $(f) 40$ & 6 & 1 & Cleansing. \\
\hline 14 & 2 & & $77^{\circ}$ & 12 & 65 & 46 & 1 & \\
\hline 15 & 4 & & $77^{\circ}$ & 12 & 100 & “ & 1 & Cleansing and dividing. \\
\hline 16 & 岳 & & $77^{\circ}$ & 12 & 67 & “ & 1 & \\
\hline 17 & 5 & & 770 & & 5 & 120 & 1 & \\
\hline 18 & 15 & & $77^{\circ}$ & 8 & (g) 70 & $u$ & 2 & Cleansing. \\
\hline 19 & 2 & & $77^{\circ}$ & 8 & 130 & " & 2 & Cleansing. \\
\hline 20 & 3 & & $77^{\circ}$ & 8 & 200 & “ & 2 & Cleansing and dividing. \\
\hline 21 & 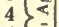 & & $77^{\circ}$ & 8 & 340 & “ & 2 & Cleansing. \\
\hline 22 & Е & & $77^{\circ}$ & 8 & 460 & 46 & 2 & Cleansing. \\
\hline 23 & 6 & & $77^{\circ}$ & 8 & 300 & 300 & 2 & Cleansing. \\
\hline 01 & 7 & & $77^{\circ}$ & 8 & 100 & & 2 & Branches are put up for the \\
\hline & & & & & (i) 2000 & & (h) 31 & coons on. \\
\hline & 6th & & $77^{\circ}$ & & & & & Gathering cocoons. \\
\hline
\end{tabular}

The worm changes into a chrysalis Immediately after it has fioished its cocoon.

( 7 th $/$ The room where the moths come out, which is on the 40 th day, Age. $\}$ should be darkened. After they have come out, the males and females should not be allowed to remain together more than 8 or 9 hours.

The females lay their eggs immedietely efter separation, each one of them laying from 300 to 500 ; they are deposited on cleun white cloth or paper. After leaving them 15 or 20 days in the place where they were laid, they are put into a cellar of the temperature of $45^{\circ}$ or $50^{\circ}$ of Fahrenbeit, until the following year, care being taken to look at them occasionally. 


\section{OBSERVATIONS.}

- (a) During the first three ages, the leaves should be cut very fine, and, instead of distributing them with the hand, much time would be saved, and the distribution made-more equally, by using wire sieves, with meshes about $\frac{3}{4}$ of inch square.

(b) Between the moultings there is always an increased appetite, especially in the last age.

(c) The cleansing consists in removing the litter from under the worms; and the dividing, in spreading them so as to leave a space between them equal to their owu size. During the last ages, two hurdles are filled from one. Dividing is effected by means of uets, with meshes-? of an inch square.-

(d) At the approach of each moulting, the worms raise and toss about their heads, and their appetite diminishes; it is not necessary then to spread léaves, except on those which have not ceased eating; and when they are all at rest, the feeding may be stopped entirely.

(e) After moulting, it is necessary to increase gradually the quantity of nourishment, in proportion to the increased appetite of the worms.

(f) During the fourth age, the leaves are to be cut, but not as fine as before.

(g) At the fifth age, cease cutting the leaves.

The worms are known to be preparing to. spin their cocoons by the following signs: -1 . They discharge all the excremental matter contained in their bodies. 2: Their skins, and especially their feet, become transparent, and partake of the color of the cocoon they are to spin. 3. They wander about on the leaves without eating, and try to climb upon every thing they meet with, dragging after them fibres of silk.

-, (h) The number of days' work does not augment in proportion to the number of ounces of eggs, because, for 10 ounces 210 days are sufficient, and 1,100 days for 100 ounces.

(i) In 1837, M. Beauvais obtained 185 pounds of cocoons from 2,000 pounds of leaves, not sorted.

Each worm requires but 3 days to wind its cocoon; but it well not to take them down until 6 or 8 days, so that the latest worms may haye 72 hours, at least, to wind. The best-formed cocoons ought to be chosen to produce eggs. One pound of cocoons will produce an ounce of eggs. The rest are placed on hurdles until the kiling of the chrysalis, which ought to be done as soon as possible.

Sumary. The strongest indioation of success is afforded, when the several changes taking place during the existence of the worm, are performed with the greatest possible uniformity, as to time; and that this indication may be fulfilled, it is necessary to maintain in the cocoonery, 1. An elevated temperature, sufficiently moist, and uniformly diffused; 2. A brisk and constant ventilation; 3. A feeding, light, frequent, and regular; 4. The greatest cleanliness; 5 . At all times an active superiutendence.

\section{CHAPTER XII. - SYSTEM OF THE MISSES REINA, OF COME, IN LOMBARDY.}

This system has been fully described by $M$. Puvis; and from its simplicity and extraordinary results, it appears to be that, which, above all others, will be eminently adapted to our climate, and the requirements of our people. The estates of the Count Reina are 36 * 
situated about two miles from Come, in Lombardy, and the several cocooneries which are establislied on that estate, are nearly all superintended by his daughters in person Hence this is called the system of the Misses Reina.

When the suitable season arrives, the eggs of the silk-worms are placed in small linen bags, between two inattresses, which are not slept upon, which preserves them at an equal teniperature; and each day, these are visited for the purpose of giving fresh air. Thus situated, they usually begin to hatch in eight or ten days. After the eggs are hatched, the young worms are emptied into baskets lined with linen, and these, being removed to the cocoonery, are covered with coarse canvass, with wide meshes, or with paper pierced with holes sufficiently large to allow a grain of wheat to pass through. Young twigs of the mulberry, being placed over these, are quickly covered with the worms. The young worms should be kept near a stove, and a temperature of at least $77^{\circ}$ of Fahrenheit should be maintained in the cocoonery, which should in all cases be erected in a dry and airy situation.

During the first and second ages, the worms are fed ten times a day, with fresh leaves chopped very fine; sufficient being given to cover the worms. During the third and fourth ages, they are fed but eight times a day; the leaves being cut coarsely in the third age; but in the fourth, the leaves are merely sorted or separated from the stems and fruit. At the first moulting, the worms usually fast a day, and two days at the second moulting, nearly three days at the third, and a little longer at the fourth moulting; but a little food is usually given at the beginning of each change, for the support of those not sick. The space which is allowed by them for the silk-worms on the shelves or hurdles during the last age, is 652 English feet for the ounce of eggs, which yield them 75 kilogrammes, or 168 English pounds, of cocoons. This is double the space which is allowed by Count Dandolo, namely, 209 English feet, or 170 worms to the square foot, of the ounce containing 31,200 , which produce, with him, 121 pounds of cocoons French, or 135 pounds English. Yet the silk-worms may be congregated more or less compactly, according to the more or less perfect system of ventilation.

The temperature of the cocoonery, which is at first $77^{\circ}$, is reduced gradually to $73^{\circ}$ in the third moulting. At this time they partially open the ventilating holes during the warmest part of the day, and, provided the weather is warm enough, no fire is made in the stove. During the fourth age, all the ventilators are opened, and at the fourth moulting the windaws are kept, at least, half open. In the fifth age, and especially when the worms begin their cocoons, all the ventilators and windows are left open night and day, for the admission of pure air, be the voeather vhatever it may. And should there not be sufficient space to allow the air freely to circulate, a part of the worms are removed to other apartments; a perfect system of ventilation, a pure atmosphere, and sufficient space, being indispensable, especially during the fifth and last age, when, from the masses of food and of litter, and the copious transpiration from the bodies of the insects, noxious or pestilential exhalations particularly abound. These must be dispelled : neither can vast numbers of silk worms be congregated with perfect impunity by any other mode. 
By this system, the Misses Reina obtain crops which average 75 kilogrammes of cocoons (168 pounds) to the ounce of eggs; and, what renders this result still more extraordinary, with a consumption of only ten pounds of leaves to one pound of cocoons; this success being rendered the more remarkable, from the circumstance, that it extends alike through all the colonies of the estate of Count Reina, and the result having been equally as great during every year for many years past, including all seasons, both good and bad.

Silk is, without doubt, destined, ere long, to become one of our greatest resources of national wealth, as it is also, at this day, in France and in Italy. It is believed that few additional improvements are now wanting to cause the scale, in the silk cultore, favorably to preponderate, and even to out-rival that of cotton. What was cotton before the invention of the Cotton Gin? Nothing. What is it now? Wonderful to relate.

In America, the culture of silk is progressing rapidly, and is fast becoming established on a sure and lasting foundation, At many of the establishments since early in 1841, the silk-worms are fed and managed on the system of Edmund Morris, Eisq., of Burlington, New Jersey, and with a success the most perfect and extraordinary. Mr. Morris is a gentleman extensively known for his practical knowledge and writings on silk. In some particulars, his system resembles that which is practised so successfully in the vicinity of Constantinople, as already described by Miss Pardoe and Commodore Porter; his being a very high improvement on that system. It dispenses with all trouble in cleansing, and makes a saving of full half the expense of feeding by other modes, while the silk-worms by this system are exempt from disease. Parts of this system are secured to Mr. Morris by patent, and these rights are disposed of by him, either to individuals, or to counties, or to states, at exceedingly. low rates; and every necessary information is furnished by him gratuitously. By this system, the silkworms are fed on the fresh twigs of the mulberry almost exclusively; by these also, they are readily removed in vast numbers. In the last age, they are fed exclusively on the feeding frames, which are of very simple construction, being formed of a single layer of straw, which is thinly secured to its place. These slide in grooves formed in upright stanchions. From these feeding frames the silkworms rise at the suitable time, and form their cocoons on the under side of other frames, similarly formed of straw, and placed over a foot above. These last, being covered with sized paper, serve also the double purpose of roofs; they defend from the continual fallings from other feeding frames, which are placed but a few inches above

\section{INSECTS.}

\section{(See also Insects, p. 49i)}

Pyroligneous Acid is not only destructive to insects, but protects the bodies of trees, to which it is applied, even from their approach.

Самpнor is powerfully repulsive, from its strong odor.

Bitter Aloks. Plants, according to Mrs. Tredgold, are com- 
Fletely protected against insects, by washing them in an infusion of bitter aloes, which does not in the least injure the plants; and the effects of a single application are stated to be lasting.

Flame Fires. Samuel Preston, of Stockport, Pa., has successfully destroyed insects in his garden and melon grounds, by flame fires of shavings, at night; the giddy insects rush into the fire from all quarters. He is satisfied that one shilling's worth of labor in an evening will secure a garden from their depredations, if not in time exterminate them. Fuel suitable may consist of the mowings of brush pastures or road-sides.

Flambeaux.. Dr. Harris recommends, as effectual, to wind round the end of a stick, about a foot and a half long, old rags and swingling tow, dipped in tar or melted brimstone; let this be stuck in the ground and set on fire; it will burn a considerable time, and prove the funeral pyre of myriads. Staves of tar barrels might probably answer as well.

- Certain trees and plants are peculiarly offensive to insects generally. Such are the Virginia Cedar, the Pennyroyal, and some others; and these being planted very near, or in contact with, the peach tree, and other plants which are obnoxious to their approach, have proved, in certain cases, effectually repulsive from their powerful odor.

Several other species of plants there are, besides the Red cedar, which, planted at the roots of the peach, and of other trees, which are liable to the attacks of destructive insects, may also prove equally repulsive from their powerful odor. Such are the tansy, and the Artemasia or Southern wood, both of which are perennial, and of the easiest culture; the first being raised by division of roots, the last by cuttings.

Forests and rivers serve, in a certain degree, to insulate, or to obstruct the march of the canker worms, of the curculiones, \&c. Thus it is, also, that in many. places which are partially surrounded by the sea, the destructive insects are not known.

Lastly, birds, of many kinds, are the natural foes of insects, from the multitudes which they devour as their principal food. Such are the crows or rooks, the blackbird, the robin, \&c.; and wherever bounties have been mercilessly offered for their destruction, the insect tribes have multiplied beyond all bounds, and gained the preponderancy, and those countries have, in consequence, and invariably, been visited with a curse. It has been computed that every crow or rook will consume a pound of worms and other insects in each week, during the whole season - a vast number, which, otherwise, would have become the parents of millions. The blackbird and the robin, together with their young, devour also a proportionate number. Incredible numbers of the butterflies or moths, the parents of the unnumbered millions of the caterpillars and canker worms, are destroyed also by the martin, and others of their tribe, which seize their prey on the wing.

In 1841, a premium was granted by the Massachusetts Horticultural Society to Mr. David Haggerston, for his discovery of an effectual remedy for the destruction of the rose-bug, and most other pernicious insects, which sometimes infest shrubs, and plants, and trees of the smaller size. The compound is composed of two pounds of train-oil soap, dissolved in fifteen gallons of water; the composition to be showered upon the trees or plants with a Willis syringe. 


\section{OF FENCES AND HEDGES.}

Mention has already been made of the $\mathrm{Ha}$ ! ha ! which is a wall constructed in the bottom of a dry ditch, and effectually concealed from the view on the interior side, or the side most exposed to view, by a lowly-graduated embankment to the top of the wall; this embankment being formed of the earth which was taken from the ditch, which is all thrown out on that side, and smoothly spread. In all those situations where division fences of any other kind would but intercept or destroy the unity and beauty of the prospect, such an invisible division wall is admirable.

A beautiful hedge may be quickly formed of the Larch; and those formed either of the Prim or of the Arbor-vitæ, or Red cedar, are eminently beautiful ; and particularly the last named, when, pruned in pyramidal form, they become remarkably compact and impervious. These are the plants which no insect or animal will devour. As to the English hawthorn and the Washington thorn, they are both obnoxious to the destructive attacks of the borer, and cannot therefore be recommended. The following plants form beautiful live fences, all being armed with thorns: The ThreeThorned Acacia, when properly trained; it is armed with triple thorns a foot long. The Shepardia is beautiful in the leaf, or when covered with its crimson berries. The Osage orange has a beautiful leaf, and a very strong thorn or spine, and makes the finest hedge in the world. It is a new species of Morus or Mulberry, and so classed by naturalists. It endures the winters well, on hills and elevated situations near Boston, but is sometimes liable to be injured in its tops by the winter, in low grounds and valleys. The Prickly or Thorny ash (Zanthoxylum fraxineum) has a good thorn: both this and the Buckthorn (Ramnus cutharticus) are of the most hardy character, will grow well on any soil, and no animal or insect can endure them. The thorns of the latter, as also those of the Shepardia, like those of the Pear tree, grow only at the extremity of the branches. The Buckthorn is deservedly a popular plant near Boston. Lastly, the Cockspur thorn (Crus galli) is of rapid growth, has a beautiful leaf, and a strong thorn or spine, and is very hardy. John Prince, Esq., of Roxbury, who has tried this plant as a hedge for more than twenty years, is persuaded that no borer will ever annoy it, and that it is the best of all thorns.

The hedge should be set out in the spring. In the autumn previous, the ground should be dug on the intended line, at least eighteen inches deep, and the yellow subsoil cast out to this depth, and the trench filled with rich soil intermixed with good compost. The young plants, which should have been transplanted in the previous year, are now to be sized, and reset in a single line, at the distance of nine inches asunder, and the ground kept in high cultivation for a few years. The next spring, cut down the deciduous thorns to within four inches of the ground, when two or three branches will start up with renewed vigor, growing several fect during that summer. But evergreen trees must never be thus cut down. In the spring following, if any of the plants have discovered a disposition to outgrow all others, let such, and such only, be again 
cut down, as before. The hedge should be pruned once a year only ; and the only suitable time for pruning deciduous plants is as soon as the buds have swollen in' spring; and as for evergreens, as soon as vegetation has fairly commenced. In pruning, use no shears, but only a sharp bill attached to a long handle, striking upwards, and giving to the hedge its desired form, exclusively by the eye; lowering the top a little at each annual pruning, and endeavoring to give to the hedge the form of a very steep roof, which form is ever to be preserved. Thns trained in the form of the quenouille, or distaff, as the hedge increases in height, so also it increases in breadth, all the branches experiencing in an equal degree the benefit of the sun and air, the falling rains and the dews ; it retains forever all its branches quite to the ground, standing impervious, like a pyramid on its base. Yet this is not the case where the sides of the hedge are pruned vertically; as, in this last case, the npper limbs, receiving, as they must, the chief and almost exclusive benefit of the sun and air, and falling rains and dews, they become the superior, and the lower limbs inevitably perish.

\section{DEEP TILLAGE.}

Owing to our remarkably transparent atmosphere, the sun, in our latitude, from its exalted elevation during sunmer, shines with peculiar brightness and intense heat; and droughts, which often and suddenly penetrate far below the limits of all ordinary cultivation, are of frequent occurrence. At such times, the trees and plants cease to grow, or become scorched with withering heat, and a pause in vegetation ensues, the best part of the summer being lost. The obvious and easy preventive remedy is deep tillage; or the earth must be loosened to the depth of at least eighteen or twenty inches, with the subsoil plough, and the operation repeated at intervals of three or four years, until the whole earth to this depth becomes of the same uniform fertility. The subsoil plough is of Scotch invention. It is formed of great strength, and chiefly of iron, without the mouldboard, and with a wing on each side. It is drawn usually by four oxen or horses, and follows in the bottom of a deep furrow, formed with the common plough. The subsoil plough serves admirably to stir and to loosen the subsoil to this extraordinary depth, without removing it from its place, or bringing the sterile earth to the surface. Thus broken or pulverized, the rains and the dews sink down, being readily absorbed, together with a due proportion of the richest juices of the manure; and the roots of trees and of plants now strike root downwards, deep into the soil, below the influence of all but very extraordinary droughts; where, finding permanent resources of nourishment, their growth continues uninterrupted and perpetual during the whole season. 


\section{G L O S S A R Y.}

1. Acuminate. Ending obtusely, with a prolonged, sharp point.

2. Alburnum. Sap-wood; the white, sof, cxterior layers of wood.

3. Anther. That portion of the stamen containing the pollen.

4. Aromatic. Fragrant; spicy.

5. Astringent. Contracting.

6. Axil. The angle on the upper side between the leaf and stem.

7. Axillary. Growing from the axils.

8. Berry. A pulpy fruit enclosing seeds having no capsules.

9. Calcareous. Containing lime.

10. Calyx. The outer covering of the corolla.

11. Cambyum. The concentrated sap or viscid substance which lies between the bark and wood.

12. Capsule. A hollow seed-vessel, which opens when dry.

13. Catkins. Flowers in tufts, arranged on a slender or flexible thread.

14. Cordate, or Cordiform. Heart-shaped.

15. Coriaceous. Resembling leather or parchment.

16. Corolla. The crown, which encloses the stamens.

17. Corymbs. Flowers having a flat summit, which is formed of numerous flower-stalks, which arise on a common stem, from different heights.

18. Crenate. See Serrulate.

19. Deciduous. Not evergreen; trees whose leaves fall in autumn are termed deciduous.

20. Dentate. Toothed; edged with large, sharp points.

21. Denticulate. Minutely dentate.

22. Drupe. A fleshy fruit enclosing a stone.

23. Genus. [The singular of genera.] A family of plants which agree in flower and fruit.

24. Glands. Small heads, or inflated bodies, which appear in different parts of plants or leaves.

25. Glaucous. Of a sea-green color.

26. Globase. Round or spherical.

27. Herbaccous. Not ligneous, or wrody.

28. Imbricate. Overlaying like scales, or the slating of a roof.

29. Lanceolate. Spear-shaped; both ends very acutely pointed.

30. Leaflet. A part or small leaf of the compound or pinnate leaf.

31. Liber. The inner layer of bark, which lies next the wood. The ancients wrote upon and formed their books of this substance; - hence the name. 
32. Ligneous. Woody.

33. Lobe. A large division of a leaf.

34. Nerves. Parallel veins.

35. Oboxate. Egg-shaped, with the smallest end towards the stalk.

36. Oval acuminate. Round at one end, pointed at the other.

37. Ovate. Egg-shaped.

38. Palmated. In the form of a hand with the fingers spread.

39. Panicle. A loose, irregular flower, subdivided into branches.

40. Peduncle. The stem, which supports the flower and fruit.

41. Pericarp. See Capsule.

42. Petal. The leaf of which flowers are composed.

43. Petiole. The footstalk, which supports the leaf.

44. Pinnate. Having two rows of leaflets arranged on a common petiole.

45. Pollen. The dust contained in the anthers.

46. Pome. A pulpy fruit containing a pericarp or capsule.

47. Pubescent. Hairy, or downy.

48. Raceme. Long clusters.

49. Reniform. Oblong, oval, or lengthened.

50. Rugose. Wrinkled.

51. Serrate. Notched in a manner resembling the teeth of a saw.

52. Serrulate, or Crenate. Minutely serrate.

53. Sessile. Attached to the stem without footstalks.

54. Species. The last or lowest division.

55. Spine. A thorn growing from the wood. Prickles grow freely from the bark.

56. Stamen. The outer circle of the slender filaments which rise around the centre of a blossom or flower.

57. Stigma. The summit of the pistil.

58. Stipule. Leafy appendages at the base of the leaves or petioles.

59. Suture. A groove, or channel.

60. Tendrils. The twining appendages of vines, by which they attach themselves to supporters.

61. Truncated. Having a square termination.

62. Umbel. Flowers having a convex summit, with numerous flower-stalks of equal length diverging from a common centre.

63. Variety. A subdivision of a species, or the lowest division. 


\section{N D E X.}

Agricultural nesources of
America, (Appendix) ....401

\section{ALMOND.}

Its History and Uses.......210 Great Double Flowering...211 Dwarf Double Flowering...211 Other varieties............210 American Citron...........311

\section{APPLE.}

Its Description and History .58

Its Uses.................58 To gather and preserve..59,106 Cultivation, \&c...............99 Of Pruning..............101 Insects, \&c. which annoy ..102 Cider..................108 Climate of the Apple, $58,81,85,97$

Varieties, American, and of Foreign Origin; adapted to our Climate, of the 1st and -2d Classes.

*Esopus Spitzenberg........70 American Golden Pippin....70 American Nonpareil........64 *American Suinmer Pearmain 61 Aunt's Apple.............64

*Bald win .................71

Baltimore.................71

Barcelona Pearmain........90

Beachemwell Seedling......90

*Beauty of the West.........7.71

Beau..................61

Belle des Quermes.........87

Belle du Havre............90

*Bellflower...................71

"Belmont. ..................71

"Benoni..................61

Beverly's Red...........84

Black Coal............72
Page.

Blenheim Urange........72

*Blue Pearmain............72

Borsdorfer...............91

"Boxford .................64

*Brabant Bellflower........64

Braddick's Nonpareil.......88

Bringewood Pippin.........88

Calville Rouge de Micoud...86

Canadian Reinette........64

Carthouse, or Gilpin........84

Chandler................72

"Chinese Double Flowering ..86

Craam .................73

Christie's Pippin............91

Cornish Gilliflower.........91

Cos Apple..............72

Court of Wyck...........91

Crow's Egg.............73

Cumberland Spice.........65

Curtis..................84

"Danvers Winter Sweet....773

D'Astems ................91

Delaware.................88

Domini ..................73

Downton Golden Pippin....88

Drap d'Or...............65

Duchess of Oldenburg......65

Dutch Codlin.............73

Dutch Mignonne..........91

"Early Sweet Bough.......6t

"Early Harvest.............61

Early Red Juneating......62

Easter or Pasque A pple......92

Emperor Alexander.......65

Fall Pippin................66

"Fameuse.................66

Fennouillet Gris..........92

$\underline{-}$ Jaune............92

Rouge..........92

Foxley.................96

Franklin Golden Pippin.....88

Gardner Sweeting..........73 


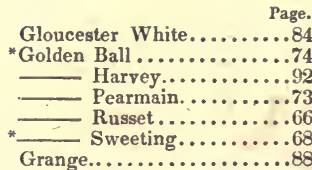

* Gravenstein .............66

Green Newtown Pippin....74 Nonpareil ...........92 Sweeting..........74

Gros Locart...............88 Hagloe Crab...............96 Hampshire Greening.......74 Harrison ...............82 Hartford Sweeting........75 Herefordshire Pearmain.....75 Hubbard's Pearmain........93 *Hubbardston Nonsuch......75 Hugh's Blush ...........76 James River.............84 Jenning's Sweet.........67 Jerusalem................93 "Jonathan .................75 "Kenrick's Red Autumn.....67

*Kilham Hill...............67 King of Pippins...........89 Kirk's Golden Reinette.....89 Lady Apple.............76 Large Yellow Summer.....62

*Late Pound Sweet.........77 La Violette...............95 Lemon Pippin.............76 Lippincot...............84 Lyman's Pumpkin Sweet...67

${ }^{*}$ Lyssoin .................667

*Mackay Sweeting.........76

*Maiden's Blush...........62

Margil ..................93

Marquis.................76

Martin Nonpareil ..........93

Mela Carla..............77

Mela de Rosmarino.........93

*Minister.................76

"Monmouth Pippin.........67

Monstrous Pippin.........77

Morgan's Favorite ........78

"Murphy................78

Newark King............68

Noble Pippin.............89

Norfolk Beaufin..........93

*Orange, or Golden Sweeting.68

*Orange Pippin............68
Page.

*Ortley...................78

Padley's Pippin...........89

Pear Rennet............94

Peck's Pleasant...........78

*Pennock's Red Winter......78

Pickman ...............79

Pigeon de Rouen..........94

Pine Apple Russet.........89

Priestley ................79

Prince's Table Apple....... 89

*Pomme Royal, or Dyer.....65

W Water.............68

de Lestre.........94

Princess ..........89

*Porter. ................6\%

Pownal Spitzenberg........79

"Pumpkin Sweeting........62

Putnam's Russet..........79

Pryor's Red.............84

Rambo, or Romanite......62

*Ramsdel's Red Pampkin

Sweet...............79

Rawle's Janiet............85

Red Astracan...........63

_. Autumn Calville.......68

*_. Ingestrie ............. 69

_ and Green Sweeting...68

*_- Quarrendon ..........63

Red Seek-no-further........80

Reinette Dorée...........94

. Franche ...........94

- Princesse Noble ...90

Triomphante.....95

*Rhode Island Greening..... 59

Ribston Pippin............80

*Roxbury Russet...........80

Royal Pearmain...........85

St. Lawrence.............63

Sapson's...............63

Sawyer Sweeting.........69

Scalloped Gilliflower.......80

Scarlet Nonpareil.........94

Perfume...........90

Seek-no-further ..........69

Siberian Bitter Sweet.......96

*ــ Crab, red.........83

$\longrightarrow$, yellow.......83

Harvey ..........96

"Sopsavine ..............663

"Spice Sweet.............69

Stroat...............69

Striped June Apple.......85

Summer Queen.........663 
Page,

Summer Rose............63

* Superb Sweet.............69

Swaar .................80

Sweeney Nonpareil........95

Sweet Russet.............70

Sykehouse Apple.........95

Taliafero...............82

Virginia Crab ...............83

- Greening .........85

Waxen Apple ............ 85

White Spitzenberg.........81

*Williàms Apple...........63

* Wine Apple.............. 81

* Winter Sweeting............81

White Calville......81

Wycken Pippin...........90

* Yellow Ingestrie...........70

Newtown Pippin....82

"York Russeting............70

Varieties of the $3 d$ Class, of high reputation in England.

These deserve trial in Canada and the northernmost States, and Oregon.

White Astracan ............97

Also, 56 others, of celebrated kinds, noted at pp, 98 and 99.

\section{APRICOT.}

Its History and Uses......212

Cultivation.............216

\section{VARIETIES.}

Alberge................213

Algiers. ...............213

Angoumois.............213

*Brussels.................213

*Cruft's Late Apricot.......213

Early Masculine.........213

Gros Musch............214

Hemskirke .............214

* Large Early..............214

"Moorpark ................214

Musch Musch..........214

Orange ...............214

*Peach Apricot............215

Portugal ...............215

Provence...............215

Roman.................215

Royal...................215

*Royal Persian ...........215

Turkey ................215

*White Apricot............215

BERBERRY:

Its History and Uses.......312

Chinese.................31:

Holly-Leaved..............312

Other varieties.............312

\section{BLACKBERRY.}

Its Uses, \&c.............313 Bush Blackberry............313 White Bush Bramble........313 Trailing Blackberry........313 Double Flowering Bramble.313

Bending limbs, causes fruitfulness, $44,49,173,205,280,327$

Canker Worm...........102

\section{CHERRY.}

Its History and Usea.....231

Its Cultivation, \&c........241

Classification ............232

Amber Cherry..........234 *Manning's Early White H. 234 "Bigarreau de Mai ........234 "Arch Duke..............238 Belle de Choisy............238 Belle et Magnifique.......239 Bigarreau de Rocmont.....234 ㄴ. New Large Black 225 Black Bigarreau of Savoy ..235 - Napoleon ........235 , White, or Graffion 235 *Black Eagle ...............2235 — Heart ............236 "Manning's Black Bigarreau 236 * - Tartarean..........236 Bowyer's Early Heart.....234 Colong Cherry ...........241 Double Flowering, Large ..240 D, Small ..240 Donble Flowering Serrulate 240 "Davenport's Early Black...233 *Downer Cherry...........236 Downton.............236 "Early Purple Griotte......239 Elton ................237 Florence ..............237 German Duke..........2239 * Gridley ...............237 Herefordshire Black......237 "Knight's Early Black......233 "May Duke..............239 Red Russian Cherry ......337 
Montmorency...........239

Morello.................239

*Plumstone Morello........239

Rivers's Early Amber Heart 234

*Sparhawk's Red Honey Cher-

ry .................237

Tobacco Leaf............240

Virginia Cherry .........240

Waterloo..............238

Weeping Cherry..........241

*White Tartarean.........2238

Chestnut................320

Chinquapin..............320

Cider.................108

Climate.......16, 58, 85, 97

\section{CRANBERRY.}

Its Uses and Cultivation...313

Cranberry Viburnum......314

Cross Fertilization.........32

Curculio...............53

\section{CURRANT.}

Its History and Uses......286

Cultivation and Pruning...288

*Black English..........287

Naples............287

* Large Red...............287

* W White ............287

Other varieties described...287

Cuttings ...............37

Debarking, its Effects......43

Decortication, or Girdling 42, 206,274

Dwarfing ..........46, 202

Elder..................315

Fences and Hedges....21, 428

Filbert...............321

Fruits, their Utility........23

$\longrightarrow$, Old, their Decline...25

Fruits, New, Page. they are produced........25

Fruitfulness, how induced $\mathbf{4 1}$ to $50,171,206,274,279,281,327$, 328.

Gardens, Landscape, or Modern ...............21

GOOSEBERRY.

Its History and Uses......2.288 Varieties described....289, 292 Its Cultivation, Pruning, \&c. .292

Grafting ...............39 Grafting the Vine........283

GRAPE VINE.

Its History and Uses.....243 To preserve Grapes.......244 Wine of Grapes......245, 281 Cultivation, Soil, \& G......262

Mode of training in France.264 atThomery 265

Training on inclined Planes and on Rocks .........277

Vinery of Mr. Wilmot....284 

Maladies..............283

FOREION VARIETIES.

Alicant ...............250

Aleppo................257

"Black Cape...............250

— Damascus. .........250

*—_ Hamburg . . . . . . ......251

*__ Wilmot's

New...............253

Loinbardy .........251

*__ Prince..............251

Raisin...........251

St. Peter's........251

Burgundy, Miller's .......252

*Chasselas, White .........246

*—, Golden.........247

$\longrightarrow$, Black ..........247

Musk ........247

$\longrightarrow$, Red...........247

, Variegated......248

"Constantia ...............252 
Page.

Early White Muscadine...254

Esperione ...............252

Frankenthal.............252

Frontignac, Black .......248



249

Gros Guillaume...........252

Gros Maroc.............253

Langford's Incomparable... 253

Malmsey Muscadine.......255

Muscat, Red, of Alexandria. 249

* White, of do....249

* Cannon Hall......248 , Wilmot's Early ...250

Pitmaston White Cluster...255

Poonah . . . . . . . . . . . . 253

Raisin de Carmes........254

Red Hamburg............254

"Seedling of Bloom Raisin..253

Scotch White Cluster......255

* Sweet Water, New Grove

End .................255

Syrian................255

Tokay .................256

Verdal ..................256

White Corinth..........255

Hamburg .........256

St. Peter's........257

AMERICAN VARIETIES.

Alexander..............257

Bland...................257

* Catawba ................258

Elsinburg ...............258

Isabella .................258

Luffborough...........259

"Norton's Virginia Seedling.259

*Prince Edward, Cunningham260

Prince Edward, Woodson..261

"Scuppernong ............261

Worthington ...........262

Growth of Trees...........34

Hedges and Fences........428

Inoculating.............37

Insects 52 to $57,102,178,315,427$

Introduction.............13

Layers..................37

Lime Plant............308

Medlar, varieties, \&c.......316 $37 *$

MELON.

Page.

Muskmelon, 20 varieties. . 308

Watermelon, varieties. ......311

Its Uses................ 311

Cultivation..............311

Mountain Ash, Uses, \&c...316

MULBERRY.

Description and Uses......242

Black Mulberry ........... 242

Red Mulberry ...........242

Cultivation..............243

For other varieties of Mulberries and their uses, see APPENDIx, 410.

NECTARINE.

Its History and Uses.......206

Cultivation .............209

FREESTONE NECTARINES.

Aromatic..............206

- Early Violet..............207

Elruge................207

Fairchild's Early.........207

Jaune Liase ...............2u7

-Lewis......................207

*Perkins's Seedling .........207

Pitmaston Orange........207

*Scarlet. . . . . . . . ........208

Temple's..............208

White, or Flanders........208

cLINGSTONES, OR PATIES.

Violette Cerise ..........208

-Golden...................208

Grosse Violette ..........208

Italian .................208

Red Roman............209

Scarlet Newington . . . . . . 209

Tawny Newington ........209

Vermash ...............209

Violet Musk ............209

\section{NUTS.}

English or Madeira Walnat.317

Its Uses. . . . . . . . . . . . 318

Black Walnnt, its Uses, \&c. 318

Butternut, its Uses, \&c. . . .319

Chestnut, its Uses, \&c..... . 320

Chinquapin. .............320

Shagbark, its Uses, \&c......321

Pacane Nut .............321

Filbert, its Uses, \&c... . . . . 321 
Page.

Varieties, Cultivation, \&c....322

Paving causes Productive-

ness ...............279

\section{PEACH.}

Its History and Uses. .....177

Wine of Peach. ...........179

Cultivation ............201

Insects which annoy......202

Pruning................204

An extensive Peach Orchard 204

Classification ............180

FREESTONE PEACHES.

*Beers's Late Red Rareripe.. 191

*Bellegarde.................185

*Belle de Vitry............ 191

Bonaparte ...............183

Brainard's Large Yellow....189

Buckingham Mignonne....186

* Burgess's Beauty ...........183

Cardinale ................194

China Flat Peach.........193

Columbia................189

*Cooledge's Favorite ........ 184

*Crawford's Late Malacatune 191

Double Montague.........185

Dwarf Orleans............194

*Early Anne .............. 183

*__ Crawford...........184

- Purple .............185

*__ Royal George........184

* _ Red Rareripe........184

* _ Robinson Crusoe .... 184

_ Rose ..............183

Emperor of Russia........185

* George Fourth.............186

* Golden Rareripe .......... 192

* Grosse Gallaude ........... 186

* Grosse Mignonne ..........186

*Heath ...................192

*Hoffman's Favorite.........187

Hogg's Malacatune ........ 190

Ispahan . . . . . . . . . . . . 193

*Jaques's Rareripe ..........187

"Lafayette Free.............190

*Malta.....................190

* Marie Antoinette..........187

*Mellish's Favorite.........187

* Monstrous Free...........187

*Morris's White Rareripe...187

Morrissnia Pound........192
Psge

Mountaineer.............187

*Nivette. . . . . . . . ............190

*Oldmixon .................. 188

*Orange Peach .............188

* President. .................188

*Red Magdalen.............188

Red Nutmeg.............. 182

* Robinson Crusoe, Late....192

*Sargent ..................188

*Smock Free..............193

* Snow Peach..............189

*Teton de Venus. ........... 194

*Tice's Early..............183

*Walter's Early.............183

*Washington .............. 189

White Malacatune......... 190

Yellow Admirable..........193

*_ Alberge ............185

*__ Rareripe............189

*__ Red Rareripe....... 190

Crass II.

PAVIES, OR CLINGSTONES.

Blood Peach.............197

*Catharine ................195

*Diana.......................195

Early Newington ..........195

Grosse Perseque ..........197

Heath Clingstone..........198

*Hyslop's Clingstone........ 197

*Lafayette.................. 195

*Lemon Clingstone... . . . . . . 195

Monstrous Pomponne...... 197

*Old Newington ............196

Pavie Admirable ........... 196 Jaune .............196 Magdeleine.........197

*__ Spanish ............196

Rodman's Red............ 196

*Smock Clingstone........... 198.

*Washington Clingstone....196

*Williamson's ............ 197

Crass III.

ORNAMENTAL VARIETIES.

Double Flowering Peach...198

Amygdalis Macrocarpæ....198 Orientalis......198

Crass IV.

Review of over 40 other fine Peaches, partly new kinds 199 


\begin{abstract}
PEARS.
Description and Uses.......115

To preserve .............115

Cultivation, \&c..........171

Old Pears..............117

New Pears.

130

[Pears I have divided into three Classes. 1st. The Old Class; these include all the descriptions of Duhamel and of Rosier, with a few others; some of which I have described, and some I have only reviewed.]
\end{abstract}

Class of Old Prars.....117 Ah Mon Dieu !..........120 Ambrette...............123 Ambrosia...............126 Amire Joannet...........117 Angelique de Bordeaux.....124 Angelique de Rome........124 Angleterre ..............121 Aurate.................118 Autumn Bounty ..........126 Bellissime d'Automne ......122 d'Eté ..........118 d'Hiver.........125

Bergamotte d'Automne....121 Cadette .......121 d'Eté ........120 d'Hollande ....126 de Pacques....124 Rouge -.......120 de Soulers.....125 Suisse ........121 Sylvange......126

Beurrée .................120 Bequesne................123 Bezi de Cassoy...........122 Bezi d'Heri............123 Bezi de Montigny.........121 Bezi de la Motte..........121 Blanquet d̀ Longue-Queue .118 Bon Chrétien d'Auch......128 Bon Chrétien d'Espagne....122 Bon Chrétien d'Eté .......120 Bon Chrétien d'Eté Musque 119 Bon Chrétien d'Hiver ......125 Bon Chrétien, Rushmore's.127 Broca's Bergamot.........127 Bourdon Musque...........118 Cassolette...............119
Page.

"Catillac .................128

Champe Riche d'Italie......124

Chaumontelle.............123

Chat Brusle ..............125

Cher à Dame.............119

Colmar .................125

Crassanne................122

Crassanne Panaché........127

Deux Têtes...............118

Donville .................125

Double Fleur.............125

Double Fleur Panaché ....128

Doyenné................121

Doyenné Gris ............122

Echasserie...............123

Elton .................127

* Epargne [Jargonelle]......118

Epine d'Eté..............120

Epine d'Hiver.............122

Epine Rose...............119

Fin Or d'Eté.............119

Fin Or de Septembre......120

Forelle................127

Franc-Real..............123

Frangipane.............121

Fondante de Brest..........120

Green Chissel ...........126

Green Pear of Yair........127

Grise Bonne.............119

Gros Blanquette Ronde ...126

Gros Hativeau ...........118

Gros Rateau Grise........128

Gros Rousselet ...........119

Hativeau................118

Holland Green...........127

Imperiale à feuilles de Chêne 126

"Iron .....................129

Jalousie..................121

Jardin ................124

Jargonelle, French ........119

Lansac..................121

Livre...................124

Louise Bonne.............122

Madeleine.................118

Mansuette...............122

Marquise................123

Martin Sec.............123

Martin Sire .............124

Merveille d'Hiver..........122

Messire Jean ............122

Muscat l'Allemand.........126

- Fleuri..............118 Robert .............118 
Page.

Muscat Royale...........119

Ognonette...............118

Orange Bergamotte.......127

- d'Hiver............125

Musquée..........119

Rouge .............119

Tulipée ..........120

Parfum d'Aout.............119

Pastorale...............122

Petit Blanquet...........118

Muscat ............117

Poire d'Ange .............118

- Figue ...............120

— à Gobert............126

de Naples.............125

d'CEuf.............119

de Prêter............125

du Prince...........127

Sans Peau..........119

de Tonneau.....125, 129

*Pound ..................129

Prince's Sugar............127

Quisse Madame...........118

Red Cheek..............127

Robine.................119

*Rousselet Hatif............119

d'Hiver.........128

de Rheims......119

Rousseline .............122

Royal d'Hiver............124

St. Augustine. . . . . . . . . 124

St. Germain. .............123

St. Père...............126

Salviati ................119

Sanguinole.............119

Sapin ................118

Sarasin ................126

September Orange ........127

Sucre Vert..............127

Sugar Top, or July ........126

Swan's Egg.............128

Tarquin...............126

Terling ................124

Tresor................124

Trouve................125

"Verte Longue ..............120

Verte Longue Panaché.....128

Vigne..................122

Virgouleuse ............124

Vitrier................123

Warden................129

[A few other old kinds are reviewed at page 130.]
Page.

Pears of modern Origin . 130

Alexandre de Russie.......134

Althorpe Crassanne.......134

D'Amande d'Eté...........131

D'Ananas d'Eté.........131

*Andrews .................134

Bartlett. See Williains

Bon Chrétien ..........155

Belle Alliance ...........135

et Bonne............135

de Bruxelles .........131

La Belle de Flanders ...... 135

Belle Henriette ........... 135

* Belle Lucrative . . . . . . . . . 135

Belmont ............... 136

Bergamot, Early ..........132

Bergamotte Pentecote. See

Easter Beurré.

*Beurré d'Amanlis.........136



*__ d'Aremberg ........156

—_ d'Argenson..........136

_

- de Beaumont .......136

*__ Bosc...............136

Bronze............157

Crapaud ..........137

Curtet ...........137

Delbecq...........137

*__ Diel..............157

Duval ...........137

Easter ............ 160

d'Enghein. .......137

Fortuné..........158

Gris d'Hiver Nouv.158

Incomparable.....158

Knox............137

Moiré............138

de Noirchain.......158

_. Picquery ........... 158

*___ Rance.............158

Romain..........138

Rouge Nouveau ....138

*

Spence..........138

Van Mons .........138

Witzhumb ....... 159

Bezi de Louvaine..........138

Bezy Vaet .............. 159

Bishop's Thumb..........138

Bleecker's Meadow........139

*Bloodgood...............131

Bon Chrétien Fondante.....139

Bourgmestre. See Clion. 
Page.

Broome Park............139

Brougham Hall...........139

Buffum ...............139

Burlinghame ............132

Burnet..................139

*Calebasse Bosc..............139

— Fondante........140

— Musquée...........139

-

Vasse...........140

"Capiaumont ..............140

"Capsheaf ...................140

Cardinale ................159

*Clion ....................160

Colmar d'Automne........141 Dewez.............160 Van Mons ..........160

Columbia................141

"Comte de Lamy........... 141

Croft Castle..............141

*Cross .....................168

Cumberland ...............141

*Cushing...................141

Darimont................142

"Dearborn's Seedling.......132

Delices d'Hardenpont.......142

de Jodoigne .......142

Van Mons.........142

De Rachinquin............143

"Dix......................142

*Dr. Hunt's Connecticut....142

Downton................160

Doyenne Santalette.......143

*Duchesse d'Angouleme ....143

Dunmore................144

Duquesne d'Eté............132

Emerald .................144

Eyewood...............144

Flemish Bon Chrétien.....161

Figue de Naples...........144

Fondante des Charneuse...144

Van Mons........144

Forme de Delices..........144

Foster ..................144

*Frederic de Wurtemberg...145

-Fulton ..................145

Garnons ...............161

Gendeseim.............145

Genesee ...............145

Gloria.................161

*Gloux Morceau...........161

Green Summer Sugar.....133

* Golden Beurré of Bilboa...145
Page.

*Gore's Heathcot ..........146

"Hacon's Incomparable.....146

*Harvard...................146

Hazel..................147

Henri Quatre............147

Van Mons .........147

Ickworth...............162

Jalousie de Fontenay Vendée 147

Jean de Witt............162

Josephine ...............162

"Julienne . ...............133

Jutte, or Buist............148

King Edward's ...........148

La Fourcroy................162

Lewis .................162

Lodge ...................148

L'Oken d'Hiver ............163

"Louise Bonne d'A vranches. 148

Louise Bonne de Jersey.....148

"Lowell...................163

Madotte.................148

Marie Louise Delcour.....149

Moccas ...................149

Monarch.................163

*Marie Louise .............. 148

"Napoleon.................149

Naumkerg ..............149

Ne Plus Meuris............163

Newtown Virgalieu.......163

* Paradise d'A utomne ........150

Parmentier...............150

* Passans du Portugal........133

*Passe Colmar.............164

Pengethly...............164

Petre ...................164

Pitfour..................150

Present de Malines.........164

*Princesse d'Orange.........151

Prince's St. Germain.......151

Poire d'Ananas ...........150

— de Boulogne.........164

— de Duverny..........150

_ـ de Lonvaine .......... 150

— de Mons...............150

Neill...............151

Pope's Quaker.............151

Reine des Poires..........151

Riche d'Epouille..........152

Rouselench..............165

Sabine d'Eté .............133

Sageret ...................165

"Saint Gbislain.............152

Saint Michel Arehangel...152 
"Seckel ...............152 Seigneur d'Eté..........133 Serrurier d'Automne......152 Shobden Count...........153 Souverain d'Hiver .........165 Striped Bon Chrétien.......153 "Summer Francreal .........153 Super Fondante..........154

"Surpasse Marie Louise.....153 Sylvange Verte. See BeurréDiel. Thompson's .............154 Tillington ..............154 Triomphe de Louvaine....154 "Urbaniste..................154 Vallée Franche..........134 *Van Mons Leon le Clerc...165 Verlaine ...............155

Vicomte de Spoelberch....165

"Washingtor ..............155

Whitefield ..............155

Wilhelmina .............166

Wilkinson .............155

"Williams Early..........155

-Williams Bon Chrétien....155

*Winter Crassanne..........166

-Winter Nelis ..............166

Wormsley Grange........156

\section{Class III.}

Notes on over 75 other new varieties of Pears.

Persimmon.............295

Pickle of the Walnut......318 of the Butternut....319 of the Olive........330

\section{PLUM.}

Its History and Uses.......216 Its Cultivation, \&c........230 Apricot Plum...........217 Banker's Gage...........217 "Bingham................218 Bleecker's Gage ..........218 Blue Gage .............218 *Blue Holland ............218 "Blue Imperatrice .........218 "Brevoort's Purple Bolmer..218

"Bruyn Gage..............219

*Caledonian ..............219

"Coe's Golden Drop........219

Col. Wetherell ..........219

Cooper's Plum...........219
Page.

*Corse's Nota Bene..........220

Cruger's Scarlet Seedling . .220

Damas de Provence.......220

"Dana's Yellow Gage... . . . 220

*Diamond Plum ............220

*Diaprée Rouge............220

Dictator...............221

*Domine Dull . . . . . . . . . . 221

Downton Imperatrice... . . 221

Drap d'Or..............221

*Duane's Purple............221

Dwarf Texas ............230

Early Monsieur..........222

Early Yellow ............222

*Elfrey . . . . . . . . . . . . . . 222

* German Prune............222

Goliah ..................222

*Green Gage...............222

Gros Damas Rouge Tardif. .223

*Ickworth Imperatrice.. . . . .223

"Italian Damask...........223

* Jenkin's Imperial . . . . . . . . .223

*Kirke's Plum............223

* Knight's Large Green Dry.

ing ...............224

Large Sweet Damson......224

Lombard . . . . . . . . . . . . . . 224

"Lucombe's Nonsuch... . . . 224

Monsieur. ..............224

Morocco .............225

*Orleans ...................225

*Pond's Purple ............225

Precoce de Tours..........225

*Prince's Imperial Gage... . .225

Red Gage..............226

- Magnum Bonum . . . . 226

Perdrigon.........226

*_. Queen Mother..... . . . 226

*Reine Claude Violette... . .226

Rivers's Early...........227

"Royal Hative.............227

Royale...............227

*Royale de Tours..........227

* Saint Catharine...........228

—. Martin's Quetsche....228

*_. Martin Rouge.......228

"Semiana ...............228

*Sharp's Emperor...........228

Sloe...................230

*Smith's Orleans. . . . . . . . . 229

Surpasse Monsieur . . . . . . .229

Virginale................229

* Washington ............229 
Page

White Magnum Bonum....229

White Perdrigon..........229

"Wilmot's New Early Orleans 2229

Propagation ...............36

Pruning.......45, 51, 204, 205

Quenouilles ......48, 171, 172

\section{QUINCE:}

Its History and Uses. .......174

Its Cultivation............176

Chinese................176

Japan ..................175

Oblong or Pear...........175

Orange .................175

Portugal ................175

Other varieties............175

RASPBERRY.

Its Description and Uses... .293

Its Cultivation ...........294

"Red Antwerp.............293

"White Antwerp...........293

"Barnet ..................294

*Double Bearing...........294

"Franconia ...............294

Other varieties described...294

Salal Berry.............317

Select List of Fruits.......446

Shagbark ...............321

Slugworm...............55

Southern Fruits.........323

Shepardia .............317

Spur Pruning $. . . \ldots \ldots 46,271$

Silk, and the Agricultural Resources of America, (A pp.) 401

STRAWBERRY.

Its Description and Uses...296

Its Cultivation .........304

Red Alpine............297

White Alpine . ..........297

*Bath Scarlet.............298

"Bishop's Strawberry.......298
Page.

Black Prince ............298

Black Roseberry..........302

Downton..............297

Duke of Kent's Scarlet....302

Elton Seedling ...........299

Green Strawberries, vari's. .300

Grove End Scarlet........302

"Hovey's Seedling.........299

Keen's Seedling ..........2999

Large Flat Hautbois........301

"Methven Scarlet..........302

Mulberry ..............299

Old Pine, or Carolina.......300

"Old Scarlet...............302

Prolific Hautbois...........301

Roseberry...............303

Swainson's..............304

Sweet Cone ..............298

Turner's Late Pine........300

Wilmot's Superb.........300

"Red Wood ...............297

White Wood .............297

List of other varieties.......303

Tea, see Index to Appendix 339

Its Imitation. ............287

Thermometer. ..........422

Thermostat.............423

Transplanting $. . . \cdots \ldots \ldots . . .35$

Vinegar...............114

Vegetables............. 356

Index to do.............443

Wine of Quinces..........175

— of Cherries.........231

— of Mulberries.......242

— of Currants ........286

— of Elderberries ......315

- of Ginger...........360

_

—

— of Orange...........344

— of Pine Apple ......346

— of Peach...........179

— of Raspberries ......293

— of Rhubarb..........375

— of Strawberries.....296 


\section{INDEX TO SOUTHERN FRUITS}

\begin{abstract}
Page.
Akee Tree ..............348

Alligator Pear ............349

Anchovy Pear............349

Araucanian Pine..........349

Banana ................348

Bread Fruit...............349

Cacao ..................350

Carob...................334

Cashew Nut.............350

Citron ...............344

Coffee, uses, preparation,\&c.351

Cocoa Nut..............352

Custard Apple, Varieties....334

Durion................352

Euphoria Longana........334
\end{abstract}

\section{FIG.}

Its History, Uses..........323

Cultivation...........323, 327

VARIETIES.

Angelique.............324

Common Blue...........324

Large Blue.............324

Bordeaux ............424

Brunswick .............325

Figue Blanche Ronde......324

Black Genoa............325

Purple Genoa............325

White Genoa.............325

Black Ischia.............325

Brown Ischia............325

Green Ischia............325

Yellow Ischia...........325

Black Italian............325

Brown Italian ............326

Long Brown Naples........326

Malta..................326

Marseilles................326

Murrey ................326

Nerii ...................326

Brown Turkey ............326

Violette................326

Small Early White........326

Granadilla, Varieties, \&c...335

Guava, Varieties, \&c.....336
Page.

Jujube ................336

Lemon..................345

Lime ...................345

Loquat. .................336

Lucuma ................337

Madi ..................337

Mammea................353

Mango Tree.............353

Mangostan ...............353

Oleaster.................337

\section{OLIVE.}

Its History and Uses. .....329

Cultivation...............333

Varieties described.........331

ORANGE.

Its History and Uses..341, 344 Cultivation .........342, 345 Blood, or Red Malta Orange 343 Common Sweet Orange...343 Mandarin Orange..........343 Seville Orange...........343 Palm, or Date............354

PINE APPLE.

Its History and Uses......346 Cultivation............247 Varieties described........347

Pinus Pinea.............337 Pistachia...............337 Plantain, its Description and

Uses ...............348 Prickly Pear, Varieties, \&c. 337 Pomegranate, Varieties, \&c. 338 Rose Apple..............354 Shaddock ..............345

Tamarind ...............354 Tchee-tse ..............341 Tea, its cultivation, uses, \& c. 339 Triphasia ...............355 Tuna ....................341 Varronia Plum............355 


\section{INDEX TO APPENDIX.}

\section{VEGETABLES.}

Preparation of the Soil.....356 Hot-Beds, \&c............356 Arachia Hypogea. ..........357 Arracacha...............357 Arrow Root ..............358 Artichoke ..............364 Asparagus...............364 Basil ...................370

Bean ..................364

Beet.....................358

Bitter Root............... 359

Bread Root...............359

Borecole .................365

Broccoli.................365

Brussels Sprouts..........366

Cabbage .................366

Cammas ................359

Caraway ................359

Cardoon .................366

Carrot .....................359

Cauliflower ...............367

Celery ..................371

Chervil ................371

Chives, or Cives..........371

Coriander ...............371

Cowich ...................360

Cress ...................371

Cucumber...............371

Dandelion..............367

Egg Plant...............367

Endive .................372

Fennel.................372

Florida Coffee...........372

Garlie ..................372

Ginger.................360

Hibiscus ....................367

Horseradish .............372

Indian Corn...............367

Italian Corn Salad..........372

Kale......................368

Leek ......................360

Lettnce .................373

Lin-kio ................360
Page.

Mangel Wurtzel ..........358

Marjoram ...............373

Martynea ................373

Marigold .................373

Mustard ..................373

Nasturtium.............373

Okra .................374

Onion.................360

Oxalis Crenata ...........361

Parsley .................374

Parsnip .................361

Peas.....................368

Pee-tsee.................361

Pepper..................374

Potatoes ................361

Pumpkin. : ...............368

Radish.................374

Rampion .................374

Rape ..................375

Rhubarb, Varieties ........375

Rocambole ..............362

Ruta Baga ..............363

Sage ....................376

Salsafy $. . . \ldots \ldots \ldots \ldots \ldots . . .6362$

Salsilla ................362

Savory.................376

Sechium ...............369

Scorzonera ..............362

Sea-Kale...............369

Sesamum, or Benne.......376

Shallots................362

Skirret.................362

Spinach, or Spinage.......369

Squash, Varieties ...........370

Sweet Potatoes...........363

Swiss Chard.............370

Taro ...................363

Thyme ................376

Tomato ................377

Trapa Natans...........363

Turnips.................363

Wappatoo...............363

Yam.................364 


\section{ORNAMENTAL TREES.}

Page.
Arrangement of Ornamen-
tal Trees, \&c.......377, 378 Abele...................378 Acacia, Purple Flowering...382 - Rose ............386 Ailanthus, or Tree of Heaven 378 Almond, Large Double Flowering...........211 Almond, Dwarf Double

Flowering ............211 Alnus Cordifolia ..........383 Althea Frutex, Varieties...387 Apple, Chinese, Double

Flowering ............86 Apple, Red Siberian Crab...83 Yellow Siberian Crab.83 Aristolochia Sipho........393 Ash ...................378 - Chinese...............383

- Curled-Leaved.........383

- Manna................378

- Mountain ...........316, 383

— Weeping...............383

Azalea..................387

Beech ................379

- Purple-Leaved.......383

Bignonia Radicans........394 Chinese, or Gran.

diflora ...............394

Broom, Scotch ...........391

$\longrightarrow$, Siberian ...........391

Button Wood..............379

Cabbage Tree .............383

Calycanthus ..............387 Chinese White

and Yellow............387

Camellia .................390

Carica Papaya.............383

Camphor.................379

Catalpas .................379

Cedar, Red...............383

L, White ...............380

Cherry, Double Flowering .222

C, Virginia..........380

一, Weeping ..........380

Chionanthus, Snow Drop..384

Colutea, two Varieties .....387

Corchorus................390

Currant, Indian .........387
Page.

Currant, Misqouri.........387 , Profuse Flowering .387

, Snowy Flow'g.287, 387

Cypress, Deciduous ........379

Daphne Mezereon, Red....390

- W White..390

Diervilla, Yellow...........390

Dirca Palustris.............387

Dogwood, Bloody.........387

, White Flowering 388

Elm, American ...........380

-, American Red........380

-, Cork Bark ...........380

- Scotch..............380

—, Ulmus Effusa ........380

Flowers..................394

Franklinia...............384

Glycine Frutescens.......392

, Chinese .........392

Halesia .................388

Hawthorn, many varieties...388

Hercules's Club ..........384

Hemlock ..............380

\section{Honeysuckes.}

—, English Fly, upright 388

, Red Tartarean......388 White do., or Cau-

casian ................388

$\longrightarrow$, Early Belgic .........395

- Italian . . . . . 395

Monthly Variegated 395 Chinese Variegated,

Twining ...............395

, Scarlet Monthly

Trumpet..............395

$\longrightarrow$, Yellow do. .........395

, Orange, or Pubea-

cent .................395

, Japan ............395

, Columbian, or Vi-

ning................396

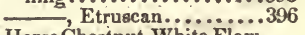

Horse Chestnut, White Flow-

ering ................379

Horse Chestnut, variegated.

leaved ...............379

Horse Chestnut,Dwarf Flow-

ering, and other varieties. 388 
Page.

Indigo Shrub ...........388

Ivy, Evergreen, or Giant....394

-, Virginian ............394

Judas Tree..............384

Juniper, Swedish..........386

Kentucky Coffee.........384

Laburnum, three varieties..384

Larch, American..........380

- Scotch, or Alpine...380

Lilac, White and Purple....388

-, Josikøa, and others. .389

, Persian, two varieties 389

Chinese Cut-Leaved.389

Lime, or Linden, three var. 380

Locust..................381

Hemlock...............380

Honey Locust, or Three-

Thorned Acacia.........381 Magnolia, Blue Flowering...381

—, Chandelier .......384

Chinese Purple..384

, Cordata.........384

Glsuca ..........389

Great Flowering . 385

, Splendid........384 Tripetala........384

Maple, Ash-Leaved ........385

L, Scarlet ............381

$\longrightarrow$, Sugar...............381

Mountain Laurel............389 Rose, or Raspberry 389

Snow Drop.......385

Mulberry, Chinese ....385, 410 Mapan Paper.385, 410 Osage Orange .............385 Palmetto Royal ............389

Pæonia Tree............390 Peach, Double Flowering...198 Pine, White............381 —, Pinus Lambertiana ...381 -, Elastic, and others...381 Pinus Cembro .............385
Page.

Pomegranate .............338

Pride of India . . . . . . . . . 386

Prim, or Privet...........388

—, Chinese ..............388

—, Variegated-Leaved....388

Quince, Chinese ..........176 Japan, or Pyrus....175

Rhododendron Maximum. 390

Ponticum ..3390

Rose...................393

$\longrightarrow$,China, or Monthly, var. 393

Roses, Climbing ..........394

St. John's Wort...........390

Silver Fir...............382

Spruce, varieties..........382

Norway Spruce Fir........382

Shepardia...............317

Snow Ball, or Guelder Rose 390

Snowberry ..............393

Sophora, Japan ...........390

Spiræa Bella .............390

- Guelder Rose .....390

Nepal............390

— , Red Flowering ....390 , Siberian. . .........390

Strawberry Tree...........390

Syringa, European Fragrant 390

, Garland, or Large

Flowering............390 - V a riegated-Leaved .390 Sycamore, European ......382 , Striped-Leaved .382

Tulip Tree..............382

Tupelo Tree..............386

Venetian Sumach.........386

Virgin's Bower............395

Wild Orange.............386

Willow, Black ............386

$\longrightarrow$, Golden ............387

—

—, Weeping..........382

—_, Weeping, Napoleon 382 


\section{NOTES ON THE AGRICULTURAL RESOURCES OF AMERICA, ON SILK, ETC.}

Chapter. $\quad$ Page.

I. Commerce of Silk, its Antiquity..............401

II. History of the Silk-Worm ..................406

III. Varieties of Silk-Worms......................408

IV. Mulberry ..............................410

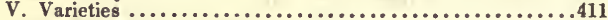

VI. Substitutes for the Mulberry ..................413

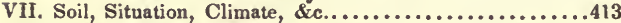

VIII. Climate, Habits, and Management of Silk-Worms......416

IX. Profits of the Silk Culture in France and Italy ..........418

X. System of M. Camille Beauvais................ 420

XI. M. D'Arcet's System of Ventilation.................421

XII. System of the Misses Reina, of Come, in Lombardy . . . . 425 Progress and System pursued in America...........427

\section{SELECT LIST OF FRUITS.}

The select list of fruits which are particularly recommended for a moderate collection, have been designated by a star throughout this work, and also throughout the Index, all these having been satisfactorily proved; but, as a considerable proportion of the highest character are new, and of recent introduction to our climate, or not having been, as yet, satisfactorily proved, and are therefore excluded, it must be evident that this list will, from time to time, require a revision. 


\section{SELECT LIST OF FRUITS.}

The following select list of fruts is recommended as a very moderate selection, for a small garden, of the kinds best known in this day. The list of all winter fruits should be increased by additions to those named, or of other kinds. The numbers refer to corresponding numbers in the body of the work.

Apples. Nos. $3,4,8,9,10,11,18,22,30,33,35,38,39,41$, $42,49,53,56,59,62,67,74,85,86,90,92,101,105$.

Pears. Nos. $3,7,13,15,22,26,33,39,41,46,69,70,77,86$, $95,96,101,110,112,115,130,132,136,137,148,152$, $158,162,166,170,181,189$.

Peaches. Nos. $4,7,8,9,11,12,18,20,21,22,25,31,34,35$; $36,45,47,48,50,51,53,62,68,74,75$.

Nectarines. Nos. 2, 3, 6, 7, 9, 13.

Apricots. Nos. 5, 9, 10, 13, 18, 20.

Plums. Nos. $3,7,8,11,14,17,18,19,24,27,30,32,33,34$, $35,36,39,46,51,53,60,61$.

Cherries. Nos. $1,2,5,9,11,13,14,16,17,24,26,27$.

MULBerries. English Black, and American Red; the last is best and hardiest.

Grapes. For the Northern States, Nos. 1, 2, 19, 24, 39, 48, 50. For cities, for vineres, or for the South, add, also, Nos. 8 , $11,13,17,23,52,53,55$.

Currants. Nos. $1,5,6$.

RAspberries. Nos. 2, 3, 12. Add, also, the American White. Strawberries. Nos. 5, 9, 13, 24, 25. 


\section{ADVERTISEMENT.}

FRUIT TREES, ORNAMENTAL TREES, SHRUBS, \&c., CULTIVATED AND FOR SALE AT THE NURSERY OF

\section{WILLIAM KENRICK, IN NEWTON, MASS.,}

FIVE AND A HALF MILES FROM BOSTON, BY THE WESTERN AYENUE, AND HALF A MILE FROM THE GREAT WESTEIN RAILROAD.

A most extensive assortment of Fruit Trees, Shrubs, Grape Vines, \&c.; selections from the original or first-rate sources, and the finest varieties known.

Ornamental Trees, Shrubs, Roses, and Herbaceous FlowERING Plants; a large assortment of the most splendid hardy kinds.

Trees and plants, when so ordered, will be carefully selected and labelled, and securely packed in mats and moss, for all distant places, and duly forwarded from Boston by land or sea. All distant orders to be accompanied either by cash, or by a draft on any eastern city.

Catalogues sent, gratis, to all who apply. Address, by mail, "Nevoton, near Boston,"

WILLIAM KENRICK. 


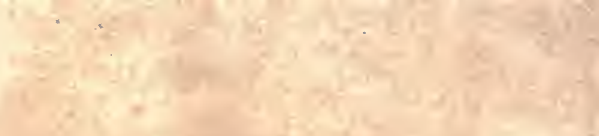

$\sqrt{2}$

$-$

$+$

-

. 

V SOUTHEAN REGION

IIII

|

A 000613241 in

$000613241^{9}$ 


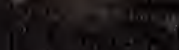

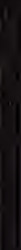

$\log ^{2}, 1+16$

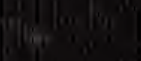

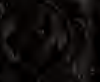

a tong

Iitia

30

6
17

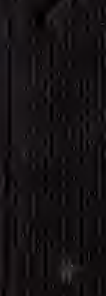

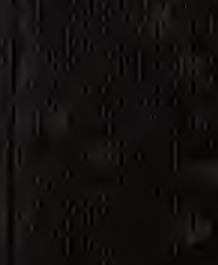

